
THE UNIVERSITY

OF ILLINOIS

LIBRARY

913.32
$\mathrm{Mg1}$

v. 3 cop. 2 
Return this book on or before the
Latest Date stamped below.

University of Illinois Library

MAR - 1955

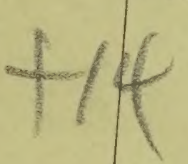

$\ldots 2 \leq 1950$

C 211950

JAN 3 root

Mav 2101903

MAY 311989

WN $\$ 39989$ 





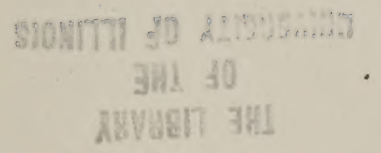




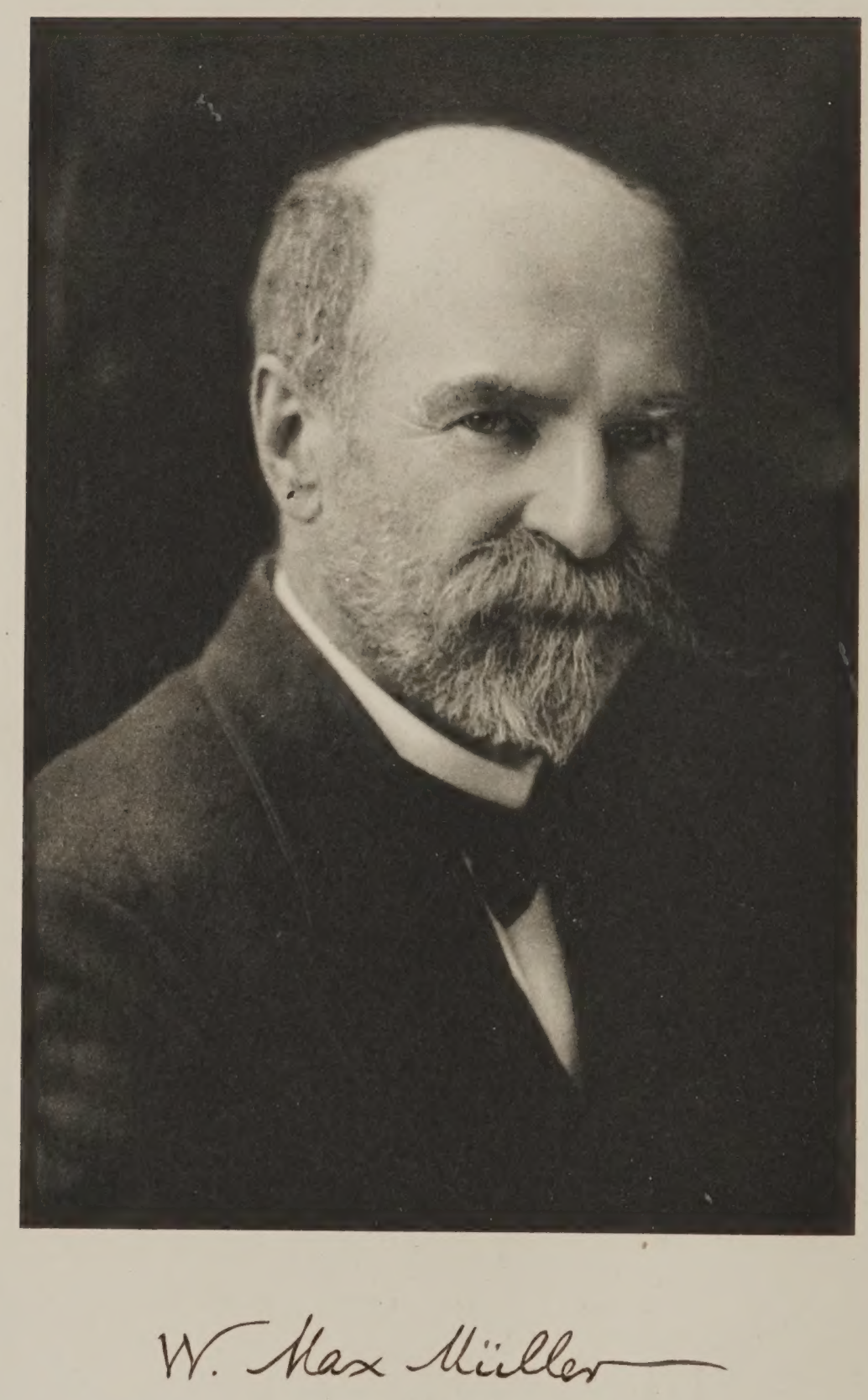




\title{
EGYPTOLOGICAL RESEARCHES
}

\author{
VOL. III \\ THE \\ BILINGUAL DECREES OF PHILAE
}

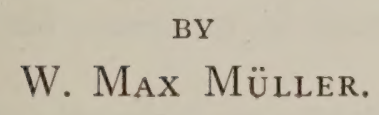

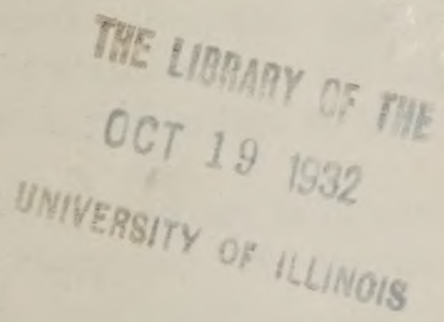

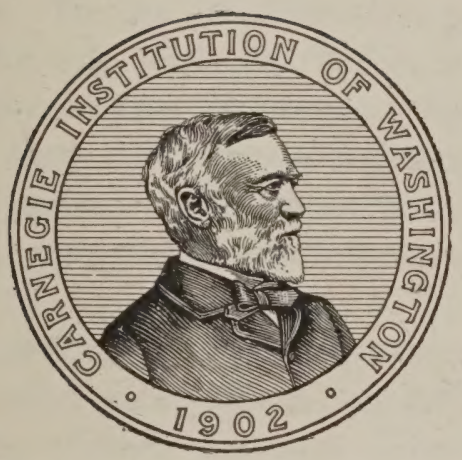

Published by the Carnegie Institution of Washington WASHINGTON, 1920 


\section{Carnegie Institution of Washington}

Publication 53, Volume III

Press of Gibson Bros. Inc.

WAshington, D. C. 


\section{INTRODUCTION.}

In I9ro, through the liberality of the Carnegie Institution of Washington, I was enabled to visit the doomed island of Philæ and to glean the epigraphic material left by the Berlin expedition. My first thought was the decipherment of the famous bilingual inscriptions engraved on the walls of the large court between the first and the second pylons. These texts had attracted the attention of the very first Egyptologists and were soon recognized as containing the greatest epigraphic treasure of the island, but their state of mutilation had caused them to remain a dead treasure for almost a century.

Champollion (1828) mentions them in his Notices Descriptives I, p. I78, describing briefly some sculptures of Ptolemy Neos Dionysos (Champollion thought Philometor). He continues: "The inscriptions are illegible because they are drawn over a hieroglyphic and demotic inscription from the reign of Epiphanes." It is thus evident that the admirable man who, with almost superhuman energy, gathered such an immense mass of material from the monuments, recognized clearly the bilingual character of those inscriptions, but he had no time for the study of such difficult texts.

In 1843 R. Lepsius noticed those inscriptions which (he thought) "had not been noticed by the French-Tuscan expedition" and observed their bilingual character. He announced this as a very important discovery (see his Briefe aus Egypten, I08-I09, English ed., I20-I2 I). In the first decree he saw nothing but a republication of the Rosettana enlarged by the honors given to Queen Cleopatra. This involved him in a controversy with de Saulcy, who, on the basis of paper impressions taken by Ampère, contested correctly the identity of the decrees of Rosetta and Philæ. (On this discussion see Zeitschrift der deutschen Morgenl. Gesellschaft, I847, 264, foll., Revue Arch., IV, 240.)

Next Brugsch passed Philæ. In his Reiseberichte, p. 26I, he described the decree of Epiphanes as "sculptured into the wall with characters so minute that I was hardly able to recognize it." In his Sammlung demotischer Urkunden (I850), pl. 3, he published some extracts from the first decree, trying to show the correspondence of the hieroglyphic and demotic fragments; also to him the text seemed to be important only for filling gaps of the Rosetta inscription. The way in which he gave those extracts was very imperfect. ${ }^{1}$ It is questionable if he copied the second decree.

In his Denkmaeler aus Egypten (IV, pl. 33, the demotic text, VI, 30 to 34), Lepsius, who, in the use of paper squeezes, possessed a great advantage over his predecessors, had a facsimile drawn after the paper impressions of both decrees. These copies, although infinitely better than the attempts of Brugsch, left the text so fragmentary that nobody utilized them.

Finally, Brugsch (Aeg. Zeitschr., I878, 44), with great sagacity, observed the connection of the second decree with the great Egyptian rebellion. His preliminary hints about the contents suggest that he then planned a more exhaustive treatment of the text, but later abandoned this undertaking.

${ }^{1}$ The most objectionable features are some wild restorations where there was absolutely nothing on the stone. 
G. Eibers, in Baedeker's first Guide Book to Upper Egypt (Oberaegypten, I 89I) stated, p. 322, after Brugsch: "Of scientific importance, but written extremely minutely and almost illegibly, are the decrees, above, on the left colonnade near the first pylon, discovered [sic!] by Lepsius in I843, written in the twenty-first year of Ptolemy Epiphanes in demotic and hieroglyphic writing, one at the celebration of the suppression of a rebellion and the punishment of the malefactors, the other in honor of Cleopatra, the wife of Epiphanes. Unfortunately these decrees have been much mutilated by the figures later (under Neos Dionysos) cut over them."

In the edition of Baedeker of $\mathrm{r} 897$, p. 354, this description of the "scientifically important" texts was limited to the first, which is called "a duplicate of the well-known inscription of Rosetta (only the Greek text lacking)." Later editions withdrew this remark.

How far those texts remained unknown to science may be concluded from the fact that E. A. W. Budge, in his first volume of The Rosetta Stone, p. 20, in I904, reproduced a small section of the so-called second decree from Lepsius's plate with the title "portion of a copy of the decree on the Rosetta stone cut in hieroglyphic upon a wall of a temple at Philæ." 'This illustrates well the illegibility of that publication.

The high importance of those texts became clear to me when, in I883-84, as a student at Leipzig, I took up privately the study of the demotic script of the ancient Egyptians. Continuing these studies at Berlin, in $\mathbf{I} 88_{4}-85$, I received from the administration of the Berlin Royal Museum permission to examine the paper squeezes brought home by the Lepsius expedition and immediately saw how that almost useless copy in Lepsius's Denkmaeler could be vastly improved by the study of the original. I devoted much time to the decipherment of those squeezes and in later years obtained collations of various details on them by Erman, Schaefer, and Sethe, and returned twice to Berlin for the purpose of collating them personally. Later, I received, through the courtesy of W. Spiegelberg, a set of paper squeezes of my own. My results, however, never were sufficiently certain. The edition presented here is based principally on my work in the summer of I 910 , when I was able to make further impressions and to compare with the original stone the results obtained by me up to that time from squeezes. Everybody familiar with epigraphic methods knows that even the best paper impression can not entirely replace the study of the original; sometimes a sign will look different on every other squeeze. Here, of course, the original is unusually difficult. The small, shallow-engraved signs become distinctly visible only during the short time of the day when they receive strong side-light; running up and down on high ladders during that time, when even the seconds seem precious, is the work of Tantalus for the scholar who would like to brood for hours over a single difficult sign. Nevertheless, this comparison of the original on stone was a very desirable and even indispensable supplement to the previous attempts of decipherment from squeezes.

What I offer as result is, I hope, almost exhaustive for the hieroglyphic text, more than can be said, e.g., of the existing reproductions of the Rosetta stone. ${ }^{1}$ A few remaining uncertain-

${ }_{1}^{1}$ The principal paleographic characteristics of the hieroglyphs and the distances are carefully reproduced, but $(e . g$.) the clumsy and irregular division-lines (both of the first and second text) are not exactly initated, because this would interfere with the legibility of the text. Therefore, I have also inverted the direction of the hieroglyphic text which, in the original, runs from right to left; in measuring the distances, etc., the inverted form on the squeezes had to be followed. The commentary has been limited to the most condensed notes possible, principally because the lack of hieroglyphic types forbids philological investigations. Likewise the transcription of Egyptian aims at simplicity, especially in the very complicated question of rendering the demotic orthography. The employment of simple $z$ for the widely different Egyptian sound $t s$, etc., is to be considered in this light. 
ties have been indicated. The demotic texts, owing to the difficult script which is so poorly suited for monumental use (a kind of stenography always depending much on the context), leave more uncertainty. I have, in their case, tried to draw mechanically only what I could see clearly and without fancy. Of course, every experienced philologist knows how difficult it is to call a decipherment of a palimpsestic manuscript final when it contains a unique text not controlled by parallel manuscripts. Here, on stone, the difficulties are increased. I hope, however, to have saved the best historic treasure of Philæ so far that scientists will not have to lament an irreparable loss when the beautiful temples of Philæ come to be completely destroyed by submerging. The end of Philæ will, I must state it with regret, come much sooner than has been admitted in the press.

\section{THE FIRST DECREE.}

The "first" bilingual decree of Philæ, engraved on the right side of the wall, is a modified copy of the famous decree of Rosetta, or rather of Memphis, in which city the priests of all the Egyptian temples (as far as they were then under control of the struggling Alexandrian government) had assembled in the ninth year of Ptolemy V., Epiphanes, to honor the king as benefactor of the temples and of the whole Egyptian nation. Two years after the suppression of the great revolution, $i . e$, in the year $2 \mathbf{I}$, the priests at another convention in Memphis are stated to have renewed that decree of thanks to the king and the establishment of his divine worship. The principal reason was that the decree of year 9 had not yet been set up in the temples of the Upper Country, owing to the long years of rebellion. The promulgation of those honors to the king seemed the more necessary to the priests because the reforms of the old decree (above all, the remission of taxes lost to the Alexandrian government in the rebellious provinces) had been extended to the time of the suppression of the rebellion, $i . e$., to the year I9 inclusive.

Of course, these reasons are not stated too plainly in the new decree; this would have meant a painful confession of past disloyalty. Still, the decree was not entirely reproduced at Philæ as it had been written in the year 9. Instead of maintaining the fiction that the Upper Country had been loyal, the text of the priestly resolution of Memphis is here given mutatis mutandis. ${ }^{2}$ Therefore it bears not the original date of the ninth year, but the date of the convention of the year $2 \mathrm{I}$.

The divine honors are extended to the queen, Cleopatra, as probably had always been done since the date of her marriage. This formal recognition of the queen's cult is, however, not the main point for republication, as Lepsius thought. The great rebellion furnished the principal reason for this republication. All references to that great rebellion, however, were taken out of the old text of Memphis; that whole unfortunate period now was left to oblivion.

${ }^{1}$ I still use this expression because the erroneous numbering introduced by Lepsius has become familiar. According to its dating the above decree is the second. See the references to the alleged "second" decree in the "first" inscription, line $9 f$ and $r 3 c$ to $d$ (demotic $13 f$ ).

${ }^{2}$ In the decree of Damanhur, of the year 23 , the scribe simply altered the protocol of year 9 to that of year 23 , but copied the text of year 9 for the rest quite mechanically. This was mere negligence, not a wilful fiction of conservatism or loyalty. I am not sure whether we can draw the inference from a comparison of the two later editions (Philæ and Damanhur) that the adaptations of the decree of Memphis were left to the scholars of each temple, instead of being worked out at the convention where the renewal of that decree was decided. The inclination of the Egyptian mind toward a ce tain laxity in execution of everything may be considered, at least in the case of the Damanhur copy. 
The modifications in the enumeration of royal reforms and benefits are the most difficult to understand; in the mutilated condition of the text we can not follow them very well nor decide whether the shortening of some paragraphs was due to cancellation of those laws ${ }^{1}$ or to the impression of the redactor that those matters were somewhat obsolete after twelve years. The most important matter of the decree, after all, claims to be the worship of the royal couple, and of this the description is given very minutely. For the rest, the redactor's mode of proceeding remains yet to be determined.

We might infer from the promptness with which the priests at Philæ engraved the two decrees, and from the prominent place which they gave to them, that they had a specially bad conscience toward the Alexandrian government. We can not, however, with full certainty, add this inference to some other indications which could be interpreted as though the rebellion had started in the cataract region or had received special aid from this frontier district. (See below, on the titles of the two rebel kings.)

The question of the original language of all those priestly decrees is now rather plain. The priests, of course, discussed their resolutions and probably sketched them in their native language. It is certain that the first form in which the resolutions went into writing was in demotic script; the hieroglyphic style was too much confined to the most learned and not practical enough for a protocol of this kind. The official form, however, finally was in Greek. After this form, authorized by communication to the Royal Government, the final Egyptian versions, such as we have them, were translated rather literally. Small additions occur for the sake of loyalty or clearness; they are of greater importance where the Greek redaction had not done full justice to matters of too special Egyptian character, $e . g$., in the description of the hieroglyphic symbols decorating the portable shrine of the king, which had merely been summarily touched by the Greek version (Rosetta, lines 43 to 44 ). There the Figyptian translations went back to the original (demotic) minutes of the priest." Elsewhere, these minutes scarcely exercise any influence. The demotic version of the official (rreek form preceded the hieroglyphic; the latter often leans more on the demotic than on the Greek text. These principles I consider now as settled, especially for the Rosetta and Philæ decree. ${ }^{3}$

Difficult and obscure as are the Egyptian versions, on account of their clumsy writing and style, nevertheless they are extremely helpful for the elucidation of the Greek text. ${ }^{4}$ The redactors of this text always strove more for elegance and terseness of style than for clearness, presupposing too much that the readers would be sufficiently familiar with the matters mentioned. Of course, the hieroglyphic versions are hampered, on their part, by their striving after archaizing beauty while expressing too modern matters. To follow a model in a language differing in expression so widely from Egyptian as does classical Greek was not much easier for the hierogrammates than it would be for a lawyer or newspaper reporter of our age to express matters of modern politics or business in Latin. The demotic version ought to be simpler and is, indeed,

1 As Mahaffy, Empire, $3 \mathrm{II}$, believes to trace the reintroduction of the apomoira from wine, in documents from the year 18.

2 Not copying them, however, word for word. The description is neither quite exhaustive nor clear in the demotic version on stone.

${ }_{3}$ Thus the remarks by Mahaffy (Empire of the Ptolemies, 302) on the succession of the versions, are to be corrected. The plan of all those decrees is, of course, very un-Greek, betraying somewhat the first conception in the old Egyptian style, but their Greek wording is excellent, at least for the contemporaries. The demotic text, on the other hand, struggles too desperately and is of ten too un-Egyptian to be literally the original version of the final official edition.

${ }^{4}$ See the honest confession of Mahaffy, Empire, 302. 
more helpful where the complicated writing, especially poorly suited for monumental use (p. 3), can be read with certainty. ${ }^{1}$ Thus the gaps and obscurities of the Greek text of the Rosettana need comparison with the Egyptian versions, while these useful commentaries themselves would be much more obscure without the Greek original. We gain now, by our parallel text from Philæ, a better understanding of all three versions of the Rosettana, principally of the hieroglyphic part. ${ }^{2}$

One general result of comparing our Philæ text with the Rosettana is the relatively close adherence to the style of the official hieroglyphic text of year 9. The Egyptian scribes of the New Empire usually showed great lack of accuracy in copying any texts; they varied their models intentionally by freely using synonymous words and synonymous orthography. We still find a great amount of such liberty in those Ptolemaic decrees, more than modern systems of writing would tolerate, but the scholars who could use archaic Egyptian quite fluently had evidently become scarcer; therefore, we observe that such masterpieces of style as the Rosetta text were followed in a fairly accurate way, especially where they contained strange and remarkable archaisms. Lack of hieroglyphic types, as said (p. 2, note $\mathrm{I}$ ), prevents my studying the very peculiar style of our decrees from the philological side; this theme invites the attention of specialists in Egyptian grammar. ${ }^{3}$

Less rich are the results for the demotic text of the old Memphis decree. The demotic hand of the Philæ text is much prettier and clearer than that of the faithful engraver of the Rosettana, for instance, but the sandstone of Philæ did not receive and preserve the signs as well as the basalt of the Rosetta stone; this writing, poorly suited for monumental use in general, as said repeatedly, has thus here in many places become indistinct. Like all kinds of stenography, it needs absolute clearness and a safe context to be readable. I have given the traces in such passages mechanically as I could see them on the stone, and only in my translation, not on the plates, have I dared to restore boldly after the corresponding lines of the Rosettana.

The two decrees can be called bilingual after their present condition or trilingual according to the original intention of the priests. The omission of the Greek version at Philæ is not with certainty significant (as though, in the cataract region, the Greek-speaking element had been scarce enough to form an excuse for the omission of the Greek part). This tendency to save some part of labor by quiet omission appears too often in ancient Egypt. A good example is the stela of Damanhur, where the priests apparently thought they had shown their good will sufficiently by some wretched extracts from the hieroglyphic text, disregarding completely the two other versions.

${ }_{1}^{1}$ The engraver of the demotic Rosettana slavishly copied his extremely hastily written model on papyrus as though he had papyrus for his material; he did not attempt to change it anywhere to clear monumental forms. We of ten doubt whether he could read at all. Therefore, the demotic Rosettana is an extremely difficult text, on the exact philological explanation of which much remains to be done after the pioneer attempts of H. Brugsch, R. Revillout, and J. J. Hess.

2 The hieroglyphic text of the Rosettana is, strange to say, one of the least treated and least understood Egyptian texts. The pioneers of Egyptology turned away from it after it had furnished, in its most frequent words, the key to more promising texts. Since the meritorious but imperfect study of F. Chabas (L'inscriplion hiéroglyphique de Rosette, i867) only the compilation of Budge (The Decrees of Memphis and Canopus, 1904, 3 volumes) treats rather superficially of the text, which is by no means intelligible in every word ot sign.

${ }_{3}$ The most interesting side of this style seems to be that we have in those decrees the last traces of the Neo-Egyptian style of the New Empire, which, however, had, in Ptolemaic time, become in turn archaic and was therefore mixed more and more with the earlier, classical styles. Notwithstanding this, the style of the decrees remained very peculiar and quite distinct from the usual, purely religious, inscriptions in hierogkyphic signs. 


\title{
EDITORIAL NOTE.
}

The sudden and tragic death of Professor Müller, on July 12, 1919, while he was spending his vacation at the seashore at Wildwood Crest, New Jersey, has closed the work of one of the most eminent representatives of Oriental scholarship, known alike in Europe and America. He had been an indefatigable student of Egyptology since his school days at the Gymnasium at Nürnberg, Bavaria, when he took up these fascinating studies as an autodidact, and he pursued them after his abiturium at the universities of Leipzig, Berlin, and Munich. The first fruit of his labors appeared in the year I 893, under the title "Europa und Asien nach ägyptischen Denkmälern." It was a work which at once drew the attention of the scholarly world upon the author and it awakened the hope that Müller would follow up the new road, which he had broken in the field of the realia. In this hope no one was deceived. But Müller showed himself also capable in the edition of texts, when in I 899 his "Liebespoesie der alten Ägypter" appeared. In the last few years prior to his death he had occupied himself extensively with the Religion and the Mythology of the ancient Egyptians, the results of which studies are laid down in his "Egyptian Mythology," which appeared only one year before his death. Under the auspices of the Carnegie Institution of Washington he was enabled to make three archeological expeditions to Egypt, the land of his boyhood dreams, and he was one of the last to make competent observations on some of the temples of the upper Nile. His plans for future scientific researches were numerous, and these he had often discussed with me, since for the last three years I had been a pupil of his and closely associated with him. During a protracted illness in the fall of 1918, Dr. Müller had expressed the wish that, in case he should be unable to finish a number of his publications, their completion should devolve upon me. Thus, after his lamentable death, his family approached me with the request that I should put the finishing touches on the present volume. To this I gladly consented, after the Carnegie Institution of Washington had approved of my doing so. The work was in its final stages when I took charge of it. Nothing has been added to it, although in some instances, I am quite sure, Dr. Müller would have introduced some further additions. I have merely added the brackets in the hieroglyphic and demotic texts and elucidated more clearly a number of notes where some uncertainty in expression was observable. I am also responsible for a few restorations in the text.

\author{
HENRY F. LUTZ, Ph. D., \\ Research Instructor in Assyriology and Egyptology \\ in the University of Pennsylvania.
}




\section{THE GREAT EGYPTIAN REVOLUTION.}

Until rather recently it was customary among the historians, even those without popularizing tendencies, to describe the age of the Ptolemaic kings as a kind of millennium for Egypt. In order to strengthen this impression of bliss, that age was usually contrasted with the preceding time of Persian rule, which was depicted in the darkest colors possible, as a time of misery and cruel oppression. Even the religion of the poor Egyptians was said to have been touched; the good, patient, harmless people were not allowed to worship their sacred animals in peace. No wonder that the oppressed again and again rose in desperate revolts against the Persian tyranny, notwithstanding the bloody cruelty with which these struggles for freedom were always suppressed. Finally deliverance came by Alexander the Great. Welcomed enthusiastically as a divine savior by all Egypt, he inaugurated there an era of peace, prosperity, and happiness, the most brilliant fruit of Hellenism. Happy in religious liberty, the Egyptians gave themselves faithfully and willingly to the illuminating influence of Greek civilization!

We have learned more and more that those lovely fancies are untrue. As far as we know the Persian administration, it seems to have treated Egypt very mildly, leaving everything in the country as much as possible in the condition in which the Persian conquest had found it. It seems rather that the numerous and serious rebellions of the Egyptians were due much more to the lax and over-liberal administration of the Persians than to oppression; another reason for those rebellions may be found in the difficult class of population which we have to discuss below. At any rate, no religious persecutions can be proved by the monuments. The calumnies of cruelty and intolerance with which Cambyses, the conqueror, is covered in the reports of Herodotus are manifestly priestly lies of a very clumsy character. The Egyptian monuments from the Persian period show us that those foreign kings tolerated and supported the gods, temples, and priests of Egypt quite as much as the Macedonian and Roman rulers did in succeeding times.

The pleasant picture of conditions under the Ptolemaic kings is also deceptive. It was too much an argumentum e silentio, based on the fact that our knowledge of the history of the Ptolemaic kingdom, as long as it rested completely on the Greek historians, was exclusively a history of the foreign relations of Egypt and of her royal family. This history, moreover, was confined to Alexandria, and whenever the Egyptian people were considered at all by the classical writers, this meant only the Greek population of Alexandria. The great mass of the native Egyptians, who by their labor and their taxes supported the court, the large armies of mercenaries, the fleets, and the expensive foreign policy, are scarcely considered in the Greek authors. Thus we have practically what we ought to call a history of the kingdom of Alexandria rather than of Egypt. If the history of Paris and of London would give only incomplete histories of France and England, the case is infinitely worse with Alexandria and Egypt.

If we should compare the position of Alexandria as capital of Egypt with that of modern Calcutta as capital of India, we should express the incongruity of the nationalities far too mildly. Calcutta is, after all, an Indian city, and the recognition of the native element in the English 
administration of India is there (as well as in the whole country) much greater than that of the Egyptian population was under the Ptolemaic rule. Alexandria was a piece of Greece transferred to the mouth of the Nile, keeping zealously its un-Egyptian character; the rich finds preserved in the modern museum of Alexandria show that only small separate quarters of native Egyptians can have existed there. ${ }^{1}$ Yet this Greek city absorbed all the wealth of the country with few returns. The kings emphasized their Macedonian blood, ${ }^{2}$ and it seems to have been quite an exception that the unusually gifted last queen, Cleopatra, as Plutarch tells us, understood the barbarous tongue of her subjects, or at least something of it. Inscriptions and papyri conceal, of course, the fact that a wide gulf existed between everything Greek and the Egyptian element, but we must not be deceived on this account. 'The best analogy is again the relation between Englishman and Hindu. The brown native in ancient Egypt often used a Greek name and imitated the dress and manners of the ruling class; ${ }^{3}$ at the same time his religion taught him that those aristocrats were ceremonially unclean barbarians, so that for a long time the contempt of the Greeks for the strange, barbarian subjects must have been reciprocated. While from the inscriptions and papyri we are apt sometimes to mistake a man using Greek writing and a Greek name for a member of the privileged nationality, the contemporaries seem for a long time to have drawn the "color-line" rather strictly, and it may be said that in reality Egyptian and Greek mixed like oil and water. ${ }^{4}$ 'This fact has been set forth very plainly by Th. Mommsen (Römische Geschichte, V, p. 56I), who correctly observed that in Egypt the legal superiority of the Greek race over the subjected natives was emphasized in a way unparalleled in any Hellenistic country. If under the Roman rule the theoretical inferiority of the Egyptians to the Greeks was maintained even in the different mode of corporal punishment for both nationalities, we may conclude that this distinction of the two nationalities must have been far more rigid and more oppressive at the time when the Greeks themselves ruled in Egypt under the dynasty of the Lagides. The most characteristic testimony on this sharp distinction is the passage of the second Philæ decree Io $f$ (page 72), which reports that Greek and Egyptian troops kept guard side by side "as though they belonged to the same race." This is mentioned as a new and wonderful fact. The demotic contracts state, in the case of Egyptians, their profession when this is different from the ordinary native occupation as farmer. With the foreigners, on the other hand, we find only the designation "the Greek" replacing the mention of the occupation. A representative of the privileged people is expected to live on a pension from the government under one or another pretext.

${ }^{1}$ For this reason Alexandria seems designated as a "fortress" (Philæ decree II, line 4; see also the Buto-Stela, line 4). This seems to refer more to the exclusive character of the city than to her walls.

${ }^{2}$ Therefore, after the annexation of Egypt by the Romans, a priest of Memplis, during the first years of Augustus, mentions the past dynasty as mere foreigners, i. e, as "the Greek kings who were on the shore of the sea towards the west, in the city . . . whose name is Rá-qodi" (i. e., Rakotis, Egyptian name for Alexandria; cp. Buto-Stela, line 4, Strabo 792, etc.). See Harris Stela, Reinisch, Chrestomathie, 2 I, 1. 9. The older "Chronicle" papyrus of Paris, which speaks of "the Greeks" in a similar way, will be discussed farther down.

${ }^{3}$ This is believed by Mahaffy (The Empire of the Ptolemies, 396) to have become frequent only at a later period; see the following note. I have no gathered data on this question, which is not quite identical with that of the real assimilation of both races.

${ }^{4}$ F. Preisigke, in Schriften der wissenschaftlichen Gesellschaft in Strassburg, 19, p. 26, uses the above expression. The fusion of both races progressed very rapidly only when Christianity spread in Egypt; it may have begun on a sma!ler scale under the later Ptolemies. Mahaffy (Empire of the Ptol.) tries to trace its beginnings to Ptolemy VII (p. 359 foll.), whom he believes to have favored the natives, and its progress under Ptolemy IX (p. 396). See the note above. Below we shall trace it to a slightly earlier time. For the first \50 years of Greek dominion, however, the above characterization may be fully accepted. 
It is also true that the Ptolemies did not rule the country in a very paternal way. They exploited the poor natives without mercy. While it must be admitted that the native rulers in ancient time never had made the burden of the Egyptian peasants too light, the Ptolemaic kings seem to have reached the greatest perfection in extorting the highest possible amount of taxation (Mommsen, 560). It is questionable, indeed, whether these burdens would have driven the patient crowds to serious insurrections. Of course, the religion of the natives never was touched, because religious intolerance nowhere existed in heathenism; only the monotheistic religions introduced it. The privileges of the temples and the priests were considerably limited under the Ptolemies; yet religious as the Egyptians were (in their own way, so different from what we now call piety), this would hardly have roused the masses of Egypt to insurrection. Nor have we evidence that the personal despotism of the kings and their vices ever had this effect. Such matters touched only the population of Alexandria. The native element does not seem to have participated much in the numerous civil wars which later were fought for the succession to the throne; it left these to the Græco-Macedonian population, which had practical interest in those struggles, $i . e$. , in their spoils. ${ }^{1}$

In general, it must be admitted that the Egyptians were unwarlike to cowardice; just as Strabo (p. 819) characterized them as being patient, and used to being dominated by foreigners, long centuries before the Persians and Greeks ruled in the Nile land. Still, we must not exaggerate this docility beyond measure. There were, at any rate, some elements among the Egyptians which were not quite as manageable as the ordinary peasants, namely, a privileged class, the warriors.

We do not know very much as to this class of population. It is not necessary to discuss here the military institutions of the Egyptians from the earliest time. On the monuments speaking of Pharaoh's troops we read mostly of mercenaries who also served as police whenever they were not needed abroad. They begin with the negro troops of the sixth dynasty; subsequently all possible nations of Africa, Asia, and Europe contributed to these troops. The soldiers of Egyptian blood are not so conspicuous; they are less well treated and in earlier time often are employed in peace, not only as policemen but as common royal workingmen, even at the hardest kind of public work. ${ }^{2}$

We know especially little about the various classes of native soldiers in the Middle Empire. According to their name, we should assume "the followers" (šmsw) to be specially privileged among them, possibly as doing personal service to the king (?); how they were distinguished

${ }^{1}$ A very interesting illustration is the quotation from Polybius given by Strabo, 17, I (791), characterizing the native population

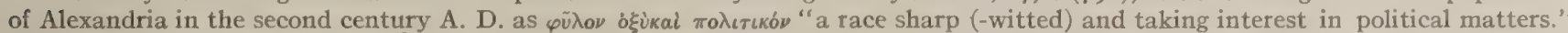
This characterization is, at first sight, very strange, because those words seem to fit only the Greek Alexandrines. Therefore, emenda-

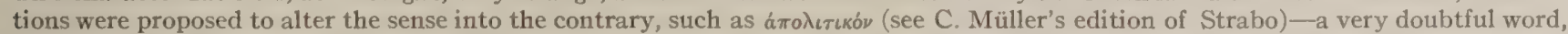
which does not harmonize in idea with the other designation "sharp, quick-witted." After thinking for a while of the emendation oú $\delta \dot{\nu} \nu \pi \pi_{\iota \tau \iota k o ́}$, which is not much more satisfactory, I believe that the passage expressed, in its original setting, the surprise of Polybius that the Alexandrines of Egyptian race were somewhat different from the dull and apathetic mass of the other Egyptian natives. Originally, Polybius, in all probability, added some limiting words, at least that their number made them an element without great influence in politics. In the present form, the passage does not so well show that an exception confirming the general rule was meant, but I now feel sure of this sense.

${ }^{2}$ E. g., on the famous representation of the transportation of the colossal statue (Newberry, El-Bersheh, I, pl. 15), the second row of the people pulling the statue consists exclusively of soldiers, as their costume and the inscription "the young people ( $z$ 'mw) of the soldiers ( $h$; wtyw) of the hare nome" shows. When we find foreign mercenaries mentioned at such public works, they do not pull stones, as some Egyptologists have thought, but superintend the work as policemen only and overseers, as said above. Cp. L. D. III, I 40 c, 2, I 7, I8, etc. 
from the soldiers called mnftyw is not clear, because the latter name seems to begin soon to be used vaguely. ${ }^{1}$ We find then "the hereditary troop of the soldiers which is (always) ready" $\left(m t p t^{\prime}\right)^{2}$ first mentioned under one of the later kings of the twelfth dynasty (Senwosret III, cp. Naville Bubastis, pl. 34A, 8). Their name means: the people who inherit with certain privileges the duty to serve in war time, probably also in peace on certain occasions. Thus they correspond, $e . g$., to the Timariots in the Turkish state. The nstitution seems to have been new then, because the inscription explains it still. In the New Empire we find "the hereditary soldiery" mentioned very often. Fron Pap. Sallier I, 7, 3, we learn that the "stable-owner" $h r y-h(w)$, represented the higher class of the "hereditary troops." It is said there: "If his horse(s) leave him (so that he is) afoot, he is taken to the hereditary class," i.e., here the infantry. ${ }^{3} \quad$ It is not expressly stated that the scenes of conscription, like Miss. Franc. V, 598, "the mustering of young recruits," where the scribe "was teaching everybody his duties of the whole army," refer to the "hereditary soldiers," but this is most probable." In these scenes they do not appear with arms; the representations in Medinet Habû (Rosellini, Mon. Stor. I 25 = Champollion, Mon. 218) show that the royal armory handed those out to the soldiers in time of war. From the Karnak inscription of Haremheb, line 25 (see my Egyptological Researches I, pl. 93), we learn that the soldiers of all Egypt were divided into two big "classes" $(s$,; not to be confounded with the small "classes," which correspond with our regiments), so that the division into the so-called Kalasirians and $\mathrm{H}$ (?)ermotybians (Herodotus, II, I64) seems to go back to the eighteenth dynasty at least. Herodotus and other Greeks describe the privileges of the soldiers as consisting in freedom from taxation and a uniform fief of arable land. ${ }^{5}$ According to the inscriptions, there was no caste system connected with this. It seems that the eldest son inherited the father's occupation and, evidently, the fief of land; the other children were free to choose their vocation and usually sought it outside of the military service. ${ }^{6}$ When there was no suitable heir to the military position, a successor was nominated by the government. Probably it was not difficult to find an applicant from the ranks of the peasant class for the use of a fief of very desirable ground. According to the Greek writers, nevertheless, in their time, the soldiers seem to have felt themselves to be a separate class of

${ }^{1}$ E. g., a prince of Elephantine (Rec. Trav. X, 188, etc.) fumished mnftyrw to the king "to overthrow his enemies." This makes us think of Nubian troops among these and makes it doubtful whether that expression marks a fixed military class even in the Middle

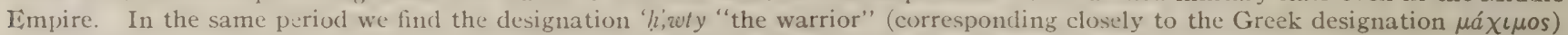
as profession, e.g., Garstang, Burial Customs, p. I91, etc.; see above on Newberry, El-Bersheh I, I5.

${ }^{2}$ Literally "from that which is on the hand." This expression seems to be explained as in the parallel English idiom, $i$. $e .$, of readiness at the calling of the king, less probably of the fact that those soldiers were bound to their place.

${ }^{3}$ See de Morgan, Catalogue I, r 20, "the stable-owners and officer-men (sw-snn!') of the hereditary class" in parallelism. Leyden, Pap. D. 132 (Möller, Hieratische Lesestiicke III, 14), 1. 15: "the officers (snny) of the soldiers of Pharaoh and his cavalry." So snny seems to be limited to the charioteers. When we find so of ten the designation of the hereditary soldiers as royal, as, $e$. $g$., $P a p$. Bologna, I, 14, "the hereditary force $(t,-y$ " $y t)$ of Pharaoh", this is no superfluous addition. E. g., L. D. III, I53, I3 "the officers of the hereditary force $\left(y w^{\prime} t\right)$ [from] the lands of Pharaoh"; similarly line 17 "from the land of Pharaoh." The contrast is furnished by Pap. Anastasi IV, 8 (Müller III, 5) "mustering soldiers (and) cavalry of the temples (their) serfs (and ?) youths at the command of the officers of His Majesty." $I$. $e$., the serfs of the temples sometimes were exempted from military service, sometimes a certain number of them were demanded for the Army, and even horses for the war chariots had to be furnished by the priests. Military service depended also in this case on land tenure.

${ }^{4}$ The pictures (ibid. 228, 288) ought not to have been explained as recruiting scenes; they represent the feeding at festivals of soldiers commanded to serve near the king. Here they are called $m n f(y) t y w$. See note $\mathbf{I}$, on the vagueness of this expression.

' In dynasty 18 special gifts of fields are given to officers, as a reward for preeminent bravery, L. D. III, x2d, 2 I. Consequently, the fiefs can not always have been of uniform size at that time.

${ }^{6}$ Diodorus I, 73, seems to assume that all children of soldiers entered on the father's profession, a proof that he had little knowledge of the ancient conditions. 
population, more than we should conclude from the above-described conditions; they formed thus a certain nobility, owing to their privileges and their esprit de corps.

This may be due partly to the fact that the Egyptian kings (from dynasty 20 on?) had settled foreign soldiers, principally Libyans, on the vacant military fiefs. Although intermarrying freely with the Egyptians and thus soon losing their racial characteristics and their foreign language, those soldiers still felt themselves to be distinct from the ordinary Egyptians. Their officers formed a still higher nobility and tried to rule over whole districts, which partly may have been given to them as royal fiefs in serfs, partly may have been usurped. The Pharaohs of later time had to fight much with these disobedient vassals, whom we find repeatedly ruling as independently as the medieval European dukes and counts. The termination of this often anarchic condition by Psammetichus's suppression of the "dodekarchy," $i$. e., the many small independent principalities, was still well remembered in the time of Herodotus (II, I47). He seems to give a correct tradition in describing how the royal government found in foreign mercenaries the best support against those unruly vassals; those nobles in their turn must have sought the favor of the hereditary soldiers by increasing their privileges. This development seems to explain why the soldiers in the later period of Egyptian history showed more pride than during the golden time of Egyptian conquests and held a more esteemed position in the state. Their history presents thus a certain analogy to that of the Mamluk nobility of medieval Egypt.

The fancifully exaggerated report that 240,000 (!) soldiers emigrated to Ethiopia (Herodotus, II, 30) when their privileges were shortened, and the not very clearly stated part which they had in dethroning King Apries, etc., again demonstrates that they continued to form a difficult element, even under the strongly centralized twenty-sixth dynasty. The Persians apparently left their prerogatives as much as possible untouched. I ascribe the endless revolutions which the Persians had to face in Egypt principally to this class of the population, as said above (p. 7); unfortunately we have no detailed information on any of those revolutions. If I am right, then the conservatism with which the Persian government treated their Egyptian province seems to have been the principal reason for their difficulties with the Egyptians.

Notwithstanding all these experiences, the Persians transmitted those conditions to their Greek successors, the Ptolemies. Under these we still have at least considerable remnants of the old system of the $\mu \dot{a} \chi \iota \mu o$, , $i . e$. , "those fit for fighting," the remu-qonqen (i.e., early rmtw qnqnw), which is the rare Egyptian name for "soldiers," according to the Rosetta stone, demotic line II. We shall find below the strange fact that the Ptolemaic hieroglyphic inscriptions lack a fixed name for them; the various words for "warriors" which they employ are so vague that they can be applied also to the privileged settled soldiers of Macedonian and Greek descent, to mercenaries, and are even more ambiguous (cp. p. 6o, note $6 ;$ p. 72 , note 7 ).

In general, we again know little as to the native soldiers in the time of the Ptolemies. On the treatment of this class see especially P. M. Meyer, Das Heerwesen der Griechen und Römer in Aegypten, I900; Jean Lesquier, Les institutions militaires de l'Égypte sous les Lagides, I9I I. For this we have, unfortunately, material only from the time after our two decrees, when probably considerable changes had taken place. We notice, then, above all, that the name

1 Twelve is merely a symbolical number. At most times the number of principalities must have been larger. 
$\mu \dot{\alpha} \chi \imath \circ \iota$ is no longer strictly limited to the native Égyptian soldiers; it is applied also to "Greek machimoi." Egyptians are then called expressly "Egyptian machimoi" and play a much smaller part than before, it seems. ${ }^{1} \quad$ Probably the Ptolemies, after the unfortunate experiences of the great revolution, had filled the vacant soldier fiefs with Greeks in order to eliminate gradually that dangerous native class.

We should expect that the soldiers, claiming to be superior to the cowardly serf-class of the peasants, rather lived from their fields by subletting them to the peasants, but it remains to be examined whether the lots of the soldiers as described by Herodotus (II, I68, "I2 Arures") allowed this plan, which would agree so well with Oriental manners. The Greek papyrus 63 of the Louvre (Notices et extr. des mamuscr., XVIII, p. 360) speaks of the economic condition of the soldiers under Ptolemy Euergetes II. (CP. Lumbroso, L'économic politique, 229. ${ }^{2}$ ) 'This petition describes the warriors as (1.87) "in the city night and day, overworked with their

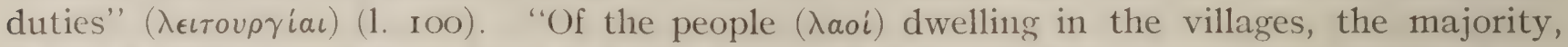
driven by bitter need, must work and earn a living; but many of those connected with the army

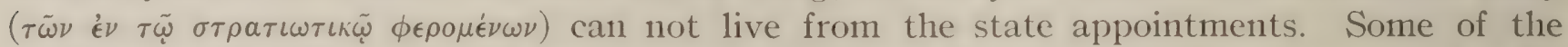
machimoi, rather the majority, can not with their own labor procure from their own lot ( $\epsilon$ k

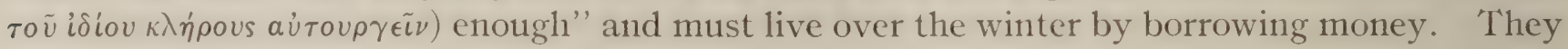
have not even enough seed for their fields (1. Iro).

Unfortunately, it is not clear how all these gloomy descriptions apply to the native warriors. The "people" ( $\left.\lambda a a^{\prime}\right)$ ought to be distinguished from them according to the ordinary use of this word (cp. below on Rosetta, 1. I2), and indeed (lines 132, I33) we find "the poor people and the machimoi." But that petition does not seem to make this distinction regularly. Finally, the needy warriors there (in 165 B. C.) appear to be largely Greeks, accord ng to what has been observed above. Therefore we are in doubt whether those complaints may be taken as a description of the natie warrior's life. Granting all this and admitting the petition to move in great exaggerations, nevertheless we may conclude that the warriors always had only a very moderate existence under the Ptolemies. We suspect also that not much remained of the freedom from taxation which they still liad enjoyed under the Persians, but we have no certain data on this point. ${ }^{3}$

It is questionable how of ten the Ptolemies armed the native warriors. I should not press the passage of Polybius (V, IO7), which we shall discuss below, so far as to imply that, up to the year $217^{4} \mathrm{~B}$. C., they never lad been used practically. It would be strange if the first three kings of the Macedonian dynasty had not needed them in their numerous wars. Diodorus (XIX, 80) refers to an employment of the natives in war under the first Ptolemy in a rather credible way. Still we may infer from Polybius that they were not used regularly and had not been called to arms for some time; the special necessity of an unusually dangerous attack on

\footnotetext{
${ }^{1} \mathrm{~J}$. Lesquier, p. Io, 105, Pap. Tebtunis, I, Index.

2 I found the edition needing many corrections, after the facsimile, pl. 6, but do not have the book now at hand.

3 The Mendes stela (1. I4) reports that the king Ptolemy selected as pages or guards for the sacred ram or goat of Mendes "of the fine youths from the warriors (mnftyw, see p. 38) of Egypt, the best $t p(y) w$ from the children . . " "This. looks as though the wealthier temples had to contribute sonething for the support of the warrior fanilies under such pretexts of an honorary employment. Such a pretext for a sinecure would be more natural with the aristocracy of Macedonian blood, but would these people send their children to the temples of the native gods for such services?

${ }^{4}$ For practical reasons I have throughout this book, as much as possible, adopted the chronology given by Mahaffy, The Empire of the Ptolemies, without touching various uncertainties.
} 
Egypt forced Ptolemy IV. not to overlook any means of defense and to resort to that force. If this had not been done for a longer time, the suspicion arises that those warriors beforehand had proved to be a dangerous element among the natives; they may have already given some trouble to the first three Ptolemaic kings.

At any rate, the number of the native warriors must have been moderate. We do not take seriously the fanciful numbers of Herodotus (II, I65-166: still 4 I0,000 remaining after the emigration of 240,000 to Ethiopia!) and Diodorus I, 54 (650,000, a number taken from Herodotus without criticism!). Polybius gives their total as 20,000 at the battle of Raphia, where Ptolemy IV. made that fatal mistake of gathering them. It is true, we can not guarantee that those 20,000 represented the whole number. Ptolemy IV. might have called only a part to arms, mistrusting them from the beginning. The great probability remains, even under this assumption, that their number did not reach that of the regular Macedonian and Greek soldiers. So, while it is not probable that the native warriors remained constantly quiet and loyal for the whole first century of Macedonian dominion, yet their limited number and their scattering over the whole country seem to have enabled the powerful first three Ptolemies to keep them under control.

Various reasons increased their dangerous character under Ptolemy IV., Philopator, a king with whom, in general, a certain decadence of the flourishing Lagide state seems to begin. Polybius, of whom we possess a very valuable fragment on the outbreak of the great revolution $(\mathrm{V}, \mathbf{1 0 7})$, attributes the reason principally to that mistake of gathering those natives for the battle at Raphia, 2 I 7 B. C. His report runs thus:

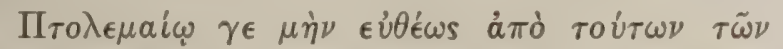

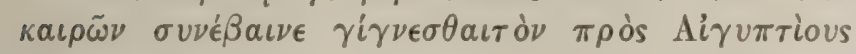
$\pi \dot{o} \lambda \epsilon \mu o \nu$.

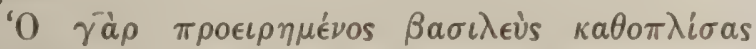

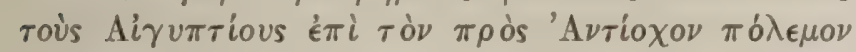

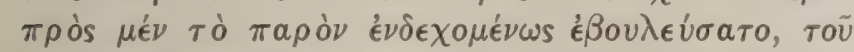

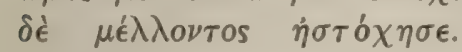

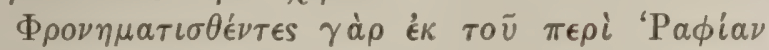

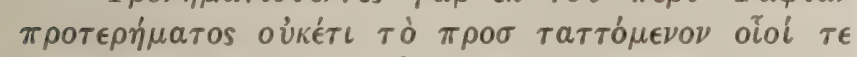

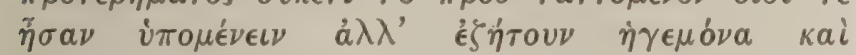

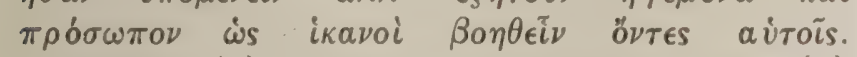

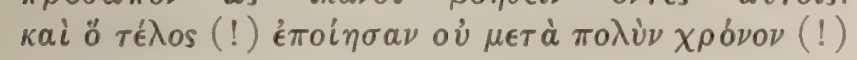

To Ptolemy soon then after those times it happened that the war against (the) Egyptians broke out.

For the aforementioned king by arming the Egyptians for the war against Antiochus followed a plan practical for the moment, but he made a mistake for the future time.

Becoming namely presumptuous by their success at Raphia, ${ }^{1}$ they were no longer able to obey orders ${ }^{2}$ but sought a leader and a pretext, as people able to help themselves. Which thing they finally (!) did, not after a long time (!).

We see here that Polybius does not acknowledge that those Egyptians had a real complaint; they ought to have been satisfied with the blessings of the Ptolemaic government, according to his opinion. The national feeling of this Greek author, who viewed that best one of the Hellenistic states with complacency and pride, is plainly visible here. Unfortunately, his report as to finding a leader and "pretext" (!) is lost. The latter expression, evidently, points to something which Polybius considered as not too unjust against the Egyptians or too grave a matter. The probability is that some administrative measure infringing on the rights or livelihood of the warrior class furnished that "pretext"; certainly it would appear, if we knew

1 So their phalanx must have played a more important part in that victory than the extant reports on that battle manifest.

2 This expression ("what was imposed on them") points to regular duties or dues demanded by the state. 
it, much more serious to us than to Polybius. As a representative of the last century of Greek independence, he was too much of an aristocrat to understand demands of the lower classes in general. Polybius, in Book XIV, I2, returns to that revolution and mentions it in a very similar way. He describes the profligate life of Philopator after his victory over Antiochus of Syria and continues:

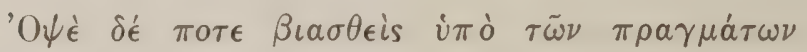

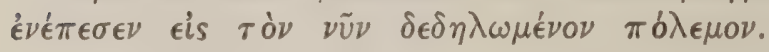

But at some near time, forced by the circumstances (!), he fell into the here-mentioned war.

This again sounds like exonerating the king and is in such contrast with the previous description of his tyranny that we can not assume the numerous personal faults of the king to be held by Polybius to be responsible for the rebellion. ${ }^{1}$ As something which might have "happened" ( $\sigma \nu \nu \dot{\epsilon} \beta a \iota \nu \epsilon, \dot{\epsilon} \nu \dot{\epsilon} \pi \epsilon \sigma \epsilon)$ also to a better king, it would again best be understood of some administrative measure based on the system of government used by his predecessors. This lenient judgment of the historian would seem to include even new taxes as something for which the subject class of natives ought not to have raised rebellion. If those natives remonstrated or demanded reforms, I fear even as sober a mind as Polybius would have considered this as unbecoming (according to Greek thinking) to the native subjects of the Hellenistic states. At present, however, it is impossible to find anything positive on that "pretext" of the machimoi.

We suspect that the forced reforms mentioned in the decree of Rosetta inc'ude the removal of that "pretext," but there is nothing among the enumeration of these reforms which refers to the native soldiers in special. This could be explained by the assumption that the odious measure which furnished the "pretext" might have been withdrawn directly under Ptolemy IV., Philopator - not a very probable explanation, according to what we know of his character. It seems more plausible that those special concessions are covered by the general statement of line $\mathrm{I} 2$ of the Greek text, "from the revenues and taxes existing in Egypt he remitted some completely and reduced (кєкои фєкє) others." The redactor of the decree, evidently, saw that the detailed description of those concessions, implying a considerable loss of royal prestige, would be tactless. That he had the warriors specially in mind in referring to those reforms becomes evident from the following clause: "in order that both the people (o vaos, see above) and all the others be prosperous." These "others" mean hardly the higher classes, such as Greek or Egyptian priests; in the first place those undeserving rebels, the warriors, are in the mind of the writer.

In both passages of Polybius the revolution is said to have followed rather soon after the battle of Raphia, 217-216 B. C. Not immediately, as we see from the lapse of time necessary for seeking a "pretext" and a leader. This points to the facts that those soldiers in time of peace were widely scattered and that the peculiar geography of Egypt, a narrow country, widely extending in one direction, made possible a comparatively slow process of communication between the dissatisfied elements after their disbanding. Thus the plotting of the revolution ought to have taken some time. On the other hand, the repeated statement of Polybius that the outbreak came not very long after that battle of Raphia, i.e., after 216 B. C. (year 6 of the 
king?) sounds like a hint at an interval of not more than two or at the most three years. Yet it seems to be an erroneous statement; ${ }^{1}$ the interval evidently was longer:

We have, fortunately, a very valuable and precise monumental statement in the two hieroglyphic inscriptions describing the construction of the temple of Edfu. ${ }^{2}$ Both texts state that the great court gates were under construction "until $(r-m n)$ the year I6 of His Majesty" (i. e., Philopator, whose name has been mentioned before). Then came the disturbance (hnw) which broke out afterwards ( $r$ [variant 'w] hpr hrr s'). There rebelled (btn) godless (lit. ignorant, know-nothing) people ( $h m w)$ in the southern half ( $m g s h n t)$ [addition in B.: and there stopped the work in the seat of the gods as there was violence $(r d n d n$ ?) in the southern part] until (nfrt-r, nfrt-'w) year I9 of the son of the Sun, the heir of the Gods Fatherloving, chosen by Ptah, etc., Ptolemy, beloved of Ptal! the blessed defunct, the God Epiphanes [repetitious addition in A.: ... the son of the Sun, Ptolemy, everliving, beloved of Ptah, the kind $\left.\operatorname{god}^{3}\right]$ who (A.) pacified the land $\left(\operatorname{sgrh} t^{\prime}\right)$ ) and conquered those rebelling against him ( $d r$ $b$ tnw-f); [variant in B.: the strong one $(n h t)$, the king who conquered the disturbance in the whole land, $d r$ hnn $r t, z r-f]$.

A still later date would, at first sight, seem to be given in the first Turin papyrus referring

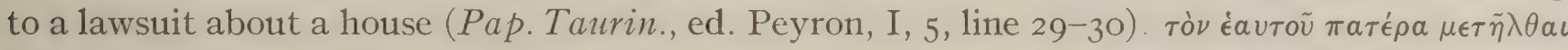

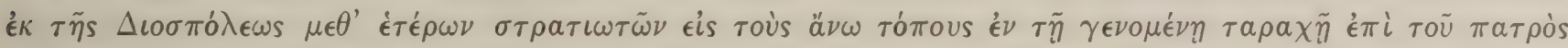
$\tau \tilde{\omega} \nu \beta a \sigma \iota \lambda \epsilon \omega \nu, \theta \epsilon o \tilde{v}$ 'E $\pi \iota \phi a v o \tilde{s}:$ " that his father had departed from Thebes with other soldiers to the regions higher up in the disturbance which broke out under the father of the kings, the God Epiphanes." Following this the lawyer counts for the time which the house of that Greek soldier had remained deserted, the full 24 years of Epiphanes, so that the passage could be interpreted as though the revolution had broken out at the death of Ptolemy Philopator. ${ }^{4}$ The above is, however, only an approximate statement. It seems that the calculation of the defendant tried to shorten the number of years, and the plaintiff in repeating that calculation could well afford to overlook a couple of years under Philopator. The general reluctance against speaking more than was absolutely necessary of that sad episode, a reluctance which we can observe throughout the Rosetta decree, seems to be noticeable also here, in this overlooking of some time under Ptolemy IV. That these years must not be overlooked by the

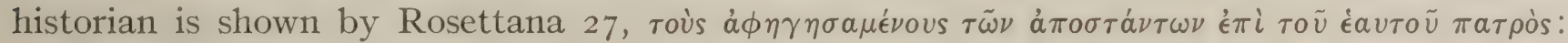
"the leaders of those who had fallen away under his father," and that Epiphanes (27-28) punished them, "taking vengeance on behalf of his father" (' $\pi \alpha \mu \nu \dot{\nu} \omega \nu \tau \tilde{\omega} \pi \alpha \tau \rho \dot{i}$; this remark is lacking in the demotic text). See also the second decree of Philæ (line I I), if my restoration "his father" is right. These hints that already Philopator had long and hard fights with the

1As pointed out in the text of Polybius, quoted above, p. 13, the expressions "finally" and "not after a long time" do not harmonize. I hesitate to decide whether this negligent style can be attributed to Polybius himself, whose language is very precise wherever we are sure of the original text. I suspect here rather an instance of hasty redaction by the epitomizer of Polybius. Thus it becomes probable that the original form of the text was much fuller and that it defined-above all-the space of time between the battle of Raphia and the revolution much better than in the extant form.

${ }^{2}$ A. Duemichen, Tempelinschriften, I, 95 (=Aeg. Zeitschr., 1878, 44; Brugsch, Thesaurus, 1330). B. Aeg. Zeitschr., I870, pl. II (p. I foll.) = Brugsch, Thesaurus, 1334 .

${ }^{3} P$-nir mnh. This title usually expresses Euergetes, but here the surname of Epiphanes, Eúxápıros. This looks like an almost inoredible error, i.e., a translation of the Greek expression without knowledge of the official hieroglyphic title. We should suppose that this title was known even to the most ignorant priestly writer, but the error can hardly be explained away.

${ }^{4}$ Thus understood it, e.g., Revillout, Revue Arch., 1877, 326, "in the moment of the death of Philopator after the Greeks themselves"(!). Similarly Chrestomathie Démotique, XCII. 
rebels agree well with the preceding general statements of Polybius. The texts of Edfu, on the other hand, leave only the years 16 and 17 and a part of the year 18 for the duration of the revolution, so far as it fell under Philopator. We should have expected a somewhat longer time, and the expression of Polybius "soon" (after the battle of Raphia) appears to us as a careless designation for a space of ten years after that battle. In defense of Polybius' "soon," we might assume that the revolution started in Lower Egypt some time before the sixteenth year. This is quite possible, because the majority of the machimoi ought to have been settled in Lower Égypt; also the hard fights in the Delta, as described in the Rosetta inscription, seem to confirm their frequency there. It does not seem, however, that by seeing in the date of the sixteenth year merely the extension of the revolution to Upper Egypt and by assuming even isolated previous revolutionary movements in this part of the country, we can save much of the authority of Polybius. A year more or less will not alter the discrepancy materially. On the other hand, it must be repeated that the approximate statement of the Turin papyrus does not warrant that the Greek soldiers at Thebes stayed there for over two years after the revolution had seized the country farther south, around Edfu. ${ }^{1}$

Polybius (XIV, I2) complains of the difficulty in following the war in detail, giving the general characterization that it was remarkable only for the cruelty and faithlessness shown by both sides, but presented no larger regular battle on land or sea or siege. Comparing this statement with the epigraphic reports on the siege of Lykopolis, etc., we must suspect that the above characterization may be somewhat exaggerated and caused by regard for readers in Greece proper. A man not very well acquainted with the geography of Egypt would find it quite difficult to follow (through the confusing nomenclature of the Greeks) the endless settlements of Egypt." Polybius may be right, however, that the war was of a peculiar type. Judging from the unwarlike, malicious, and perfidious character of the Egyptians and the character of their country, I believe that the rebellion did not cause a general rising of the whole Eigyptian population against the hated foreigners through the whole country at once. Where the native warriors could assemble in considerable numbers, the rebellion, indeed, may well have assumed the character of a general rising of all natives. In other places, however, those open belligerents, the hereditary warriors, according to their small number, may have formed only roving bands, massacring and plundering the Greeks here and there ${ }^{3}$ and retiring to the small islands in the Delta or, in the South, to the desert mountains when larger bodies of royal troops appeared. The populace probably joined them in plundering and murdering the foreigners where it could be done safely. When regular troops approached, only the guiltiest, I believe, withdrew to the strongholds of the machimoi; the majority subjected themselves again to the Greek authorities whenever these had any considerable number of soldiers, proclaimed their unshaken loyalty to the royal house, and denounced eagerly their personal

${ }^{1}$ If we can use the Apis inscriptions collected by Brugsch, Aeg. Zeitschr., I 884, I 27 (a rather doubtful material, I fear), we should know that an Apis from a place in "the territory of Thebes," $i$. $e$., the Thebais, called P-ha or Ha (Brugsch, 1.1. 129, identifies it with Denderah, which is very improbable; it may be a mere village) was brought to Memphis about 5 years before the enthronement of Epiphanes. This presupposes that Middle and Upper Egypt were under control of the Greek government about the year 12 to 13 of Philopator, a good confirmation of the Edfu text against Polybius' remark about the time of the outbreak.

${ }^{2}$ Polybius, nevertheless, must have given some account of the war. For the above reasons, however, this report was, it seems, omitted by the copyists of the manuscripts of his history. European readers found too little interest in it.

${ }^{3}$ In Pap. London, II, ed. Forshall, a Greek, who died during the revolution, is mentioned. The way in which he died is not defined, because it did not appear loyal to speak too much of that sad time, as we have seen repeatedly. 
enemies as rebels. Such a condition of irregular warfare is betrayed, indeed, by the mention of military guards, which, apparently, had to be distributed through the loyal parts of Egypt to protect life and property of loyal subjects (see Philæ decree II, line $\operatorname{IO} d$ to $f$ ). We need not follow too literally our priestly historian, who clumsily limits those guards to the protection of the temples and priests. The most interesting light on the warfare is thrown when he claims (line $I O e$ ) that the guards against the rebels could also be recruited from native Egyptians, even from "soldiers," i.e., from those who had deserted from the ranks of the machimoi. We may, perhaps, apply this condition more to the later period of the insurrection, when the cause of the insurgents was in the decline and the weakness of the Egyptian character would manifest itself very readily. In the first years, $i . e$, in the reign of Philopator, the rising of the natives must have been more general, to judge from the results of the revolution. Furthermore, we are warned also against underestimating its importance by the way in which Polybius mentions it. He reveals its very serious character by calling it a regular "war" (see p. I3). We must not take too seriously the expression $\tau a \rho a \chi \eta^{\prime}$ : "disturbance, disorder" (with the exact Egyptian equivalent $\underline{h n n}, \underline{h} m w)$, which later was used officially for that period. It is a euphemistic word and seeks to minimize the seriousness of the national uprising. ${ }^{1}$

At any rate, we may be sure that the greatest part of Egypt was in the hands of the insurgents during the first years of Ptolemy Epiphanes. Conditions were worst then, when the guardians of the royal child fought among themselves for the control of the government, i. e., for possession of the treasury in Alexandria, and when the adjoining kings attacked the Ptolemaic provinces outside of Egypt. It seems that the Egyptian government concentrated its whole power on the defense of the Syrian provinces against the Seleucidan attack, a proof that it considered the military power of the insurgents as far inferior to that of Antiochus. This meant the temporary abandonment of the largest part of Egypt. We must ask whether much ground could be maintained outside of Alexandria "in the nomes" (as Ros. hierogl. I, demot. I6, Philæ II, $g d$, characterizes the interior country) during the most critical time." Unfortunately we have no knowledge what city in the Delta at that time possessed a Greek population large enough to maintain itself against the natives. ${ }^{3}$ It would be very interesting to know something about the fate of the exclusively Greek cities higher up, e.g., about the colony Ptolemais. Most likely their whole Greek population had to flee northward.

It was during that critical time that the government thought it wise to offer to the natives

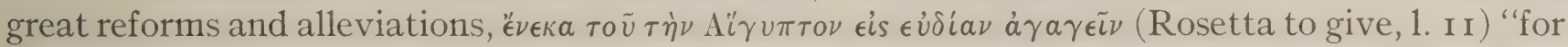
bringing Egypt to a quiet condition," demotic text (1. 7), "to create (e t(y)-hpr) quietness

${ }^{1}$ See this expression already, Ros. Greek 19. For the hieroglyphic equivalent cp. the foundation texts of Edfu. The demotic expression thith, thith (Ros. II).

${ }^{2}$ A recollection of this condition, Diodorus, XXVIII, I5: (Ptolemy V) "was hated by the Egyptians and was in danger of losing

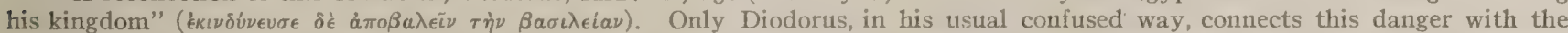
ungrateful execution of the guardian Aristomenes (about which the natives certainly did not care) and thus leads to a wrong chronology, etc. See also the statement of a fragmentary extract from Polybius in Angelo May, Script. vet. nov. coll., II, 544:

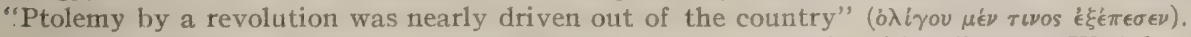

${ }^{3}$ It is difficult to draw a conclusion from the stela of a Syrian (?) policeman $K h a^{\prime}-h a p$, who according to the calculations of $L$. Stern (Aeg. Zeitschr. 1884, 108), died in Memphis "in the fifth month of the second year," i.e., of Epiphanes. That, in this biographic notice, he leaves it to the reader to supply the names of the kings under whom he lived is very common in such inscriptions and must not be explained as caution. The Asiatic population of Egypt always seems to have considered itself as superior to the native Egyptians and more akin to the Greeks, so we could not well expect the man in question to have sided with the insurgents.

"The old meaning of this causative formation, originally "quieting," seems to be lost (as in Coptic sğraht, sğreht: quietness) or is, at least, uncertain. 
$(m t-s g r h)$ in Egypt" - a very remarkable confession by an inscription in the official style. After a remark on liberality to the Greek troops (see below), the same inscription informs us:

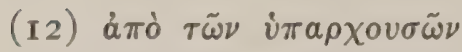

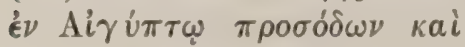
$\phi \circ \rho \circ \lambda o \gamma \iota \tilde{\omega} \nu, \tau \iota \nu a \dot{s} \mu \dot{\epsilon} \nu$ $\epsilon \dot{s}$ $\tau \dot{\epsilon} \lambda o s \quad \dot{a} \phi \tilde{\eta} \kappa \epsilon \nu, \quad a ́ \lambda \lambda$ as $\delta \dot{\epsilon}$

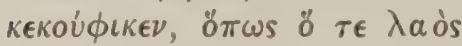

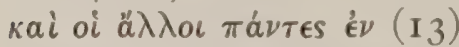

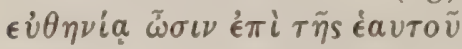

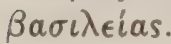

Of the revenues and taxes existing (before) in Egypt he abandoned some entirely and lightened others in order that both the (ordinary?) people $e^{3}$ and the whole rest (!) be in prosperity under his reign.
DEMOTIC TEXT (1.7).

The taxation (hty) (and) revenue $(s k r)^{1}$ which had been continuing $\left({ }^{\prime} h\right)^{2}$ in Egypt, he had taken parts $(p \xi s ?)$ from them (and) he had abandoned them entirely $\left(z^{\prime \prime}, z\right)$ to make the people (? see below) and all the other men to be well (off) at the time of his reign.

See above on the excessive caution manifested in these reluctant allusions to the rebellion and on the distinction of two classes of population which seems to contain a hint at the warriors. The great difficulty is that the word of the demotic version, which corresponds

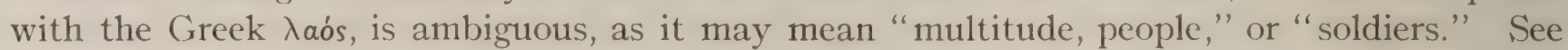
below on Philae II, I $7 e$, etc., about the difficulty that both Egyptian versions lacked a clear distinction between those two expressions. The possibility that the demotic writer may have thought here of the native warriors as the element first to be placated is increased by the hieroglyphic version (Damanhur, I 2). It has "mnft-soldiers," i. e., a word which ought to designate even a privileged soldier class (p. 10; cp. p. 60). 'The hieroglyphic version, as usual, follows the demotic and seeks to make its sense more distinct; it seems here a valuable guide, although its strong disfigurement by the illiterate engraver would not exclude the possibility of connecting that expression "mnft-soldiers" with the Greek $\delta$ iós instead of with "the rest."

Even more important seems the next concession (Greek, line I3):

DEMOTIC TEXT (1. 8.)

$\tau \dot{a} \tau \epsilon \beta a \sigma \iota \lambda \iota \kappa \dot{a}$ ó $\phi \epsilon \iota \lambda \eta \dot{\eta} \mu a \tau a d$ $\pi \rho \circ \sigma \dot{\omega} \phi \epsilon \iota \lambda \circ \nu$ oi $\dot{\epsilon} \nu \tau \tilde{\omega} \mathrm{A} i \gamma \hat{v} \pi \tau \omega$

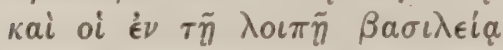

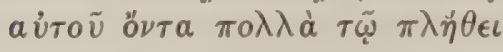
á $\phi \tilde{\eta} \kappa \epsilon \nu$. and the debts due to the government which still were owed by the inhabitants of Egypt and of the rest of his kingdom, he remitted, (although) being a great amount. of the king which owed the Egyptians and all those in his kingdom, amounting to ('r) a great figure, he abandoned to them.

In connection with this, a far-reaching amnesty to criminals was granted, liberty to those imprisoned and a remission of private debts of long standing (1. I4); this latter concession meant, likewise, a freeing from imprisonment in many cases. ${ }^{3}$

The inscription passes over to the concessions to the priests, which are rather moderate, I think. Some modern writers exaggerate their importance in order to prove that the Ptolemaic government wanted to win the pious masses first by benefits to their gods and priests. Whosoever is not deceived by the prominence which the priests, of course, must give to their special grants, and looks at the practical meaning of these grants, will judge more soberly. I think an unprejudiced examination will not confirm the belief that the Egyptian rebels had fought in any religious interest, for their gods and temples. The prominence given by the priests to their

\footnotetext{
1 This word means in Coptic: "rent, income from the use of something."

${ }^{2}$ Lit. "standing, remaining, established."

That is, the natives; but compare the other versions.
} 
own benefits received from the crown must not be overrated also for another reason. In the priestly decree of Memphis-Rosetta the priests, after all, act as spokesmen for the people and thank the king principally on behalf of these, although pretending that they have been specially benefited by him.

At the side of those great reforms for the natives in general, we find no special concession for the future to the rebelling warriors, as stated on page I4. The view that this silence of the decree was nothing but tactful caution (p. I4) seems most plausible. Otherwise we might interpret this absence of special consideration of the warriors as though the government wanted to win the unwarlike masses and to separate them from the warriors, who alone were hardly numerous enough to be very dangerous, as shown on p. I3. An amnesty, however, was offered to the warriors and to all insurgents, another very great concession from the point of view of such a despotic government as that of the Lagidx:

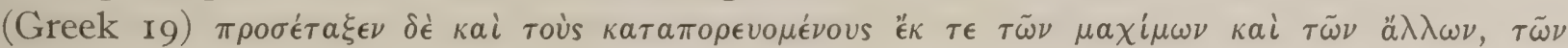

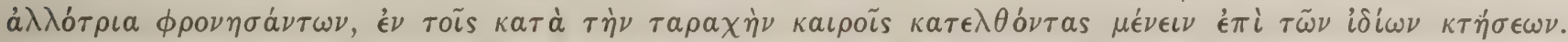
"He ordered also that those of the warriors and of the others, having different (political) views (!), who, during the time of the disturbance (cp. above, p. I7) surrendered (lit. came down), should remain in possession of their property."

The demotic translation is here specially interesting, showing much more clearly than the Greek text that not an amnesty to those who had already deserted the rebels is meant, but a promise held out to the rebels in order to make them return to loyalty:

(1. II) "he ordered again concerning those who would come (n-nt $\ddot{e}-w e \hat{\imath}$, future!) (from) among the warrior class $(n-r m(t) w$ qnqn, cp. p. 6o) and the rest of men who had been $(\ddot{e}-' r$ $h p r)$ on other ways $(h r k t h t m(y) t)^{1}$ in the disturbance which had been $(!)$ in Egypt $(n p$-thth $\ddot{e}-' r h p r(n) K m t$ ) should be left (remaining?) (1. I2) in their places (e t(y) [hpr?]-st [n] $\left.n w-m^{\prime} w\right)$ and that their goods should be theirs" (nt(u) ww-nk(w)t hpr hr-w).

This version distinguishes thus more clearly between the two classes of rebels than the Greek original. It divides the Greek expression $\tau \dot{\alpha}$ i $\delta \iota a$ "their property" into movable and immovable property in order to show the full value of the amnesty, and, as said above, represents it more distinctly as an offered inducement to the rebels by employing the verb in the future. We see thereby that the government did its best to win the natives, but it contains also the proof of the desperate situation in which the Ptolemaic dynasty was placed.

It is not likely that all this enforced liberality and mildness had much effect as long as it could not be backed up by military successes. After such successes of the governmental troops, however, the cowardly character of the Egyptians, of which we have spoken so often, probably began to manifest itself and to find the reforms tempting enough to desert the national cause or even to turn against it, as described above.

${ }^{1}$ Most curiously, after mentioning the remission of the yearly trip of the Egyptian priests to Alexandria for presentation (before the high priest of all Egypt), the writer of the decree by the mention of this voyage (which, of course, was made almost exclusively by water) seems to be reminded of a similar matter referring to navigation, and inserts, as a postscript to the general reforms:

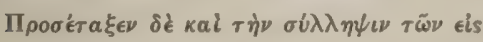

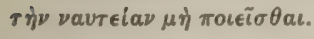

He also ordered that the "pressing" of people for the navy should not be made. (demot. 9) $\mathrm{He}$ ordered not to seize rowers (?).

Notwithstanding the fact that this reform falls out of the carefully arranged order as said here, it is not to be limited to the priests; it means another great general concession for all the natives, to whom that levying of rowers must have been a great oppression. 
The turning point was, evidently, the end of the war with Antiochus of Syria, I98 B. C. (year 7 of the king). The large army ${ }^{1}$ under Skopas became free at this moment and could be used against the rebels. ${ }^{2}$ These, in all probability, had no uniform plan of defense. On the other hand, the numerous water-courses splitting up the Delta made it difficult for the royal troops to deal promptly a decisive blow. As such the capture of Lykopolis, in the year 8, is represented by the Rosetta stone. This inscription, dated in the 9th year of Epiphanes, month 6 (I96 B. C.), describes the king as in possession of Memphis and of a great part at least, possibly all, of the Delta. Apparently also a good stretch of land south of Memphis was in the hands of the king; otherwise the coronation ceremony at Memphis would appear out of place. That coronation seems to have been almost contemporary with the decree; likewise the victory of year 8 over the rebels in Lykopolis, which secured apparently the possession of the Delta, must have preceded it rather directly. That it was this victory which brought wider parts of Egypt to subjection is visible from Ros. Gr. 29: the debts of the temples must be overlooked by the Ptolemaic government to year 8 (demot. 1. I 7 corrects this to "year 9," perhaps because the demotic version, out of flattery, wished to bring that benefit near to the date of the coronation; probably because the actual subjection of the rebellious regions was very near to the beginning of year 9, as said above).

The remarkable report on this military operation is as follows (Rosetta stone, Greek 1. 2I):

$\pi a \rho a \gamma \iota \nu \dot{o} \mu \epsilon \nu o s$ (1.22) $\delta \dot{\epsilon}$

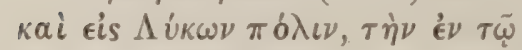

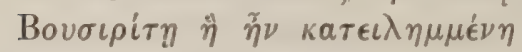
каi $\dot{\alpha} \chi \nu \rho \omega \mu \dot{\nu} \nu \eta \quad \pi \rho$ òs $\pi \circ \lambda \iota \rho \kappa i a \nu, ~ o ̈ \pi \lambda \omega \nu \delta \dot{\epsilon} \pi a \rho a \theta \dot{\epsilon} \sigma \epsilon \iota$

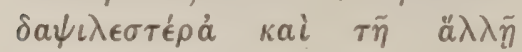

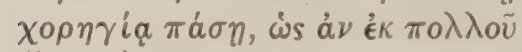

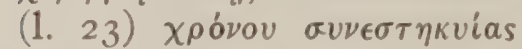

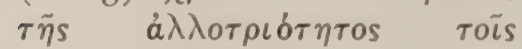

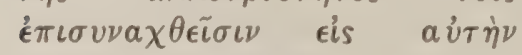

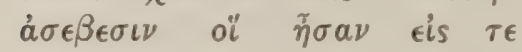

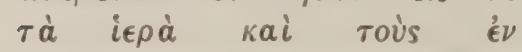

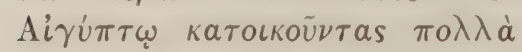
кака̀ $\sigma \nu \nu \tau \epsilon \tau \epsilon \lambda \epsilon \sigma \mu \dot{\epsilon} \nu \circ \quad \kappa a i$

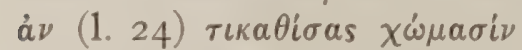

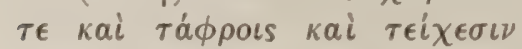

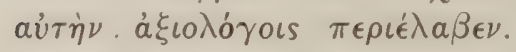

\section{DEMOTIC TEXT (1. I2)}

But moving to Lycopolis in the Busirite (nome), which had been captured and fortified for a siege and with a rich store of weapons and all other equipment, as for a long time enmity (i. e., all hostile elements) had been gathered by the impious men collected into it, who had committed much evil to the temples and the inhabitants of Egypt, and encamping against (the city), he surrounded it with remarkable mounds and ditches and walls.
(I2) He went to the city of Shekan (i3) [which had been captured] and equipped $(\text { ? })^{3}$ by the impious people (with?) all [fortifications?], there being much outfit, all preparations, in its middle.

He besieged the mentioned (lit. named) city with wall (and) $\operatorname{dam}(\mathrm{s})(\text { ? })^{4}$ (on its) outside because of the impious people who were in it, who were leaders of doing much violence against Egypt, having deserted the way of the commandments of the king and the commandments (I4) of the gods.

\footnotetext{
${ }^{1}$ Determined with the sign: "bad, hostile," owing to the special sense of the context.

${ }^{2}$ In the meantime the Alexandrian government had to keep the soldiers, the Egyptian Macedonians and Greeks, as well as the

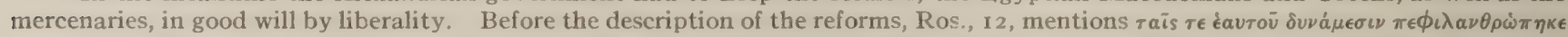

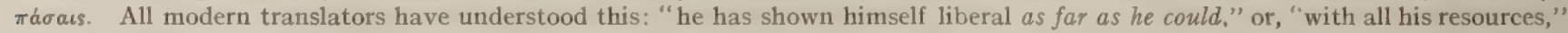
etc. The demotic translation is, however (1. 7): "he has given more and more $(w h-f t y)$ gift (s) ( $\xi p)$ to the whole army $(t-m i g t i)$ which

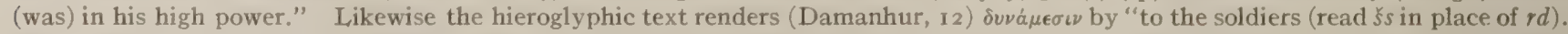
This looks at first like an incredible mistake, but at close examination proves to be the only correct sense of the obscurely worded Greek text. The decree characteristically hints that before all liberality and kindness to the native masses the king first did good to those who had the first claim, the Macedonians and Greeks constituting the nobility and the officials the ruling classes. This thought is expressed so awkwardly, obscurely, and hastily, possibly because it was embarrassing to state in that decree, which represented the thanks of the masses of the Ligyptian natives (p. 19), that the government once had shown some consideration to them.

${ }^{3}$ Correct, ' $t b$ to $s b t$ ?

4 The word $w n$ is suspicious. Read $t(i) n=t n$ below?
} 


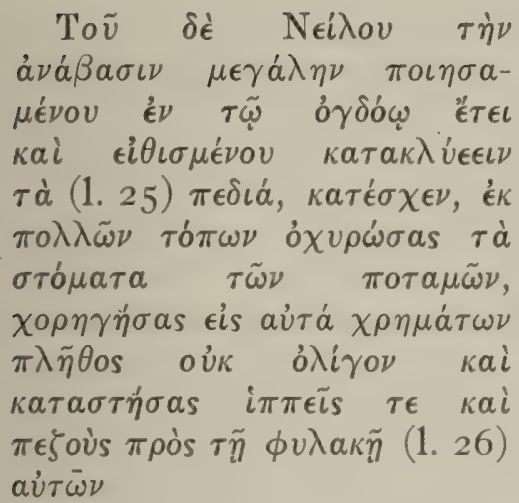

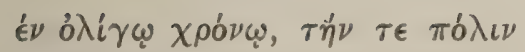

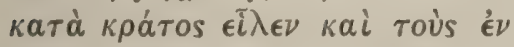

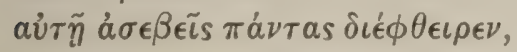

$\kappa a \theta \dot{\alpha} \pi \epsilon \rho\left[{ }^{\prime} \mathrm{E} \rho \mu\right] \tilde{\eta} s$ каi $\Omega \rho o s$ ó

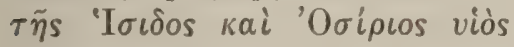

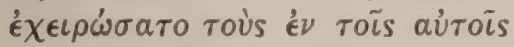

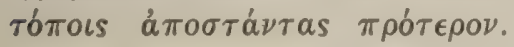

And when the Nile had made its (yearly) rise (specially?) great in the 8th year and was expected to flood the plains, he held (the Nile) under control, damming up in many places the mouths of the rivers (i. e., canals), spending for this not inconsiderable sums of money, and establishing cavalry and infantry for their (i.e., of the canals) guarding,

he took in short time the city by force (i. $e$, by storm)

and annihilated all the impious men in it,

as Hermes (!) and Horus, the son of Isis and Osiris, had overthrown the rebels in the same places aforetime.
He put dams (to) the canals which brought water to the city mentioned (above, a thing) which the former kings were not able to do thus; ${ }^{1}$

they (!) spent ${ }^{2}$ much money for them.

He counted (off) troops, men on foot ${ }^{3}$ and horses, to the mouth(?) of the rivers mentioned, to guard them safely on account of the [inundations] of water which were great in the year $8(1.15), \ldots$ to the mentioned (lit. named) rivers which brought water to much ground (!), being extremely $\operatorname{deep}(?) .{ }^{4}$

The king took the city mentioned by force within little time.

He made a massacre of the impious ones in it. He made it a slaughter, as did the sungod ${ }^{5}$ and Horus, the son of Isis, to those who had committed impiety towards them at the places mentioned formerly.

The remarkable liberty with which the demotic text proceeds makes it again a source of history of its own, although its clumsiness, its dependence on the Greek text, and its inferiority to the latter source must not be denied. The hieroglyphic version as preserved in the stone of Damanhur, lines 19-20, is incredibly mutilated and shortened. It reads:

"His Majesty went to Khentiwy [repeated]; she was ... (which) were in it, because they had made the beginning $[i . e$., leadership] of many acts of violence; they had transgressed against the way of His Majesty and the commandments $(s h n)$ of the gods." The rest is too unsafe and does not yield anything new. The incredibly disfigured hieroglyphic name of the city can now be restored. The demotic orthography has been elucidated by Spiegelberg's discovery of the

${ }^{1}$ It is not safe to draw from this free addition the inference that Ptolemy Philopator had attacked Lykopolis unsuccessfully.

2 Probably the third person plural is only an expression of the passive: "there was spent." It could, however, also be understood of the former kings; possibly, the demotic writer understands it thus: "(although) these spent." This would disagree, however, with his usually very good understanding of the text.

${ }^{3}$ Text erroneously: his foot!

${ }^{4} \mathrm{By}$ this addition the demotic writer wishes to show that he understood the inundation of year 8 as unusually high. That the Greek text is the original is shown by these explanatory words in a specially convincing manner.

"Thus also the hieroglyphic text of Damanhur. The god "Hermes-Thouti" in such a prominent part is surprising. Still I hesitate to restore the Greek text to $[\phi \rho] \eta s$ "the sungod" after the other versions. The engraver, at least, seems to have intended "Hermes," only we should like to assume that the reading was a misunderstanding of the name Phrê, "the sungod." 
name in a demotic schoolbook, the papyrus 3 I 16, of Cairo (Die demot. Papyrus von Cairo, text

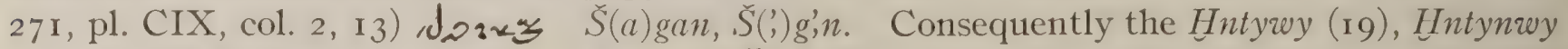
(20), of the Damanhur stone is to be read $\breve{S}^{\prime},(=H n t+,=t y) g(=n t y) n w$, exactly as written in demotic. The orthography of the Rosetta text (line 12 ) $2 / 52 \sigma_{-3}$ is now to be understood as $\breve{S} k a n$ or $\breve{S}(a) k \hat{u} n$. The varying expression of the palatal $k / g$ may betray the beginning of the soft pronunciation of that letter which we find in the Coptic letter Jima. The grouping of the names in the Cairo papyrus does not help us at all; a preceding city "house of Osiris of Rakotis" confirms only the neighborhood of Busiris, evidently not of Alexandria, for which the copyist seems to have misunderstood it. Would it not be possible to find our name also in the part of the Busiris nome which appears in the geographic lists as $\breve{S}^{\prime},-t p-n t y$ or $\breve{S}^{\prime}, s f(!)$ ? Cp. J. de Rougé, Géographie Ancienne de la Basse Égypte, 58.

The description of the campaign shows that the city was surrounded by water like so many Delta places and that the summer inundation had increased the strength of these natural fortifications. From the sentimental story how the noble king had even to pay the guards of the dykes, the inference could be drawn that the commander of the royal army wanted to protect the fortifications around the city mound, and at the foot of it, situated still in the plain, against flooding by piercing the dykes. 'This would mean an extremely difficult task, however. Simpler is the assumption that there is meant only the protection of the long highroads, which in summer stand like dykes from the inundating water; the rebels coming on boats from the city tried to cut these at the proper places ("at the mouth of canals," $i . \ell$., where navigable canals met those highroads at right angle) and to isolate the besieging Greek troops. The insurgents may have done this with success repeatedly; otherwise the efforts to protect the dams would not be mentioned. ${ }^{1}$

The final capture of the city was followed by a general massacre, as the Rosettana clearly states (cp. Damanhur, 22: "he made (of) them a great slaughter" ( $\check{s} d$ ",). 'Those occupants of the city, who even endured a formal siege, must have been the most desperate elements among the rebels, who had forfeited their lives repeatedly. 'Thus, it seems, the Greeks made an example of them, which impressed the other rebels deeply.

Here Polybius sets in with a fragment of the excerpta Valesiana (23, I6 Schweighaeuser, 2 I, I9 Dindorf):

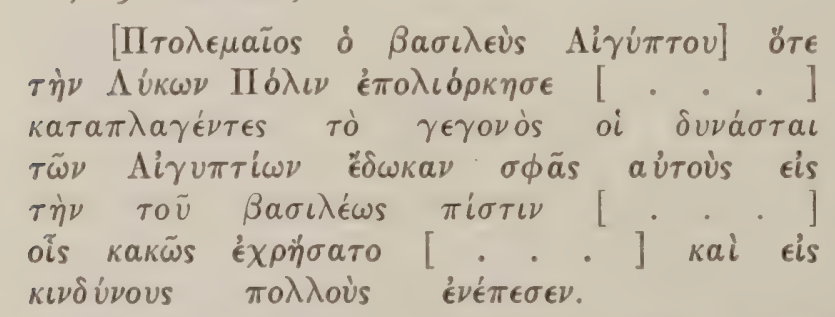

When he [Ptolemy the King of Egypt] (had) besieged the city Lycopolis [ . . . ] frightened by that which had happened, the chiefs of the Egyptians gave themselves into the faith of the king [ He treated these badly [ . . ] and fell into many dangers.

This very fragmentary excerpt ${ }^{2}$ confirms the Rosettana in reporting a formal siege of Lycopolis and terrible cruelties of the king's forces (indicated by the terror which seized the

${ }^{1}$ Budge, in his The Rosetta Stone (The Decrees of Memphis and Canopus, vol. II), pp. 30 to $3 \mathrm{r}$, strangely understood the description in the Rosettana that the king shut off the rebels from drinking water, until they "were driven to surrender; immediately all the stale water which lay a few feet telow the canal-bottoms was exhausted." A strange fancy! In summerly Egypt, at least in the Delta, the slightest digging strikes ground water and should have prevented a surrendering for the sake of thirst.

${ }^{2}$ Schweighaeuser, 7,516 , remarked correctly: in brevius haec contracta esse a compilatore eclogarum satis apparet. 
rebels), but its second and third sections must not be interpreted, as usually is done, as recording the surrender of the rebels inclosed in the city, so that "what happened" would be the progress of the siege. My understanding of the text is that it records the completed (aorist) siege; the verb thus includes also the final capture of the city. The description of the Rosettana excludes a capitulation. To assume that the priestly writer wanted to hide the breach of the capitulation by his expression "he took the city by storm" seems to me very unsafe. Such a concealing would look like embellishing the actions of the divine ruler, the king, i. $e$, excusing them. This could be interpreted as criticizing them, and those poor priests were careful enough in their expression, especially at that time, to avoid the punishment of laesa majestas. Thus I take the storming of the city and immediate massacring of the defenders quite literally. The surrender of the rebels seems to mean those in adjacent districts of the Delta, east (and south?) of Busiris. This and the breach of the capitulation by their execution, namely, is indicated somewhat also in the following words of the Rosettana:

\section{(27) $\tau o v ่ s\left[\delta^{\prime}\right]^{1}$ ả $\phi \eta \gamma \eta \sigma a \mu e^{\prime} \nu o v s$}

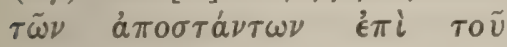

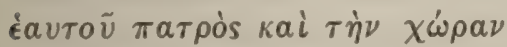

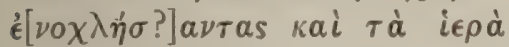

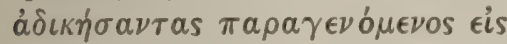

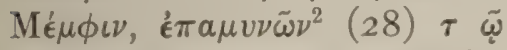

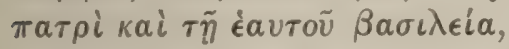

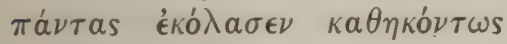

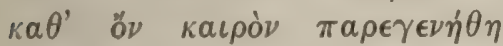

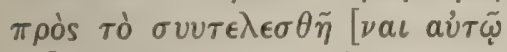

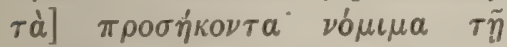
$\pi a \rho a \lambda \dot{\eta} \psi \epsilon \iota \tau \tilde{\eta} s \beta a \sigma i \lambda \epsilon i a s$
(And) the leaders of those who had fallen away under his father and had troubled the country and had wronged the temples, when he came to Memphis, (for?) avenging his father and his own royal power, he punished them all as they deserved, at the occasion when he appeared, that there should be accomplished to him the proper ceremonies for the taking over of the kingship.
DEMOTIC TEXT.

(16) The impious ones who had assembled soldiers, becoming leaders to trouble the nomes, doing wrong $\left(\mathrm{gm}^{c}\right)$ to the temples, deserting the way of the king and his father, the gods gave that he made a slaughter among them at the festival of receiving the high(est) dignity which he received (lit. did) from his father. He caused them to be killed (on) the wood.

The demotic text here again is an important source on account of its free rendering. Also the hieroglyphic text is fortunately preserved, Ros. I (cp. Damanhur, 22-23, which is much mutilated):

[Det. impious people] also $(N . B . !)^{3}$ who had amassed $\left(z d b^{4}\right)$ soldiers $(N . B . !)$, who had been at the head of them, upsetting (?sdm) the nomes ( $t$ šw) (and) violating ( $t h$ ') the temples [Damanhur completes this: at the receiving of the kingship from his father . . killing, ${ }^{5}$ placing them (?) on ${ }^{6}$ the wood].

The greater dependence of the hieroglyphic version on the demotic text than on the Greek (p. 4) is remarkable; it elucidates the demotic somewhat, notwithstanding its mutilation. For example, it confirms it in the statement that those leaders of the rebels were soldiers, ${ }^{7}$ and furnishes the best confirmation of the fact that the native soldiers formed the nucleus of the

${ }^{1} \mathrm{My}$ conception of the text prefers the restoration $\delta^{\prime}$ to that of ' $\tau^{\prime}$ which is usually employed.

2 Or '̇ ${ }^{2} \mu u \dot{\nu} \omega \nu$ part. pres. "avenging."

3 'sk (cp. p. 32, note 6) "and, moreover, also."

${ }^{4} \mathrm{Cp}$. Senuhyt, line $\mathrm{1} 30$, this verb for the gathering of armies.

"Only $m ; m$ left of the verb $s m ?(m)$ "to kill."

"The circle and stroke seems to mean $t p$ "on." The plural strokes behind belong to the pronoun (sn or $s t$ ) "them" which ought to stand before $t p$.

7 That the word $\zeta s$ means here "multitude," not "soldiers," is extremely improbable. See $\varsigma_{s}$ for regular soldiers, $4 Z$. I 884, IO4. It is true, the peculiar use of the Egyptian expression for "multitude" causes many difficulties, as we have had to state repeatedly 
rebels. Furthermore, both Egyptian versions give us the unedifying detail that the execution, which embellished the celebration of the coronation at Memplis, was done "on the wood, " i.e., by empaling or crucifixion. The Greek text hints very delicately at the cruelty of the punishment, while the Egyptian scribes, wishing to show their loyalty, become brutal in their faithful description. Modern commentators have always connected this latter section, about the execution of the insurgent leaders, with the capture of Lycopolis by assuming that the majority of the rebels fell at the storming, and that some, especially the leaders, were spared for a more cruel and solemn death. A careful examination of the text will show that two different groups of rebels are meant; the wording of the Egyptian versions shows it much more clearly. Even the Greek text would force us to accuse the writer of a very careless style, especially of repetition in describing the crimes of the rebels and contradicting thoughtlessly the previous statement that all defenders of Lycopolis had been killed. We see that the Greek text is very carefully worded. The way in which those rebels came alive into the hands of the king is quietly passed over, and a hidden excuse for their execution is given in the description of their specially great guilt; so far it was possible to go in representing the facts pleasantly without criticizing His Majesty. 'Thus not a breach of the capitulation is meant by Polybius' criticism that the king broke his faith to the rebellious natives, but a breach of the general amnesty described above, p. I 4. The priestly historian finds it quite proper, of course, that the special crimes of those leaders excluded them from royal clemency.

The fall of Lycopolis and the coronation at Memphis can not have been widely apart, according to our passage. Wre liave shown this above (p. 20). I leave it to others to determine from the mention of the high Nile something about the relation in which the shifting civil year of the Egyptians stood to the astronomical year and to our present system of arranging the antique chronology. The capture of the city could be assumed to be later than the time of the high Nile and to fall into the autumn, but this can not be proved with certainty.

The vague final words of the extract from Polybius seem to hint that the cruel execution of those rebel leaders proved to be a great mistake, $i$. $\iota$., that, notwithstanding the concession to Egyptian national feeling by a crowning ceremony in Memplis, parts of the Egyptians rose anew, fearing the faithless cruelty of the king, so that he "entered into many dangers," i.e., so that he suffered defeats. This must refer to Lower Egypt, the part of the country most difficult for military operations, where also most of the machimoi were settled (p. I6). In any case, at the time of the coronation, early in the year 9, Upper Egypt must still have remained independent. ${ }^{1}$

The Rosettana (1. 20, see p. I9), it is true, speaks of "the times during the revolution" (literally: "disturbance," cp. p. I9), as though these times belonged, in the year 9, entirely to the past. However, we must not be deceived by this loyal pretension. It does not furnish any clue for tracing the reconquest of Upper Eigypt. All the inscriptions we have of Ptolemy V. above Memplis (Max L. Strack, Die Dynustic der Ptolemäer, p. 245) mention Epiphanes together with the queen Cleopatra, $i$. e., these inscriptions are at least later than the marriage

${ }_{1}^{1}$ Letronne, Recueil d'Inscriptions, I, 298, wondered that the enumeration of benefits done to all temples of the whole country contrasts with the mention only of the Apis and Mnevis, gods worshipped near Memphis; he missed especially a mention of the gods of Thebes. This argument may be of some value, but it is not forceful. Thebes, at that time, had lost most of its ancient importance, and the Apis and Mnevis were best known to the Greeks as the most famous sacred animals, so that they might simply stand as types of the native Egyptian pantheon, even when the whole country was accessible. 
of 193 (year 12 ?), even later than the reconquest of the Thebais in the nineteenth year." Mahaffy (The Empire of the Ptolemies, 3I3) believes that "dated documents among the Petrie Papyri (II, XLVI, VIII) show that in the fourth and the eighteenth years of Epiphanes, the Ptolemaic law-courts and the farming of taxes, etc., were undisturbed in the secluded Arsinoite nome." But there is the possibility that documents written during the time of the revolution and lacking thus the correct and legal dating were rewritten after the suppression of the rebellion; the "legal government" would not recognize a document without proper dating, and rewriting such objectionable documents was too fine a pretext for officials and lawyers to obtain extra fees. Thus we must not too easily be deceived by those dates. On the other hand, it is probable that the Fayum, with its strong Greek population, could be maintained against the rebels as long as the royal power reached to Memphis. We may venture to draw an inference as to the time of the reconquest from the legation sent by Ptolemy Epiphanes to Rome in I9I B. C. (year I4?) to offer an enormous sum of money and his armies to the Romans as aid in the impending war with Antiochus of Syria. If this was not a grotesque deception, the Ptolemaic government ought to have had the greater part of the arable ground of Egypt under its control at that time, so that the taxes flowed again into the depleted treasury of Alexandria, minus those of the Thebaïs only.

I place here another fragment of Polybius, the continuation of the passage from the excerpta Valesiana (2 I, I9 Dindorf, cp. p. 22):

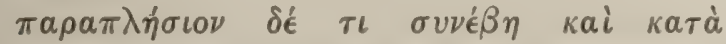

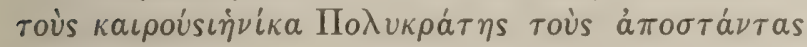
$\dot{\epsilon} \chi \epsilon \iota \rho \dot{\omega} \sigma a \tau o$.

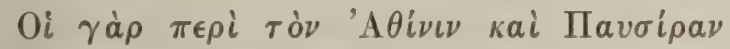

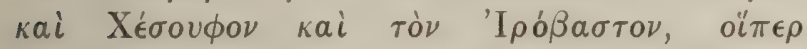

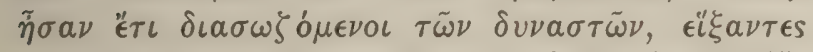

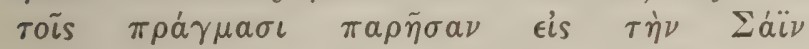

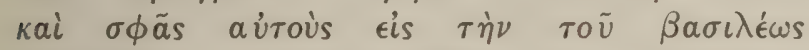

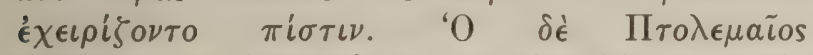

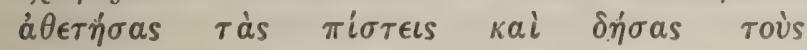

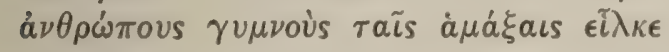

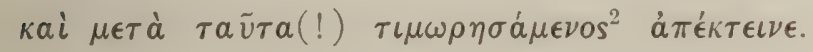

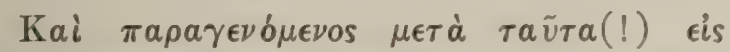

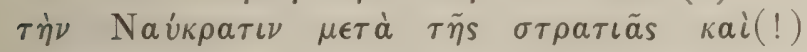

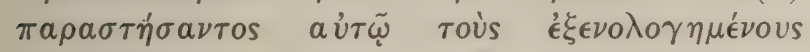

And something similar happened also at the time when Polycrates (had) subdued the insurgents.

For the followers of Athinis and Pausiras (!) and Chesuphos and Irobastos, who still survived of the (rebellious) chiefs, yielding to necessity, appeared at Saïs and surrendered themselves to the discretion of the king.

But Ptolemy, disregarding the pledges and having the men tied naked to the (!) carts, had them dragged

and after this (!) had them vengefully (!) killed.

And going after this (!) to Naucratis with his army, when Aristonicus had presented to him the men enlisted for him as mercenaries from Greece, he received

${ }_{1}^{1}$ From the time before the year 19/20 date Strack, No. 7 I (from Benihasan) and No. 73 (from Tehneh), because they still use the

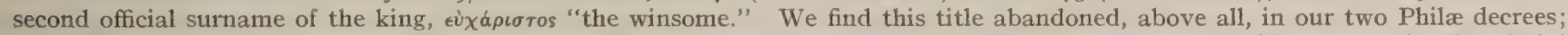
that of Damanhur, copying the old decree of year 9, partly keeps mechanically that title, partly omits it. The reasons for the official omission of that surname tempt us to think that the king, regarding himself a great conqueror after the first victories, did not wish to be called "kind" any more. That it was omitted, e.g., on the dedicatory Greek inscription of the Asklepios temple at Phila only to save space (Letronne, Recueil d'Inscr. I, 9, after Parthey), is, of course, impossible, The Egyptian priests, in other inscriptions, tried partly to replace it by other titles. Those two inscriptions ( $7 \mathrm{r}$ and 73 ) thus show that Middle Egypt had been regained between the years 12 and 19.

${ }^{2}$ A. Mai, Nova Script. Coll. II, 4I2, gives this as from book 2 I with the variant $\tau \iota \omega \omega \rho \eta \theta^{\prime} v \tau$ as. "The text seems to aim at expressing the idea for stating a warning, example." 


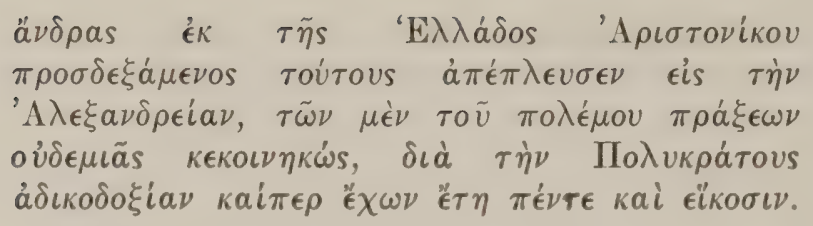

This fragment is apparently not in good condition. It speaks of the followers of the rebellious chiefs, but not of those chiefs themselves. The number of names given for the chiefs makes it plain that the chicfs themselves surrendered and were executed, perhaps after having been deserted by their followers. After having been dragged by carts, not much of them ought to have remained for execution; indeed, the strange $\mu \epsilon \tau \dot{a} \tau a \tilde{u} \tau a$ returns directly below and this looks thus like a doublet, $i$. $\iota$., as though an attempt had been made to remove these words further down to a better place. Also elsewhere, the text does not seem to be intact. Consequently, the fragment needs more criticism than it has received so far.

'The difficulty to fit it into the events which we know is due to the statement that the king was 25 years old. This would bring us into the year I 8 I B. C., the twentieth year of his reign. This is the time when our two decrees were engraved and when all Upper Egypt had again been subjected. It would be very surprising to find then the king still fighting rebels in Lower Egypt and raising mercenaries in Greece. Lower Egypt, namely, is clearly the scene of the fragment. The king's encampment is at Saïs and the rebels have, evidently, not far to go to find him. Furthermore, the surving dynasts point back to the part of the country where those chiefs were mentioned before. In Upper Erypt we have only the one rebel leader, according to our second decree, hardly various independent chiefs. ${ }^{1}$ 'Thus it would be difficult to explain them as Upper Egyptians. That Lower Egyptian chiefs, however, would fight through from the eighth to the twentieth year, even to the time after the subjection of the Thebaïs, seems impossible. A still greater incongruity between that date and the events described lies in the commandership of Polycrates. That this old commander of Ptolemy IV. kept his position and his favor with the king so long in that time of constantly changing officials is too great an improbability; the fragment itself points to the instability of that turbulent period, mentioning the suspicions which filled the old commander. Consequently, that date of the twenty-fifth year of the king's life does not agree with the above details. It either has been taken over erroneously from other, later, events or it has been disfigured. To suit the narrative of the fragment we might propose to change the number $\overline{\kappa \epsilon}$ "twenty-five" to $\overline{\imath \epsilon}$ "fifteen." 'The emphasizing of the fact that the king possessed a sufficient age for taking part in military operations, however, would not be very forceful; only for a precocious young king an age of fifteen would justify that remark. Neither would an emendation to $\bar{\kappa}$ "twenty" (omitting the 5 !) clear away the aforementioned difficulties. At any rate, the commandership of Polycrates and the surrender and execution of the rebels belong

\footnotetext{
${ }^{1}$ We are not yet sufficiently advanced philologically to explain the Egyptian etymologies of those four names of the chiefs and to determine their home from the dialect betrayed in them and from the theophorous parts. Ir(?)-obastos does not necessarily come from the city of the goddess Bubastis. Pausiras is evidently to be corrected into the ordinary Pausiris; Wilcken ( $\ddot{A} Z$. 1883,164$)$ and Herodotus $(3,15)$ show it specially as Low Egyptian and Fayumic; the Pha- which we should expect after the Coptic form for the dialect of this part of Egypt, in place of the $\mathrm{Pa}$ - of our text, is not yet the rule in Ptolemaic time. For Chesuphos and Athinis I prefer not to try uncertain guesses; their form may need correction. We must not overestimate the tradition in Polybius as to its accuracy in these details; the names may have suffered various mutilations, even before they reached him.
} 
to a time not long after the events of the Rosettana, $i . e$, not later than the fifteenth year of the king. The question remains whether the following narrative really fits the twenty-fifth year of Ptolemy Epiphanes. At first we are tempted to stretch the date somewhat and to find a connection of the report with the events of the nineteenth year of the king's reign, if not with the twentieth. Great preparations have been made, according to Polybius, for a military expedition. The king, however, does not take the Greek mercenaries where they are needed, $i$. e., to the scene of war. Instead, he leads them to Alexandria, evidently for executing in the capital some coup d' état, to free himself of some too powerful official, ${ }^{1}$ evidently of Polycrates himself. The mentioning of the suspicions of Polycrates point to this. Thus it would not do to assume that we have here the preparations for the great expedition against the Thebais in the year 19 and to harmonize (as a small slip of Polybius or the excerptor) the discrepancy of one year (as twenty-five years of life would seem to bring us into the twentieth year of Epiphanes' reign according to the current chronology). It seems impossible, I repeat, to assume that Polycra $\mathrm{es}^{2}$ then was still in command of the army and influential enough to keep the king, against his will, from the war plans and operations. Assuming that the fragment begins to describe his downfall, we are again brought into a period considerably anterior to the eventful year 19, and again come to the result that the remark about the 25 years of life can not be correct. At least I should advise the use of that fragmentary extract with the greatest possible caution and should, for the present, assume that it confounds names and events of different periods, although they seem to date principally from the time when the king began to make himself independent from his so-called guardians, $i$. $e$., presumably the time after his marriage in $193 \mathrm{~B}$. C., near the date of that embassy to Rome, when some serious efforts were made to consolidate the Kingdom, as we have seen above.

The Thebais, at any rate, must have been independent from the Alexandrian government during the whole twenty-one years indicated by the building inscriptions of Edfu (p. 15). This fact, so surprising to those who are still under the influence of the deceptive Greek historians, has been revealed by the dates of Theban demotic business documents, referring to the new government and the native kings installed by the rebels. These documents were discovered by Revillout (Revue Archéologique, 1877, 926 foll.). Brugsch (Aeg. Zeitschr., I878, 43) commented upon them (independently?). Revillout (ibid., I879, I3I), in a short final discussion (also in notes, Revue Égyptol., I, I90; II, 145, etc.), did not add much to his former results. ${ }^{3}$

The names of those two kings are $\mu[\{, 3, \operatorname{Iiar}-(e) m-h[e b]$, pronounced Harmah, Greek Harmais, and 2. $\{\leqslant \mathrm{G})\left[{ }^{\prime} A n\right] h a^{4}-(e) m-h[e b]$, pronounced Khamah, Greek, after the analogy of the other name, probably ${ }^{*}$ Chamais. The pronunciation of the last group in both names has, so far, not yet been determined with absolute certainty. It is written by a

${ }^{1}$ Certainly not for parading the troops in triumph, as was conjectured by Sharpe and Duemichen.

2 That a different Polycrates was meant would be very improbable.

'The essays by Baillet on these questions repeat only Revillout's data, with the addition of some errors.

${ }^{4}$ The root ' $n h$ suffers in such names a strong mutilation, which is indicated orthographically by omission of the initial letter 'Ain (erroneously omitted Ros. demot. 2, $p-t w t$ ' $n h$ in the very awkwardly engraved text). The pronunciation is furnished by the bi-

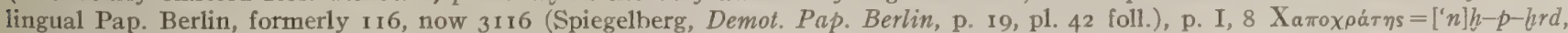

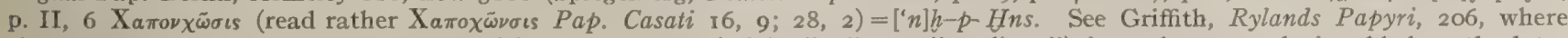
the Coptic particle looking like a preposition, "̌- "by" (originally "as well as lives"), in oaths, correctly is added as the later pronunciation of the above verbal form. 
conventional ligature which does not give a certain clue to its pronunciation and, therefore, has been read in various ways. The Greek pronunciation (') A $\rho$ mass for the above first name has been known for a long time; see the bilingual Pap. Berl. 3ir6, I, 30, with the enlarged forms [Pet]armais II, 25, (P)senarmais II, 27, and compare as a further proof, Griffith, Rylands Pap., p. $457 .^{1}$

Egyptologists still hover doubtfully between the explanation of the last part, corresponding to Greek -ais, as ah(i), ahct "horizon, splendor" (still so Spiegelberg, Pap. Berl., I 7) or heb "festival" (Griffith, Rylunds P(ıp., 457). However, both words, ahi and heb, are written differently in demotic orthography. The truth is, the group of signs in those personal names is abbreviated in a way leaving no trace at all of the original etymology, as we just have stated. The only explanation of this is that the name was gradually mutilated to the senseless pronun-

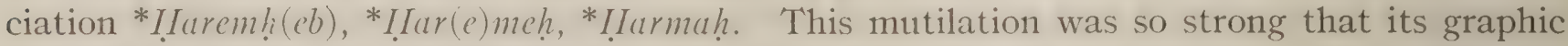
expression very early abandoned all connection with the old etymology. ${ }^{2}$ 'That Manetho expresses the name of the old king Har-em-heh of dynasty ig by Apuas is remarkable; we should hardly have expected of that historian such a consciousness of the connection between the original etymology and the living pronunciation of his age for a name mutilated I,300 years previously, or longer. For the other proposed etymology of both names, "Horus in the horizon," and "(may he) live in the horizon" ( $i$. e., in splendor, like a rising celestial body), might be referred to the fact that, while the inscription at the great sphinx of Gizeh (Letronne, Recueil d'Inscr. II, 467) calls the sphinx the god (H)armachis, Diodorus I, 64, speaks of the king A pua os who built the first pyramid, meaning exactly the same name as above. With this writer, however, that mutilation of the name ILar-(e)m-ah(i) [older ",ht, akhet] "Horus in the horizon" does not mean very much. We can admit that the late abbreviation IIarmah may have included also the rarer name Har-(e)m-akhet in parts of Egypt where the pronunciation of the gutturals began to be confounded, but this does not alter the fact that the popular name, after becoming meaningless, is to be traced back in the first line to "Horus in the festival" ( $i$. e., the god at his best time, in his best appearance, in his most clement mood, as Griffith had correctly supposed).

This discussion of the original etymology may seem useless here, but it will be seen from the

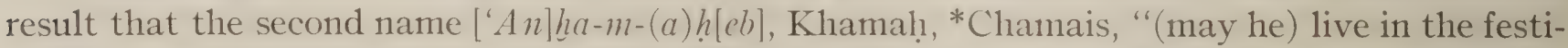
val," seems to be formed after the first. 'This would militate somewhat, of course, against the fact established above, that the name Harmais, II ar-mah, had become meaningless for the multitude. If Manetho, however, still knew the old etymology of the mutilated name Harmais and connected it with the king Har-em-heb, the scholars of Thebes may well have known as much as he, so that they were able to form the second name, Khamah-Chamais, after the first. Therefore the formation of the names discloses that Chamais was the successor of Harmais. The same conclusion was reached by Spiegelberg (Demot. Pap. Berlin, p. I 7 ) by a different method, $i . e .$, from

${ }^{1}$ See also the corresponding name Thotmais (?) Griffith, Rylands Pap., 464.

${ }^{2}$ Thus, already in the inscription of Amen-em-heb (ult.), $M a-\not h u$ occurs as a familiar abbreviation of this name, $i . e ., M a h$. We can trace such mutilating abbreviations of long names and their strange orthography (which gives up conserving any trace of etymology) to the pyramid time. Cp. the analogous mutilations of English names like Dick, Jack, etc. The above-mentioned abbreviation $M a-h u$ is very common in the New Empire; see Lieblein, Dictionnaire de Noms Index. Its frequency is explained by the fact that also other names, containing various divine names composed with "in the festival," could suffer the same abbreviation. 
the contents of the Berlin contracts of those two kings. Closer examination of the witness lists on those documents, etc., will probably confirm this result.

We have of those two kings the following dates:

\section{ITarmah-Harmais:}

Year 4, month 6 (?).-Pap. London, Revillout, Chrestomathic Démotique, 395, note; Revne Archéologique, 77,328 .

Year 4, month 3, is now furnished by a papyrus in double execution, in Five Years' Explorations at Thebes, by the Earl of Carnarvon, plates 35 and 38.

Year 4, month I I.-Pap. Berlin, 3i 45, Revillout, Nowvelle Chrestomathic, io9; Spiegelberg, Pap. Demot. Berlin, 17, pl. 37 .

Year 6, month Io.-Pap. Berlin, formerly I43, I44, now 3I42, Revillout, Nourelle Chrest., I26: Spiegelberg, Pap. Demot. Berlin, p. I7, pl. 36.

\section{Khamah, Chamais:}

Year 7, month I.-Pap. Berlin, formerly I46, now 3I46; see Revillout, Reille Ëg., II, I 45.

Year I4, month I I (?).--Pap. Marseille, Revillout, Chrestomathie, 395; Revue Arch., 77, 1. 1.

We see this gives at least part of one year and four complete years for the first king, one year common to both kings, twelve complete years and over ten months of a year for the second, $i$. e., a total of seventeen complete and two partial years. This minimal date comes very near the duration of the rebellion as furnished by the inscription of Edfu (p. I 5) : one year and part of a year under Philopator, then (counting year i 8 of Philopator and I of Epiphanes as identical) eighteen years and part of a year under Epiphanes. The text of Plilæ states more precisely that the incomplete last year of the rebel king comprised io months and 24 days. This allows the last-mentioned contract of Khamah-Chamais to be written in the month of the decisive battle which ended the native dynasty of the Thebaïs. ${ }^{1}$ We have thus, after the Edfu text, as maximum, nineteen complete and two incomplete years. This agrees extremely well with the minimum years of the demotic documents and makes it probable that those two rulers represent the whole native dynasty of rebel kings in the southern part of Egypt.

Modern historians, writing under the spell of Greek thinking, like Mahaffy and Bouché Leclercq, have found it inconceivable that the Thebaïs could be independent for such a long time. Thus Mahaffy (The Empire of the Ptolemies, 3 I3) eagerly grasped an hypothesis of J. Krall (Studien zur Geschichte des alten Aegyptens, II, 43) ${ }^{2}$ that those kings of the Thebais were Ethiopian kings who had penetrated into Egypt during those troubled years and "counted their years as kings of Ethiopia, not of Upper Egypt," so that "the long period of eighteen years of successful rebellion is not necessary." Bouché-Leclercq (Histoire des Lagides, 365) likewise mentions this theory with favor, but he finds it difficult to believe even in any fixed government of the insurgents: "C'est une exagération que de parler alors de Thébaide indépendante. Ces roitelets étaient des chefs de bande qui pouvaient inquiéter, mais non dominer la Haute Egypte." The latter statement shows that the writer had not taken time to examine thoroughly the extracts from the demotic documents communicated by Revillout, a splendid illustration of the

${ }^{1} \mathrm{Cp}$. also the second Philæ text, line $12 a$, about some prominent part played by the son of the "pretender" in the final battle. So, the latter would not seem to have been a young man.

${ }^{2}$ Similarly Revillout, Revue Égyptologique, v, 99, Mémoire sur les Blemmyes, etc. 
contempt generally shown by the "classical scholars" of the old school towards any source not written in the only decent languages imaginable, $i . e$, in Greek or Latin. The long duration of the reigns of those last native Pharaohs, their full and formal titles, and the fixed forms of government revealed by the contract protocols ought to have shown to any careful reader that those native rulers were no leaders of roving insurgent bands.

The Ethiopian hypothesis of Krall, which once seemed very attractive, is now exploded by our Philæ text. The vanquished "impious man" is most distinctly designated as an Egyptian rebel who had called the Ethiopians to aid him (line $\mathrm{I} 2 b$ ). If the reverse had been true, i. e., if an Ethiopian ruler aided by the Egyptian rebels had been conquered, our text would certainly have designated him as such; it would have added so much to the glory of the victory that we could not expect it to be suppressed.

That a great part of Egypt was independent to the year 19 is confirmed also by the general remission of unpaid taxes to that year (Philæ I, demot. $5 f$ ), which forms a parallel to the first remission of taxes unpaid during the revolution to the year 8 (Rosettana, 1. 8).

Another valuable result which can now be taken from the second Philensis is that in the Thebaïs we have one ruler of all the rebels, not those many small $\delta v v a$ ara or "chiefs" of Polybius which the peculiar geographic formation of the Delta produced there among the insurgents. Also in this case the decree would rather have spoken of a plurality of rebel leaders if possible; this would have sounded much better as increasing the value of the victory and showing more clearly the illegality of the secession. The mention also of the crown prince of the native kingdom (line I $2 a$; see above, p. $74, \mathrm{p}$. 75 , note $\mathrm{I}$ ) is a certain confirmation of the uniform government of the Thebais.

With this agree the official protocols of those native rulers on the Theban business documents mentioned above. They are: "the king Harmah, living forever, beloved by Isis, beloved of Amen-Rê', the king of the gods, the great god." The second king's titles are quite identical. These titles are very interesting. In demotic contracts the royal titles are always shortened, also with the Ptolemaic kings. Moreover, the second "cartouche," containing the official name of the earlier style, is always omitted in those private documents, so that we need not conclude from the above protocol that a shortened titulature, indicating a more democratic government, was used by those native rulers. On their own official documents and on buildings they certainly employed as pompous and full titles as any rulers of gentile Eigypt ever used. Characteristic is the mention of Isis and Amon. It is tempting to think of the Isis of Philæ and to assume that the rebels came from the southern frontier of Egypt, but this is by no means certain. Isis had so many temples. The mention of Amon indicates probably that the residence of the native dynasty was at Thebes. 'Thebes still seems to have been the most populous city of Upper Egypt and it had an important situation. The mention of the "land of Thebes" in the Philæ decree (line $5(l)$, of course, proves nothing to that effect; it is merely an awkward translation of the old Greek term "Thebais" and thus quite vague. 


\section{THE "FIRST" DECREE. \\ THE RELIGIOUS OCCASION FOR THE DECREE.}

\section{HIEROGLYPHIC TEXT.}

DEMOTIC TEXT.

[The high priests and the prophets and those

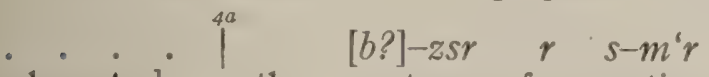
who enter] the sanctuary for vesting ntrw $m$ hhbsw-sn hn $h^{\prime} h^{\prime} ; w$ the gods with their vestments and the scr bes

$$
\text { zmiwt(?) ntr } \quad t_{s} y(!)^{1} \quad \operatorname{pr}(w y)-
$$

of the sacred books (and) the faculty (of) the (double)

$$
\text { 'nh hli } n \text {; - }\left.\right|_{\mid} ^{4 b} \text { kyw }
$$

house of life (i.e., the library) and the other

$$
\text { w'bw } y(y) \quad m \quad \text { 'trty }
$$

priests coming from the twofold sanctuaries

$$
r s y(?) \quad m h y t(?) \quad \text { 'w ' } n b-h z
$$

of the South (and) North to The White Wall

$$
\text { (i.e., Memphis) }
$$

'w $\quad s h n^{2} \quad H p-' n h \quad$ ' $b-\left.s n\right|^{4 c} r$ for installation (of) the Living Apis, who have met at $\operatorname{sh} z^{\prime} t^{3}$ the sanctuary of the (One in His) Southern Wall . . $\left[k^{\prime}\right]-s n:$

(i.e., Ptah) $\left[\begin{array}{lllllll}n t & \check{s}(m) & e(?) & p(?)- & m^{\prime} w b & e & ' r\end{array}\right.$ [who go to the sanctuary to perform $m n h \quad n \quad n$-ntrw $] \stackrel{4 a}{\mid}\left[\begin{array}{ll}n m & n-s \underline{h}(;)\end{array}\right) w$ the clothing of the gods] [and the scribes $m] z y w(?)^{4} \quad n m \quad n-s \underline{h}() w \quad,[p r(w y ?)$ of b]ooks and the scribes (of) [the (double) ' $n h \quad n m \quad n-$ house of life (i.e., the library) and the k"w w'bw ̈̈-'r- $y(y)$ other priests who have come $n \quad n$ - 'rpyw $t$ ', $-K m y]$ ] e $M n-n f r$ from the temples of Egypt] to Memphis

$e \quad p-s h n \ddot{e} n$ IIp-'nh 'r to the installation of the Living Apis, having $\left.t(w) t \quad e\right|^{4 c} h t-n t r \quad n \quad P t h(?)$ assembled at the temple of Ptah

[in the Southern Wall?] [who have said:

\section{REASONS FOR THE DECREE.}

\section{THE ROYAL BENEFITS.}

$m-d(y)-n t y$
because has continued

$$
\text { s,-r' }\left.\quad\right|^{4 d} \text { Ptw',rwmys, 'nh }
$$

the son of the Sungod, Ptolemy, who lives

$$
\text { zt, } \quad m r(y) \text { Pth, ntr pr, }
$$

forever, beloved of Ptah, the God Epiphanes,

$$
\text { s', }
$$
s' $n$ n-st 'byty the son of the king of Upper and Lower Egypt,

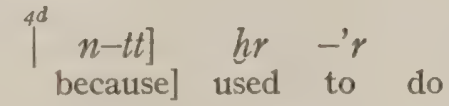

pr-'Ptlwmys " " $n$ h at Pth king Ptolemy, living forever, of Ptah

$$
\text { mr p-ntr [ntpr (p-?) sy }
$$

beloved, the God [Epiphanes, the son of

$$
\text { pr-'Ptlwmys nm] }{ }^{4 f} \quad \text { pr-'t }
$$

king Ptolemy and] (of) the queen

${ }^{1}$ A disfigurement of the old word gnbt "commission, committee, faculty," through the hieratic abbreviation of this word which was first misread $t, y$. It occurs frequently; see Damanh. 7, our second decree, $4 a$, etc.

${ }^{2}$ Lit. "the meeting, happening, lucky appearance."

${ }^{3}$ Originally "chapel," but here used freely for "temple" in general.

${ }^{4}$ The traces before the big, vertical, palimpsestic line look much like ' $n h, i$.. ., as the order of both classes of hierogrammates had been changed in the Philæ text. I have, however, followed the text of the Rosetta stone. 


\section{THE ROYAL BENEFITS-Continued.}

HIEROGLYPHIC TEXT.

Ptw'rwmys $h^{\prime}$
Ptolemy, and the $\mid$ queen (and) $\begin{gathered}n b t-t \text { ',wy } \\ \text { mistress of both } \\ \text { countries, }\end{gathered}$

Qrw'w,pdr, $(t)$ ntrwy $m r(w y) \quad y t w y$, Cleopatra (!!), ${ }^{1}$ the two Gods Loving (their) Parents, $h r-' r(t)(') h(w) t \quad n b(t) n f r w(t) \dot{m}$ hwt(?)-ntrw doing all things good in $(!)^{2}$ the temples $h^{*} \quad w n(!) \quad m-\mid \underline{h} n t \quad y^{\prime},(w) t-f \quad m n h t^{3}$ and (to) those being within his benevolent office (i.e., kingdom)

$r-\quad ; w-s n \quad(') r(y) w$

a'l of them, thereof $(? !){ }^{4}$

'r-sn (') $h t-n b(t) \quad \operatorname{twtw(l)} n-' r(t)$ my ' $r-n$ they doing everything behooving to do as did

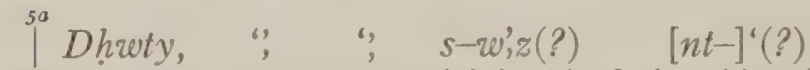

Thout, the very great one, ordaining the fitting things(?)

$m \quad$ 'b $n$ [ntr-mnh] hr ntrw

with the heart of [a kind god] towards the gods.

$R d y t(!)-n f n b(? !)-w r w \quad$ hy $q n w^{6}$

He gave much money (and) grain in abundance 'lsyn', n-ntrw

Arsinoë, the Gods
DEMOTIC TEXT.

${ }^{48} m r-y t w$,

Philopator,

$n m(?)[p r-' t$ Glwptrë, n-ntrw $n t p r]$

and [the queen Cleopatra, the Gods Epiphanes],

[mt-]nfrt ['sy $n \quad n$-'rpyw Kmyt

bene[fits many to the temples (of) Egypt

$n m]\left.\right|^{5 a} n-n t \quad \underline{h n} \quad[t f-]^{\prime \prime}, w t \quad[p r-'$ and] to those who (are) within [his royal] office,

$$
t r-w]
$$

[all of them. $]^{7}$ [being his heart kind] to the gods, $^{8}$

$\ddot{e}-f-\quad$ ty $h t \quad \operatorname{pr}(t), \operatorname{pr}(! l)^{9}$ 'ry $n \quad n-$ (as) he gave money (and) grain much to the

${ }^{1}$ The text is disfigured by running together the mention of the mother (Arsinoë) and the wife (Cleopatra) of king Ptolemy V. Epiphanes.

"We should expect the dative $n$ "to." The sign $m$ was begun like the hawk (ntr), which sign follows directly. The engraver tried then to correct the faulty text in a vague way.

"This poetic expression for "reign, government" hovers between the epithet ", "great" and mnht "benevolent" in the various places, as the signs are quite similar.

"This use of ' $r(y) w$ is very obscure and seems to be due to some misunderstanding. Is "thereof" merely an erroneous doublet of $-s n$ "their"?

${ }^{5}$ Corruptions have arisen because the redactor thought he could put in place of the comparison with Horus (Ros. Gr., IO) another comparison with a god, i.e., an abridged redaction of the Greek text, line 18 to 19: $\phi \rho 0 \nu \tau i \zeta \omega \nu$

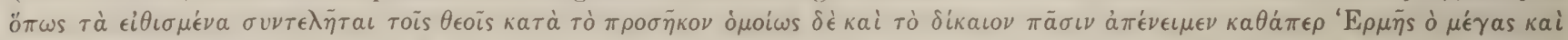

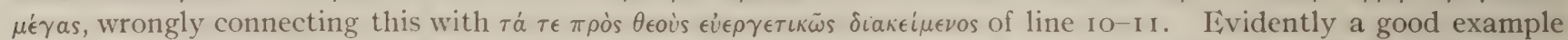
of hasty redacting. The demotic text does not correspond strictly, and the corrected rendering above still remains uncertain, particularly my restoration of $n t t^{-}$, ent $\hat{e}$ : "what is on the hand, what is necessary, becoming, customary, proper." No $n$ is risible above. Certain seems the emendation, sw',z. "The restoration "kind god" is furnished by Damanhur II (corrected reading found by me after the stone in the Cairo Museum).

${ }^{6}$ See Ros. Gr. $\mathrm{I}_{4}$ to $\mathrm{I} 5$, demot. 6, Damanh. I4. The Philæ text is abridged. ( $N b$ or $h z$ disfigured to $h b$.)

7 Thus after Ros. dem. 6 . The traces on plate 13 , line $5 a$, do not agree sufficiently to allow many safe restorations. Possibly the Philæ text is changed or corrupted.

${ }^{8} \mathrm{Cp}$. Ros. dem. 6, near the end. The remarkable determinative of divinity after $m n h$ seems to be kept here, but we must assume a strong disfigurement.

${ }^{9}$ The $e-w$ ' $h f t y$ "he added to give" of Ros. 6 has been modernized by the redactor, who then seems to have mixed w', $h$ : "to add," and $n b$ : "gold." After noticing this, he or the copyist seems to have tried to repeat pr, which certainly is superfluous. 
THE ROYAL BENEFITS-Continued.

HIEROGLYPHIC TEXT.

\section{DEWOTIC TEXT.}

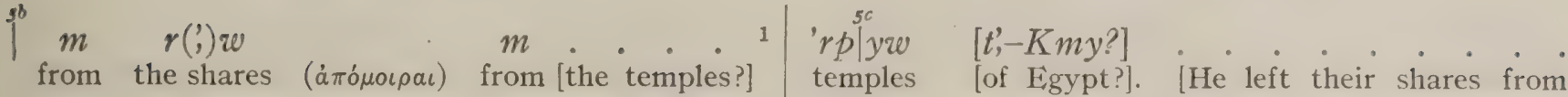

$d y-n s(!)^{2} \quad h n b$

(which) were paid (from) gardenland

[. . ?] 'w $m n$ [my] wn [and fields?] to remain [like] that which existed [since?]

$[r] k \quad[y t-f] \quad n-[s t-s n ?]$

the time (of) [his father] at [their place? i.e., former condition].

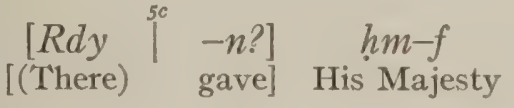

wn hr $\quad[p r-n-s t$ ? $]$

(that which) was with (i.e., due to) [the government](?),

. . $s n(?)$

(should) be [remitted ${ }^{3}$ to the igth year?]

$m$ [htr?] nw s['nh??] $h^{\prime}$

With [the du]es of the fields of revenue(?) and

Id yं'wt

hmw-ntr(?)

$n$

the office $(-\operatorname{tax})$

(of) the prophet(s)(?) for the

$p r-[n-s t ?] \quad n(?) \quad$ ' $r-n[f ?] \quad s h y^{4}$

[royal] house, not(?) did [he] exercise the right vineyards $\left.\right|_{\text {and gardens? }]} ^{[e]-h-n} \begin{array}{lll}n\left({ }^{d},\right) y & e-w n-n ;-[\ddot{e}-w \\ \text { those } & \text { which had been }\end{array}$

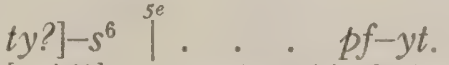

[paid?] under his father.
$\ddot{E}-t y(?)-f$
He gave (that) were remitted . . .

If . . . . tšw hn-e hspt

[the taxes of?] the nomes (?!) until year

$X I X \quad n-y h w-m ;(?) \quad{ }^{5 \rho} h n^{6}(?) \quad n-s^{*} n h w$

$19{ }^{7}$ (of?) the new(?) fields, ${ }^{8}$ and(?) the revenues

$n m \quad n-(?) \quad y h w(?)$

and the(?) [divine domains?] .

${ }^{1}$ We should expect "(the shares) of the gods" (ntrw), after Ros. demot. 9, and we are tempted to read or to emendate ( $m$, etc.) thus.

${ }^{2}$ Correct $d y-s n$. The disfigurement has caused the loss of the preposition $n$.

${ }^{3}$ Ros. Gr. $15-16$ ? This would rather require: that which was due to the temples!

${ }^{4}$ Seems to be demotic shy, shy, syh, syh, infinitive, or noun sht, sht, of the ordinary contract formula, which Griffith, Rylands Pap., 203, compared with Copt. shishi "power, might," evidently too narrowly, as the masculine derivation $p$-shish "vengeance" shows, for which the analogy of the Greek $\delta$ ik $\eta$, "right" and "punishment," forms the connection.

${ }^{5}$ The text of Ros. (Greek I4 to I5 $_{5}$, demot. 8 to 9) seems to have been shortened here, in both versions, combining the $\sigma v \nu \tau \dot{\alpha} \xi \epsilon \iota s$ and the ámómoı $a \iota$, etc. 'Therefore, I have not dared to restore too closely after the early model. The most important guide for us is the trace of $\underline{h}(e)$ "like."

${ }^{6}$ The text looks like ' $n-b n$ "to bring bad," which, of course, would be senseless. I do not understand the single groups as reproduced on the plates and must help myself by assuming here strong corruptions. In the translation I have corrected boldly after Ros. Greek I6, demot. 9 end, Damanhur I 5 . For the obscure pronunciation of the preposition "at the time of, under," see p. 4r, note II.

${ }^{7}$ This shows that the remission of taxes not paid during the revolution in "the nomes," i. e., "the inland," is meant.

${ }^{8}$ This group resembles the orthography of $m$, (e.g., in Copt. mue, mui, "island," or m', l, "new"), but must have a different meaning here. 
THE ROYAL BENEFITS-Continued.

HIEROGLYPHIC TEXT.

$h r-[s] n$

with them ${ }^{1}$

[m-?] (hnt?)

[from?] among(?) the appointments(? $)^{2}$ to(?) the priests

$h^{\circ}{ }^{\text {se }}(') h(w) t$

and the things (i.e., work)

[hr-?] $t p(?) \quad r($ ?') $w$

?] $t p$
$\operatorname{over}(?)$

the shares

(i.e., taxes)

'w w'bw

of the weaving

mrtyw $\quad r d y t(!)-n \quad h m-f$

(of) serfs, (there) permitted His Majesty

$n f r y(!)-r$ hspt $X I X(?) \quad h m(?)-s n$

until year $I 9(\text { ?) what they had forgotten (?) })^{3}$

[m?]y $n(?)$

trw(?) If $h^{\prime} k t-\left({ }^{\prime}\right) h(w) t m$

as in (their) [part, time?] and other things in

tnw [",?] $\quad r d y(t)^{4}$ st $h m-f$

number [great?], (there) gave them His Majesty

$[r] \quad t$,

[to] the ground (i.e., dropped, remitted, them).

$$
[S-] w \text { 'ww }\left.\right|_{\text {They }} ^{\sigma a}-s n \text { 'sk 'w(!) } \quad p q \text {, }
$$

$r(') w \quad m y d \quad p g(!)$

the shares, the piece(s) of byssus

\section{[h?] $r$}

(which were) with (i.e., due to? $)^{6}$

pr-n-st
the government

$m$
from the temples
until
DEMOTIC TEXT.

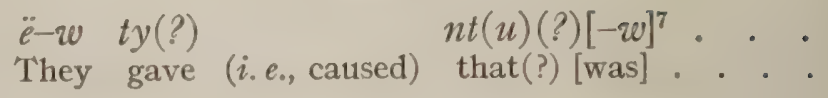

\section{${ }^{6 b} W y-f \quad n(?)^{8} \quad$ 'r $\quad[n-?] r w(?)$ He remitted to make [the?] shares(?) (of) šsw- nst(?)w -nt the "royal" (i.e., fine) linen (pieces) which $\ddot{e}-b n p-w$ 'r | $\quad$ oc $n \quad n-[n t$ had not been made among those [which $\ddot{e}-w-' r-w \quad n \quad p r-p r-'$ (?) $n \quad n$-'rpyw were made for the government (?) in the temples? $]^{9}$ . . . which (they) owed(?) [to year XIX?].}

${ }^{1}$ This seems to correspond with Ros. Gr. 16, about the remission of the tax for every priestly office. It is strange, however, that in the hieroglyphic version (Damanh. 15), as well as in the demotic (Ros. 9), the wording is so very different, while otherwise our text follows the original edition as much as possible. Then, numerous difficulties in detail still need elucidation, above all the groups preceding shy', where I can not find $d n w=\tau \dot{c} \tau \epsilon \lambda \epsilon \sigma \tau \iota \dot{\nu} \nu$, which we should expect. 'This tax here seems to be entirely remitted, while (Ros. Greek I6) the remission was only partial.

${ }^{2}$ I have tried to understand $t s(w)$ according to its Coptic meaning (not according to the old sense "districts"). The preceding group is not easily explained as $\underline{h n t}$ for $h n$ "within, among, out of " (nor as part of $h n t-s(y)$ "garden-land"). So I feel uncertain whether the same income from the temples is still meant.

${ }^{3}$ We should expect: "what they lacked, in what they were behind." 'The above proposed reading $h m-s n$ "what they had forgotten" or "had neglected" agrees well with this sense, but this ought to have a different determinative. The restitution $[k] m-s n$ "they completed" would remain very obscure. Cp. Ros. Gr. 29.

${ }^{4}$ Thus for the $n d y-y$ of the sculptor. Cp. Ros. hierogl. 2.

${ }^{5} \mathrm{~A}$ very archaic use of ' $s k$. The ' $w=e$ can not be explained with certainty. If it was intended for the preposition $e$, the construction might be understood as abandoned from "he commanded concerning the byssus," but this would require $h r, h i$, or $r-d b, t$, etbe $(t)$, as preposition rather than $e$. Above I have tried to explain $e$ as a mistake for en, the genitive-particle or (cp. $5 d$ ?) earlier em "from."

${ }^{6}$ This seems to be the easiest reading, considering the very tempting traces over $r$ as accidental.

${ }^{7}$ Everything in this line is very uncertain. The beginning seems to be analogous to Ros. dem. 17, Gr. 29: the remission of many arrears in money and grain (thus above?) to the temples.

${ }^{8}$ We should expect at least $e$ "to," but the whole group might be disfigured for $r$ ', "shares" (?).

${ }^{9}$ Thus after Ros. dem. 10. This passage has, however, been changed considerably in our text (complete remission in place of a partial one). 


\section{THE ROYAL BENEFITS-Continued.}

HIEROGLYPHIC TEXT.

$$
W s \underline{(y)}-s n \quad \text { 'sk. 'w- sbwt }
$$

They ordered also [concerning?]

$$
s(?) \text { [the artaba] }
$$

$$
s[t t m ?] \quad h n b w \quad n w \quad[n t r w ?] \quad h_{s}^{6 c}
$$

(of) [the arura from] the fields of [the gods?] and

$s-n b w \quad($ read: $s t t !)$

the arura (stone: anybody!) [from the vineyards of?]

$$
\text { ntrw } \quad r r d y(t) \quad d y-s n
$$

the gods in order to cause (that) be given

(this to the ground, $i_{.} e .$, remitted? $)^{1}$

$[M ?]-t w t w \mid{ }^{6 d}[m+$.
And that be

$\begin{array}{ccc}k b n w t ?] & m & q d t \\ \text { galley]s } & \text { as } & \text { [crew?] }\end{array}$

$$
\zeta s p-w(?)
$$

They undertook(?)
(') ht my $n \quad z($ ?) $d-w t$ thing $(\mathrm{s})$ as not were said ${ }^{2}$ (i.e., reported?)
DEMOTIC TEXT.

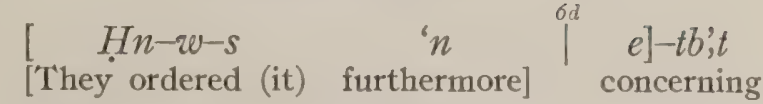

$$
\text { ' } r t b I \quad s t^{3} \quad[e-w n-n,-\ddot{e} w
$$

the one artaba (of) each arura-measure [which was

$$
\text { šty-f } n]^{4} \quad n(?)-y h w^{5} \quad n \quad n-\left.\right|^{6 e} n t r w \quad n m
$$
collected from] the fields of the gods and

$n(w ?)-y h w^{6} \quad ; l l y^{7} \quad[n n-h t p-n t r$

the(ir?) fields (of) vineyards [of the divine domains

$n \quad n$-ntrw wy-f e-rw-]

of the gods, he $(\text { ? })^{8}$ remitted these.]

${ }^{1}$ A very difficult passage. It corresponds with the Rosettana and the demotic version (see this) in general, but the remark about "anybody" or "everybody" can not be fitted in, if we do not assume that a confusion with the passage speaking of the abolition of "the press system" for rowers for the navy (Ros. Gr. I 7, dem. Io, Damanh. I6) has been committed in both texts (!?). After all, the most plausible explanation is that the hieroglyphic text has, following the demotic version as its model, misread "one artaba" to rome $(t)$ "man" (cp. on this possibility the remarks on the demotic text) and has tried to improve this senseless reading by adding the word $n b$ " every." By this emendation we obtain a reading perfectly parallel with the demotic text, only that the artaba and the keramion seem identified here. The space and the traces make the restoration "(it?) to the ground" (sw? $r t^{\prime}$ ) very difficult. As the general sense of a remission is certain, apparently a shorter synonym was used here ("they gave the back to it" s', $r-s$ ?) or something similar.

${ }^{2}$ After the couple of determinatives, which we can recognize, it would seem as though the passage mentioned the pressing of civilians as rowers of the war-galleys (Ros. Gr. I7) among the practices abandoned by the reforms of the king. But it is true that the hieroglyphic text (Damanhur 16) can not easily be harmonized with our traces; therefore, at least our text must have been redacted strongly to differ so widely. Our restoration $s-n b$ " anybody" is taken from $6 c$, where this group is out of place, as shown above. The group $z d$ is not quite certain; $s d-t w$ "it was collected, demanded," however, would hardly be possible without a determinative. Cp. note I.

${ }^{3}$ Without Ros. dem. I7, Gr. 30, it would hardly be possible to decipher these groups. The article $p$ - is disfigured; the sign for "artaba" is so indistinct that I read it $r m(t) w$ : "people" for a long time; the sign for "arura" is hazily engraved or stands over an erasure.

${ }^{4}$ I read after Ros. 17 . Our stone offers indistinct, senseless traces, as though the engraver had erased his blunders and had forgotten to reengrave the passage, omitting the auxiliary verb "it was," etc.

"This is in Ros. "the fields of the divine domain(s)" $n-y h w(n) p-h t p-n t r$. Here corrected as above.

${ }^{6}$ Also these groups corrected over. The dot after the plural article $n$-looks as though the engraver had thought of the possessive form new, neu, for a while. This may be accidental, however. After Ros. the word

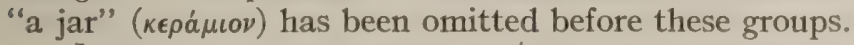

${ }^{7} \mathrm{~A}$ single stroke represents $i / y$, as often in the cursive script of contracts.

${ }^{8}$ Or $w y-w$ "they remitted," $i$. e., king and queen? The whole decree is very inconsistent, ascribing the benefits sometimes to the king alone, sometimes to the royal couple. 
THE ROYAL BENEFITS-Continued.

HIEROGLYPHIC TEXT.

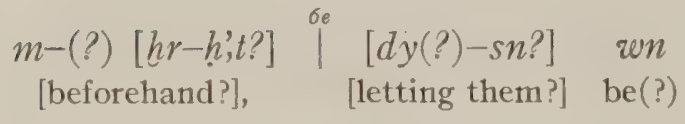

[-sn?] $\quad n[t y ?] \quad m y h ;, w(?) \quad n$

[them?] From those [which (were?)] oppressive(?) of(?)

phy(w?) ty (') $h(w) t \quad n$

the honors(?), ${ }^{1}$ taking (away?) the thing(s) of

(i.e., taxes for)

of wdnw nw. [ntrt?] $s n(w)-m r t$

the sacrifices of [the Goddess?] Loving the Brother

$h^{6}$ ntrwy $m r(w y)(y) t w y$.

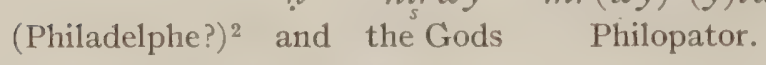

'Skw $r d y-n$ hqt $n b(t)$

Also gave the queen, the mistress

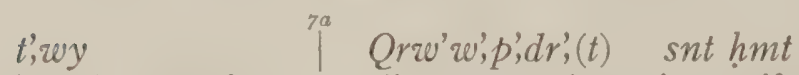

of both countries, Cleopatra, the sister-wife

$n \quad$ s', $R^{\prime} \quad$ Ptw'rwmy[s ' $n h$

of the son of the Sungod, Ptolemy, living

zt, $\quad$ Pth $m r \quad . \quad . \quad \cdot$ ]

$h z, \quad n b,\left.\quad\right|^{7 b}$ ", $w t-n b(t) \quad n-[m ;, t]$

silver, gold, all stones [genuine] (i.e., precious),

$$
m y-\dddot{s} \quad \because n \quad[k t ?-] w
$$

in great quantity for [the others?] (of)

\section{DEMOTIC TEXT.}

$$
t r-w \quad\lceil\ddot{e}-w \quad s-m n[-w ?] \quad n t(u)-w t y
$$

all of them they established [them?] $]^{4}$ and they took

(away) ${ }^{5}$ [the taxes for the service of the Goddess Phila-

$7^{a}{ }^{a} \cdot 0^{\circ} \cdot 0^{\circ} \cdot 0^{\circ}$

delphe and the Gods Philopator as being burdensome

$\begin{array}{cc} & n-r m(t) w \\ \text { to] } & n b(?) \\ & \text { the people all (?) }\end{array}$

${ }^{7 b} \quad \operatorname{Pr}-' t \quad$ Glwptrë $t-s n t \quad t-\left.\right|^{7 c} \operatorname{shm} m \cdot n$ The queen Cleopatra, the sister (and) wife of

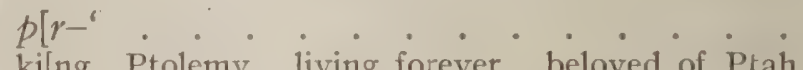

ki[ng Ptolemy, living forever, beloved of Ptah, gave] (signs of) honor [of gold, silver, stones]
(n) $m^{\prime}(t)$
$' s(y$ ? $)$
$n$
$n-k t(i)-w^{6}$
genuine $^{7}$ in great quantity for the others

${ }^{1}$ Two words, the sense of which remains doubtful for the present. For phy I have compared the demotic $m t-p h t(y)$ : "that which becomes, is due, honor." The trace of the determinative might point to the arm with a hook (or to the plural ending -w?). The $h$ '-sign of $m(y) h$ 'w seems to be certain, although on the stone it looks more like the ideogram (s) mn. The word means "weighty, burdensome."

2 This means Arsinoë, the sister and wife of Ptolemy II. The group which I have restored to "goddess" might be merely the feminine article, $t$ '. The above expression refers to the ámómoıpa of one-sixth, from gardens and vineyards, formerly paid to the temples, then transferred to the royal house, under pretext of a cult to the divine queen, which began in her lifetime. (See Mahaffy, Empire of the Ptol., I 43.) That cult was based, I believe, principally on the return to the old institution of sister-marriage, by which the royal house of Egypt once had imitated the gods. The above expressions referring to it are very remarkable, trying to disguise the material aim of the institution. The true character of that tax is, however, betrayed by its parallelism with what is mentioned before as oppressive usage. (The orthography of $s n$ "brother" with the phonetic complement $n w$ is not rare in Græco-Roman time. The graphic arrangement of the groups, with the object written before the verb and pronounced after it, is the same archaism which we find in the name of Ptolemy "beloved of Ptah," written $P$ th-mr $(y)$.

${ }^{3}$ The space somewhat narrow for this? An indistinct bird only visible.

"Not participle: "(they being established)" as written here. Cp. Ros. Gr. 33, dem. I 9. our text.

${ }^{5}$ Apparently thus, although the ornamental filling stroke (usually a dot) under the sign $t y$ is not regular in

${ }^{6}$ Not the usual orthography for the plural of $k t$, but archaic.

${ }^{7}$ Thus rather than $[\ddot{e}-w] m y-' \xi y$, which would be too remarkable an archaism for demotic. 
THE ROYAL BENEFITS-Continued.

HIEROGLYPHIC TEXT.

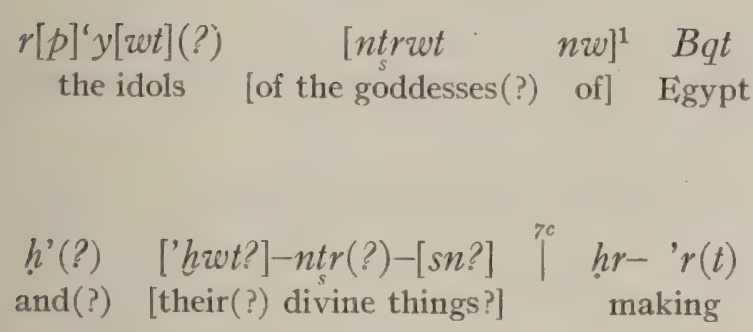

",bwt $s[q r \quad w d n . .$.

sacrifices, [pouring out of libations(?)

holocausts(?) and the rest of the things done(?)]

$n \quad r[p r ?] w$ nw ntrw

in (?) the temples of the gods [of Egypt?]

$h^{\prime}($ ?) [ntrwt? . . .]

and (?) [all the goddesses?]

7

$h r h t p r(?)-s n \quad h r \quad h w o t(?)[-s n]$

for(?) their cults(?) together with [their] temples(?). (or: estates?)
DEMOTIC TEXT.

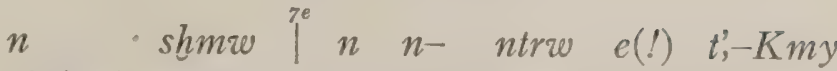
of (the) statues of the $\operatorname{gods}(!)$ of Egypt, $\ddot{e}-w$. . . . . . . . . . . . they [doing everything in their honor?] ${ }^{5} \ldots \ldots$. [e] $t(y)$ ' $r-w$ hbw $e(?) \quad n-n t r w \quad n$ [to] let be made festivals for $^{6}$ the gods of

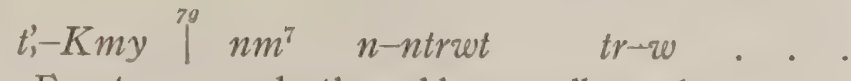

Egypt and the goddesses all together.

\section{THE THANKS OF THE GODS.}

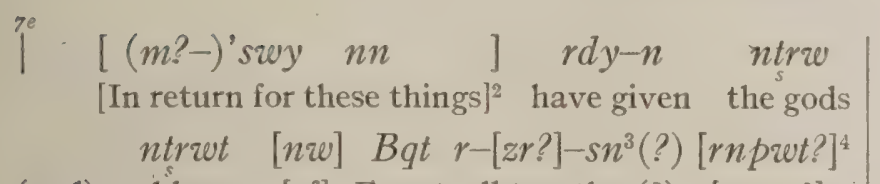
(and) goddesses [of] Egypt all together(?) [years?]

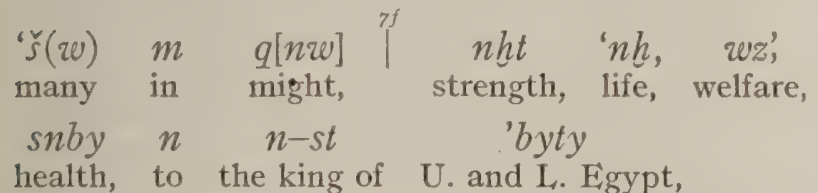

health, to the king of U. and L. Egypt,

1 The traces make the restoration ntrw, "gods", of which we should think first very difficult. If we have to restore $r[p]^{c} y[w t]$, this word, limited to female statues, alone requires a limitation of the gifts to "the goddesses." This shows the queen as feeling herself one of the goddesses in mentioning the goddesses first or exclusively. (The demotic betrays its confusion of "gods" and "goddesses" in the feminine form "others"). Meaning: the queen renounced an income from an alleged cult?

${ }^{2}$ After Ros. hierogl. 5. Possibly for $n n$ "these things" a fuller expression is to be restored.

${ }^{3}$ The traces would then seem to be accidental.

${ }^{4}$ The trace below would suggest that the ideograph stood between the determinative (?) and the plural strokes, but it is of rather peculiar shape. I first read it $n w$. The text certainly varies from the Rosettana.

${ }^{5} \mathrm{~A}$ verb ought to follow in this construction, which is usually "participial", according to the usage of Coptic grammar.

${ }^{6}$ Instead of $(e) n$.

${ }^{7}$ Incomplete group. 
THE THANKS OF THE GODS - Continued.

HIEROGLYPHIC TEXT.
DEMOTIC TEXT.

s; $\quad R$ ' Ptw',rwmys ' $n h$ at $\mid n$ pr-' Ptlwmys I ' $n h z t$ the son of the Sungod, Ptolemy, living forever, to the king Ptolemy, living forever,
Pth $m r \quad \stackrel{8 a}{\mid}\left[h^{6} s\right] n t h m t-f \quad h q t$ beloved of Ptah, [and h]is sister-wife, the queen

$$
\text { nbt t,wy Q Qrw', p', dr, }(t)
$$

(and) mistress of both countries, Cleopatra,

$$
\text { ntrwy } \quad \operatorname{pr}(w y) \quad h r-s-[m n \text { ? }]
$$

the two Gods Epiphanes, [establishing(?)

$$
\text { . . } m \text { 't, }-z r-[f \text { ? ] }
$$

their throne (?) $]^{1}$ in the whole land,

$$
\begin{array}{cccc}
\left.\right|^{8 b}\left[y^{\prime}, w t-s\right] n-w r t & d d[w t ?] & h r[-s n] & h^{\prime} \\
\text { their great [dignity] } & \text { consolidated } & \text { for them } & \text { and } \\
{[m] s[w-s n]} & {[r]} & z t &
\end{array}
$$

[their] children [to] eternity. [beloved of Ptah, and the queen Cleopatra]

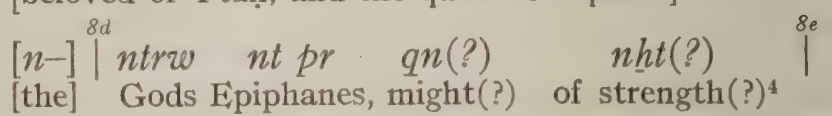

$n-w$ (?)

together $(?)^{5}$

$n t u-w(?)[t y$ ? $] \quad n w-' w t(?)-p r-'(?)^{6}$

\begin{tabular}{|c|c|}
\hline $\begin{array}{cc}H^{6} & \operatorname{shn} n-n[f r] \\
\text { With } & \operatorname{good} \text { luck }\end{array}$ [it entered into the heart of & 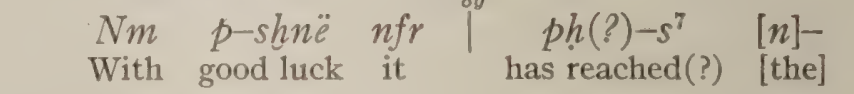 \\
\hline 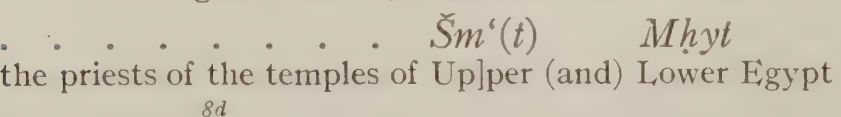 & $\begin{array}{l}\text { (n) } n- \\
\text { of the [priests of the te }\end{array}$ \\
\hline $\begin{array}{l}y-q[d]-s n \mid \\
\mid 1 \text { together }\end{array}$ [to in]crease [the honor & all together, with regar \\
\hline $\begin{array}{l}\text { lys ' } n h \\
\text { ly, living }\end{array}$ & $\begin{array}{l}\text { ys } \quad n h \\
y, \quad l i v i n g[\mathrm{f}\end{array}$ \\
\hline
\end{tabular}

and they [give?] their royal(?) dignity(?)

[established in the whole land for them and their

$[h r t(i)] w(?) \quad s^{6}-z t$.

childr]en forever.

\section{HONORS FOR KING AND QUEEN.}

${ }^{1}$ The above restoration makes that which follows appear as somewhat repetitious, and is, of course, only one of many possible guesses ("kingdom," etc.). The redactor has, indeed, tried to enlarge Ros. 5 in a way which must involve some pleonasms.

${ }^{2}$ Comparing this with Ros. hierogl. 5. The ideogram for "dignity" is possible, although not clear. Behind $d d$ the sign above seems to be a rude book roll; below, nothing is certain. A large $z$ is probable, as trace of $z t$; other traces are only misleading.

${ }^{3}$ Very difficult traces which are not favorable to the restitution [mdt-] pht or phyw (cp. 6e).

${ }^{4}$ We should expect such, or a similar reading, after Ros. dem. 20, but the text engraved offers such difficulties that I know, so far, no better explanation for it than that it has been mutilated by a senseless contraction of the above words. This hazardous explanation is, of course, very unsatisfactory and not convincing. Brugsch tried to obtain sense by violent changes of the signs in his copy. The second group, in which I have tried to find nht "strength," is written like 'wt(i)-w "between them," trom which hardly any sense can be gained. Thus it seems to need an emendation; see above. It might also be explained as having the group "(their) children" worked into it, which we find below. The first group would permit also the theory that it meant rnpwt "years" before its disfigurement.

${ }^{5}$ Not a satisfactory explanation, because $n-w$ in this sense would be a strong archaism. (Brugsch's ' $r w=$ Coptic er (r)ou "towards them" is both a bold forcing of the engraved text and senseless).

${ }^{6}$ This is what we should expect after Ros. dem. 2 I, but the traces are again difficult, especially the alleged pr-'.

${ }^{7}$ Or abbreviation for " $q-s:$ "it has entered"? The feeble stroke behind might be understood as a trace of the singular article $p$ - (correctly in Ros. $2 \mathrm{I}$ ), either an abandoned attempt to insert it or erased erroneously. 
HONORS FOR KING AND QUEEN-Continued.

HIEROGLYPHIC TEXT.

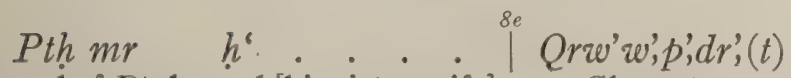
beloved of Ptah, and [his sister-wife] Cleopatra,

ntrwy $\operatorname{pr}(w y) \quad m(?) \underline{h} n t(?)[h w t-] n t r$

the two Gods Epiphanes, [in the temples?] ${ }^{1}$

['],(?) \& $h^{\circ} \quad n t r w y \quad m r(w y)[y t w y]$ much(?) together with the Gods Philopator

. . . $-s n^{2} \quad h^{6}$ ntrwy mnhwy

[who begot] them (!) and the Gods Benefactors

$$
[q m] ;,-s n \quad h^{\circ} \text { ntrroy snwy }
$$

who created these, and the Brotherly Gods

$\operatorname{sh} \stackrel{\rho a}{p} \mid r(?) \quad[-s n ?]$

who begot [these], (and) the Gods Saviors,

$z s(!) n(w)^{3}-s n \quad[q] m,-s n$.

their ancestors, who created these.
DEMOTIC TEXT.

$m r$ Pth . . . . . . $]^{o b} n t r w$ beloved of Ptah, and of queen Cleopatra, the] Gods $n t$ pr $\quad$ hn $n$-'rpy(w) nm ${ }^{9 c} \quad n-n t$ Epiphanes, in the temples and those which

$n t(u) \quad n-n t r w$ [mr-ytw $n m \quad n-n t$ belong to the Gods [Philopator and those which $n t(u) \quad n t r w \quad m n h]^{o d} \mid n-' r-t(y)-h p r-w$ belong to the Gods Euergetes] who begot them $n m \quad n-n t \quad n t(u) \stackrel{9 e}{\mid} n-n t r w \quad s n(w)$ and those which belong to the Brotherly Gods

'r-t(y)-hpr [n-'r]-t(y)- hpr-w nm who had begotten [those having] begotten them and $n-\quad\left[\begin{array}{lllll}n t & n t(u) & n-n t r w & n t & n h m\end{array}\right.$ those [which belong to the Gods Soter,

their forefathers, to increase them. $]^{5}$

\section{THE ROYAL STATUES.}

Mtrotw $s-\left[{ }^{[} h^{c}\right] \quad$ rpyt i $n$ hqt

And be [set up] an image of the queen,

$n b t-t, w y$

the mistress of both countries,

Qrw'w'pw'dr, $(t)$, snt hmt $n$ s; $R^{\prime}$

Cleopatra, the sister-wife of the son of the Sungod,

Ptw',rwmys ' $n h$ g ${ }^{g c}[z t] \quad$ Pth $m r$

Ptolemy, living [forever], beloved of Ptah,

ntrwy $\quad p r(w y) . \quad\left[\begin{array}{lllll}h ? & m & k, t^{4}\end{array}\right.$

the two(!) Gods(!) Epiphanes, [ . . executed?] in work
${ }^{\circ}$. . . $w^{\dagger} t$ rpyt $t-p r-{ }^{\dagger} t$

[And be set up] an image (of) the queen

\section{I’ Glwptrë}

Cleopatra, [the (sister?)-wife of king Ptolemy, living

. . . . . . . . . . $[e-\underline{h}$

forever, beloved of Ptah, the God Epiphanes, according to

$\begin{array}{llll}y p t & n & r m(t) & K m y t ?]\end{array}$

Egyptian (?) sculpture (?)-style to be placed (?) into

${ }^{1}$ Cp. Ros. hierogl. 5. Visible are $m$ (the key), the ear of hnt-head, the hawk $n t r$, ', incorrectly for ', $t$.

2 The plural mechanically placed according to the following enumeration, while the second decree seems to have the correct limitation to "His Majesty" ( $13 d)$.

${ }^{3}$ Read: $z f n(w)$. The following relative sentence here only as superfluous adaition. Comparison of the other decrees will show that the synonyms for "parents" are carefully selected and kept in a fixed, climatic order while the demotic does not possess a literary style sufficiently developed to imitate those variations.

${ }^{4} \mathrm{Head}$, two (3?) feet, and less distinct traces of the wings of a rather rudely sketched bee are visible.

${ }^{5}$ Thus, following the version of Ros. dem. 22. 


\section{THE ROYAL STATUES - Continued.}

HIEROGLYPHIC TEXT.

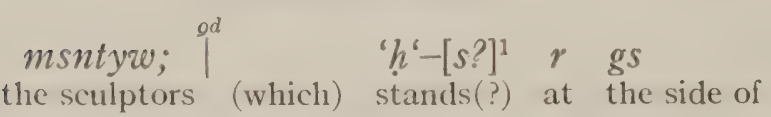

[hnty] $n$. . . . s, $R^{\prime}$

[the image] of [her husband?], ${ }^{2}$ the son of the Sun,

Ptw'rwmys ' $n h$ zt
Ptolemy, Pthing forever, beloved of Ptah,

[ntr pr]

[the God Epiphanes,] [together with the

$$
\text { [ntr-tp?] p'wt(? })^{3}-n t r
$$

highest(?) god of] the (local) divine company

$h r-r d t$ nf $h p s$ n $q n$

giving to him the sickle sword of victory,

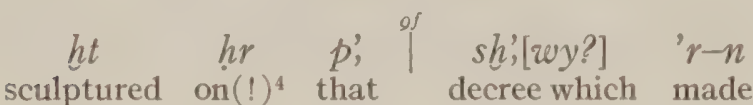

wbw [nw] prw-m;'t(?) $n$ hspt $I X(?)$ the priests [of the] temples in the year 9 (?)

. . $I^{10 / 2} n \quad$ s, $R^{\prime} \quad$ Ptwirwmys

[Mesorê 9? $]^{6}$ of the son of the Sungod, Ptolemy,

' $\mathrm{hh}$ zt, Pthmr, hr

living forever, beloved of Ptah, containing

DEMOTIC TEXT.

[m,- $n t-w n h ?]$

the (most) prominent place?]

(of)

'rpy-nb

every temple

$t,-K m[y$

(of) Egypt [at the side of the image of king]

rob

Ptlwmys,

' $n$ ht Pthmr p-ntr nt pr

living forever, beloved of Ptah, the God Epiphanes,

ioc $n m \quad p$-twt $p-[n t r$

together with the image of the [god

$$
t-p^{\prime} w t(?)^{7}
$$

of the divine circle

$$
\ddot{e}-f t y \quad n-f \quad h p \check{s} \quad q n y
$$

who is giving to him a sickle sword of victory,

(as) engraved on(?!) the decree of the priests of

$$
\begin{aligned}
& \text { Iod 'rplyw(?) n(?) hspt IX(?) } \\
& \text { the temp]les [from] the year } 9(?) \\
& n \text { pr-" } 1 \text { Ptlwmys ' } n h \text {, zt } \\
& \text { of king Ptolemy, living forever, } \\
& \text { Pth } m r \quad h r n f-[m t ?]-q n w(?) \\
& \text { beloved of } \mathrm{Ptah} \text {, containing his victories }
\end{aligned}
$$

1 The reading Bqt, "(the sculptors of) Egypt," which we should expect after Ros. Greek 39, demot. 23, Philæ II, I $f$ c, can be forced only with difficulty on the stone; the big oval hollow, in which I first tried to find the sign $b q$, is secondary. The traces look most like a broad ' $h$ ' with a small 'Ain stuck through it and, after'a gap, an $s$. This yields, of course, an awkward construction where we should expect, at least, the causative verb: $s-$ ' $h$ ' "it shall be established." (The mention of "Egyptian style" must stand in the gap before ht).

${ }^{2}$ We should expect $n h, y-s$, as above restored, but the traces are very different. After the rather probable high $n$ (the crown), there seems to stand an irregular, very broad $n$; the traces under its nearer end like two legs (?). Read simply: "the king of Upper and Lower Egypt"?

3 'The sense is secured by Ros. Gr. 39, "the chief god." Tp "first, chief," is extant only in uncertain traces, and p', $w^{\prime}$ (or psst?) "divine cycle, divine company," is engraved as though it was misread $n w$. Cp. the "second" decree, lines $I 5 b, 15 d$, for an apparently different treatment of the same expression.

${ }^{4}$ We imitate the ambiguity confusing the flat pictures on the stela and the portable statues in the round.

${ }^{5}$ More favorable to the reading XIX (cp. $I 3 d$ ), but see the demotic.

${ }^{6}$ I first thought of the date, not of the priestly convention at which the decree was passed, but of the day when the victory was reported to the king, and read "year XIX," seeing an abnormally large and straight X in the two strokes over and before the IX and then, before these, the abbreviation for "year." The latter group, however, seems to be the last signs of 'rpyw "temples"; therefore the expression "year" is to be found in those two strokes behind, so that we have to read "year IX." Consequently, the decree of Rosetta is meant, especially its lines 22-23. The priests evidently thought that the time was too short to execute the honors to the king set forth in the decree of year XIX, and rather connected the new honors with those of year IX without consideration of the fact that the latter had not been executed in many temples, owing to the insurrection. See "second" decree, hierogl. $15 \mathrm{c}$, for the question of a reference.

${ }^{7}$ Thus the group (Ros. dem. 23) is to be read. See Rhind, Gloss. Moeller, No. 126. (Less probably $t$-pszt: "the circle of nine, the ennead"?) 


\section{THE ROYAL STATUES - Continued.}

HIEROGLYPHIC TEXT.

DEMOTIC TEXT.

$r, w \quad q n[w-f(?) \quad m t s] w$

the reports ${ }^{1}$ (of) the victor[ies of him(?) and th] at

[ . . . . ] $\left.\right|^{\mathrm{Iob}} n \quad\left[{ }^{\prime}\right] q w \quad n w \quad h t-n t r$

[the priests officiating] as ${ }^{2}$ attendants of the sanctuary

$n\left({\text { ? })^{3}}^{3} \quad r-p r w-n b \quad[h r]-r n[-f] \quad\right.$ šms

in all temples on (i.e. bearing) [his] name ${ }^{4}$ serve

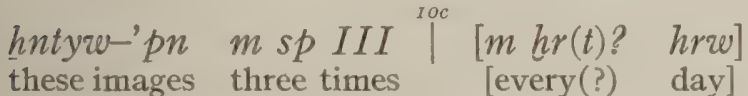

$[h ?] r-r d t^{5} \quad d b h w(t ?)^{6} \quad[m-b ; h-s n$

placing (sacred) apparatus [before them

and do to them] all [things prescribed],

twtw(?!)-nb(?) $\quad$ iod $n[t t ?] \quad$ ' $r[-t w(?)$

everything(?) becoming which is done(?)

\section{$h r$ ?] $s-h^{\prime} \quad$ [ntrw] $n \quad n t(l)$}

bring[ing] out in procession [the gods] of the city $(?)^{8}$

$m$ hbw tp $\operatorname{trwt}(!)^{9}$ hr hrw $n^{10}$

at the festivals (of) each season and the days of

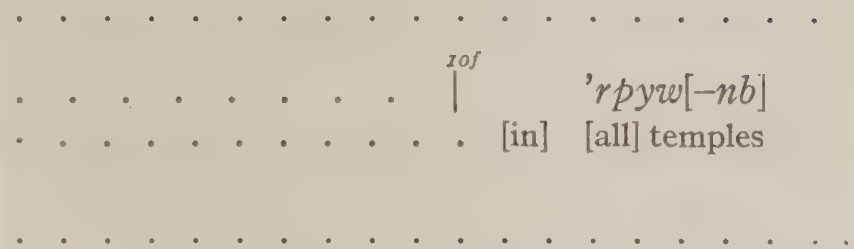
$\begin{array}{ccc}n t(u)-w & h ;, & \left.t b h \quad\right|^{\text {Ioj }} \\ \text { and that they } & \text { set } & \text { (sacred) apparatus }\end{array}$ $-t(u)-w^{11} \quad n t(u)-w \quad$ 'r $n-w \quad[p-s p$ them and that they do to them [the rest

$$
m t-n t-n-h p \quad e-\left.\underline{h}\right|^{\text {Ioh }} p-n t \quad \ddot{e}-w-r-f
$$

(of) the things lawful like what they do

$$
n]-k \text { " }\left.\right|^{I I a} n t r w \quad[n-] h b w
$$

(to) the] other gods (at) the festivals

1 Lit. "the chapters."

${ }^{2}$ The $n=m$, "as," suggests this restitution.

${ }^{3}$ A very short $n$ (in place of the older preposition $m$ ).

${ }^{4}$ That is: where the king finds worship.

${ }^{5}$ Accidentally the $r$ indistinct so that we think of its disfigurement to ' $r$, Ros. 7 ; also the following $r$ is corrected.

${ }^{6}$ The engraver seems to have been uncertain with the last sign of the word. Probably his copy on papyrus

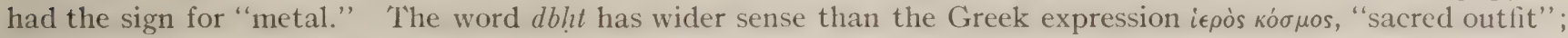
it includes also sacrificial ressels, etc. 'The pronunciation dbht for the unusual ideograph of the corresponding passage, Ros. 7 , is to be noticed. (There that ideograph seems to be disfigured from a square sacred chest (mrt?) with ostrich plumes.)

${ }^{7}$ Although we know the general sense, the traces do not allow any safe identifications of special signs. The second (lower) sign after the big gap does not seem to be $n$.

8 The stone shows that the reading $n-n t$ "of the city, local ones" has been corrected over the earlier reading $\operatorname{spl}(y w)$ of Ros. 7 and 8, "of the nomes" (as still is read in the earlier "second" decree $15 a$ ). Also "is done" stands over erasures.

${ }^{9}$ Literally "times, periods." (In Ros. 7, the ordinary ideogram $t r$; therefore I assume that the termination - $t$ is abusive, taken from the $t$ on which the ideogram often rests, so that the group looks like "year.")

${ }^{10}$ The sculptor seems to have corrected a broad $s$ into $n$; the sign could be read either way.

${ }^{11}$ I do not dare to transliterate this obscure group. J. J. Hess read it (Ros. 9, 24) e-lire, overlooking completely the third sign. This alone proves that it is to be read quite differently (although the Egyptian engraver, Ros. 25, made the same mistake of skipping this sign). In Ros. the second stroke is always bent strongly, almost to a half circle. Canop. I5, 16, indeed, has the first two strokes straight, like $\ddot{e}$, but our text agrees with Ros. in the second stroke and treats the first like $b$. That the last sign is not hr can be concluded from the addition of $-t$ in Philæ, once written $t u$, once $t e, t i$; $i . e$, like the abbreviation of $t o(o) t$ "hand." In place of $l i r$ we might, therefore, try to read $t i$, but the whole group, evidently, consists of abbreviations. I can not think of a hieroglyphic or Coptic preposition including both the meanings "at the time of" and "before"; certainly hieroglyphic $h r$ does not correspond, nor $m-h^{\prime}(w), n-h^{\prime}$. See above, p. 33, line $5 e$. 


\section{THE ROYAL STATUES - Continued.}

HIEROGLYPHIC TEXT.

$h^{\prime} \quad ; y(?) \quad n \quad r n-f$ procession, also (?) of his(!) name (i.e., specially consecrated to him!) $\left.\right|^{\text {Ioe }}\left[m\right.$ twtw $\left.s-h^{6}\right] \quad s \check{m} m t-h w t^{2}$ [and be brought out in procession] the venerable

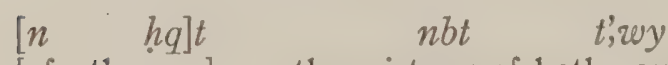

[of the que]en, the mistress of both countries,

Qrw'w, $p^{\prime}, d r,\left.(t)\right|^{\text {zof }}\left[\begin{array}{ll}n t r t] & \operatorname{pr}(l)\end{array}\right.$ Cleopatra, [the Goddess] Epiphanes, [snt]-hmt $n \quad n-s t$ 'byty the sister-wife of the king of Upper and Lower Egypt, s', $\quad R^{\prime} \quad$ Ptw'r'mys ' $n h \quad z t$ the son of the Sungod, Ptolemy, living forever,

Pth $m r$ $[n t r]$ pr beloved of Ptah, [the God] Epiphanes,
DEMOTIC TEXT.

$n-h^{\prime} w \quad[n-h w] w$

(of?) the processions, [on the d]ays (bearing)

$r n \rightarrow w \quad n t(u)-w \quad t(y)-h^{4}$

their name, ${ }^{4}$ that they bring out in procession

$t-I^{1 r^{b}}\left[\begin{array}{llll}r p y t & n & p r-' t \quad . . & .\end{array}\right.$

the [statue of queen Cleopatra,

$t$-sn]t $t-s(t)-h m t \quad(n) \quad p r-“$ the siste]r (and) the wife of king

Ptlwmys IIc ' $n$ h zt Pth $m r$ Ptolemy, living forever, beloved of Ptah,

$p-n t r \quad[n t p r]$

the God [Epiphanes].

\section{THE ROYAL SHRINE.}

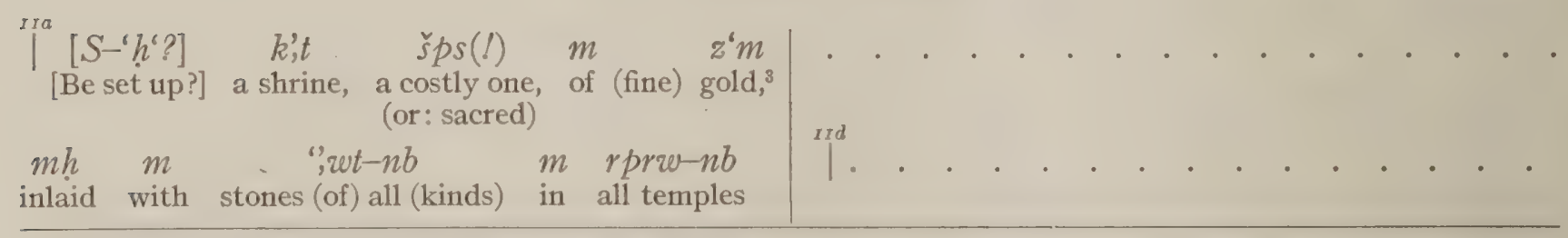

${ }^{1}$ This very difficult group, which has given much trouble to Egyptologists, I propose to treat as a particle belonging to the vernacular language. So, at least, our redactor seems to understand this mysterious group. In the original form of Ros. $7, h^{\prime} ; y h(r w)-f m(!) r n-f$, the meaning is the same, though the position of the particle is different, $i . \epsilon$, it seems to be there a particle strengthening the $l . \imath^{\prime}$ "and, with." Could the Coptic particle $\epsilon \iota \epsilon, \epsilon \iota$ be compared? 'The latter, however, has become so strongly confused with the Greek $\epsilon i$, that we can not separate the Egyptian and Coptic meanings clearly. (I thought, at first, of a corruption of " $t$ "time." This explanation would yield only very forced literal translations; nevertheless the particle ; $y$ might have originated from ,' " time," less probably the Coptic $\epsilon \iota \epsilon, \iota \epsilon$, according to what we know of the phonetic development of later Egyptian). I see now that Revillout, in his Chrestomathie Démotique, understood the particle correctly ("aussi"). Philæ, II, I5a, shortens the passage considerably, but very unsuccessfully. It is noticeable how anxious the copyists are to preserve the strange words and forms of their model, considering them as stylistic gems.

${ }^{2}$ 'The signs behind $s \xi \xi m t$ are indistinct. The fist holding the whip is clear and at first made me think of a sps run together with the $n$ underneath; but the sign $s p s$ below looks different and other details make that reading uncertain. (The oblique broad crossing-stroke is secondary.) During the impression I saw that we have nothing but the arm holding the whip (hw) and a poor $h$ over it. For this adjective "sacred, holy" cp. line $I I b$, and Ros. 7 , in both cases used with a statue.

${ }^{3}$ The original meaning of this word: "light gold, electrum," is retained no more in later time. Šps signifies: "fine, costly, magnificent," as well as "holy, sacred."

${ }^{4} I$. e., special memorial days for the gods, bearing their name in the calendar as their $\dot{\eta} \mu \dot{\epsilon} \rho a \iota$ é $\pi \dot{\omega} \nu \nu \mu o$. Cp. Philæ, II, demot. I2c, hierogl. I5a (much disfigured). Without the context the above demotic expression could also be translated: "the days mentioned (before)." The hieroglyphic parallel is corrupted; see on the "sacond" decree. 
THE ROYAL SHRINE - Continued.

\section{HIEROGLYPHIC TEXT.}

hr $\quad r n-f$

on (i. e., bearing) his name,

$\left.[m t w t w . . .-w]^{1}\right|^{I I b} \quad t w t^{2}-h w$

[and be placed there] the venerable image

$n$ n-st 'byty s', $R^{\prime}$

of the king of Upper and L. Egypt, the son of [the Sun],

Ptw'rwmys, ' $n h \quad$ zt, Pth $[m r] \quad h^{\text {' }}$

Ptolemy, living forever, [beloved of] Ptah, with

$[\operatorname{shm} t]^{3}-\left.n \quad n t r \quad n\right|^{I I C}[s n t]-h m t-f \quad h q t$

the divine statue of his [sister]-wife, the queen $n b t \quad[t ; w y$

and mistress [of both countries, Cleopatra,

$n t r t ?] \quad \operatorname{pr}(t) \quad[m t w t w ?] \quad s-[h t p-$

the Goddess?] Epiphanes, [and be] put

$s]\left.m\right|^{r r d} \quad b-^{5} z s r^{6} \quad \cdots \quad\left[k^{\prime}, w t\right] \quad n w$ [this] $]^{4}$ in the holi(est) place [with] the shrines of
DEMOTIC TEXT.

Ptlmwys $\left.\right|^{\text {IIe }}$ ' $\mathrm{nh}$ at Pth $m r$

Ptolemy, living forever, beloved of Ptah,

$n m \quad p-\operatorname{shn} t(i) t(!) \quad(n ?-) n t r \quad n \quad t f-[s h m t$

with the statue(!) ${ }^{7}$ (the) divine, ${ }^{8}$ of his [wife,

$p r-' t$.

the queen, Cleopatra, the Goddess Epiphanes] . . 9

${ }^{I I f} h n-s \quad n t(u)-w \quad t(y)-[h t p ?-s \quad e p-] \quad m w ' b$

in it, and they shall deposit(?) ${ }^{10}$ [it in the] holiest place

$n m n-k^{\prime \prime}(w) \stackrel{I I g}{\mid l} g,(w t)^{11}$

with the other shrines

${ }^{1}$ Perhaps the passive - $t w$ was placed after the verb "be placed."

${ }^{2}$ Notice the transliteration twt of the unusual ideogram of Ros.

${ }^{3}$ The narrow place allows only this word (written with the sistrum); $\mathrm{cp}$. the demotic equivalent.

${ }^{4} S[-h t p]$ to be supplied after Ros. demot. 25 , while Ros. hierogl. 8 has the simple verb htp "rests."

5 The foot of $b$ is not to be seen with certainty; the determinative "house" is strangely rounded and enlarged by secondary additions. The vertical, filling dash above is visible only with imagination. Nevertheless, the reading is rather certain. Cp. Ros. 8 .

${ }^{6}$ To see an $r$ under the lion requires some imagination; the following ( $-t$ and determinative of the house? $)$ is quite invisible. (The reading zsr has its origin from a lion holding a feather, which sign, in hieratic, looks quite like the arm holding this symbol, so that both signs can be interchanged.) 'The hlr "with," which we should expect after Ros., is not readable; the ideogram "chapel" requires much imagination, and the following $n w$ can be concluded only from the vertical stroke below. Traces of the lower part of the sign $s p t$ seem to be visible. Of the ' $r$-' $r$-f (lit., "referring to it, as concerns it") only the $f$ seems to be easily recognizable, if a large space below be admitted which may have been filled by a misplaced vertical stroke. Still we can risk restoring much after Ros. hierogl. 8 , and the other traces agree.

${ }^{7}$ Written in a very peculiar way. The scribe seems to have hovered between the two confused words $\operatorname{sh} m(t)$, shnty "statue" (cp. also the orthography sšmt, line $I 0 e$, etc.), and the similar word shnty (=hieroglyphic shmtt, shmiy) "crown." Notwithstanding the masculine article, a feminine ending $-t$ is added mechanically, because the word is used of a goddess. The orthography is also otherwise hazy. The parallel Ros. dem. 24 fortunately furnishes a plain shm "statue." See page 45, notes I and 5, about the difficulties with the obsolete word for "crown."

${ }^{8}$ Literally the "god-statue" (not with the adjective ntry "divine," which ought to be written differently). See the parallel expression $s \underline{h} m-n t r$ in Ros. dem. 24. The adjective, however, is required in English.

${ }^{9}$ The big gap between plates $e$ and $f$ allows for the demotic text some additions or repetitions.

${ }^{10}$ The traces are unfavorable to this reading and look rather as though the engraver really put down by mistake $t(y)-h^{\prime}$ " bring out in procession." Above the context has been followed, however, and Ros. demot. 25.

${ }^{11}$ Strangely disfigured ligature for $g$ ',. The meaning, however, seems clear. 


\section{THE ROYAL SHRINE-Continued.}

HIEROGLYPHIC TEXT.

ntrw-sptyw. . ['r-'r]-f [m?] hrw-hbw

the local gods. When [at] the festival days

wrw $n \quad p r(t)$

the great ones of the coming forth (of) a god

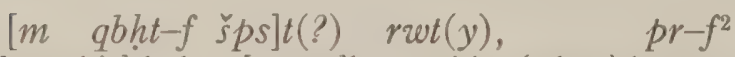
[from his] holy [recess] ${ }^{1}$ outside, (when) he comes out

$$
\text { 'm-sn mtwtw s-h' }
$$

on them, (then) shall be brought out (also)

$$
k, t-\left.\right|^{I I f} \check{s} p(t) \quad n \quad \text { ntrwy } \operatorname{pr}(w y)
$$

the sacred shrine of the two Gods Epiphanes

$h^{6}-s n$.

with them (i.e., with the other shrines).

$$
R-r d t s^{\prime},-t w(?)^{3}
$$

In order to make (that) be known this shrine

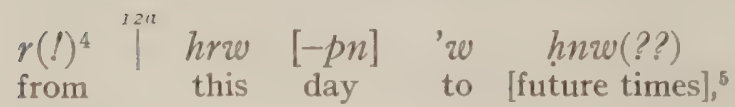

mtwtw dy

shall be given (i.e., placed)
DEMOTIC TEXT.

$$
\text { before it }-t(?)-s
$$$$
n-\text {. }
$$

(on)] the [great festivals (?) when the gods come forth, etc.]

$$
\left.\right|^{I / h} \ddot{e}-w(?) . . \quad[n t(u)-w \quad t(y)-] h^{6} .
$$

they (?) . . . and [be] brought out in procession

$$
t-g,\left.t\right|^{32 a} n n b(?) \quad\left[\begin{array}{llll}
n & n-n t r & n t & p r
\end{array}\right]
$$

the shrine of gold(?) [of the Gods Epiphanes]

$n m-w(?)$.

with them.

$$
\begin{array}{cc}
E & t(y)-h p(r)^{6} \\
\text { To } & \text { effect }
\end{array}
$$$$
\ddot{e w-s w n} \quad t-\left[g^{\prime},(t)^{7}\right.
$$

(that) be known the [shrine

$p-h w \quad n m \quad p-s p \quad t(i) ; \quad m n-s,-s$

to day and the remaining time henceforth,

$n t(u)-w$ ty

shall be placed

${ }^{1}$ Lit. "cool -place," i.c., closet, recess, shrine. The orthography of $s p s t$, which we should expect after Ros. would be strange. Possibly the synonym hait is to be read instead of spst as p. 42 , roe, if we recognize the ending - wet.

${ }^{2}$ 'This remarkable orthography for $(r)-r w t(y)$ and the following verb furnish a very valuable explanation for the strange groups, Ros. 8, which Chabas translated "à son jour," understanding them as $r-s$; $h(r w)-f$ "after (i.e., according to!) his day," very improbably in both cases. We sce now the text in Ros. is corrupted; the pr-f becomes intelligible only by our parallel based on a better copy, and the rwty (somewhat pleonastic at the side of the verb pr "to come out") could hardly have been guessed correctly beforehand. "On them" refers back to the festival days, in a relative construction familiar in Semitic languages but looking very pleonastic in English.

${ }^{3}$ Another instance where, if the stone was broken, we should feel confident to restore every sign according to the parallel text in Ros., while the extant traces are simply hopeless. Nothing certain can be seen of the word "to know" before the very plausible determinative of the squatting man putting his hand on his mouth. Before the chapel-sign the basis and the feeble body of a bird-like $w$ seem clear at first sight, but the sign before this $w$ looks more like a clumsy $s$ than a $s^{\prime}$. Before the chapel two small, vertical strokes, almost too deep for the first hand. I thought for a while of the ideogram $s 5 \mathrm{~m}$ "to lead" with preceding phonetic complement $s-$, but neither will this do. Therefore I have not attempted to harmonize between the conjectural restoration as given above after Ros. 8 and the traces on the stone. It seems the engraver blundered strongly and then tried confusing corrections.

${ }^{4}$ The $r$ is quite plain, but must be a mistake for $m$ after Ros. and the similar error, p. 45 , note 4 .

${ }^{5}$ Thus after Ros. Greek 43, dem. 25, but the identification of the extant signs is again very difficult. The sign l.n "period, age, long time" seems visible, but the surrounding signs are quite uncertain, e.g., the group preceding it is hardly $s p$ "remnant, rest."

${ }^{6}$ The prolongation of $h p r$ looking like $-f$ seems rather an accidental scratch.

${ }^{7}$ The restorations are supplied according to Ros. dem. 25. The space suggests additions in Philæ. 


\section{THE ROYAL SHRINE-Continued.}

HIEROGLYPHIC TEXT.

$\begin{array}{cc}\operatorname{shn} n(t)^{1} & h r-t p \\ \text { a(!) double crown on top of } & {[k, t-t n \quad m-' s(w y)-n} \\ \text { [this shrine instead of }\end{array}$

wrty wn $(t) \quad h r-t p]$

the two (kinds of) uraei $^{2}$ which are on top of]

k'; wt

the (ordinary) shrines,

(there) $\begin{array}{cc}r(!)^{3} & \operatorname{shn}(t) \\ \text { being } & \text { (that) double crown }\end{array}$

$m \quad h r-{ }^{\prime} b \quad-(') r(y) w \quad z r-n t t \quad p s d$

in the middle thereof, since (there) resplended

$n$-st 'byty

Ptw'rwmys

the king of Upper and L. Eigypt, Ptolemy,

' $n$ zt, I2c Pth $m r \quad$ ' $m-f \quad r(?)$

living forever, beloved of Ptah, with it towards (?) ${ }^{4}$
DEMOTIC TEXT.

$\operatorname{sh}(?) n t \quad n-n b \quad X \quad$ ?] $\left.\right|^{12 b} \quad h r(?) \quad n b(?)$

ten(?) golden double crowns?], on a nêb-hieroglyph(? $)^{5}$

$e^{6} \quad w^{6} t-r^{6} y t \quad e(?)-\underline{h} p-\left.\right|^{12 c}[n t] \quad h p$ being an uraeus-asp like that [which is] proper (or: custom)

${ }^{\prime} r-[s ?$ ? $]$ e $n^{7}-s \underline{h} n[t i ?] \ddot{e} w(!) \quad n-n b(?) \quad[n-z z$ to make for the double crowns!] of gold [upon

$t-g^{\prime}, t \quad n-t-s ̌ b y t(?) \quad t$-' $\left.r^{\prime} y w t \stackrel{i 2 d}{\mid l} n t\right] \quad h p r$ the shrine instead of the uraeus-asps which] are $e-z z^{8} \quad[p-s p \quad g ;(w t)]$

upon [the rest of the shrines].

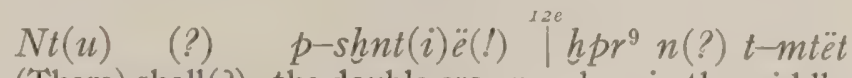
(There) shall(?) the double crown be in the middle

$n \quad n-s \underline{h}(?) n t(i) w \quad n t-\ddot{e} \quad n t(u) f^{10} \quad n t-\ddot{e}$ of the crowns which is the (one) (with) which

${ }^{1}$ This orthography imitates the demotic form. It seems to betray that, in some parts of Egypt, $h$ and $h$ began to be confounded as in Coptic pronunciation; also a popular etymology from slın: "command" seems to underlie. In Ros., the sign $n b$, originally the basis for the crown and not to be pronounced, has been detached erroneously(?). this reading, which our text avoids, might also be interpreted as "a double crown with a lord-sign ( $n b$ ) underneath." See note 5 on the demotic text for a possibility of finding this sense also there. 'The demotic orthography in Ros. tries to distinguish $\operatorname{shnt}(i)$ as the ordinary, $\operatorname{shnt}(i)$ as the archaizing, solemn form of the word for "crown," but fails in this distinction. See also above, on demotic line, p. 43 , note 7 , on the orthographic difficulties which this word gave to the scribes.

${ }^{2}$ With allusion to the mythological double character of the uraeus serpents. That the ornamental crowns were to be ten (as Ros. states in the Greek and demotic text) is not expressed here and, consequently, does neither seem to have been expressed in the hieroglyphic text of Ros., which furnishes, in general, a very poor description of those details compared with the demotic version.

${ }^{3} E(r)$ stands erroneously for the correct $e(w)$ of Ros. as in the demotic parallel and often.

${ }^{4}$ We should expect $m$ "in" (Ros. Io) and the $r$ might be disfigured from this (see above, IIf) but it is also possible that the writer, having in mind the demotic expression $h^{\prime} e(r)$ "going in procession towards, " really meant (e)r "towards," as written above.

5 The text is very puzzling. The model text (Ros. demot. 25 ) reads: "and that be given ( $i$ e., p'aced) twin golden king's crowns" ( $\left.\operatorname{shnt} n n b X(n) p r-^{\prime}\right)$. The place on which those crowns are to be placed ( $i . e .$, the shrine) follows (1. 26). The unusual expression "of a king, royal" agrees with the Greek text, line 43 : $\tau \dot{\alpha} s \quad \tau o \dot{u} \beta a \sigma \iota \lambda \epsilon^{\prime}$ $\chi \rho v \sigma a \tilde{s} \beta a \sigma \iota \lambda \epsilon i a s \delta_{\epsilon}^{\prime} \kappa a$, in which that expression seems doubly strange to us, being alréady contained in the likewise unusual word $\beta a \sigma \iota \lambda \epsilon i a$ "sign of royalty, royal crown." The demotic text of Philæ, $I 2 b$, could be brought into an approximative agreement by reading "king" and seeing before it "gold" as a disfigured sign (or X?). I believe, however, that I recognize $n-b$ either as original reading instead of "king" or as half-finished correction of the latter word, and have tried to restore this sense, whether it be original or an improvement, after these traces and the hieroglyphic text. Cp. directly below $(I 3 b)$ the same word, as $n b \ddot{e}$. This interpretation leads to assuming an exceptional independence of the demotic Philæ text and can not be considered as quite certain, but the possibility of such a correction deserves,attention.

${ }^{6}$ Rather common, faulty orthography for $\ddot{e}$. See on the hieroglyphic parallel.

7 The engraver made the $e$ too vertical or, rather, treated $s$ and $e n$ - as a doublet.

8 The traces look like this rather than like the $h r-2 z$ of Ros. 26. Notice the variants with $h r-, n-$, and $e-$.

9 The $e$ before $h p r$ seems accidental or abandoned from "which $(e)$ is."

${ }^{10}$ An interesting parallel to Ros. dem. 26, which confirms the reading entof in that text and tries to express itself more clearly than the original decree, correcting the short relative $e-$ before the verb to an apparent repetition $n t-\ddot{e}$. 


\section{THE ROYAL SHRINE-Continued.}

HIEROGLYPHIC TEXT.

$H t-\quad[P t h] \quad[m ?] \quad h^{\prime}(?) \quad[-n-s t ?]$ the temple [of Ptah] [in the royal?] procession(?)

$\left[m-s(!)^{1} \quad\right.$ 'r $\left.\quad n-f \quad t\right] w t^{2}-n b \quad n$ [when were done to him] all things proper for

$$
[b s]-n-\left.s t\right|^{12 d} \quad r \quad h t-n t r \quad h f t
$$

the royal procession to the temple, when

$$
\text { šsp } p^{3}-n f \quad \text { y';wt-f-wrt }
$$

he received his great dignity,

$$
\text { mtwtw } s-h^{6}
$$

and be decorated ${ }^{4}$

$$
[m-?] m y(t t)(? ?) \quad k, t(?)^{5}
$$

likewise(?) the shrine (?) [with the double crown

$I^{22 e}$

of the princess and mistress of both countries]

$$
\begin{gathered}
\left.Q r w^{\prime}\right] w, w^{\prime}, d r,(t) \quad n_{s} t r t \quad p r t \\
\text { Cleopatra, } \quad \text { the Goddess Epiphanes, }
\end{gathered}
$$$$
r-g s-f(?)
$$

beside it

mtwtw

( $i . e$, beside the double crown of the king); and be

$$
\left.\right|^{12 f} \begin{array}{cccc}
r d y & m & g s-h r(y) & n \\
\text { placed } & \text { on } & \text { the upper side(!) } & \text { of }
\end{array}
$$

\section{DEMOTIC TEXT.}

pr-' [h' $m-f$ the king [appeared (in procession) (therewith) in

$$
\text { ht } \quad M n-n f r \quad \ddot{e}-w-]\left.\right|^{I 2 f} r-n-f
$$
the temple of Memphis (when) were] done to him

$$
p-h p \quad{ }^{\prime} r-w \quad(n) \quad[p-\check{s}(s) p
$$

the proper (things) done at [the receiving

$$
\begin{aligned}
& \text { t- ,']wt- }\left.\right|^{I 2 g} h r(t)^{6} \\
& \text { (of) the] high(est) dignity, }
\end{aligned}
$$

$\begin{array}{cc}n t(u) & p-\operatorname{shn}(t i ?)^{7} \\ \text { and the (double) } & \text { crown(?) }\end{array}$

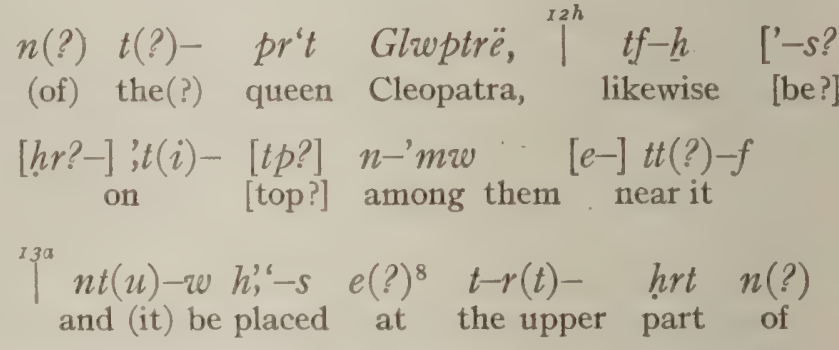

${ }^{1}$ In the strange $m-s$ of Ros. the $s$ is evidently $s e=s e t$, sen "they." The $m$ seems to follow the analogy of $m t w$, Coptic $(e) n t e-$, of the subjunctive, betraying already the shortening of the latter to $(e) n$, so that we have here the extremely modern form (e)nse "and they" of both Coptic dialects. It is, however, not impossible that the unusual employment in temporal sense has been caused by the archaic conjunction ' $n$, en "when, if " which, in mss. of the New Empire, often becomes $m$.

${ }^{2}$ The ideogram of the ostrich feather of Ros. $\left(s^{\xi}\right)$ is explained here by a synonym.

${ }^{3}$ This sign in unusually low form, like $d y$, but the reading "was given $(d y d y)$ to him" would be unsatisfactory.

${ }^{4}$ "The passage is not very clear. We expect the decorations of that shrine further described. The verb $s-h^{\prime}$, "to show," may be understood also: "to make appear brilliantly, to decorate," and the demotic text confirms that the crown of the queen was decoratively used at the side of the royal crown. Ordinarily, the double crown of the queen does not differ from that of the king; here, a combination with the vulture-cap seems to be meant (cp. $I_{3} a$ ). (If we give to the above verb its usual sense and assume that the "bringing forth" of the shrine and statue of the queen at processions, at the side of the shrine of her husband, is meant, then we must assume that the redactor of the decree very awkwardly inserted this remark, which introduces a repetition, into the description of the distinctive decoration.)

${ }^{5}$ The traces of the sign of the shrine are indistinct; the posterior traces may be all accidental and secondary. 'The preceding sign is unusual, bearing a faint resemblance to $m y$ "like" (it is, however, open above) or to the high $n$. Originally, probably, it represented the double crown of the queen (here misunderstood, as above, for $m y$ ?).

${ }^{6}$ We wonder at first sight at the great space filled by this restoration. It proves, however, to fit in exactly. $\check{S}(s) p$ is a sign which allows great extension. Of "dignity," ", wt, the preserved determinative as below $\mathrm{I} 4 a$ and Ros. demot. 6 and 7 (later abbreviated). Hrt "high(est)" also Ros. 5, etc., abbreviated without the feminine $-t$.

${ }^{7}$ This word also here treated so strangely that no exact transliteration is possible. Cp. above on I2a, etc.

${ }^{8} \mathrm{We}$, rather, should expect a compound preposition. 


\section{THE ROYAL SHRINE-Continued.}

HIEROGLYPHIC TEXT.
DEMOTIC TEXT.

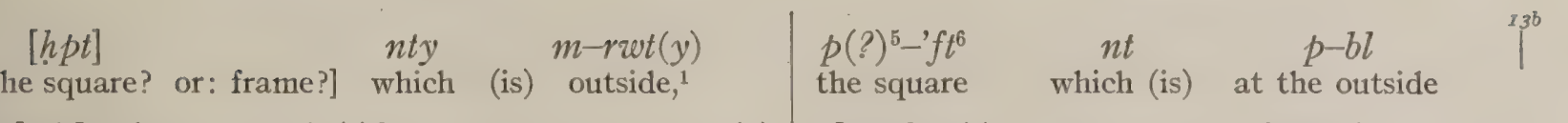

$\begin{array}{ccc}{[n f r] w-p n} & m-' q(!)^{2} & n(?) \\ \text { these decorations } & \text { opposite (i.e., as supplement?) }\end{array}$

${ }^{\text {i3a }} \operatorname{shmtyw}(y)-'[p n]:^{3}$

these (twofold) crowns:

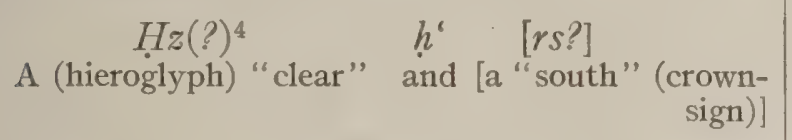

$[n-\operatorname{shnt}(i) w \quad p-m t \ddot{e}$

$p-\operatorname{shn} t(! ?)$

$n \quad n b$

[of the crowns, before the crown of gold

$\begin{array}{ccc}n t & s h(?) & h r \\ \text { which is } & \text { described } & \text { above, }\end{array}$

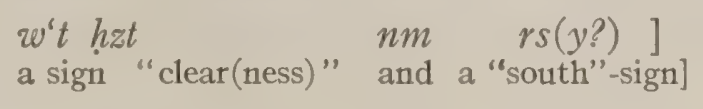

${ }^{1}$ Ros. tries by elaborate ornamentation to distinguish this sign from the ordinary s'; "back, behind." Still better, the demotic version in Ros. shows that rwt "outside" is meant. Chabas ("le dessus du support qui est derrière(!) ces insignes") and others misunderstood it entirely. This mistranslation leads us to the question whether we ought not to read: "which is outside (of!) these (i.e., the aforementioned) decorations" (thus Chabas, etc.). Although this follows closely the Greek (and seemingly, i.e., e silentio, the demotic), I prefer to refer "these decorations" to what follows as introducing the description of the further hieroglyphic symbols accompanying the decorative crowns. Thus those two hieroglyphic words correspond to the Greek explanation:

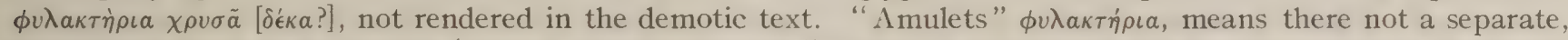
detachable piece of decoration (Ricardi even explained, "bands"!), but simply the brief inscriptions, the hieroglyphic signs or groups, such as were used for symbols, emblems, mottoes. This peculiar designation for the (mostly flat engraved) hieroglyphic symbols is chosen, not only because such symbols were largely used on amulets for persons, but because they served to hallow the cultic object, showing its use and owner, just as a Christian church might seem to become sacred by the decoration of the cross surmounting it. That "amulet" has this unusual meaning of "religious symbol" was not recognized by any commentator of the Greek text, as

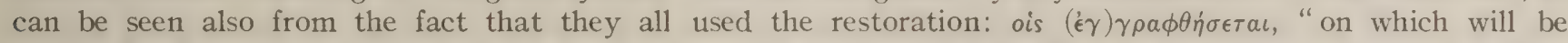
written," a restoration which now has become generally accepted. According to the context gained from the Egyptian version, I supply, rather, ois $\sigma \eta \mu a \nu \theta \dot{\eta} \sigma \epsilon \tau a$ : " by which will be expressed, signified, indicated." The hieroglyphic group itself is the "amulet," it does not form part of it. Notice another attempt to make the description in hieroglyphics specially precise, with regard to those details, in the expression above, "at the upper side," which aims at the sense: "at the (vertical) side of the top piece, of the frame above," a sense which it renders not very successfully, it seems.

${ }^{2}$ Text ' $\%$, while Ros. omits the $g$. Both follow the same faulty or indistinct original. We see here that those difficult texts were copied much more slavishly by the scribes than we should have thought (p. 5). The preposition is not vague in its meaning as an archaizing play for "near to." It seems to express a very peculiar meaning. (Of course, it never can mean "to the right side of," as Chabas proposed to explain this unusual archaism.) The corresponding Greek word $\kappa a \tau \dot{\alpha}$ ( $(\dot{o} \beta a \sigma i \lambda \epsilon \iota \nu)$ seems just as unusual. According to good Greek usage it can not mean merely a vague "near to." which Heyne, Drumann, Letronne, etc., tried to find, evidently simply to obtain some sense. I assume that the classical meaning, "corresponding with," has found here the very unusual application "in symmetry with," i.e., "in a way forming a symmetric group." This can be inferred from the two Egyptian renderings (although I am not at all sure that the demotic $p$-mte corresponds to the Coptic $p$-emto: "front, before"). Possibly, the Hebrew expression, Genesis 2, forms a parallel.

${ }^{3}$ The curved front ornament of the double crown seems to be visible and traces of the crown itself are plausible; then I believe to see distinctly three plural strokes, one over another, and the reed-leaf of ' $p n$. 'The traces after the ideogram of the double crown seem to represent the vulture-crown of the queen (p. 46 , note 4 ).

${ }^{4}$ The $M$ above reading accor ding to the demotic text of Ros. 27. After the traces of our text we should guess rather: "a (ush stalk," $i$. e., the emblem of the south. This would, however, be synonymous with the $r s(y)$ "south" restored below. The following expression of "Southland, Upper Egypt" is clear as far as the $\bigcup$ symbol of the vulture goddess Nekhbet is concerned; the preceding sign admits various guesses.

${ }^{5} N$ is not visible, but the article $p$ rather probable.

${ }^{6}$ With strangely written determinative. The serpent-like sign of Ros. 26 is probably $t(i)$, a pleonastic repetition of the $t$, and the determinative is lacking. Our scribe seems to attempt the correction of this. 


\section{THE ROYAL SHRINE-Continued.}

HIEROGLYPHIC TEXT.

\section{$n h b t(?)^{1} \quad$ hr $n b$}

(and) a vulture (goddess) on a basket (="lord")-sign,

$\check{s} m^{6}$

$h r-s$

a bush of rushes (="south") underneath

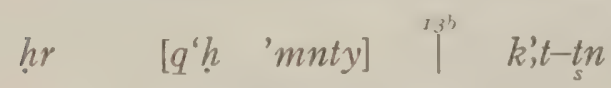

(are) on [the right side ${ }^{1}$ of] this chapel.

$$
\text { ' } r \text { 't dšrt(?) hr nb }
$$

An uraeus (and)a "north" (hieroglyph) ${ }^{2}$ on a "lord"'(-sign)

$$
\text { h', } \quad h r-s^{3}
$$

(with) a papyrus bush (i.e., "north")-sign underneath

$$
\begin{aligned}
& \text { hr } \quad q^{\prime} h-s-y b t(y) \\
& \text { (are) on its left side. } \\
& W h^{6}-f \quad p w: \\
& \text { Its explanation is: } \\
& { }^{23 c} \quad \text { Nbtyy }{ }^{4}
\end{aligned}
$$

the Master of the vulture and uraeus crowns

(of Upper and Lower Egypt) who illuminates

$$
\text { [šm't mhyt] }
$$

[the South and North.]

\section{DEMOTIC TEXT.}

$$
\begin{aligned}
& { }^{13 b} h r(?) \quad w^{\prime}(t ? !)^{5} \quad n b \ddot{e} \\
& \text { on (?) a } n e \hat{b} b(=\text { lord }) \text {-basket-sign. }
\end{aligned}
$$

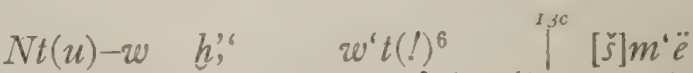

$$
\begin{aligned}
& \text { And be placed a "south" sign (i.e., a bush of rushes) } \\
& h r-r t-s \quad p(?)^{7}-\left[p(r){ }^{\prime} m n t y(?) \quad n(?) \quad p-q h\right.
\end{aligned}
$$

underneath it (on) the (?) ${ }^{8} \quad$ [right of the side

$\left.e-z z \quad t-g^{\prime}, t\right]\left.\right|^{13 d}\left[\begin{array}{ll}n & n b(?)^{9}\end{array}\right.$

upon the shrine] of gold(?).

$N t(u)-w \quad\left[h ;{ }^{\prime} \quad w^{6} t-r^{6} y t \quad w^{6}(t ?)^{10} n b(\ddot{e})\right.$

And be [placed ạ uraeus (with) a $n \hat{e} b$-sign

$h r-r] t-s \quad \int^{13 e} h r \quad w^{6} w t(i)(t)$

un]derneath it on a papyrus stalk

$$
p(r)-y b t y
$$

on the left side,

$$
n t-\ddot{e} \quad p f(?)-2 x^{\prime} h m(?) \quad p,(?)^{11}
$$

of which its interpretation is:

$$
\text { pr-' }\left[e-{ }^{-} r \quad s-h z\right.
$$

the king [who hás illuminated

$$
\text { šm't } \quad m h t \text {.] }
$$

the South (and) North.]

${ }^{1}$ The front ornament of the white crown is visible (perhaps in an unusual form, like the red crown below).

"The uraeus as symbol of the Delta goddess Buto is clear, but the following symbol of the north, Damanhur 27 , disfigures it to mytt "likewise," proving that our sign appeared disfigured on its papyrus copy, whether it is to be corrected simply to the hieroglyph of the red crown or not.

${ }^{3}$ The second half of $r$ and $s$ are visible, $h r$ is preserved in less certain traces.

${ }^{4}$ Thus the later Egyptians seem to have expressed this old title, $i . e$. , "the one who has both goddesses," (evidently with a possessive ending $-y$ after the dualic sign $-l y$ ); the original lengthy transcription remains unknown.

"See below (note in) on the strange feminine indefinite article with this word, although the word itself lacks the feminine ending - $t$ (like $\zeta m^{\prime} \ddot{e}$ in note 6). The determinative "wood," with $n b \ddot{e}$ " basket sign," is remarkable.

${ }^{6}$ Ros. 27 more correctly the masculine for the strange feminine article; see note 5. Our text adds a remarkable $-\ddot{e}$ to $s m^{\prime}$; can this be the "nisbe" (i.e., derivative adjectival) ending?

${ }^{7}$ The article $p$ - ought not to stand there, of course.

${ }^{8}$ Thus after Ros. Our text seems to differ and to be longer, offering, $e_{.} g_{\circ}$, the sign X. It looks like: "they are ([ë]w hpr) lords (nbw, i.e., here, probably, 'lord signs'?) ten upon (?) [it?]."

${ }^{9}$ Following again Ros. The traces on the stone are widely different, it seems (like "ten crown"??), indicating changes in the Philæ text of the obscure style.

${ }^{10}$ See note 5 on the feminine indefinite article. On the contrary, the word wt(it) below has the masculine article, as Ros. 27 , but adds the feminine substantive ending $-t$, lacking correctly in Ros.

"Again very uncertain traces which never could be explained without the parallel of Ros. Particularly $w h m$ (?) is quite in the dark; pef "its" and still more p', pe "it is," are barely possible. 


\section{THE SPECIAL FESTIVAL DAYS FOR KING AND QUEEN.}

\section{HIEROGLYPHIC TEXT.}

\section{DEMOTIC TEXT.}

- $s(?) n$

[Now for (?) the festival days which are mentioned]

$h r$ shiww $\left.n\right|^{13 d}$ hspt
on the decree of
$z r-n t y^{1}$ year

since there was (of) the I 2 th month (Mesorê),

$$
\text { ['rq] hrw } n m s(t) \quad n t r \quad n f r
$$

[the last day], the day of birth (of) the good god,

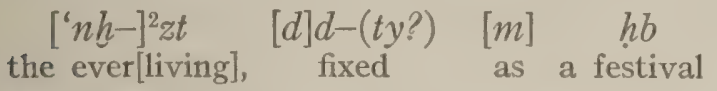

${ }^{132} h^{\prime}(?) \quad n(?)^{3} \quad[h w t ?]-n t r(w) \quad h r-h ', t$

(of) procession(s) in the temples formerly,

$$
\text { mytt-(')ry(w?) } n \text { 'bdII ",ht hrw [XVII] }
$$

likewise on the second month, day $[\mathrm{I} 7]$

${ }^{13 f}, r-n f$
when he did all things proper for (or: at)

$$
h^{s}-n-n-s t \quad m \quad \check{s} p
$$

the royal procession, at the receiving

$y^{\prime} w t \quad(!)-f \quad n w^{5} \quad n-s t y t \quad m-\left.d y(?)^{6}\right|^{14 a} y t[f]-f^{7}$ of his dignity of kingship from his father
Now for the days of festivals which are mentioned on

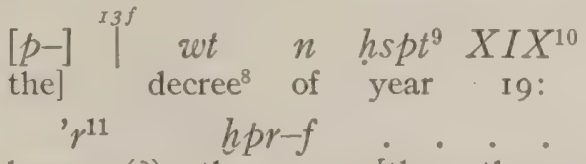
because(?) there was [the I 2 th month (Mesorê),

day 30 , on which is held the birthday of the king,

- . . $\left.\right|^{130}[n] \quad h b$

it was established] as a festival

$$
h^{\prime} w \quad n(?)^{12} \quad n \text {-'rpyw } \quad[t-h ; t ;
$$

(of) processions in the temples [beforehand:

ps-smt 'bt II, ",ht(?) hwXVII]

likewise month 2, day 17$]$

${ }^{\text {I3h }} n t \quad \ddot{e}-w \quad$ 'r $\quad n-f(?) \quad n$-',yrw(?) $)^{14}$

when were made to him the rites (of)

$$
{ }^{\text {I4" }} \begin{gathered}
p-h^{6}[n] \\
\text { the procession (of) his (?) }
\end{gathered} \quad \begin{gathered}
p f(s) p \\
\text { receiving }
\end{gathered}
$$

$p\left(\right.$ ?) - ', wt-hrt $n-t t p f-y t^{15} \quad \ddot{e}-{ }^{\prime} r-f$

the high(est) dignity from his father which he made

${ }^{1}$ A very awkward literal appropriation from Ros. hierogl. Io. The traces of the $r$ under $z r$ are feeble, looking like an abandoned blunder.

2 This sign omitted by the engraver.

${ }^{3}$ Looked at first like $-r m y$, but read rather as above. Has an $m$ been corrected over these groups or vice versâ?

${ }^{4}$ Agreeing thus completely with the dating of Ros. hierogl. Io and Damanhur 28 against the demotic text of Ros., which dates 4 months later.

${ }^{5}$ We must change the senseless sign $h r$ of the stone as done above (the $n w$ would then treat this word as a plural, which it was originally, having collective sense: "the distinctions"), or would we better restore after Ros. (Damanhur), $m$ šsp-nf nstyt "when ( $m$ as Ros. 9, see note I on our line I2c) he received the kingship."

6 This group crowded into the small space at the end of $\mathrm{I} 3$.

${ }^{7}$ We have to recognize, at the beginning of line $\mathrm{I}_{4}$ : first the reed leaf $(y)$; behind, there is space left for a small sign like the cake $t y$, which serves, sometimes, as word sign for $y t$ "father." Then four signs: the $t$ small and very high; below $f$, vertical stroke, another $-f$. The other traces are accidental.

8 The determinative of the loose papyrus roll preserved or simply the sign corresponding in hieratic to the man with the hand to his mouth?

${ }^{9}$ With corrections? The $\mathbf{X}$ is not distinct. We thus might infer a wavering between the dates IX and $\mathrm{XIX}$, but the hieroglyphic text is distinct.

${ }^{10}$ In my plate, the signs may stand too close together. A little intentional gap seems to follow the date, showing thus the earlier decree to be quoted.

"In Ros. dem. $27 n-t(t) h p(r)-f$. The shortening in our text is remarkable.

12 To be concluded from space. Absent in Ros.

${ }^{13}$ It is not possible to harmonize the following difficult traces with certainty with the text of Ros. 28 .

${ }^{14}$ Restoring thus after Ros. 28, I assume that the text has been corrected in several places and that the word for "rites, ceremonies," has a different orthography or an (erroneous?) addition before it.

${ }^{15}$ The strange and hazy signs of this phrase give us the impression that at first the different text of Ros. 28 was copied on papyrus and then changed into the above words lacking in Ros. Cp. above, p. 46, note $6 . \quad T h e$ signs seem to stand over erasures. 


\section{THE SPECIAL FESTIVAL DAYS FOR KING AND QUEEN-Continued.}

\section{HIEROGLYPHIC TEXT.}

DEMOTIC TEXT.

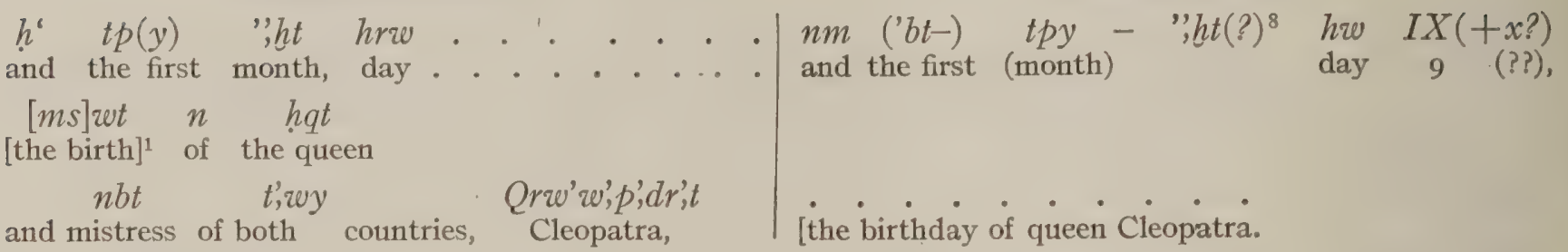

Since these days were] the beginning

$n-m t-n f r w \quad \ddot{e}-r-h p r \quad n \quad r m(t)-n b]^{x a b} \ldots$ (of) the benefits which came to all men [under - . 9 pr-' ' $n h$ at Pth [mr] the rule?] of the king living forever, (by) Ptah [beloved], ${ }^{10}$ $[p]-\left.\right|^{x a c} m s, \quad p-\check{s}(s) p \quad t-", w t-h r t$ (namely:) [the] birth, the receiving (of) the high(est)

dignity [and the birthday

$\begin{array}{ll}\text { of queen } & \text { Clleopatra, } \\ \text { Cle } & \end{array}$

$n t[r t \quad n t \quad p r \quad m y(?) \quad ' r w(?) \quad n ' y-h w w$, the God[dess Epiphanes, may(?) be ${ }^{11}$ made these days,

[his sister-wife, the princess and mistress of both countries

$\left[Q r w w^{\prime}, d r\right], t \quad h w(w)^{7} \quad$ [']pn 'rq ${ }^{\text {rad }}$ XVII Cleopatr]a, these days: the last, the r th $^{\text {th }}$

${ }^{1}$ See below, $I 4 c$. True, we find in $I 3 d$ the singular $m s(t)$ "birth," against the plural of the above orthography, but such late inscriptions vary in their expressions, in order to show that the learned writer is familiar with the orthography of all ages.

${ }^{2}$ Erroneously for $n$ in Ros., which we follow.

${ }^{3}$ So far after Ros. Greek 46, hierogl. ro. In the latter passage the traces of wrw become now intelligible only by our parallel text.

${ }^{4}$ This expression was intended, as we see from the following repetition of the reference to the coronation day, but omitted by the present text, through confusion with the preceding reference to the king. The "living forever" would fit better after the mention of the birthday.

${ }^{5}$ Rather thus than ", $t$ "great," cp. also Ros. hierogl. I I and above, p. 32, note 3, on the changing epithets of this expression.

${ }^{6}$ The traces lead to the sign $m s$ in a somewhat awkward form. (No other reading is possible. For the marriage day as an official yearly festival, analogies are lacking.)

${ }^{7}$ A broad $h$, perhaps a trace of a small $w$ behind. Below only two of the vertical plural strokes are visible. The following abridges Ros. hierogl. I I.

${ }^{8}$ The date looks disfigured, at least in the season sign. We might find a trace of the day number in the horizontal stroke running under this group. It is not sufficiently explained as prolongation of ' $r-f$; it looks like IX - at least in the original form prolonged further to the left, where an X or XX might precede it. Such a restoration can not be harmonized, however, with the hieroglyphic traces, especially of $I 4 d$.

${ }^{9}$ The visible traces allow no certain restoration like ", wt "dignity, office."

${ }^{10}$ The space is, it must be admitted, quite insufficient for $m r$ followed by the article $p-$; the engraver may have omitted some signs here.

${ }_{11}$ The text of Ros. dem. 28 seems to be corrupted here, where we must expect a wishing form, like Coptic mar-u; this is also required according to the hieroglyphic text. 'I restored it accordingly. 


\section{THE SPECIAL FESTIVAL DAYS FOR KING AND QUEEN-Continued.}

HIEROGLYPHIC TEXT.

$X X I I(?) \quad[' r-] t w \quad ' b d^{2}-n b \quad[m h b(w ?)]$ (and) the $22 \mathrm{nd}(?),{ }^{1}$ be held every month [as festival(s?) ${ }^{3}$ ] $m$ prw-m;'t(?) nw Bqt r-;w-sn $m[$ twtw in the temples of Egypt all of them, and [be $w, h{ }^{\text {Iqe }}$ ' $h(w ?) \quad s q r$ ] wt(?)nw $h$ ' set up ovens ${ }^{4}$ (and) be poured out $]^{5}$ libations and (')ht-nb twt $n-$-' $^{\prime}\left(l^{6} \quad m \quad h b w{ }^{14 f}\right.$ 'pn all things proper to do, at these festivals $t p$ ' $b d-n b$.

every month.

$\begin{array}{ccc}\text { ' } r-w & m \\ \text { (Which things) } & m \\ \text { are done } & \text { in(!) }\end{array}$

$r(') w-p n \quad s m^{9} m^{9} \quad n \quad s-[n b ?]^{10}$

these rules $(\text { ? })^{8}$ (they are) prescribed (?) to everybody(?)

DEMOTIC TEXT.

$\left.{ }^{i} r q \quad X V I I, \ldots \ldots\right]^{14 e} h b^{11}$ the last, the I $7_{\text {th }}$ and . . . ] a festival $h r-b t-n b$ hn $n$-'rpyw $n$ t',-Kmy every month in the temples of Egypt

$$
t r-w \quad n t(u)[-w \quad \text { 'r } \quad \text { gll wtnë }
$$
altogether and be [made holocaust(s), libation(s) $n m \quad p-s p \quad n-m t-]^{14 f} n t-n(?)-h p \quad{ }^{2} r-w$ and the rest of the things] which it is proper to do $n(?) \quad[n]-h b(w ?) \quad(h r ?)-' b t^{13}[-n b ?]$ (them) at(?) ${ }^{12}$ [the?] festival(s) [every: month.

$$
[N-n t \quad \ddot{e}-w \text { ' } r-w
$$

[The (ways in) which they (have to) bring sacrifice(s) $n t(u)-w \quad t^{2}{ }^{148} h r-, t(?) . n-r m(t) w$

${ }^{1}$ Proposed because we must expect the larger number to follow the smaller. The last number might have this place, however, as being less important, and the signs before the two certain vertical strokes are very difficult. The upper trace might be an irregular (rather triangular) ten; the lower trace looks somewhat like an arm, but the space for such a sign is insufficient. It might be a narrow ten, the space before it hiding two strokes of XVII.

2 The determinative below is a sundisk rather than a star, as in Ros. I , but both readings are possible.

${ }^{3}$ Singular, "a festival," Ros. II.

${ }^{4}$ For burning holocausts (which excluded larger animals).

${ }^{5}$ Literally: "struck (i.e., hurled) down."

${ }^{6}$ Disfigured in a remarkable way into one sign (like the "sacred eye") by the engraver. See Ros. I I for the correct form.

${ }^{7}$ Or: the better things (to be) done; see below.

${ }^{8}$ Literally: "chapters, paragraphs." The meaning "rules, prescriptions" is otherwise not known. Cp. above the same word in line roa. The preposition $m$ is unusual.

${ }^{9}$ The determinative of two feet may be found with some space for a small sign above. Our text enables us to understand the obscure group, Ros. II. Lepsius's edition (Auswahl I 8 ) gives an absolutely senseless $s^{\prime} w$ with which no later Egyptologist could do anything. Young, Hieroglyphics 28, and Champollion-Figeac, L'Égyple (German ed. of $\mathrm{r} 839$, pl. 77; after the Déscription?), show the group to be uncertain, perhaps on account of being erased and corrected, or engraved tentatively and incompletely. The reproduction in Budge, The Rosetta Stone, vol. I, plate I, likewise shows the ' $w$ very indistinct, as though it had been corrected; through the $s$ runs an oblique scratch which could be interpreted as though $s .5 m$, poorly engraved or abandoned, was intended, provided that the scratch is secondary. We see how far all editions of this important text are from being exhaustive. We can now

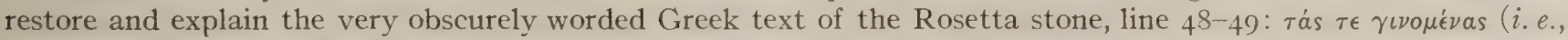

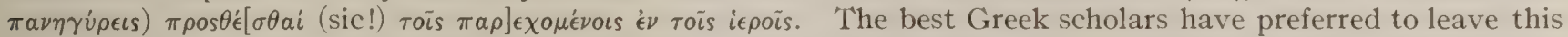
untranslated, others have been misled by the wrong restoration $\pi \rho \theta^{\prime} \theta \dot{\epsilon}[\sigma \epsilon \iota s]$. I understand the passage with the help of the Egyptian versions thus: "and that the (newly) celebrated ones (i. e., festivals) be imposed as new (duty) to them that present themselves (as priests) in the temples." The demotic text, Ros. 1. 2 (see above), explains the Greek text completely. The hieroglyphic text follows it fairly well according to our new version. Whether our redaction contains the original reading or a correction of an unfortunate, unintelligible archaism may be decided later. $S \zeta m$ literally, "explained, described."

${ }^{10} \mathrm{~S}$ after Ros. II. Perhaps, the $n b$ "all" of Ros. was omitted in our text; it is difficult to find space for it.

${ }^{11}$ The word corrected over (with $h^{6}$ "procession"?) so that it would hardly be intelligible without the help of the parallel texts.

${ }^{12}$ Stone $e$.

${ }^{13}$ Our text shortens the expressions of Ros. 29.

${ }^{14}$ Literally: "commanded, ordered, prescribed." The preposition which follows remains uncertain. 


\section{THE SPECIAL FESTIVAL DAYS FOR KING AND QUEEN-Continued.}

\section{HIEROGLYPHIC TEXT.}

$\begin{array}{lll}m(?) & w(n) \mid n w[t]^{1}-s n & m \\ \text { at(?) their hours (of officiating) in }\end{array}$

$$
h[w] t-n t r \quad m i w t w \text { 'r } \quad h b^{2}-h^{6}
$$

the temple[s], and be made a processional festival to . . ${ }^{25 b} n-s t \quad$ ['byty]

honor? $]^{3}$ the king of Upper and Lower Iigypt,

$$
s \text { ', } R \text { ' Ptrww'mys ' } \mathrm{hh} \text { it }
$$

the son of the Sungod, Ptolemy, living forever,

Pth $m r$

beloved of Ptah,

$$
h^{\prime} \quad s n t-h m t-f \quad n b(t) \quad t ; w y
$$

and his sister-wife, the mistress of both countries,

Qrw|' ${ }^{i s c}, p^{\prime}, d r,(t), \quad n t[r w y \quad \operatorname{pr}(w y)$

Cleopatra, the two Gods Epiphanes,

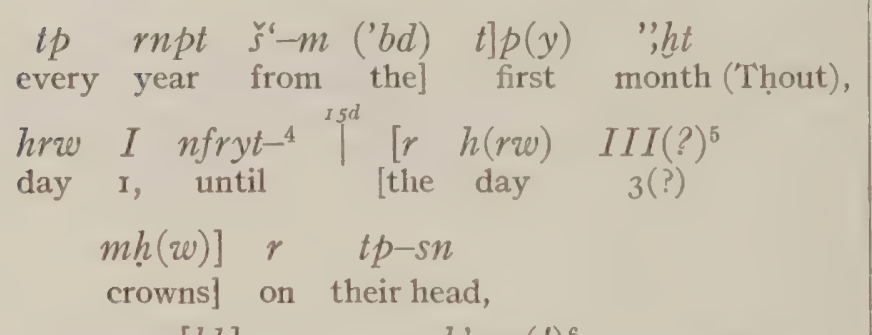

$$
s-[h b] \quad h ; ; w y(!)^{6} \quad s q r
$$

\begin{tabular}{|c|c|c|c|}
\hline $\begin{array}{cc}n t & \text { šms } \\
\text { who functionate } & \end{array}$ & $\begin{array}{l}(n) \\
\text { (in) }\end{array}$ & $\begin{array}{l}n w] \\
\text { their] }\end{array}$ & $\begin{array}{l}\text { 'rpyw(? } \\
\text { temples }\end{array}$ \\
\hline$n t(u)-w(?)$ & & [hbw] & $n$ \\
\hline
\end{tabular}

putting in festival state the altar(s), pouring out

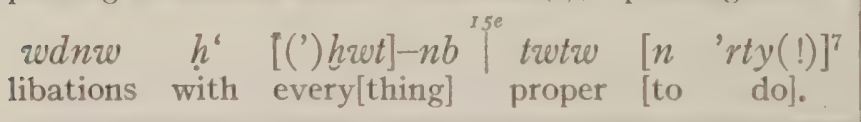

DEMOTIC TEXT.

and that be(?) made processional [festivals]

$n \quad n$-'rpyw t', $-K m y(?)^{10}{ }^{15 \alpha}[t r-w] h r(?) \quad p r-“$ in the temples (of) Eigypt (?) [all] for (?) the king Ptlwmys ' $n$ h zt Pth $m r$

Ptolemy - living forever, beloved of Ptah,

[and the queen Cleopatra

the Gods Epiphanes,

15b

1.

every year] (from) the first day of the year],

('bt) tpy(?) "'ht st $h[w] \quad V$

(the) first month, until (the) [Five Days??]

isc $\ddot{e}-w$ ty $k l m \ddot{e}$

they wearing crown(s)

$\ddot{e}-w \quad$ 'r $\quad[g l l \quad w \ddot{e} \quad n m \quad p-s p$ (and) making [holocaust(s), libation(s) and the rest (of) $m t-n t]-p h(t ?) \stackrel{\text { Ist }}{\mid} e(?) \quad$ ' $r-w$ things] becoming to do (them).

${ }^{1}$ A high $m$ (the "key"-sign)? The trace, like broad $m$, behind, is too hirh and seems secondary; it could be understood, however, as the ' $r$ of Ros. I I, so that we should have.to read, like the Rosettana: "who perform their hours." At the end of the line is a group which appears to be at a first glance either a high $n$ or an asymmetric my: "like, as." It is, however, more probable that we have the hind part of ain, and of an $n$, of which latter also the first stroke may be visible. No certain trace of the determinative (a star) is visible in $15 a$, yet tine word seems to be intended after Ros. I I (entirely misunderstood and changed to $w$ by Chabas).

${ }^{2} \mathrm{Hb}$ appears on the stone often like $n b$.

${ }^{3}$ The space requires more than "for the soul $\left(k^{\prime}\right)$ of" which we should like to supply after Ros. 7.

${ }_{4}^{4}$ The book-roll would not fill the great space and the $t$ is so unusual that we must suspect an attempt to engrave an $h$ under or over it; also the following traces do not fit the necessary restoration after Ros. very well.

${ }^{5}$ Thus after Ros. Greek 50. See Philæ, II, I $6 c$, on the change of the duration of the festival from five to three days.

${ }^{6}$ For $h_{i}(y) w t$. The side-support in the sign of the sacrificial table is not quite certain.

7 This strange form after Ros. 12 (for ' $r$ - $t w$ or ' $r t$ ?).

${ }^{8}$ Literally: "serve."

9 The hopeless traces lead to the conjecture that the scribe tried to correct the above erroneous reading of Ros. 29. The correct word a'nu' "hours", which must be expected here, can not be read into the text, but the initial signs of erpe(y) "temple" are visible.

${ }^{10}$ Thus (after Ros.) on the assumption that the engraver, working mechanically, disfigured various signs: €. g., the oblique stroke of $k m y$ seenis never to have been on the stone, nor the usual horizontal stroke above; the group looks more like $\mathrm{hn}$ "in." 


\section{THE PRIESTHOOD FOR THE NEW CULT.}

\section{HIEROGLYPHIC TEXT.}

$W^{\prime} b w^{1} \quad n w$ prw- m'; $t(?) \quad m$

The priests of the holy places in

$r-p r w^{2}-[n b]$

$\begin{array}{lc}h r & r n-f^{3} \\ \text { on }(i . e, \text { bearing }) & \text { his name }\end{array}$

[all] the temples on $(i . e$., bearing) his name

$k ;(w-)^{155}-t w \quad n(?)-s n \quad[h m(w)-n t r]^{4} \quad n t r w y$

(shall) be called prophet(s) (of) the two

$$
\operatorname{pr}(w y) \quad m \quad h r[w] \quad r \quad y^{\prime} w t-w ' b w
$$

Gods Epiphanes in addition to the priestly offices

$$
n(?)^{5} \quad \text { ' } m \mid y-s n(!)
$$

to which they belong.

$$
h t(?)-s n \quad s w(?)^{6} h r-t p-t, ; \quad . \quad-[s] n
$$

They (may) engrave(?) it upon ${ }^{7}$ their [documents?]

[and they (may) write]

iob

1. . [ [y,zwt? $]$ w'b $n^{9}$ ntrwy

. . . [the office of a] priest of the two Gods

[ prwy ] hr $h t(m)^{10} d t-s n(?)^{11}$

[Epiphanes] on the seal (on) their hands

$(r ?)-r d t$

causing

$h t-s n$

it $^{12}$ to be engraved.
DEMOTIC TEXT.

$N-w^{\prime} b w \quad n t \quad n \quad n$-'rpyw (n) $t,-K m y$

The priests who (are) in the temples of Egypt,

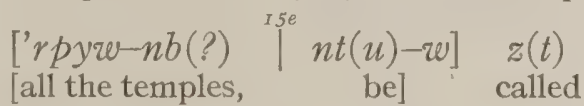

$n-w b w \quad n \quad n-n t r w$

the priests of the Gods

$[n t] \operatorname{prw}^{13}(? !) \quad e(?)^{14}-w, h \quad n(?) \quad k^{\prime \prime} w^{15}$

Epiphanes in addition (to) (the?) other

$r n[w] \quad\left[n-w^{\prime} b\right]$

[priestly] names

$\left[n t(u)-w \quad s h(;)-f \quad n \quad g^{\prime}, y-n-z l^{6} \quad m t-n b\right.$ and they shall write it as protocol ${ }^{16}$ (of) everything,

$$
n t(u)-w \quad s h ;, \quad t \text {-',wt (n?) }
$$

and they shall write the office of

$\begin{array}{cccc}\left.{ }^{15 f} w^{6} b\right] & (n ?) & n-n t r w & p r \\ \text { priest }] & \text { of } & \text { the Gods } & \text { Epiphanes }\end{array}$

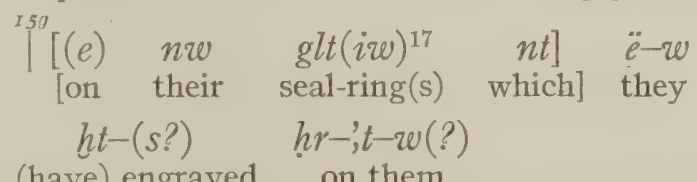

(have) engraved on them

( $i . e$, on which they used to have engraved signs).

${ }^{1}$ The determinative "man" evidently to be restored above the plural strokes.

2 Determined by "city" exactly as in Ros. I2.

${ }^{3}$ Three to four signs here very big and clumsy (as though over erased signs?).

${ }^{4}$ Omitted by the engraver, who was confused by the three-fold repetition of the sign for "god."

${ }^{5}$ The first sign is not high $n$, rather a vertical stroke, the lowest of the 3 plural strokes of $w^{6} b w$. 'The $n$ of the very archaic expression $n-s n$ ' $m y-s[n]$ of Ros. 12 seems to have been engraved over ' $m$ (or the expression was unintelligible to our redactor, who shortened it erroneously?).

"Sw in rather probable traces. The preceding verb is, probably, ht "to engrave." What looks like a small $w$ may be the hook held by the strong arm. Before it, $h$ and $t$.

${ }^{7}$ The senseless $t$ ', "ground" (literally "on the ground of"), might have crept in by a popular etymology of $h i-o(o) t-$ "on" and by its analogy to $h r-t p$; but see the following note.

${ }^{8}$ The traces of this word are very uncertain. The first group does not show a bird's feet; after it a $b$ might be found; the following round sign is not the disk with asp, but probably only a secondary hole. The whole compound reminds of $t p-(t)-,r d$ " precept(s)" as written in the second decree, line $8 b$, and the upper part of the bent leg is possible for the third sign, but the lower traces are unfavorable to this reading. Hardly htmw "seals."

${ }^{9}$ Good traces of a high $n$.

${ }^{10}$ The word is abbreviated or mutilated.' The determinative "seal ring" of the hieratic model copy is disfigured to a crude book roll and a (correcting?) blotch below. Without Ros. I 3 it would hardly be possible to recognize the word $h t m$.

11 The probable ' $r(y)$ "belonging to" of Ros. 13 is erroneously omitted. Behind, over an erroneously engraved bird like "eagle" or "chicken," the engraver seems to have tried to put a high $n$.

12 St "it" ought to be read in place of $s n$ "them," or after it.

${ }_{13}$ The group is written very strangely, perhaps by correction, but the stroke which seems to make here the declension of $p r$ is noticeable as quite an unusual detail.

${ }^{14}$ Read $e$ (in place of $n t$ ) $-w$,' $h$ "to add," which is better than the seeming $n-w, h$ "in addition" of Ros. 30 .

${ }^{15}$ The word is engraved in an indistinct way, which suggests that the engraver at first did not recognize its meaning and had to make corrections.

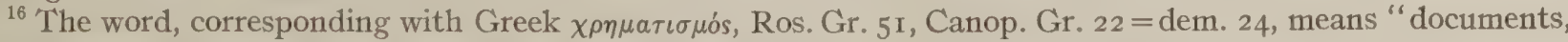
documentary expressions, legal titles of a person in writing."

17 The word, see Griffith, Rylands Pap., III, 237, 400. Ros. Greek 5 I has generally been restored: kai eis rov̀s

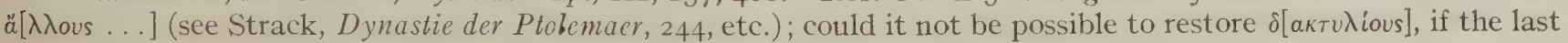
letter before the break is not quite certain and might be $\delta$ instead of $a$ ? 


\section{PRIVATE CULTS OF THE ROYAL COUPLE.}

HIEROGLYPHIC TEXT.

'sk $\left.\right|^{36 c}\left[\text { 'ffy? }^{1}\right]^{2}$ wnn-s $m-d y$
Also thus it be permitted

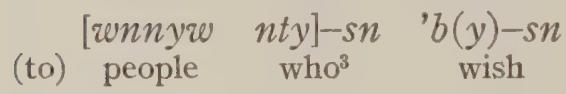

$s-\left.\right|^{\text {I }}$ ' $h$ ' $\operatorname{mytt}(!) \quad k, t-t n \quad n$

to set up likewise this shrine of

$$
n t r w y \quad p r(w y) . \quad r-[r d t] \quad w n n[-s]^{4} \quad m
$$

the two Gods Epiphanes to let (it) be in

pr-sn $m\left[\left.\operatorname{twtw}(!) ?^{5}\right|^{\text {roe }}-s n \quad\right.$ 'r
their house, and they

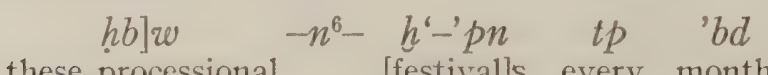

these processional [festival]s every month

$\left[\begin{array}{ll}-n & t p\end{array}\right] \quad r n p t$.

[(and) every $]$ year.
DEMOTIC TEXT.

$$
\left.\left[N t(u)-w t(y)-h p r^{7}\right]^{15 h}\right|^{\prime} s(?) \quad(?)^{9}-(n) ?-t t
$$

And (it) be made] also (?) $)^{8}$ at the disposal

$n-r m(t) w \quad p-m \check{s}^{2}(?)^{10} \stackrel{I}{I \sigma a}^{\prime} n t \ddot{e}-w(?)-w h ;-w$ (of) the men (of) the people who are wishing

$$
[t(y)]-h^{\prime}(l)^{11} \quad p(!)-s m t \quad t-g^{\prime}, t[-n b]
$$

to bring out in procession(!) likewise the [golden] shrine ${ }^{12}$

$$
n-n t r w \quad n t(?)\left[p r||^{16 b} \quad n t h r\right.
$$

(of) the Gods [Epiphanes], which (is described) above,

$e(?) t(y)-h p r(-s ?) \quad n w-m ; w \quad n t(u)-w \quad ' r$ (to) let it be (at) their places, they shall make ' $n-h b w \quad n-h^{\prime} w \quad n t \quad s \underline{h}$; the festivals (of) the(!) processions which are described hr hr-rnpt.

above, every year.

1 The strange archaizing pleonasm of Ros. I3, 's-' $r y-f-s w$, was unintelligible to our redactor; he first omitted the $s w$, not recognizing that it stood for swt and expressed a contrast: "but, moreover, however." Replacing the 's by the fuller 'sk, the redactor shows that the whole series of adverbial (demonstrative) particles was a meaningless stylistic ornament to him. (I am not sure whether the two very low and deep oblique scratches below the secondary vertical line division express a final $y$; the other traces are difficult.)

${ }^{2}$ Literally, "on, at, hands." Ros, 13 reads $m-$ 'wy, which I consider merely as an artificial archaism, without historical foundation. We might find traces of this ending $-w y$ also here.

${ }^{3}$ The redactor shows that the affixing of the personal pronoun $-s n$ to the relative (?) $n t y$, Ros. I3, looked very strange to him. He wishes to move the suffix $s n$ to its regular place behind the verb ' $b(y)$, but has not the courage to remove that interesting form $n t y-s n$ entirely, so he leaves it at the side of his correction.

${ }^{4}$ The engraver omitted the $s$ (see Ros. I3); whether he made a feeble attempt to scratch it over the $m$ or erased it in favor of the $m$ is uncertain.

${ }^{5}$ Confused orthography in Ros. I3, after which we restore here as though the third plural and the passive endings were united by pleonasm.

${ }^{6}$ This $n$ added in our text (disfigured to $m$ ?). Cp. the demotic version.

${ }^{7}$ The small space suggests omissions.

${ }^{8}$ This does not seem to be es: "she is=it is"; this would hardly be possible grammatically. We are tempted to find $h p r$ in this ligature; the space would then, however, be too small. It is in any case insufficient; see above. Our redaction, certainly, omits the " $n$ "again" of Ros. 3 I as superfluous.

${ }^{9}$ Literally, "(at) the place of the hand." The first ligature is engraved quite senselessly and does not seem to have been understood by the sculptor. Cp. the parallel, Ros. dem. 31 .

${ }^{10}$ Literally, "of the multitude." Egyptian lacks a good expression for the Greek "private people," as we see especially in the hieroglyphic version.

${ }^{11} H^{\prime}$ "to show, to parade" seems in Ros. and here to be written erroneously for h,; "to place, to set up." The other versions demand this emendation.

${ }^{12}$ Evidently omitted in Ros. 3 I by confusion of $n b$ with the following plural article. Before might be read $n t w h ;-w$ "and they wish," which, however, could be read as in Ros. $(u)-w$. 


\section{PUBLICATION OF THE DECREE.}

\section{HIEROGLYPHIC TEXT.}

$\left.R(?) \quad r d t \quad s()^{\prime}\right) ; w(!)-1{ }^{16 f} t w$

In order to let it be known (that) there are the

' $m(y) w^{2}$

$T,-M r(t)$

inhabitants of the Inundation Country (i.e., Egypt)

$h r-z s r \quad n t r w y \quad p r(w y) \stackrel{i 7 a}{I^{2}} m y(?)^{3}[n] t t$

honoring the two Gods Epiphanes according to that which is

$\begin{array}{cccc}r & \text { ['swy?] } & n f r & s p t(?)^{4} \\ \text { for } & \text { [compensation] } & \text { (of) } \operatorname{good}(\text { ness) } & \text { of action (?) }\end{array}$

$h t w(?)^{5}-t w \quad s h$ 'wy-pn hr ' $h$ ' $[y] \quad n[t y$ be engraved this decree on stela(e) o[f

",t$\left.t^{x} T^{b}-r d(t) m\right] s \underline{h}, \quad[n] \quad m d w(t)-n t r(w)$ hard stone in the writing of the divine words,

$s \underline{h}, \quad n \quad \check{s}^{\circ} y w^{6}$

$$
\text { - sh', }
$$

$n$

the writing of letters (and) the writing of

$H^{\prime}, w(y)-n b w w^{7} Y^{r c c} r d(t ?)-h^{\prime}-f \quad m \quad[p r w-m ; ' t(?)$

the Greeks, setting it up ${ }^{8}$ in [the holy places

$m \quad r-p r w-n b \quad h r \quad r n]-f$

in all temples on (i.e., bearing)] his [name,]

$m h-I, \quad m h-I I, \quad m h-I I I{ }^{17 d} r-g s \quad h n(t y)$ (of) first, second (and) third (order) beside the statue

\section{DEMOTIC TEXT.}

$N t(u)-f \quad h p r \quad$ 's swn $z(t) \quad n-n t$ And that it be also (?) $)^{9}$ known that those who

$$
\begin{aligned}
& \text { (n) } \quad t,-K m y] \\
& \text { (are) in Egypt] }
\end{aligned}
$$

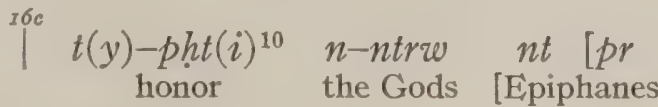

$$
e(?)-\quad h \quad p-n t-n-h p \quad n \quad \text { ' } r-f
$$$$
\text { according to that which is proper to do (it) }
$$

$n t(u)-w \quad s h() \quad p-,w t \quad n \quad w y t$

be written the decree on stela(e) (of)

'ny-zry $\quad n \quad s \underline{h}() \quad m t-,n t r$

hard stone in (the) script (of) divine word(s),

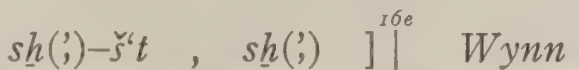

letter script, (the) script] (of the) Ionians (i.e., Greeks)

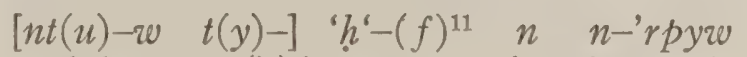

and that (it) be set up in the temples

$$
I(=t p y),\left.\quad n(?)\right|^{16 f}[n-' r p y w \quad m h-I I
$$

(of) first (rank), in the temples (of) second (order)

${ }^{1}$ The ideogram of the verbal root "to know" (Pan's flute) disfigured to $t$.

${ }^{2}$ In Ros. ' $m$ slightly disfigured?

${ }^{3}$ Like a high $n$, but the lower part as far as visible would be too low for this, so I rather read $m y$, but the sign is not quite clear. The Demotic version supports this reading $m y$ "like."

${ }^{4} \mathrm{I}$ do not understand the above expression in detail, owing to the difficulty in identifying the sign after $r$. The above reading must assume that the 's-sign was disfigured somewhat; $t w t$ "proper thing" can hardly be found there. Above, I suggest, after the apparent $n f r$, an emendation of $s p t$ to $s p$, "time, case, example, action," $i . e$., of $t$ to a circle (with two strokes inside). So far this is very uncertain, although the general sense is plain by the Greek (53) and demotic $(3 \mathrm{I}-32)$ versions of Ros., after which we should expect twt "proper." Is it possible that the passage was disfigured so strongly by the engraver? Or read simply nfrw-st(!) "their(1) goodness"?

${ }^{5}$ Expressed by an arm holding a stylus? The traces are strange (more like a foot?) and the $w$ as third consonant of this verb is quite unusual, so that we must again suspect corruptions (like confusion with miwtw).

${ }^{6}$ Written ' $s y w$ by mistake.

7 The true pronunciation of this very ancient name does not seem to be known yet; I use above the popular transliteration.

${ }^{8}$ Or particularly, "being set up." The $-t$ of $r d t$ is, probably, without signification.

${ }^{9}$ See above, p. 54 , note 8 , on this 's. Here it is even clearer that it can not be verbal.

${ }^{10}$ Notice well the final $-t(i)$ of our text, also with the above verbal form.

11 The Philæ text omits the $-f$ of the subject, probably having a mere oblique dash which could be confounded with the following smaller stroke, a negligent $n$ (like $e$ ). Also the verb 'ohe' is negligently written as though not understood. We correct after the general parallel (Ros. dem. 32), disregarding the two vertical strokes which stand there after $t(y)$. 


\section{PUBLICATION OF THE DECREE-Continued.}

HIEROGLYYPHIC TEXT.

$n$ n-st 'byty

of the king of Upper and Lower Egypt,

nb t'wy s', $R^{\prime}$

the lord of both countries, the son of the Sungod,

nb h'w , Ptw'rw[mys ' $n h z t$, the lord of diadems, Ptole[my, living forever, mr Pth $\left.\quad h^{\prime 1}\right]$ rpyt hqt beloved of Ptah, and $\left.{ }^{1}\right]$ the image of the queen,

wrt

$$
n b(t)
$$

t'wy

the great one, the mistress of both countries,

$Q r w^{\prime}{ }^{\prime 7} w^{\prime}, p^{\prime}, d r ;(t) \quad n t r w y \quad p r(w y), ~ d y ~ ' n h$, Cleopatra, the two Gods Epiphanes, giving life, $n b w \quad s n y b-n b w(!) \quad m y \quad R^{\prime} \quad z t$ lords of all health like the Sungod eternally.
DEMOTIC TEXT.

$$
\begin{array}{cc}
n \text {-'rpyw } & m h-I I I \\
\text { (and) the temples (of) third (order) before }
\end{array}
$$

$p$-twt $n$ pr the statue of king

$$
P t] \operatorname{lwm}[y] s \text { ' } n h \text { [zt Pth } m r
$$
Pto]lemy, living [forever, beloved of Ptah,

$n m \quad t$-rpyt $\left.n \quad p r^{4} t\right]$

and the image of queen]

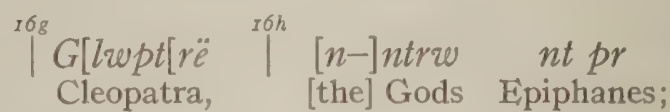

$n t(u) w \quad . \quad n-n b] w$

they [are(?) the master]s(?) (of) life for ever

$n m(?) \quad h h(?)^{3}$

and(?) eternity(?)

1 The space would allow fuller expressions for this word.

${ }^{2}$ Evidently the same preposition which we have discussed in the note on $I \cap g$ (p. 4I). Notice in Ros., which we have followed in our passage, the treatment of the final $-t(e)$ as if it were $t t$ "hand."

3 'The conclusion can not be read with entire certainty. It is terminated by a few groups a line below, plate $g$ (19), not returning to the regular beginning of the lines. 


\section{THE SECOND DECREE.}

The so-called "second" (in reality first) decree ${ }^{1}$ stands to the left of the decree treated so far, with only 2 to 3 inches space between. The hieroglyphic hand is very similar to that of the "first" decree and may be identical, although considerably more elegant; evidently, the engraver took more time in the first half of his work, so that we have here a further proof that the sequence of both documents is to be reversed. The demotic text begins a little over 4 inches under the last hieroglyphic line. Its writing, at first elegant, firm, and intelligent, becomes heavy on plate $e$, and on plate $f$ as clumsy as if the signs had been recut for correction. I do not hazard an explanation of these latter changes.

THE DATE.

(THE HIEROGLYPHIC TEXT OF THE SECOND DECREE IS DESTROYED FOR THE FIRST THREE LINES).
DEMOTIC TEXT OF THE SECOND DECREE.

\begin{tabular}{|c|c|}
\hline $\begin{array}{l}\text { Hspt XIX, } \\
\text { [Year I9, }\end{array}$ & $\underset{29(?)}{X X I X(?)}$ \\
\hline $\begin{array}{ccc}n t & \text { 'r } & \text { 'bt } \\
\text { which } & \text { makes } & \text { (as) month }\end{array}$ & $\begin{array}{l}n \quad \text { rmtre } t,-K m y \\
\text { of Egyptian people }\end{array}$ \\
\hline $\begin{array}{cc}I V(?)-\check{S} m w, & h w \\
\text { Mesorê (r2th month), } & \text { day } \\
p r-6 & p-[h]\end{array}$ & $\begin{array}{l}I X, \\
9,{ }^{2}\end{array}$ \\
\hline
\end{tabular}

(of) the king, the young one,

$$
\text { ' } r-h^{6} \quad p r-6 \quad n \quad t^{3}-s t \quad\left[\begin{array}{ll}
n & p f-y t(i)
\end{array}\right.
$$

who has appeared (as) king at the place [of his father

$$
\begin{aligned}
& \left.\left.n b \quad n-r^{\prime} y(w) t \text {, nt } \ddot{e} \quad n ;-\right)^{\prime}(,)\right] \text { | } t f-p h t(i)-t \\
& \text { lord (of) the diadems who great is] his might, } \\
& \text { 'r-smn } \quad t,-K m y \quad[\ddot{e} f] \quad t(y)-\left.\right|^{I, l} n f r-f
\end{aligned}
$$

who has established Egypt, (as) [he has] improved it,

[nt n,-] mnh [ht (i)-f . . . . . . . ${ }^{4}$

[who] kind (is) [his heart towards the gods, who .

his enemies (while) he improves the life of (the) men,

${ }^{1}$ See p. 3 , on the error in this conventional name and the demotic text on the exact date.

${ }^{2}$ The date is not clearly readable. Neither the signs for the season nor the preceding number are plain. The traces at the latter place look like a II, and thus my first reading was: second month of the second season, i. e., Mechir (sixth month). This would have brought us into the middle of the twentieth year, a time when order would have been restored sufficiently throughout all Egypt and the priests would have had time to come from every corner of the country. But the "first," in reality second, decree mentions "the decree of the year I9" (at least, line $I 3 d$, demotic $I 3 f$ ) and thus fixes our date, for it is not advisable to assume that "year 19 " would refer only to the victories over the rebels, not to the following priestly convention and its resolution. It is also much more probable that the priests of Egypt did not wait for half a year to show their loyalty on such an important occasion. Evidently they acted wisely and promptly, assembling as many priests from the Delta towns as was possible within six days, to speak in the name of all the rest. 'Thus I have tried to read the third season and to find traces of the month No. IV above that faint deceptive trace, considering this trace (which resembles a II) as secondary. The number 9 for the day is fairly clear, less the 20. I leave it to others to control the correspondence of the Macedonian date.

${ }^{3}$ On the stone by mistake $t f$, evidently by confusion with the following possessive $p f$ "his."

${ }^{4} \mathrm{I}$ do not repeat the transliterations for these long restorations. See the first decree for them. 


\section{THE SECOND DECREE - Continued.}

THE DATE-Continued.

HIEROCLYPHIC TEXT.

\section{DEMOTIC TEXT.}

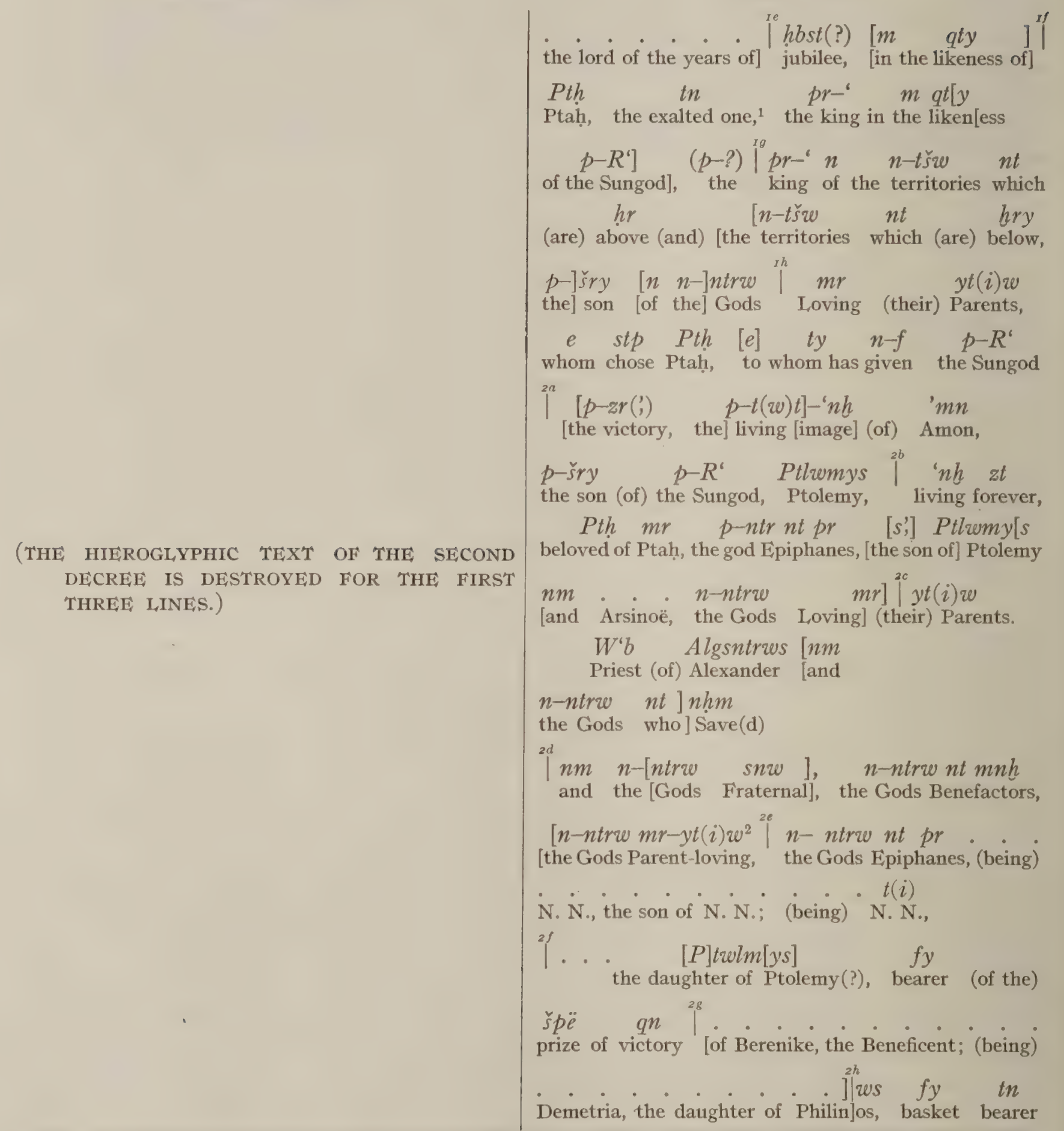

${ }^{1}$ See the first decree on the double sense of this word. Probably, it means here "the ancient one."

2 'The traces on $2 e$ belong to the priestly name rather than to this title, although strongly reminiscent of the group "father." 


\section{THE SECOND DECREE-Continued.}

THE DATE-Continued.

HIEROGLYPHIC TEXT.

DEMOTIC TEXT.
[before Arsinoë, the one Loving her Brother; (being)
H]ryn', s't $n$ Ptlwmys w'b
Ei]rene, the daughter of Ptolemy, priest(ess)
$1^{3 b}[] r s,[y] n ; \quad t-m r(t)-y t(i)-s$.
of Arsinoë, the one Loving her Father.

\section{THE RELIGIOUS OCCASION OF THE DECREE.}

Wt $\quad$ 'r $\quad n-[m r(?)-\check{n} n w$

Decree (which) have passed ${ }^{2}$ the [high priests

$n m \quad n-h n w n t r \quad n m \quad n-]\left.\right|^{3 c} w^{6} b w \quad n t$

and the prophets and the $]^{3}$ priests who

$\check{s}(m) \quad e(p-?) \quad m$ 'wb $\quad e^{\text {'r }}$

go to (the) sanctuary to perform

mnh $\quad\left[\begin{array}{ll}n & n-n t r w\end{array}\right.$

the clothing [of the gods,

[shri,w] $\quad 4^{a} z m ; w t(?)-n t r \quad h^{\prime} \quad t y(!)$ (the scribes of) the holy writings and the faculty $\operatorname{pr}(w y)-\quad " n h$

of the (double) house of life (i.e., the library)

$h^{\prime} \quad n ;-k y w \quad w^{\prime} b w$

and the other priests

$m$ 'trty šm't

from the (two classes of) sanctuaries of the South

$\begin{array}{lll}\left.\begin{array}{l}\text { mhyt } \\ \text { (and) North who (are) in }\end{array}\right|^{4 b} \text { "the Fortress } & \text { of }\end{array}$

'r $(w) k s d r s$

'b-sn 'w

Alexander" (Alexandria) (who) have met at ${ }^{1}$

$$
\text { shat nty 'st | } h^{40} \text { ntrrey snwy }
$$

the sanctuary of Isis and the two Brotherly Gods

$\begin{array}{cccc}h^{*} & n t r w y & m n h w y & h^{*} \\ \text { and the two Beneficent Gods }\end{array}$

and the two Beneficent Gods and

ntrwy $\quad m r(w y)$ ytwy $h r$

the two Gods Loving the(ir) Parents and

ntrwy pr(wy) nbw Bqt

the two Gods Epiphanes, the "Lords of Egypt," $n m \quad n-s \underline{h}() w] \quad m z y$,$\left.w \quad | ^{3 d} n m \quad n-s \underline{h}(),\right) w$

and the scribes of] books ${ }^{4}$ and the scribes

$\operatorname{pr}(w y ?)-$ ' $n h$
(of) the (double) house of life (i. e., the library)

$n m \quad n-\quad k$ "w w'bw

and the other priests

[who have come from the temples of

Egypt (to Alexandria?)

to the temple of Isis and the Gods

. . . . . . nt $m n h$. \% . .

Philadelphus and the Gods] Euergetes [and the Gods

$[m] r-y t(i) w \quad\left[\begin{array}{ll}n m & n-\end{array}\right] n t r w \quad n t p r$ Philo]pator [and the] Gods Epiphanes,

$n b w$

$B q[\ddot{e} t]$.

the Lords (of) Egypt

${ }^{1}$ Literally: "towards, into."

${ }^{2}$ No space for the usual words summing up the long date "this day," which we should expect before "decree."

${ }^{3}$ Very abundant space, suggesting some unusual orthography or additions (?).

"Strange orthography of this word (the pronunciation of which is not quite certain). 


\section{THE POLITICAL OCCASION OF THE DECREE: SUPPRESSION OF THE REBELLION.}

HIEROGLYPHIC TEXT.

DEMOTIC TEXT.

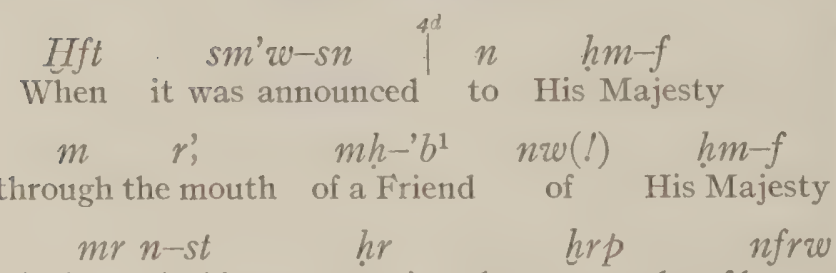
who loves the king, concerning the commander of horse,

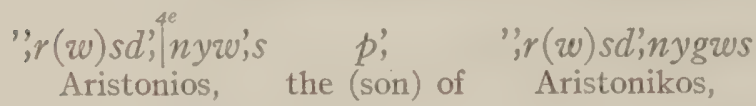

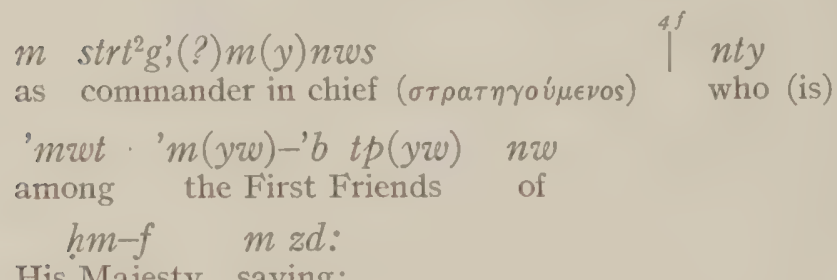

His Majesty saying:

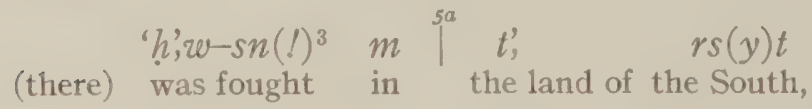

$m \quad w w \quad$ W'st

in the Territory of 'Thebes, ${ }^{4}$

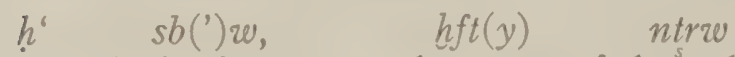

with the impious man, the enemy of the gods,

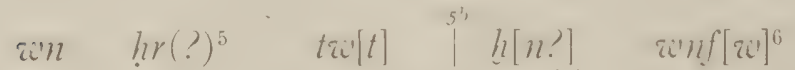

(who) had been assembling from(?) the warriors(?)

[who had raised rebellion?]

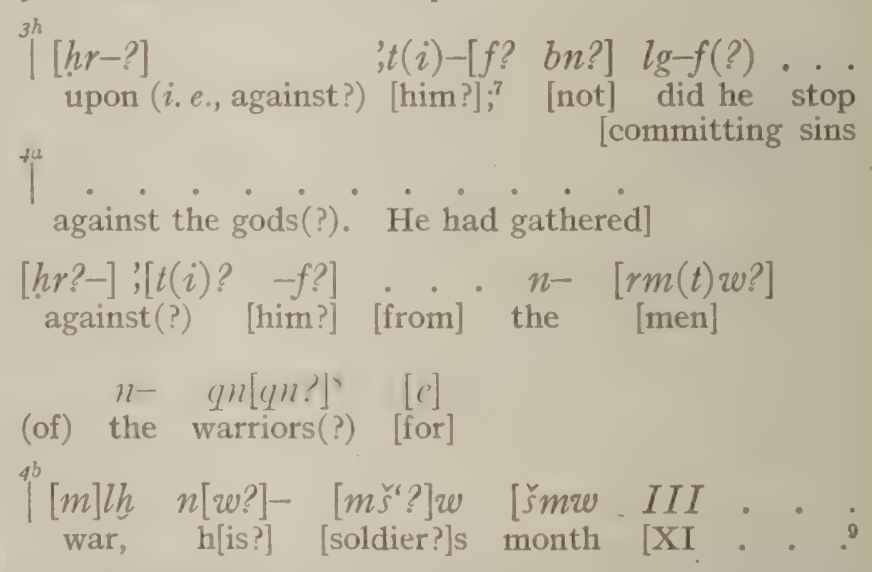

${ }^{1}$ Literally: "who filled the heart of II. M." 'The following synonymous expression shows that the Greek original must have designated him as a "Special Friend"

2 'The rare sign in the value of $r t$; in later time ordinarily used for $r$. The following $g$ is very small, almost like $n(w)$, for which it could be held. The next sign might also be $w$.

${ }^{3}$ The sign $s$ is left incomplete.

${ }^{4}$ An awkward translation for "the Thebais."

5 The questionable hr - traces might be secondary in part. The group before may have an $n$ below; the sign above seems to be a very narrow $w^{\prime \prime}$; at least the peculiarly forked tail, which our two inseriptions give to this sign, secms clearly visible. In expresses a continual past action. It is neither the eneny striking himself nor do the readings nty' or h $\mathrm{pr}$ of the whole group appear possible. 'The reading l.wt ntr(w) "the temples" (taking the second vertical stroke as part of the temple sign), is equally impossible.

${ }^{6}$ The orthography of $h n$ ( instead of the exact $m$ - $h n$ " from among") is unusual and uncertain. The unique word wh (see again ob, IIf), written here with the determinative "wicked man," shows that it was used as synonymous with "rebels."

${ }^{7}$ Not quite certain, but the sense is clear.

${ }^{8}$ Abbreviation or mutilation of the expression Rंos. demot. II ?

${ }^{9}$ 'The group looks like a date, though this does not correspond with the hieroglyphs. This must be said also of the preceding words and of the whole passage, which makes us think of additions in the demotic text. 
THE BILINGUAL DECREES OF PHILAE.

\section{SUPPRESSION OF THE REBELLION-Continued.}

\section{HIEROGLYPHIC TEXT.}

\section{$h^{6} \quad t s w w^{1} \cdot n w$}

and troops of

$$
N h s(y) w \quad d m z-s n \quad h^{6}-f
$$

the Ethiopians who had united with him,

Ic $s m,-2^{2} m(?)-s n \quad ; m \quad m \quad s q^{3}$
slaying them, seizing as captive
$p n^{4} \quad\left[{ }^{4} n h\right]$.
this (wicked man) [alive].

DEMOTIC TEXT.

\begin{tabular}{|c|c|c|}
\hline $\begin{array}{lc}h s p t & X] I X \\
\text { year } & \mathbf{1}] 9,\end{array}$ & $\begin{array}{l}{[\mathrm{nm}]} \\
{[\text { and }]}\end{array}$ & $\begin{array}{l}{[n-\ldots] w} \\
{[\text { the troop?] }}\end{array}$ \\
\hline
\end{tabular}

Ethiopians having gathered with him.

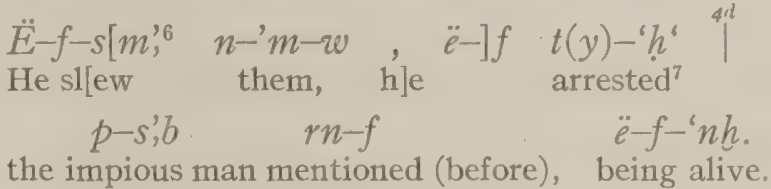

\section{THE BENEFITS BY THE KING TO THE GODS IN GENERAL.}

$$
\begin{gathered}
K,-s n: \quad m(y)-n t y \\
\text { They declare: inasmuch as }\left.\right|_{\text {there was }} ^{s^{d}} \text { wn }^{5}
\end{gathered}
$$

$$
n \text {-st 'byty }
$$

the king of Upper and Lower Egypt,

$$
s^{\prime},-R^{s}
$$$$
\text { Ptw'rwmys }
$$

the son of the Sun, Ptolemy,

$\begin{array}{lcc}\text { ['nh. } & z t & m r \text { Pth }] \text { ], } \\ \text { [living } & \text { forever, beloved of Ptah], }\end{array}$

$$
\text { s', } n \quad n-s t \quad \text { 'byty' }
$$

the son of the king of Upper and Lower Egypt,

$$
\begin{gathered}
\text { Ptw'rwmys } h n^{\prime}{ }^{\text {se }} \text { hat } \\
\text { Ptolemy, and the queen (and) mistress }
\end{gathered}
$$

$$
\text { t'wy 'r } \quad \text { (w)syn't ntrwy }
$$

of both countries, Arsinoë, the two Gods

$$
m r(w y) \quad y t w y \quad h^{6} \quad s n t-h m t-f \quad h q t
$$

Loving the(ir) Parents, and his sister-wife, the queen

$$
\text { nbt t'wy }
$$

and mistress of both countries,

$$
\begin{aligned}
& \ddot{E}-w \quad z(t): n-t(t) \\
& \text { They say: since }
\end{aligned}
$$

[the king Ptolemy, living forever,

beloved of Ptah,

the son of king Ptolemy and of]

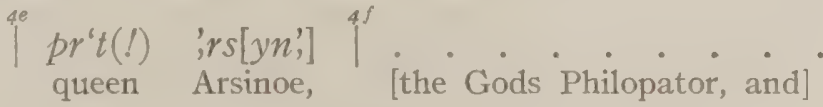

tf-shmt r $\left.^{\prime} t \quad\right|^{49}$ Glw $[p t r] \ddot{e}$,

his wife, the queen Cleopatra,

${ }^{1}$ The $t$ is not quite plain. 'The sign $t s$ (Theinhardt's catalogue $2.5 t$ ) as a vocal determinative occurs below IIC. The word $t_{s}(t)$ means usually "troops;" it seems to have an unusual sense here, and is not absolutely certain. 'The usual words for "tribe" are impossible. In demotic only the determinative "foreign" is preserved (mtgt",?).

${ }^{2}$ Participial construction without suffixal possessive. Determinatives "knife" and "arm" (destroyed). The expression of the object by $m$ has, by no means, partitive sense (as though meaning: "(some) of them") (see on this interesting influence of the vernacular grammar, demotic text, line $g a$ ).

${ }^{3}$ The orthography is not entirely clear and is certainly unusual. (Second determinative "club.") The word ' $m$ before it is written with eagle and horizontal $m$ in ligature, as $I 6 a$.

" $P n$ "this" is rare in this absolute use (like the more frequent $p f$," "that one," with contemptuous sense); the demotic version insures the general sense, however. We might also assume that the repetition of the determinative "bound captive" has caused the omission of the word $s b$ " $(w)$ "impious man."

${ }^{5}$ 'The $n n$ like $m$, but the error possibly abandoned. On $w n$ of the imperfect, cp. p. 6o, note 5 .

${ }^{6} S$ seems to be visible; the $m$ ',-sign seems to have been as straight and as far to the left as in Ros. demot. I6, where this rare, obsolete word, mutilated $g d$, occurs. The verb may also be treated as participial, "slaying."

${ }^{7}$ Exactly the same double sense as with the English word "to arrest." Coptic taho has the same meanings. 


\section{THE BENEFITS BY THE KING TO THE GODS IN GENERAL-Continued.}

\section{HIEROGLYPHIC TEXT.}

ntrwy $\quad p r(w y) \quad h r-' r(') h(w) t-n b^{1} \quad n f r w$ the two gods Epiphanes, doing all things good $n \quad h w t-n t r^{2} \quad h^{\prime} \quad{ }^{6 a} m \mid t y(!)^{3}-s n$

to the temples and their inmates

$\begin{array}{ccc}h^{\prime} & w n(y w) & m-h n t(!) \\ \text { together with } & \text { (those) being } & \text { within }\end{array}$

\section{y'wot-sn mnht}

their beneficent dignity (or office)

$$
r^{4} \quad \text { ' } b-s n \quad m n h \quad h r
$$

being their heart kind towards

$$
r-; w-s n
$$

all together,

$$
\begin{aligned}
& \text { htpw(?) }-s n \\
& \text { their sacrifices }{ }^{5} \text { (i.e., incomes?) } \\
& \text { 'w } \operatorname{tr}(t)-n b \\
& \text { at all time } \\
& \quad r-s b w t \quad s k \\
& \text { for the sake of the institutions(?) of } \\
& \text { formore }{ }^{6}
\end{aligned}
$$

\section{$m h$}

'w-'w-sn $\quad h^{\prime} \quad{ }^{o c} \quad[h t p w]-n t r^{9}$

altogether, together with the divine [domains?].

['w?]-sn $r d t \quad m n \quad k,-s n \quad[' b ?]^{10}$

They gave (i.e., made) (this) firm (as) they thought(?)
DEMOTIC TEXT.

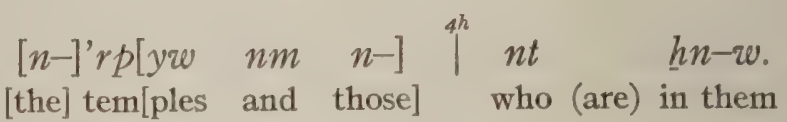

${ }^{1} \mathrm{Nb}$ seems to be corrected over three plural strokes.

${ }^{2} N$ as simple stroke; of the divine hawk, whip and tail are visible.

${ }^{3}$ Incorrectly in place of ' $m y(w)$, the $-y$ being disfigured to $t y$. 'This is then abbreviated to one sign. The analogy of ' $m w t$ "within" ( $4 f$; $g b$, etc.) may be considered, likewise.

${ }^{4}$ Might be, also, a small low $m$ or an irregular $n$ ("in their heart"), but $r$ (='w "being") is most probable.

${ }^{5}$ We should expect: "filling their hearts, their wish," (i.e., satisfying them), but the traces are unfavorable, as also they are against a restoration like: "their storehouses, their magazines." The horizontal traces above are somewhat high for $h t p(w)$ "sacrifices," but the $t$ and irregular $p$ below show that this word is meant. (The cake and the plural strokes have been effaced behind.)

${ }^{6}$ See below, demot. $5 d$, the translation of this archaistic expression with 'on "again."

7 Thus, rather than $r n p t$ "year," which the orthography would indicate. With $t r$ the final $-t$ is senseless, but may be taken erroneously from the foot of $t r, l^{\prime}$.

${ }^{8}$ I tried, at first, the reading sndw "the respectful (people or subjects)," literally "those who fear," which seemed to me an awkward translation for some Greek expression like $\epsilon \dot{\nu} \lambda a \beta \epsilon i s$, "the careful, considerate, prudent." The reading is, however, too uncertain, and the last two determinatives would be quite unusual. Therefore, I have preferred the restoration $s t[s ?](w)$, as meaning "institutions, traditions" or the like. It must be admitted that with the above reading the two signs following the determinative of "saying, thinking" remain inexplicable; these, furthermore, look as if preceded by a small gap above. Nevertheless, the following "all of them" shows that a noun in the plural is meant. Thus we can not read: "for the sake of restoring order," or similarly with an infinitive. To change the redundant last two determinatives to qnw "many" does not yield any better sense.

${ }^{9}$ The signs look like ntrwt "goddesses," but this is senseless. Evidently the text is corrupted. The guess given above (htpw ntr "divine domains," with the goddess sign for that of the broad cake, cf. $6 d$, etc.) presents only the difficulty that these domains are mentioned in the next section.

10 The traces fit neither this restoration nor very well $n n$ "these," which we should like to see after the demotic. 


\section{THE BENEFITS BY THE KING TO THE GODS IN GENERAL-Continued.}

HIEROGLYPHIC TEXT.

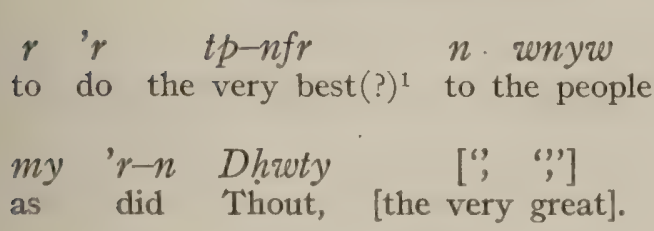

\section{DEMOTIC TEXT.}

I $n ; y \quad n \quad n-' r-w \quad p-h p$

these (things) to those who do (?) $)^{10}$ what is right

$\underline{h n}$. . [ [e-h] $p-\ddot{e}-' r$ Throty $\left.\right|^{5 d} p-", p-"$,

in [Egypt(?)] as did Thout the very great

\section{SPECIAL BENEFITS TO THE PRIESTS.}

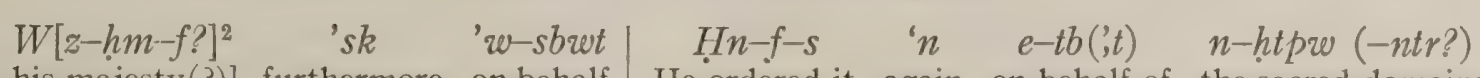

Ord[cred(?) his majesty(?)] furthermore on behalf

$\left.h t p w[-n t r ?] \quad n \quad n t r w\right|_{s} ^{6 e} h^{*} n b$ of the [sacred?] domains of the gods and the gold,

hz hy $\quad r[d y$ ? $] \quad r$ hwot-ntrw

silver (and) grain (to be) given for the temples

$m(!)-h r^{3} \quad h s p t \quad h^{\prime} \quad p(s)$ šret(?) $r w^{4}$ every year (of the king) and the corresponding(?) shares

$n w[? ! n t r] w \quad m \quad h s p \quad n w(?)^{6} h w(t)^{7}$

of the [god]s from the vineyards(? $)^{5}$ of the fields(?)

hr hnbw [...?] (') $h(w) t-n b$

and gardens, [and?] all things

$$
\text { wn }\left.\quad h r\right|^{7 a}-s n
$$

(which) were (due) to(?) them ${ }^{8}$
$m \quad r k^{9}$
$y t ?[-f]$
$[m n-s n] \quad r(?)$

in the time [of his] father [should remain] at(?)
He ordered it again on behalf of the sacred domains

$n n-n t r w \quad$ se $\left[\begin{array}{lll}n m & n-n b \quad n-p r\end{array}\right.$

of the gods; [and the money (and) the grain

$$
n t \ddot{e}-w-t y-s t \quad n \text { sntgsy(s?) (e) nw- ('rpyw) }
$$

which was given as tax for their (temples)

hr-rnpt nm n-t'w. nt hpr $n$

every year and the portions which were for

$n-n t r] w \quad n n-y h w w(t)-' l l t \quad[n-]^{11} \quad y h w(t)^{5 !}-t k \ddot{e}$

the god]s from the vineyards (and) the gardens.

$n m \quad p-s p \quad[n k t \quad t r-w$

and the rest [(of the) things altogether

$$
\begin{array}{cc}
e-w] n-n ; \ddot{e}-w(?) & m h[t](?)-u(?) \quad ' m-w^{12} \\
\text { which] they had been } & \text { receiving(?) }
\end{array}
$$

[under his father

${ }^{1}$ Literally, "the top (i.e., beginning, or the best) of the good."

2 The $-w$ seems to be the phonetic complement following the sign wz, wt.

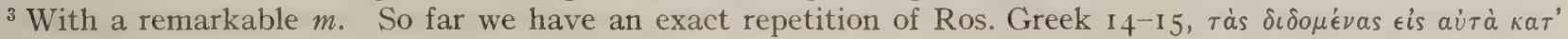

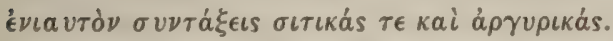

"For 'ry $(w), i$. e., "belonging to them, due, proper" (каөпкои́бas). Reading r'w "parts" would be tautology.

${ }^{5}$ We must follow Ros. Greek I 5, and the demotic. Our scribe has exchanged agricultural words as meaningless for him. Damanhur, $\mathrm{I}_{4}-\mathrm{I}_{5}$, suggests that the obscure passage was confusing even in the original. (Cp. Brugsch, Wörterbuch, 968, boldly restored.) The effaced group after hnbw seems disfigured for $h^{\prime}$ "and."

${ }^{6}$ Not the middle stroke of the plural strokes above; it is too high. Neither is $h r$ "on, and" probable.

${ }^{7}$ The abbreviation $h t=y^{\prime}, h t$ is very archaic, like the (threefold) omission of the plural strokes.

${ }^{8}$ Thus, reading the last sign on line 6 as the determinative "book-roll." $\operatorname{Hr}\left[h^{\prime}, t\right]-s n$ "before them" seems not possible.

${ }^{9}$ With an abnormally large determinative "way" the limits of which are not clear.

${ }^{10}$ Grammatically doubtful. Could it not rather be read $e-t(y)$ ' $r-w$ "to make them do, to cause to be done"? The dot after the ambiguous sign, however, seems to point to the reading $n($,$) -, not t y$.

11 The plural article $n$ - seems to have been omitted by homoioteleuton with the first sign of the group $y h t$, $y^{\prime}$, ht. See the Rosetta parallel.

${ }^{12}$ So far simply after Ros. dem. 9, with which the traces in our text do not all agree. 'The $w n-n, ' \ddot{e}-w$ can be found most easily, but the $m h$ requires fancy. $M h(t)-n$ usually means "to seize, to grasp." The reading "(they were) owing" $h r-w$ would have a sign too much and would present other difficulties. The reading š "to demand" likewise remains uncertain. Is our text corrupted? Next we might try to see also $n n$ - "in the [temples?"]. 


\section{SPECIAL BENEFITS TO THE PRIESTS - Continued.}

\section{HIEROGLYPHIC TEXT.}

DEMOTIC TEXT.

$[s t(-s n ?)]^{1} \quad w, h(?)-s n^{2} \quad \operatorname{grg}(?)^{3}$

[their place] (and) be added(?) foundation(s?) (of)

,$h(w) t-\left.[s n]^{4}\right|^{7 b} w(?) \quad g s-s n(?)^{5}$

[their] fields to their part.

'w-[dy-f?] $n b \quad h z \quad "(w) t \quad n b \quad n-m ; " t$

He [gave?] gold, silver, all genuine stones

$$
m y-s-s n \quad \text { 'w } s-h^{6}
$$

in great quantity, for the decoration of

$\prod^{7 c}[P t] h \quad w n(? ?) \quad n t r-n b(?)^{7}$

Ptal! ('s temple)," (and what) there was (for) any god(?)

$m$ wร $m$ hmw 'w-[f?]-rdt wn-sn

in ruin in the sanctuaries [he?] caused them to be

hr st-sn

on their place (i.e., in the former, good state).

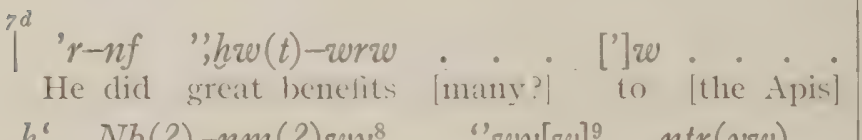
$h^{\circ} \quad N b\left(\right.$ ?) $-n m(\text { ?) wy } \quad \text { "wy[w] }]^{9} \quad n t r(y w)$ and the Mnevis (and) the sacred animals hw $\left.\right|^{7 e} n[K m] t m$-hi;w- $\quad r \quad$ wn venerated in Egypt more than (those who) were $h r-h$ 't $-f . \quad$ ' $b-f \quad$ ' $q$

before him. His heart entered (i.e., was willing to serve)

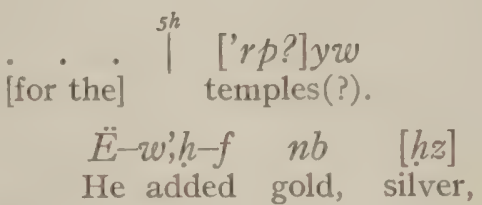

'ny $\left.\right|^{6 a}[n-m ; '(t)$. . . . . ]

stone(s) [of value for the decoration of]

$n w-r p[y w](?) \quad y(y)(?) \quad$.

their(?) teinples(??) going(?) [to ruin? he was?]

$t y(?)$. . . . . . . . . .

giving(?) (i.e., causing?) [them to be repaired]

$6 b$

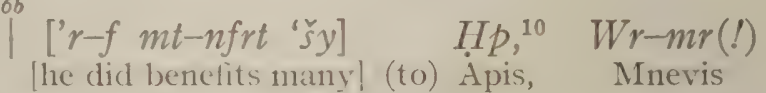

$[n m \quad n-k$ " w ", $n t \quad h w y \quad(n)$ [and the other animals which (are) venerated in $\left.t^{\prime},-K m y \quad h w ; \quad n ; y(?)-\right]\left.\quad\right|^{\sigma c} w n-n ;-w \quad h ;, t(i)-f$ Egypt more than those who] were before him 'r (-w? ) [e]

had done, [being]

I The passage can not be filled after 1 )amanhur 15 , because the text has been considerably varied, expanding the first words and crowding or shortening the rest. 'The traces behind the large determinative of $r k$ are: a round top of a high sign which might be the idcogram yt "father." Below is a heavy oblique stroke, suggesting the hind $\operatorname{leg}$ of a $\pi$, thongh it is too heay and the other traces do not conlirm a $i i^{2}$. It may be secondary, a continuation of the crown cut over most of plate $a$. Next follows a sign which looks like a big square, irregular in front. The following $r$ is very high, but fairly certain.

${ }^{2} W^{\prime}, h$ in irregular form.

3 This (at first) very difficult group) begins $g($ ? $) r$. 'The next sign above proved to be $g$, being different from the ordinary form of min in our text, and this led to the correct reading grg. Consecunently, the sign below, looking half like 'm "ship," half $i^{\prime \prime}$ " "net," is the leg in a trap. A gap for a narrow sign remains, possibly filled by a bookroll.

${ }^{4}$ The three parallel plural strokes of the noun can be guessed from the traces of the first.

${ }^{5}$ I suppose $s$ is to be corrected to $\mathrm{sn}$. I have tried to understand the whole passage as expanding Ros. Greek I5-I6, from a mere conservation of the priestly lands to an augmentation.

"The expression "for adorning Ptah" is thus to be understood because this section treats of buildings. See p. 46 , note 4 , on the double sense of sh" "to show, to decorate." At any rate, the space does not permit a noun before "Ptah."

${ }^{7}$ All these restorations are $11 n c e r t a i n$ and poor Egyptian. The traces do not agree with $n b$ "all, every," but still less with $h t$ "temple."

${ }^{8}$ The nane is disfigured in the sign $n m$ (micread $m$ by Iigyptologists and later Figyptians) and has unusual form, also, in the addition of $n b$ "lord" (if this is not to be read $n$ "to").

${ }^{9}$ The first stroke of final $-y$ is preserved.

11) With a remarkable archaizing expression of the $l-$ of $I I p$. The name Mnevis, with a strange determinative. 


\section{SPECIAL BENEFITS TO THE PRIESTS-Continued.}

\section{HIEROGLYPHIC TEXT.}

$h r \quad s$ š-sn $\left.m \operatorname{tr}(t !)\right|^{7 f} n b^{1}$

for that which was becoming to them, the whole time.

'r-nf $z$ 'r $r-b \quad z t-s n$

He did (what was) required for their (dead) bodi(es) wrwt $\quad z s r \mid w[t]$.

in a great (and) magnificent way.

Ty-nf $\quad s\left[h n-s n\right.$ ' $\left.^{2}\right]$ hwt-ntr-sn

He took (on himself) [their] ex[penses for] their temples,

$\begin{array}{cccc}\text { [?] } w-s n & m & h b^{3} & w, h(?)-[h ?]^{4}\end{array}$

${ }^{8 b}[s] g r(?)^{5} \quad w d[n]^{6} \quad h^{6} \quad t w t w(!)-n b$ the outpouring (of) libation(s) and everything proper

my ' $r-s n, \quad t p-t,(!)-r d-n b$

as is done, (and?) everything prescribed

$\left.n \cdot\right|^{8 c}$

for

[the temples of Egypt(?)

\section{DEMOTIC TEXT.}

$h t(i)-f \quad h r \quad\left[n w-t s^{2}-\operatorname{shn} t\right] \quad t(i)^{\prime}-n b(!)-w$ his heart for [their command] all the time.

$\stackrel{\sigma d}{\mathrm{E}}-f[t y$ ? $] \quad n(, ?) \quad n t \quad \ddot{e}-w-w h ;-w \quad w b$

He gave those (things) $)^{8}$ which were required for $n w-$ qst $\ddot{e}-w-", \ddot{e}-w(?) ' s ̌(!), 9{ }^{9} \ddot{e}-w||^{6} \check{s}^{\prime}\left[\check{s}^{\prime}\right]$ their burial largely, plentifully, liberally $[\ddot{E}-f-t y \quad n-n t \ddot{e}-w \quad s h n y-w \quad(e) \quad n w-$ [He took that ${ }^{10}$ which was spent (for) their 'rpyw $\ddot{e}-w$-r $\quad$ hbw $\quad \ddot{e}$-w-'r temples (when) were held festivals, (when) were held $g l l] w^{12} \quad n m \quad p-s p \quad m t-\left.n t\right|^{6 f} p h n(!)^{13}$ holocausts] and the rest of the things proper to

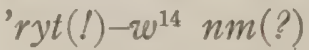
do (them) and(?)

${ }^{1}$ Erroneously engraved $k$ for $n b . \quad \operatorname{Tr}(t)$ is so written that only the context enables us to distinguish it from rnpt "year."

${ }^{2}$ We can restore thus after Ros. hierogl. 3. The word shn the determinative of which, $i . e$., the two arms reaching down, is visible in rather indistinct traces) is a modernism which nobody would understand without the parallel translations; see note I I on the demotic shny'. According to the prevailing archaizing tendency of the hieroglyphic text we should have guessed at a sense: "installation(s)." Ty "he took away," $i$.e., to his account, had them charged to himself.

${ }^{3}$ A high sign $h b$ (the upper traces of which first gave the impression of $z s r$ ).

4 Thus after Ros. hierogl. I ; literally "a setting-up of oven(s)." 'The presupposed sign w' $h$, does not show the characteristic form of the upper part; it looks more like a simple $h$ (cp. $7 a$ ). Likewise the following traces are indistinct ("Ain and "metal"). The sense is, however, rather certain.

${ }^{5}$ With the frequent confusion of $g$ (instead of $q$ ) and $h r$, and, probably, without determinative, $i . e$, in abbreviated orthography.

${ }^{6}$ Traces of $w$ and of a $d$ crossing it are visible rather high up. Behind, the determinative of water flowing in an elongated spiral from the libation vase; above, space for $n$.

7 The hieroglyphic traces do not enable us to find the above restoration on the stone. The bird-sign, which begins $8 c$, is $m$ or', As sign of the hawk, expressing "god, divine," it would probably have the whip behind, of which we here have no trace. The apparent $t$ before the secondary vertical line might be an accidental hole (in traces like $r$ or ' $r$ ?).

${ }^{8}$ The group $n^{\prime},(y)$ here seems to be confused with $t y$.

9 The text of Ros. 18 here is disfigured. The copyist of Philæ did not understand the form "y "large" and separated it into two words, rather unsuccessfully it seems.

${ }^{10}$ Plural, the (things) which.

11 The exact sense of this business word seems to be "to draw from the bank, "or "to incur a debt," or some-

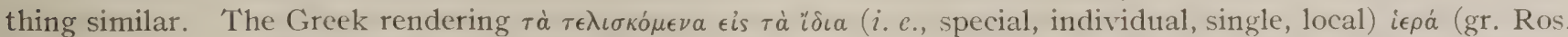
32) explains it, together with the use of $\operatorname{shn}(\hat{e})$ "credit, expense, banking account," or similarly, Griffith, Rylands Papyri, III, 287 , note 3 .

12 So far filled-in after Ros. dem. I8-19, with some probability, but not absolute certainty.

${ }_{13}$ The Philæ stone here confirms the small $n$ which my personal copy of the Rosettana has as a doubtful dot; it is lacking in the edition of Lepsius.

${ }^{14}$ A very remarkable orthography, which shows that the form before personal suffixes $a i-$ of the verb $\hat{\imath} i$ in Lower Egyptian Coptic is more archaic than the corresponding $a a-$ of the Sahidic dialect. 


\section{SPECIAL BENEFITS TO THE PRIESTS - continued.}

\section{HIEROGLYPHIC TEXT.}

DEMOTIC TEXT.

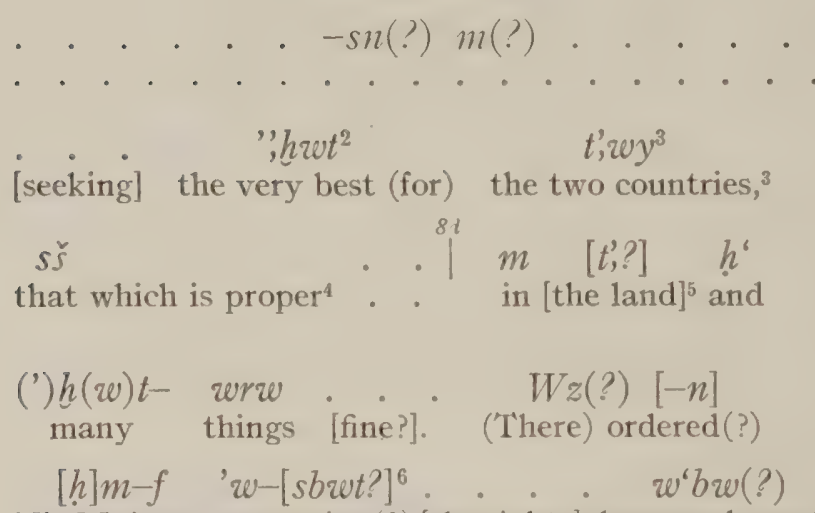

His Majesty concerning(?) [the rights] the sacred ones(?)

$$
r(l) \quad[' b]-f \stackrel{\text { se }}{\mid}[m n h] \quad h r \quad[n t r w]
$$

being his [heart] [kind] towards [the gods] $]^{7}$

$$
h r-b(!)^{8} \quad \text { spw-sin nfrw }
$$$$
\text { wishing (read: seeking) benefits for them }
$$

'w
to renew them in his $w$

$$
\begin{aligned}
& \text {. } \quad[n-?] n t(?) \quad c-w(?) \\
& \text { - . which(?) are(?) }
\end{aligned}
$$

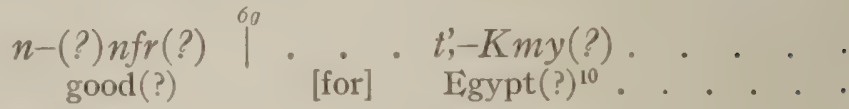

$$
\begin{aligned}
& \text { Inm n-k"w mtw-pht(i) nt(?) t'-Kmy } \\
& \text { and the other proper things of(?) Egypt } \\
& \text { (i.e., traditions) }
\end{aligned}
$$$$
7^{7 n} \quad[' r-f-s m n-w \quad h r \quad n w-g ; y
$$$$
\text { [he let them remain }{ }^{11} \text { on their condition }
$$$$
e-h \quad p-h p^{12} \quad \ddot{e}-f \quad n \quad h t(i)
$$
according to what is right, he being in the mind (of)

$$
n t r-m n h \quad h r \quad n-n t r w, \quad \ddot{e}-f \check{s} n]^{13}
$$$$
\text { a kind god for the gods inquir]ing (for) }
$$

$$
\begin{array}{cc}
n w-p h t(i)^{14} & n n \text {-'rpyw } \\
\text { their proper (honors) in the temples }
\end{array}
$$

$$
\begin{aligned}
& { }^{7 b}\left[\begin{array}{lll}
e & t(y)-' r-w & m, y ?
\end{array}\right] \text {. } \\
& \text { [to renew them?]. }{ }^{15}
\end{aligned}
$$

${ }^{1}$ Also the traces between the next two secondary vertical lines offer nothing positive. Group I at first looked like $n[t] y$ " "which," but the final - y' would show only one straight stroke with certainty. Sn "their" (or with a verb "they") is more probable. The remaining traces of signs are even more problematic.

2 The $h$ before the heron stands in a secondary hole. A bookroll between $t$ and the plural strokes is possible, but the engraving would be very shallow.

${ }^{3}$ Or, we may read the two plant-signs more fully: "Upper and I,ower Egypt."

4 Or, plural š̌w?

5 This word after the trace.

6 Thus, after the analogy of line $6 b$, etc. Otherwise ' $w$ might also be the auxiliary of a verb, etc.

7 Thus, after Ros. (ir. 34, dem. 20, as the following words suggest. Where we have restored $m n h$ "kind," stands a high $n$ under or over an erasure. "The engraver put this $n$ beginning the words $n n t r m n h$ "as ( $n$ or, of) a kind god" and omitted the next two signs, confused by the double occurrence of the sign "god."

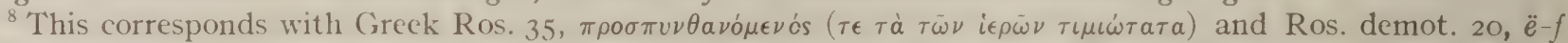
$s n$, "he inquired." Consequently, the verb seems to be corrupted from snw "asking, inquiring" (read sn, $\xi n$, for ' $b$, nw for the heart-sign).

9 The determinative of the sundisk looks strangely disfigured, so that at first it gives the impression of ' $b$ " heart."

10 'These three doubtful traces of groups do not agree with Ros. I 9, which has merely the words $n-m$ w $p h(w$ ? $)$ $n t$ pl $n n$ - 'rpy' " the things proper, which are proper in the temples." (Our inscription must have expanded those words considerably, perhaps, in order to improve the style which in this part of the demotic version must appear to the hasty reader confused and full of repetitions.

11 Thus : i.e., "he confirmed" (better than "he established").

${ }^{12}$ So far according to Ros. I9, but it is true that the space is not very favorable to this restoration; ncither is the hieroglyphic text.

${ }^{13}$ Unusual determinative of $\xi n(?)$ or of $w b$ "for," then corrected.

${ }_{14}$ This word seems to be recognizable under corrected traces and thus insures this whole piece of restoration after Ros. demot. 20.

15 Thus, after Ros. 20 and our hieroglyphic text, but the space is again so scanty that we must ask whether the text has not been mutilated. It is quite certain that the following words of Ros., $p \cdot f-h($ ', $)$ pr- ' " in the time of his kingship," must have been onitted, notwithstanding the fact that their equivalent has been kept in the hieroglyphic version. 


\section{THE THANKS OF THE GODS.}

HIEROGLYPHIC TEXT.

$$
R d y-n^{1} \quad \text { [ntrw] } m y-q d-s n
$$

(There) have given [the gods ${ }^{2}$ ] all together

$$
h^{6} \quad n t r w t \quad r[-d b, t ?]
$$

and the goddesses ${ }^{2}$ [in?] [return?] (for)

\section{$\rho^{a}-s n$}

them (i.e., for these things?) ${ }^{3}$

(that) ${ }^{\prime} r-n(?)$ [the king of Upper and Lower Egypt,

the son of the Sungod],

Ptw'rwmys ' $n h$ at, Pth $m r$,

Ptolemy, living forever, beloved of Ptah,

$[n t r] \quad p r$

[the God] Eipiphanes (the success described below):
DEMOTIC TEXT.

$$
\text { [Ty? } \quad n-] \text { ntrw }
$$

[(There) have given] the gods

[nm $n$-ntrwt $] \quad$ trw

[and the goddesses] all

$[n-t-s ̌ b y t \quad n ; y$

[in reward for these (things) ${ }^{5}$

to the king Ptolemy,

. $\overbrace{}^{7 c}$. . Pth] $m r$,

living forever,] beloved of [Ptah,]

$p$-ntr $\quad n t p r$

the God Epiphanes, (the following):

\section{THE BAD TIMES DURING THE REBELLION.}

$B(!) t n^{4} . \quad n \quad n t r(w)(?) \quad[p ?] n$

The rebel against the gods, this- (one) $n-t t(? ?) \quad . \quad . \quad s b,\left.\quad\right|^{7 d} n \quad n-n t r w$, namely(?) [that man] impious against the gods,

${ }^{1}$ Or more mechanically, following Ros. 5, "(there) have given [to him]" (n-f), with a later resuming of the object ("to the king"?). This would, of course, be awkward style. (For "have given [to them]," n-sn, the space is insufficient).

2 Thus, after the parallelism. The strange traces are explained by the ligature of "god" and "goddess" (=serpent), Ros. 5. Our text seems to have given erroneously both that ligature and its explanatory dissolution into two groups.

${ }^{3}$ We should like to restore after Ros. 5 , but first, it is impossible to find ( $m$ )-' swy "in reward, in return" in the traces. An $r$ (or ' $r$ ??) is certain; above, to the right, there seems to be merely a vertical stroke; this is probably, but not clearly, one of the plural strokes of $n t r w t$; the traces to the left confirm this, although they are irregular and partly too high to be intentional. What follows is obscure and very unlike the regular orthography of $z b, t$, $d b, t$ "return, compensation," which we should expect. We have to read it without phonetic complement (and determinative?), treating as secondary all the traces over my "sic" and running through the head of the $d b$,'hieroglyph.

${ }^{4}$ Evidently the $\mathrm{kln}$ of the stone is to be corrected into $b \mathrm{tn}$. The demonstrative has an unusual position.

5 This space, again, is scanty, and furthermore, the hieroglyphic text does not seem to contain these words. They ought, however, to be here, forming the important logical connection between the part made up of quotations from the Rosettana and the part treating the new theme of the decree. 


\section{THE BAD TIMES DURING THE REBELLION—Continued.}

HIEROGLYPHIC TEXT.

$\eta^{p b}($ ? $) r \quad$ wnfl š, $\quad b^{\prime} r \quad$ 'mty

who had caused?] fighting(?), instigating ${ }^{2}$ war $^{3}$ within

$K m t$, twt 'wny|w $w^{4} \quad n \quad m \check{s}^{4}($ ? $)$

Egypt, gathering insolent people of the soldiers(?)

$m \quad w(?)\left[h^{\prime}\right](w) t-n b \quad h r(?) \quad b t^{\prime},(?)[w]-s n$

from(?) all districts ${ }^{6}$ on account of(?) their crimes(?)
DEMOTIC TEXT.

šnt(i)(?) $n$-'m-w(?) 'r 'r(?) ${ }^{8} \quad h h^{\prime} t(i) \quad n$ blaspheming(?) them(?), having acted as leader of $\left.\begin{gathered}b k s^{9} \\ \text { rebellion in } t \text { ', } K m y\end{gathered}\right|^{7 e}$ ' $r(?)$

${ }^{1}$ This meaning of the root wnf, which usually signifies "to be glad," seems to occur only here. As noun, it is rendered by emlah: "war, fight, battle" ( $g b$ demot. $4 b$ ?), cp. $5 b$. Is it the same word as old wnp, Naville, Deir el B. 57, 10, wnpw-t $m$ Thnw: "thou (fem.) fightest (?) in the Libyan land"?

2 Or rather: "leading war, being leader in war." 'The verb $s$, (with a weak third radical, appearing as $w$ or $y$; in Neo-Figvptian stve also as ' $i$ ') has not been correctly understond, Brugsch, Dirt., I t24, Suppl., I 2 I 8 . Better Maspero, Etudes Ligypt. 25. It is often a synonym of wzy: "to order, to command;" LI). III, 29a, both rerbs are connected, likewise $R I H .160=M a r . K a r n .15,25$; connected with another symonym, shnw $n$ ś, $y$, Ostracon Florence (AZ. I $880,98=R e c$. Trä' 3, 5). It is a more solemn word, therefore used principally of the decrees of the highest authority, of the decreeing god (Stabl . Intar I I, I) II I, II, fr, $t=R I I I$ 1.39, LD. III, 2fo, Senuhyt i 26), whence the god Say (Creek Psäis): "destiny, fate." Or it is used at least of the king decreeing specially important

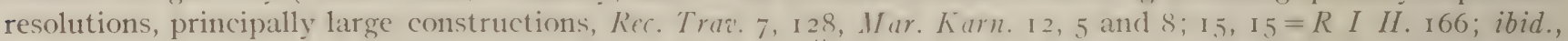
I50; Mar. Abyd. II, 7, LD. III, 24n; s; 72; Berlin Pap. 29 (AZ. 74), I 4; 8; II, I3; Siut-Rifeh IV, 56; of the very highest authority, Scmuhyt 5I. 'Therefore L.D. II, I +9 ' $w$ '; -ny bkw must be understool in passive sense: "works were charged to me." 'l'his dative is, therefore, expressed more solemuly hy m hr, see Maspero-Brugsch: "not did I forget what was ordered to me," a phrase in which we lind also hr "to," Loure C. 5.5 ; even $n$-tp-hr is employed, Senuhyt I2r. Of the "imposing" of regularly returning work, $L D$. II, 122, I.3 (Ameni); of imposed socage Harris I 2a, rb, 9; 32, 7, etc., of taxes (ibid., passim, DH I, II, 42, Io, P S B A. I887, 42), of a time, Anast. VIII, 5 , 3, 3 . See also Mar. Abyd. II, 30, 35; Prisse I4, I2, Ä. I880, 49, D H I, 7, Louvre C I67. "To appoint (an official to, $r$, a position"), Pap. Turin I7, 5; Pithomstela, 2, Pap. Salt rev. 2, I. In evil sense as here, it is rare; see the great inscription of Har-em-hel) in my Eglptol. Reseurches I, 59, fragm. I.5 and (p. pl. 9 I, 1. It "the insolent people ("i'nw, as above)-who instigated acts of insolence ( $s, s p a '-n-' i n)$ in the land;" with a living object, LD. III, I $2 \mathrm{~d}$, 19, of a rebel: "he instigated his lot of companions" ( $s i$ ' $f$ hbsi' $f$, a rather obscure passage). 'Thus the above usage remains peculiar, like so many expression; of our text.

${ }^{3}$ In Latin this would be rendered by comcituns. If artem, i.e., with a poetical use of the name of the Semitic war god, Ba'al = "war, battle," like Latin Mars or Greek Ares for "war" in poetical style.

4 The determinative of the sparrow partly visible.

5 'The apparent absence of the bow and of the plural signs make this seductive reading difficult, it is true, but it seems to be parallel to Ros. hierogl. I.

${ }^{6}$ 'The first seeming $i$ may be secondary. We might try to read a preposition composite with $m-$, like $m-\underline{l} n n(t)$ "from within." 'lhe following feminine noun in the plural, however, can not well be anything else but whit, wh',w "tribes," which often is used poetically for "districts, written with the stick as ideogram (as l'ap. Harris I)."

7 'The first group certainly is $\$ n$, snty in the sense: "to offend, to curse, to blaspheme" in the "Negrative Confession" of the Book of the Dead (ed. Naville, $12.5,29,35,36)$, etc. 'The - $t(i)$ is here, in a remarkable way, separated from the root, showing that the writer knew well the original form of the root to have been $5 n$, sny. Under this primitive form appear both the meaning "to conjure," most akin to the above sense, and "to quarrel," while they seem to have been separated, in Coptic, as sine and sont. Some may find this distinction here in snt and may translate "who quarrelled with them, strove against them, but"; I prefer the meaning intermediate between both developments. (The Paris "Chronicle" (ed. Spiegelberg), has, pl. vira, 1. r, a sinilar group which the editor compares with šn: "to exclude, to keep back." The lack of a coherent context makes this comparison quite unsortain, as well as that with the verb of our Philæ passage.) The object ( $n$ ) - $m$ " " "them " has been disfigured by the engraver.

${ }^{8}$ 'The first ' $r$ could be explained as the sign of the perfect participle, but more likely we have simply an erroneous repetition.

${ }^{9}$ Demotic Chronicle of Paris 3, 7, bgs. Spiegelberg (Cxloss. No. 78), connects this with the older $b a-g a-s a$ of the Dakhel-stela (Rec. Traz'. 2 I, I f) "confusion" or "rebellion." Whether this be developed from the older word bgs "to be sad" (Spiegelberg, 1. 1. I9) or not, our spelling bks seems to treat the g erroneously as merely assimilated to the sonant letter $b$ from original $k$; it is evidently the same word as above. 


\section{THE BAD TIMES DURING THE REBELLION-Continued.}

HIEROGLYPHIC TEXT.

['?] $w^{\prime}, y(t !)$

in treating violently ${ }^{1}$ (those who) administered ${ }^{2}$

$I^{o d} t^{2} w \quad h r-s k^{4} \quad h m w(t !)$

the nomes, ${ }^{3}$ profaning the sanctuaries ${ }^{5}$

$[t h ;, s h m w-n t r]-s n$

vio[lating] their [sacred idols?]

$$
h^{\prime} \quad w n[y] w
$$

together with those that were (in) the temples

$\begin{array}{cccc}-s n(?) & h r^{6}(?) & h h^{\prime} w y(!)-s n & h s f-s n^{7} \\ \text { of them } & \text { and(?) } & \text { their altars } & \text { [pro]hibiting } \\ \text { ' } r & \text { twot } & -s n \\ \text { to do that which is proper } & \text { (for) them }\end{array}$

DEMOTIC TEXT.

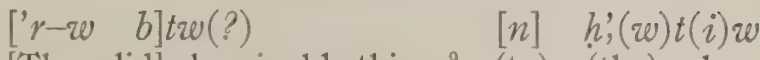

[They did] abominable things ${ }^{9}$ (to) (the) rulers

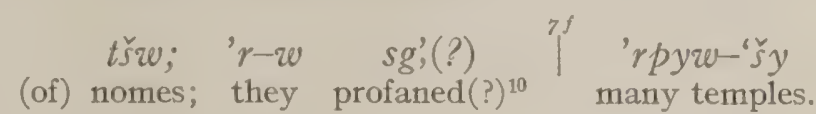

$t(y)-, t(?) \quad[n w-s h m w n] n t r(?)$

injuring(?) ${ }^{11} \quad$ their] divine [statues]

and their priests? . . . . . suppressing(? ${ }^{12}$

$\left.\right|^{70}[n-1 \quad m t-p h t(i ?) \quad[n \quad n w-h w y] w$

[the] due honor[s for their altar]s

1 'The $-t$ ought to stand before the determinative, whether it was the feminine ending or a silent part of the determinative "locality." (The word w', 't: "ruin," can be used only of buildings falling to pieces. Neither is a guess like "[driving into] exile" more probable). Thus the most plausible translation is the one given above, assuming that the two signs after the "bad bird" are corrupted from the "strong arm." 'The restoration of the preceding word, $b t^{\prime}, w^{\prime}$, is made rather certain by the traces of the sign $t^{\prime}$; ; the reed-leaf in place of the determinative, of course, needs an emendation, probably into the "bad man."

2 The $h r p$ - scepter very poorly engraved, nevertheless sure after the demotic version. If the $-s n$ does not stand at a wrong place, hrp has here a rare verbal use.

${ }^{3}$ 'The plural expressed by repeating the determinative "city" three times; the third time it is misunderstood by the engraver as two parallel lines, $i$. e., final $y$.

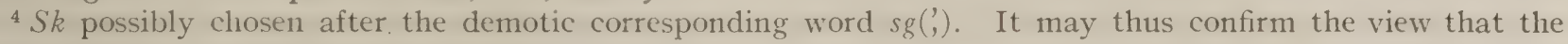
demotic version preceded the hieroglyphic.

5 The $-t$ seems to be a mistake for the determinative "locality" or "house"; the word hm: "holiest room, sanctuary, adytum," which the demotic version demands, is masculine. See the same $h m t, I 4 b$.

${ }^{6}$ I try to separate the group (which looks almost like $s$ and the determinative "cake") into $n$, horizontal $h$ (the lu of syllabic orthography), and a poor, round $r$, misread from the hieratic. This is a violent makeshift, but other explanations (as taking the $r$ for disfigured $h$ before $h^{\prime}$ ) would be much more doubtful.

${ }^{7}$ The verb haf in unusual form, with the crossing $\int$ quite ligh (and, perhaps, a short "strong arm" crossing it below?).

8 'The bookroll as determinative is to be read after traces of the mummy-like statue. The sn, which then follows, is the possessive suffix of twt and the sense is literally "their proper things."

${ }^{9}$ 'The usual orthography of this word is bta', but the shortening here could be explained as dropping only the final $-w$ for the sake of the following plural ending - $i$ '. The above restoration remains more probable than other guesses, $c . g$., than: "they killed, ill treated," etc. 'l'he suppression of an $n$ of the dative is quite ordinary.

${ }^{10}$ 'The word is, so far, known only from this passage. Whether it is related to the substantive $s q$ ', of the Paris Chronicle $(5,22)$ and distinguished only by the determination can not be decided while the latter word remains obscure. Coptic šo(o) g้e, "to hurt, to violate," seems to be used mostly with persons as object.

11 This looks like the verb 't: "to do wrong, to injure," Demotic Book of the Dead, 29; written like ; $t \ddot{t}, K u f i$ Io, 29. I do not know, however, what the causative construction with $t y-$ would mean. For this reason and on account of the fact that the determinative seems to be the "bad bird," I consider as possible also the reading $t(y$ )-', $q$, Coptic tako, $i$. e., "ruined, destroyed." 'The $q$ would then be poorly engraved or corrupted to $t$, and the expression would refer to iconoclasm, while the reading given above would point to offending and wronging the majesty of the gods residing in heaven. It would, however, apply poorly to the priests.

12 Of the verb, only the determinative "strong, violent, action of the arm" is clearly preserved, parallel with the determinatives of the hieroglyphic text. (Before it a group like "gods.") 


\section{THE BAD TIMES DURING THE REBELLION-Continued.}

HIEROGLYPHIC TEXT.

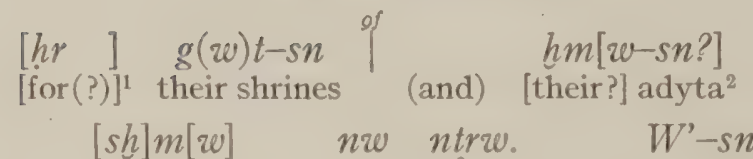

[(and) the stat]ues ${ }^{3}$ of the gods. They devastated(?) ${ }^{4}$

$$
n w t^{5} \quad h^{6} \quad m s^{6}(w ?)-s n
$$

the cities together with their populace $(?)^{6}$

$I_{\text {(even) of [women(?) and little children. }}^{m}$

- . mytt- ${ }^{\prime} r(y) w(?)^{7} \quad k-h w$

committing crimes] of such kind other ones ${ }^{8}$
DEMOTIC TEXT.
${ }^{7 h}[n w-?] \quad(h t p ?) w h n n-w-g, w t(?)-n-n t r$ (and) their sacrifices(?) in their divine shrines(?) ${ }^{9}$

1 Or $m$, "in?"

${ }^{2}$ The word is probable but not absolutely certain.

${ }^{3}$ We guess this restoration from the determinative. The space would also allow the supplying of a verb of its own (like "they dishonored, profaned," etc.) before this noun.

${ }^{4}$ 'This verb is not frequent and therefore presents difficulties. It may be related to the root w(',y), "to be distant"; we find the Egyptian scribes, at least, confounding both words in the variants of Totb. Leps. 99, 23, 29; also the verb ri": "to remove," is not easily separated from it. II"), (determinative: I, soft action of the hand; 2 , action of the feet) means "to remove," of booty, Merneptah-inscriplion (I) HI I I, 5, 6I, etc.), of persons (determ.

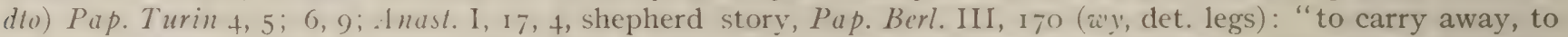
kidnap." Hy in obscure passage, Ree. Traz. 8, i6 I. Causative $s-w$ ' (determ. legs) likewise: "to remove (thirst),"

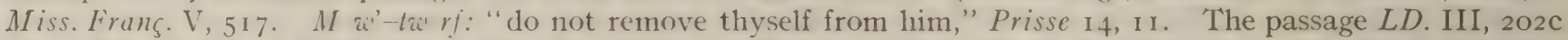
( $u^{\prime} g r g$ ) is obscure. libers 109,8 , Stern's reading $s t w^{\prime}, t$ (det. arm) might be questioned; in Pap. Ebers the noun a', $t$ : "disgust," seems to mean: "the impulse of removing, abhorrence." Other passages may rather belong to re', e. g., Anast. VIII, 3, I3, Sullier I, 5, I (of "unloading"). The reduplication w' w', is known only from a single passage (.1nast. I, 28, 2, det. "confusion" or "separation," and "wickedness"), applying it to a faulty literary style The meaning given by our text seems thus to be rather peculiar, including "to devastate, vacate, expel, plunder.'

5'The arrangement shows that three parallel plural strokes stood below, thus indicating space for a small sign like $-t$ behind the half-preserved circle of "city."

${ }^{6}$ I assume the hieroglyph "soldier" here to have the same meaning as Coptic me $\left.(e)\right)^{\xi} e$, "multitude, people in the widest sense," as irregularly in demotic use.

'The above translation (assuming an archaic use of the noun mytl: "likeness, identity, copy, likewise," instead of the preposition $m y$ : "like," so that we should obtain $m$ tt $-($ ') $r(y)$ ' " "likewise") must remain uncertain with such fragmentary text. 'Thus I have hesitated for a long time as to whether the three traces behind, running in horizontal direction, could not be read as ' $r$ - $r$ " they did;" I seek these words now rather in the gap. See the following note. Lacking the context, I am unable to decide.

${ }^{8}$ This pronominal form seems to stand here not absolutely, $i$. $e$, as substantive, as mostly in archaic style. Later the absolute is not the exclusive usage, as might erroneously be concluded from the too scanty quotations in Erman, Teuacgypt. Gramm. \$92. Yet it stands as epithet always before the noun, e. g., Anast. I, 22, 3; Sallier II, 9, 5, Harris I, 6, 6; 76, II, etc., Canop. 33. Already Totb. x 75, Ani, 1, I8 (=kt, Naville, 1. I 7), often in demotic, e. g., Canop. I 8, Ros. I I, I9. "lhe Coptic kekouni, kekauni "others," which, notwithstanding the assimilation of the second consonant $(h)$ to the first $(k)$, has originated from our $k t-h t$, $k t$-(') $h t$ " another kind" (kekauni meaning really "another kind of beings"), stands between both usages, taking the place of $k t$ - $h t$ as substantival plural and yet showing in its composition the prefixed employment of an adjective, before $u n i$ " being(s)." 'The substantival use $k t-h t$, indeed, still occurs in demotic (Ros. 20), and the postposition in our passage seems unique for the latest style, so that it could be explained only as having half-independent, appositional, supplementary character. Otherwise, taken as quite substantival, it would confirm the reading "they did" ( $r$-sn), which we have con idered in the preceding note and would furnish thus the translation ". . . likewise. 'They did other such (things), did the like." The demotic text, however, seems to point to the above translation.

"It is easiest to consider the strange group for "sacrifice" simply as disfigured form hitp. The next questionable group seems g', wt "shrines" (with $g$ and ' in ligature) rather than $h[m w]$ "sanctuaries."

${ }^{10}$ In this hazardous restoration we have to admit that the orthography of hrlw, "children," is unusual (assuming a varying repetition of the ideographic sign "child" as determinative) and uncertain. 'The group suggests $b t(w)$ and seems verbal. Probably the determinative of the "wicked bird" stands there as the sign before the last. For the restoration of the last group to $k(t) \underline{h} \ddot{e w: ~ " o t h e r(s), " ~ s e e ~ t h e ~ n o t e ~ o n ~ t h e ~ h i e r o g l y p h i c ~ t e x t . ~ I ~ f i r s t ~ t h o u g h t ~}$ 


\section{THE BAD TIMES DURING THE REBELLION - Continued.}

\section{HIEROGLYPHIC TEXT.}

\author{
$m-t p \quad \check{s} w$
}

in the condition (of) anarchy(?). ${ }^{1}$

$[I] l f^{2}-s n \stackrel{i o b}{\mid}$ htr nw

They robbed the taxes of the (administrative)

districts:

\section{$h b-s n$}

$m w$

they damaged ${ }^{3}$ (or: ruined) the water (constructions);

$h, ;-s n$

they abandoned [the dam (?) constructions]. ${ }^{4}$

DEMOTIC TEXT.

${ }^{8 b} \quad n-h[t y w] \quad[n-t s ̌ w$.

[stealing] the [taxes of the nom]es.

$\ddot{E}-w \quad h b(?) \quad m w$

They damaged ${ }^{7}$ (the) water (works).

$\ddot{E}-w$

They

\section{THE KING SPECIALLY PROTECTS THE TEMPLES DURING THE REBELLION.}

' $r t-n \quad \begin{gathered}n-s t \\ \text { (There) made }{ }^{5} \text { the king of Upper and Lower Egypt, }\end{gathered}$
$s$ ', ||$^{\text {Ioc }}\left[R^{\prime}\right] \quad$ Ptw'twmys, ' $n h z t$,
the son of [the Sun], Ptolemy, ever living,
Pth $m r \quad s-w r w(?) \quad s(?)$ 'w $[s b w t]$
beloved of Ptah, orders(?) also(?) for these

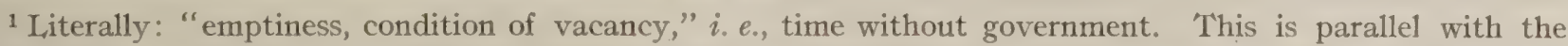
famous passage (Harris, I, 75, I) where the years of anarchy, without a legitimate king, are called "empty" (św'yw) (priests), Mar. Abyd., I, 6, 30, (of desolated and dilapidated tombs), where we see that $t p$ has lost its original meaning "beginning," and may freely be translated "state, condition" (or "pitch, height"?). Second determinative "arm."

${ }^{2}$ Read $h$ tf. The earliest examples of this word betray, by the syllabic orthography $h u-t-f$, that it is a Canaanaic loanword, $i . e$. . Hebrew luta $p h$ (not hataph, which seems to have a $h$-after the cognate languages); like that Hebrew word it expresses "(open) plundering in war" (LD., III, I6a, 6; 65a, 4; Mar. Karn. 37, 30=RI H. 36), while Coptic hoft has assumed the sense "to steal." In our passage we can follow the transition to a disgraceful meaning.

${ }^{3}$ The word $h b($,$) might be understood also as "to diminish, to cut short," cp. e. g., Sallier II, 7, 3=$ Anast. VII, 2, 4, (of failure to clothe), IZ. I884, 39, 1. I7 (of temple income); similarly Rec. Trav. 16, 43, Mon. Div. 29a, 5, Mar. Abyd, II, 36, 4, Totb. Nav. 125, Intr. I3 and I6 (of sacrifices). Eloquent Peasant, Berl. II, I8 = IV, 48, parallel with $h z$. The word has, however, often stronger sense: "to ruin, destroy, annihilate," $e . g$., Lepsius, Auswahl I 2 (object: tribes), Totb. Nav. 154, 6 (corpses), Pap. Leyden, I, 344, 15, I (a country), Hierat. Inscr. 29, 7 (the god

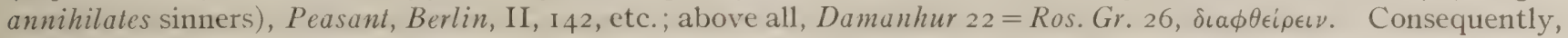
I should not limit the above passage to the tame measure of "digging off irrigation canals," but would include the opening of dams, a means of warfare as common in Egypt as in Babylonia or Holland; cp. Polybius, V, 62, 4. It was considered as a desperate action and not quite fair because it entailed long labor for restorations.

${ }^{4}$ The determinative "house, building" seems to be recognizable. It would be easy to restore the traces to ht -ntr "temple," but the profanations of sacred property by the rebels have been described before. There is also no space for a plural mark with "temple(s)." Thus it is difficult to fill the gap after the verb; with "dam" we should not expect the determinative "building."

${ }^{5}$ The first idea suggesting itself is to make this a relative clause: "[the constructions] ( $w$ hich) the king had made." I think, however, the style (perhaps also the unusual verbal form in $-t-n$, which, of course, must not be treated after the classical grammar) points to the beginning of a new section. Constructions of Ptolemy V. could not be meant.

${ }^{6}$ This meaning is probable according to the context. The reading of the hieroglyphic traces seems partly: wz (with small, crossing serpent $z$ ?), bookroll, plural strokes. If the word shnw "expenses," discussed above (p. 35, note 2) was meant, it would be strongly disfigured. S-wz-w means: "orders, administrative measures."

${ }^{7}$ See note 3 on the hieroglyphic word $h b\left({ }^{\prime}\right)$, which seems also to be employed in the demotic text. 


\section{THE KING SPECIALLY PROTECTS THE TEMPLES DURING THE REBELLION-Continued.}

\section{HIEROGLYPHIC TEXT.}

$\begin{array}{cccc}-n n & w r w & \text { 's } & \text { ' } r[-f] \\ {\text { things }{ }^{1}} & \text { many } & \text { and } & {[\text { he] showed }}\end{array}$

rod

$m h^{3}-n b t \quad r \quad s-w z ;(!)^{4} \quad[h w t-n t r]$

all care in order to protect [the temples].

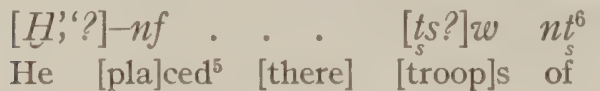

$H, w-n b w$

Greeks (and)

I $m \check{s}^{\text {rog }}[w]$

$[' m] w t(y$ ? $) \quad w n y[w]$

(from) among the people (who had) moved $^{8}$ $m \underset{\text { in Egypt }}{\text { Bqto) obeying }} \quad \begin{gathered}t p-t,-r d w y-f \\ \text { his orders, }\end{gathered}$

$h n m h\left[\left.r\right|^{\text {Iof }}-[s n]^{10}\right.$.

being joined together [with them in zeal for the gods?]

[']w-sn my ms hn'-sn.

they were like (people) born with them. ${ }^{11}$

DEMOTIC TEXT.

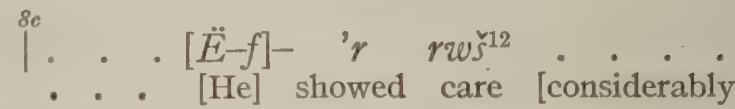

$e(!)^{13} \quad t(y)-w z,\left.\quad\right|^{8 d} n$-'rpyw.

for protecting the temples.

$$
H \text { ', }-f^{14} \text { mtkt(i)',t } n \text { Wynn 'm-w }
$$

He placed a force of Greeks in them

(from) among the $\left.\underset{h n}{n-} r m(t) w\right|_{\text {mho had }} ^{8 e}$

[reformed?], (?or: done according to $\left(\dot{n}-s^{\prime}, ?\right)$ his will)

$$
' r(?)-h n(t ?)-w \quad[e] \quad n-r m(t) w \quad t,-K m y \stackrel{8 f}{\text { i }}
$$$$
\text { moving themselves }{ }^{15} \text { to the people (of) Egypt }
$$$$
n t \ddot{e}-' r \quad \underline{p}-h p \quad \underline{h} \quad t,-K m[y
$$

who did the law(ful things) in Egypt . . .

${ }^{1}$ Supplying (')ht: "things," seems unnecessary.

2 The traces can be restored with great probability after the demotic text.

${ }^{3}$ The $n$ stands for the horizontal hieroglyph $h$, the $s$ for the sign "vertebræ."

${ }^{4}$ 'The small $w$ slung through the $z$ ', has become meaningless.

${ }^{5}$ To be supplied thus evidently. The seeming $h$ is strange, however.

${ }^{6}$ For $n t y$.

7 This word hardly refers to the "Greek troops" as a superfluous apposition. It seems that we can find here a valuable indication that those repenting rebels belonged to the soldier class; see "warriors" $5 b$.

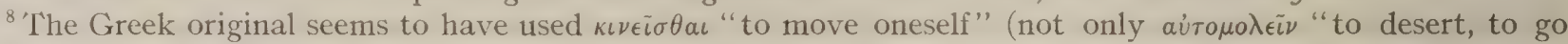
over"). The awkward Egyptian imitation employs a very archaic word nwz, later $n w d:$ "to move oneself, to shake oneself, to wriggle, to jump up." (See Pyr. P. I07 $=N .75 ; M .73$, Harhotep I 91, 330, 369 (causative $s-$ ), LD. II, 52 (s-nwz), Totb. Naville 64, 10, 19, 35; 78, 12, Med. Berlin 20, 10, Ebers 19, 5; Berlin Amonritual 7, 4, Louvre C. I07 (corrupted to $n w r$ ), Peasant-story, Berlin II, 6, 98, I06; IV, 25, 34, etc.) The demotic rendering seems even more awkward and artificial.

${ }^{9}$ The sign in unusual form, assimilated to the human ear.

${ }^{10}$ Behind $h n m(w)$, "(they) being joined," the horizontal $h$, with space for $r$.

${ }^{11}$ Greek original, probably: like relatives, $\dot{\omega} s$ v $\gamma \gamma \epsilon \nu \epsilon i s$, or similarly.

${ }^{12}$ This reading is guessed from the rather uncertain hieroglyphic parallel. The extant traces point to an unusual group (hw(w)t: "abodes?").

${ }^{13}$ Incorrectly $n$ for $e$ as often.

it The stroke between the group expressing the root and the termination $-f$ is strange and might lead to finding in it various archaic elements of inflection. It is best understood as erroneous, having arisen from a filling-point in the original manuscript on papyrus.

${ }^{15}$ See Spiegelberg's Petubastis-glossary, No. 247, for the demotic use of Coptic hon. The demotic version seems to incur repetition in rendering the difficult Greek clause. Cp. with the hieroglyphic equivalent. We might find in $h n(t$ ? $)-w$, "they moved (themselves)," also an indication of volunteering by those Egyptian armed guards, but the passage remains partly obscure. 


\section{THE KING SPECIALLY PROTECTS THE TEMPLES DURING THE REBELLION-Continued.}

\section{HIEROGLYPHIC TEXT.}

DEMOTIC TEXT.

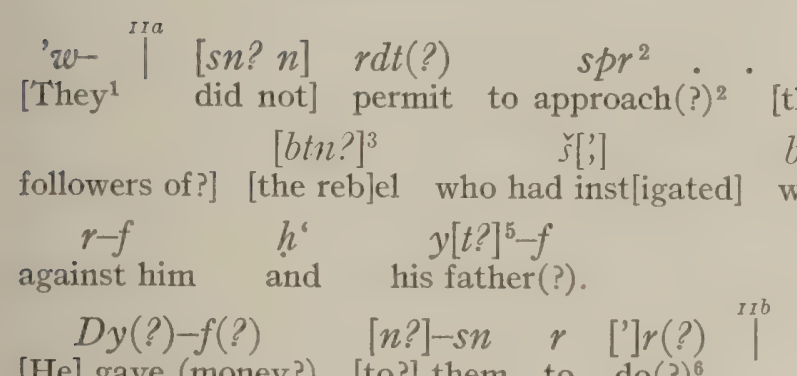

[He] gave (money?) [to?] them to do(?)

$m y-n n . \quad R d y-n \quad h m-f \quad t y-w t^{2}$

thus. $^{7}$ (There) caused His Majesty that be taken hz $\quad n b \quad m \quad$ tnw-', (w) 'w $t$ ', silver (and) gold in great quantities to the ground ${ }^{3}$ ire I $[r-d] b,(?)[t]$ for the purpose of $(?)^{9} \quad$ causing ' $n[-t] w \quad t_{s} s w \quad$ 'w $B q t$ (that) be brought troops to Egypt $m-\operatorname{swn} \quad[s]-{ }^{\prime} p \quad{ }^{I I d}$ wre for the $\operatorname{tax}(\mathrm{es})^{10}$ (of) the nomes ${ }^{11}$

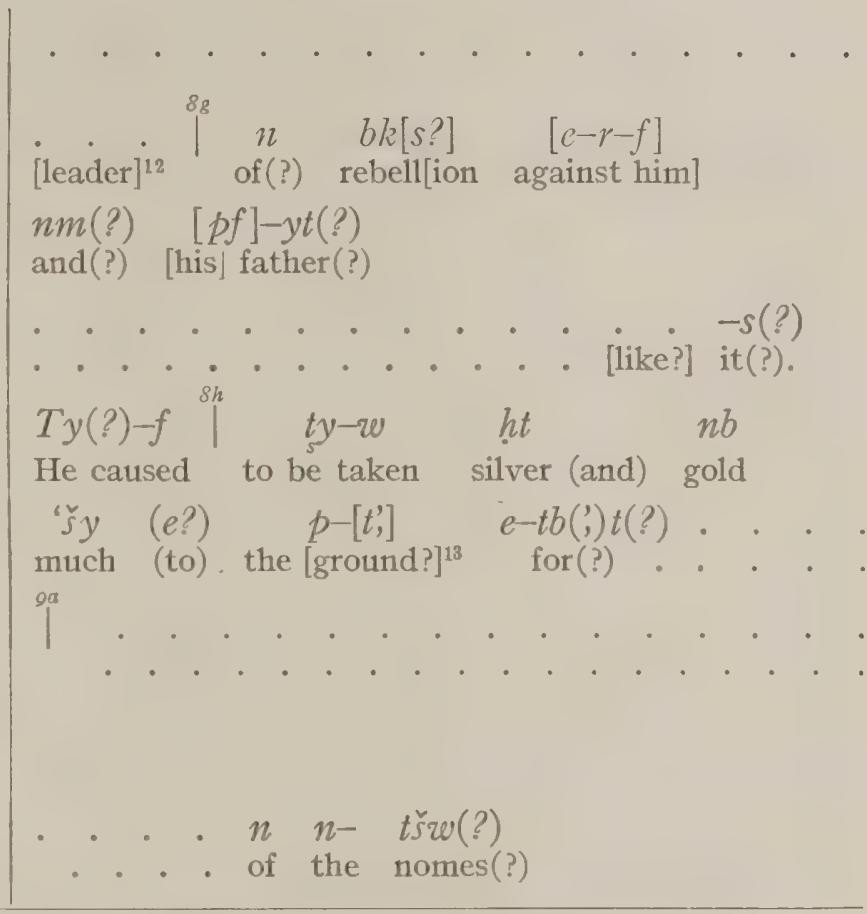

${ }^{1}$ Or, "he," the king?

${ }^{2}$ 'This last group at lirst seems clear, but the traces may be deceptive. A big $t y$ "to take" could also be found in the seeming spr. 'The first gap of the line could also be filled by the restoration ' $i$ ' $t m$ rdt "in order not to permit."

${ }^{3}$ The apparent $h^{6}[-f ?$ ? ] "with [him??]" yields no sense. It must consequently be merely accidental.

4 'Thus to be restored after line $9 d$. 'The $s$ ', is partly visible (the captive before it has exaggerated execution of his bound arms); the determinative of $B^{\prime} r$ (see on $g d$ ) is disfigured from the Seth-animal to the hare.

5 The traces over $f$ are not very favorable to reading the cake $y t$, it is true, but the space behind (for the ideograph stroke).

${ }^{6}$ So according to the traces, but it yields no convincing sense. The last group seems to be clearly $r r$; the above translation as ' $r$ is almost a correction. He gave for (hr?) them "two parts," i. e., "two thirds," however, would yield difficult sense; the temples would hardly have paid the missing third. A tempting restoration would be ' $n($ ?) $-s n r$ ' $r$ "they turned again to doing," $i$. $e$. , "did again," implying a pause in the rebellion. The space under ' $n(?)$, however, seems insufficient for the necessary determinative "legs."

"Or connected with the following words: "thus, likewise, H. M. caused."

8 The phrase: "to give to the ground," usually means "to remit, to overlook" (cp. Ros. hierogl. 2). The above variant: "to take to the ground," must mean: "to expend." Cp. for this sense that $h$, w "expenses, spending" means, literally: "the falling down."

${ }^{9}$ The above translation is not easily harmonized with the space at the beginning of $I I a$. It seems impossible to find there the preposition $[r-d] b ;[t],[r-z] b^{\prime},[t]$ or its apparent variants $m d b w I_{2} f$. 'Thus I have assumed that the two signs $r$ and $d b^{\prime}$, z $z b^{\prime}$ ', were crowded over the foot of the $b$. 'The following gap, requiring a normal square of signs, is to be filled with $t$ and a bookroll.

${ }^{10}$ It would be easier to read simply 'p: "taxation," but the gap must be filled. The above restoration seems to amount to the same sense, however, literally meaning "inspection, revision."

"It is tempting to correct the w-bird into the hawk, so that we should obtain "temples." The sense of the whole passage might then be changed into a statement of absolute liberality towards the temples, without taxing them. It remains, however, safest to assume here a much more modest sense, namely, that the king is praised for spending the income from the taxes "of the nomes" (i. e., of the whole inland, all Egypt outside of Alexandria) on recruiting Greek mercenaries instead of using it for himself. (The preposition $m$ 'swy seems to be used more as "for" in the sense of "in return for something," synonymously with "because of," while $r d b$, $t$ and its synonym $r$ sbwt stand often also with final sense for "obtaining results.")

12 The space suggests that the demotic text was shorter than the hieroglyphic version. Both writing systems, however, admit much arbitrary crowding together and extending of the text.

${ }^{13}$ See the parallel hieroglyphic expression for the meaning of this phrase. 


\section{THE KING SPECIALLY PROTECTS THE TEMPLES DURING THE REBELLION-Continued.}

\section{HIEROGLYPHIC TEXT.}

'we $s-20 ;$, $^{-1}$

in order to protect

$[s b]^{\prime} w$

the impions one [the temples of Jigypt against? $]^{i}$ ['r?]

(who) [had?] violated ${ }^{2}$ them.

$[t] h ; y \quad-s n$

\section{DEMOTIC TEXT.}

$[n-'] r p y[i v] \quad K m y t(?) .\left.\right|^{o b} .$. [to protect ${ }^{4}(?)$ the] temples (of) Eigypt(?) [against

- . s,b(?) . ... thy(??) -s(?) the imlpious [ones?] (who) violated them. ${ }^{9}$

\section{THE DOWNFALL OF THE REBELLION IN THE THEBAÏS.}

Ire 'w-sn s-'r spr $m-b ; h \quad h m-f$

('There) was brought up. a report before His Majesty

$n$ 'bd IV šmw [hrw] . . . 4 m-zd:

in the I2th month, day [3], thus:

$$
h f^{6}-\left.s n \quad\right|^{1 f f} h,[q]
$$

(there) has been seized captive [that wicked $\operatorname{man}^{5}$ in]

$$
\text { wnf ir } h^{\circ}-f \text { hspt XIX }
$$

the battle delivered with him, year I9,

šmw 'bd III [hrw XXIVmsq 'nh?]

the II th month (Epiphi) [day 24, as live prisoner(?)]. ${ }^{6}$

$$
\begin{aligned}
& s(?)\left[m^{\prime}\right]-s n \quad s^{\prime},-f[\ldots \text { ? }] \\
& \text { They } s[\text { lew }] \quad \text { his son [the eldest?], }
\end{aligned}
$$

' $r[-w] \quad n-\quad s m y \quad \cdot \quad \cdot . \cdot{ }^{\circ}$

['There was] brought report [before the king,

\section{$[e-t b(;) t(?)$}

[concerning?

$$
p-s] ;,[b(?)
$$

that impious one(?).10 [II was captured?] in

$$
p-\left.m l h\right|^{d / 2} \ddot{e}-p-w \quad n m-f \quad n \text { hspt XIX }
$$
the battle delivered with him, in the year 19 ,

'bt III šm(w) 11 hw XXIV $\ddot{e} f-' n h$ month II, day 24 , he being alive.

(There) was slain $\left.^{12}\right|_{\text {[his eldest(?) son] }} ^{\ddot{E}-w}$

${ }^{1}$ There is space for one or two more words.

2 'This restoration seems to be quite certain; the position of the $t$ (before the $h$, instead of over it) shows that a sign must be restored. 'This learls to the restoration of ' $r$, the sign of the perfect tense (or the relative $r$ ).

${ }^{3}$ That is, to the high throne.

"A rather small number as date according to the space.

${ }^{5}$ The trace at the end of line II seems to point to the above (slightly pleonastic) restoration.

${ }^{6}$ This restoration adds pleonasms, but seems unavoidable.

7 The space permits the filling-in of one narrow, high sign, like the standing man with staft =sms: "eldest."

8 'The traces fit this restoration (which requires $t\left(y^{\prime}\right)$ w', or $l\left(y^{\prime}\right)$ ' $r \cdot w^{\prime}$ w'; ) very poorly, although it would seem to be quite certain after the context. Those traces make us rather think of "sins" committed against the temples. So we must assume that the engraver disfigured the passage strongly, and corrected only "the nomes" over the errors, leaving the corruption for wz',

${ }^{9}$ We can guess after the hieroglyphic parallel as I have rendered above, but the single traces allow no certain restoration. If the word $s, b$ was employed here it ought to have the plural sign, which is certainly absent; it is not very likely that the word is used as an adjective after $r m[t]: 0$ " people." Thy "to violate" is usually written very differently from what we can recognize here on the stone.

10) 'lhus I venture to restore the isolated traces in the inner angle of the arm of the figure cut above the inscription. Consequently, the verb must be sought in the following gap. ( $K p$ "to capture" is written in Ros. Io in a way wh:ch forbids to restore those traces to $[g] p$ or $[k] p$.)

11 'The season sign has not the regular form, but it can not be read with a different value. Some scratches before it look as though the date had been erased and recut.

${ }^{12}$ We have to restore this verb according to the sense and the hieroglyphic text, although the engraver has mutilated it quite badly. Since he did not understand the rare word in che ink copy written on stone, he cut in three parallel vertical strokes instead of the horizontal $s$ and interrupted the very long $m$;-sign; : che following group likewise is disfigured. The word seems to be used in the shorter form sm', (Ros. dem. I6), not in the more archaic orthography smim (Gnost. Paris ed. Maspero, I, $1 \%$, etc.). The mutilation by the engraver looks, at first sight, like an abnormal $p g \ddot{e}$, but this would be senseless. 


\section{THE DOWNFALL OF THE REBELLION IN THE THEBAÏS-Continued.}

HIEROGLYPHIC TEXT.

$m r-\left[m \check{s}^{c}\right]^{1}$

the chief [commander of the army]

$s b^{\prime} w$

DEMOTIC TEXT.

(of) the godless ones(?) together with [the chiefs? $]^{2}$

$\left.\right|^{x 2 b} n t \quad N h s(y) w \quad[m ?] s(y) \quad h n^{6}-f$

of the Ethiopians brought with him.

'w-sn ' $n$ ' $m-f \quad\left[\begin{array}{ll}\text { 'w } & s\end{array}\right] t$ nty $r^{3} . h m-f$ He was led to the place where was His Majesty.

I' $w-[d y ? ?]-s n \quad h s f(?) \quad n(?) \quad b[t, w]$

He was punished ${ }^{4}$ for the cr[imes]

' $r(?)-s-n f(!)^{5} \quad w z ; w$

(which) he had committed, (by) death

$m \quad s p r-f(?) \quad r-f$.

at his(?) approaching to him.

$M y\left[t\right.$-'$^{\prime} y$ ? . . . sb'] w $\left.\right|^{12 d} n n^{6} \quad w n$

Like[wise the (other?) criminal]s those who had been

. . two $n m-f . \quad \ddot{E}-w{ }^{\prime} n(y) n^{7}-m-f$

. . . gathered with him. He was brought

$e \quad p-\left.\right|^{o f} m, \quad n t-\ddot{e} p r-n^{7}-{ }^{\prime} m-f . \quad \ddot{E}-f \quad[t y$ ? ]

to the place (at) which the king was. He [gave(?)

. . . . . $I^{g}[n-m t] w-b t w$

(i.e., caused) him to be punished?] [for the] crimes $^{8}$

nt

which [he had done]

${ }^{1}$ For a long time I read $k$,. $K$, " "to name, to think," furnishes, however, no sense at all. The ligature ' $m$, "to seize," is quite impossible. Finally the ligature proved to be $m r$ (the archaic abbreviation for ' $m y-r$ '), "overseer, superintendent, chief." Thus the son of the pretender appears as chief commander, probably "of the army, the soldiers" ( $\left.m s^{*} w\right)$. Less probable would be restorations like "chief of the horse" (hipparch, cp. line $4 d$; we should expect rather hrp nfrw for this expression), etc. Space and traces (bow, arrows, arm) favor the above restoration.

${ }^{2} \mathrm{Wr}$ is probable and a disfigured plural stroke.

${ }^{3} R$ for ' $w, e$. The omission of the ' $m$ "there," pointing back to the relative pronoun, is unusual and seems to be due to the preceding ' $m-f$.

${ }^{4}$ Although the general sense is tolerably certain, the restoration is very difficult in detail. In the above translation I have assumed that the hieroglyphic text changes the subject of the verb from the king (see the demotic text) to more impersonal -sn "they," which expresses the passive. The single trace above, which would then remain for a verbal root, is unfortunately very high, even for as low a sign as $d y$ "to give," so that an erroneous transposition $n s$ for $s n$ might be considered. The following word shows an initial hieroglyph like hz, wz (not like h) and behind a small "strong arm." Below I believed at first to see traces of a "wicked bird," but as this would have an impossible position after the arm, instead of before it, I have rather tried to find a horizontal line, $n$, in an irregularly high place. Read hsf (with an $f$ supplied over the arm or through the top of $h s f$, as ge) "to hinder, to ward off, to put an end to," here as "to punish," in a somewhat unusual sense. (Or, correct to nz "to revenge, punish," after I 4 e?).

${ }^{5}$ We assume a corruption of ' $r-n-f-s$, the $s$ standing for $s t, s e$, the plural or neuter collective of the personal pronoun. "They did (i.e., imposed) to him death" (assuming only the assimilation of the $n$ of $n a f$ to the preceding sen) seems to be a less probable explanation; the verb ' $r(y)$ hardly could be used in such a way.

${ }^{6}$ This demonstrative form seems to be used in imitation of the pe, pai, plur. ne, nai, strengthening the relative pronoun in Coptic, $i . e$. , it belongs to the following relative verb wn, not to the preceding noun.

${ }^{7}$ The distinct $(e) n$ before ' $m-f$, in place of Coptic emmof, is remarkable in both instances. The construction of the object with ' $m$ - in the first instance is a very interesting modernism. It would be possible to say simply $\ddot{e}-w$ ' $n t-f$, "they brought him," but in order to give the fully accented pronunciation of the characteristic verb, i. e., to emphasize the disgraceful fact of captivity, that direct attachment of the verb is avoided. (Cp. L. Stern, Koptische Gramm., §493). We understand now why the hieroglyphic text, generally so strongly archaizing, uses this modernism for emphasizing the awful fate of the rebels, ' $m-w t$ ' $m-f$ : "he was seized" ( $6 \sigma a$ ), and $s m$ ', 'm-sn: "killing them" $(5 c)$. As said there, the latter expression is intended to show how complete the slaughter of the insurgents was; it stands thus in direct opposition to the archaistic use of $m$, after which we might think that "(some) from $(m)$ them" had been killed.

${ }^{8}$ Because ending in $-w$ the word "crimes" might receive the plural sign irregularly, as also in other instances. The plural sign, however, seems to stand before it and leads us to the compound $m t$-btw, unknown to Coptic, as far as I know. 


\section{THE DOWNFALL OF THE REBELLION IN THE THEBAIIS-Continued.}

HIEROGLYPHIC TEXT.

$t p-' w[y ?]$

at the head lof the rebels,

$-w \quad r-r^{\prime},-s[n]$

he decreed various punishments?] against ${ }^{1}$ th[em]
DEMOTIC TEXT.

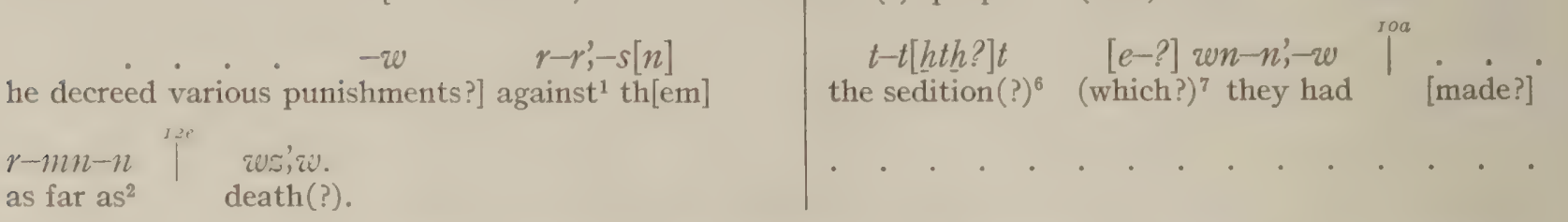

\section{THANKS AND HONORS TO THE ROYAL COUPLE DECREED BY THE PRIESTS.}

\section{$R-[n t t$ \\ In[asmuch as have done] His Majesty,}

n-st 'byty; Ptw'rwmys 'nh zt the king of S. and N. Egypt, Ptolemy living forever,

$$
\text { Pth } m r \quad h^{\prime} \quad \text { snt-hmt[-f] } h q t
$$
beloved of Ptah, and [his] sister-wife, the queen,

$$
n b(t) \quad t, w y
$$

the mistress of both countries,

$$
{ }^{\text {I }} \text { [Qrw'] } w^{\prime}, p^{\prime}, d r[, t,
$$
Cleopatra,

$$
\text { nirwy] pr my wt, }
$$

[the two Gods] Epiphanes, according to the decree ${ }^{3}$

$$
\text { šs } n[t t \text { ? }] \quad m-d b w
$$

(the) proper (thing?) [which is?] for the sake of(?) I $3 a$

$$
\begin{aligned}
& \mid-n \cdot m \\
& \text { [the welfare of (?) the gods?], the gods (are) }
\end{aligned}
$$

$$
\begin{aligned}
& n(?)-r m(t) w[e-?] w n-n ;-\left.w\right|^{o h} \text { bks } n \\
& \text { the(?) people (who })^{5} \text { had rebelled in }
\end{aligned}
$$

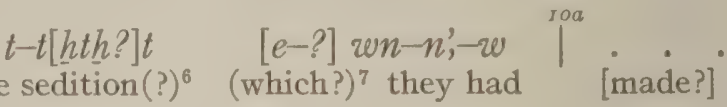$$
\text { oa ..... } n h \text { ot }
$$$$
\text { .. . [King Ptolemy] living forever, }
$$

Pth $m$ r

beloved of Ptah, [and his wife, the queen]

$$
{ }^{\text {rob }} G l[w p t r \ddot{e}]^{8}
$$$$
\mathrm{Cl}[\text { eopatra,] }
$$

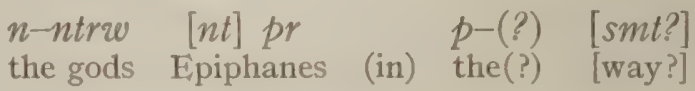

${ }^{1}$ Neo-Egyptian orthography, it seems.

${ }^{2}$ A very remarkable archaism, if understood correctly by me. But I fear that the above restoration of the passage attributes a little too much mildness to that unmerciful time. We should expect capital punishment for all prominent rebels.

${ }^{3}$ Does this mean "according to the foregoing description of the decree, according to the text above"? IIt $t$ (for early a: might, however, mean also "order, command," and might refer to the ordering of the right things by the king. Thus the sense of this phrase, occurring only here, remains very problematic in the single words, although the general meaning is clear. Also the following words are unusual. See next note.

${ }^{4}$ If we should understand $m(l)-d b w^{\prime}$ in its earliest sense: "in return of," we should obtain a superfluous parallel to the words following below: "in return for [the benefits]," $i$. e., the reason for the honors due to the king. We can, however, treat that preposition as analogous to Coptic etbe: "for" pressing intention, as we have it also in our demotic texts (l $l n-s e-t b$ "to order for the sake of "). See also above, note on $I I c, d$. Whether the $m$ in place of $r$ has any significance is questionable; it may be merely a graphic crror for $r$. 'The first signs on line I 3 (like the strong arm, then effaced traces, then $n$ ) would point to "for them," but these traces are very difficult.

5 If the word "people" is preceded by the definite plural article $n$-, then a relative $e$ - would seem to have been suppressed before the verb $i n$. That article $n-$, however, is not quite certain; the trace on the stone might also be considered as the final $-t$ of $h t, l, t$ " before," and then the verb would not have the definite relative construction.

${ }^{6}$ We have a feminine noun (i. e., an abstract?) describing something bad. In place of the above bold guess we might try to restore also in various other ways. Thith is usually written differently. Yet "the punishment" of the rebels could hardly be meant here; the leading verb is an imperfect, with wn, and not a narrative aorist.

7 The suppression of a relative $e$ - before $a \cdot n$ is not easily explained. It would be easier, grammatically, to take the two verbs with wn-n'-- as parallel principal clauses.

${ }^{8}$ The traces have been rendered on the facsimile quite mechanically, without restoring them according to the context. They look like an erroneous addition, possibly abandoned by the engraver. 


\section{THANKS AND HONORS TO THE ROYAL COUPLE DECREED BY THE PRIESTS - Continued.}

\section{HIEROGLYPHIC TEXT.}

$h r$-'r $n-s n^{1}$. . . . . . . . . [wrw?] making to them [and to their children(?) rewards many]

$$
\text { zsr } \quad m \text {-'swy } n \quad\left[n f r w w^{2}\right.
$$

(and) liberal in return for [the benefits

${ }^{136}$

$$
\begin{gathered}
\text { ' } r-s] n \quad n \text { ntrw } \\
\text { which th] ey [have done] to the gods. }
\end{gathered}
$$

$H^{6} \quad s h(?) n^{3}-[n f r] \quad m s b \quad m$

With [good] luck it has been thought out ${ }^{4}$ in

$$
\text { 'b } n \quad \text { 'ryw-ntr (w) }
$$

the heart of the companions of the gods (i.e., the priests)

$$
\therefore \text {. . . } m(?) \text { not }-[n t r]
$$

[who have come?] from the temples

$$
\begin{array}{ccc}
m y-q d-\left.\right|^{13 c} s n & m & \\
\text { altogether, } & \text { [to increase?] } & q n w(?) \\
n & n-s t & \text { 'byty honors(?) } \\
n & n & s,-R^{\prime}
\end{array}
$$

for the king of S. and N. Egypt, the son of the Sun,

Ptw'rromys, 'nhzt

Ptolemy living forever, [beloved of Ptah

\section{DEMOTIC TEXT.}

$\left.\right|^{\text {Ioc }}[n-]$ ntrw $\ddot{e}-w$

the gods, they are making [for them rewards]

$[\ddot{e}-w] \quad$ 'y $\quad \ddot{e}-w \quad \check{s}$ sc $\left.\right|^{\text {Iod }} n t-s ̌ b y t . n$ [which are] great, which are liberal, ${ }^{6}$ in return for $n-m n h w \quad \quad \ddot{e}-{ }^{\prime} r-w \quad n[n-] n t r w$. the benefits (which) they have done to the gods.

$N m \quad p-s h n \ddot{e}-n\left[f_{r}\right] . .$.

With the good luck [it has

Ioe

entered into the heart of the priests]

${ }^{1}$ Thus? The traces which at first look like $l ı r$ after $s$, are accidental; the first stroke of an $n$ (water line) is rather visible above.

${ }^{2}$ We should like to supply $n n n f r w$ " these benefits," but the space seems to be insufficient. $\quad I$ in trace above.

${ }^{3}$ Hieratic $h$ disfigured by the sculptor to the two parallel strokes of final $-y$.

${ }^{4}$ We should expect "it entered ("q) into the heart of the priests" (Ros. 5) or "it was put $(r d y)$ in the heart," etc. (Canop. II). Our scribe wanted to use a more choice word which implied not only a momentary thought but hinted at profound deliberation. $M s b(b)$ seems to mean originally "to turn oneself to ana fro," then "to make an effort, to labor, to strive, to exert oneself, especially in thought." El Amrah $\&$ Abydos, pl. 33 (of a kind and popular person) mssbbw (Det. thinking, speaking, man) $l_{r}-f$, "one for whom care was taken, an effort was made," $i . e .$, "one who occupied the thoughts." Harris 500, 4, 10: "I move myself (l.m), reflecting (" $x-y$ ' lir msb, Det. thinking man) under (hr) my love;" see my Liebespoesie der alten Aegypter, p. 22. Griffith, Siut (Rife) VII, 29: ("I am sitting to equip my tomb) reflecting ( $m s b b$, Det. Antelope, possibly a mistake for the jackal?, see below) for the sake (llr mrt) of my tomb." I do not understand Rec. Trav. 9, 96: (I am alone) $n t m-f$ msbb (det. jackal turning the head back as phonetic determinative for $s b$ and at the same time determinative of sense, then legs) $h r n b-f$; the negation $t m$ makes the sense of the phrase, "making an effort, thinking, for his master," obscure. Also, Pap. Turin 60, 15: $m$ msbw (Det. bookroll, plural) ' $w$ ' $r w-f$ stands in obscure connection. B. H. I. 8, 2: "the gods shall listen to my (poetical) reflections" ( $m s b b$, det. thinking man); the parallelism brings it side to side with hknw: "songs of praise." The word seems related to $s b b$.

5 The general sense of the passage is clear by the sense analogies of other texts, but the restoration of the single signs is difficult. "Honors" is seemingly rendered by qnw (determ. "strong arm" and plural strokes) which would be a very peculiar expression. Understanding the two words as "[recollections(?) of] the victories" we are puzzled by the first word beginning with $m-$. The mutilated parallel, Decree I, $8 d$, seems to differ. Is the above text mutilated by omission of the verb $[s-w r]$ "to increase" in the infinitive, so that only "many (quw!) honors" remains? The traces also do not favor the reading of the first group mtw-w "that they," assuming that both the verb and the object have been omitted.

${ }^{6}$ Written as in Canop. 10, 49, 53, while Ros. (18) has $\xi^{\xi} \xi$. Also elsewhere the orthograplyy often wavers hetween these forms.

${ }^{7}$ Here rather indistinct (over a correction?); restore the clear form after Ros. dem. 22. 


\section{THANKS AND HONORS TO THE ROYAL COUPLE DECREED BY THE PRIESTS - Continued.}

\section{HIEROGLYPHIC TEXT.}

\author{
[and his sister-wife,] $\left.\right|^{\text {I3d }} \underset{\text { the queen }}{h q t}$$$
\left.n b(t)-t^{\prime} w y\right] \quad \text { Qrw'w; } p^{\prime}, d r[;, t]
$$ \\ (and) mistress of both countries, Cleopatra,
}

[ ntrwy pr(wy)] [the Gods Epiphanes,]

[in the temples?]

[and the honors ${ }^{1}$ of the Gods Philopator who]

$$
\begin{gathered}
\text { begat } h m-f \operatorname{shpr}(-s n ? ! !)^{2} \quad h r{ }^{13 e} \\
\text { His Majesty, and } \\
\text { ntrwy mnhwy } q m,-s n
\end{gathered}
$$

the Gods Eivergetes who created them (i.e., these)

\section{$h^{\prime} \quad$ ntrwy snwy $h^{\prime} \quad n t r w y$ nzwy}

and the Brotherly Gods and the Gods Soter,

$$
\text { zfnyw-s[n? } \left.]^{3} \quad[q m ; ?]\right]^{13 f}-s n
$$

[their] ancestors [who created?] them ${ }^{4}$
DEMOTIC TEXT.

$\begin{array}{lll}n m & t-f] \quad s h m t\end{array}$

[and his] wife,

$$
\stackrel{200}{\operatorname{pr}^{\prime} t} \quad \begin{gathered}
{[G / w] p \operatorname{tr}(!)^{8}} \\
\text { the queen } \\
\text { Cleopatra, }
\end{gathered}
$$

$$
\left[\begin{array}{ll}
n-n t r w & n t
\end{array}\right] \text { pr } \underline{h n} n-\left.\right|^{10 h} \text { 'rpyw }
$$

[the Gods Epi]phanes, in the temples

$$
n m \quad n, y^{9}-n t \quad[n t(u)] n-\left.n t r w^{10}\right|^{I I a}[m r-y t(i)
$$
with those which (are) [of] the Gods [Philopator

$$
\text { 'r } r(y)-h p r-f(?)] \quad n m \quad n \text { ',-[nt] } \quad n t(u)
$$

who had begotten him(?) $]^{11}$ and those belonging to $n$-ntrw $\quad[n t] m n h \quad\left[\ddot{e}-' r t(y)-h p r \quad n-\ddot{e}-{ }^{\prime} r\right.$

the Gods Euergetes [who had begotten those who had $t(y)-h p r-f] n m \quad n-n t||^{I h b} n t(u)[n-n t r w \quad s n w]$ begotten him] ${ }^{12}$ and those of the [Brotherly Gods . . . . $n m n-n t n t(u) n-n t r w] n t n h m$ who begat them ${ }^{13}$ and those of the gods] Soter, $n-y t(i) w \quad\left[\begin{array}{lll}n & n-f & y t w\end{array}\right]$ the ancestors [of his fathers?] ${ }^{14}$

\section{THE STATUES COMMEMORATING THE VICTORY.}

$$
\begin{array}{ccc}
m[t r o t r]^{5} & s-1 h^{6} & s h m t y(!)^{7} \\
\text { and [that] be } & \text { set up } & \text { a statue } \\
n-s t \text { 'byty } & s,-R^{\prime}
\end{array}
$$

(of) the king of S. and N. Egypt, the son of the Sun,

1 'The ample space shows that these words were expressed (and the text read not merely: "and of the gods,"etc.)

2 The text seems to be in disorder; as it stands, we read: "His Majesty (who) begat" (shpr rather than shr?). Probably the plural was written first ("who begat them") and the correction to the singular was hastily executed, If the traces before the secondary vertical line are indeed $h^{\prime}$, we must suspect more corruptions.

${ }^{3}$ 'The traces above represent a horizontal $s$, although this ends much like a waved $n$.

"It remains doubtful whether we have to read as is given above (cp. decree I, 1. ga) or with Ros. 6: "the parents of their begetters," $n-t w t-s n$ (written there playfully, as though it meant "of their image").

${ }^{5}$ The determinative (thinking man) seems to be visible.

${ }^{6}$ Strangely abridged orthography (by confusion with the following $\operatorname{shm}$ ). See next note.

${ }^{7}$ Written shtht (with the determinative of a clumsy double crown). The repetition of ht expresses the dual ending: $-t y$ '. 'The preceding ' $h$ ', engraved very much like $s h m$, may have had a part in the omission of the sign shm which we should expect. The origin of this curious word, "the powerful (image)," is but a playful, incorrect etymology of the word hnty, "statue," which we find in the corresponding passage, Ros. 6. Compare the parailel etymological struggles with the words $\psi \chi \epsilon \nu \tau$, shmtt "crown" above, p. 43 , note 7 .

8 Thus quite distinctly.

${ }^{9}$ Only here this demonstrative form for the ordinary plural article $n$ - before the relative.

${ }^{10}$ The trace of a dash behind is strange and superfluous.

11 'Thus, after Ros. demot. 22.

${ }^{12}$ After Ros. without consideration of the extant traces.

${ }^{13}$ Possibly shortened, as the space is small.

${ }^{14}$ After Ros., not with full certainty of the single words. 


\section{THE STATUES COMMEMORATING THE VICTORY-Continued.}

\section{HIEROGLYPHIC TEXT.}

DEMOTIC TEXT.

$t_{4 a n}$ P[w, rwomys $\mathrm{P}$ [tolemy, living forever, beloved of Ptah, ]

$[k],-$ tw $n f$ (which) be called:

Ptw'rwmys, Ptolemy, $n b-q n(w)$

Lord of Victory, $h^{\circ} \quad r[p y] t$ ${ }^{14 b}$

\section{$h q t$}

and an image of his sister-[wife,] the queen (and)

$n b(t) \quad$ t,wy Qrw', w', $p^{\prime} d r,(t)$

mistress of both countries, Cleopatra,

ntrwy $\operatorname{pr}(w y) \quad m \quad q b h(w y !)$

the Gods Epiphanes, in the (twofold) holi[est!]

$$
\text { place(s) }
$$$$
\begin{array}{lclc}
n & h m t(!)-n b & h r & r n-f \\
\text { of every adytum(!), } & \text { on }(i . e ., \text { bearing) } & \text { his name, }
\end{array}
$$

$x, 4 c$

$$
\begin{aligned}
& \text { wosht } \\
& m s^{\prime} w(?) \\
& n t \quad h t-n t r
\end{aligned}
$$

(in) the court of the multitude ${ }^{3}$ of the temple,

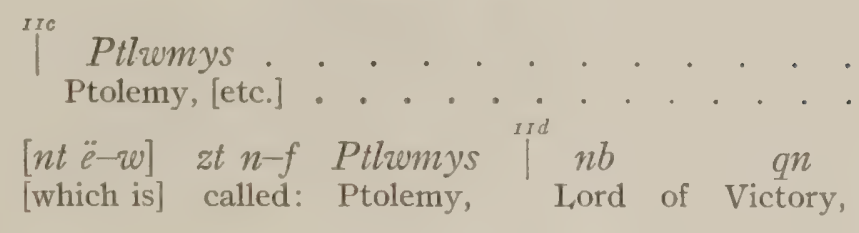

nm rpyt

and an image [of his wife, ${ }^{4}$ ]

$t\left(\right.$ ?) $\left.\operatorname{pr}^{\prime} t\right|^{I \ell}$ Glwotr[ $[\ddot{e}]$

the queen Cleopatra,

[ntrw nt pr]

[the gods Epiphanes]

${ }^{1}$ Thus, whether we take $g b h$ literally as "the coolest place," $i . e$., synonymous with the following word, $h m$ "adytum," or merely as a general word for "temple." 'The awkward translator wanted to use elegant words and to emphasize the special holiness of the place, so that we should think of the adytum, the coolest, darkest, and holiest room of the temple, if the following words did not contradict this. Not the holiest but the most accessible place of the temple is meant. According to the space and traces, the sign $q b l .2$ has been repeated to express the idea: "temples of the South and North," as line $16 a$ (literally "in the twofold temples").

2 This phrase, "on his name," $i$. e., where he is worshiped, can be traced back to Ros. hierogl. 6 and 7 , where it has no counterpart in the Greek, and possibly has been repeated erroneously. Here it is equally vague. Cp. Philæ, I, Iob, I I $a$, I 5e, I $6 c$.

${ }^{3}$ The first translation would be "court of the soldiers," $\mathrm{cp}$. below, line 17 . The soldiers belonging to the temples in earlier time have been discussed by Wiedemann, 1Z. 1885, 82, Erman, Aegypten, 41 I, 7I 4. Cp. the inscription of Haremleb in Turin, 1. 25: "(the king equipped the temples) with priests and ritual priests and picked men $(s t \dot{p})$ of the mnfyt-soldiers." It is probable that those soldiers acted as a police troop to keep order, principally for the vast domains of the temples. For keeping order in the temple itself and to restrain the multitude at processions, etc., we find the s'sty of the temple, Lieblein, Dict. I 186, Cat. Abyd. I 229; 1far. $1 b y d$. II, 8 (also Dévéria in his commentary on the Pap. Jud. Turin). Cp. as secular parallels, $e$. g., the "harbor beadles" (s styw $n t$ mryt), Pap. Harris I, 28 b. Those "beadles" of the temples sometimes are distinguished from the special "gatekeepers" of the temple, 1.1.28, 7 , etc. We must assume that the sticks of such small officials usually were sufficient to protect the temples; but we can imagine that in the case of some larger and wealthier temples arnied soldiers may have been necessary to reinforce the temple guardians. Indeed, Revue É gy.ptol. i 88 I, No. 2, pl. 35, in Greek time enumerates "the soldiers" n-stratiat(e)s, among the personnel of a temple. Revillout, PSB A., I887, IX, 230, claims that a temple in Memphis had a garrison of Greek and Egyptian troops. The latter statement needs verification; at any rate, we must not think that temple troops in the manner of the Middle Empire were possible under the strictly centralized Ptolemaic government. Although we might thus understand the designation "soldiers' court" as the place at the entrance where soldiers watched the gate, nevertheless that explanation is not certain. We find, namely, that in earlier style the above-mentioned place, the court for the laity, is designated as wht šs(w?), Louvre A 88 (Pierret II, I6) "court of the common people, the multitude" and thus still, Canop. 37 (in Reinisch's second edition; det. "people male and female"). Consequently, the sign for "soldier(s)" seems used here merely in the sense of "multitude" and may be read ss; also the sign $m s^{r}$ has, in Greek time, the same double sense, "soldiers" and "multitude, people." See the same orthography as in our text, in Brugsch, Zwei Festkalender, 1. 24, " hyw $n(w) p-m s^{*}($ ? $)$ "the court of the people(?)". Above, p. 70 , we had a certain example of $m s^{4}$ "multitude" ( $q f)$, corresponding with Coptic mếs, mêêse. (For the development of sense cp. the use of bezûh "many, multitude" as equivalent to "troop, army" in Ethiopic.)

${ }^{4}$ A strangely wide space.

5 The $n$ might also be explained as local: "the place (most) conspicuous in the temple." This would, however, be archaic style. 


\section{THE STATUES COMMEMORATING THE VICTORY - Continued.}

\section{HIEROCLYPHIC TEXT.}

[m] k,t msntyw nw Bqt

[in?] work (of) sculptors of Egypt.

Mtwtw $[s-]^{\prime} h^{\prime}$. . . . $\left.{ }^{x y d} n\right] \operatorname{tr}^{1}-n t(y)(?)$

And be set up [an image of] the local ${ }^{2}$ [go]d

$m \quad h t-n t r-t n$

in this temple [giving a (royal?) sickle-sword of vic-

. . $[t] w t w(!)^{3} n \quad n b \quad[q n w ?]^{4}$

tory to] the image of the Lord (of) [victory?]

ise $n z(?)-n-f^{5} \quad$ " h[wy?]

punishing for him a smitten (captive)(?)

$n[t y ?] \quad$. . . . ' $m(?)-[s ?] n$

[which is?] [imploring?] [th]em(?), ${ }^{6}$

$$
r d y(?)-n
$$

(and shall?) give (? $i . e .$, place) the officiating priests ${ }^{7}$

\section{DEMOTIC TEXT.}

$\begin{array}{ccccc}\ddot{E}-w & \text { ' } r y t[-f]^{8} & e-h & y p & n \\ \text { It is made } & \text { like work of Egyptian people. }\end{array}$

$N t u-w \quad t(y)-' h, \quad w^{110}-t w t \quad n \quad p-[n t r$ And shall be set up a figure (of) the god $\left.t-p^{\prime}, w t ?\right] \quad n \quad p$-'rpy $[\ddot{e}-f(?)-t y$ of the divine cycle] of the temple [who gives $h p 5$ s ] $\left.q n(!)^{9}\right|^{I I h} n$ p-twt $n$ a sickle-sword] (of) victory to the image of

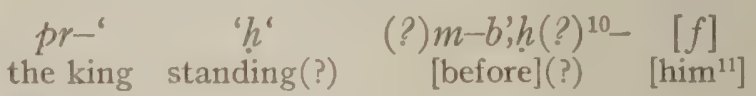

$\stackrel{12 a}{\text { I. . . } n t(u)-w(?)}$

and they(?)

1 The determinative of the sitting god is preserved, but rather rudely drawn.

2 This reading "city god, local god," seems clear on the stone and gives an excellent sense, especially if we compare it with the mention of the "nome gods," Ros. 7. The demotis parallel, however, seems to show that the

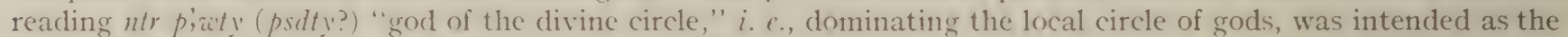
original sense, at least in the Rosetta decree. The circle sign admits either pronunciation in abbreviated orthographies. The parallel passage, decree $I, o c$, renders the passage differently, it seems, $i$. e. more elaborately.

${ }^{3}$ The $t$ is not certain; the first sign looks rather like traces of $w$ than of $t$. The word "image" is here written twit $i^{\prime}(c p) . \delta b$, etc.). The restoration $\left[k ; \mid t_{i}[-n-f]\right.$, "which is called," is risked; at any rate, there seems almost nothing between $n$ and $n l$; the space points to as narrow a sign as that of "statue." (The vertical stroke after the vertical palimpsestic line belongs to this line as a tentative scratch.)

"The traces do not favor the restoration $n b q n\left(w^{\prime \prime}\right)$, "lord of victory," it is true, but the demotic text seems to leave no other choice.

s"To stand," " $h$ ', is improbable without determinative, so I find a club-like ideograph and the strong arm as $n \approx$ (cp. I2c? or hisf, ge?). Again, the reading (after Ros. 0$)$, "he has defended $(n z-n-f)$ Egypt" militates against the rather clear $h$, which could hardly be read Bqt "Ligypt." "The least probable explanation of the above group is as a verb ending in $s$.

${ }^{6}$ I assume that the (very probable) ' $m$ - expresses, as explained in the note on demotic line ge in a modernizing way, the object of a somewhat emphasized verb. 'This verb might then be dw', "worshipping, saluting," $d b l$ " "begging," or the like; the space is, however, very narrow (especially if we understand the horizontal stroke above as pointing to $n[t y]$, the relative to identify it in the traces below that stroke. I3old also is the restoration of $h_{l}\left[a{ }^{\prime},\right]$, "a smitten man," as crowding and archaizing. (I considered, for a long time, a restoration like lln' or hr "with, and.") 'l'he description of that representation, of course, admits much variety of expression.

${ }^{7}$ The group $r d y-n$ "have given" is by no means certain. We can not restore the group determined by "people" to w'bu "priests"; the high size of - wi would be intelligible only after a $u^{\prime \prime} b$ written with $b$ underneath, for which group space and traces are unfavorable. The $-t$-like trace under $w$, if not secondary, would also be against that restoration. 'The expression 'trty' seems, however, always to refer to the sanctuaries of Egypt (cp. Philensis I, $4 b ; \mathrm{II}, 4 a$, etc.). so that the priests must be meant. Si) we read, after the initial traces, wnoty "the officiating pricsts"; literally "those in their hours" (cp. decree I, I ff), as synonyonous with "the attendants" (I, $I O b)$, although the space is scarcely sufficient and indicates unusual crowding of the signs.

"Unusual verbal form, disfigured by the engraver. The text is already difficult in Ros. 23; especially the sign ' $r$ "make" is similarly disfigured.

${ }^{9}$ 'The enormous extension of the last stroke does not seem to indicate a division.

${ }^{10}$ This restoration is not at all certain. The preposition $m-b ; h$ "before" would be strongly disfigured; it looks quite different directly underneath in line $I 2 h$, namely, like 'ro "they made." Yet, a reading "they (st) (are?) made (' $r-w)$ " would not easily fit into the context.

${ }^{11}$ 'The passage, very negligently written in Ros., seems, according to the space, to have been shortened (probably the verl)). 'The determinative "metal" of $h p s$, apparently, is further disfigured (like $t$-), etc.

${ }^{12}$ I do not succeed in connecting the demotic and hieroglyphic texts. Worthless guesses from the isolated traces are better not discussed here. 


\section{THE STATUES COMMEMORATING THE VICTORY - Continued.}

\section{HIEROGLYPHIC TEXT.}

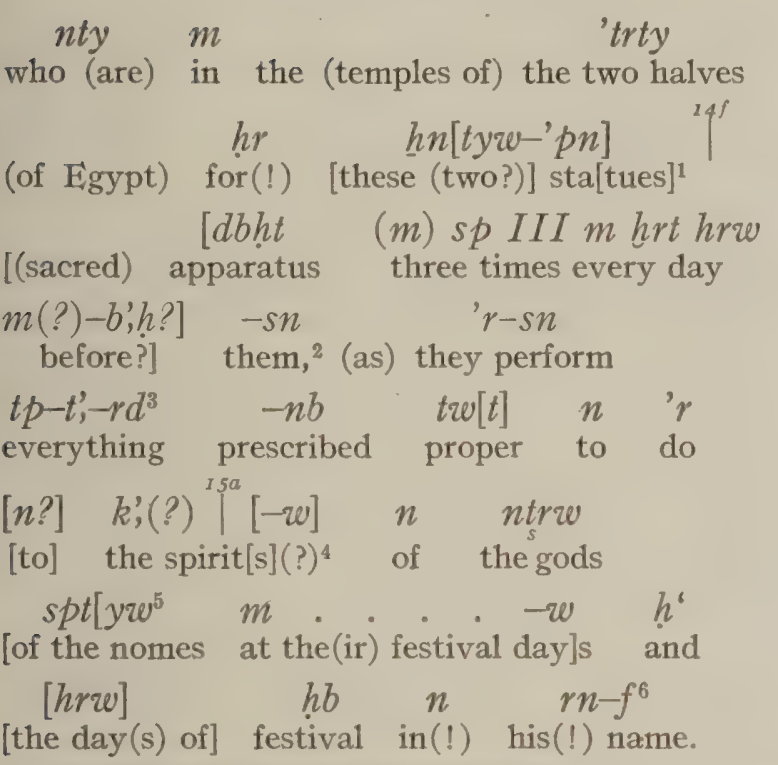

DEMOTIC TEXT.

$$
\begin{aligned}
& { }^{12 c} n t \quad \ddot{e}-w \text { ' } r-w \quad n \quad n-k \text { " } w \quad n t r w \\
& \text { which are done to the other }{ }^{7} \text { gods } \\
& {\left[\begin{array}{ll}
n-h b w & n
\end{array}\right] \quad h^{\prime} w} \\
& \text { (at) [the festivals of processions }{ }^{8} \\
& n m \quad n-h w(w) r n \\
& \text { and the name days. }{ }^{9}
\end{aligned}
$$

1 The $h r-$ "for" before $h n t y(w)$ is very peculiar; it is not impossible that it stands there by a contracting adaptation of the text as preserved in Ros. 7 and Philæ, I, IOb, $i$. $e$., we must suspect that the above text was simply mutilated from $h r[\zeta m s]$ hntyw ' $p n$ " [worshipping] these statues." Assuming the verb $\check{m} m s$, "serve," to be transposed to a later place, in the gap following the object, we should have even a more awkward adaptation. Ros. 7 reads: "two statues," but Philæ, I, Iob, the simple plural.

2 The space suffices for this restoration after Ros. 7, Philæ, I, Iob, because the hieroglyphic writing allows easily the necessary crowding together which we must assume here.

${ }^{3}$ Is the sign $r$, which follows the group $t p-t_{j},-r d$, a disfigured bookroll?

${ }^{4}$ Guided by Ros. hierogl. 7, twt $n k$, -sn "proper for their spirit(s)," $i$. $e$., for them, we can guess that the vertical stroke represents the pole of the standard on which the $k$; -sign rests. It seems to have two pendants, radiating from the point where the horizontal and vertical pole meet, a somewhat unusual hieroglyphic form. The above poetical use of $k$ ', "spirit, soul, double, self," is common. Our redactor has shortened the text slightly. This original text seems to have been corrected, however, since on the plates I have tried to read: $s-\left[h^{6}\right]-s n$ " (when) are brought out in procession," changing the unusual k,-sign to $s$. At least, we can see that this disfigurement of sense has been accepted in the other Philæ decree, Iod, which again shows its later date in this development of redaction.

5 That is, the local gods. Cp. Ros. hierogl., 7 and 8. A trace of (the second?) spt is visible.

${ }^{6}$ This error is common to all hieroglyphic parallels. Even the seemingly more correct text of Ros. hierogl. 7 reads: "At the festivals of each season and the day(s) of procession and also (see Philæ, I, Iod) the day of ( $m$ erroneously for $n$ ) his(!) name." Philæ, I, Iod, copies the Rosetta text faithfully. But the last expression is correctly "the name days," in the demotic text in Ros. 24 and Philæ, I, I $a$, the latter document trying to be more clear by marking the plural $r n-w$. (This expression could, unfortunately, be understood rather as "the (afore) mentioned days" than as "days of their name.") See our demotic text above. So $n$ rn-f, understood here as synonymous with $h r-r n-f$ " (the days) on his name," $i$. e., "bearing his name," ought to read "their name days." As, here and in the model text, the Rosetta stone, the special days to be celebrated for the king were defined only in the following section, we have a good illustration of how carelessly the Egyptian versions were worded where they wanted to be more explicit than the condensed Greek text. The singular "day" of the Rosettana, in the hieroglyphic text, is especially negligent and obscure.

${ }^{7}$ Exactly as in the demotic (24) and Greek (40) Rosettana. The hieroglyphic version, "nome gods," $i . e .$, "principal local gods," improves the above vague expression.

${ }^{8}$ That is, festivals, on which are held processions, as in better parallels.

9 That is, at the days devoted specially to the local gods, bearing their names. This expression corrects the corresponding hieroglyphic text. See note I. 


\section{SMALLER REPRODUCTIONS OF THOSE STATUES.}

HIEROGLYPHIC TEXT.

\section{DEMOTIC TEXT.}

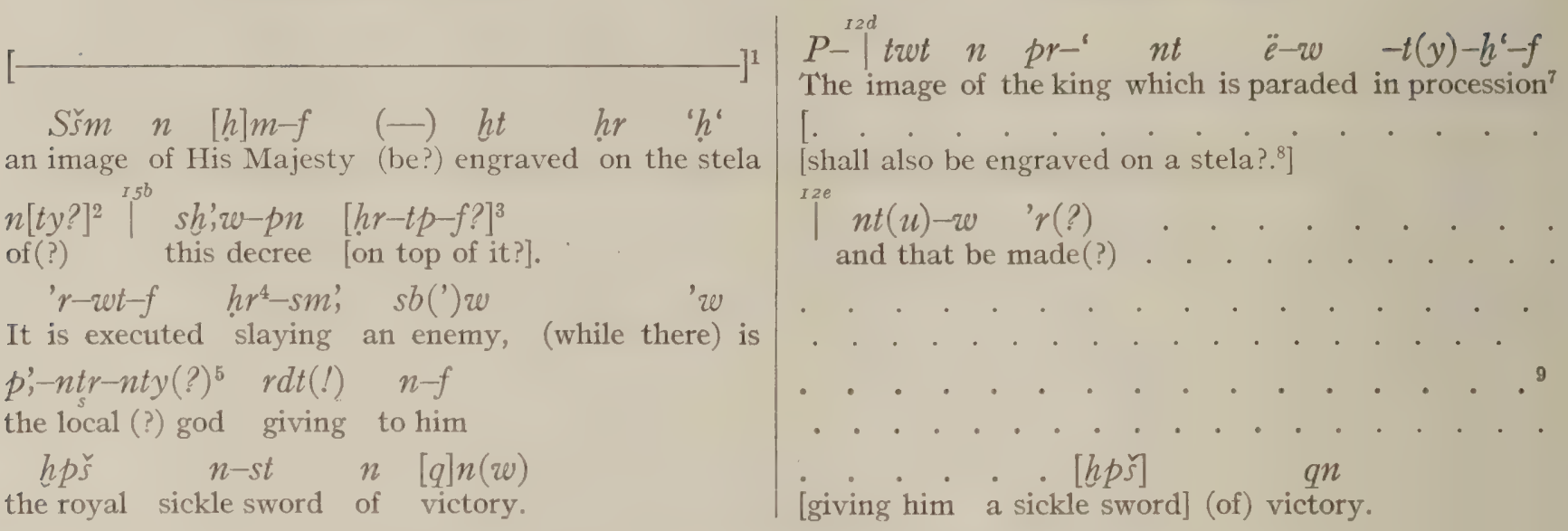

\section{FESTIVALS COMMEMORATING THE VICTORY.}

Mtwtw ' $r-w(!) \quad[' b d I V]$ šmwt(!)

And be made [the I2th] month

hrw III [hrw] $n$ sm'w-s 'w

day 3, [the day] of reporting it towards ${ }^{6}$

$[h] m-f$

His Majesty [through the mouth of a Friend of

\section{$N t(u)-w \quad(' b t) I V \quad s ̌ m w$,}

And that be made the I 2 th month,

(hw) $I I I$, day 3 ,

${ }^{1}$ The text contains a serious gap. It jumps from the portable, statuary, picture of the king mentioned in the demotic text (apparently much more briefly than in Ros.), to a flat picture on an immovable stone. The mentioning of both pictures close together seems to have created confusion. We have noticed some rash and unsuccessful shortening before. Perhaps we should place that gap in the line below, for š̌m seems to stand usually for images in the round. Otherwise we might fill the gap simply with ntwow "and that be."

"If we supply "of stone" ( $n-' n r)$, then the next word would need an $n$ "of" as connection.

${ }^{3}$ The chief difficulty of this restoration is the small space left for $-f$. Read s mply "on top," hr-tp?

${ }^{4}$ As though a vertical stroke had been changed to hrr, or rather vice versa? How would the gap be filled in the first case?

${ }^{5}$ See above, p. 80 , note 2 , on the corresponding uncertainty of $I 4 d$.

${ }^{6}$ Less direct expression than the ordinary $n$ of the dative and more respectful, consequently. Cp. the "before His Majesty" of line $4 f$. (Or simply $e$ as a mistake for $(e) n-$ ?).

${ }^{7}$ The text of Ros. 24 has here: "and that be paraded the image of the king," so that it looks as though our relative clause $n t-\ddot{e} w$ had been confounded with the conjunctive $n t(e)-w$ : "and they." Otherwise, however, the wording differs. We have not read anything on bringing forth that picture. See on the hieroglyphic text, note $\mathrm{I}$.

${ }^{8}$ Thus I try to bridge over the apparent gap between the last and the present section. This is, of course, a rather violent expedient. See on the hieroglyphic version of this passage.

${ }^{9}$ I have not attempted to explain all isolated traces, $e . g$., plate $d$.

${ }^{10}$ I believe that to the scribe of the demotic text the suppression of the name of the courtier who had brought that important report to the king seemed as strange as it does to us; he inserted there the name of the probable prime minister and victor in the Thebais, leaving this name, however, also in its proper, later, place, so that a doublet resulted, each time with some mutilations of the name, showing how hastily the scribes worked. This theory seems to me easier than to assume that we have a correct tradition of a second name suppressed by the other passages, although the hieroglyphic parallel, likewise, may be not quite in order, as said above. The incredible confusion of the names seems to have been caused also by confounding the title strategumenos with them, which title, apparently, has been omitted.

${ }^{11}$ One small letter effaced after $s$; less probably another over this. The $t$-like next letter may be read $q$ without too great difficulty, but we gain nothing by this.

${ }^{12}$ Preserved either $-g s(l)$, or $-w(?) s$ preceded by $t$ or $q$ (or parts of a round $n^{\prime}$ ). 


\section{FESTIVALS COMMEMORATING THE VICTORY-Continued.}

\section{HIEROGLYPHIC TEXT.}

His Majesty], $\left.\right|_{\text {a Lover of the King, about }} ^{m r(!)} n \begin{aligned} & \text { L } \\ & \text { Holl }\end{aligned}$

- . . . . . n n $n y] w, s \quad p^{\prime},-$

[the commander of horse, Aristo]nios, the [son] of

[']', $[r w] s \mid[d]$ ' nygw(?) $[s]$

Aristonikos,

[hr?]

$m h(?) t$

[about?] $]^{1}$ the capture(?)

$n(? ?) \quad[s b]^{\prime} w \quad n w \quad b t n w$

of the (most) wicked (one) ${ }^{2}$ of the rebel(s),

$h^{\prime}$ ('bd) III šmw hrw [XXIV]

and the IIth month (Epiphi), day, [24]

$1^{15 f}[r] d t(?) \quad, m(y)[n] w^{4} \quad n t y$

(when) caused $^{3}$ [this Strateg]umenos, who (is)

$' m[w t] \quad ' m(y w)-\left.{ }^{\prime} b\right|^{16 a} \quad[t p \quad n \quad h m-f$

among the Friends, [the First ones of His Majesty?

. . . ] $h m-f \quad, m-w t(!) \quad$ ' $m-f$

that enemy of ? $]^{5} \quad$ His Majesty to be captured on it $^{6}$
DEMOTIC TEXT.

$n t$ who [is of the friends of the king(?) about the - . $g($ ? $) s^{7} \quad\left[s^{\prime},\right] \quad[$ [?? $] s(?)$ commander of horse], [Aristoni]g(!)os son of $\left.\right|^{12 h}$ rynyqs

Aristonikos

$n-b ;\left.h\right|^{13 a}[p r-6$

before [the king, and the 24 th day of the I th

• . . . . . $p-] \quad s b^{\prime}$

month, ${ }^{8}$ there was captured the] enemy, ${ }^{9}$

$$
p r-' n-m-f \quad m h(t ?)-f \quad[n-m-f ?] \quad \text { ' } n h .10
$$

(of) the king on it, he took(?) [him?] alive.

${ }^{1}$ Reading thus, I must admit difficulties of the group explained as $m h l-n$, "to seize, to capture." (Only a $t$ is certain; against $m h t=$ Coptic amahte, "to seize," speaks the absence of the determinative.) The sign $m h$ is low (like a $z$ ). But $n$ (for classical $m$ ) is very questionable; we must prefer to see the broad $s$ or $s b$ ' in that horizontal line above, because there is no trace of a high $s$ below. It seems that this preposition $n, m$ has been omitted by mistake, since intentional omission would be unusual and strange. I find, however, no other explanation. $M z t$ for the correct $m z d$, "saying, thus," is much less plausible.

${ }^{2}$ The adjective receives superlative sense by the following genitive, as often in Egyptian and in other languages (above all the Semitic). In our text we may have, however, merely an archaistic phrase taken from ancient literature with little or no understanding, which might mean also "the wickedness of the rebels."

${ }^{3}$ The small $w$ looks also like a small $n w=n$. Cp. 4e. Hardly a proper name.

${ }^{4}$ This most probable restoration can not consider the apparent tail of a sign hanging down behind. This looks like the tail of $m h$, so that we should have the verb mllt, amahte, of the preceding note in normal orthography, "(when) seized N. N." The only explanation of such a strange doublet with the verb "be captured" following below would be a grave stylistic negligence resulting from a hasty correction of the text. As we have similar confusion in the parallel demotic passage, we could explain that stylistic blunder as a later attempt to minimize somewhat the personal merit of the general Aristonios after he had lost favor with the king. Stuch an explanation would be more plausible than a simple stylistic improvement producing the doublet (substituting archaic ' $m$ for modern $m h, m h t)$. However, we better abstain from building too much on a small stroke, knowing how much we have to expect blunders of the engraver. A space shows that a preposition has been effaced and that the following name is not the subject of the verb "to report."

5 The large space warns against connecting the group, "His Majesty," directly with " first friends," tempting as this seems after $4 f$.

${ }^{6}$ The "on it" points back to a preceding, supplied relative, so that we obtain, more freely translated, "the day on which N. N. caused to be captured," etc. (Less probable, as object of the verb.)

${ }^{7}$ Preserved either $-g s(l)$, or $-w(?) s$ preceded by $t$ or $q$ (or parts of a round $n ?$ ).

${ }^{8}$ In demotic this restoration requires very little space.

${ }^{9}$ Or wicked, impious, against the king.

${ }^{10}$ Only the $h$-circle and the vertical dash for the " $n h$-ideogram seem fairly certain. The group before the vertical line of the palimpsestic text seems to contain an $-f$ in ligature, which makes us think of a verb followed by the suffix $-f$ as subject or object, but this does not admit any certain reading. 


\section{FESTIVALS COMMEMORATING THE VICTORY - Continued.}

\section{HIEROGLYPHIC TEXT.}

$$
\begin{aligned}
& m \quad h b \quad w r^{1} \quad m-h n t^{2} \\
& \text { as a festival a big one in }
\end{aligned}
$$$$
\text { qbhrwy } r-t p
$$$$
\text { the sanctuaries (of both parts of Egypt) each }
$$

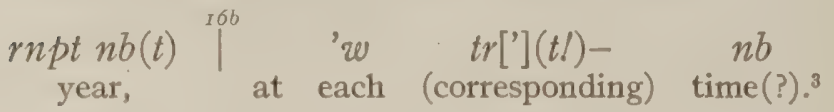

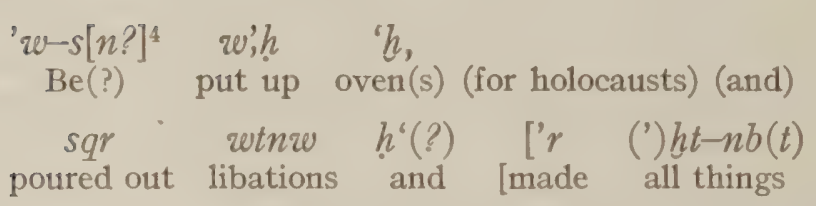

$\begin{gathered}t w t] \\ \text { proper }]^{5} \text { to }\end{gathered}$ ' $r$,
$m-\left.\right|^{16 c}[t] w t w$
and $\quad$ be

\section{DEMOTIC TEXT.}

$[n] \quad h b(?)$

[as] a festival

[n $n$-'rpy $] w^{7}$ [in the temple]s

$$
\begin{aligned}
& {[r n p ?] t-\left.n b \ldots\right|^{3 b} n t(u)-w} \\
& \text { every [yea] }{ }^{8}
\end{aligned}
$$

[held these festivals(?) (also when) correspond(?)

$$
\text { ... hr?] wh(',)-nb '[rpy nb }
$$
days?] every [season?] [every temp]le(?) . . .9 $\left[n t(u)-\left.w\right|^{i 3 c}, r\right] y t-w \quad h r-r n p t-n b \quad s s(w) I I I$ [that] they be held each year three days, $n t(e) w \quad$ 'r kll , win and that be made holocaust(s), libation(s), ' $b$ ', $\left.\quad\right|^{23 d} p-s p \quad\left[\begin{array}{ll}n & m t n t] p h t \quad n ' r y t-[w]\end{array}\right.$ oblation(s), the rest [of the things] proper to do

${ }^{1}$ This looks like a bold restoration. The trace above, preceding the big vertical line, does not resemble the head of the wr-bird. It may, however, be executed negligently.

${ }^{2}$ The calf's head is distinct; it stands without complementary $-t$ as it seems.

${ }^{3}$ 'This remark is not quite easy to understand. It looks at first like a pleonastic repetition paraphrasing the words "each year"; this superfluous character is not removed by connecting it with the following description of ceremonies ("each time be put up," etc.). The demotic text, which contains an addition in extending the celebration over three day's, suggests that the hieroglyphic text here has been mutilated. I think it has been condensed awkwardly from Ros. I I (demot. 29, Greek 48), changing the monthly repetition of those festivals to a more vague recommendation of repetition at any shorter interval than a year. The scribe of I, Iod, feels the obscurity and tries to correct it.

${ }^{4}$ A trace above might indicate a horizontal $s$.

${ }^{5} \mathrm{Cp}$. Ros. hierogl. Ir, etc., for this restoration.

${ }^{6}$ A rather indistinct determinative ("garland") used as ideograph.

${ }^{7}$ Narrow space only for this group; also the following restorations imply crowding together.

8 These restorations must assume an unusual crowding together of the required groups.

${ }^{9}$ In opposition to the preceding note we must assume lengthy additions in the demotic text, which is not very satisfactory. 'The probable group $m h$, usually "to fill, to fulfill," has, apparently, here the uncommon meaning "to return, to correspond," a sense which can be explained by the analogous use of mall-forming the ordinal numerals. The above word for "season" (probably not quite correctly engraved) occurs again in Canop. demot. 39 (incorrectly reproduced by Krall; my personal collation confirms the reading by Revillout and Brugsch, although the engraver seems again to have erased the vertical stroke. (See Kôm el Hisn.) The Greek (20) renders "the times," the hieroglyphic text doubly, by trw "times" (as in our hieroglyphic Philæ text) and by phry "returning time." The strange addition (Canop., 39) $n$ ws, looks like a second ctymology of the same word. Kôm el Hisn, line II (again poorly reproduced by Krall), mutilates that addition as unintelligible to the engraver, but gives the group wh', better than Canop. We have now the etymology of the Coptic p-wois "the time," pointing to the root wh,", originally "to go around, to send around," later "to go around (for) something, to seek," Coptic wốs "to desire." Spiegelberg, Petubastis glossary, No. 99, was misled by the erroneous doublet of the Canopus text, as Griffith was previously by the $n-p-w s^{5}$ of $2 \mathrm{~d}$ Khamuas 6,36 (Rylands Papyri, glossary, 343). The latter may, however, be understood "in the gap, to fill the need," so that the popular etymology of Canop. 39 seems to be isolated. 'That derivation from ws "to be empty, to be lacking, delicient" can now be abandoned as very improbable. 


\section{FESTIVALS COMMEMORATING THE VICTORY - Continued.}

HIEROGLYPHIC TEXT.

\begin{abstract}
$r \quad t p[w]-s n$
on their (i.c., the people's) heads $s, ;-n(l)$

' $r(?)$

beginning from the celebration(?) (of)

$m \quad h b r-p n$

at these festivals

$h b$

the festival

[of the New Year (on the first day of the first month?)

to-day (of this month?) $]^{1 / 16 d} \operatorname{III(?)}{ }_{\text {three(?) }}^{2}$
\end{abstract}

DEMOTIC TEXT. $k \operatorname{lm}[w ?]^{5} \stackrel{{ }^{3} 3}{\mid}\left[\begin{array}{ll}n & p-\end{array}\right] \quad h b$

[at the] festival [and that they] wear crowns

[n] rpy $[-n b ?]$.

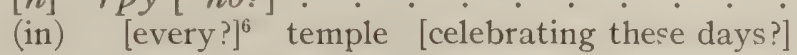

\section{SPECIAL HONORS FOR THE QUEEN.}

Mtwtwe
And (when) will be [brought out in procession the $\quad \begin{gathered}N t(u)-w \\ \text { And (when) will be brought out (in procession) } \\ p(?)-t[w t] \\ \text { that statue }\end{gathered}$

${ }^{1}$ This restoration taken from Ros. I2, and decree I, I 5c, is somewhat long. We might try to shorten it by assuming that the preposition $\xi^{\prime \prime}(-m)$ had here passed from the ancient use "from" (still so, Ros. hier. I2) to the latter and opposite sense which we find in demotic and Coptic sa: "until." It would then be possible to explain thus the above passage "to [the end of?] the festival." As long as the text is incomplete, the decision is impossible. $\breve{S}^{\prime}-n(!)$ with an infinitive is, of course, an unusual construction, but the whole passage is unusually worded. Ros. Greek 50 , states plainly that the fifth day of the same month (Thout) was meant, $i$. $c$., that the celebration extended over five days. The hieroglyphic text, Ros. I2, taken by itself could also be understood: "from the first day of the year to the Five Days," $i$. e., to the last, epagomenal, five days of the year. The priests, who were inclined to think first of those closing days of the year which were so important in the sacred calendar, could easily misinterpret that date thus (i.e., from the first festival of the year to the last, through the whole year). Consequently, our text seems to attempt to make that date clearer by some changes; it is quite possible that even the reduction of the festival from five to three days aimed at nothing else than avoiding that obscurity. For the amiable negligence of ancient Egypt the duration of the festival through five days ought not to have been oppressive enough to shorten it. To show some good will was sufficient and the execution of all details was not expected. So the correct date seems to have been more important than the extension of some cheap ceremonies.

${ }^{2}$ I first tried to read zsrw "in splendid ways" after the demotic text. (The traces which I once tried to find before the plural sign are absolutely uncertain and even improbable.) Zsr means also "holy, sacred" (but hardly thus the demotic corresponding word). It occurs to me now that the three strokes are nothing but the numeral. After their arrangement that number seems to be complete (III) and is not to be considered as a part of $\mathrm{V}$, so that this would seem to agree with the demotic text.

${ }^{3}$ The $-w$ is not certain enough to insure this restoration, for which the space is rather limited. (Or' $w, e=r$.)

${ }^{4} S_{w}=$ swt of early Egyptian.

${ }^{5}$ The $-m$ half preserved, followed by part of the determinative "flower."

"The "every" can be inferred from the absence of the article with the (not absolutely certain but very probable) word "temple."

7 The ability of demotic writing to be crowded or extended in an incredible way makes the estimation of the lost words very hazardous. The above space looks too large after the hieroglyphic text.

${ }^{8}$ On $\xi^{\star} \xi^{\star}$ "extended, numerous (NB!), liberal, magnificent," cp. line $6 e$.

${ }^{9}$ Rather as subordinate, conditional clause (as in Coptic) than as emphasized principal clause. 


\section{SPECIAL HONORS FOR THE QUEEN-Continued.}

\section{HIEROGLYPHIC TEXT.}

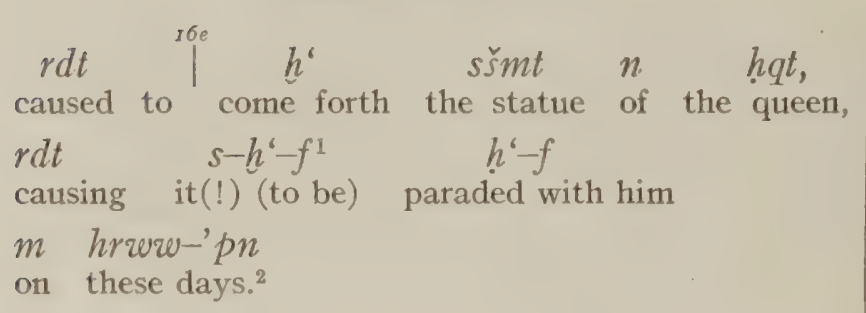

DEMOTIC TEXT.

$$
\text { ['s?] } n t(u)-w \quad t(y)-\left.h^{\prime}\right|^{139} p-\operatorname{shm} n
$$
[at that time?] $]^{7}$ (that) be brought out the statue of $n t r(t ?)^{8} \quad[n t p r, \quad t f-p n t s-h m t n m ?]$ the goddess(?) [Epiphanes, his sister-wife also?]

$$
-f \quad n t(u)-w \quad t(y)^{9}-h^{6}-f \quad n m-f^{10} . n
$$
with him they (shall) bring it out with him on $n-h w(w) \quad r n-w$ the days mentioned,

$$
N\left[t(u)-w \quad t(y)-h^{\prime}(?)\right.
$$

And there shall be set up(?).11 $r 4 a$

$$
n b(t)
$$

of the royal statue the statue $]^{4}$ (of) the mistress

$$
\text { t'wy } \quad m \text { hrww-pn tp-rnpt-nb(t) }
$$

of both countries on these days, every year

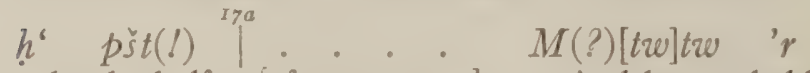

$$
\begin{aligned}
& \text { and the half of every year]. And be held }
\end{aligned}
$$

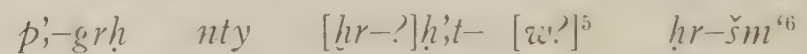

$$
\begin{aligned}
& \text { the night which (is) before them, making music }
\end{aligned}
$$

\%.

[the statue of the queen every year and the hallf(?)

$$
\text { rnpt } n-t t(?) \quad\left[\mathrm{pr}-\text { '(?) }^{-} \quad e-f-t y ?\right]
$$

(of) the year at the side of [the king who gives]

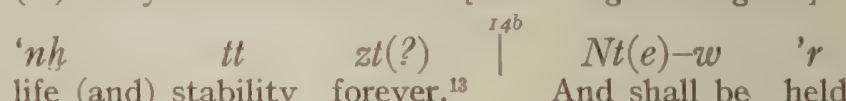

life (and) stability forever. ${ }^{13}$ And shall be held

$$
p-g r[h]^{14} \quad[\ddot{e}-v(?) h, ; ?]-s(?)
$$

the night (before) ${ }^{15}$ [placing $]^{16}$ it(?)

${ }_{1}^{1}$ 'This looks like a pleonastic connection of the ancient $\left(s^{-}\right)$and later $\left(d y^{\prime}\right.$, infinitive $\left.r d t\right)$ expression of the causative verb. Notice the erroneous gender of the pronoun.

"Written like "these three days," but the stroke between hro and the plural strokes is to be considered a mistake of the engraver.

${ }^{3}$ Written 'hr. The learned scribe had in mind the archaic 'hr (for later hrr), "now, then, furthermore." It is also one of the possibilities that grt, later $g r$ : "but, then," had been in his mind and that the sculptor confounded $g r$ and $h r$. This would even connect the above form with later usage, which preserved that grt in Coptic je.

${ }^{4}$ The restoration offering itself at first is: "[a special festival be installed for] the queen." The traces of the demotic text force us, however, to find a restoration of more specific sense. 'The trace of the verb somewhat like ' $h$ ', at the end of $I 6 e$, may be deceptive. The restoration used above is crowded.

${ }^{5}$ That is, before those (3) days. The very narrow space makes the later $-w$, "their," probable in place of the earlier pronominal suffix $s n$.

${ }^{6}$ The hieratic sign $s m^{\prime}$ is mutilated by the engraver. The presence of the queen's statue causes special music to be introduced according to the old tradition that goddesses and queens have to exhilarate their divine husbands by music, which is more proper for women than for men.

${ }^{7}$ I suppose that the senseless two parallel strokes have been corrupted from the ligature 's=Coptic is, "behold, then." Hardly to be read $\ddot{e}$. For the subjunctive after the eonditional conjunctions see Stern, Koptische Grammatik, $\$ 442,62$ I, 626 .

${ }^{8}$ The stone seems to bear the masculine ntr: "god," but surely not the group "queen," which we should expect. Is the text in order?

${ }^{9}$ This sign confounded with the two preceding vertical strokes.

${ }^{10} \mathrm{~A}$ senseless stroke after $n m$ ?

11 Only the determinative "feet" is visible, but this leaves us the choice only between the above verb $t$ - $a h_{0}$ " and $h ;, ;$, both being used of the setting up of concrete objects, never figuratively of times, days, festivals, etc. This seems an important clue ro restoration.

12 The ending $-t$ and, perhaps, part of the determinative ("strong arm") visible.

${ }^{13}$ As there is no trace of a hieroglyphic parallel for those loyal, archaistic, phrases, I assume that the redactor of the demotic text has transferred the last words of the decree (see the hieroglyphic text, I $f$ ) to a place higher up. This furnishes another clue to restoring the sense.

${ }^{14}$ Grh quite distinct; only the $h$ destroyed.

${ }^{15}$ Hardly space for $h() t-$,$w ; the sense, "eve of the festival," seems to be certain.$

${ }^{16}$ Again only the determinative part of the ligature visible. The $-s(?)$ behind is difficult. The following stroke might point to $\mathrm{nm}$ "with." 
THE BILINGUAL DECREES OF PHILAE.

\section{SPECIAL HONORS FOR THE QUEEN-Continued.}

\section{HIEROGLYPHIC TEXT.}

DEMOTIC TEXT.

\begin{abstract}
$m t p^{1}-\left.\right|^{r>b} r d(w y) \quad m$
in the way prescribed in
\end{abstract}

'trty (') $h(w) t-n b$ the temples (of both parts of Egypt, $)^{2}$ all things

$r(?) \quad h b w-p n$ sšm [-pn?]

for $(?)^{3}$ chese festivals (in) [this?] manner, ${ }^{4}$

- . . $-\left.s n \quad m\right|^{17 c} h t-n t r$

[when they serve] them ${ }^{5}$ in the temple.

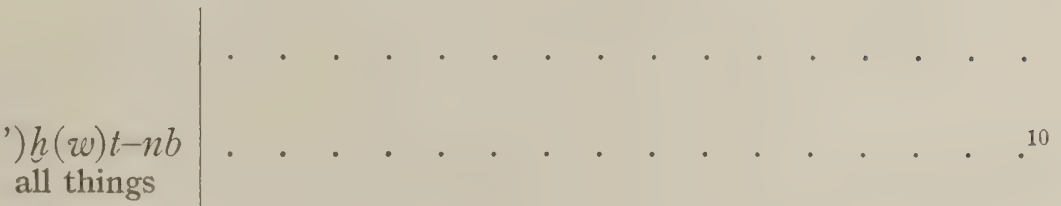

${ }^{I 4 c} p f-s m t(? ?)^{11} \quad \ddot{e}-w-r \quad g l l$,

(in) this manner, making holocaust(s)

win 'b'w 'w $n t(e) w$... .

libation(s), oblations, and shall be [made?] ${ }^{12}$

- . $-n b$ nt $\check{s}(m) s(?)^{13} \quad n p-[' r p y$ ?]

all [ceremonies?] of service(?) in the [temple].

\section{PUBLICATION OF THIS DECREE.}

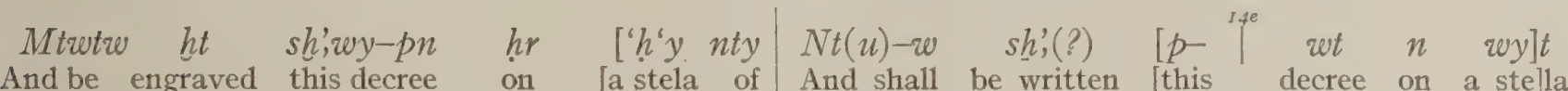

And be engraved this decree on [a stela of And shall be written [this decree on a ste]la

\section{' $\left.t-\left.\right|^{17} r d t \quad m\right]^{6}$ sh', $\quad[(n ?) \quad m d w t-n t r$}

hard stone in] the writing [of the divine words,

$$
s h ;-n-s^{\prime} y
$$

the letter writing (and) the writing

n] $\quad I^{\prime}, w-n b w$

I7

$$
{ }^{I 7 /} s-{ }^{\prime}-f \quad m \text { wht } m \check{s}^{6}(w)
$$

setting it $\mathrm{up}^{7}$ in the court of the (common) people

\section{$[m] \quad h t-n t r \quad m$ rprw-nb hr $[r n-f \mid$}

in the sanctuary, in all temples on [his name $n(?) \quad$ ' $n[y$ zry

of [hard stone in the writing of the divine words,

the letter writing (and) the writing of (the) Gree]k(s),

$$
n t(u)-w t(y)-h^{\prime}-f \quad n p-m \text { ' }\left.n \quad m \check{s}^{\prime \prime 4}\right|^{\prime 4}(w)
$$

and it shall be set up in the place (of) the multitude

$n \quad$ 'rpy 'rpy-nb(?) ${ }^{15} \quad n$

of (the) temple each(?) temple, (namely) in (the)

1 Thus, evidently, the $t$-like sign below is to be read.

${ }^{2}$ See above, p. 80 , note 7.

${ }^{3}$ We should expect "in," $m, n$. Indeed, the trace might indicate also a clumsy $n$.

4 'Thus more probably than $s s m=$ "the statue."

${ }^{5}$ We should like to restore the stereotyped expression "[all things which it is proper to do] them," but the demotic text seems to point to a different expression of this idea. The $-s n$ might also refer to the subject of the verb, not only to the object as assumed above.

${ }^{6}$ After Ros. hierogl. I4; cp. also Philæ, I, I7a.

${ }^{7}$ Shortening the text of Ros. In the classical language this would be the circumstantial infinitive.

${ }^{8}$ See above, page 79 , note 3 , on the possibility of reading "soldiers' court" and the greater probability of the translation followed here (literally "crowd, multitude").

${ }^{9}$ Notice the substitution of this ordinary word for the more obscure ideograph (pr-m'“t?) of Ros. I 4. 'This does not furnish the pronunciation, of course.

${ }^{10}$ The demotic text must have been shorter here than the correspondence with the hieroglyphic parallel would require, because it is fuller below.

11 Thus I should propose to correct the text. The difficult traces do not look much like that reading, it is true.

12 The traces would rather point to $h$ ': "to parade," but the general sense required must be as translated above.

13 If this literal translation is correct it means "ritual ceremonies."

${ }^{14}$ Cp. Ros. dem. 32.

15 The repetitions of the word rpy may not all be correct. The text has undergone hasty shortening by the redactor, as also in the hieroglyphic version. 


\section{PUBLICATION OF THIS DECREE-Continued.}

HIEROGLYPHIC TEXT.
- . . ] $m h$ h, $m h$ h $I I, \quad m h I I I$ in the temples] ${ }^{1}$ (of) first, second (and) third (order)

DEMOTIC TEXT.

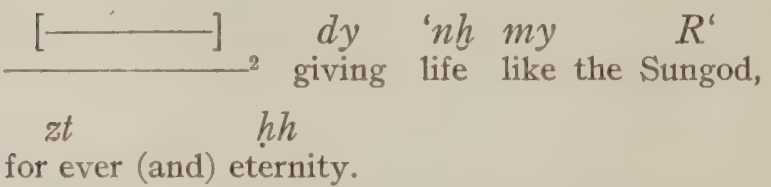

1 The space proves this addition over Ros. 14 .

${ }^{2}$ A stupid omission of the words "at the side of the statue of the king." See Ros. and Philæ, I, ult. $d$, for

$$
\begin{gathered}
\text { 'rpy } \\
\text { temple(s) } \\
\text { (of) first, }
\end{gathered}
$$$$
\text { 'rpy } \text { I4o }^{2} \text { h II } m h I I I \text {. }
$$$$
\text { temples (of) second (and) third (order). }
$$

\section{the correct text.}




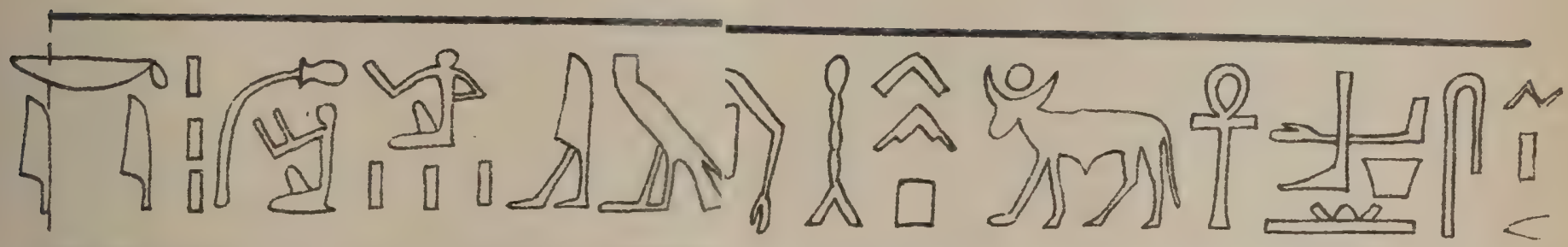

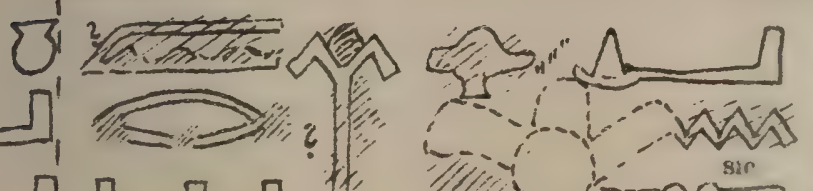

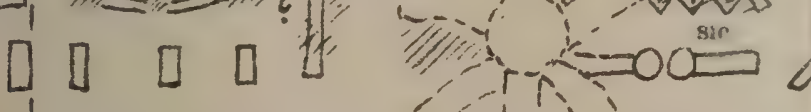

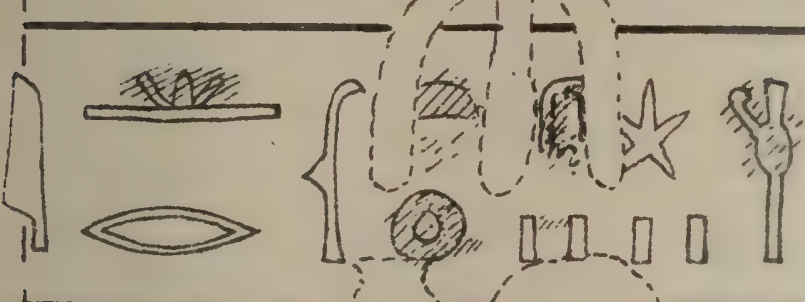

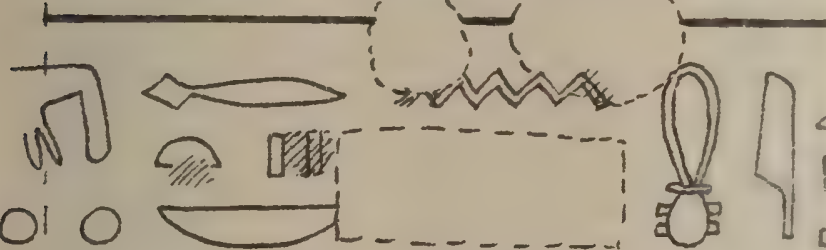

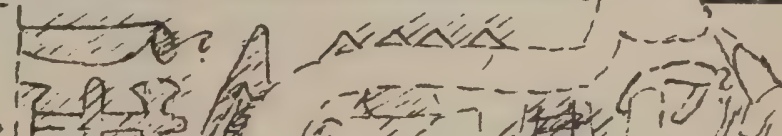

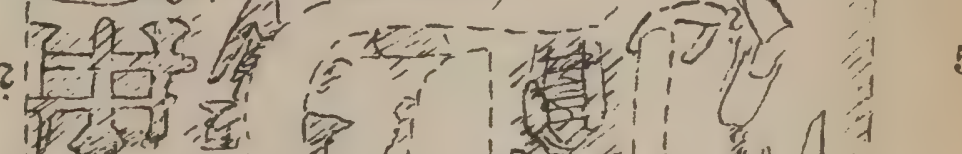

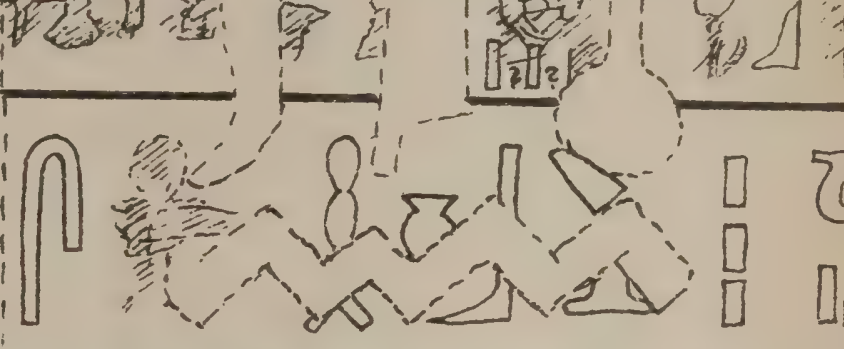
A $\triangle$ (c)

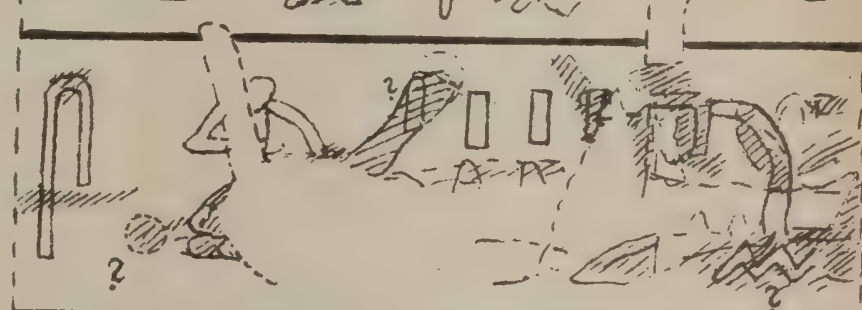

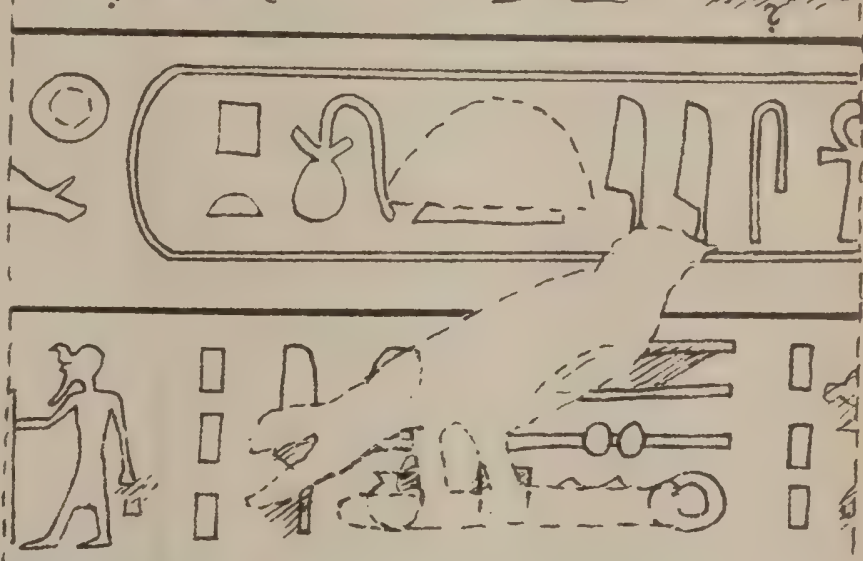




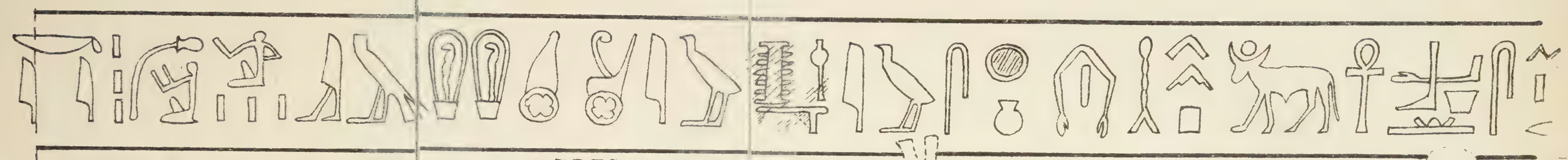

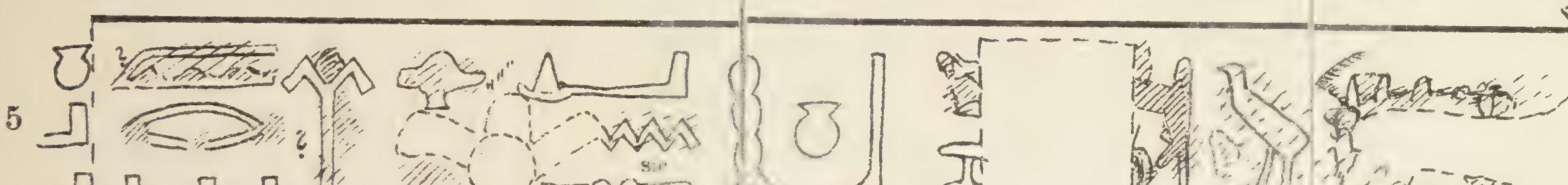

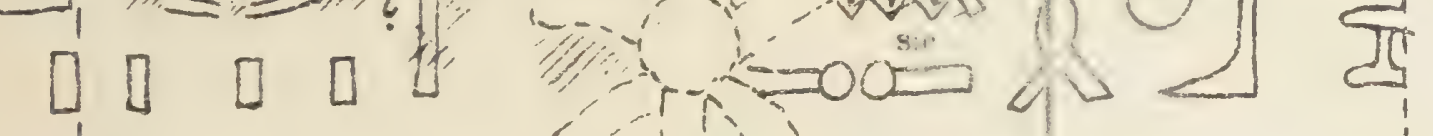

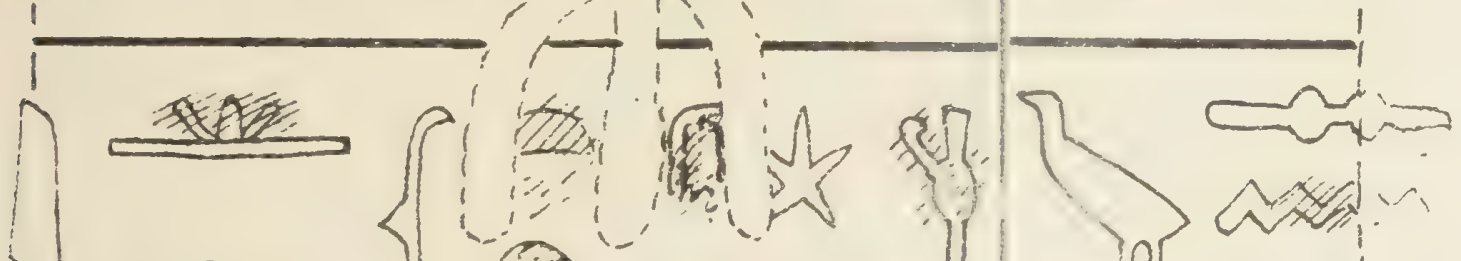
is $\infty$ i.

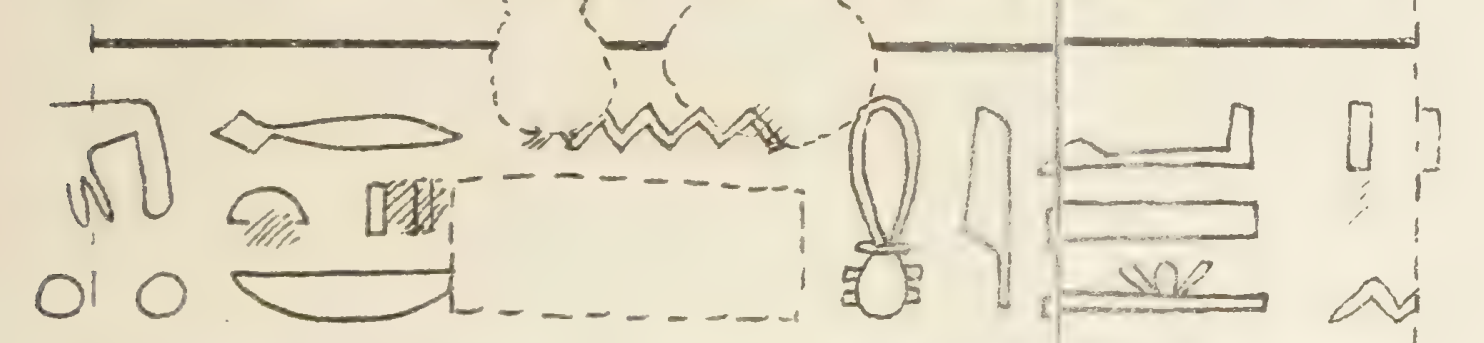

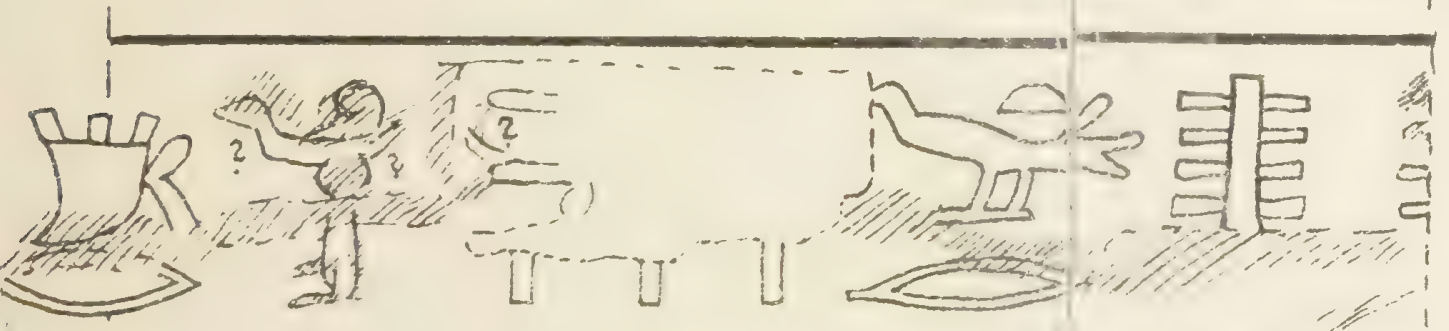

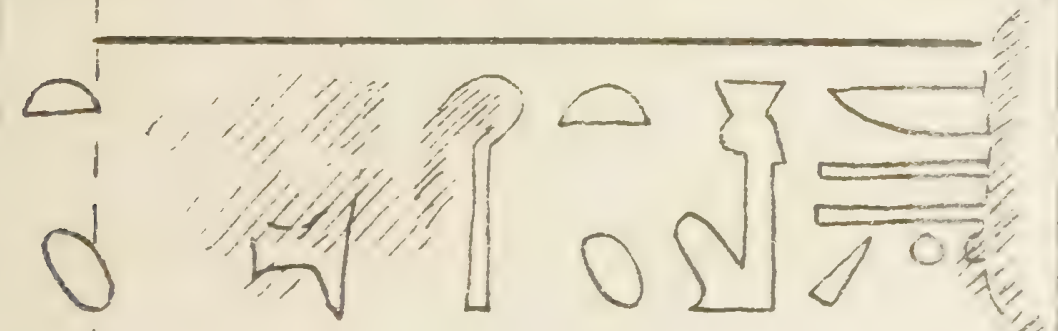

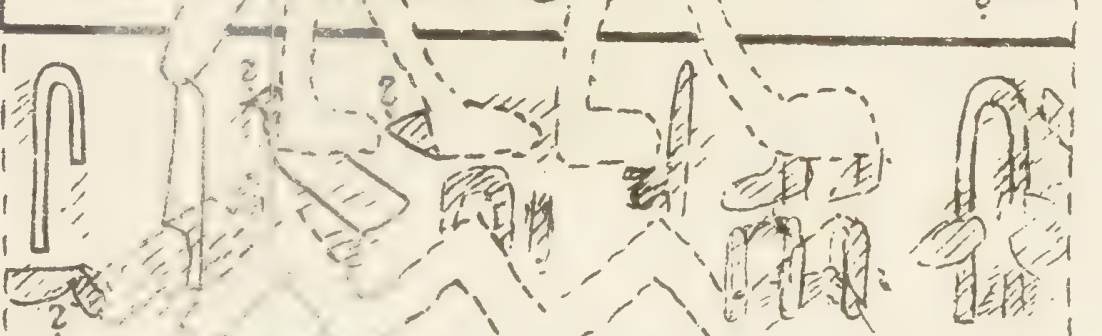

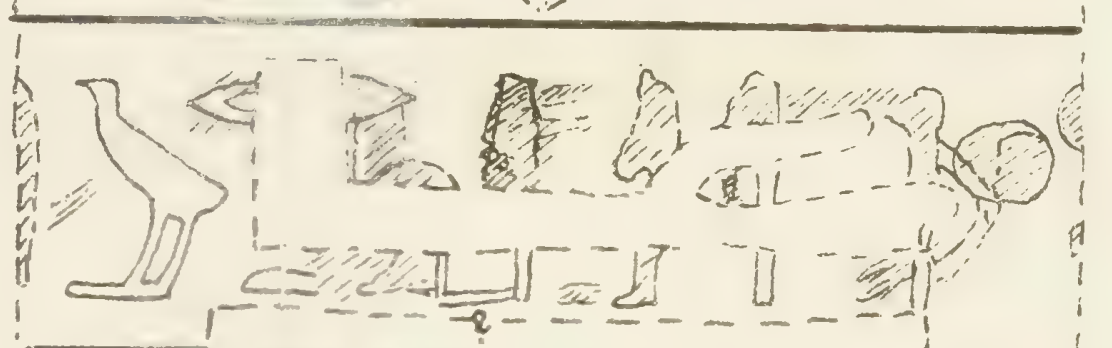

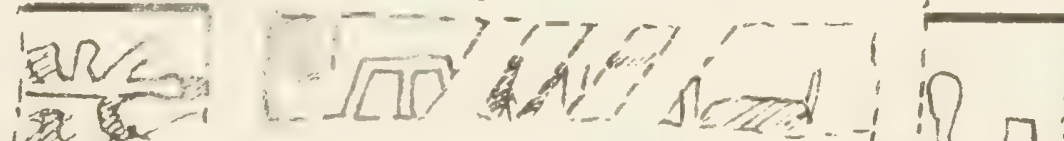

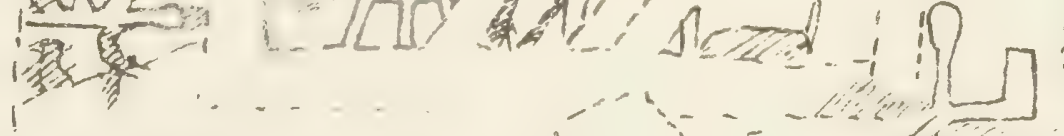

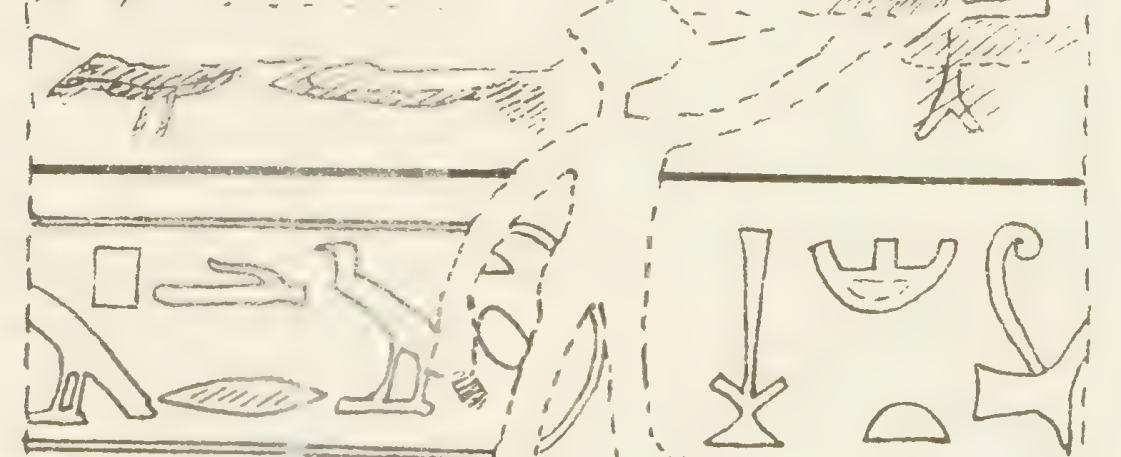

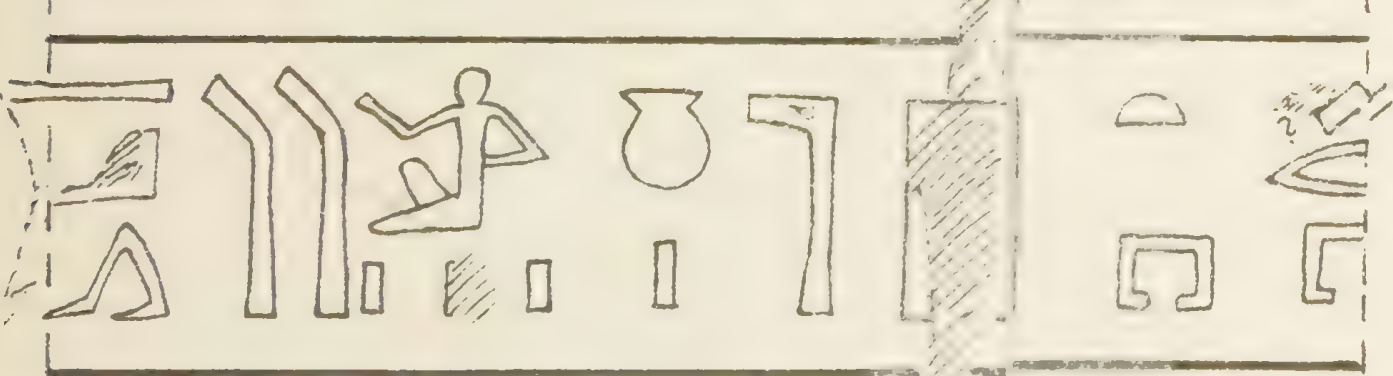

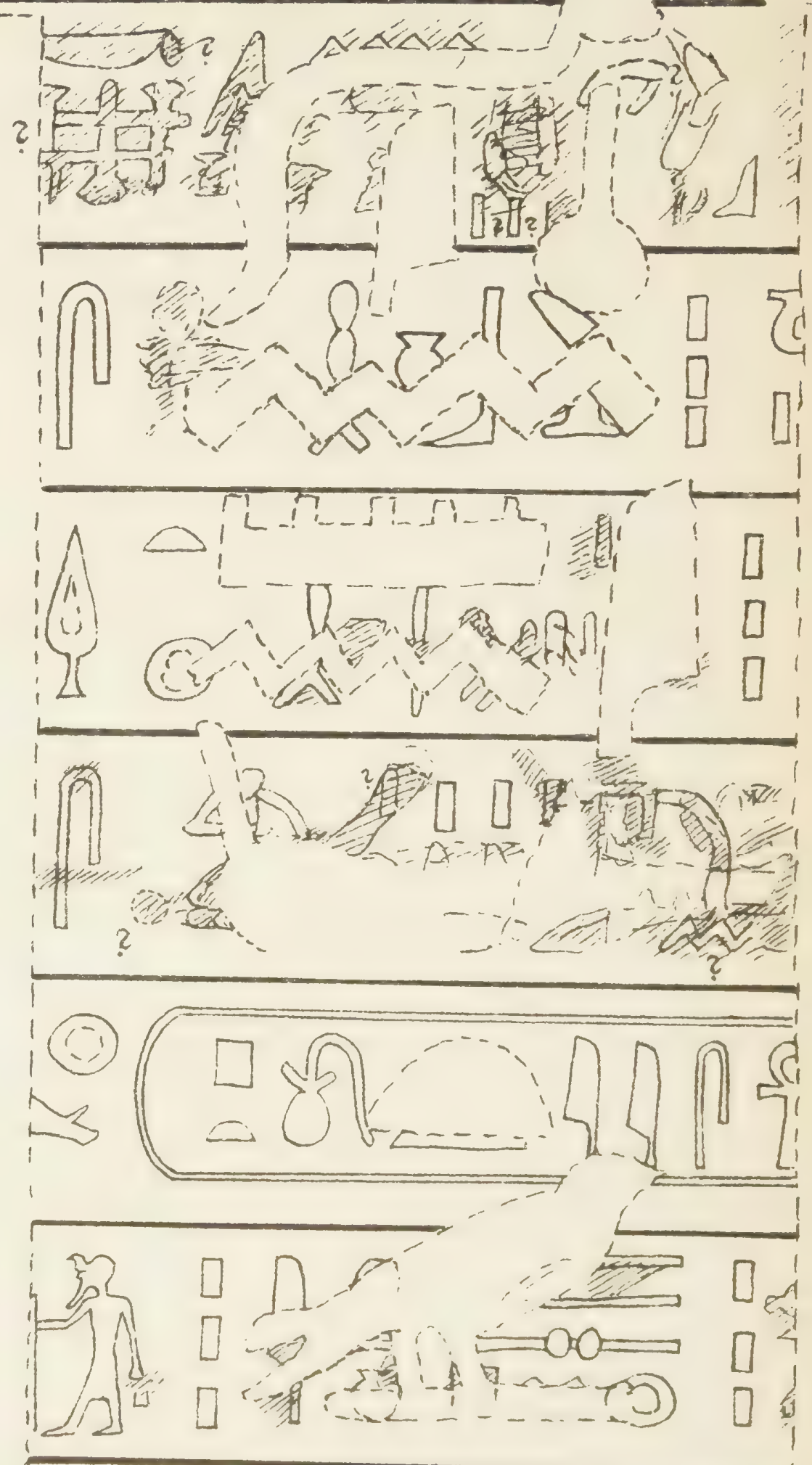


First Bilingual Decree of Philae, $c$ (upper half).

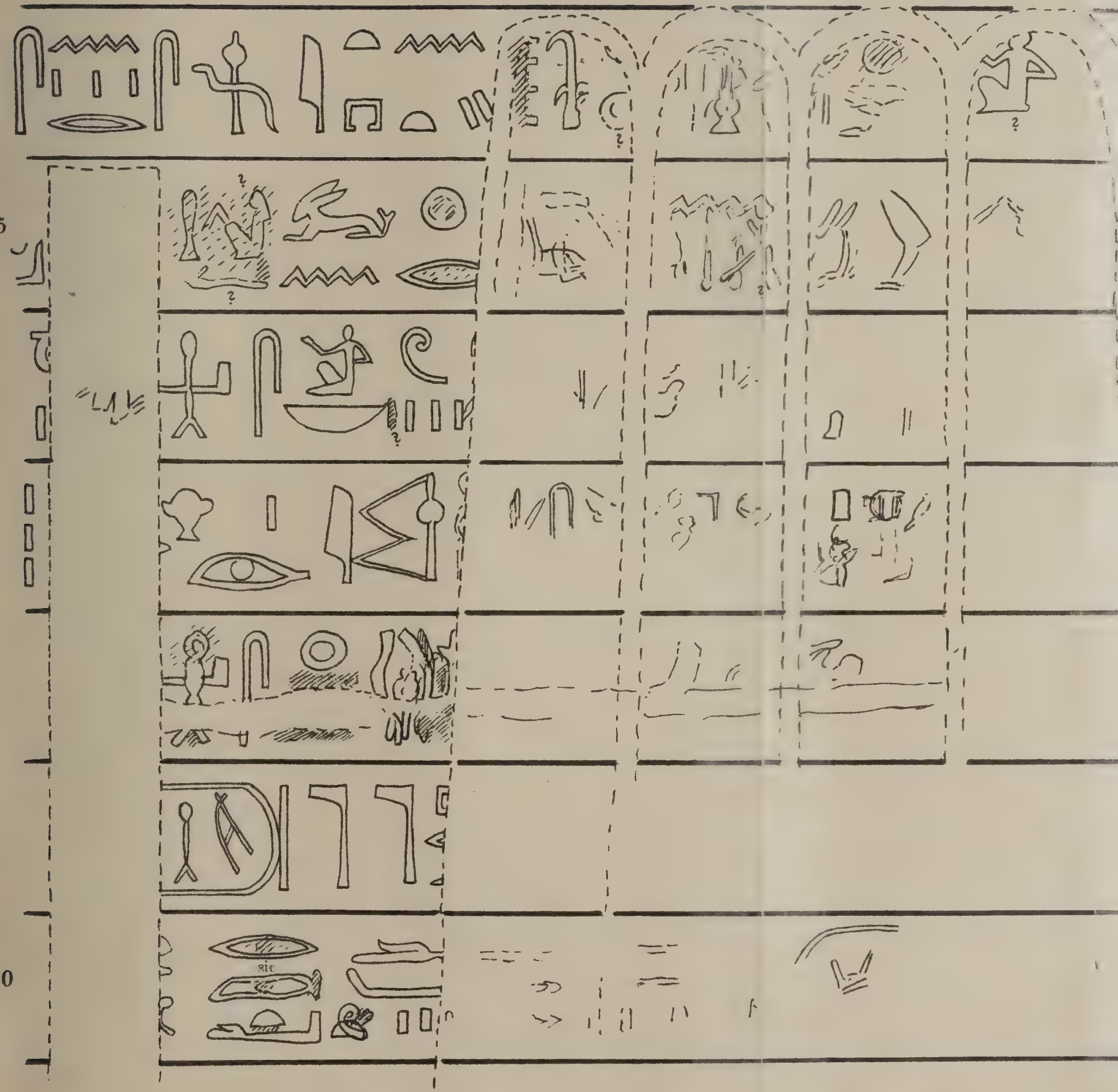




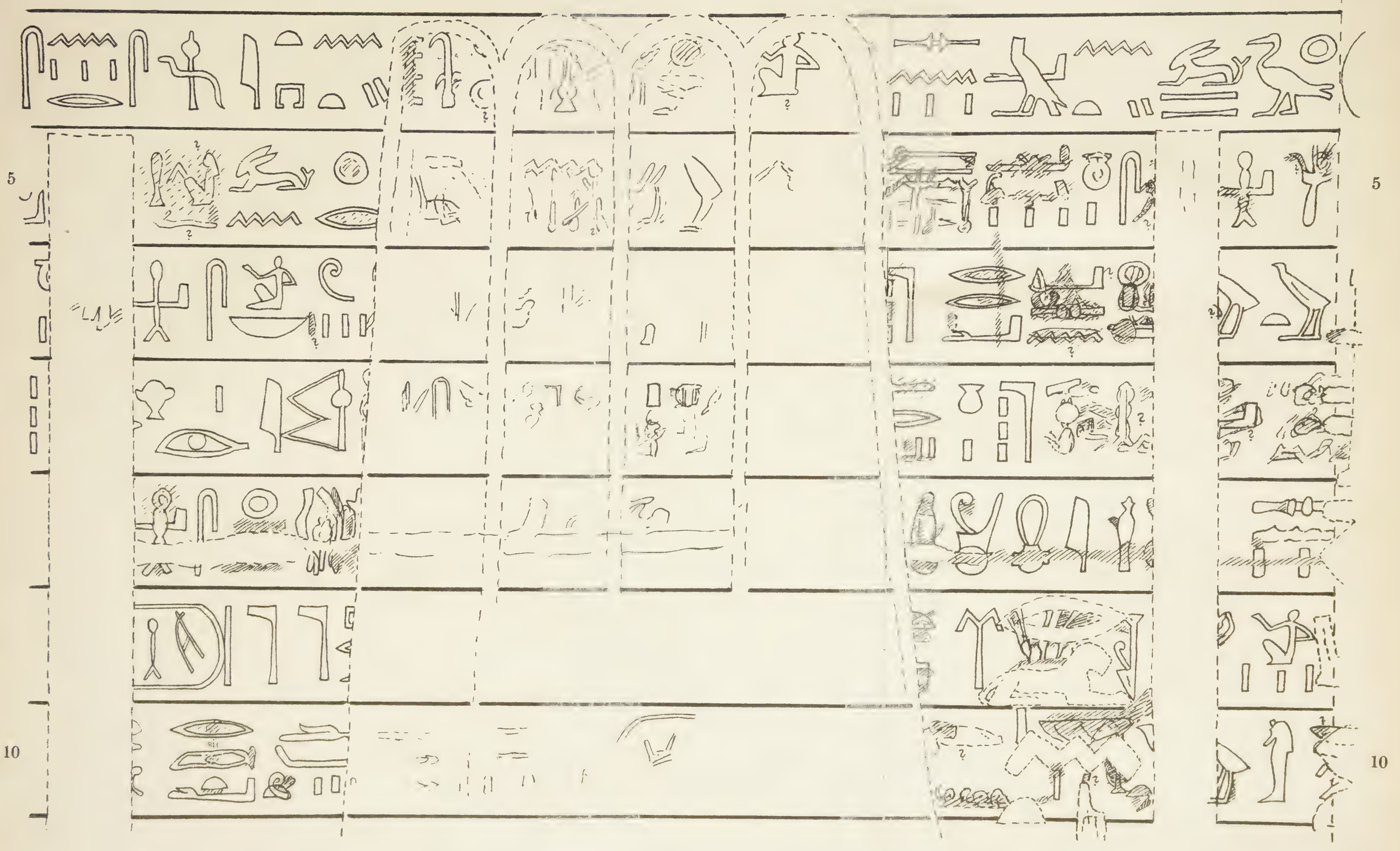


ecree of Philae, $d$ (upper half).
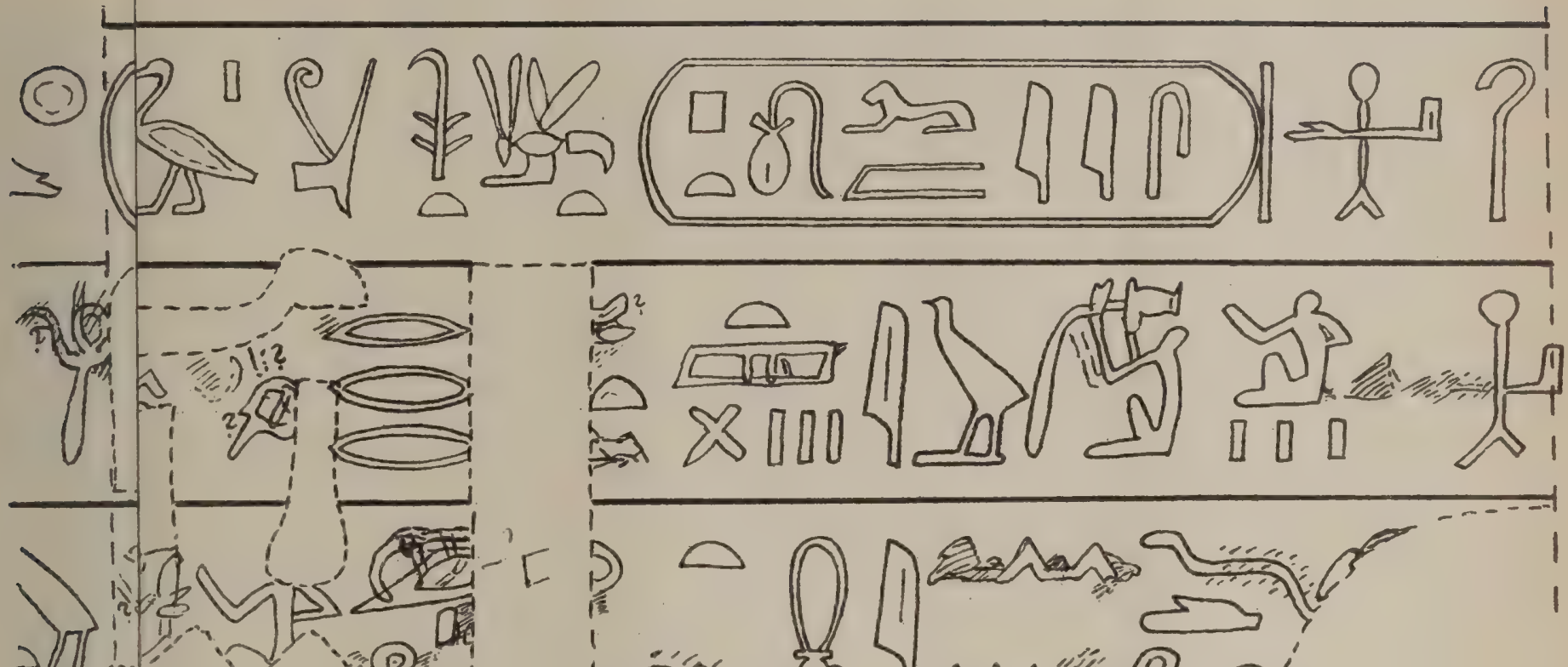

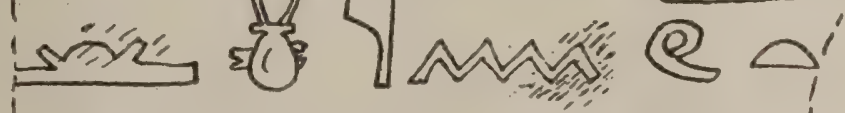

sid?

[

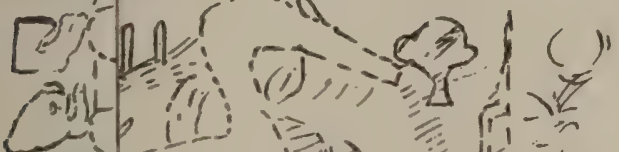

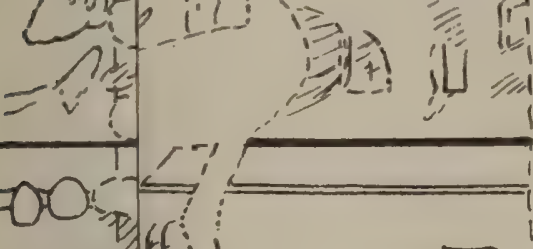

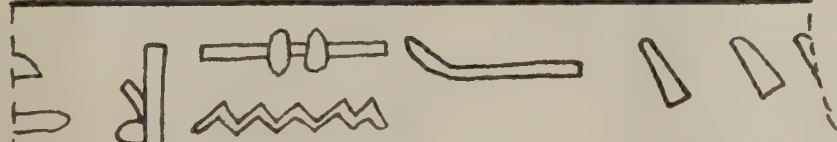

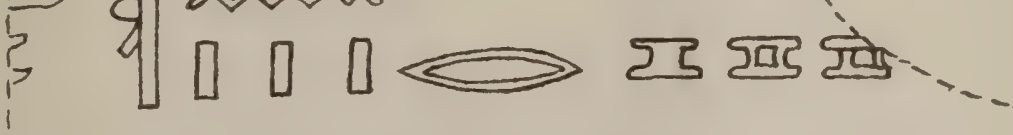

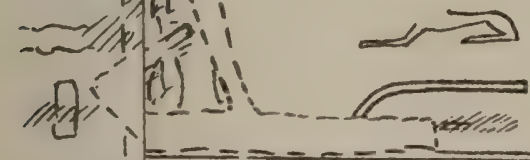

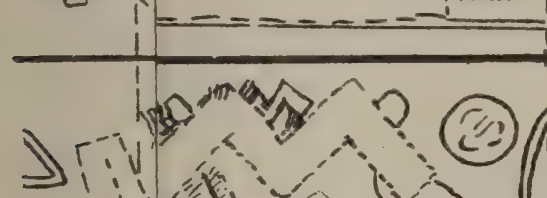

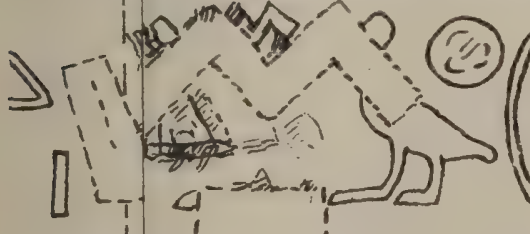

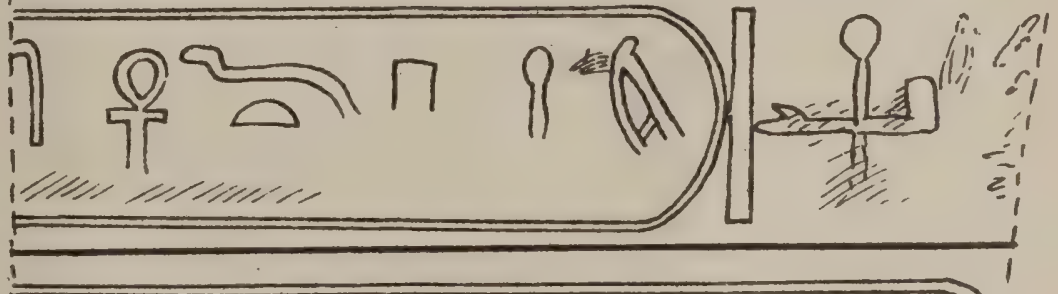

(2)

10

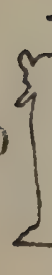

$\frac{1}{c}$

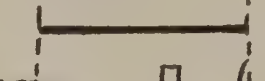




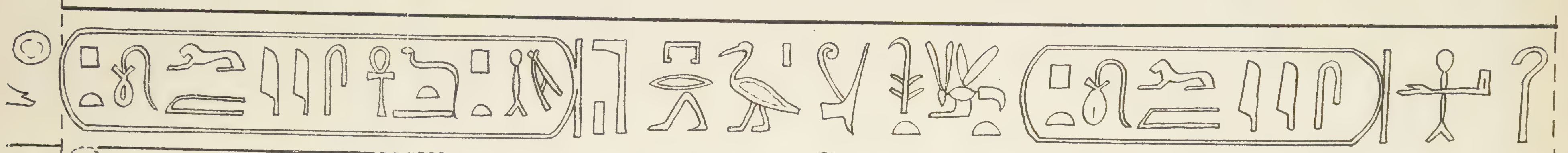

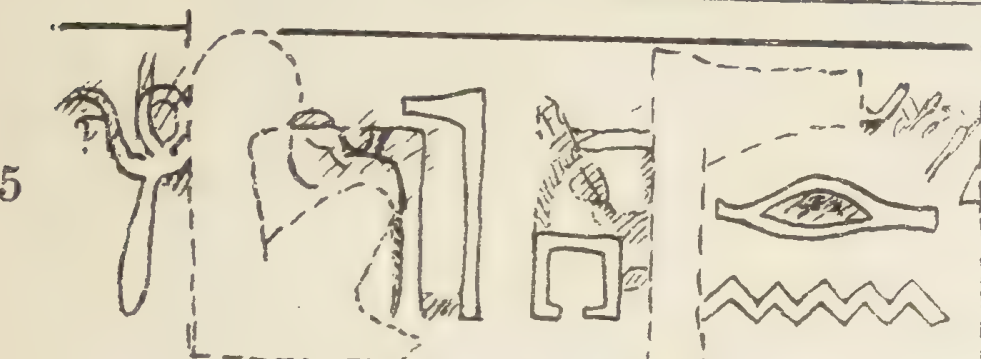

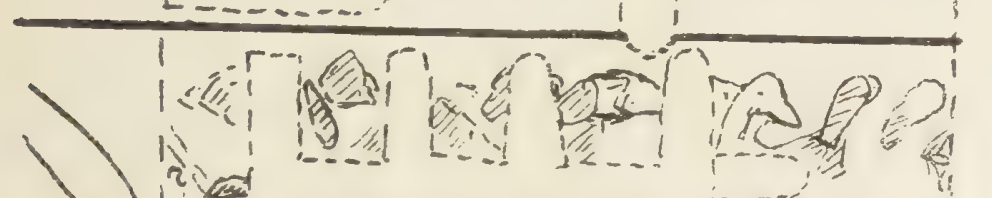

$\rightarrow \pi r^{2}$

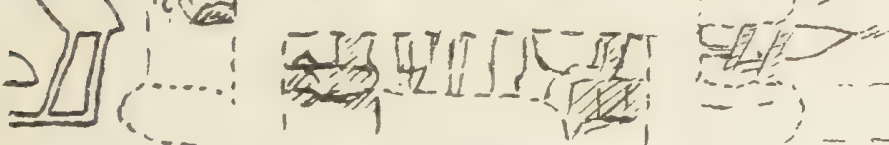

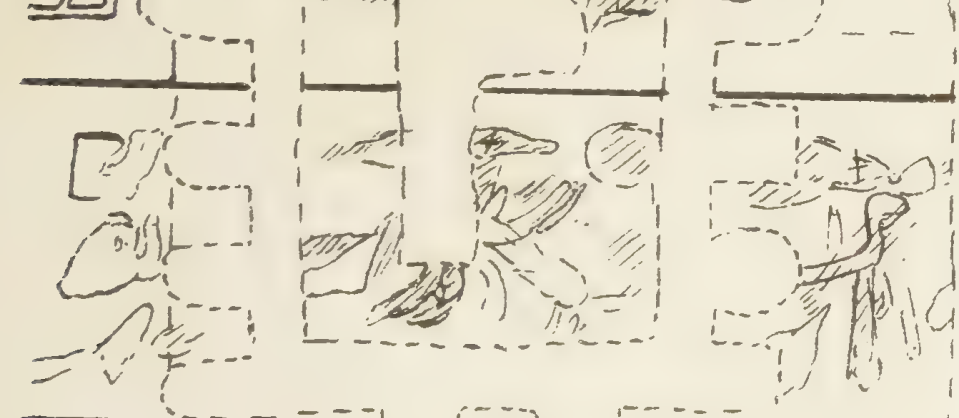

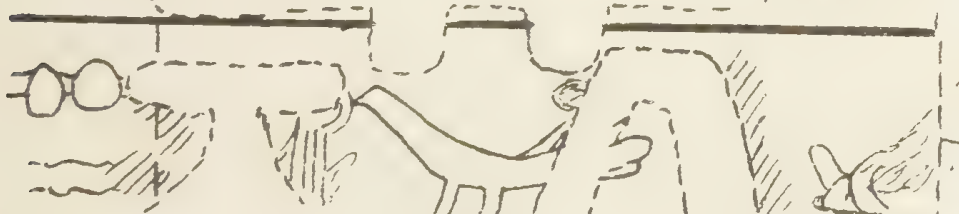
晾

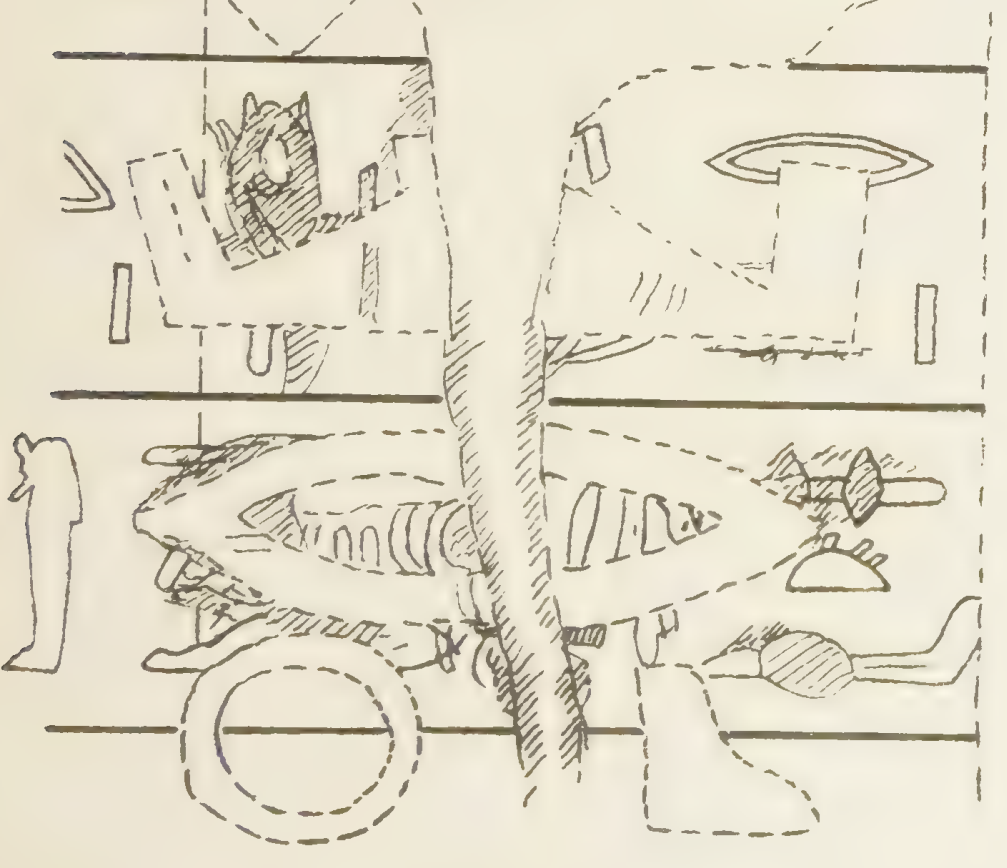

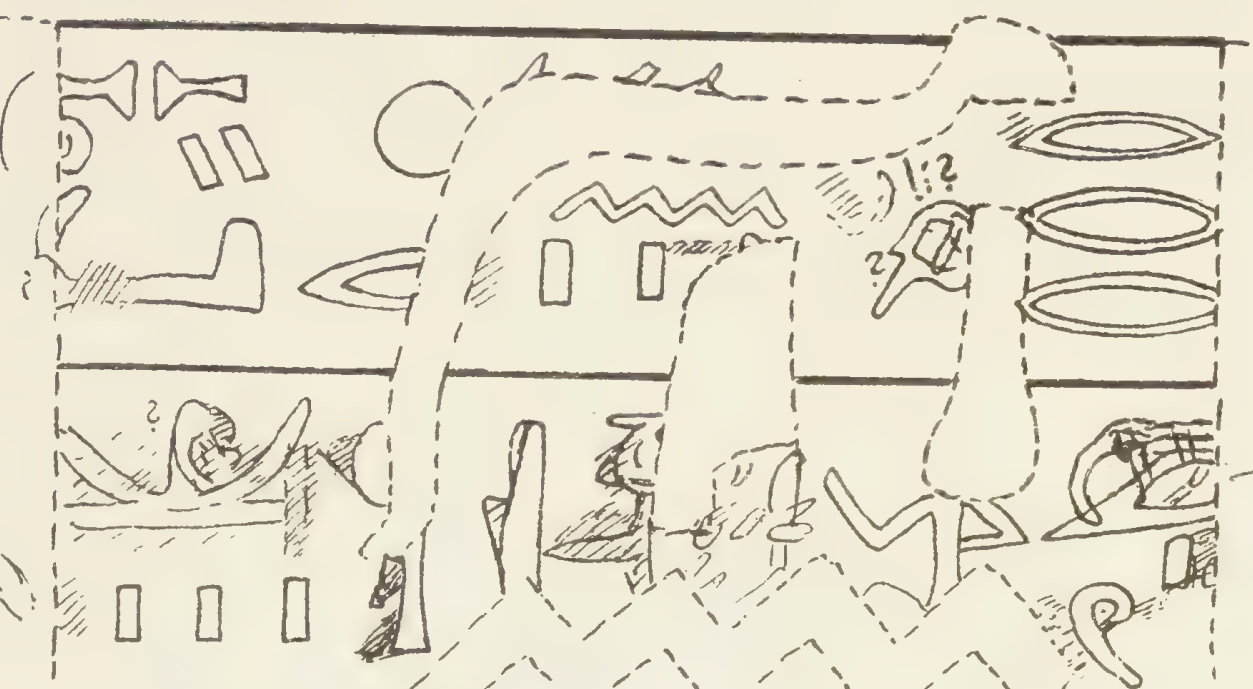

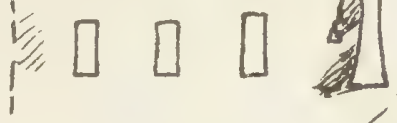

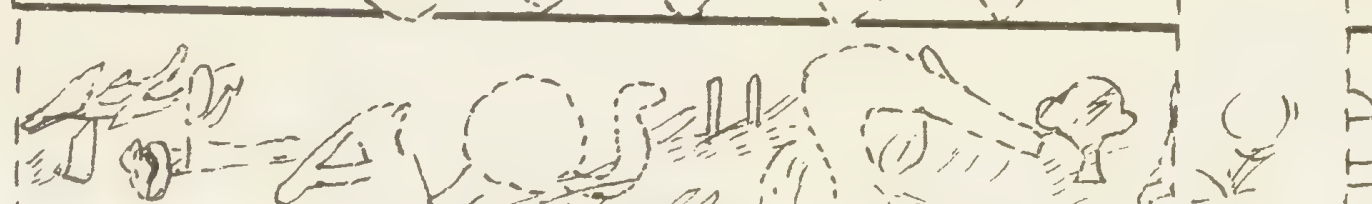

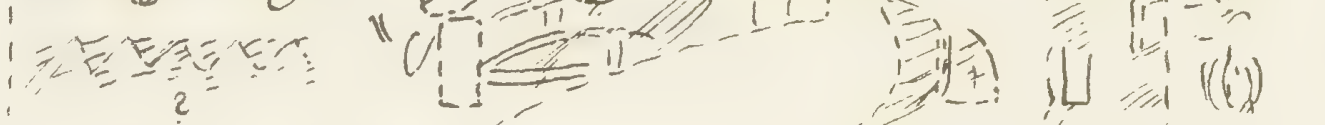

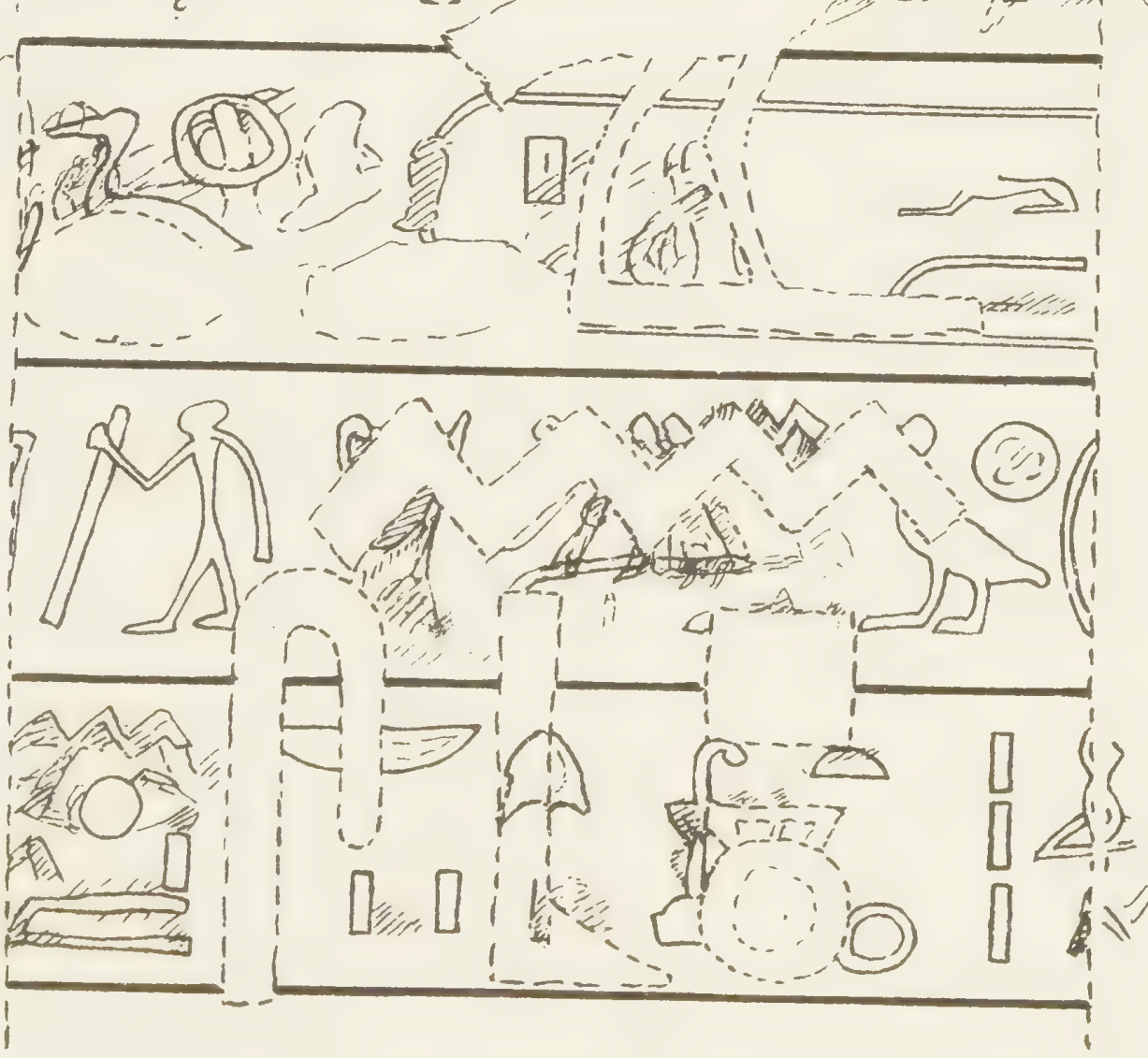

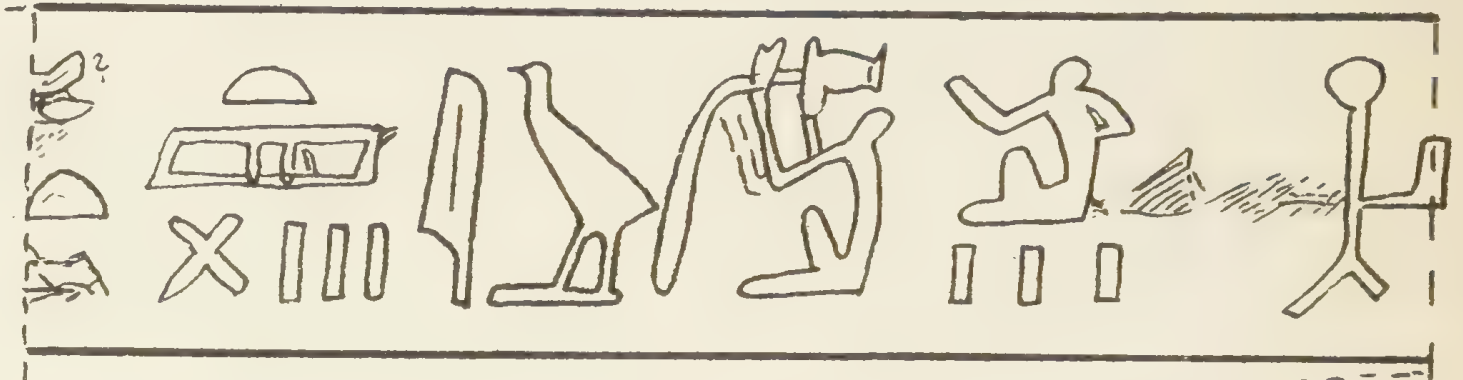

(P)

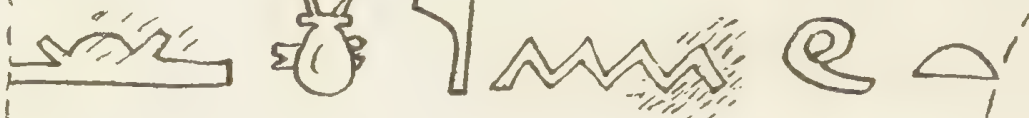
$\Rightarrow d$ 瓜

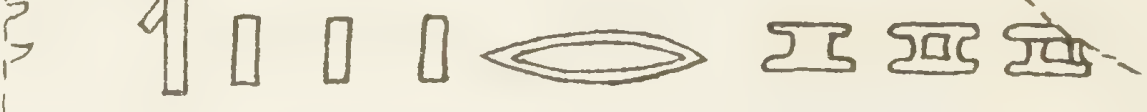
i. 1)

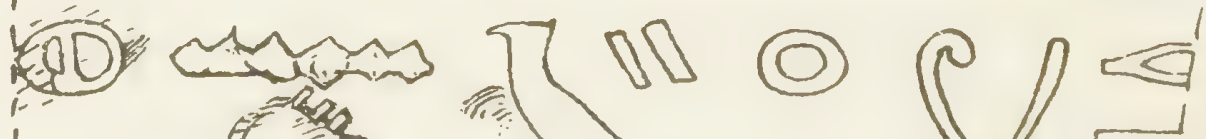

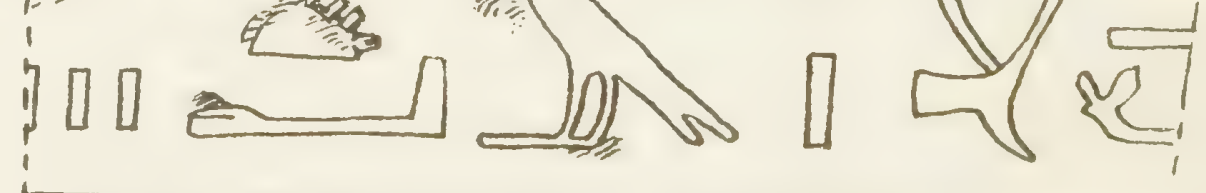


ecree of Philae, e (upper half).

P.
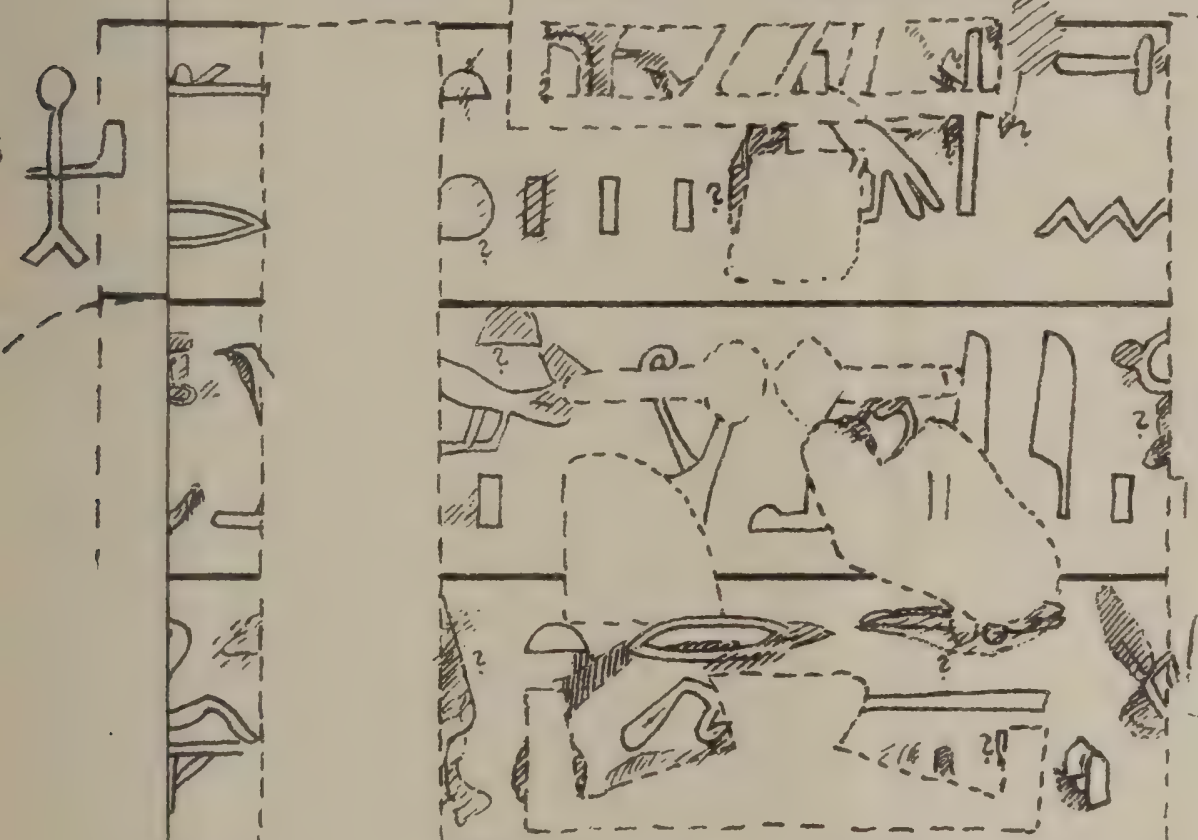
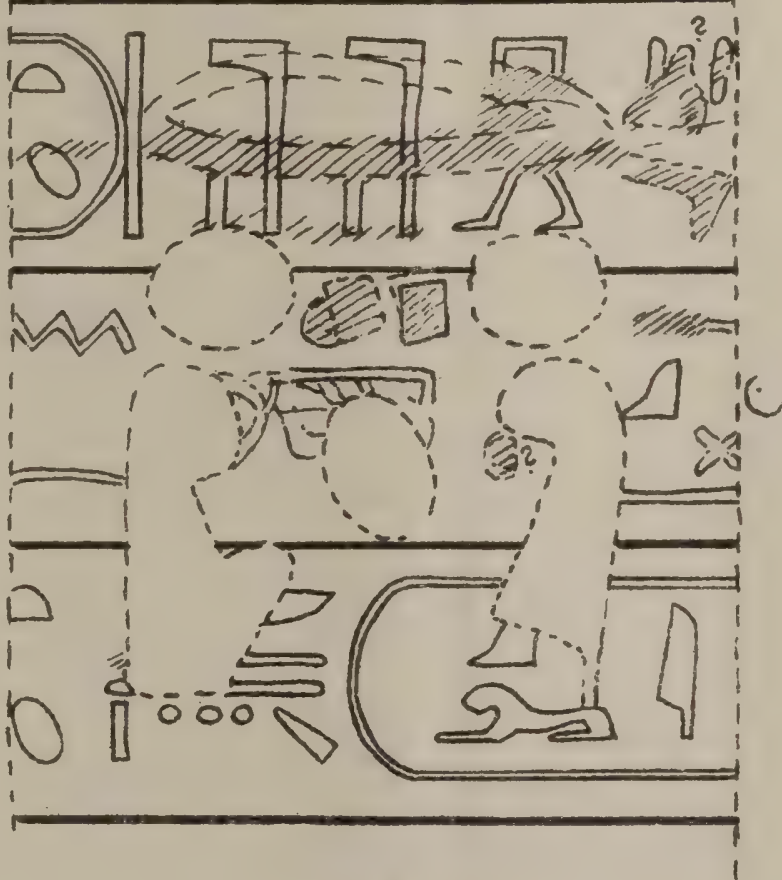

n.

? 4 ?

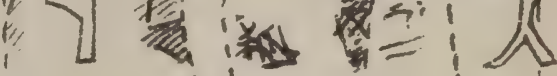
एका (20) 남,

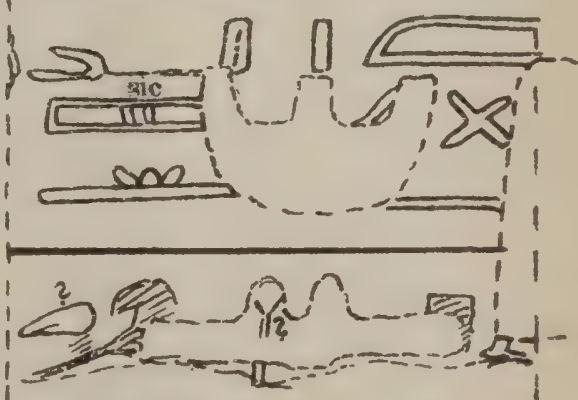

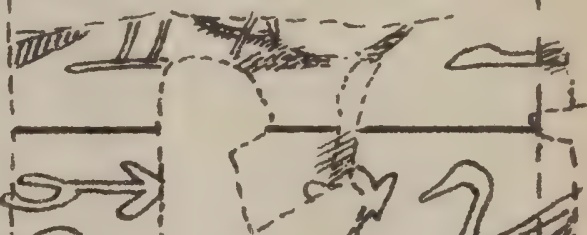
(2) 4 a is 4 , on

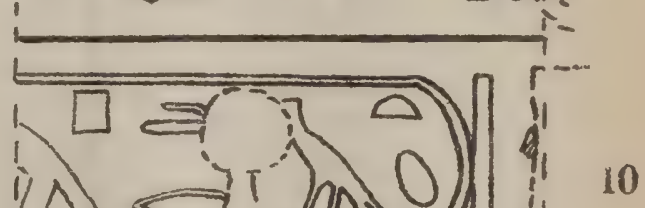

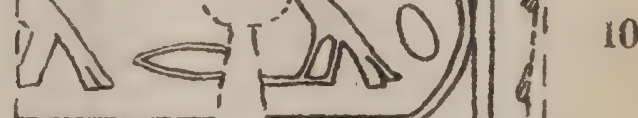

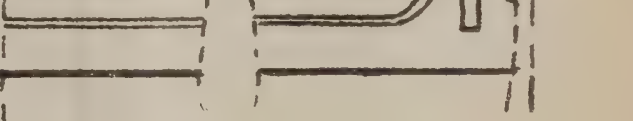



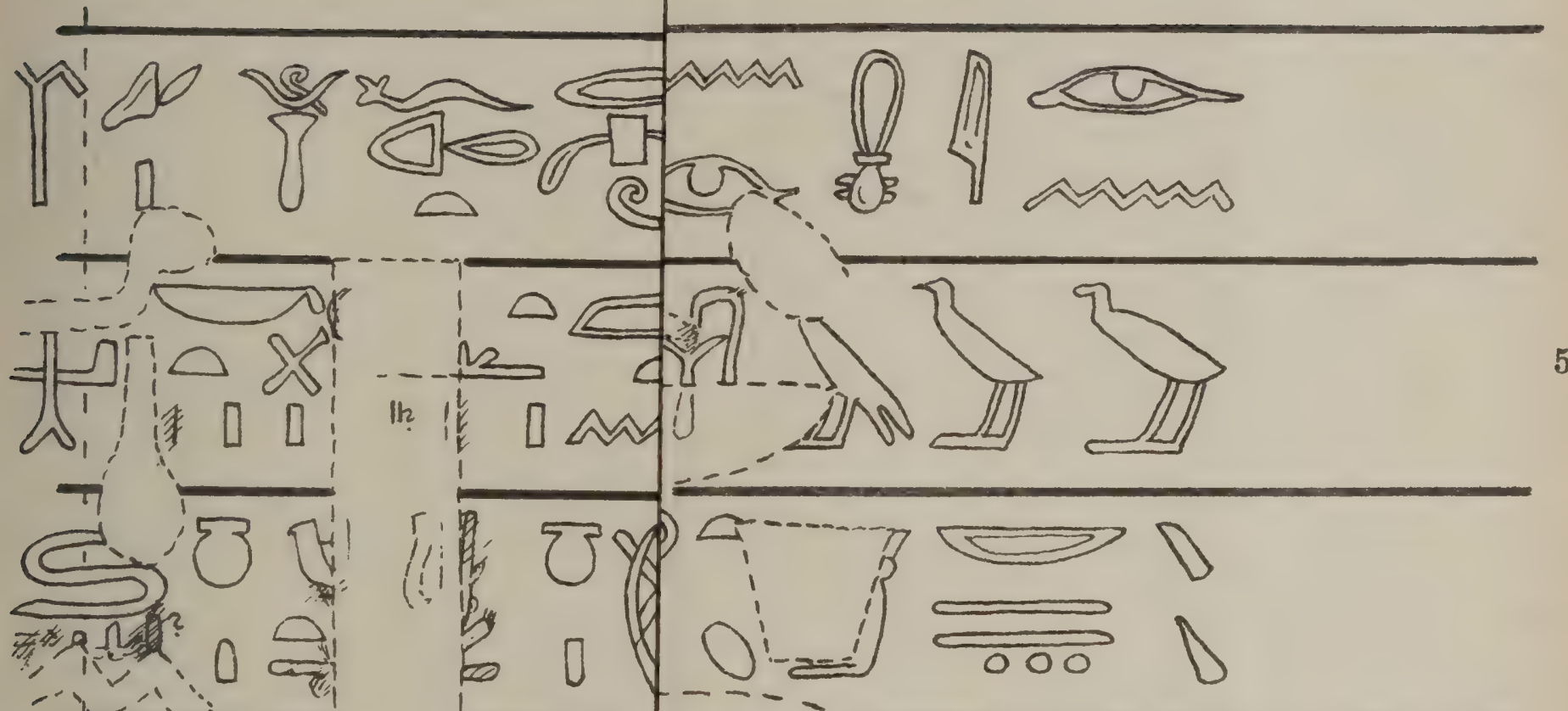

紧监 1 a

2) NDN

2

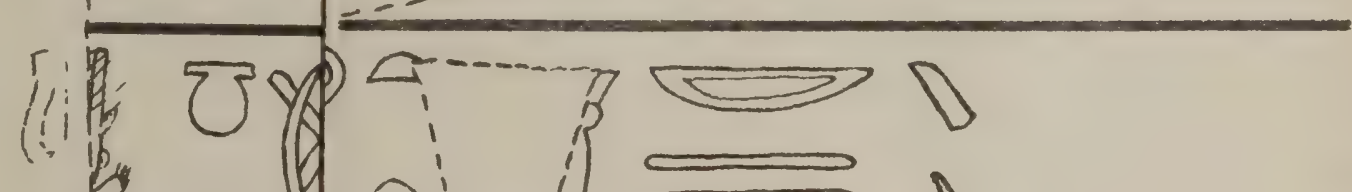

,

政 $D$

2 of

$i_{i,-1}$

in

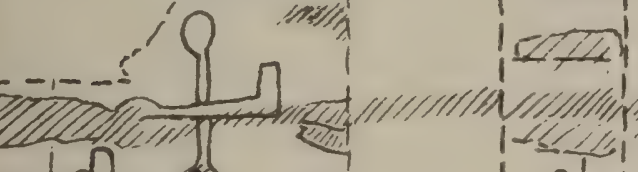

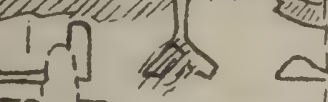

to.

s 10 गार्य

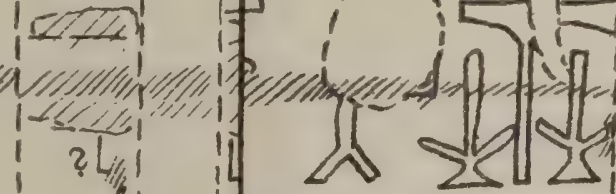

iLly in a $2<\sum S_{1}$

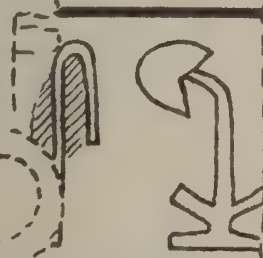

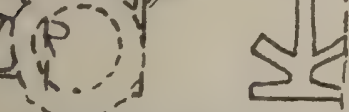

IIII

(1)

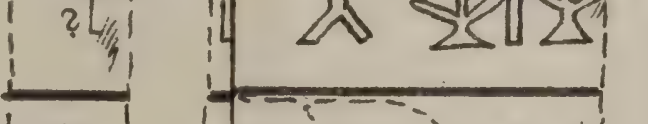

Sa

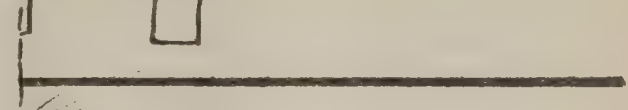

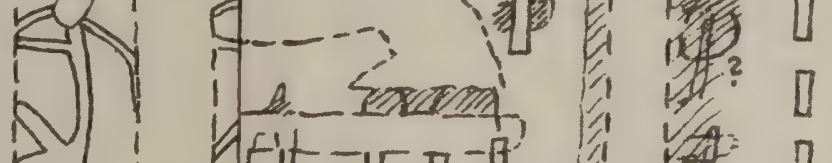

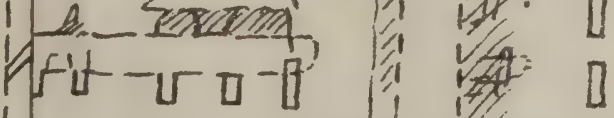

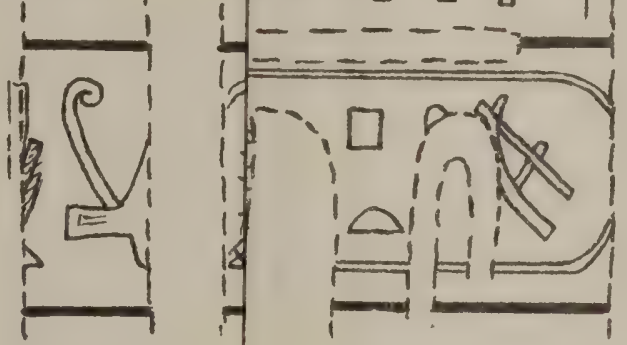




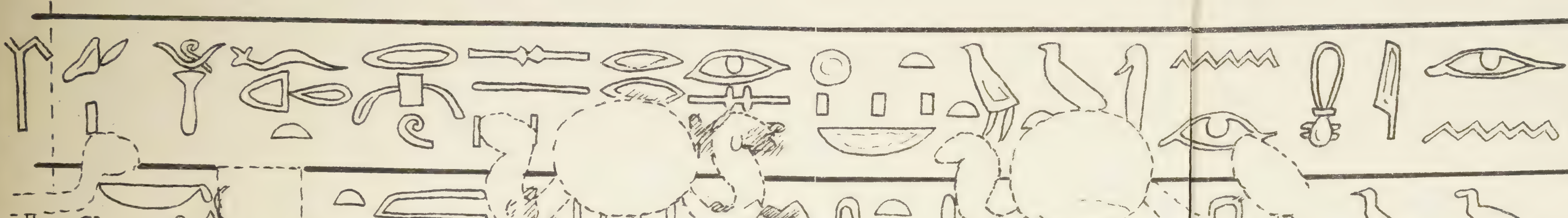

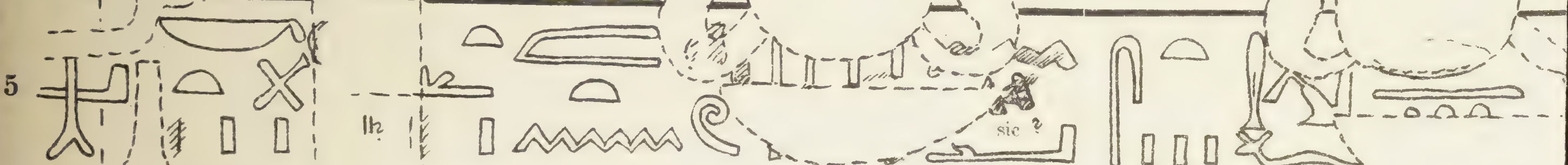
W. C他! 类然基, 0 - 1 p ond P 10 1,4 1 $\sim 10$

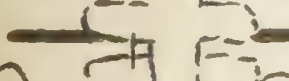
Ui! 3

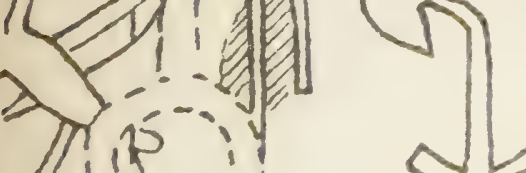
2.1
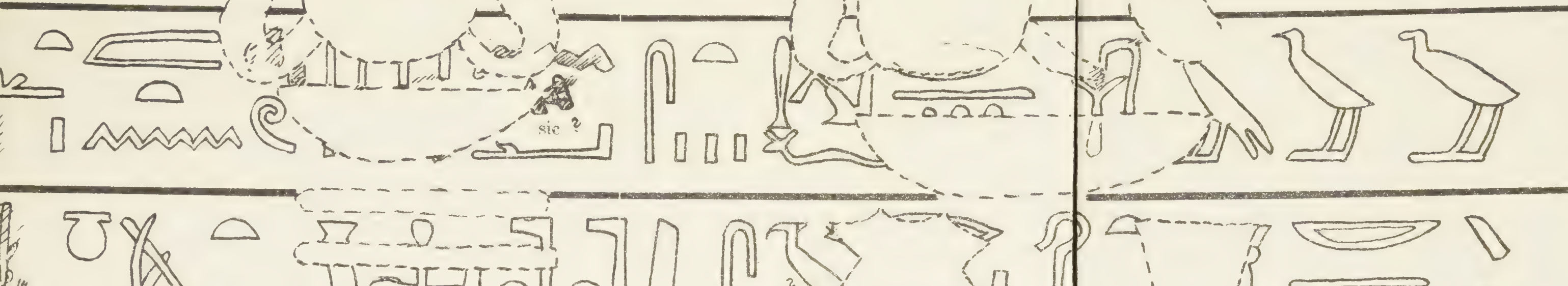
\&

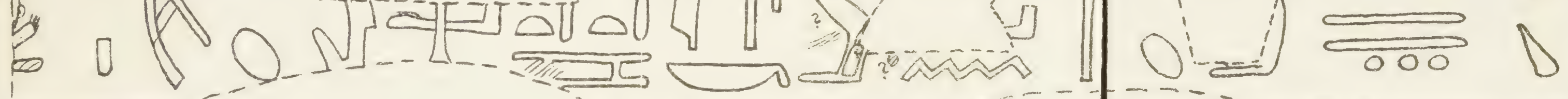

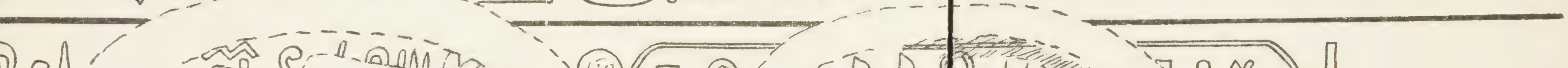

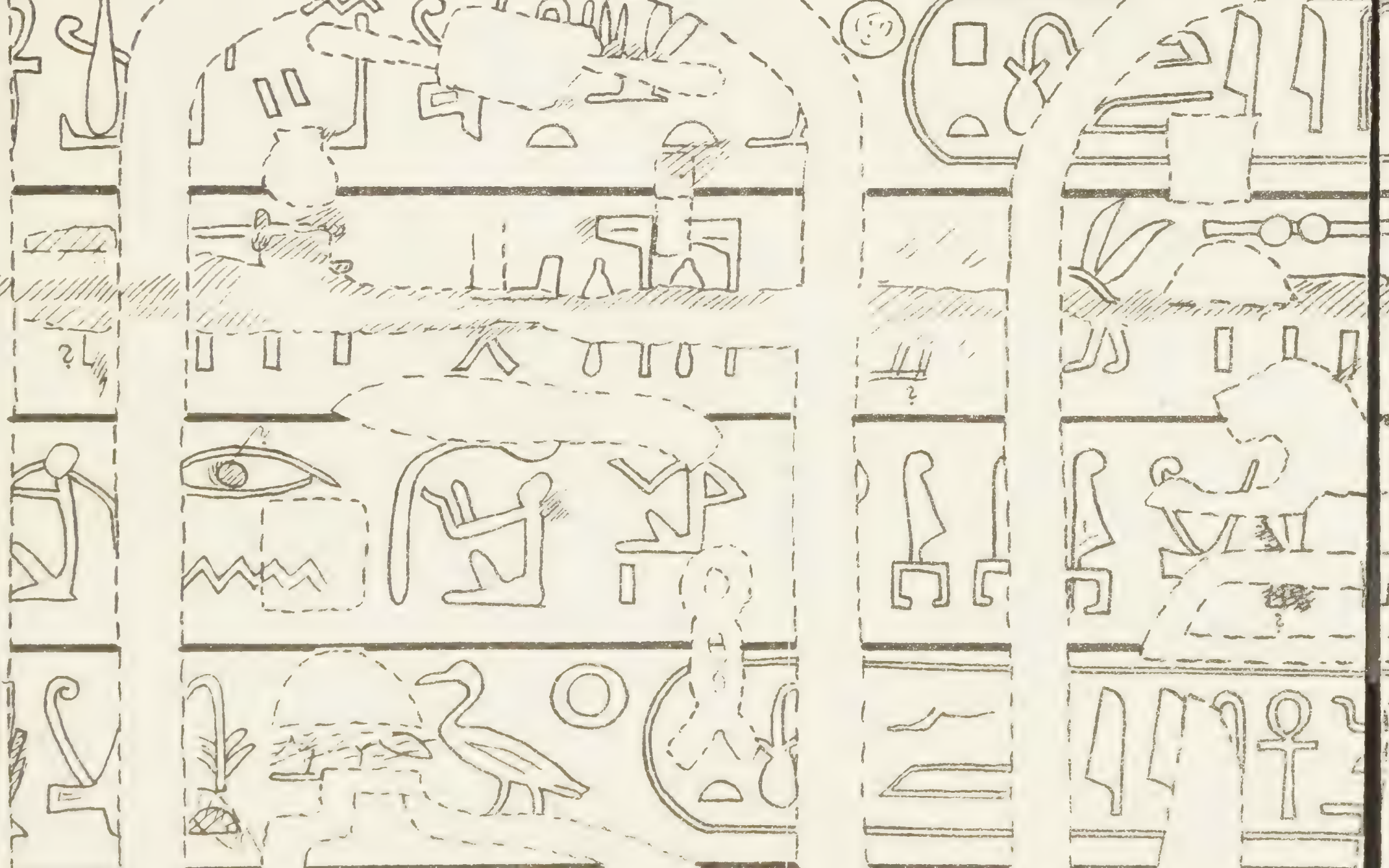

$\int \frac{1}{4}$

10
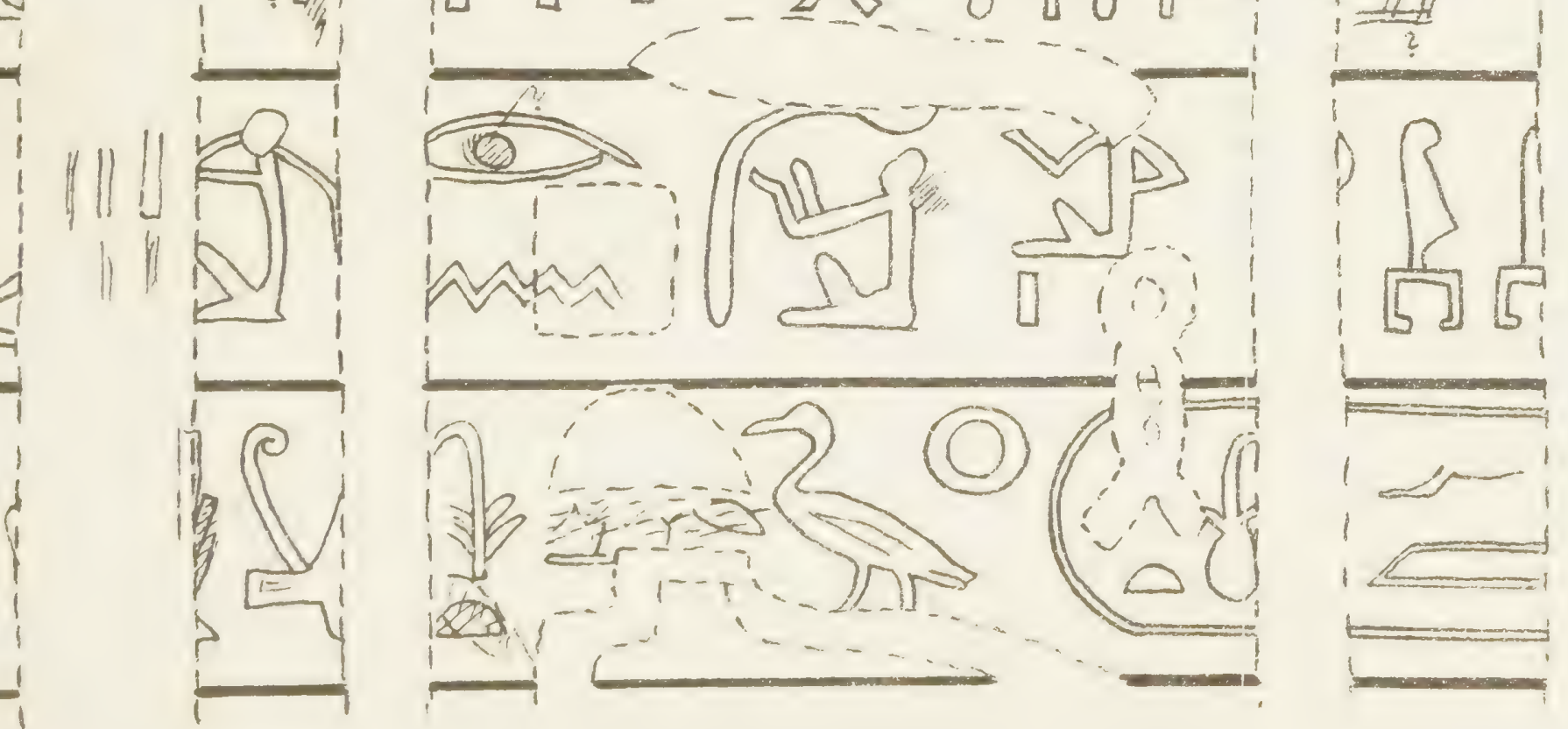
9,

$i$ E

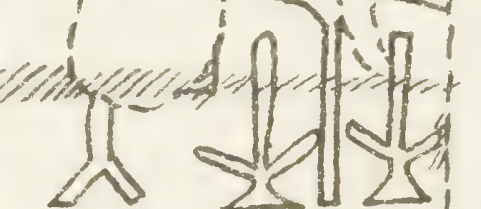

ก ……

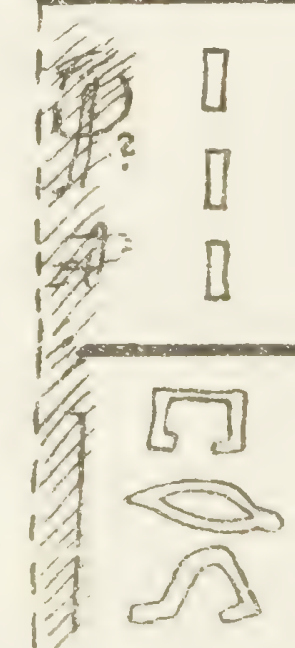



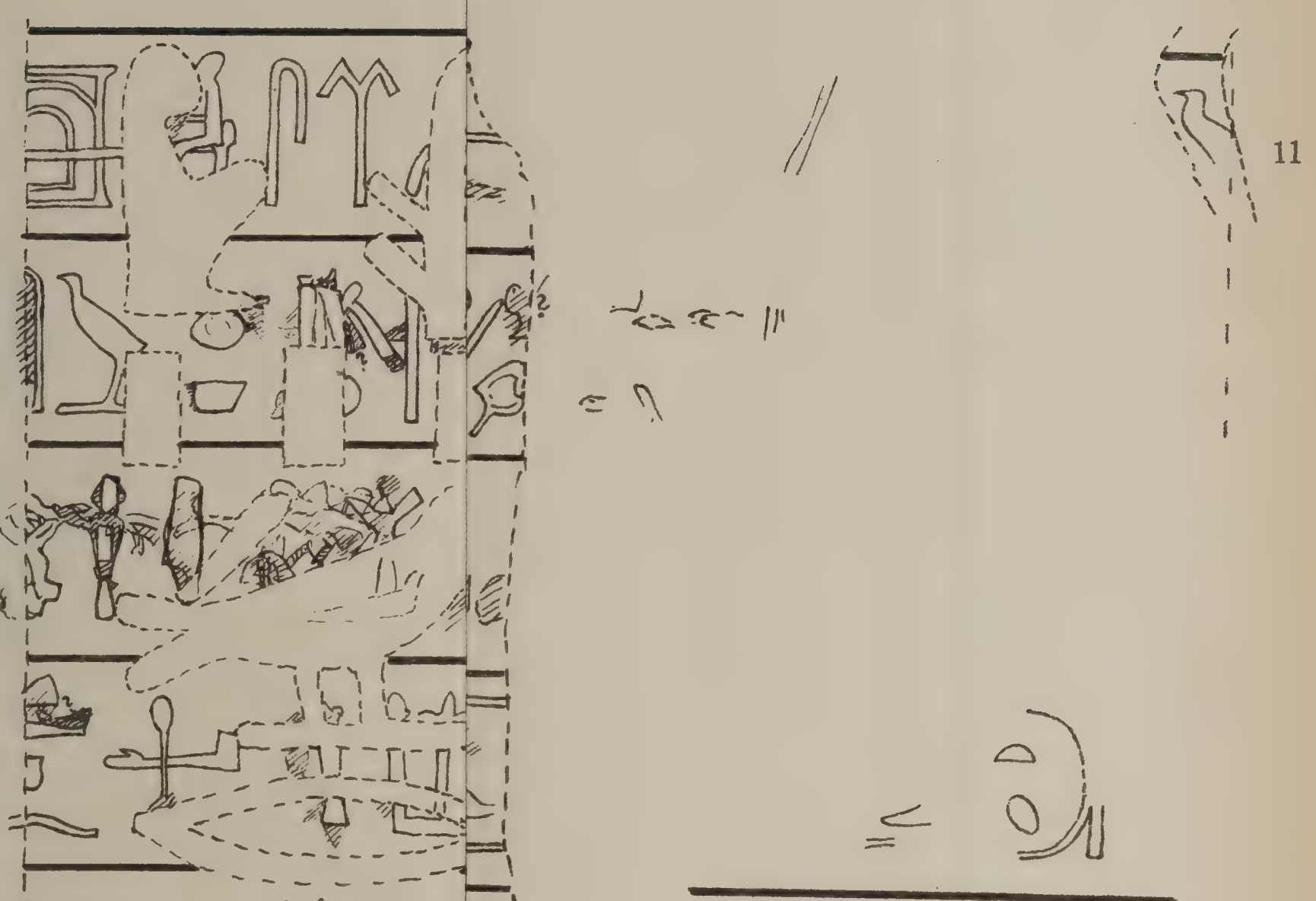

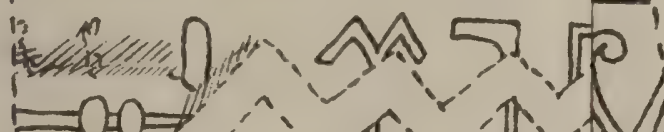

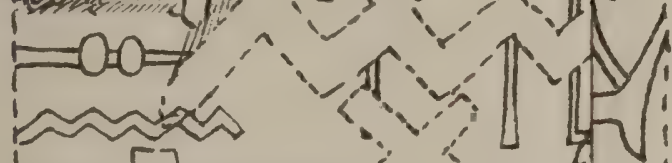

(e)

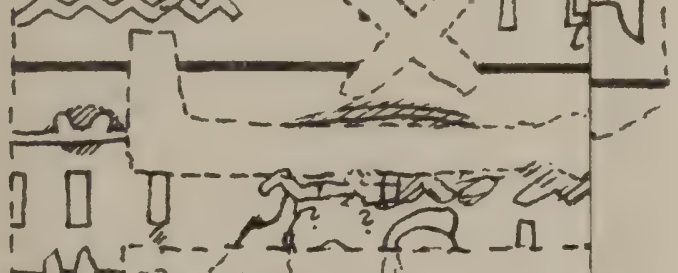

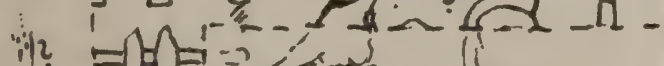

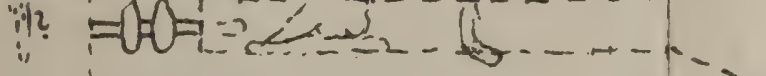
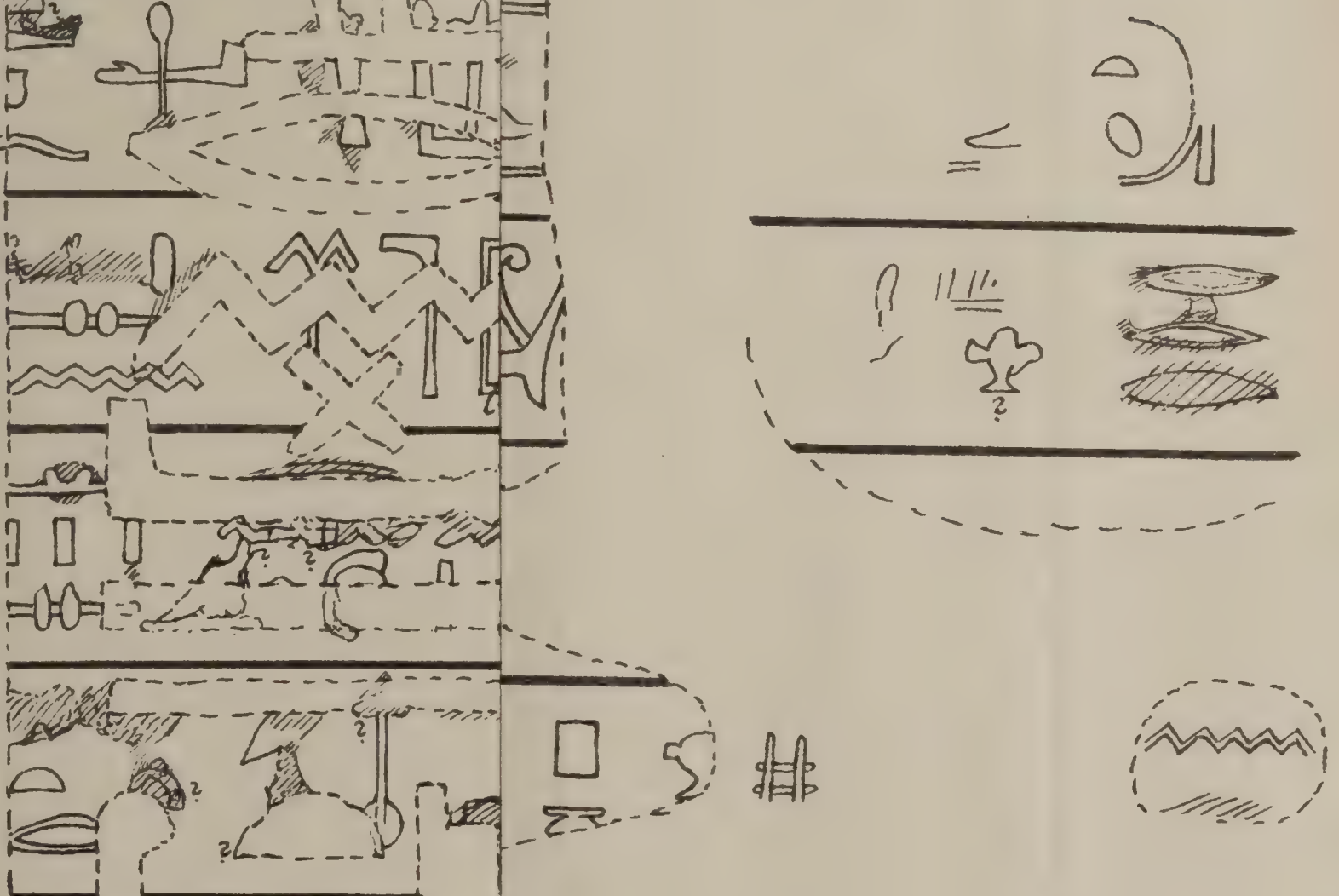

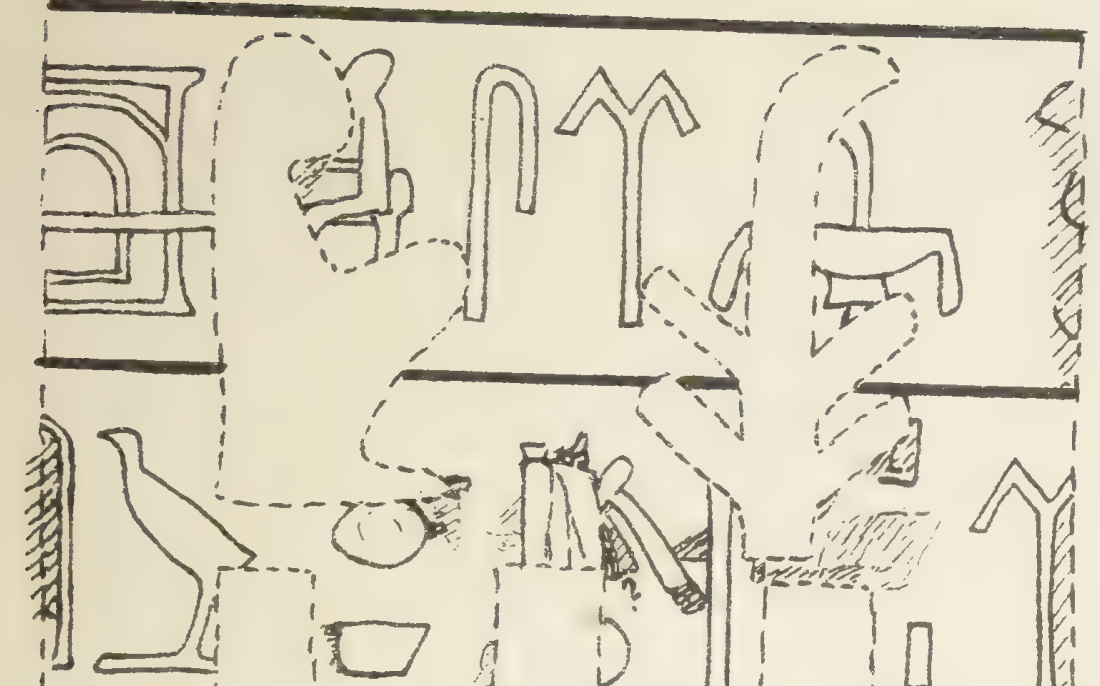
$\square \quad 10$ ?

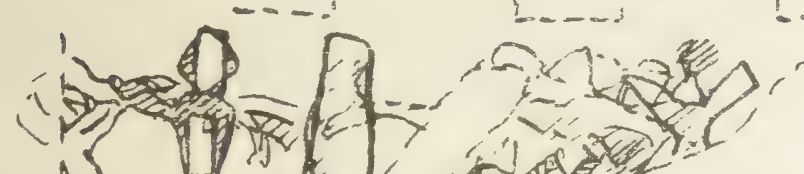

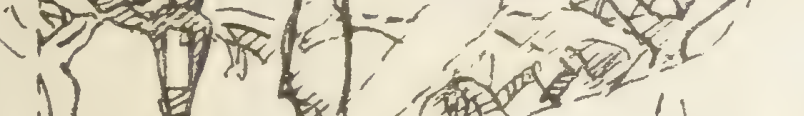

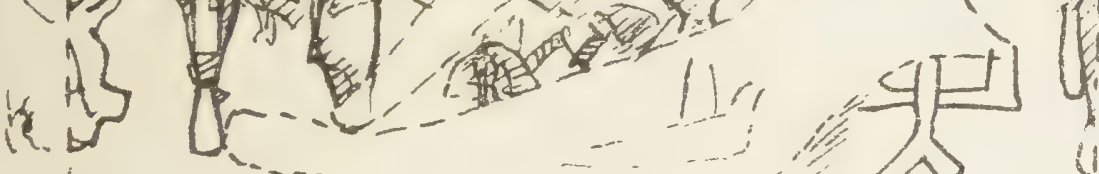

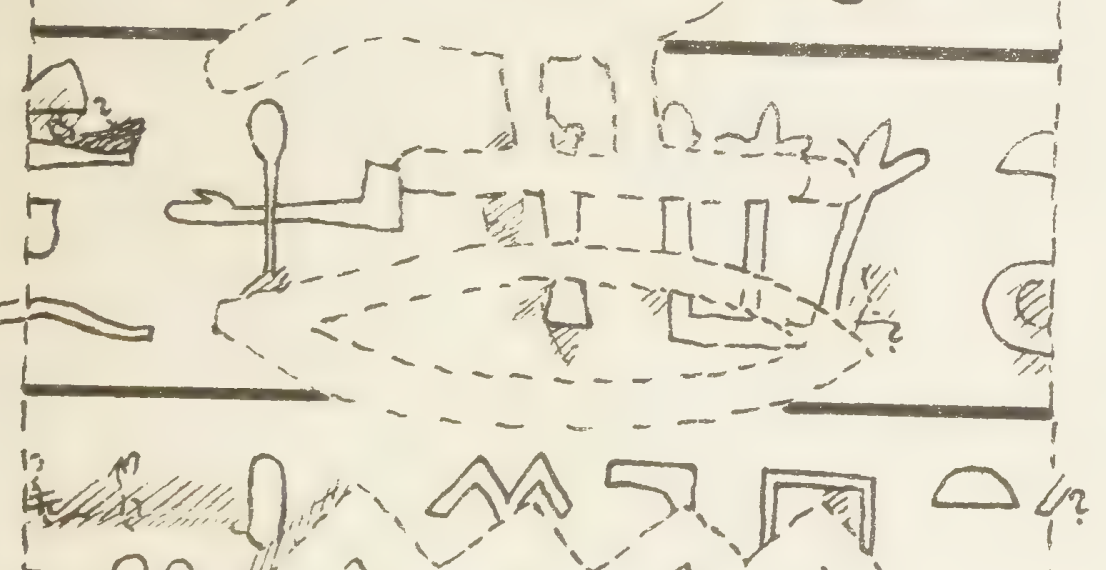

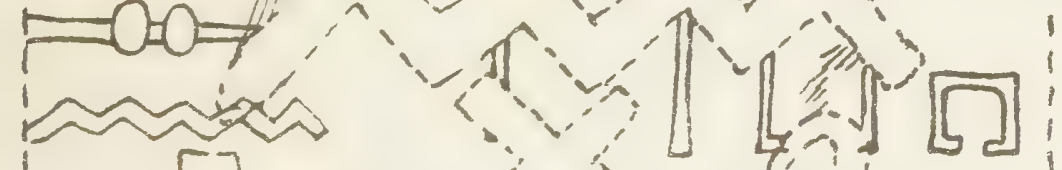
Den 政

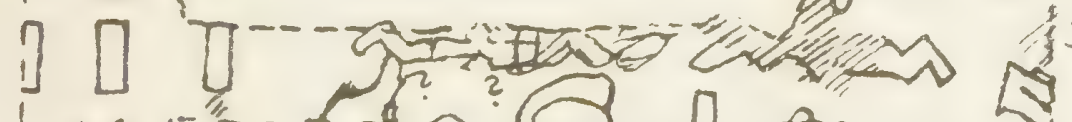

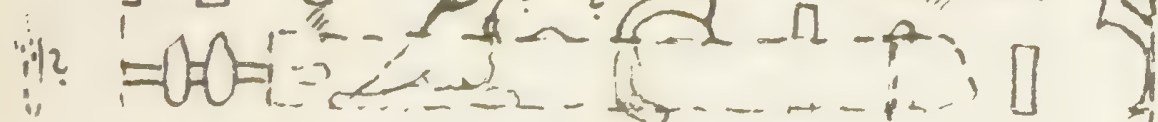

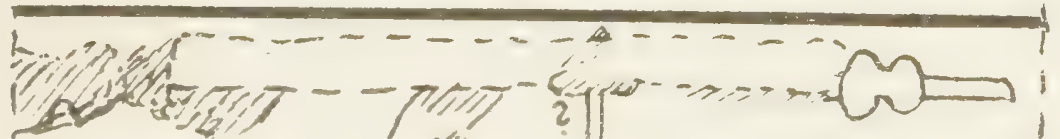
$\infty$ 瓷

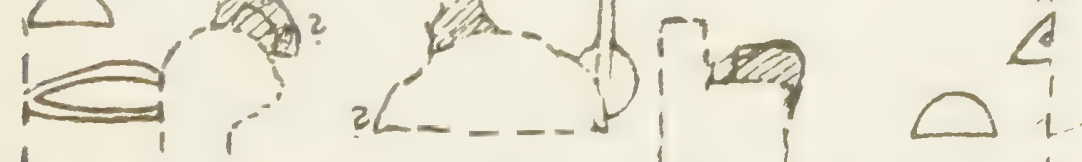

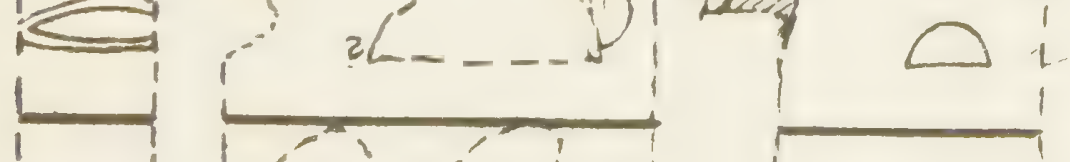
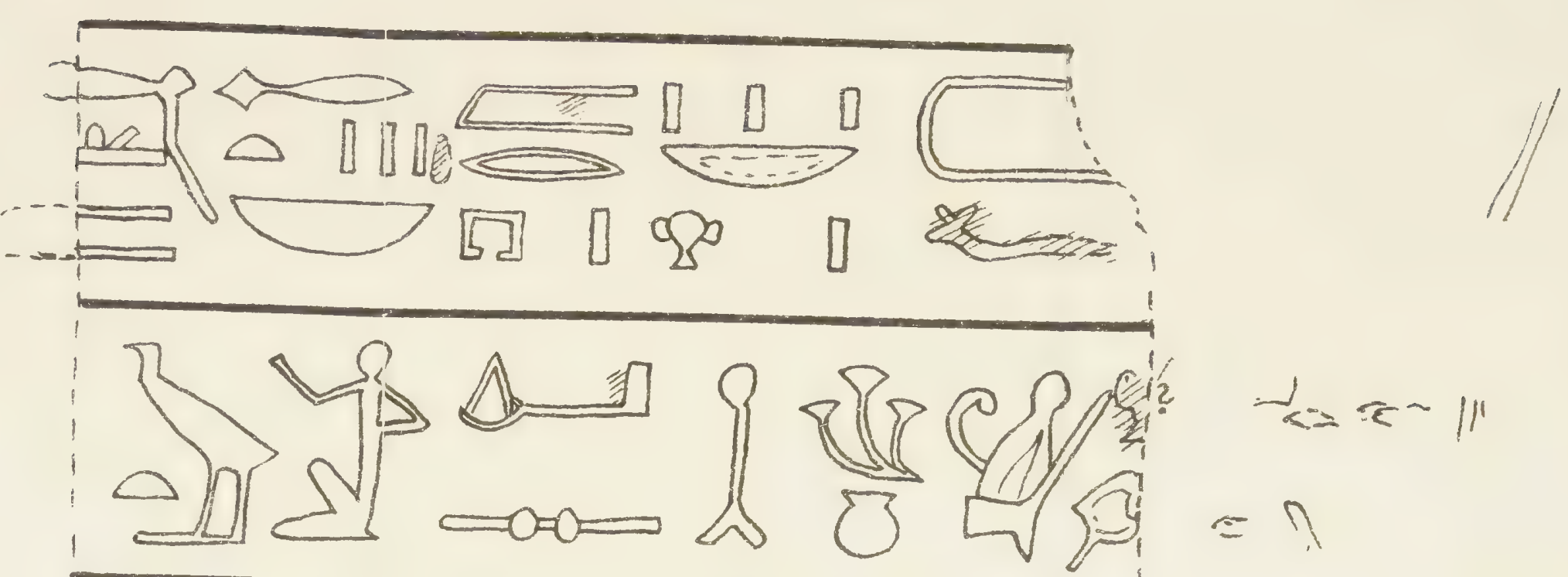

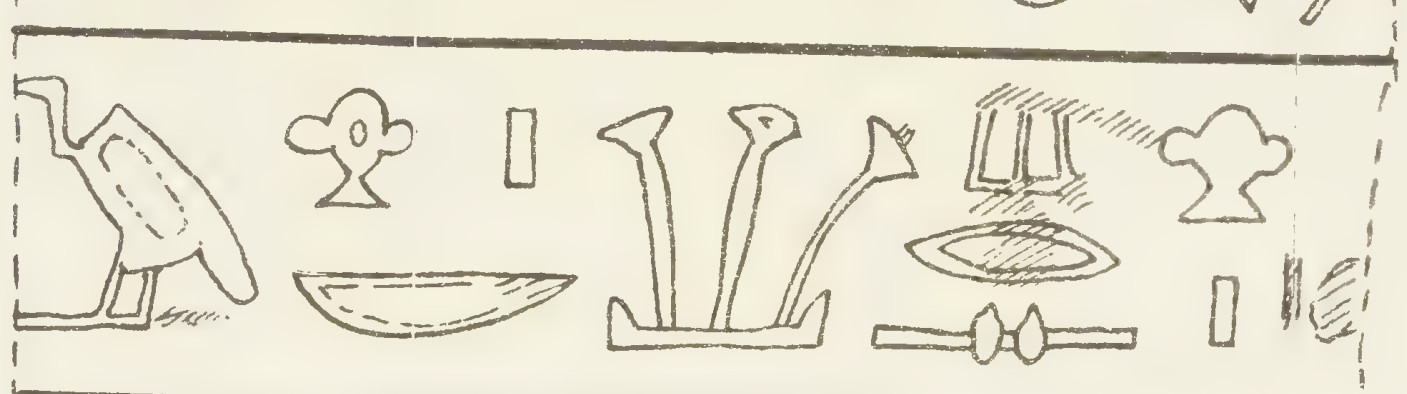

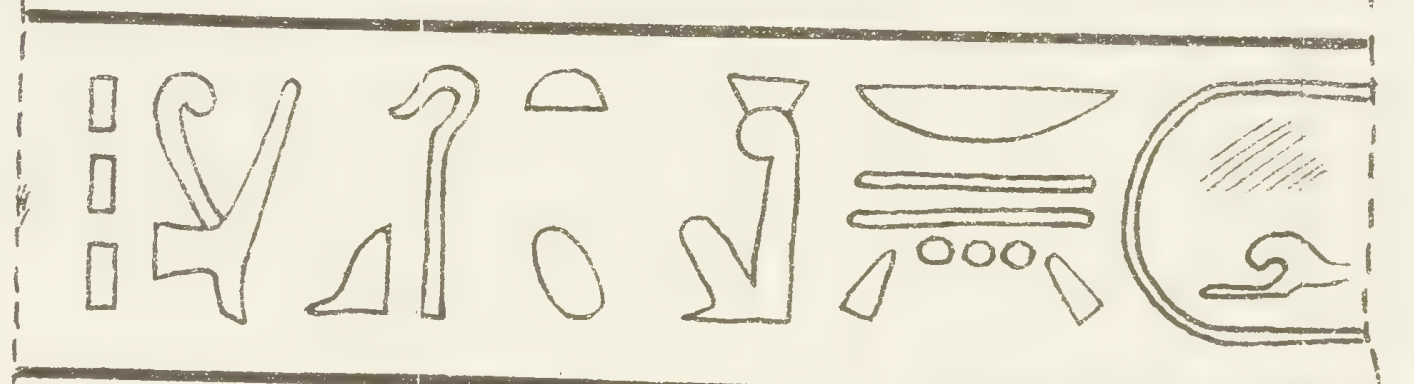

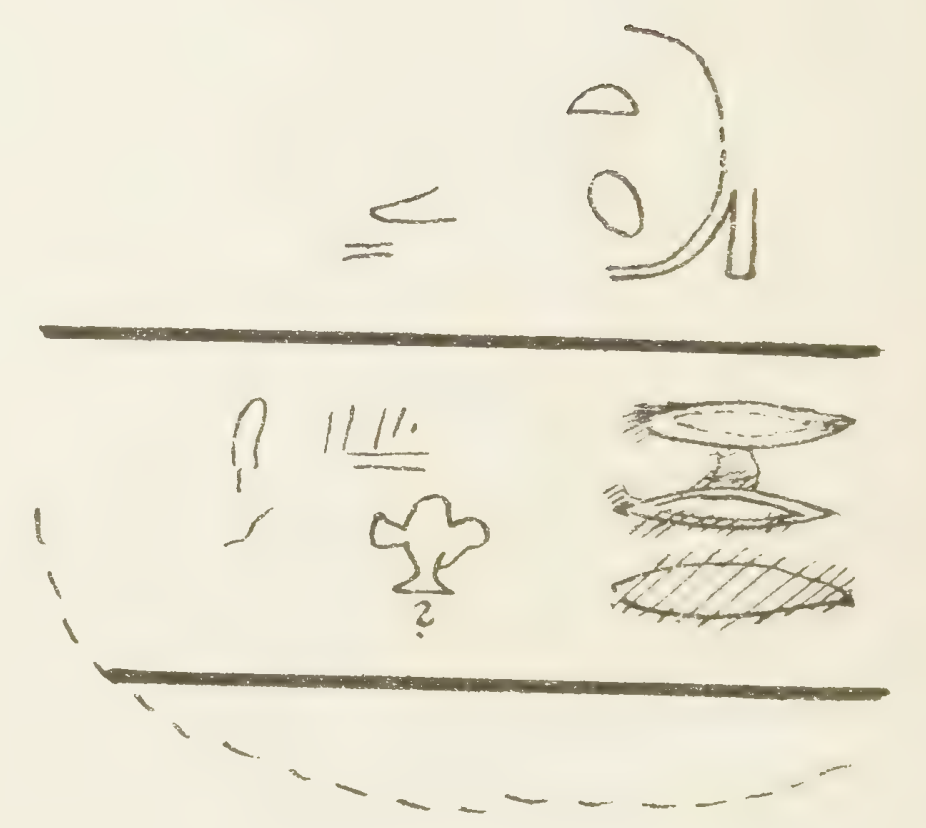

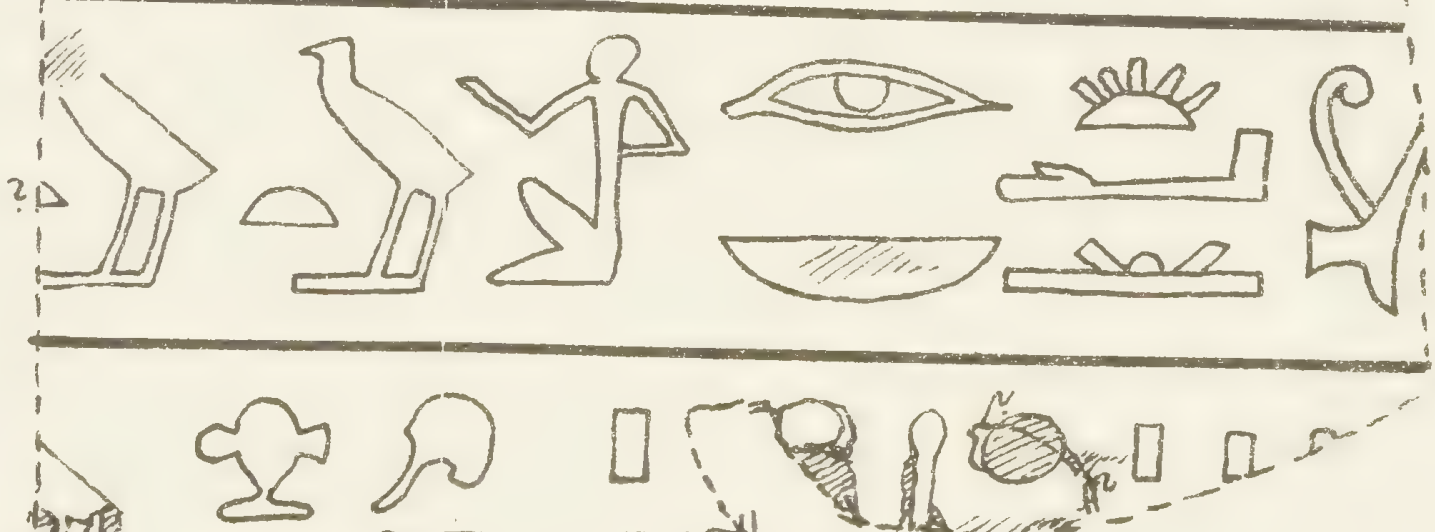

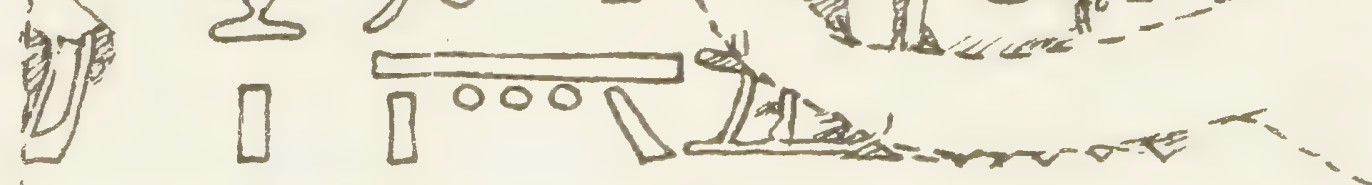

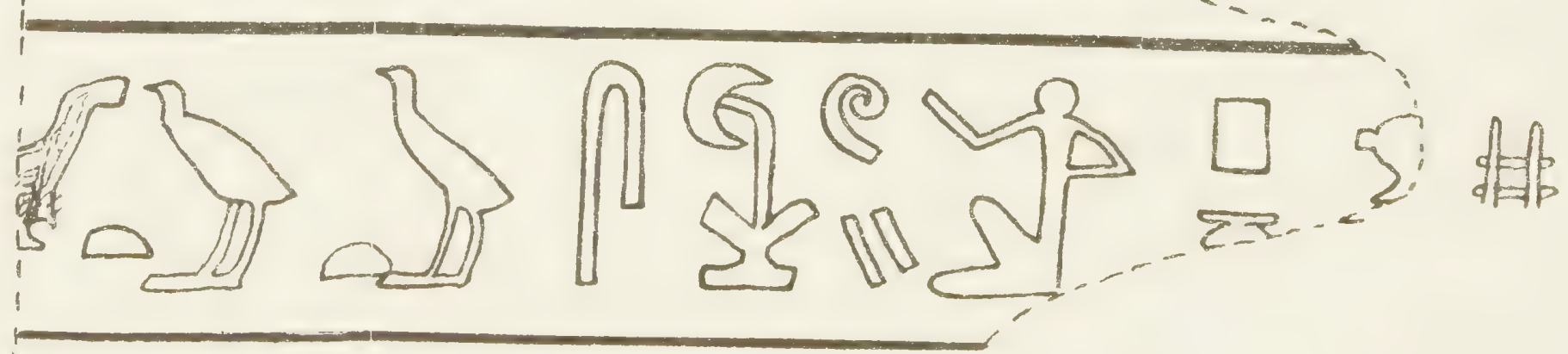




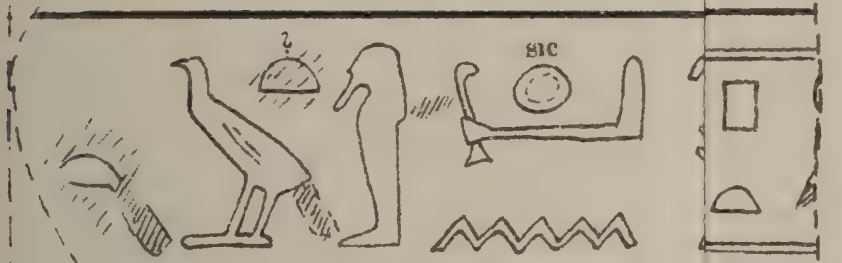
1

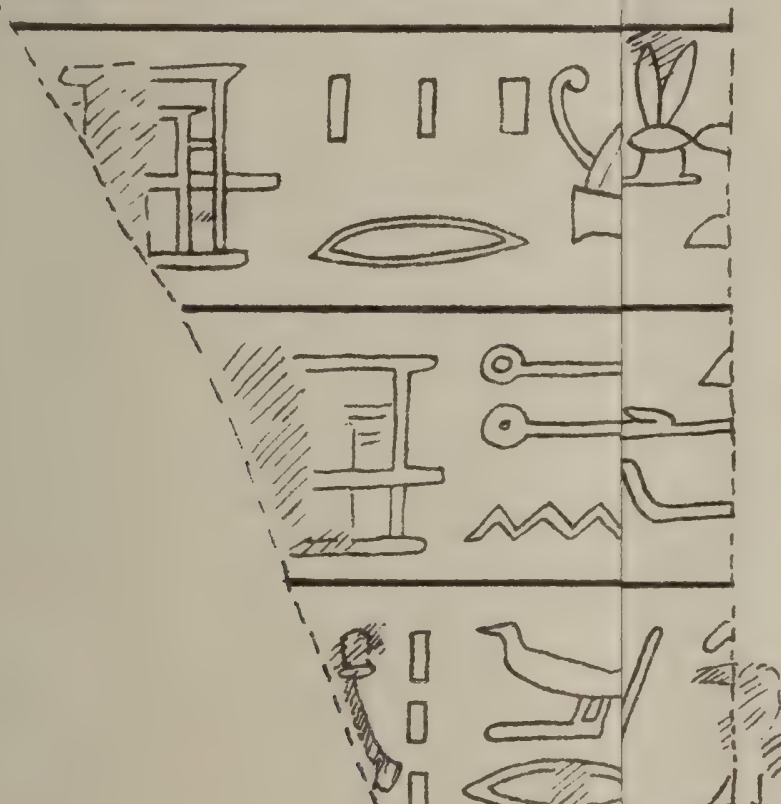

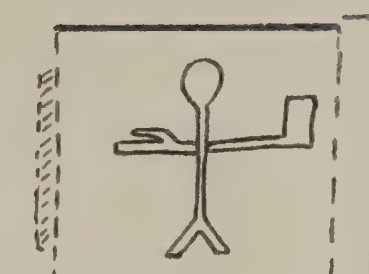
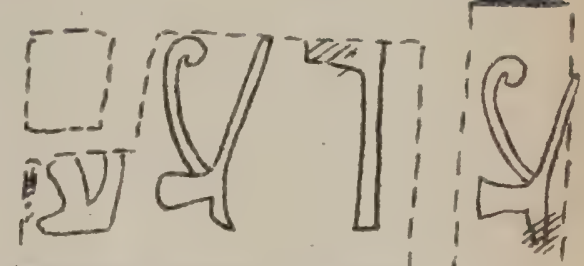

11

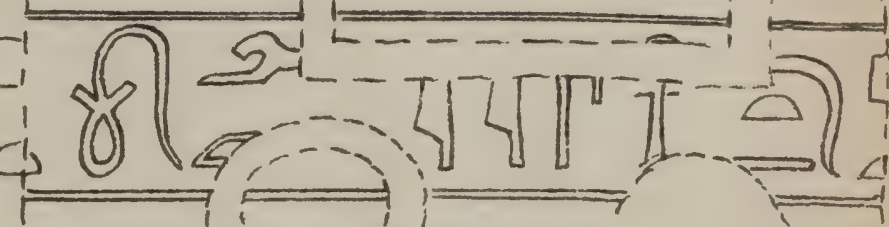

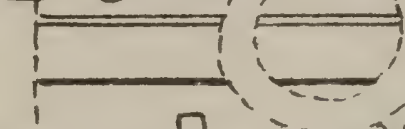

'-......

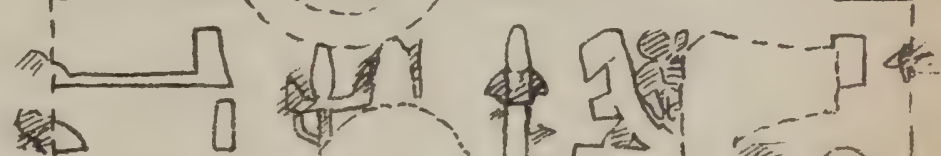

部)

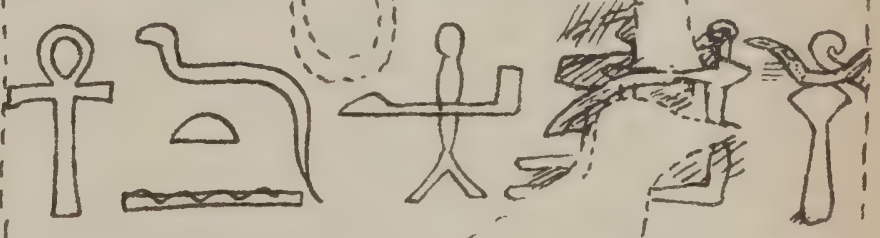

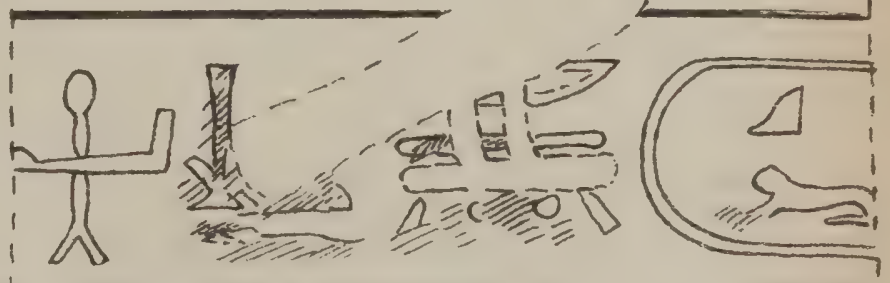

sins

Ceverere.

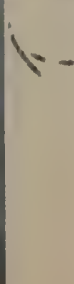

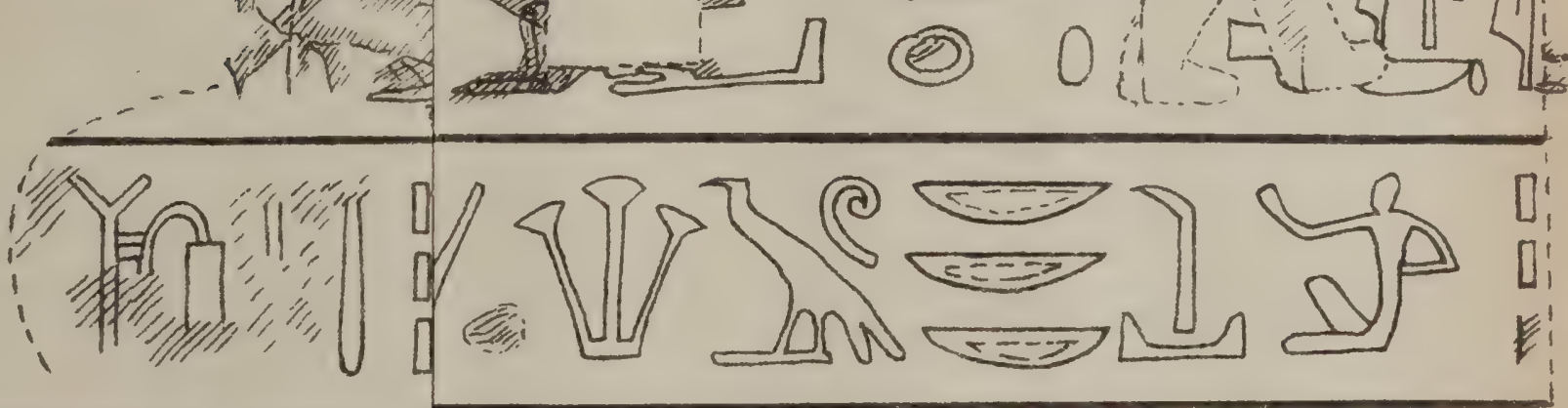




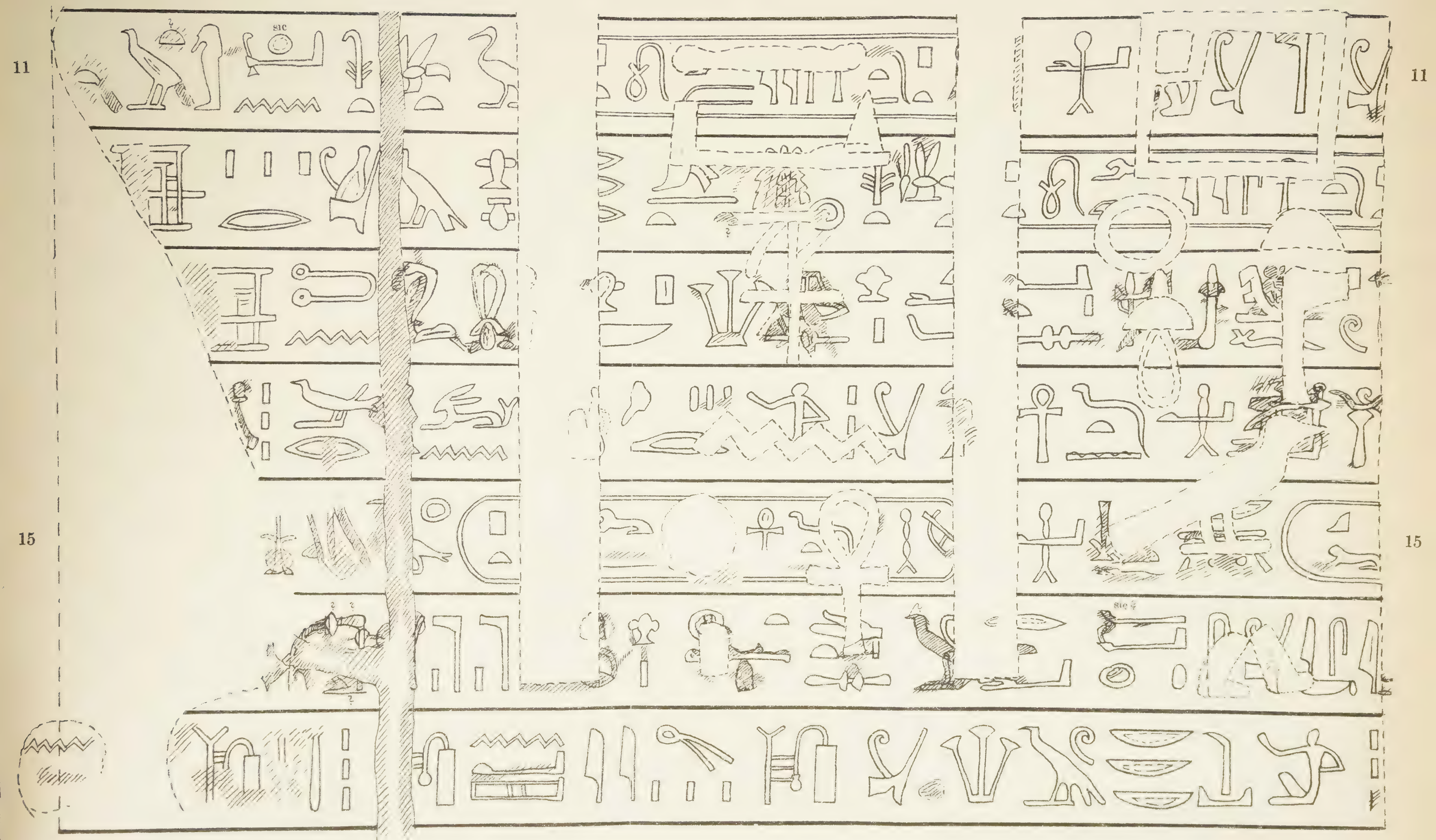



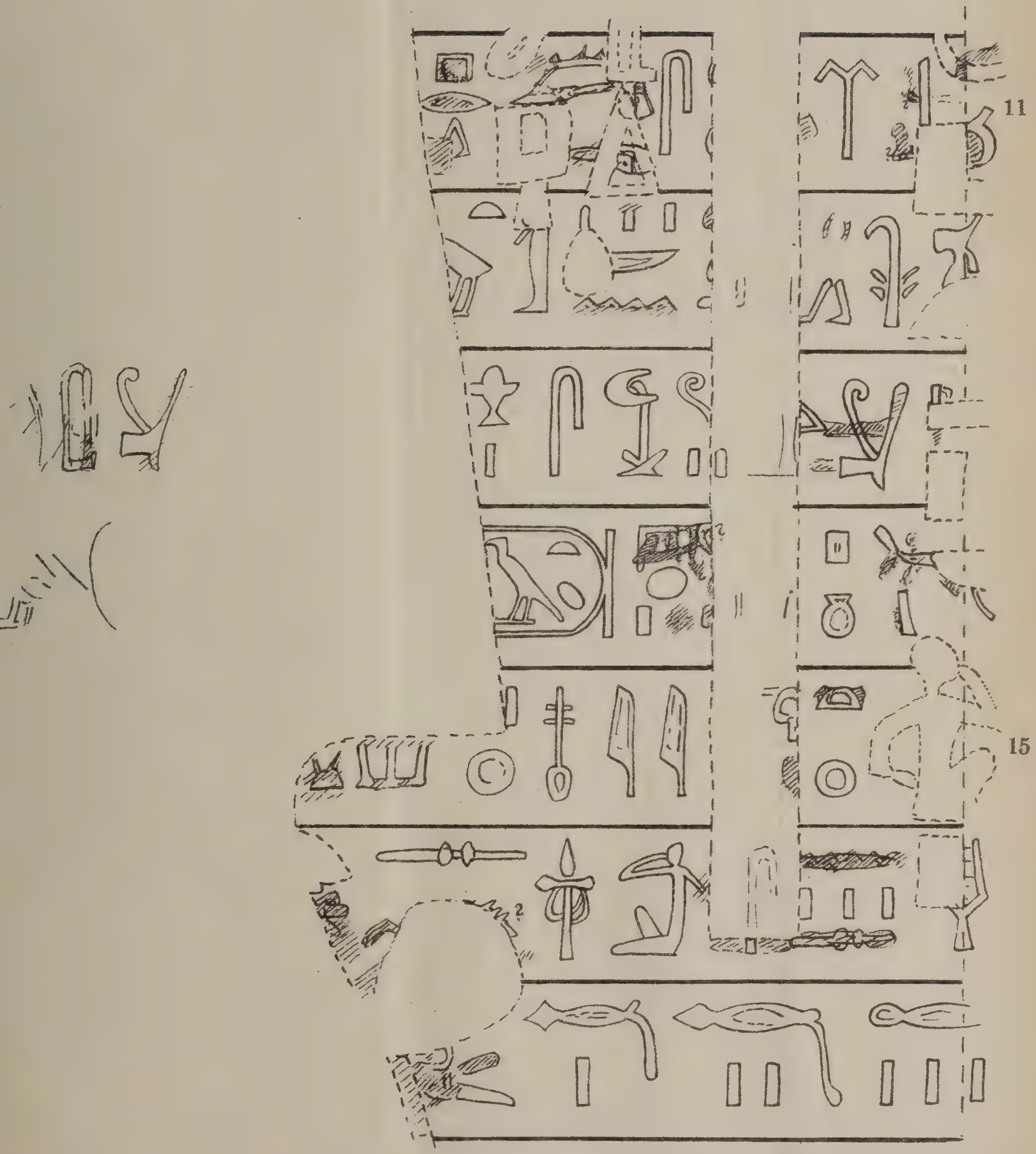


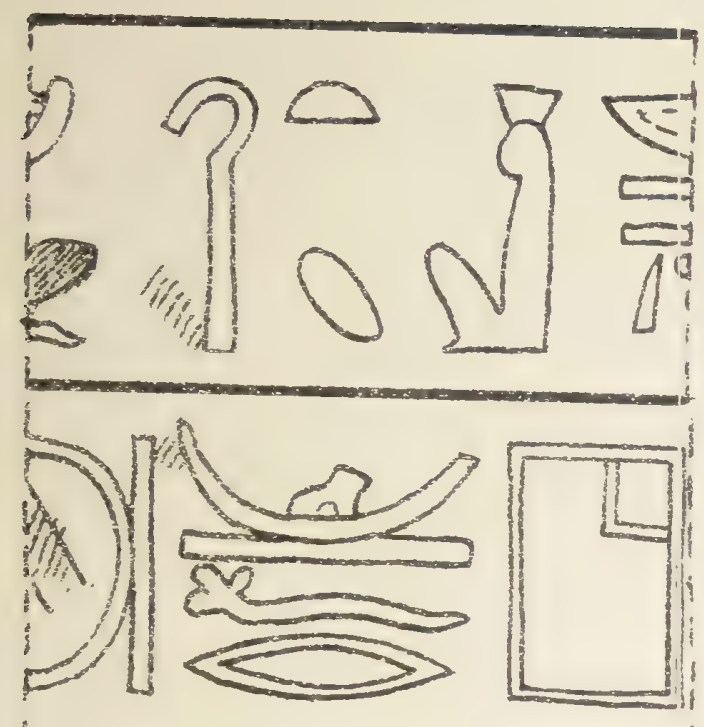

4

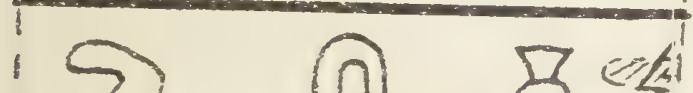

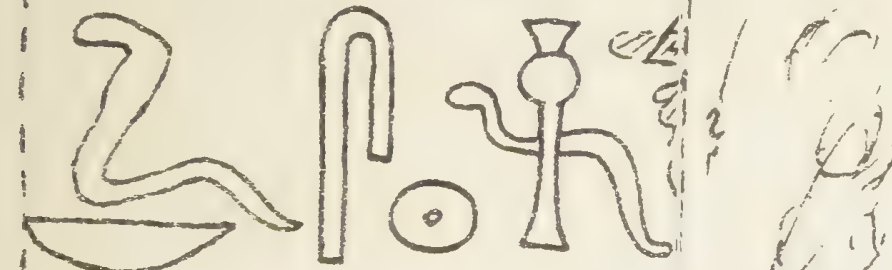

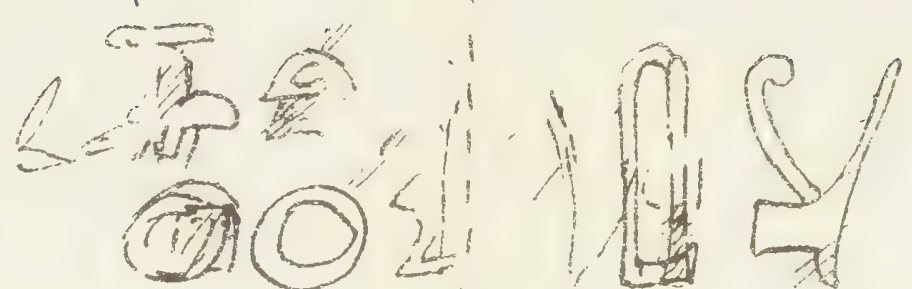

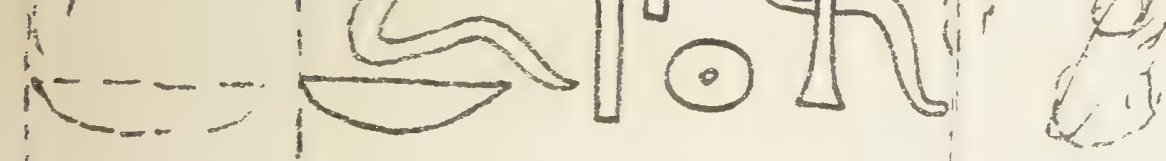

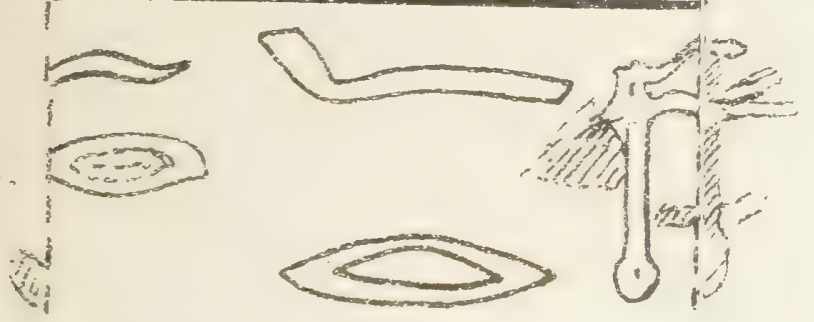

\section{$+$}

(2) $\square$

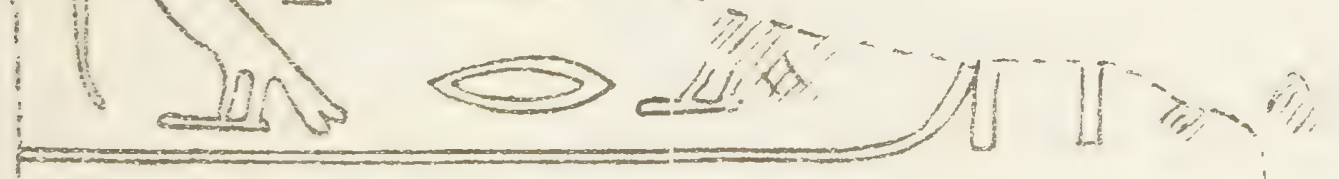

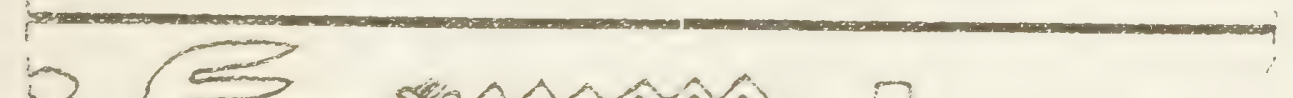

$-P$ hes

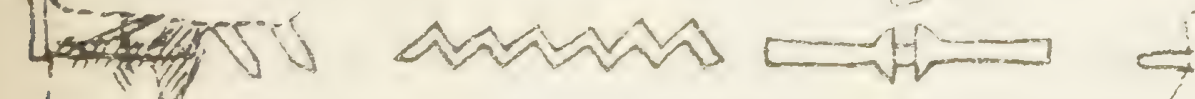

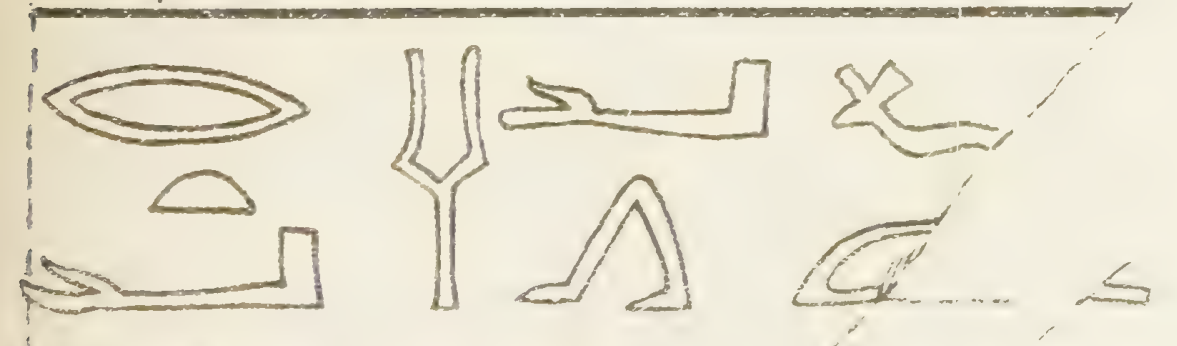

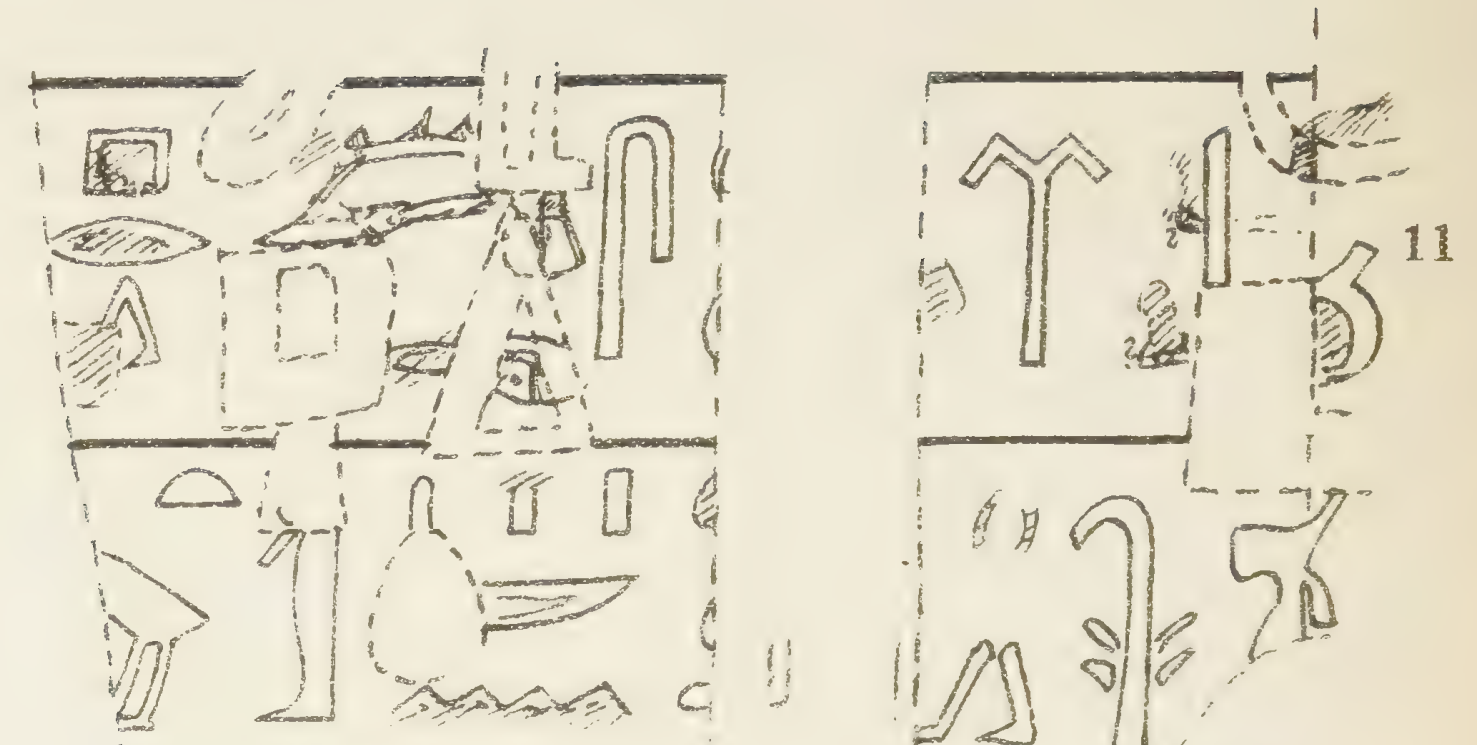

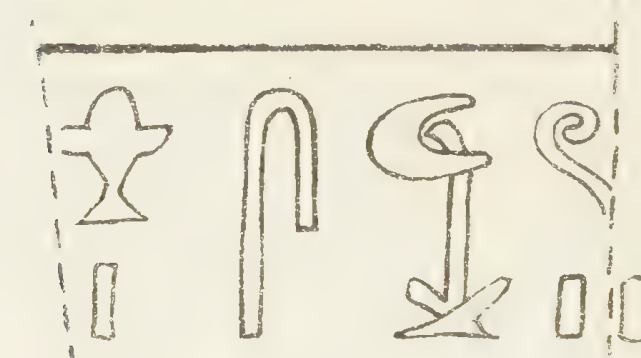

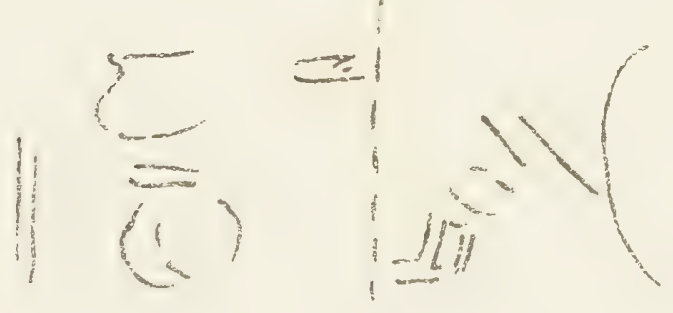

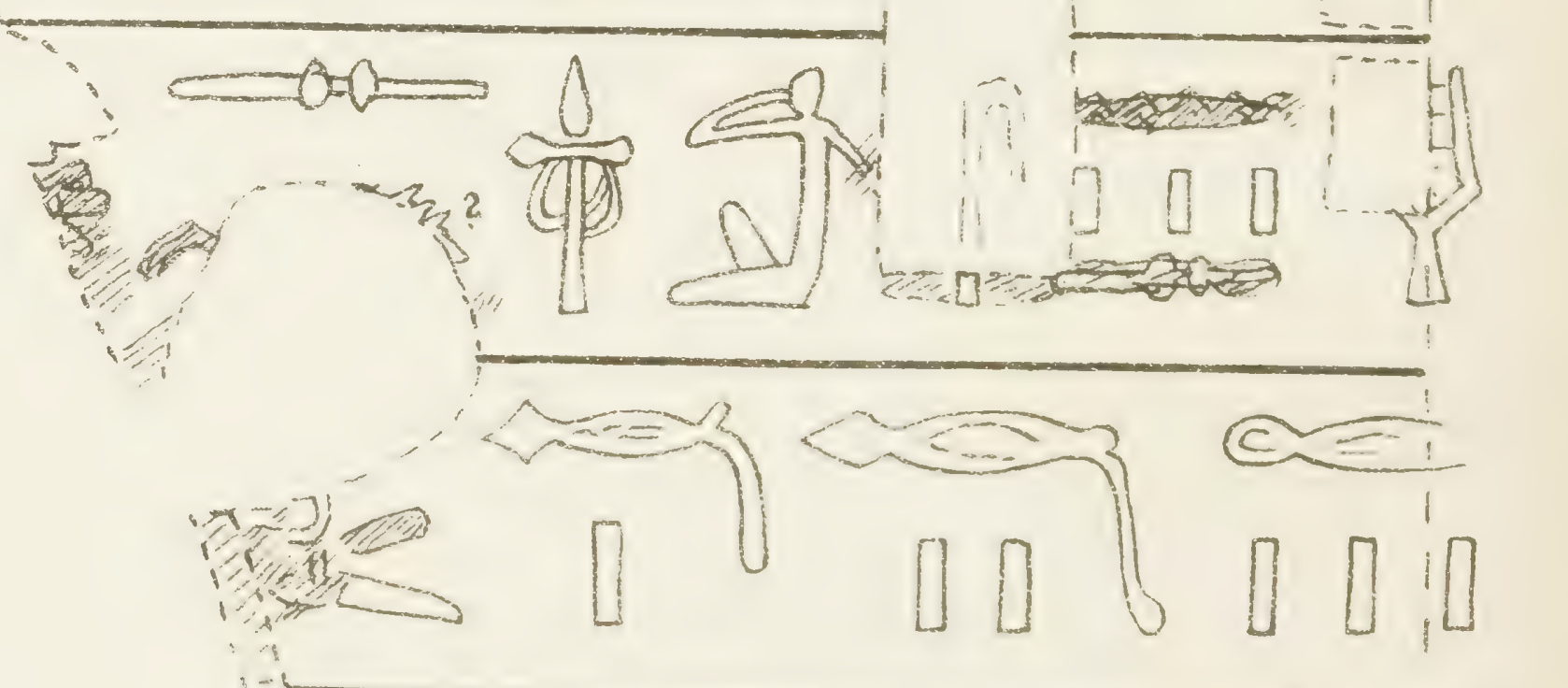

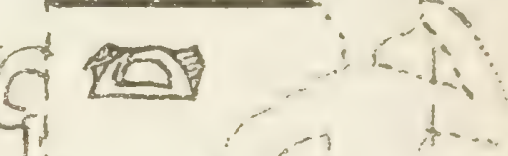

4 (1) 11,15

(0) $-1 ; \vdots 1$

20 I] $\square \square: \cdots+$ 1 \& 0 a 
一 ' 11 inen 2) b

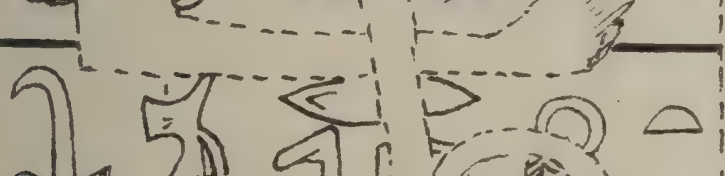

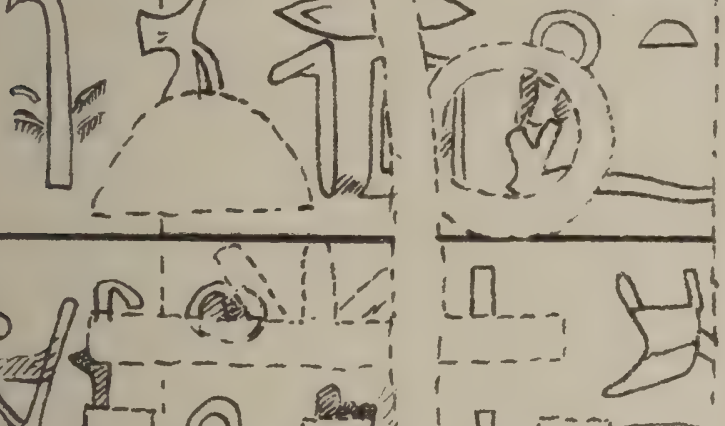
4

Q (1)

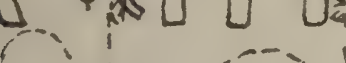
in蓉 15 Cirlon

(1) $2 \frac{10}{20}$ $0 \Longleftrightarrow$

$\sqrt{\Omega} \sum_{S}^{\infty}$
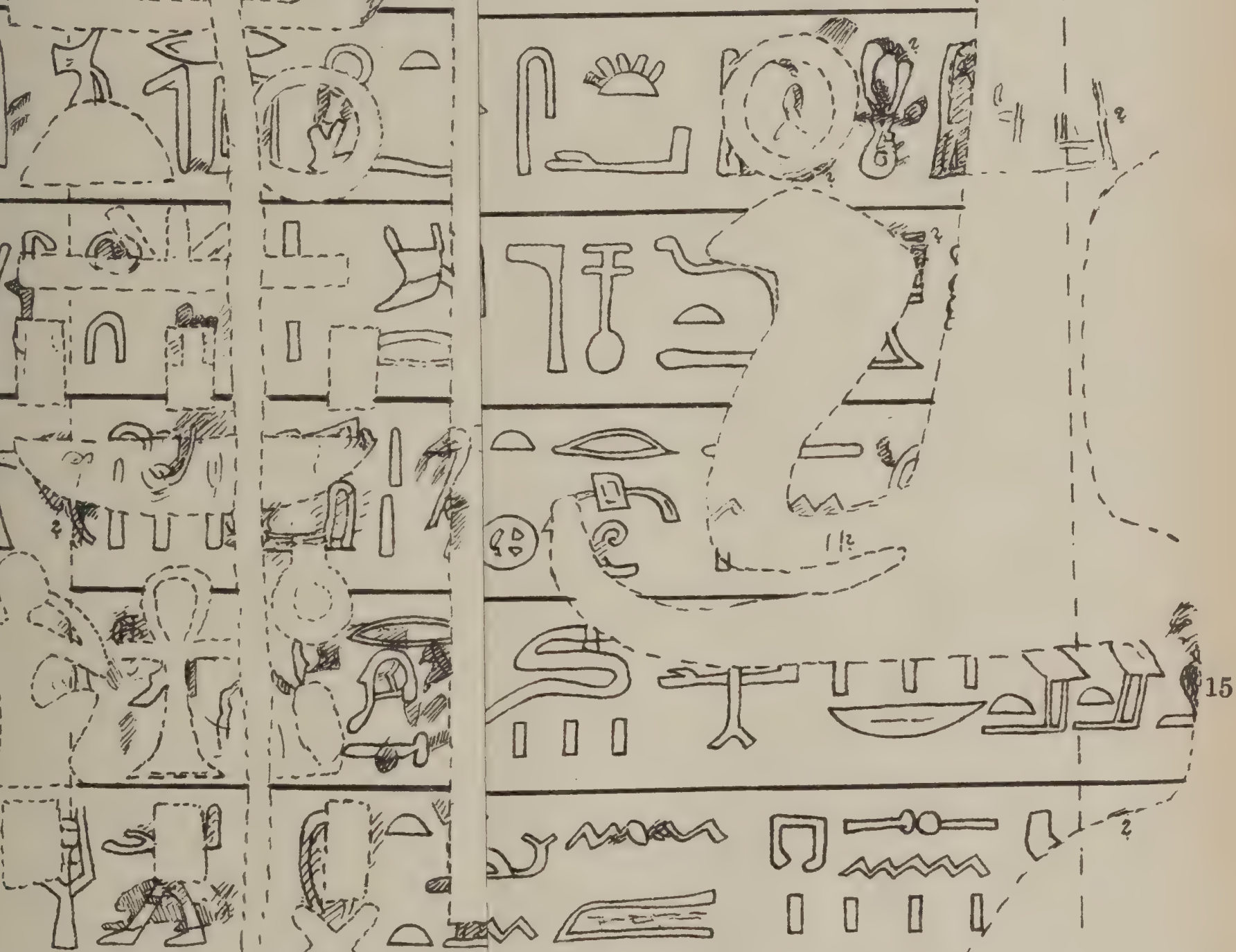

rav

2) 200

[1] $\Rightarrow 0 \approx$

1

प0 प प

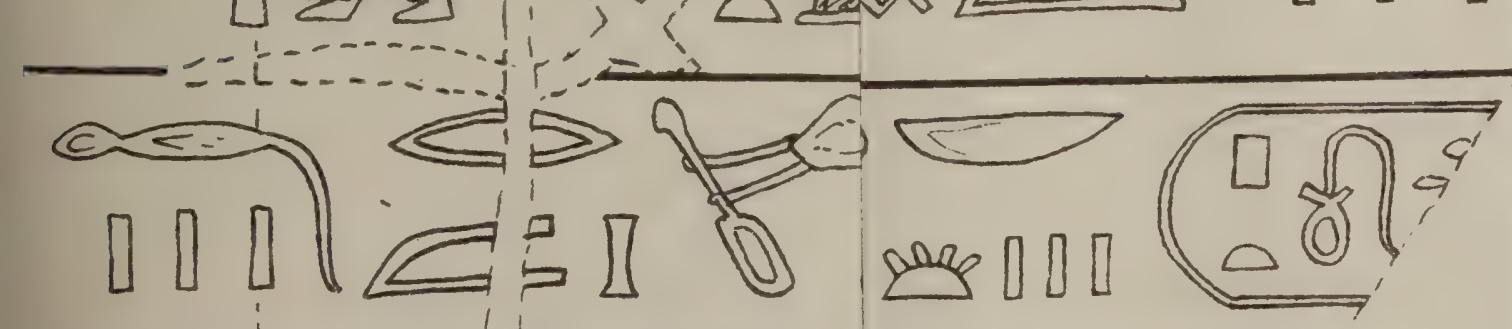




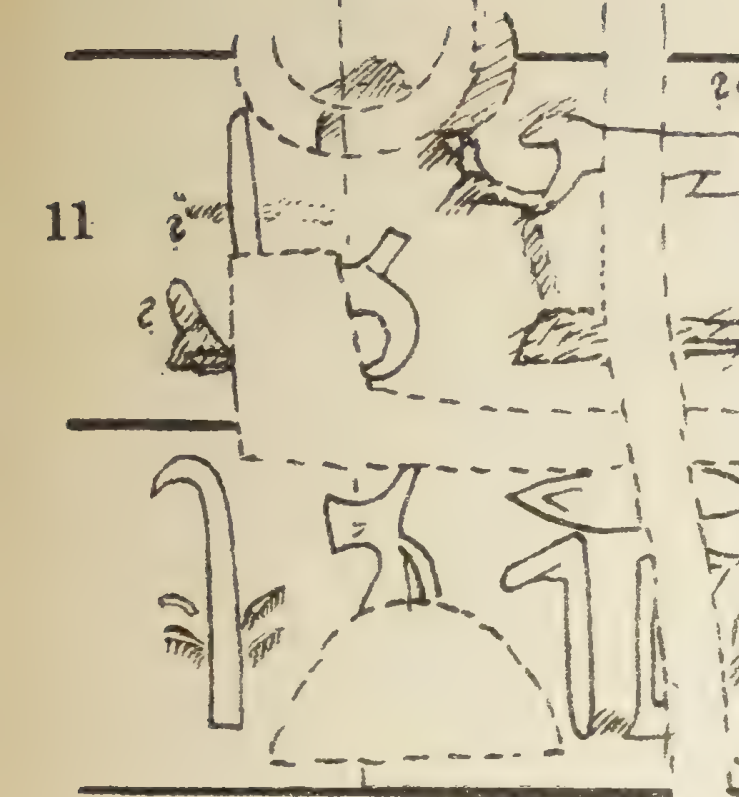

A I

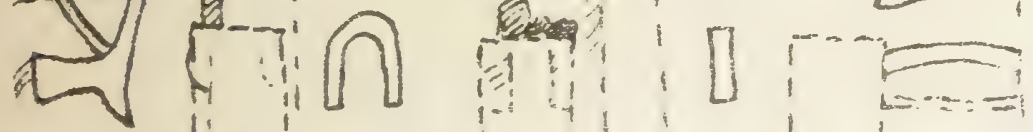

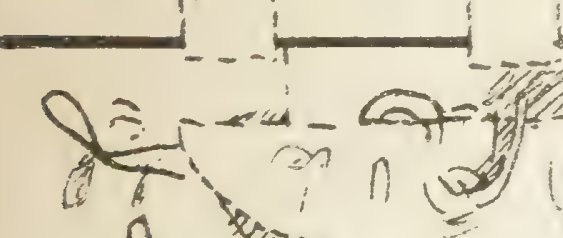

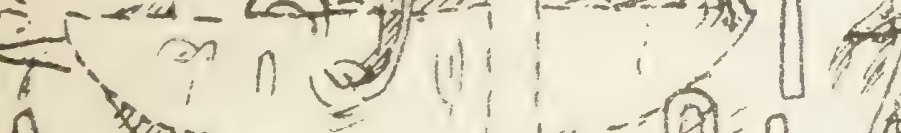
U.

\section{-}

15 !

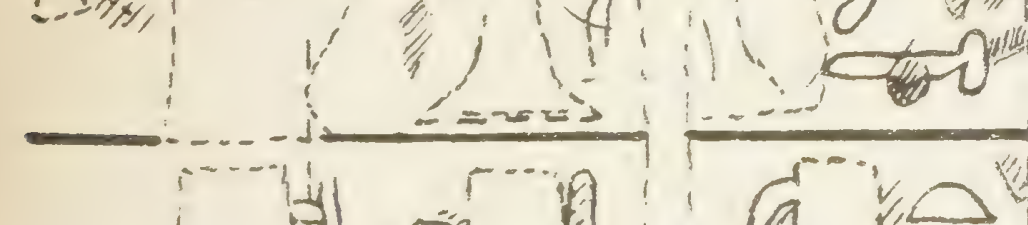

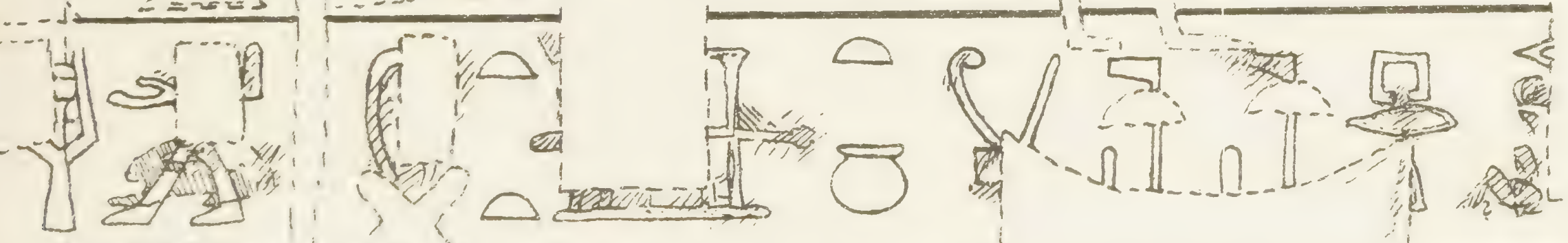

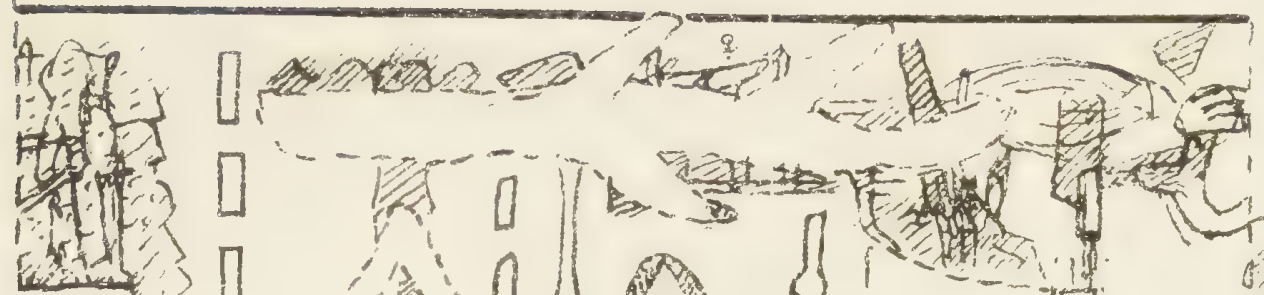

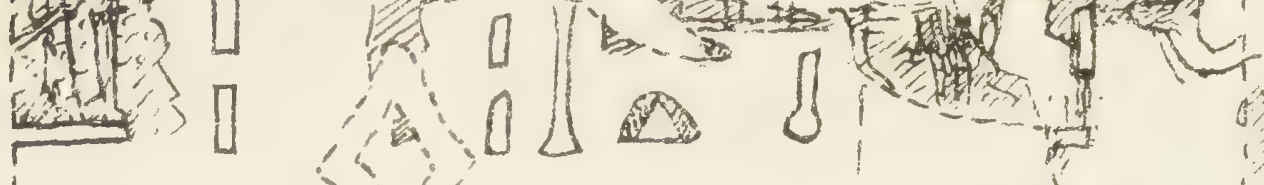

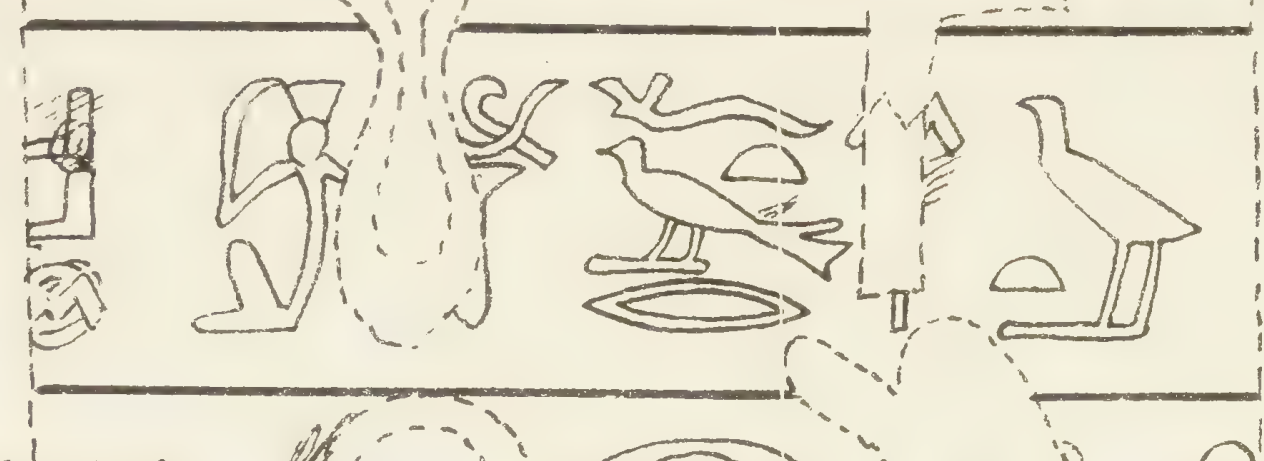

ENA

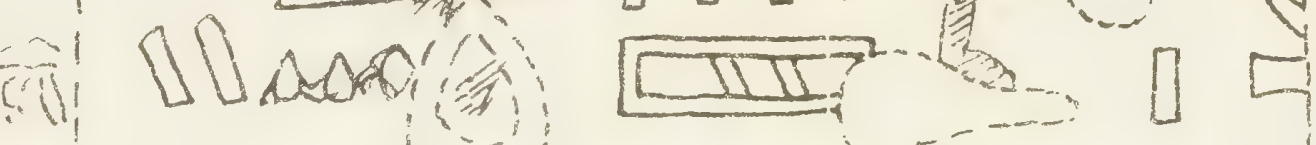

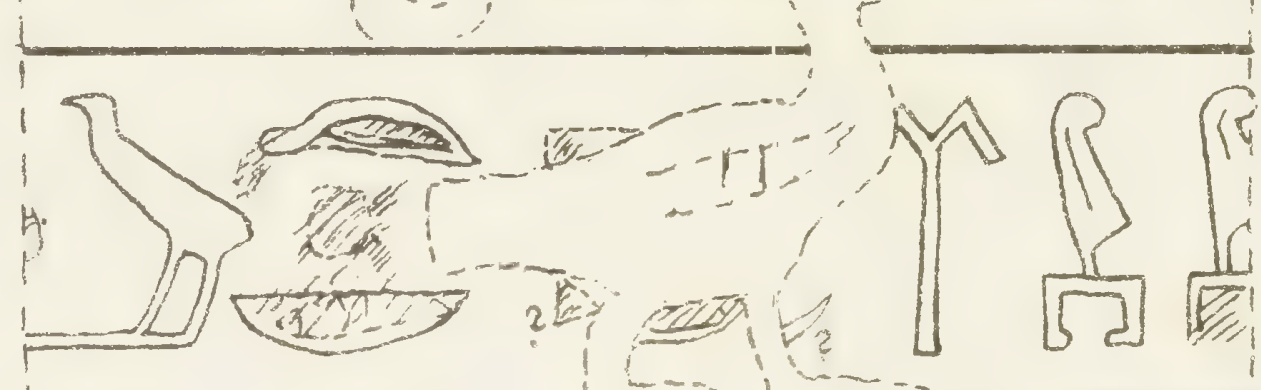

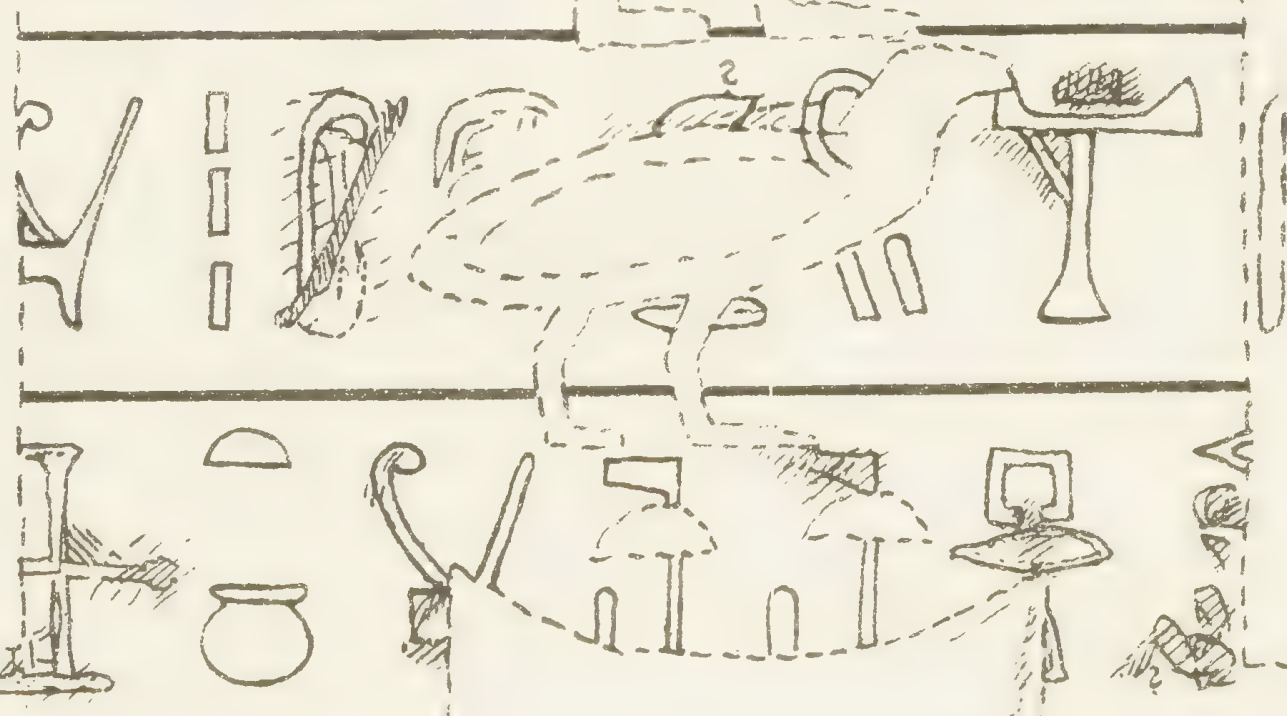

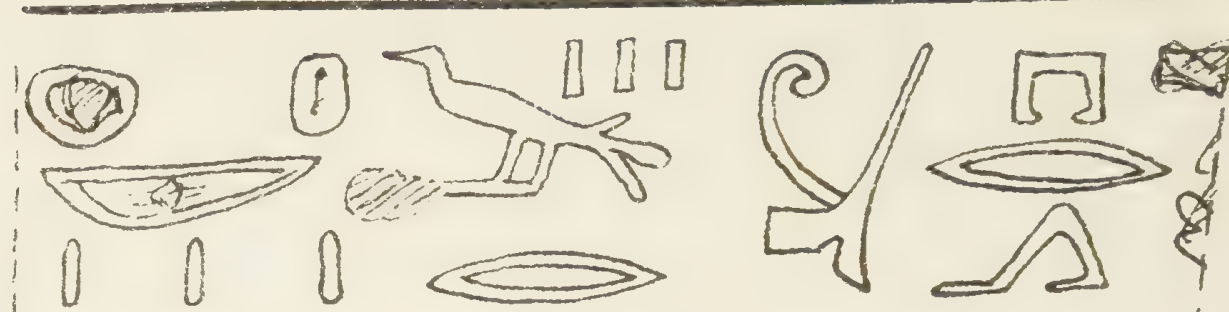

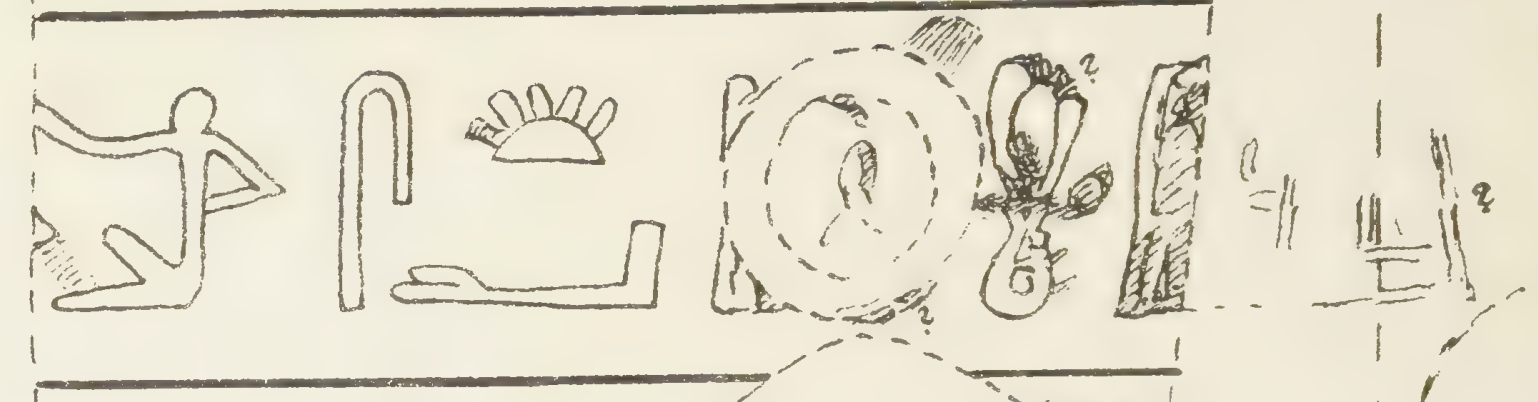

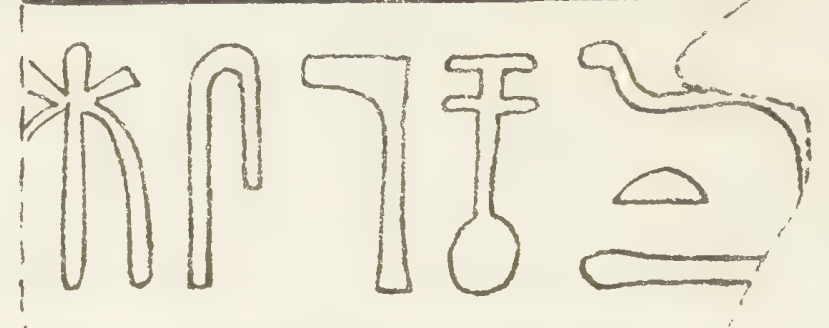

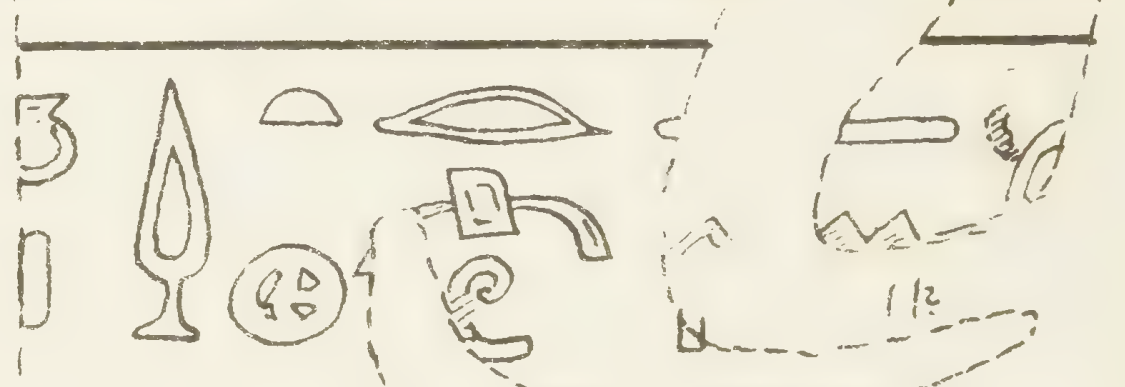

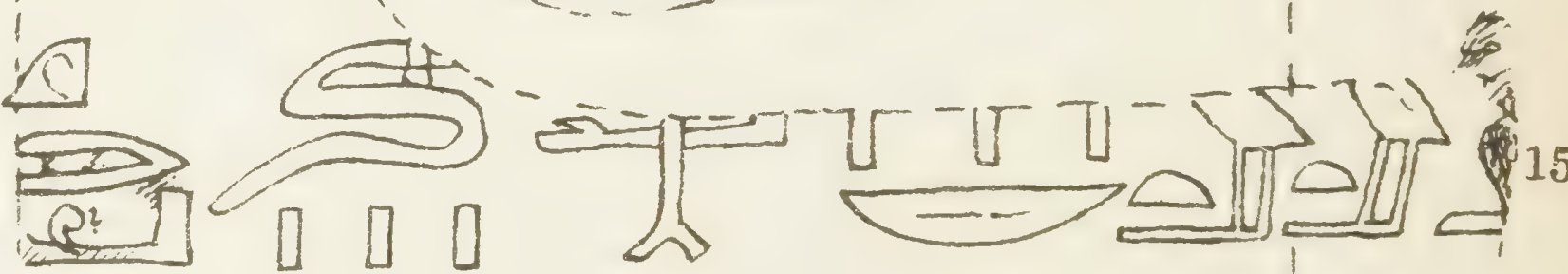

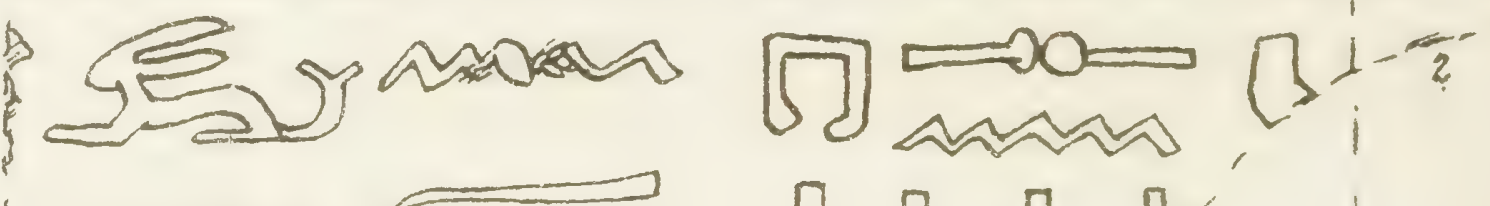

cum




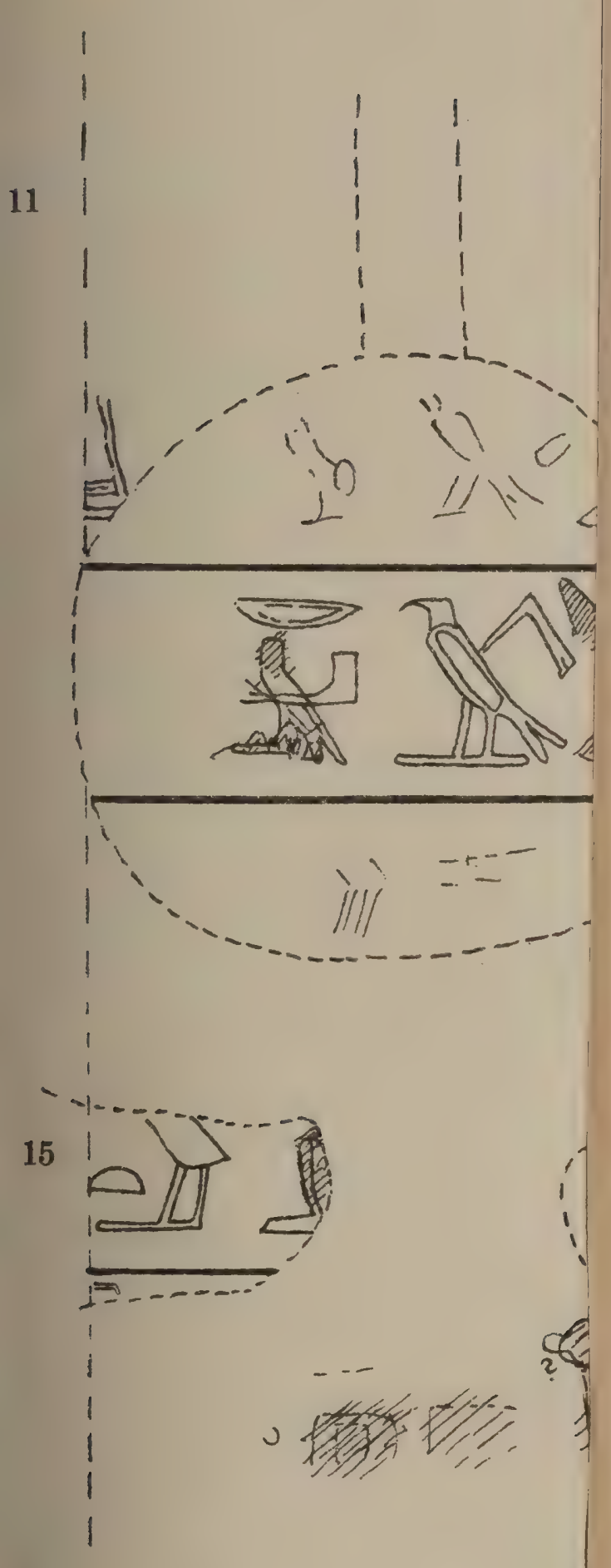




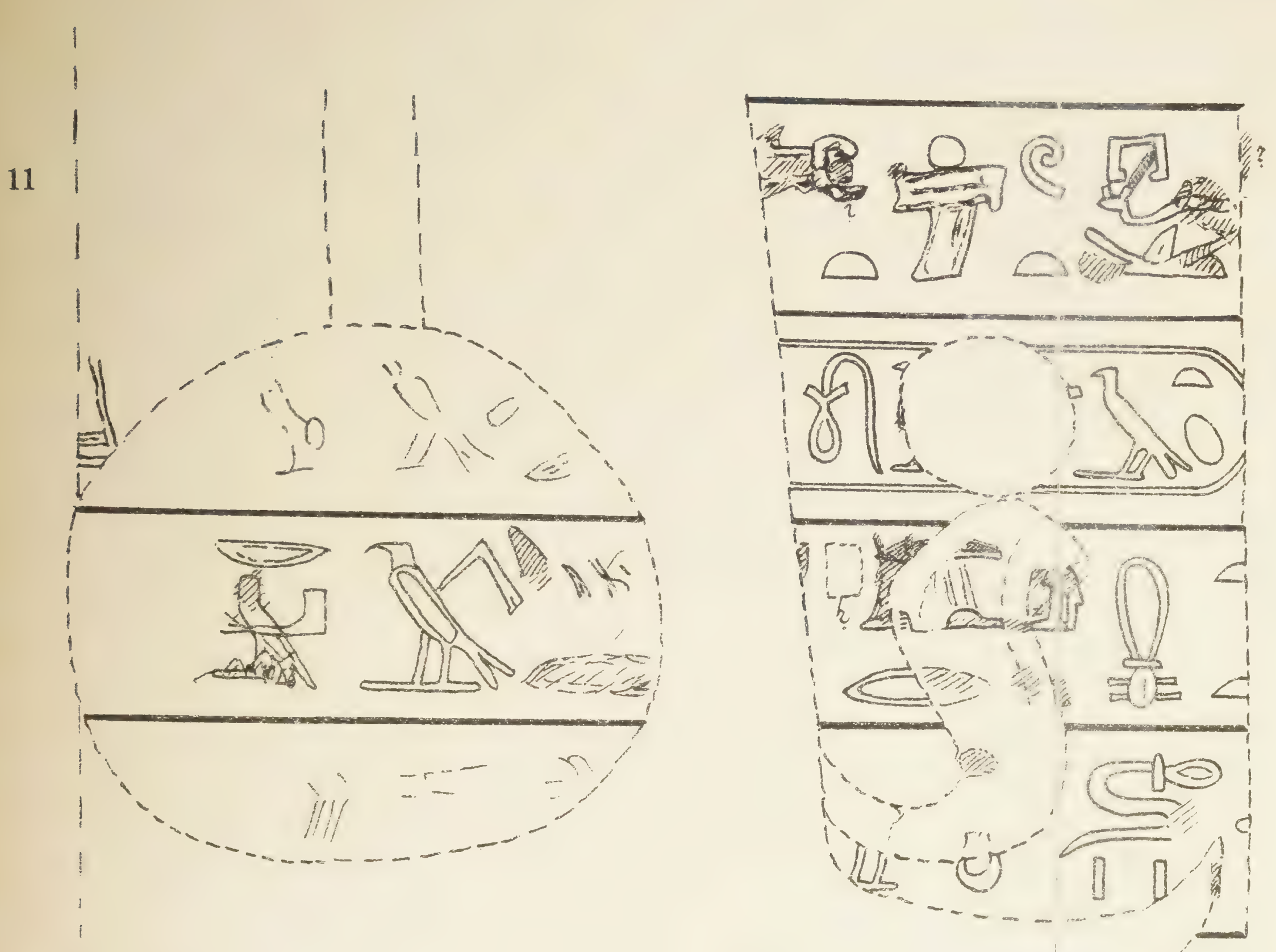

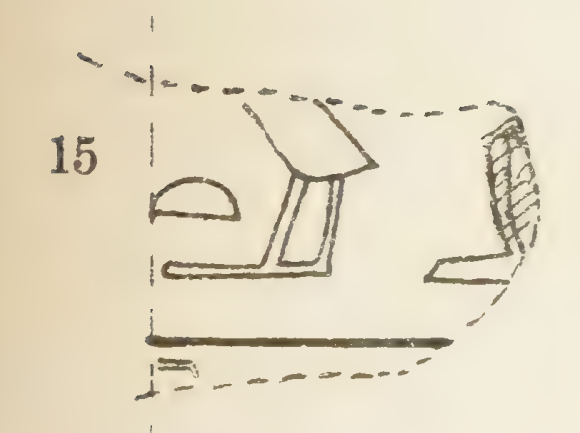
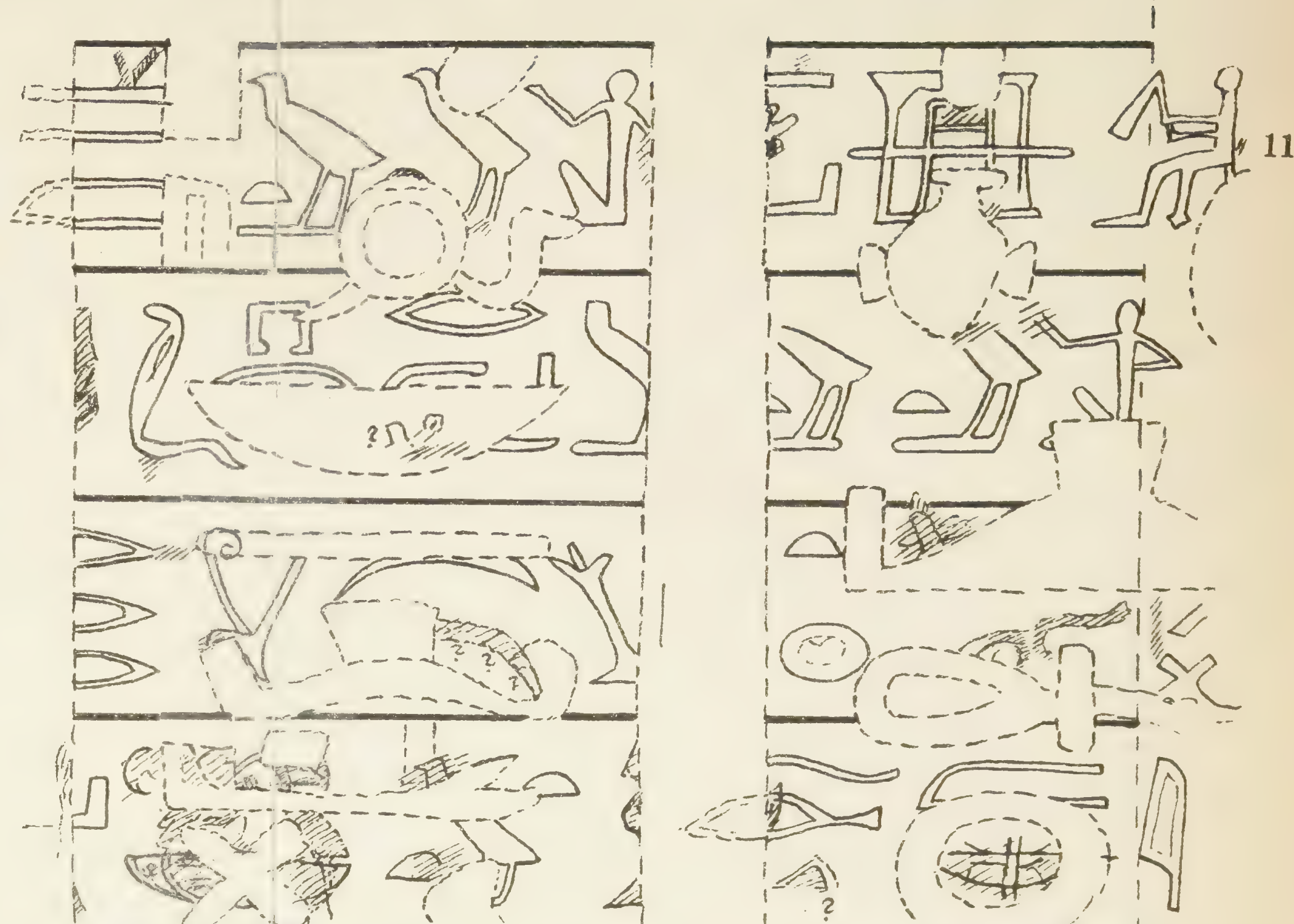

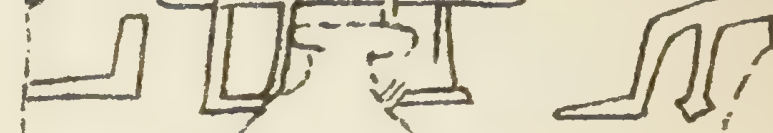

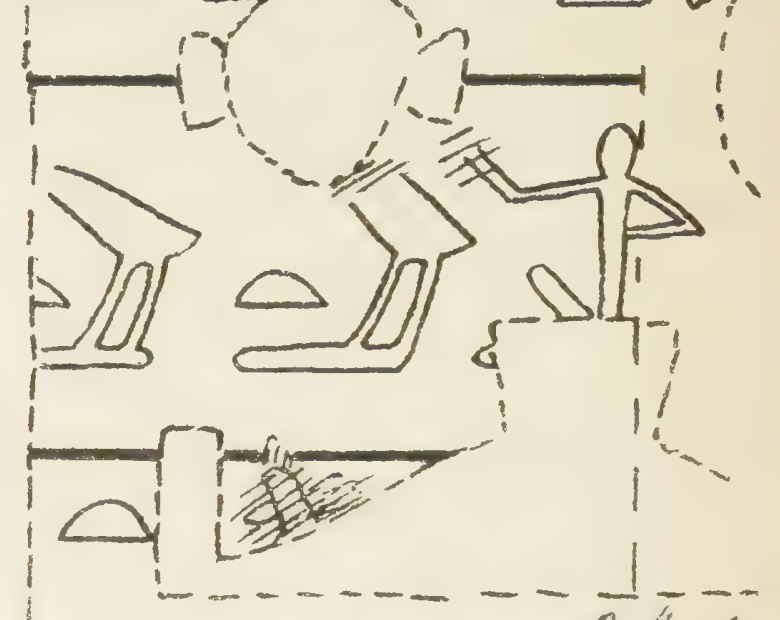

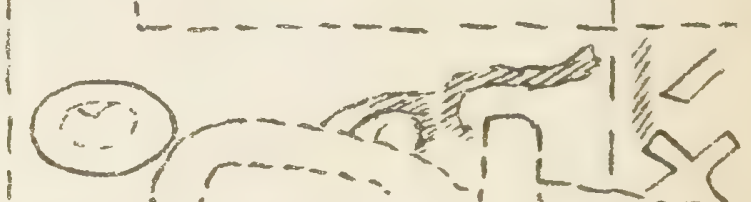

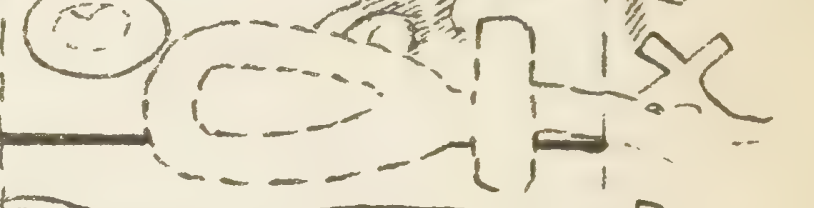

$\simeq$ 网

1

s...…ㄴ.

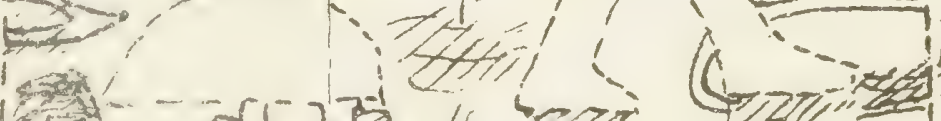

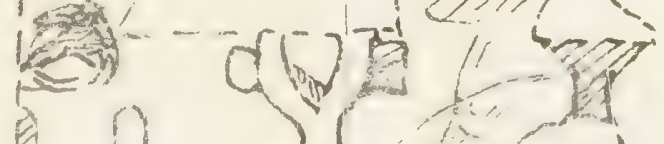

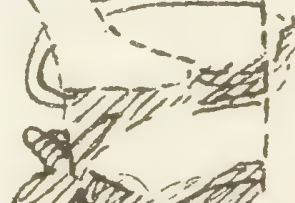

拿 !

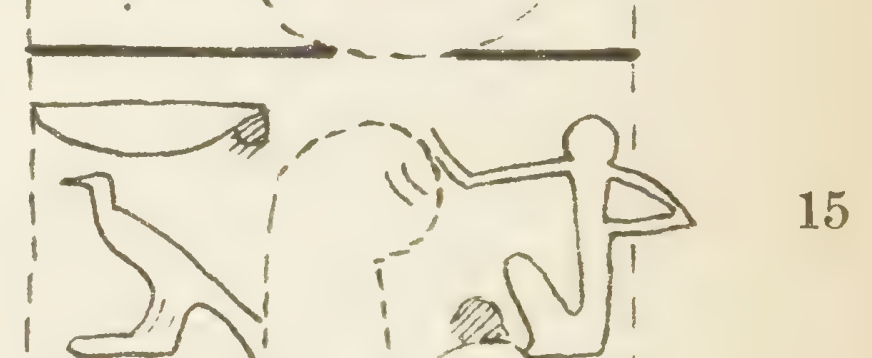

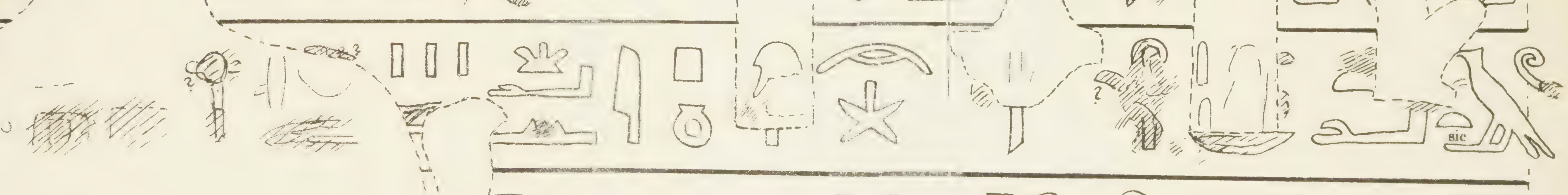

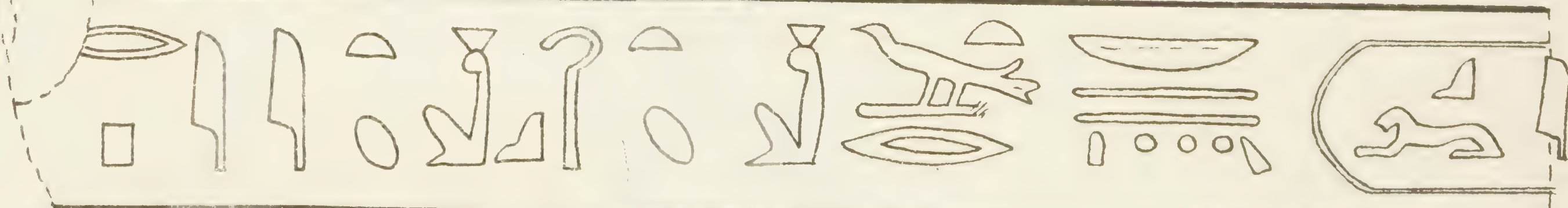


$\sqrt{\sqrt{5}} \cdot \sqrt{10}$

$-k=1-2$

$R \stackrel{2}{2}$

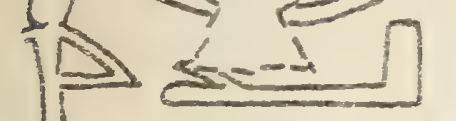

A

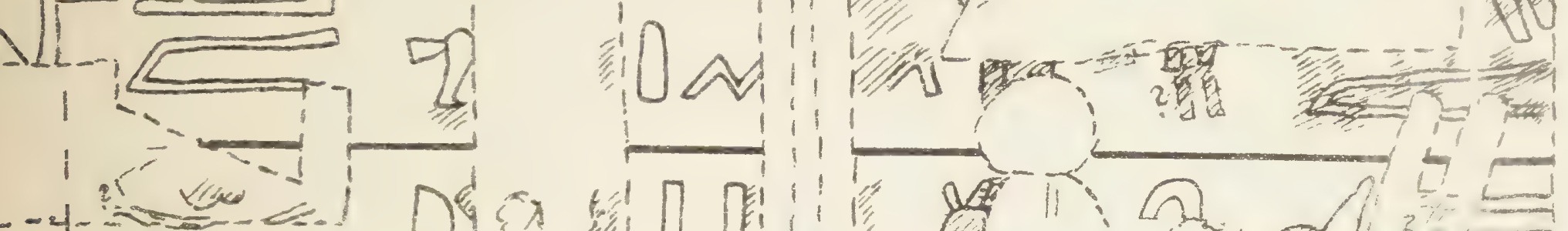

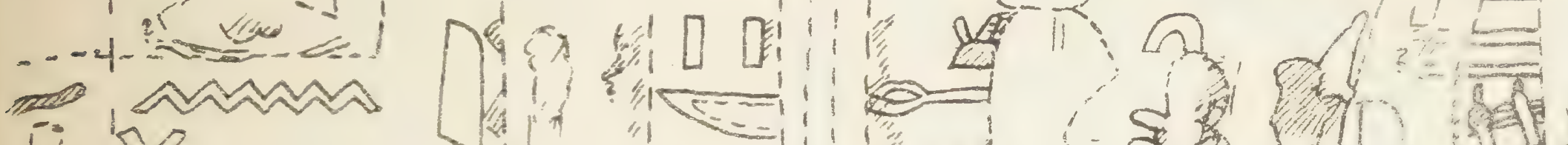

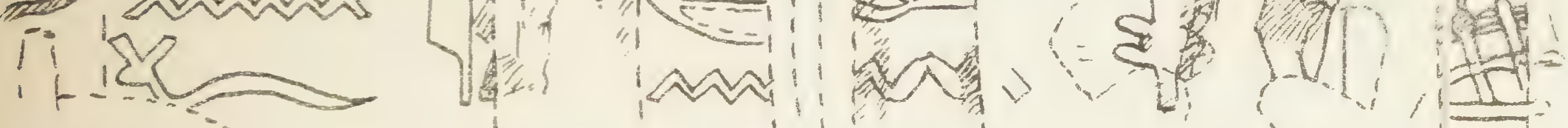

$=\sqrt{1103}$

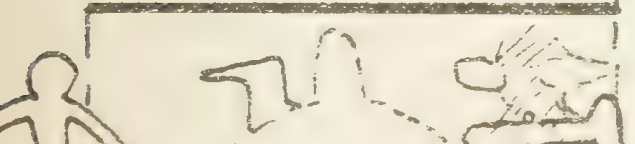

1570

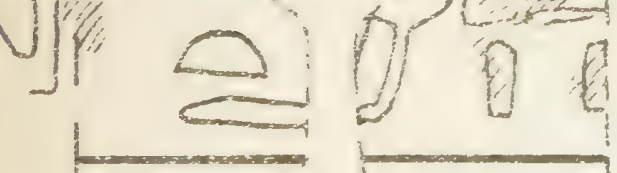

5120

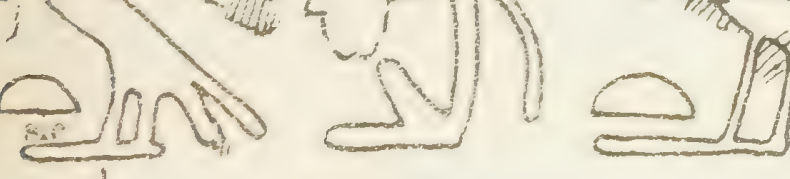

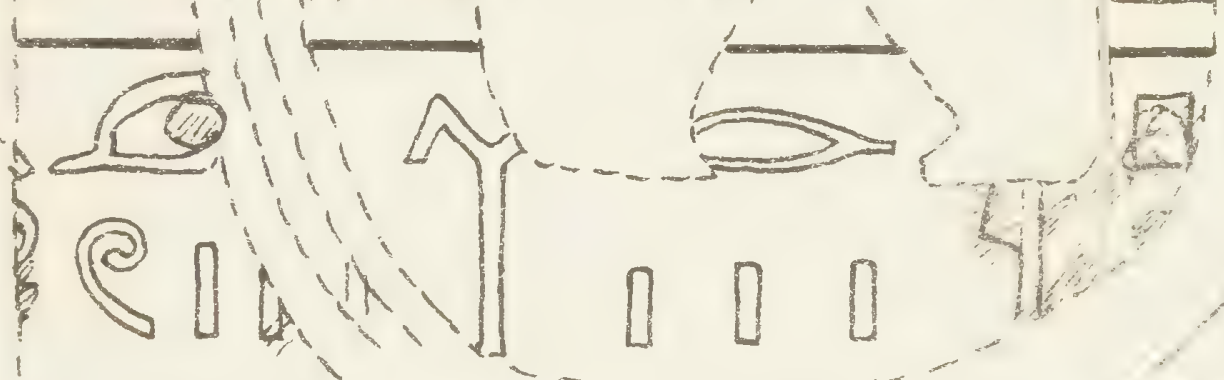

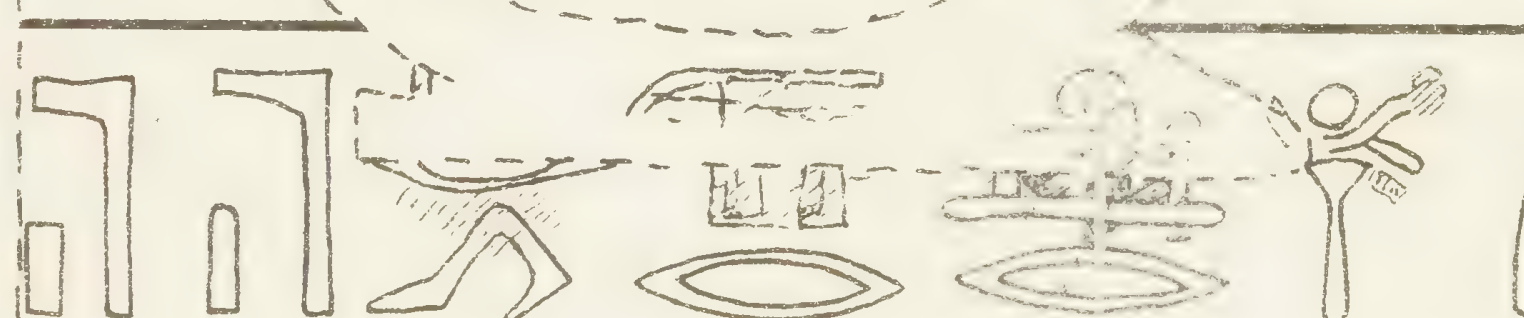

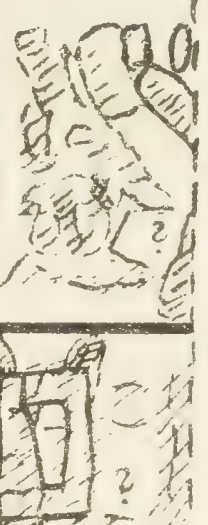

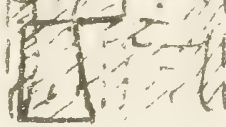

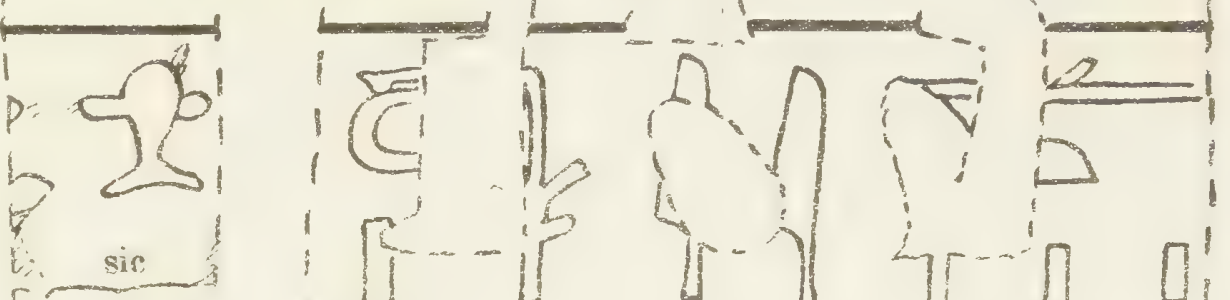

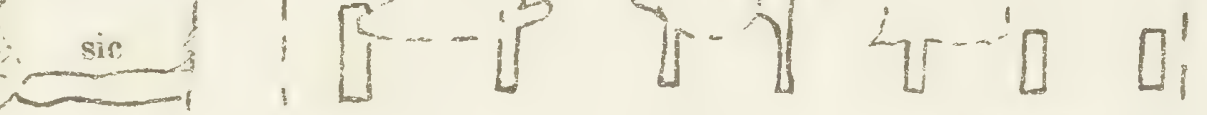

象

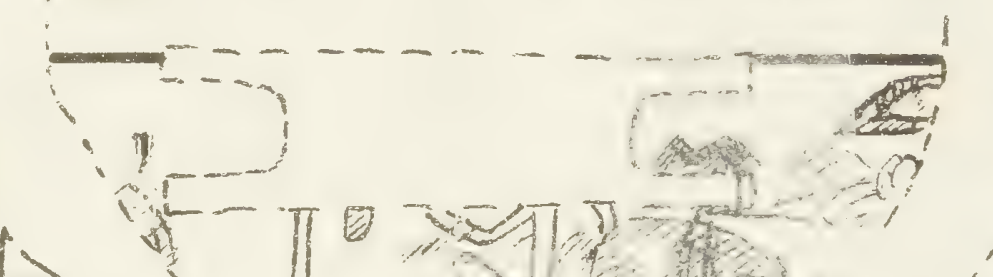

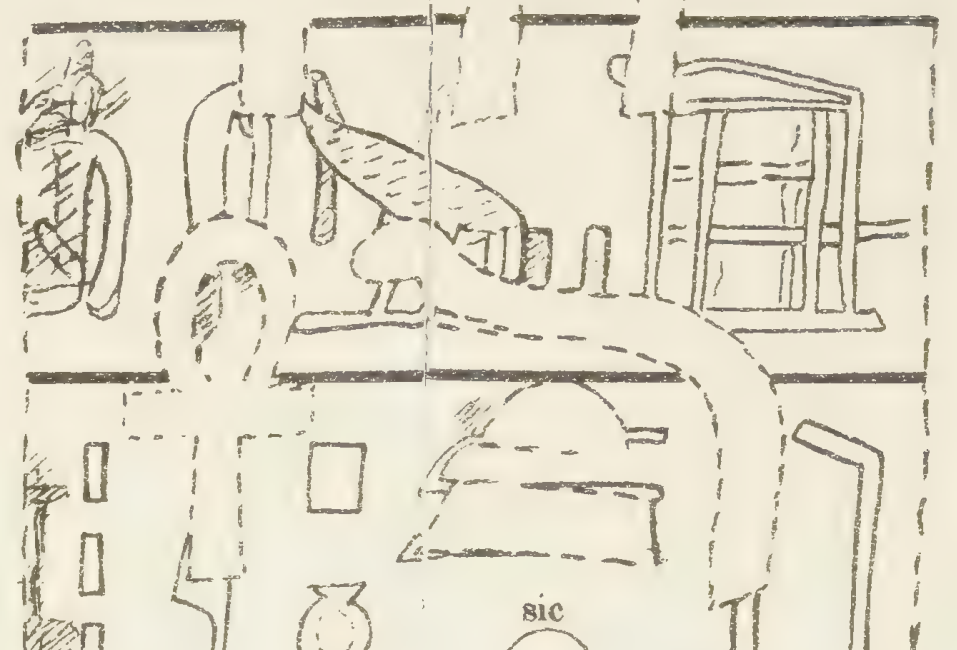

$\longrightarrow$

$=-1$

P

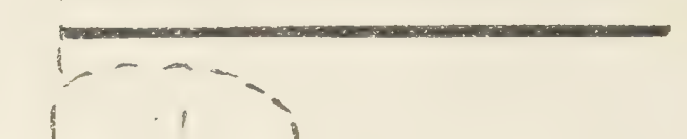

k=-

ry

$1>$

!

1

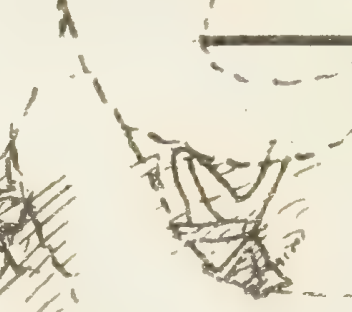
?

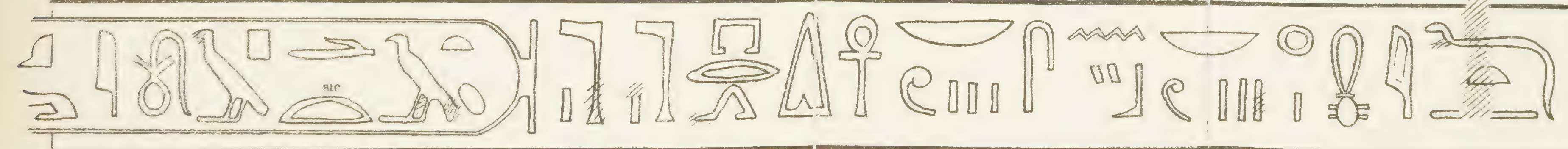




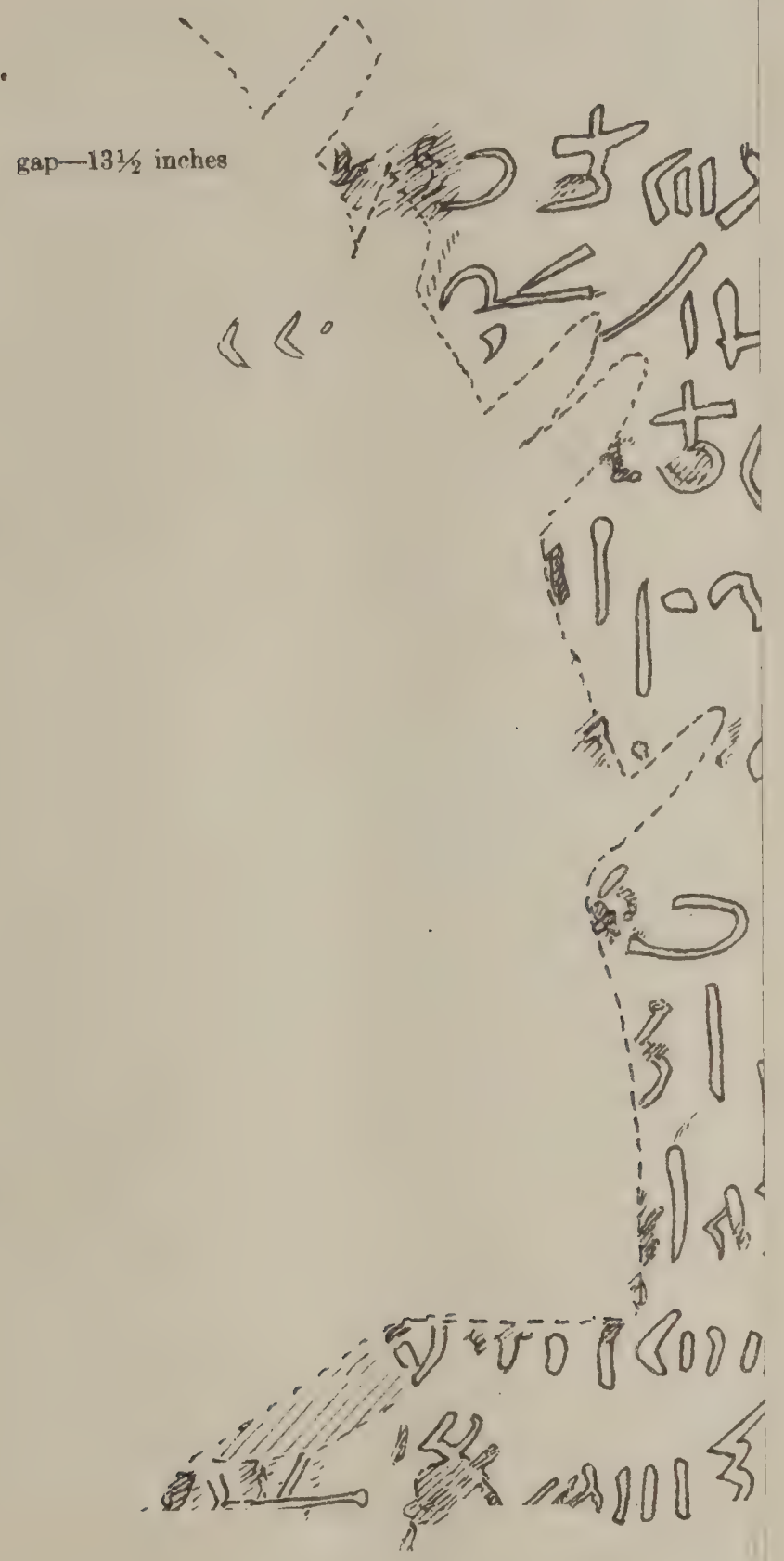




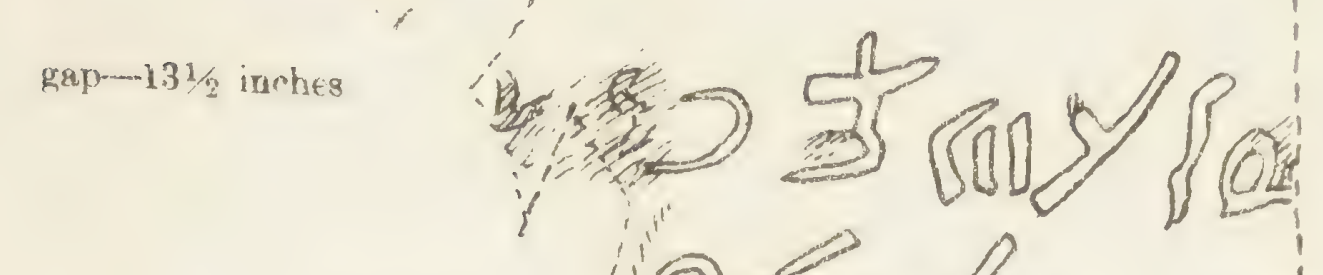

$2 \ll 0$

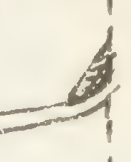

通 4012 109

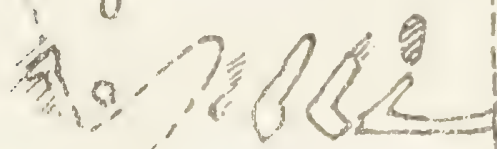

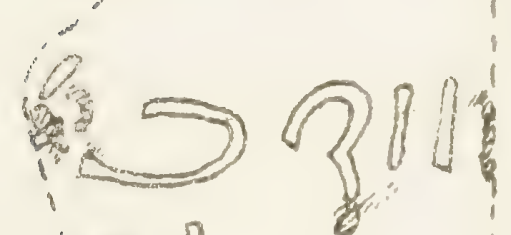

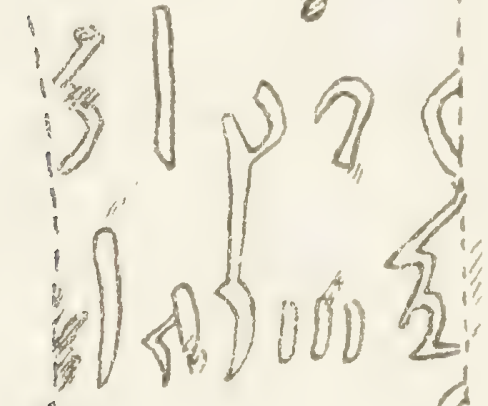
(v) 500800003

10

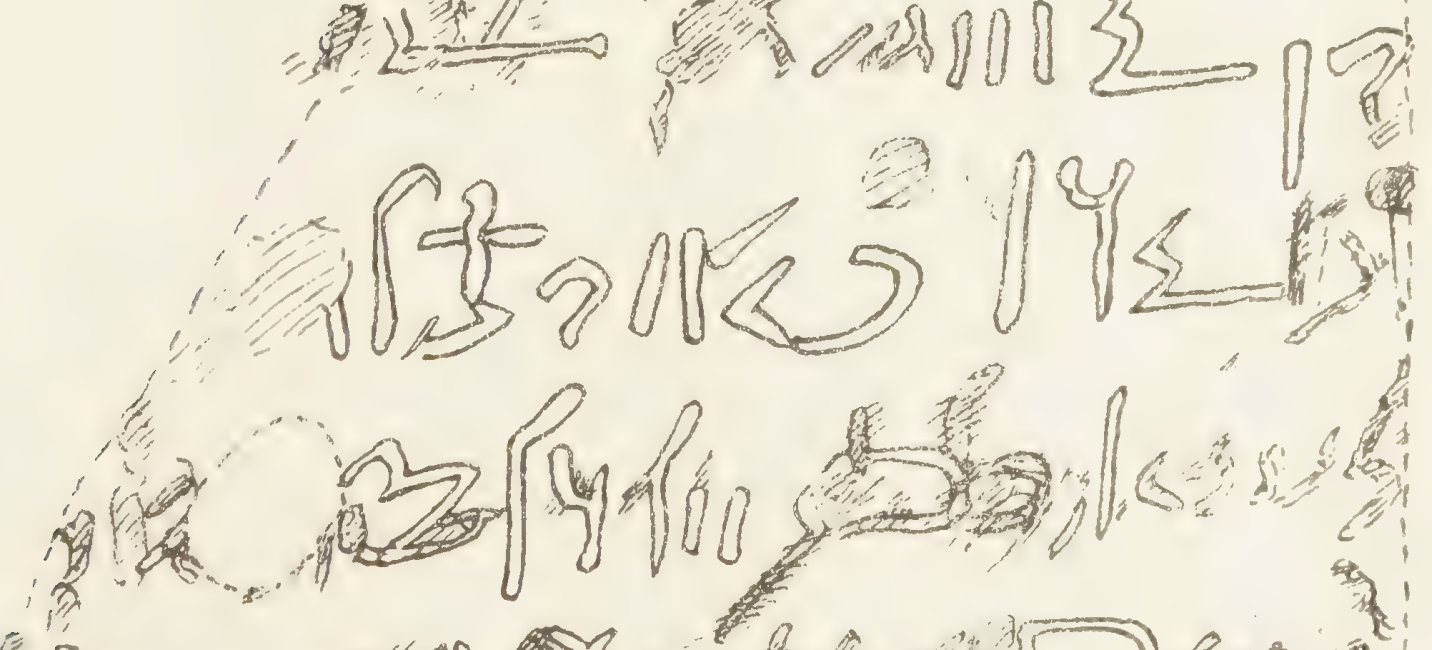

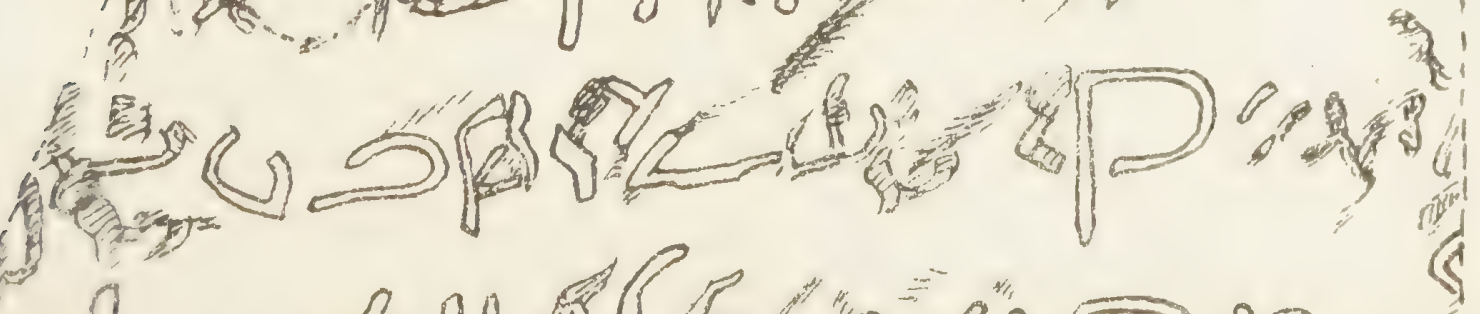

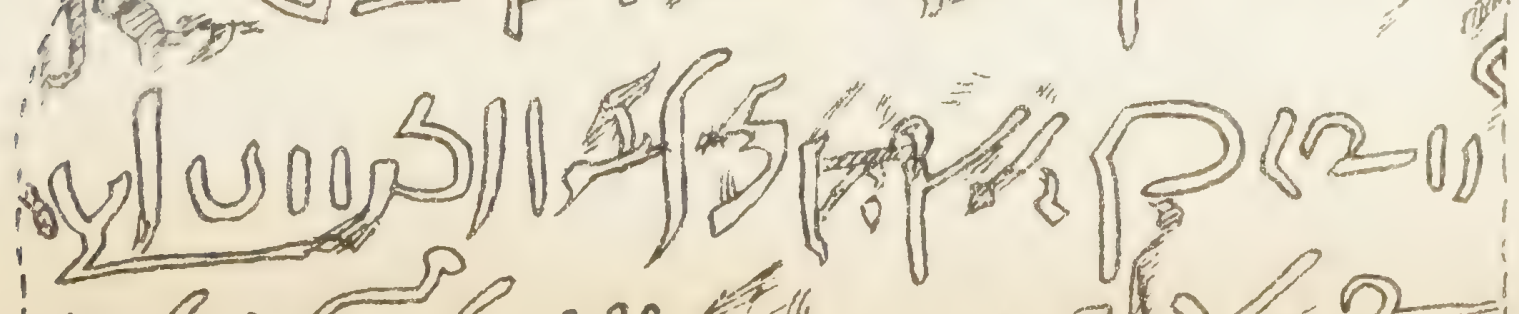

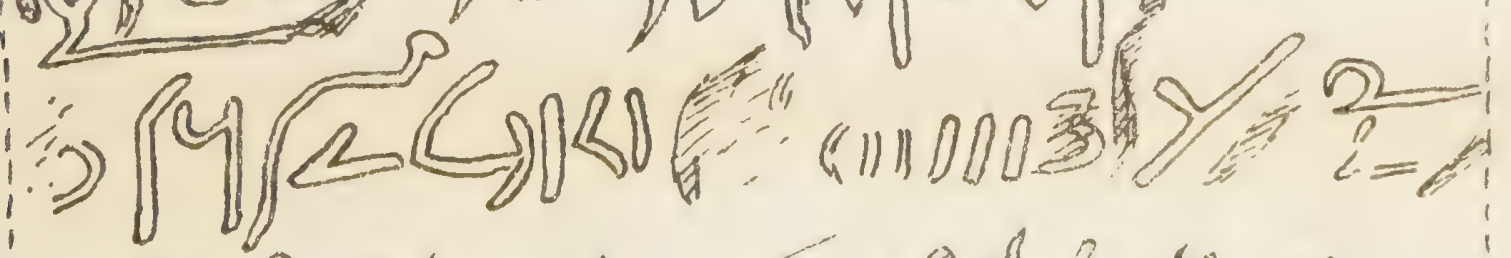

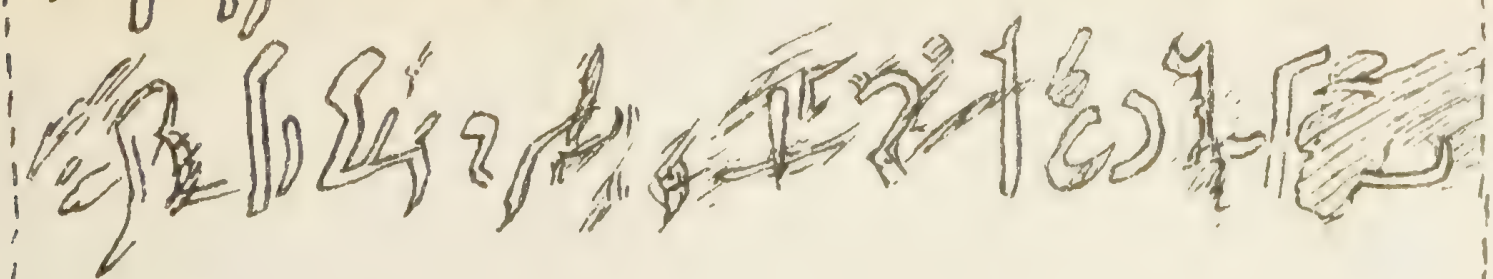

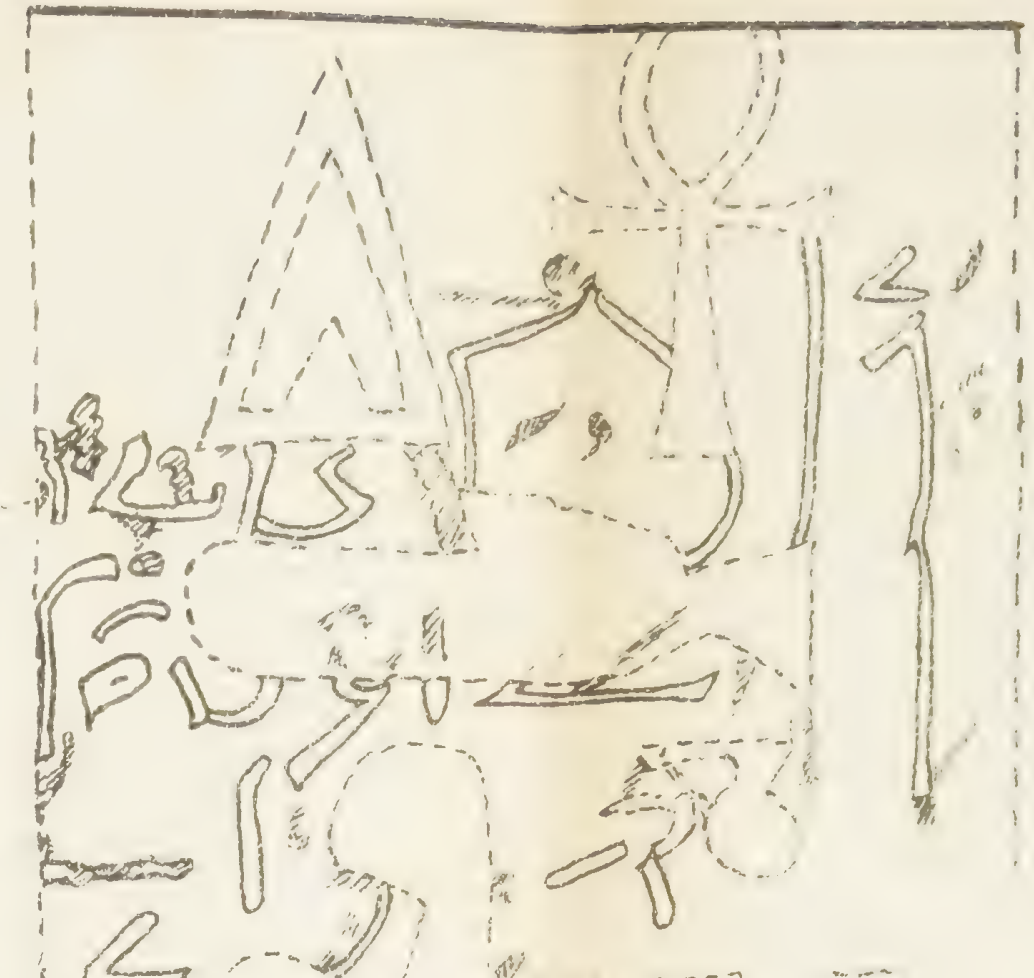

$(20)$

告: and 的 2. 2 1) $\int(605020$ 3) (ك)

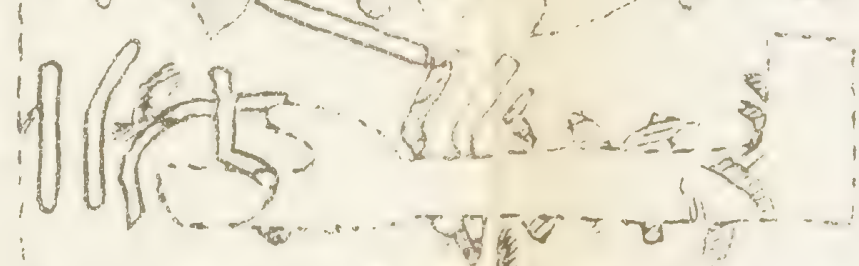

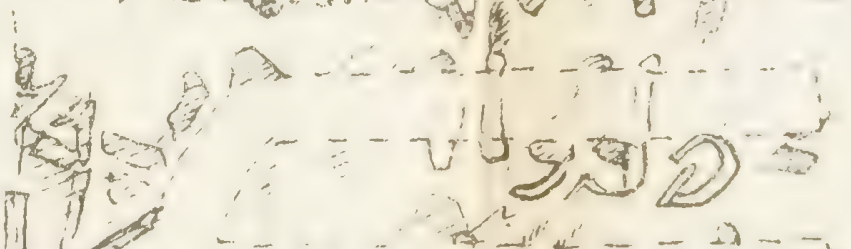

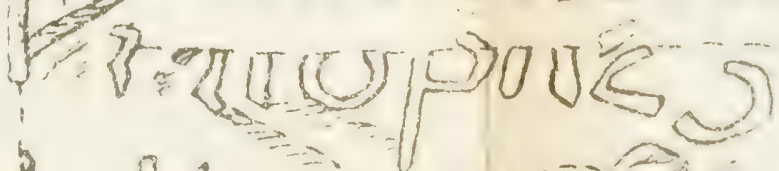

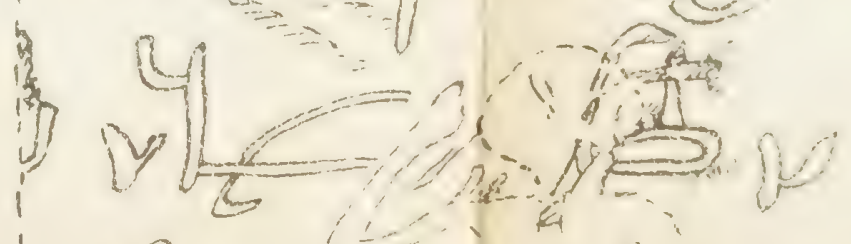
$\sqrt{2}(2 n)$ $\int_{0} \int_{S}(4)=0$ 
First Bilingual Decree of Philae, De

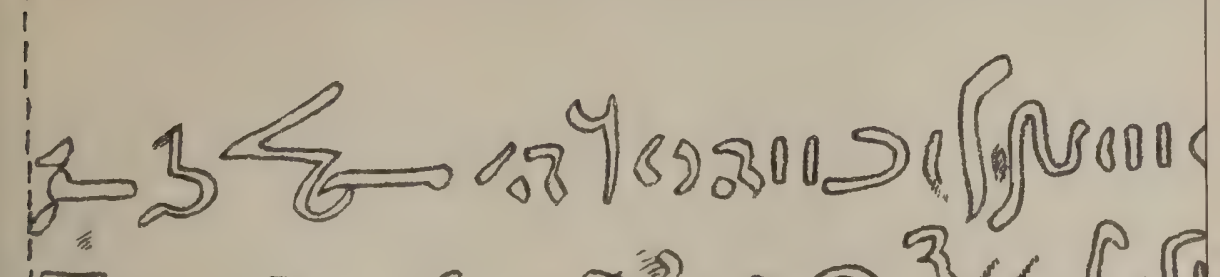

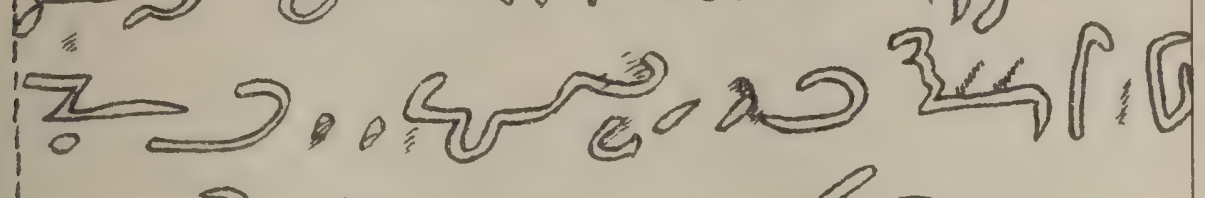

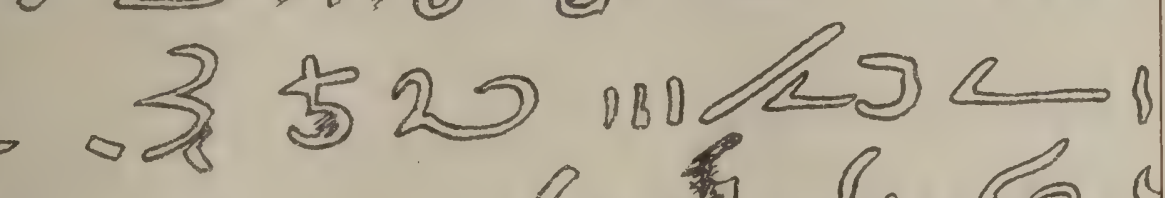

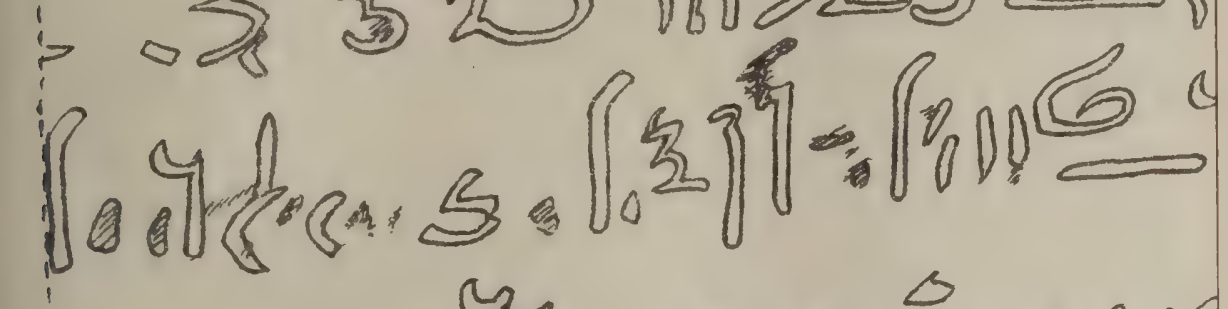

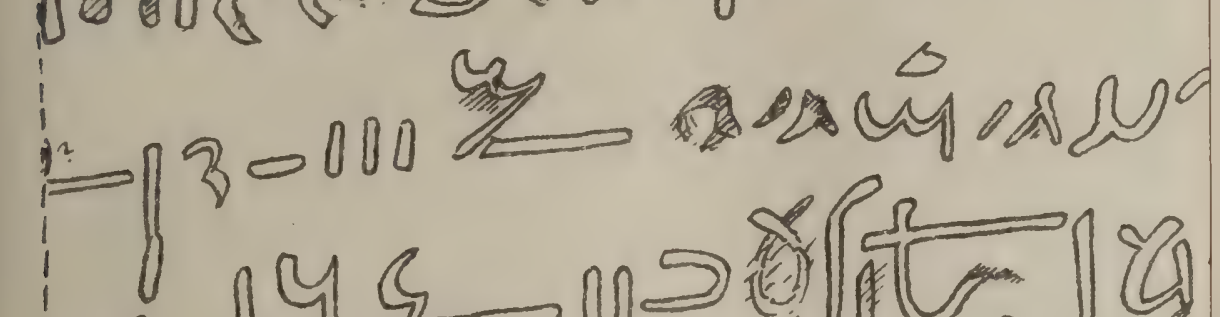

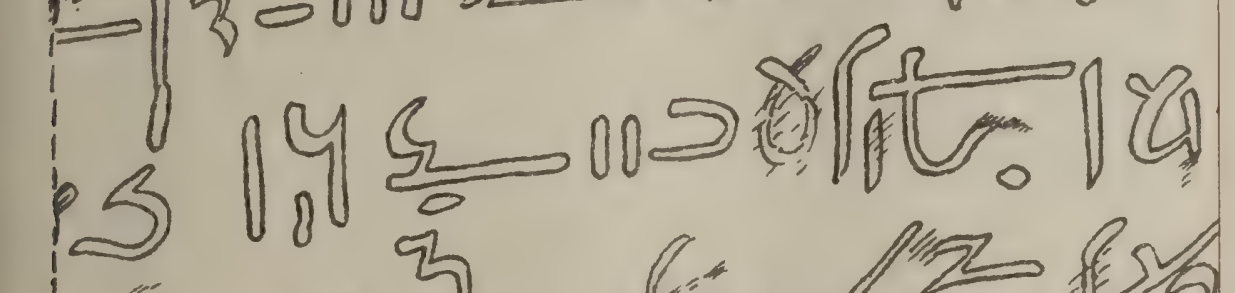

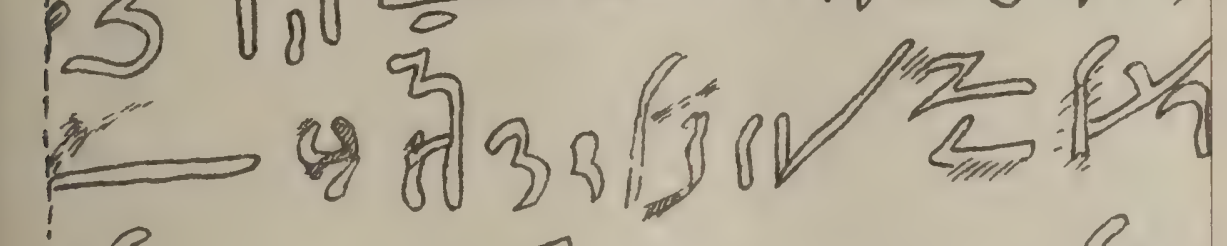

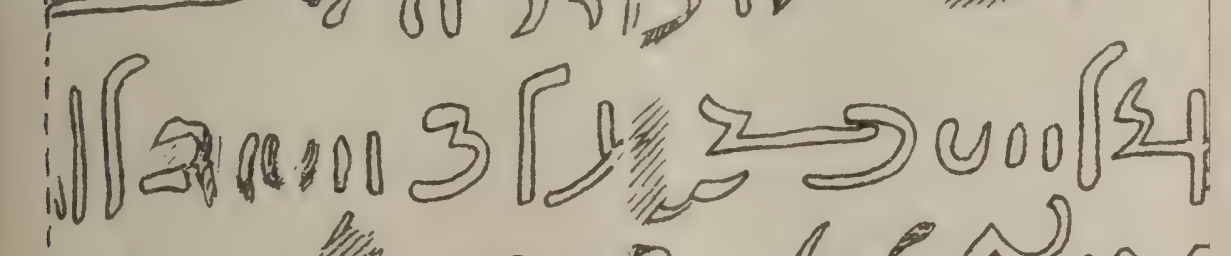

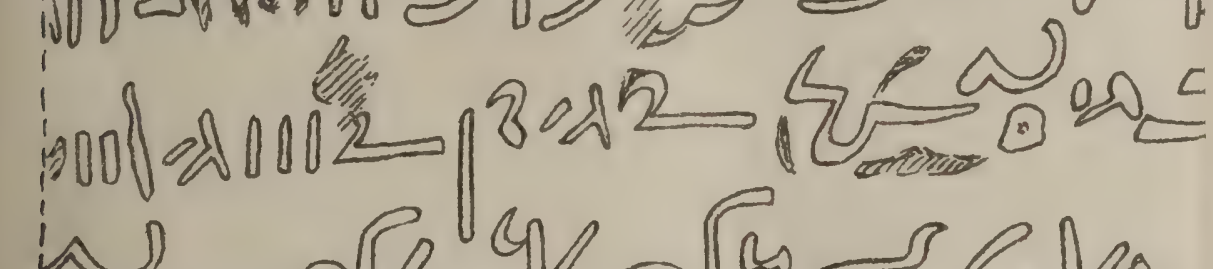

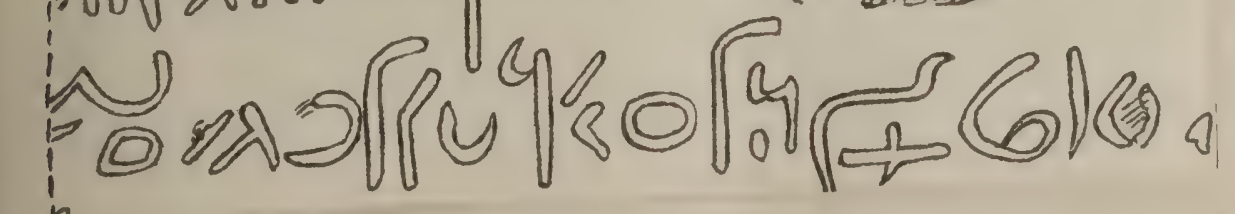


First Bilingual Decree of Philae, Demotic text

$61 / 2$ inches

竞900

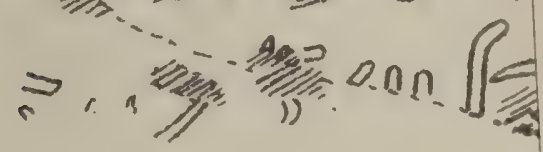

5

- Y. D. Dol 


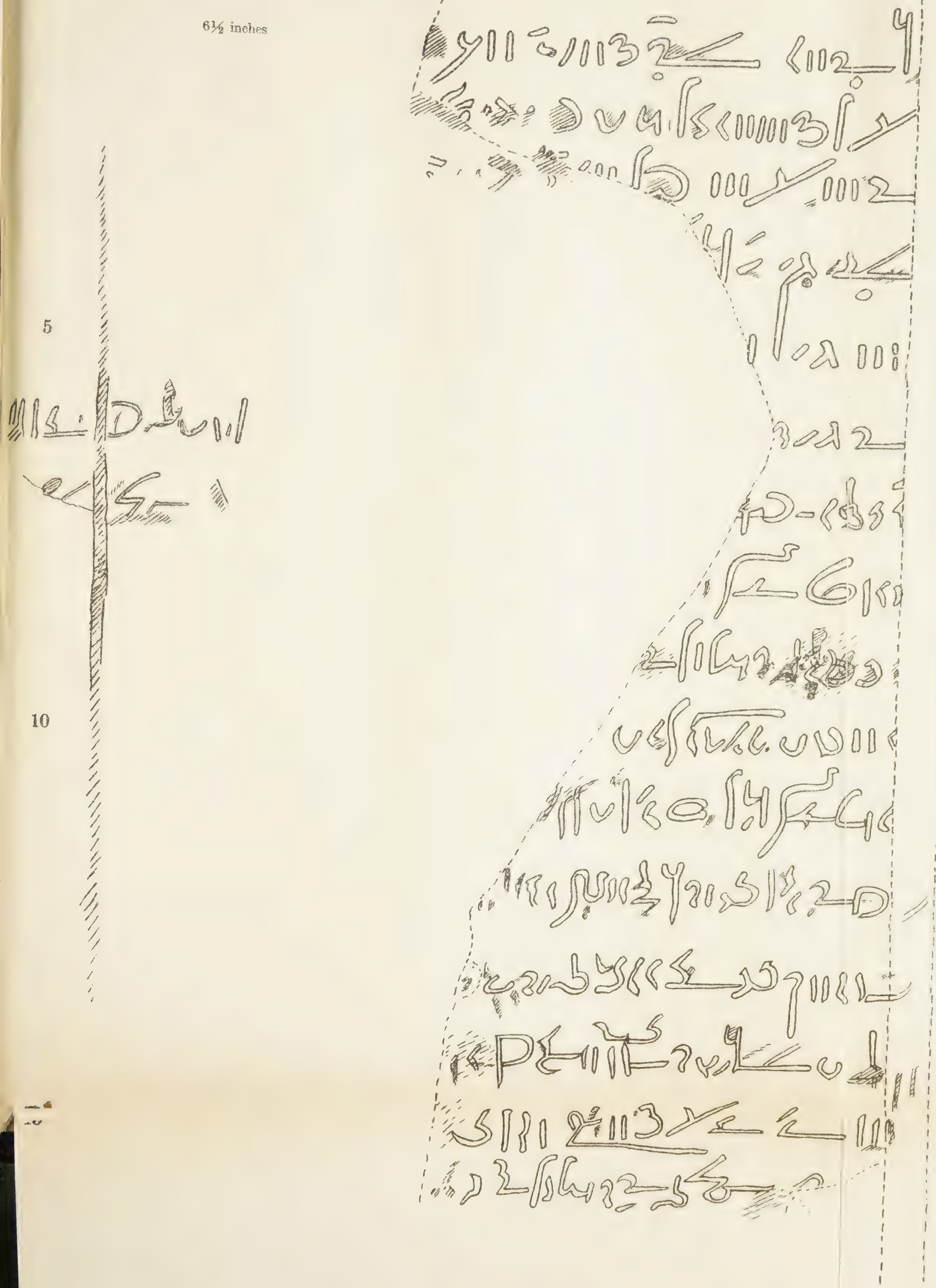




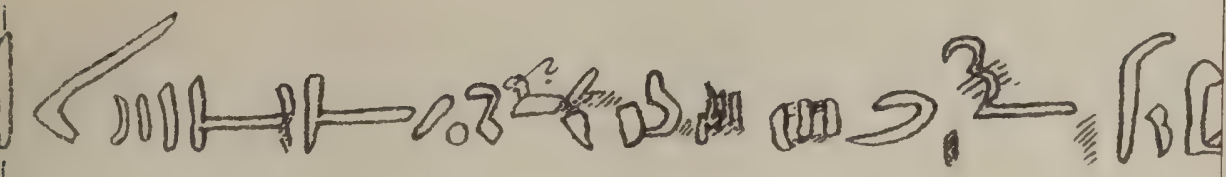

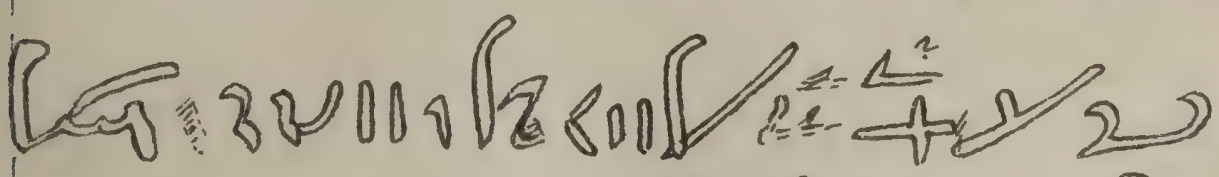

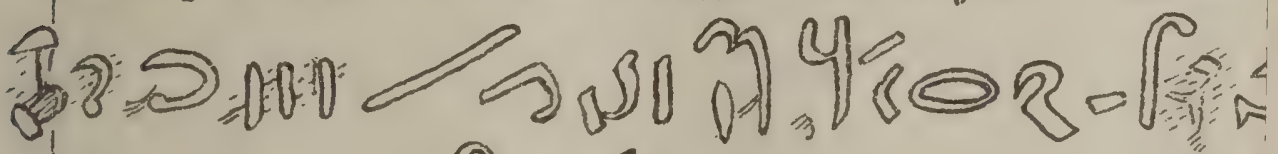

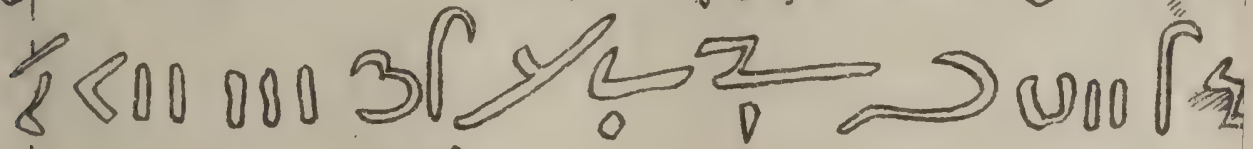

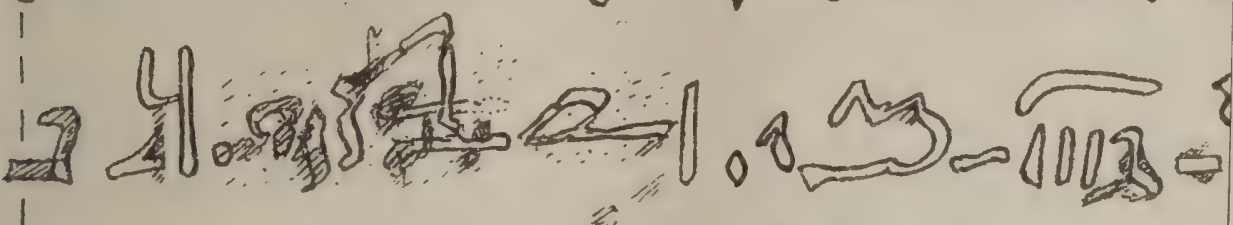

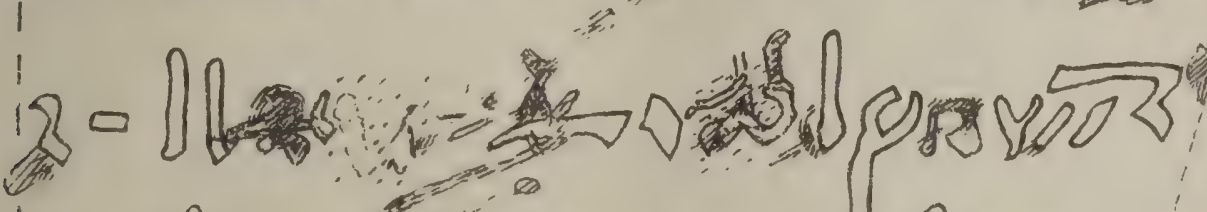

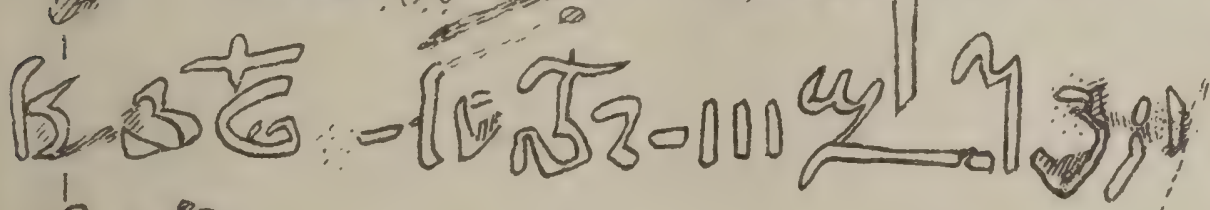

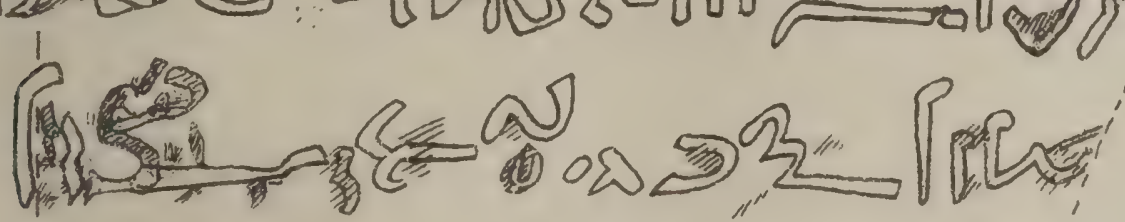

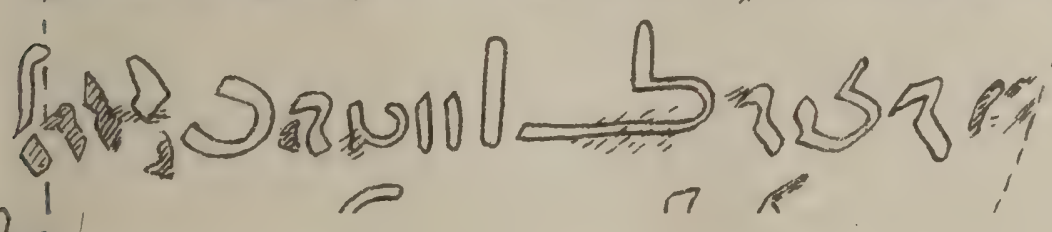
10 
First Bilingual Decree of Philae, Demotic text $d$.

PLATE 16

1 S J OOH

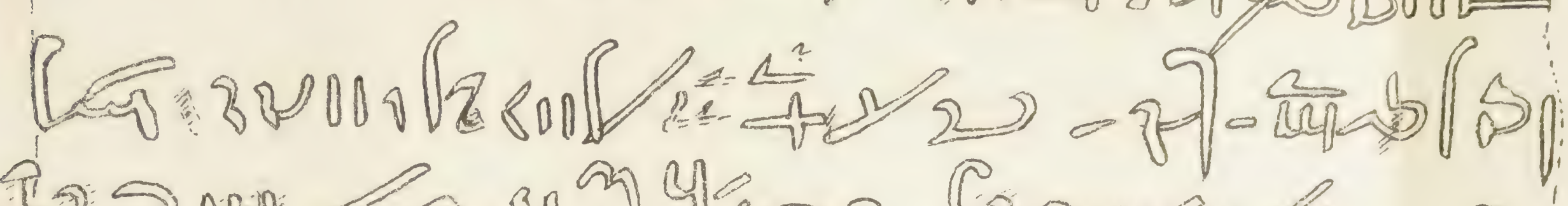
B.

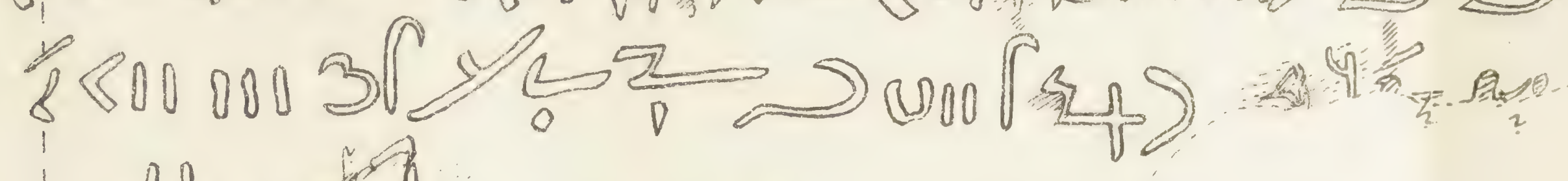

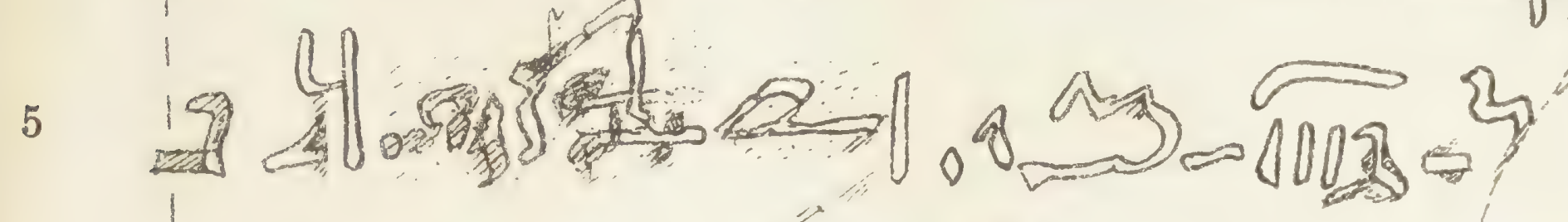

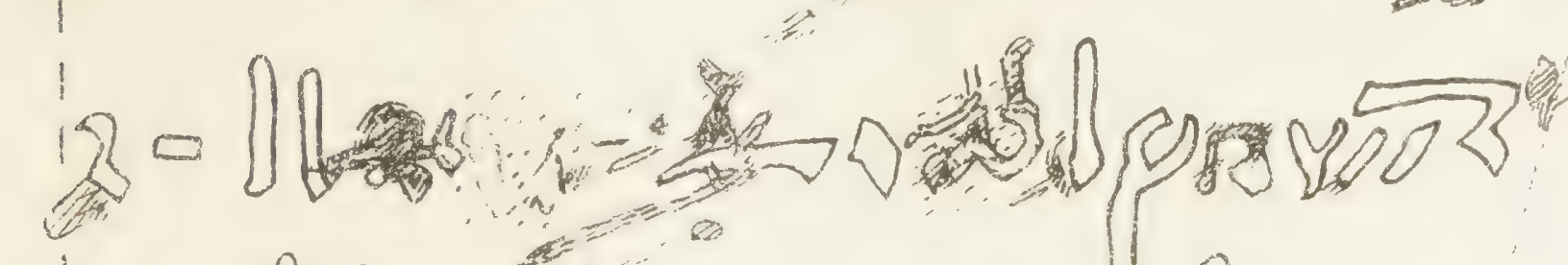

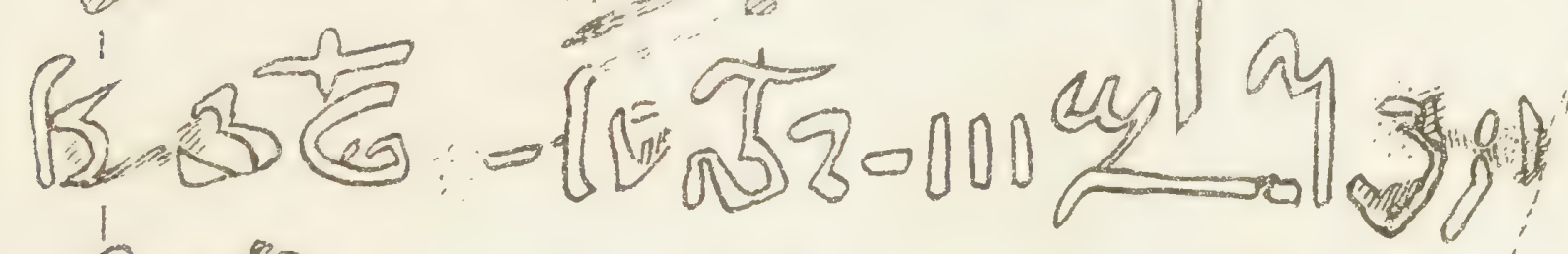

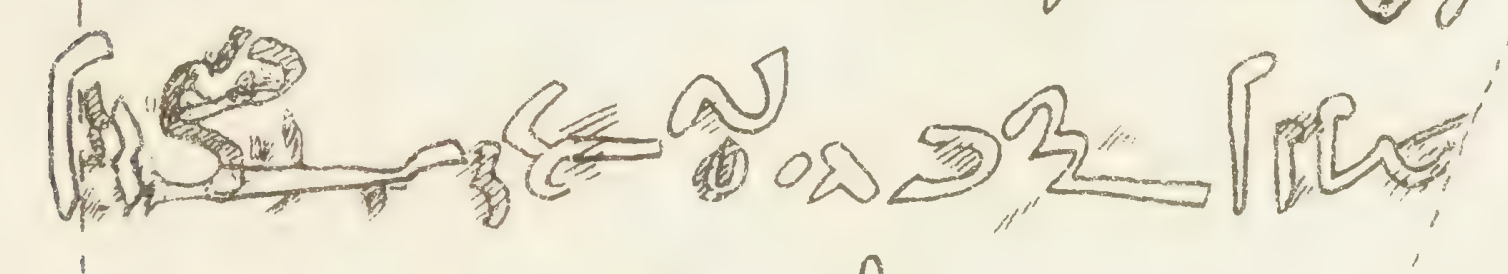

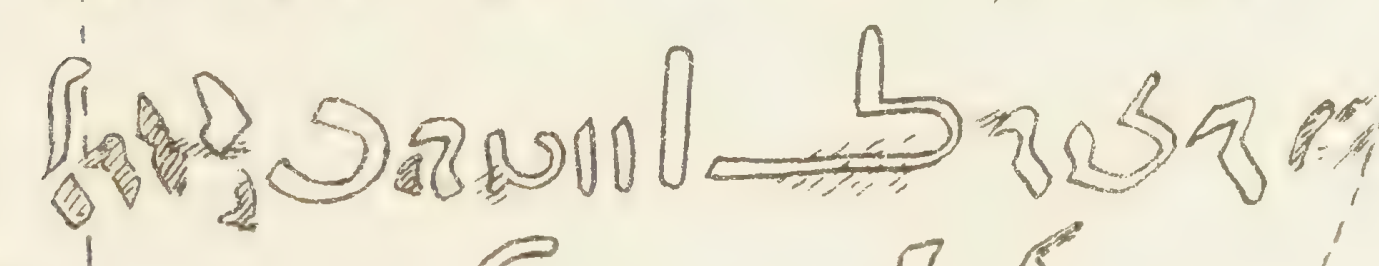

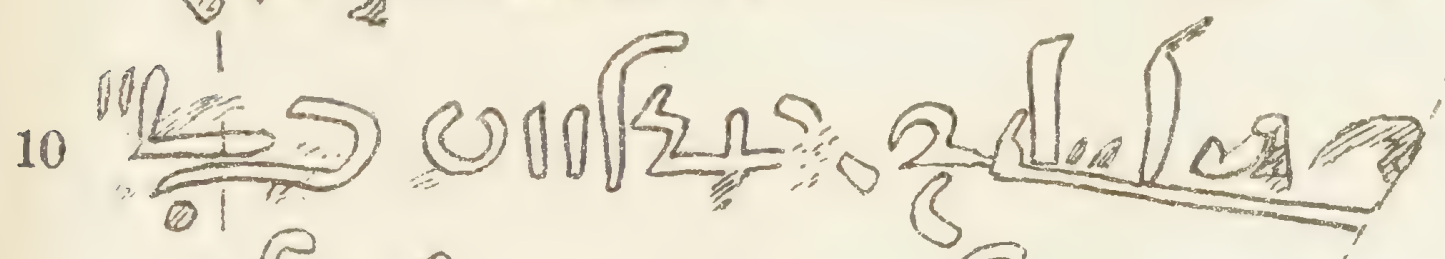

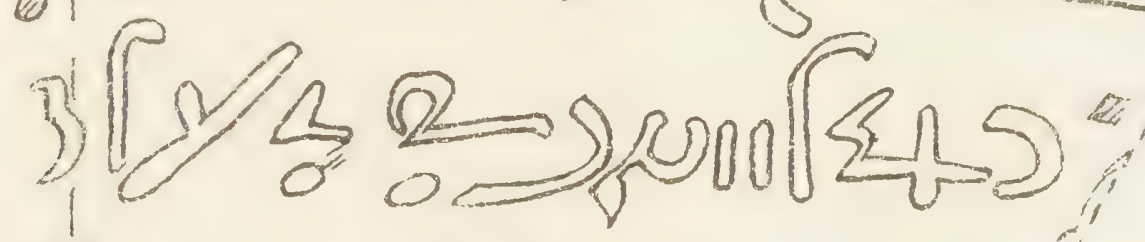

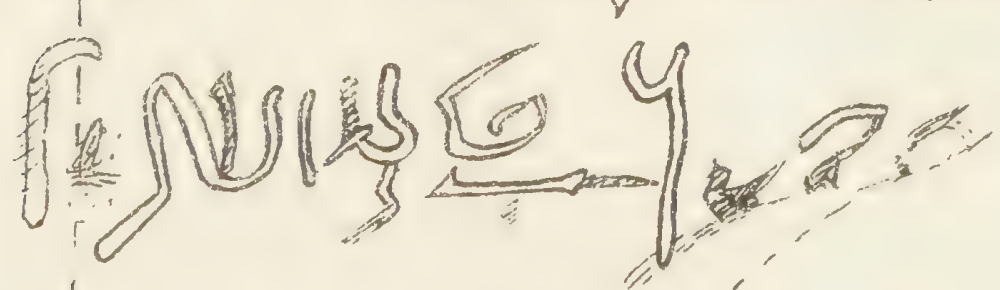

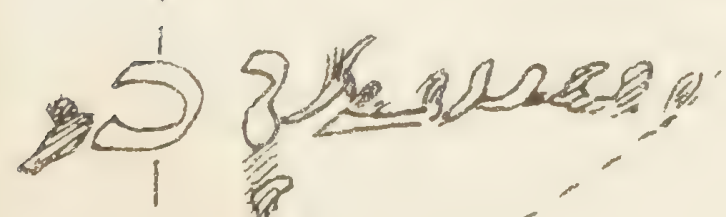

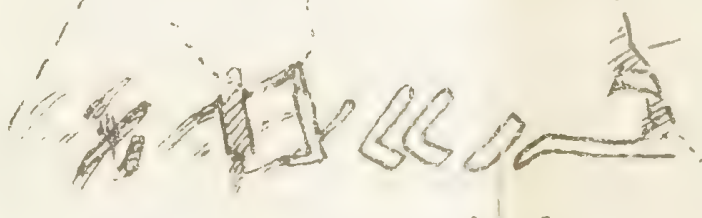

10

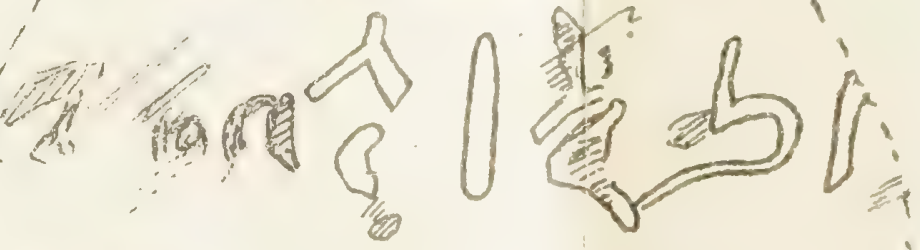

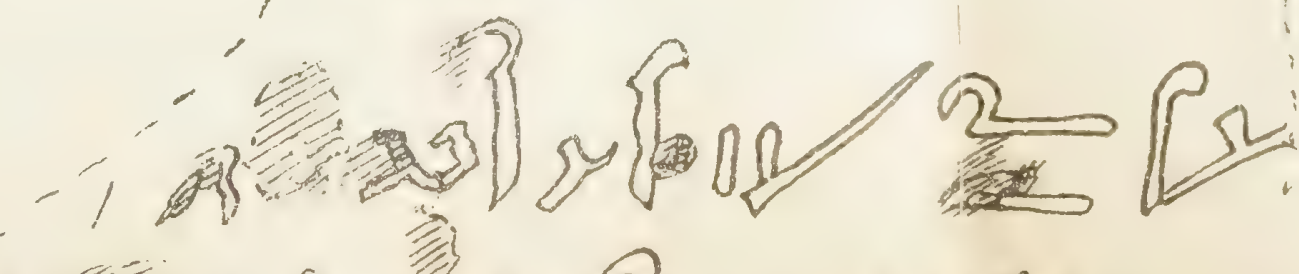

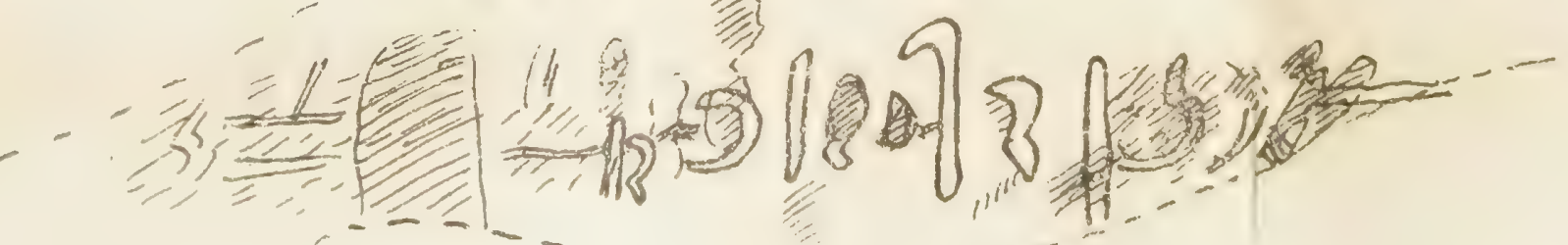


First Bilingual Decree of Philae, Demotic text $e$.

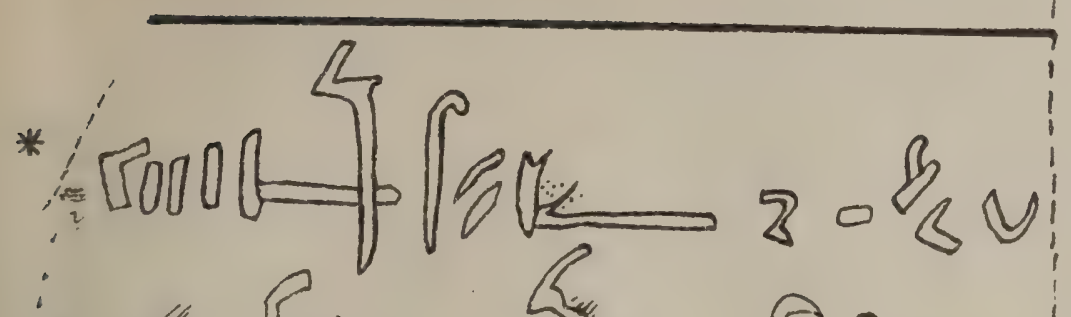

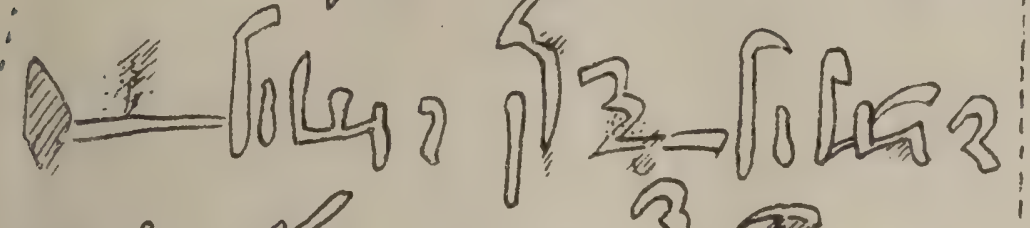

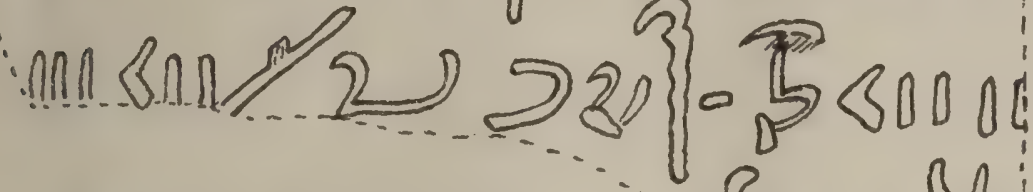

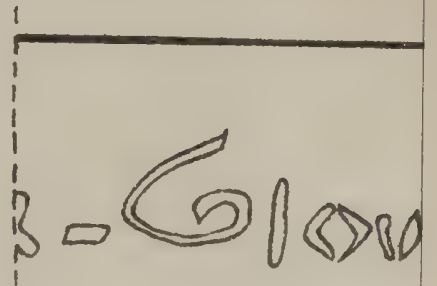

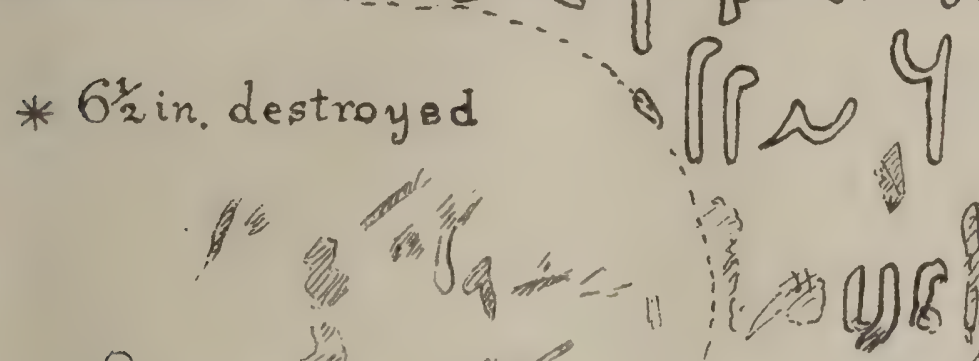

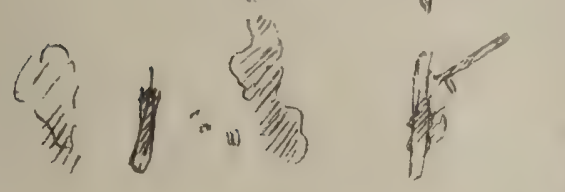

$l_{0}$

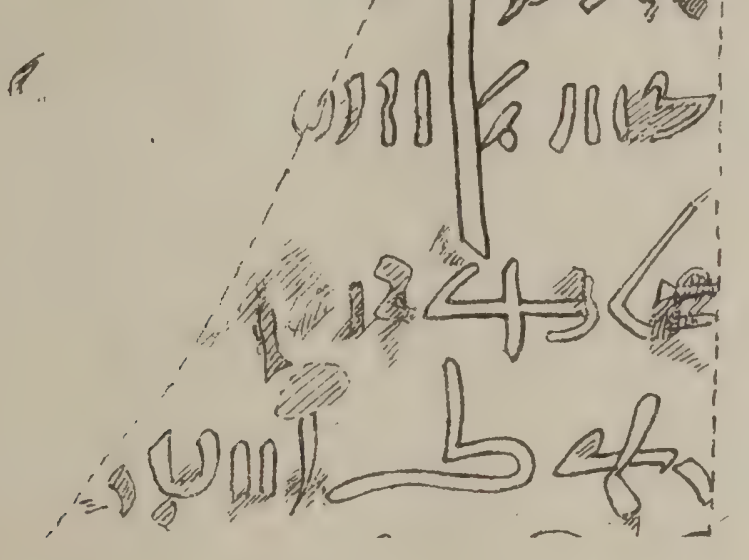

min $223=$

3) $\int_{0}^{\pi / 2 \pi} \frac{\pi}{\sqrt{2}}$

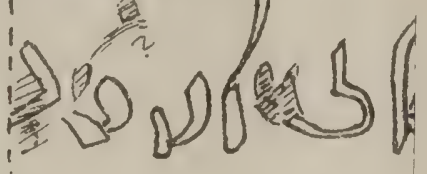

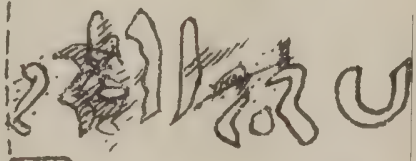
$\frac{2}{\sqrt{2}}$ 50 


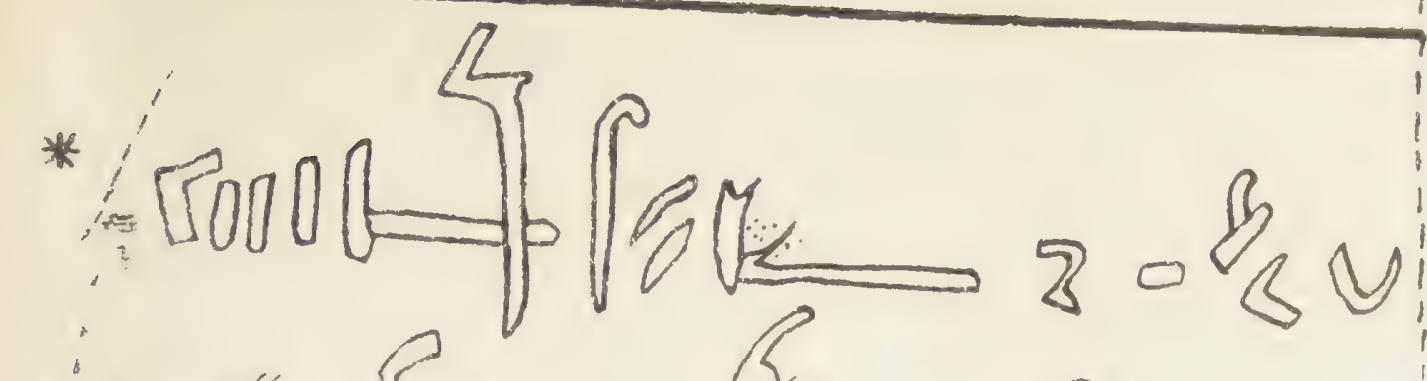

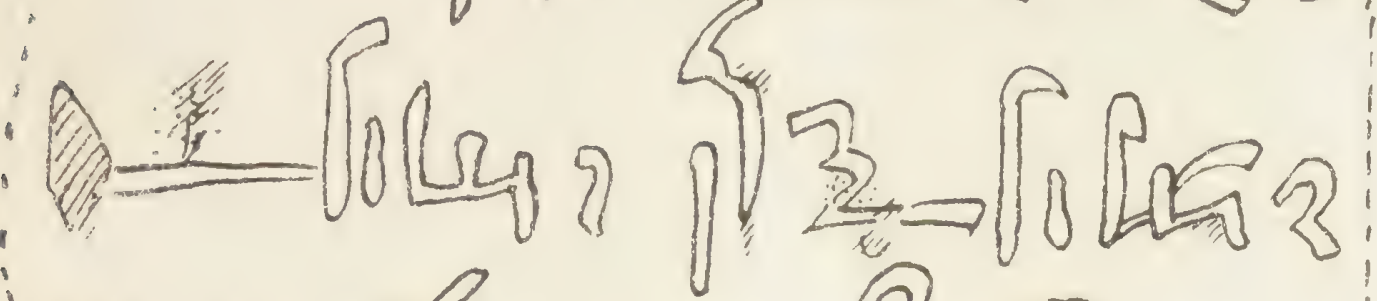
mann 2238$\}=0300$

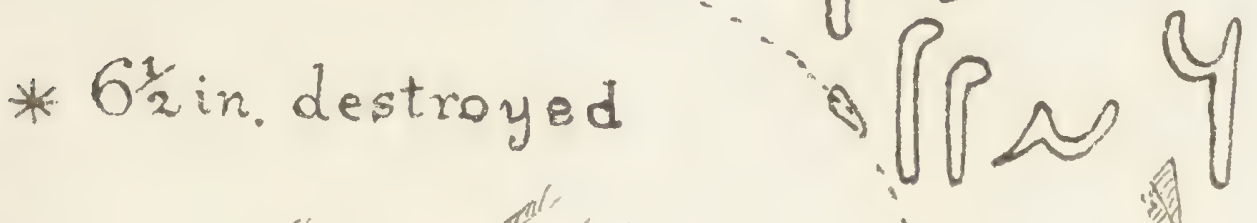
5

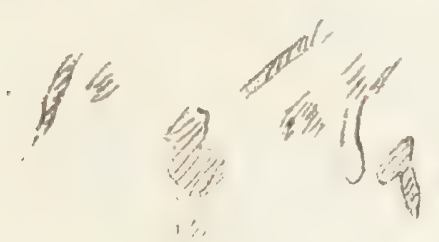

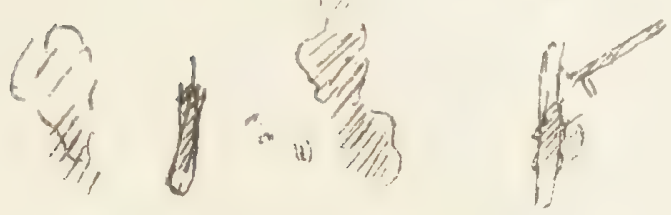

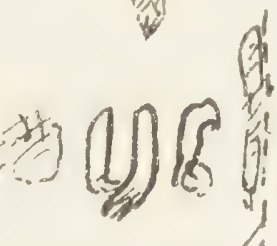

$\sqrt{6}$

$$
\text { r. }
$$$$
\text { ( }
$$

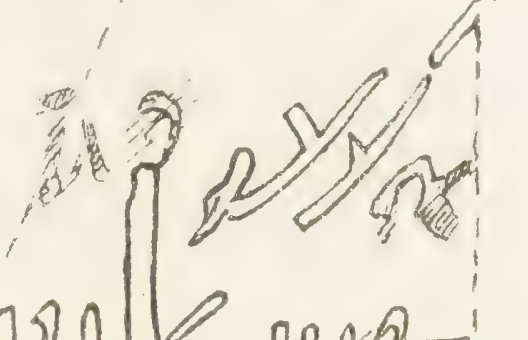

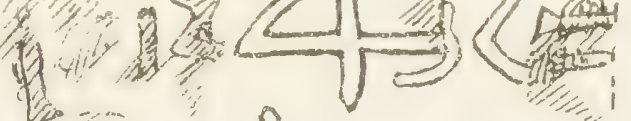
Q won 5 \& 40 $3,135450 \sqrt{3} \sqrt{2}$

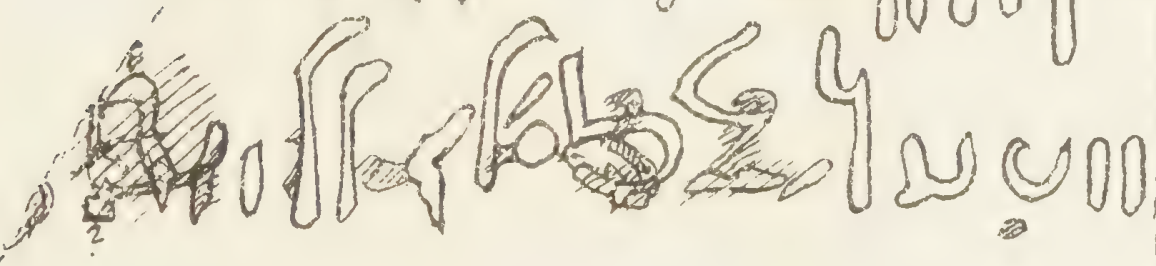

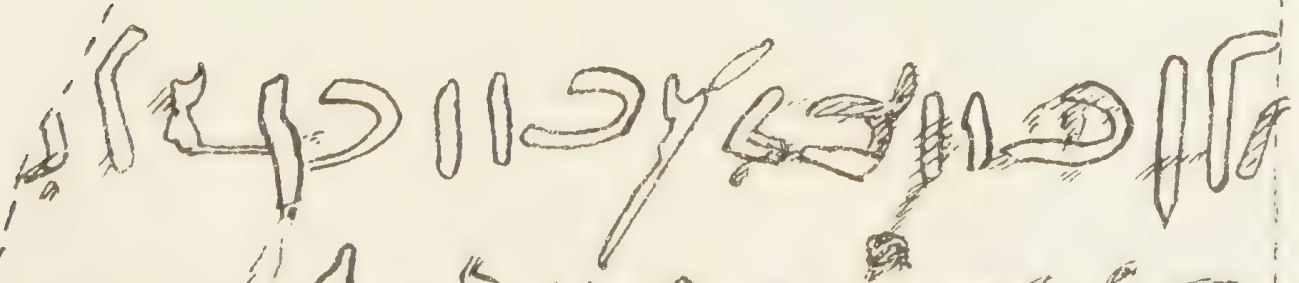

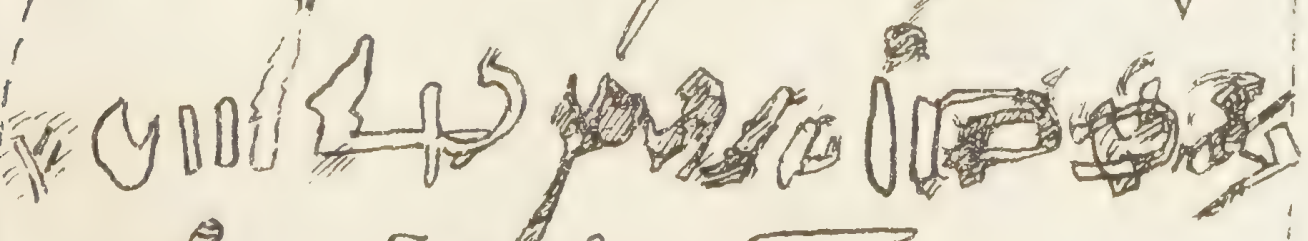

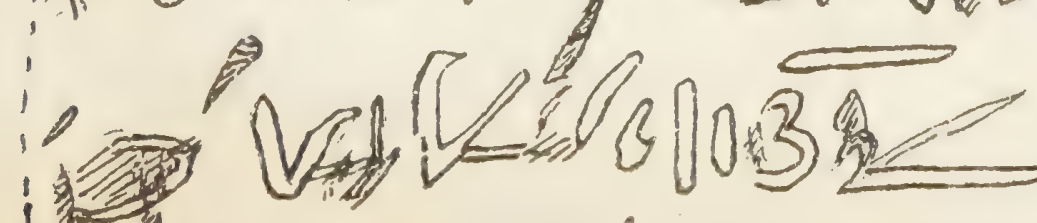

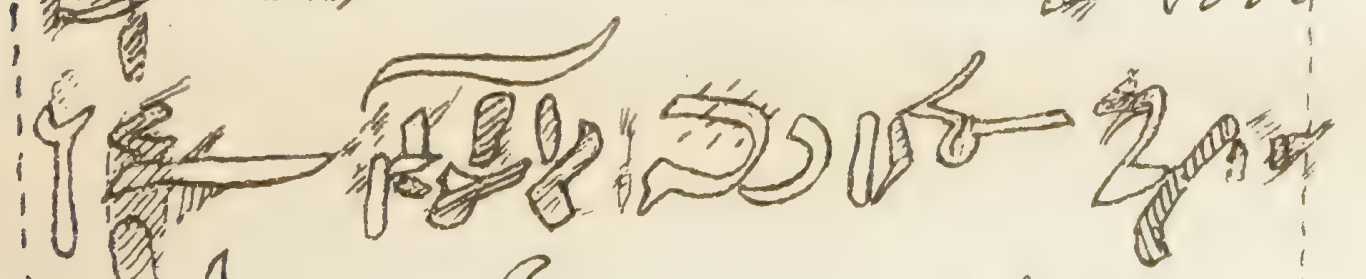

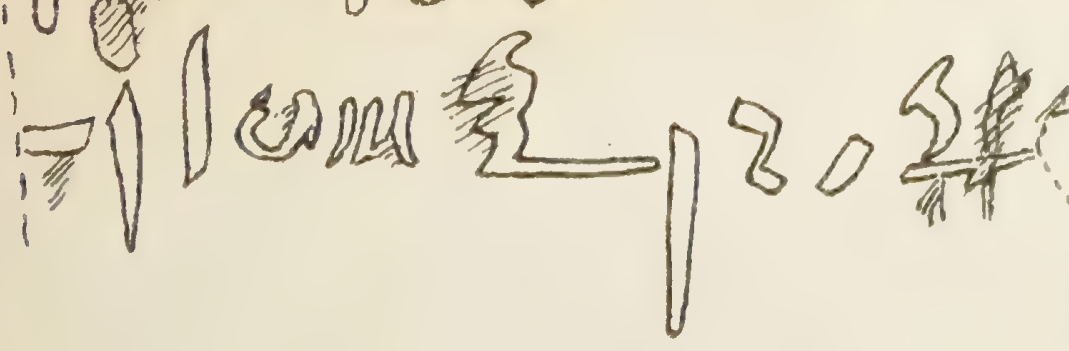

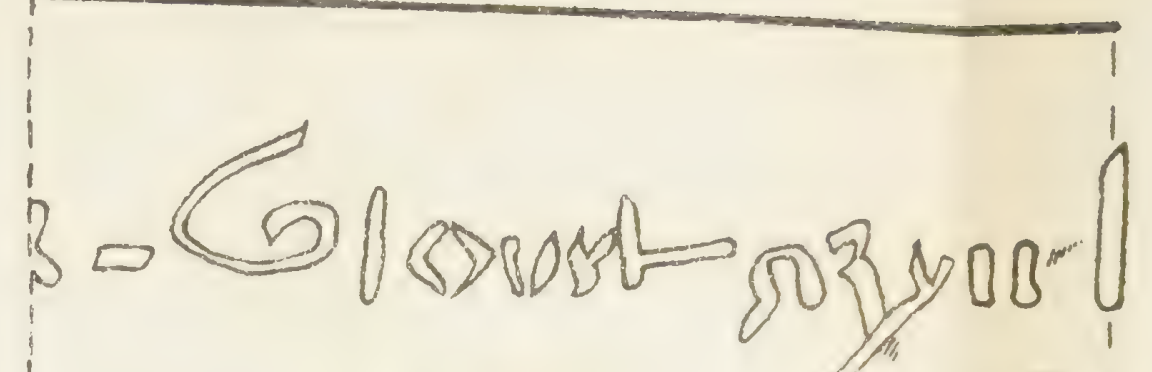

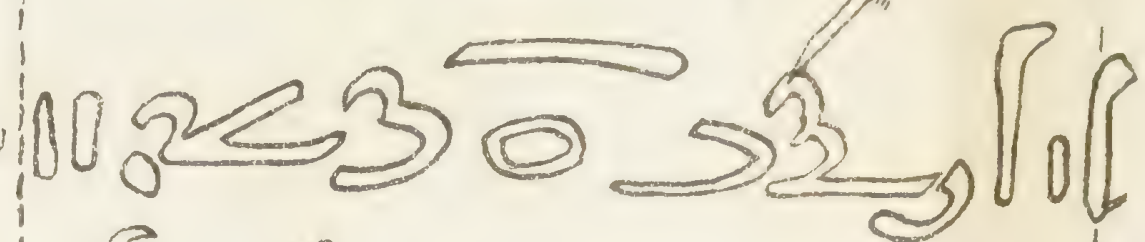
$3 \sqrt{2} \cdot 2 \cdot 0 \frac{2}{2} 4$ - $\int_{0}=(013) \times \sqrt{3}$

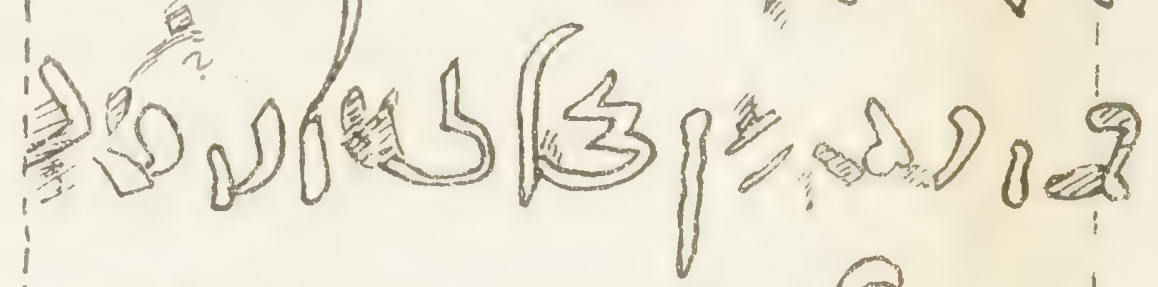

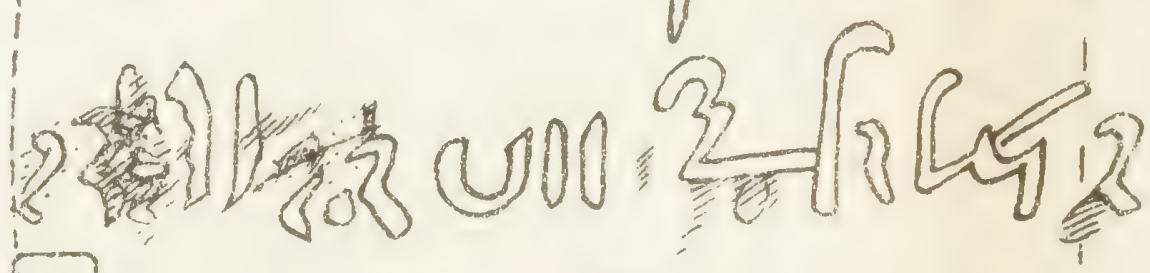

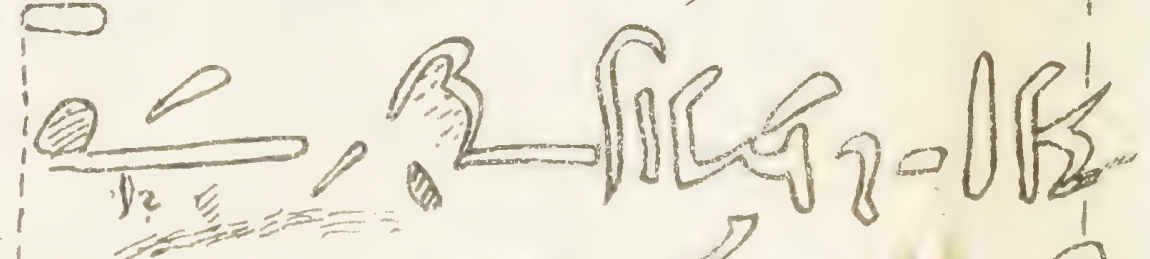

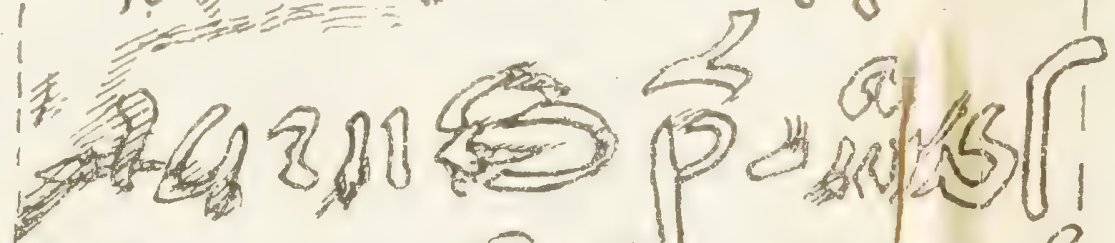

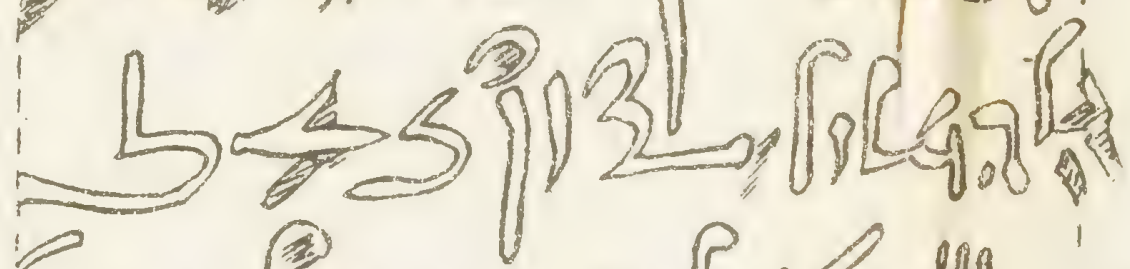

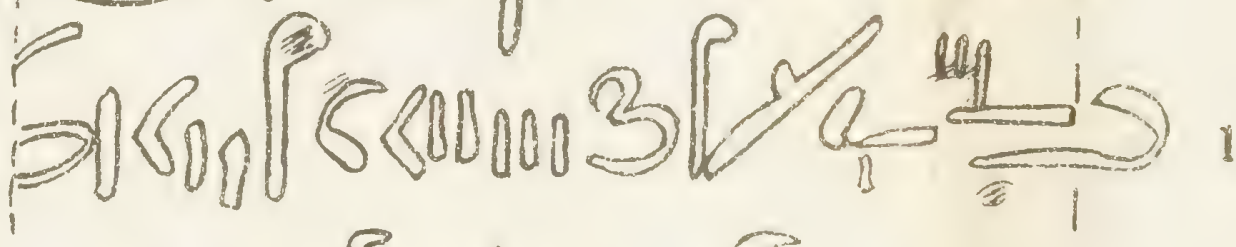

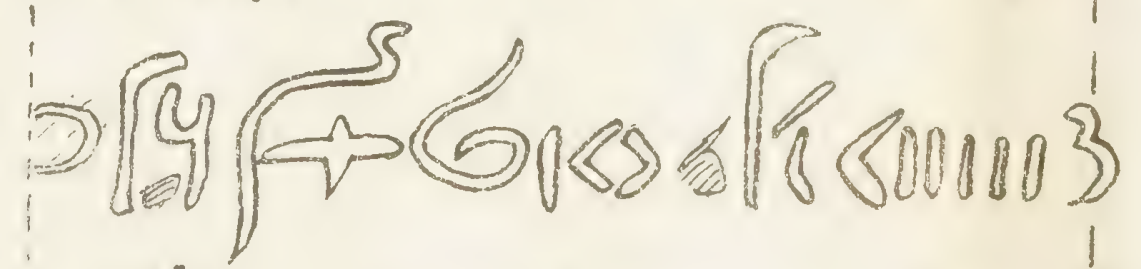

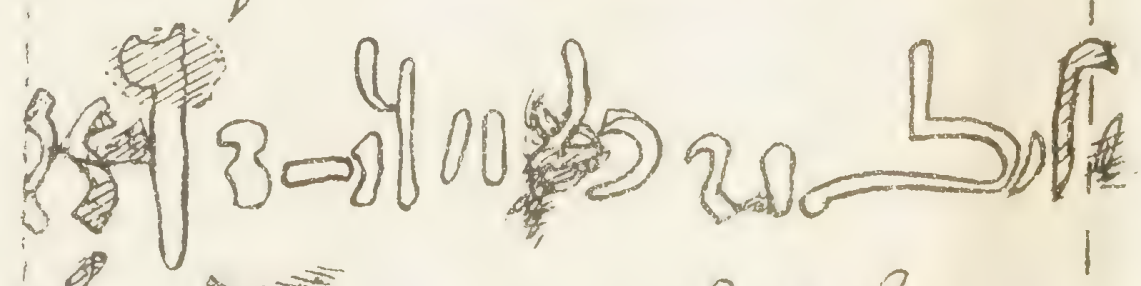
(1\% 2 30 a $=0$ 
First Bilingual Decree of Philae, Demotic text $f$.

PLATE 18

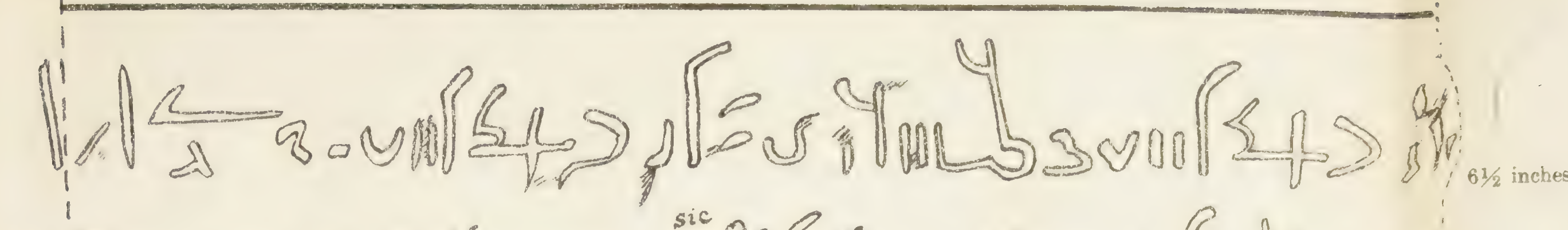

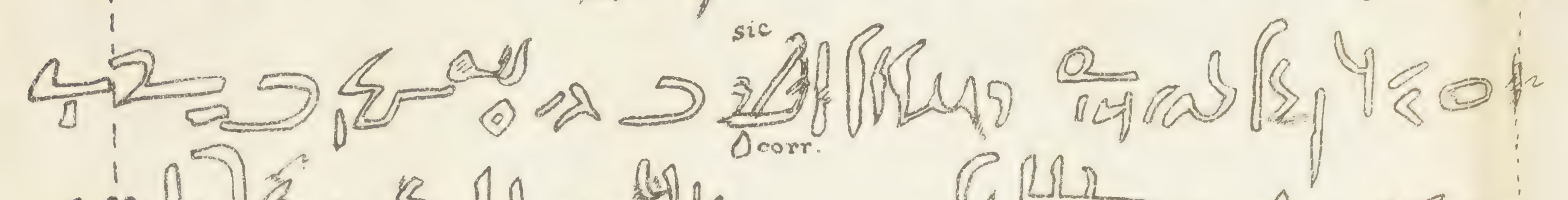

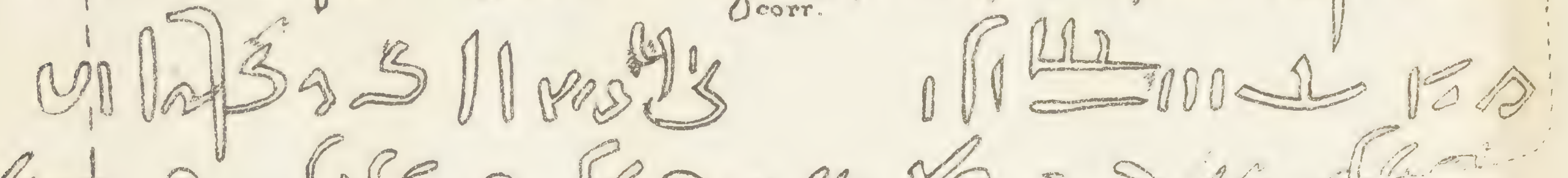

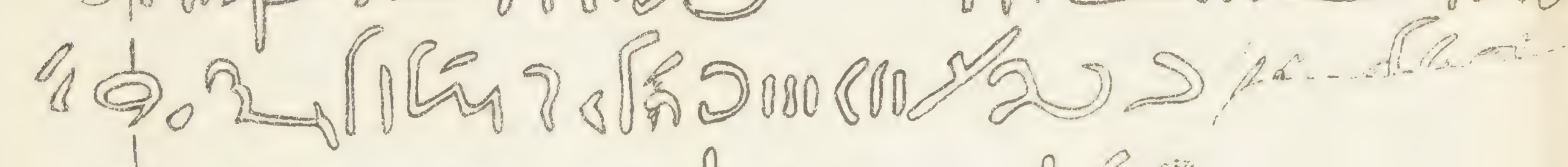

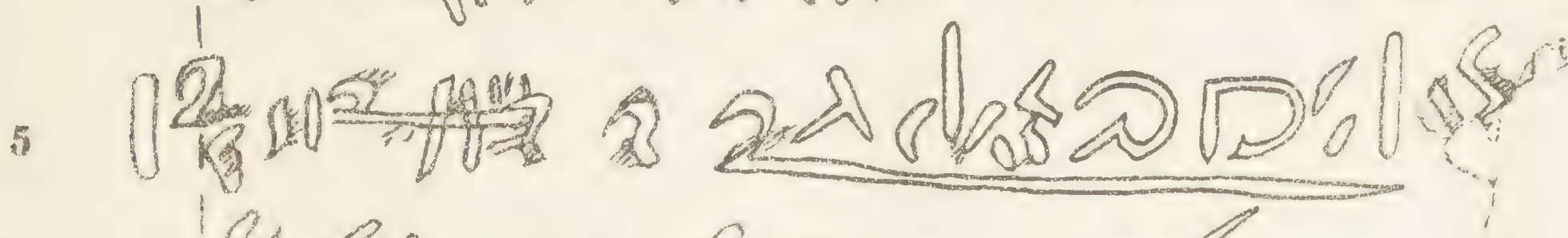

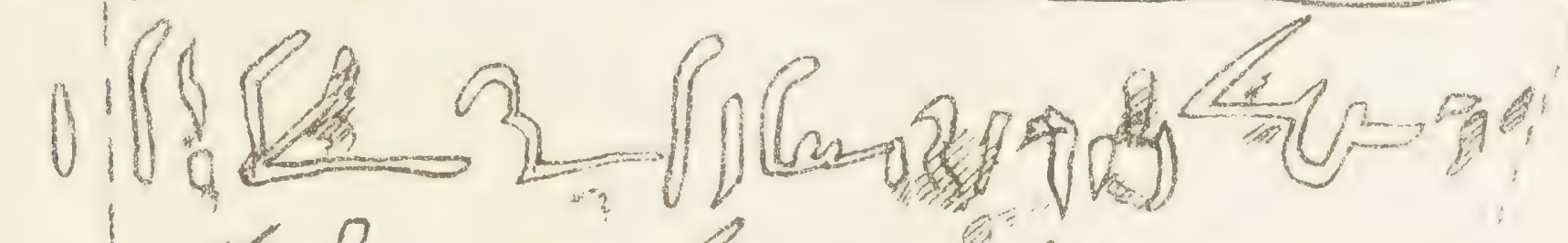

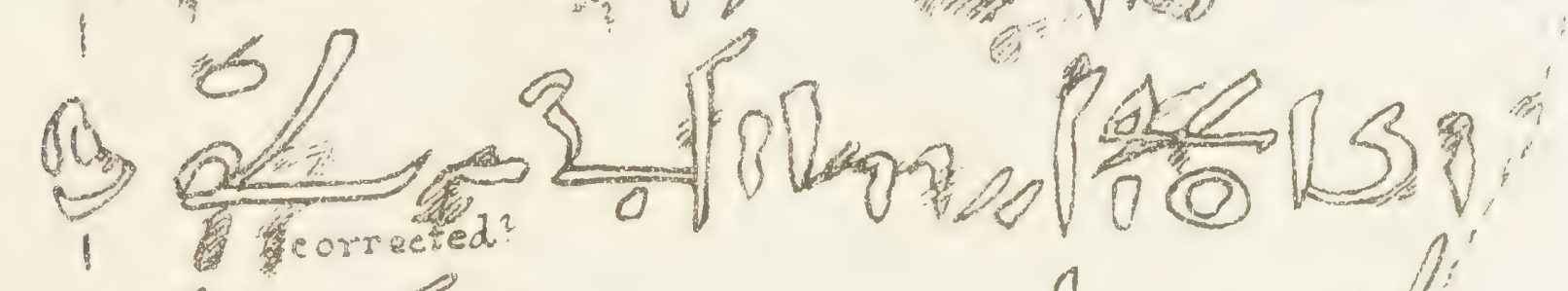

9.9.

S)

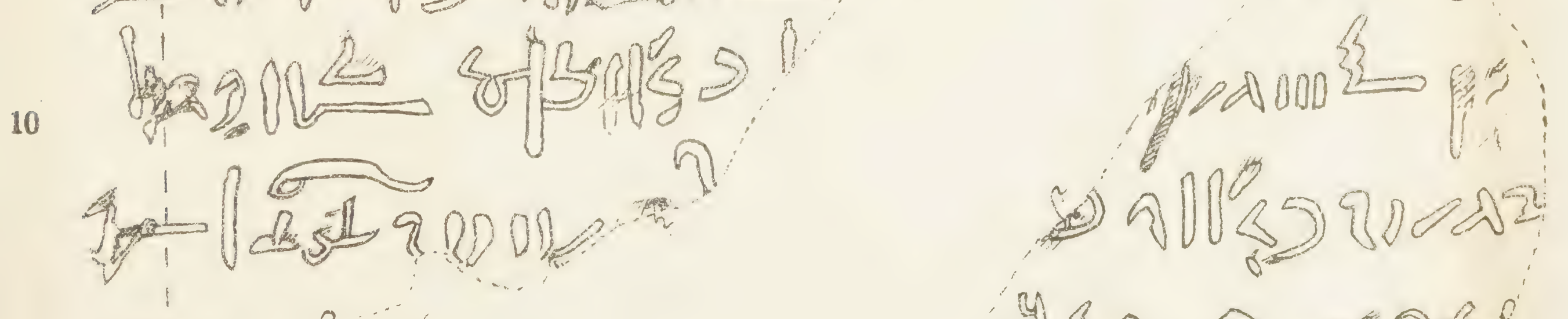

10

$\sqrt{2} ?$

$343200030^{\circ}$

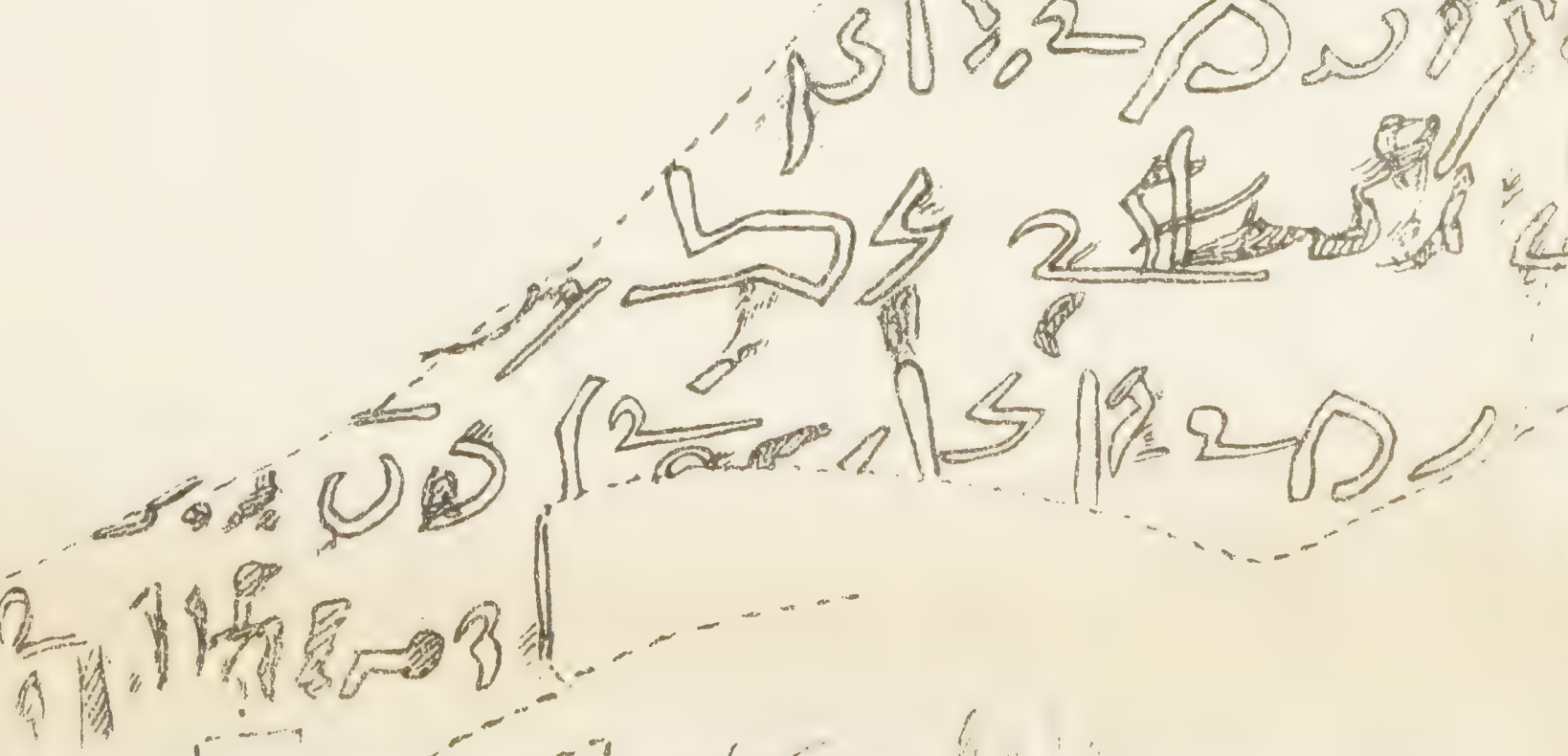


First Bilingual Decree of Philae, Demotic text g.

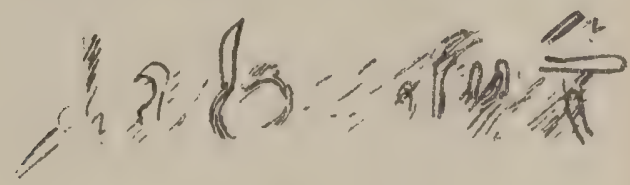

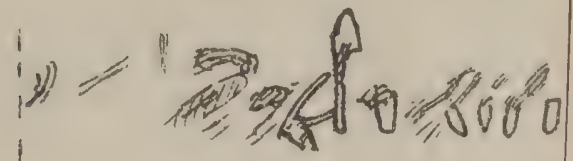

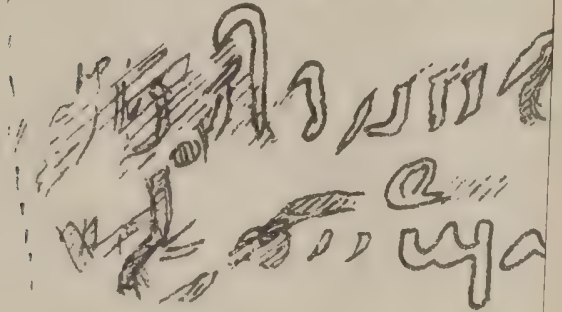

$$
\begin{aligned}
& \text { 1 } \\
& \frac{2}{0} \text { NPs }
\end{aligned}
$$

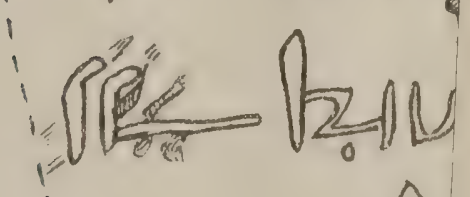

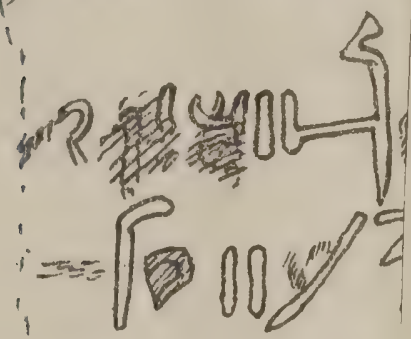

$$
\begin{aligned}
& \text { कsont }
\end{aligned}
$$




$$
\text { 4. }
$$

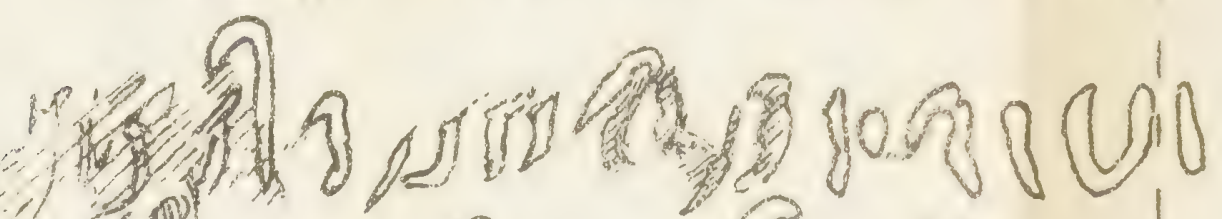

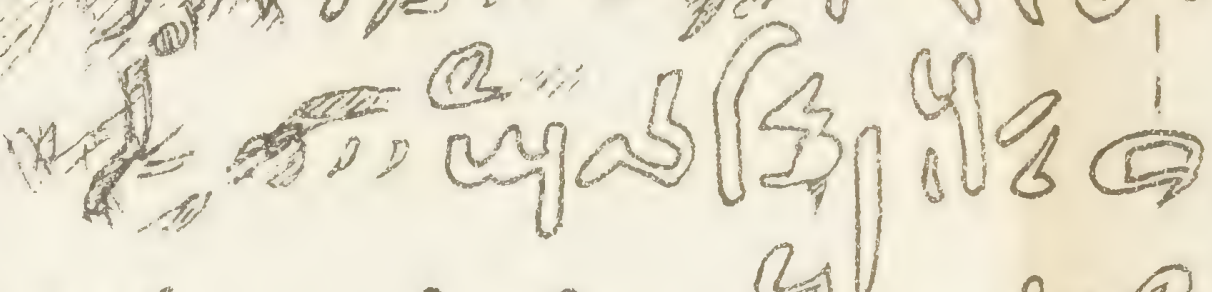
A

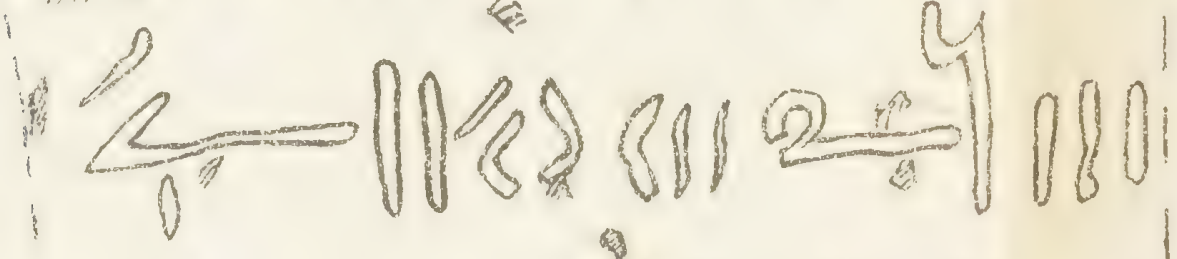

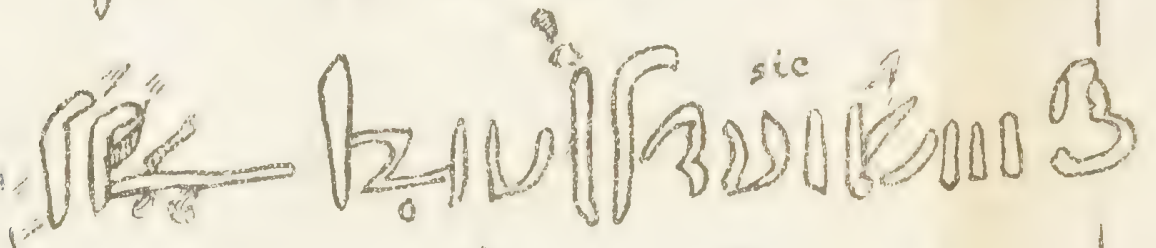

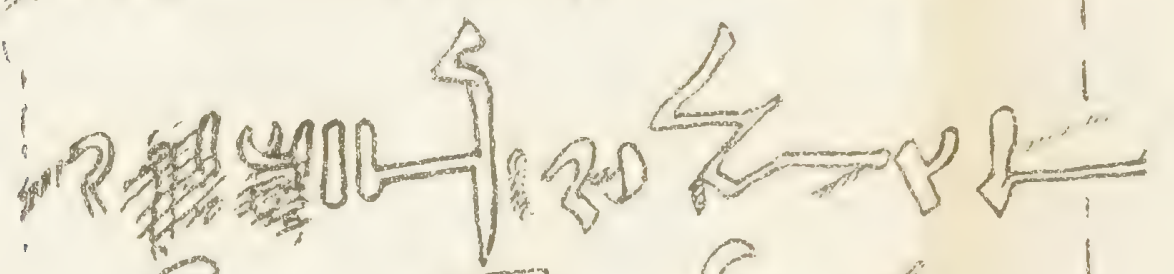

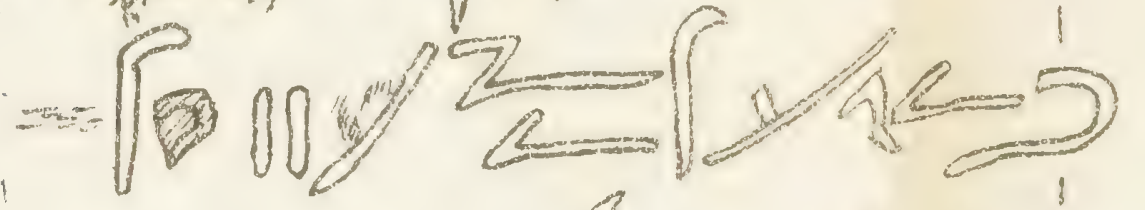

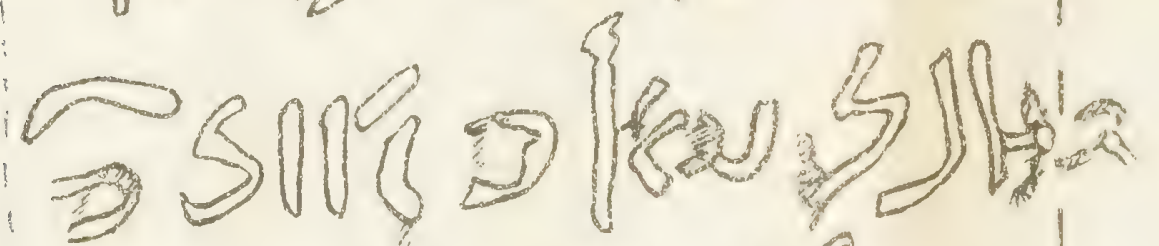

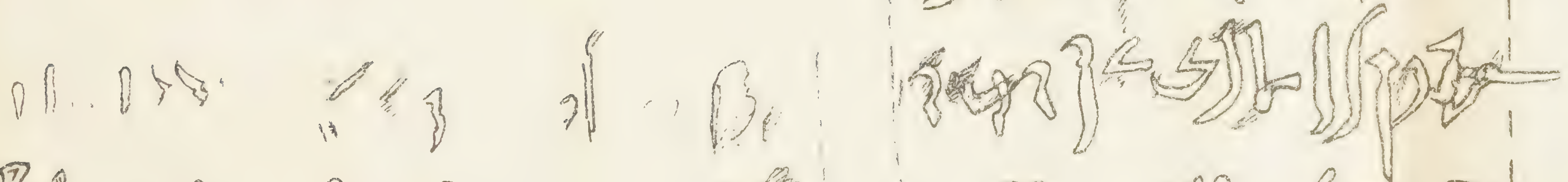

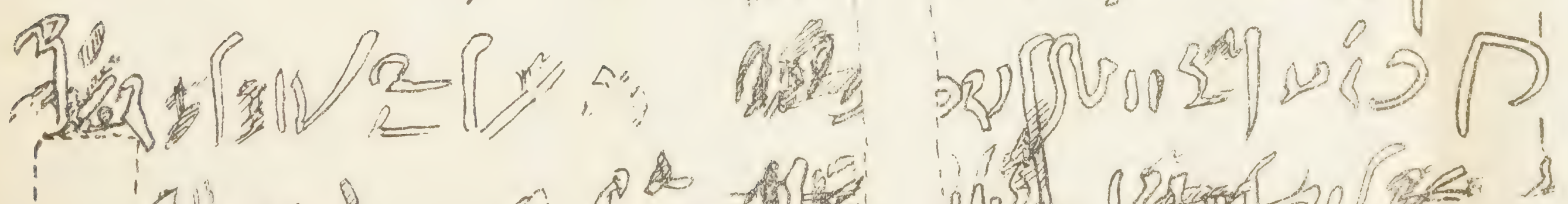

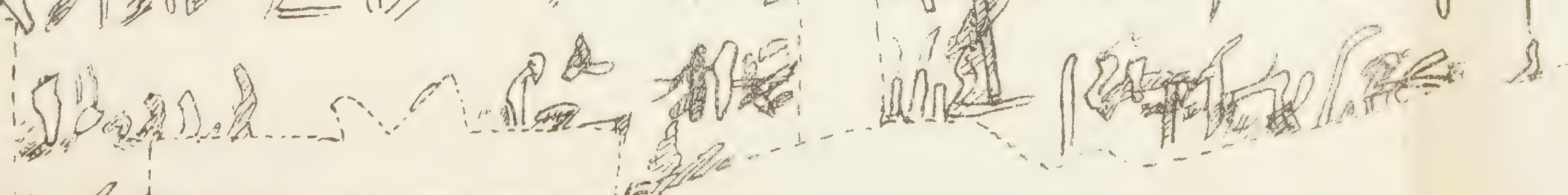

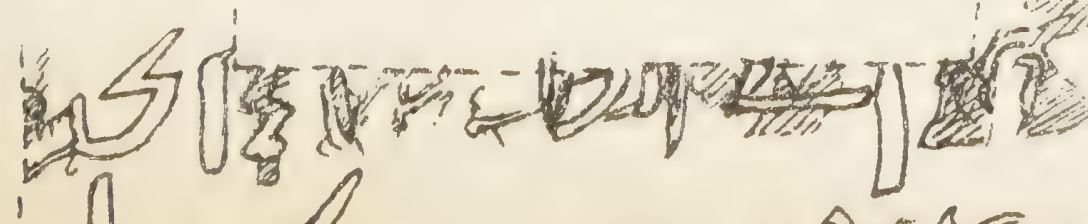

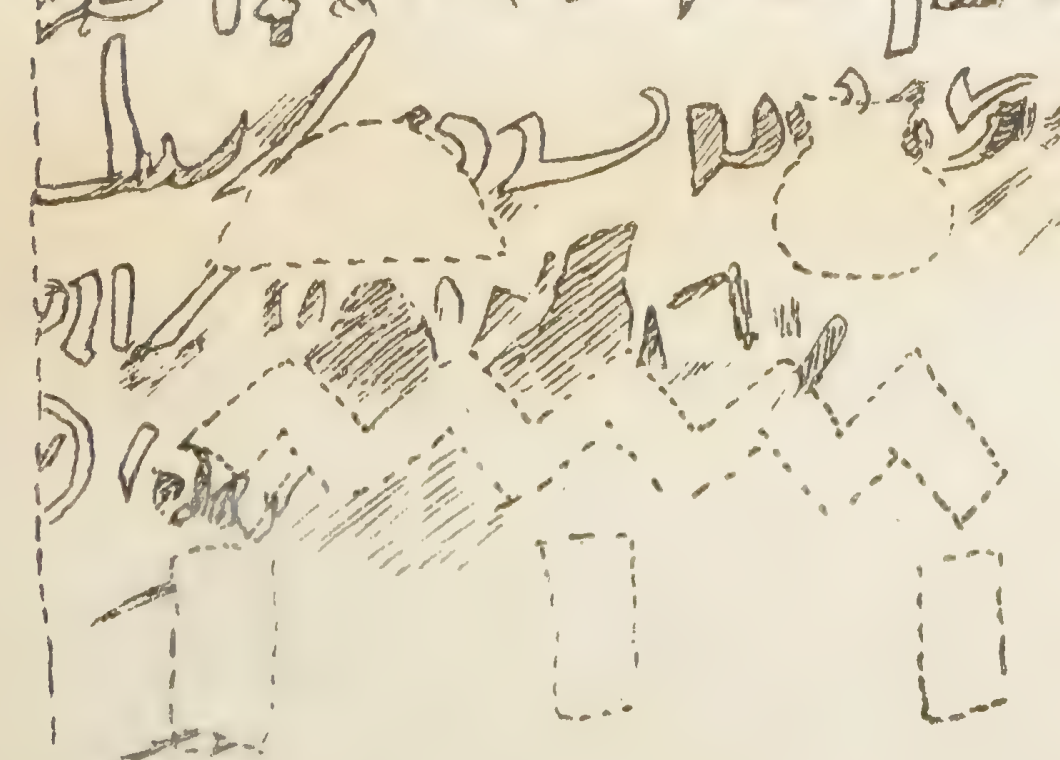


First Bilingual Decree of Philae, Demotic text $h$.

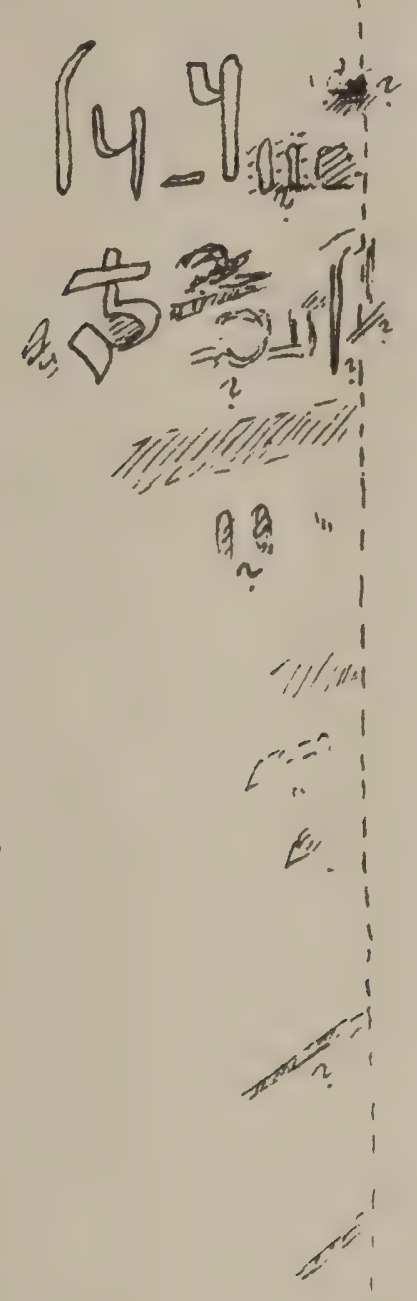




$$
\text { Un }
$$

5

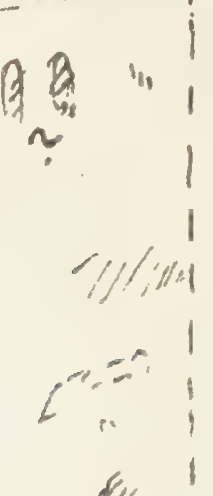

E.

10

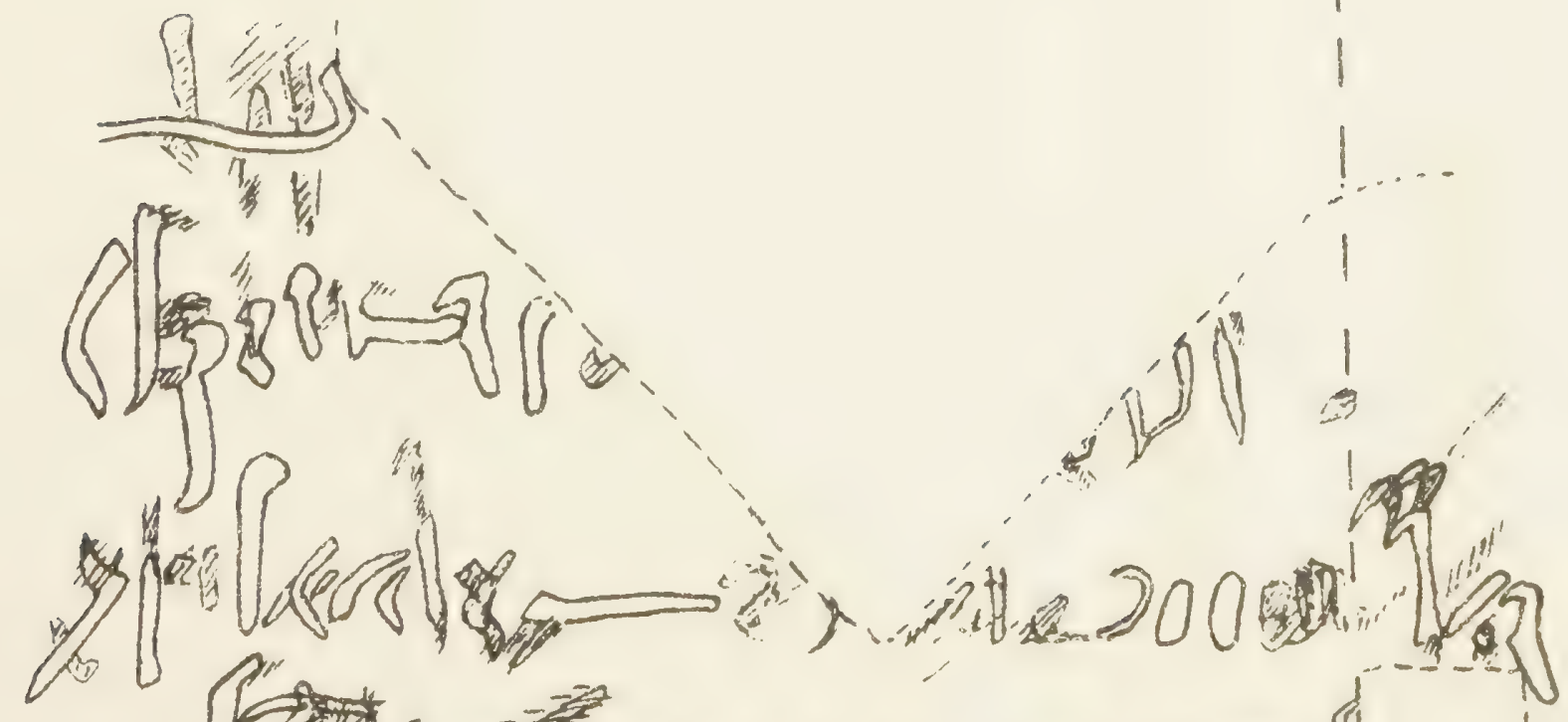
(

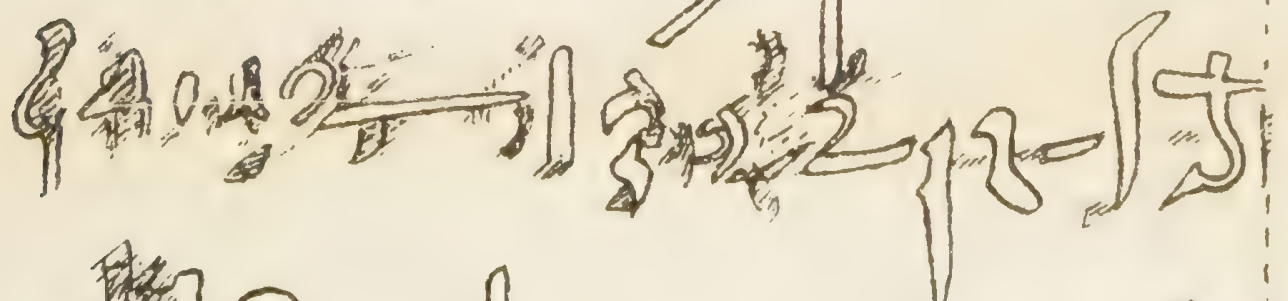

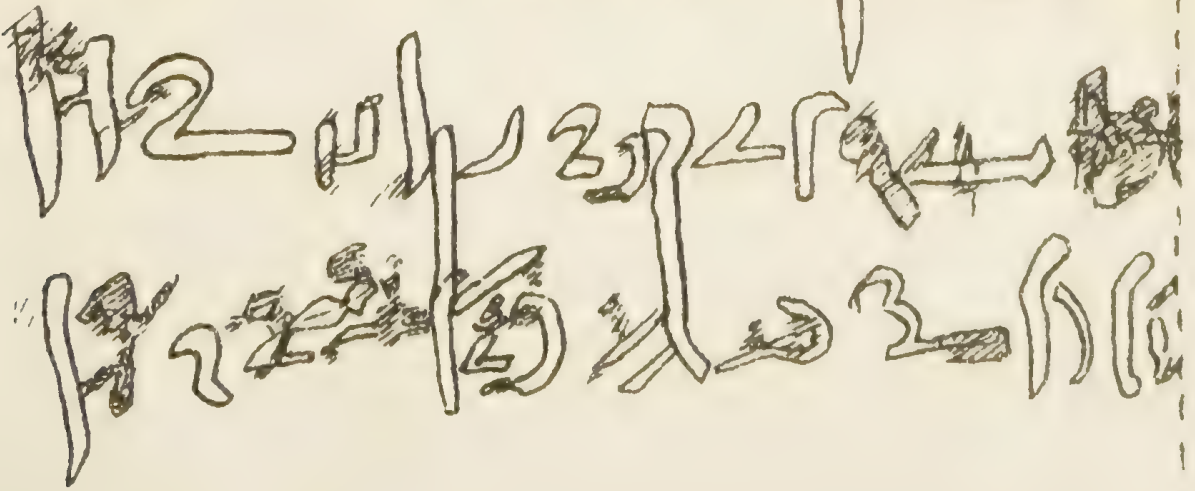




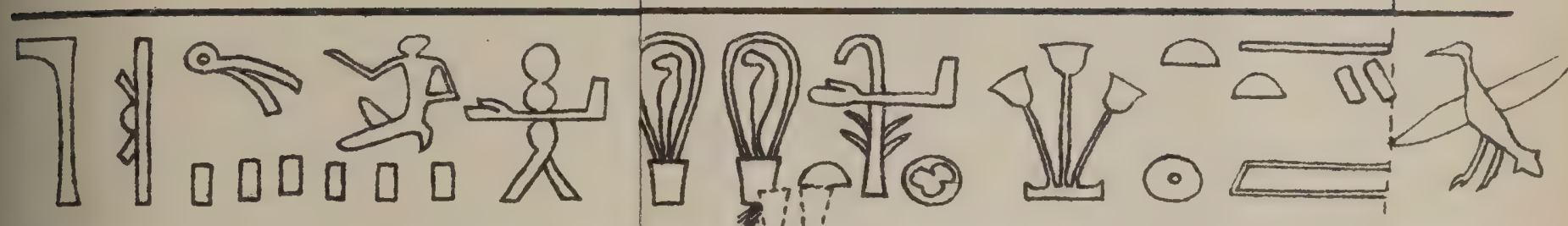

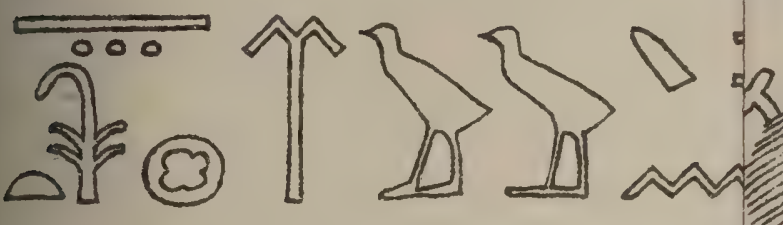

\section{wa}

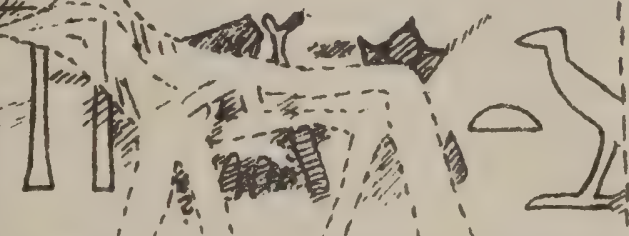

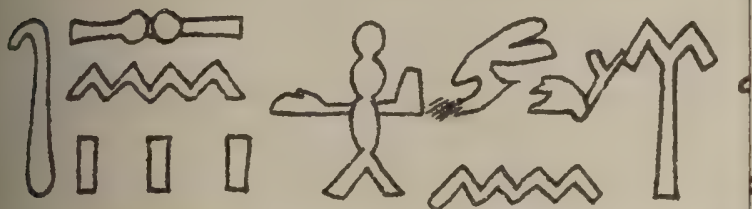

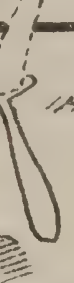

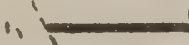

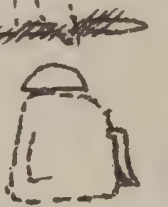

Aीw2 E in (1)

(

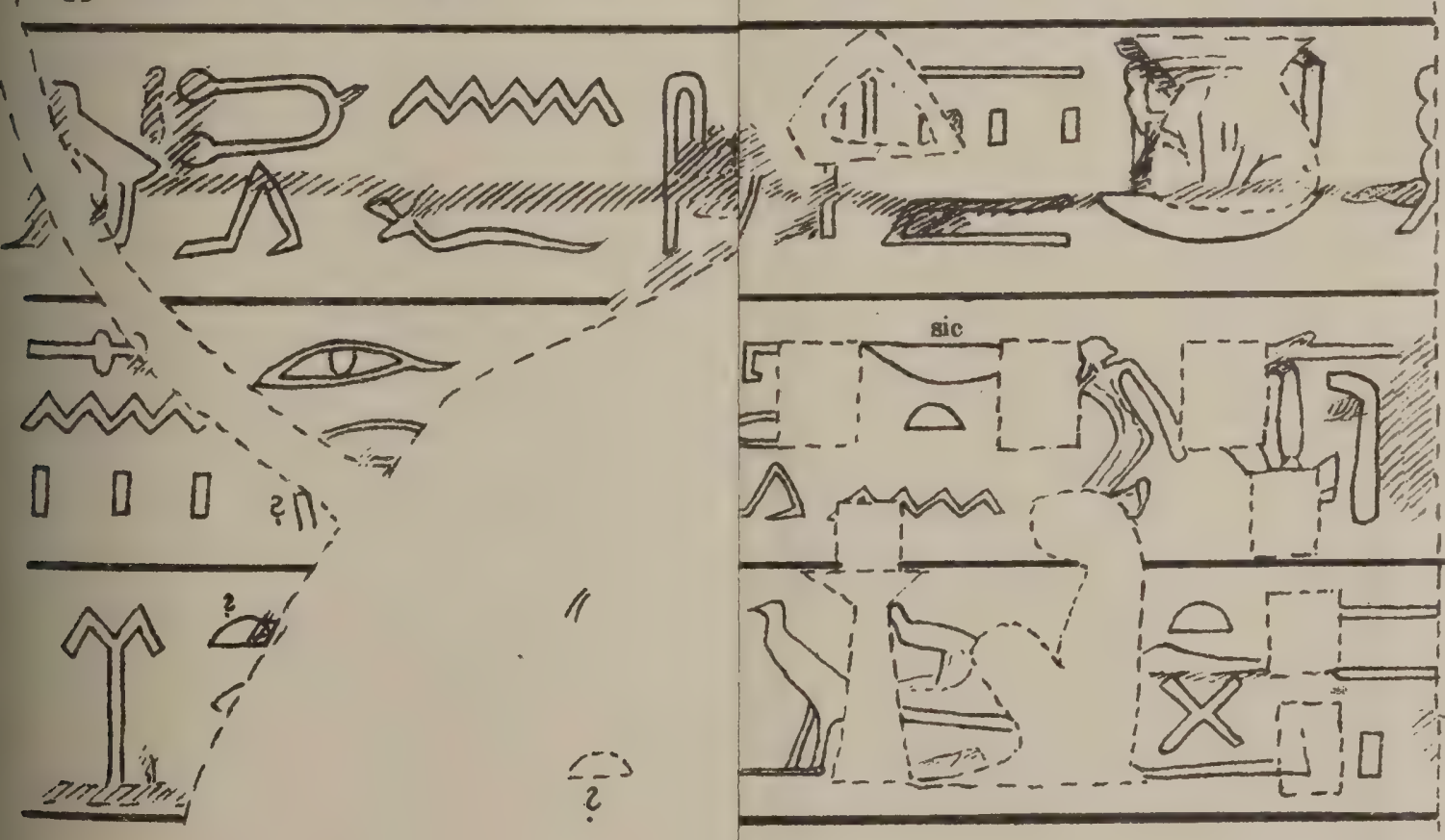

2

0

in

10

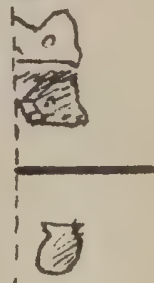

进

$\Longrightarrow$

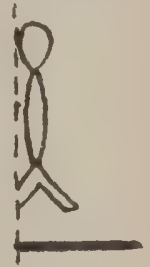




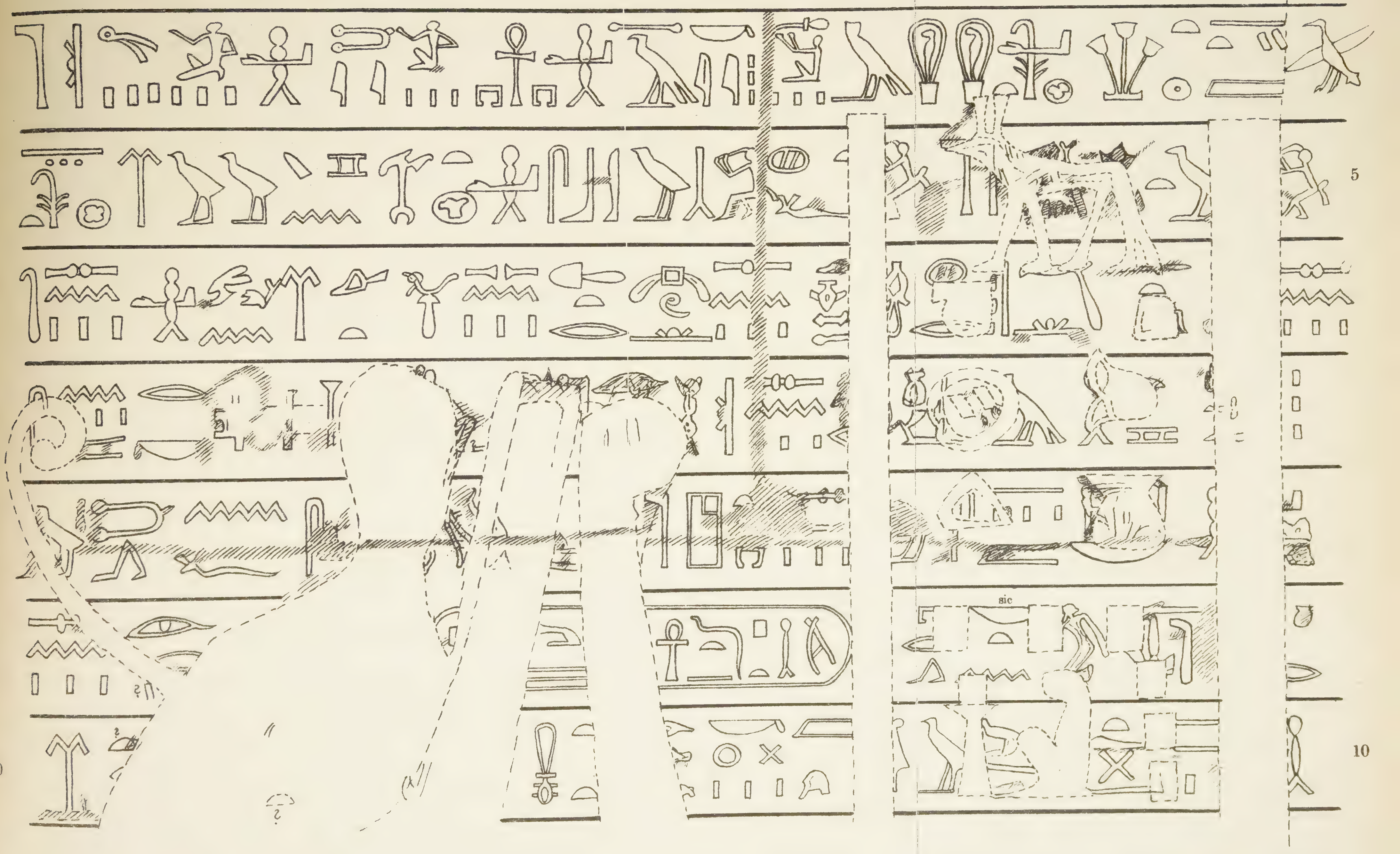




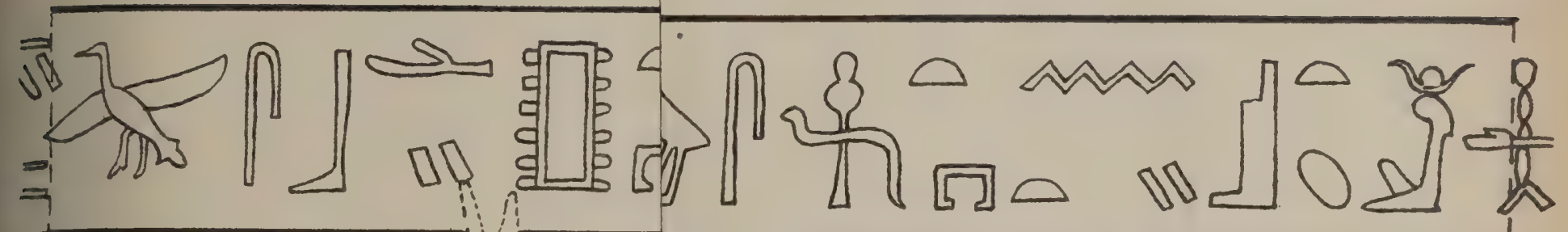

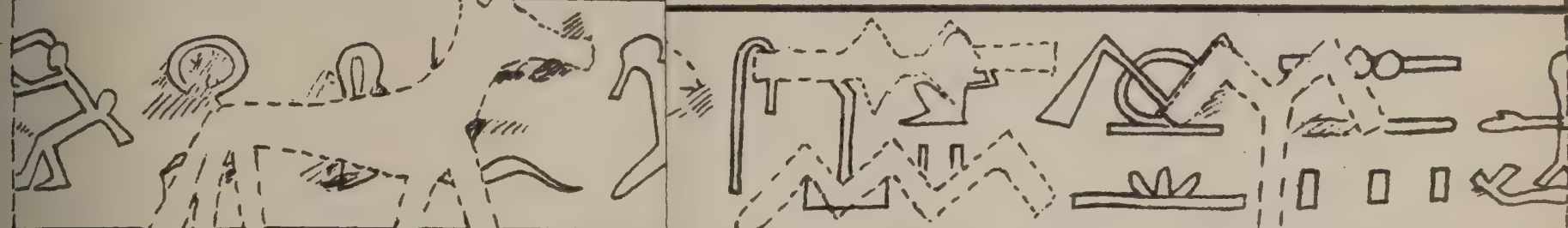

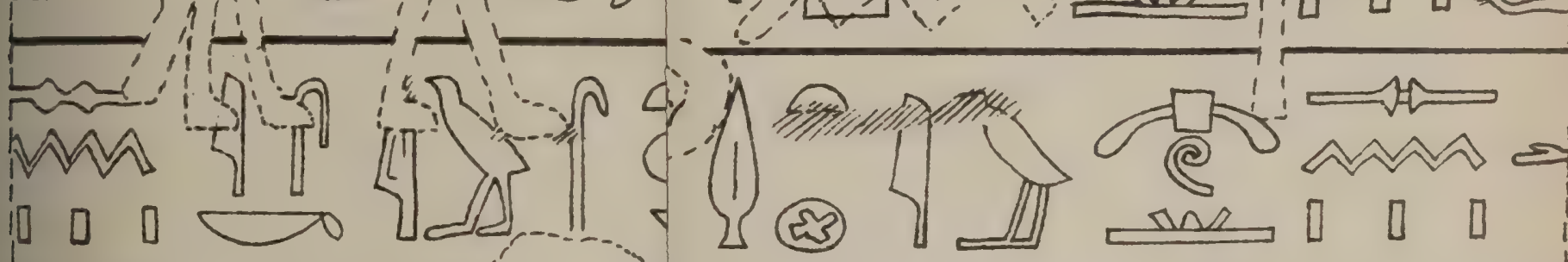

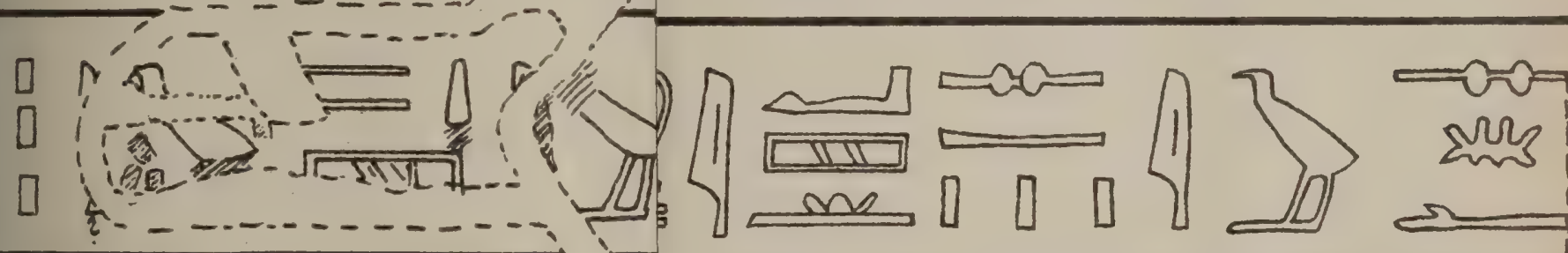
近 0 ก be 0 a 


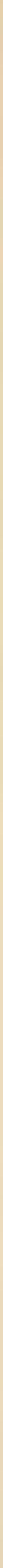




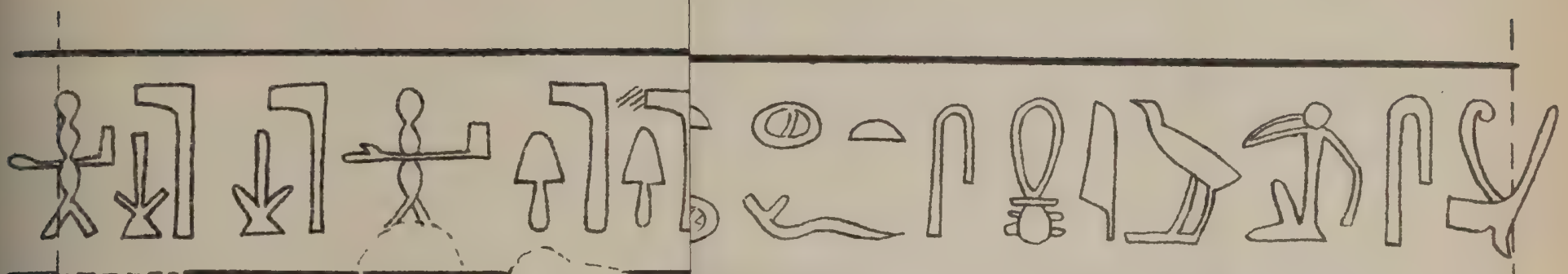

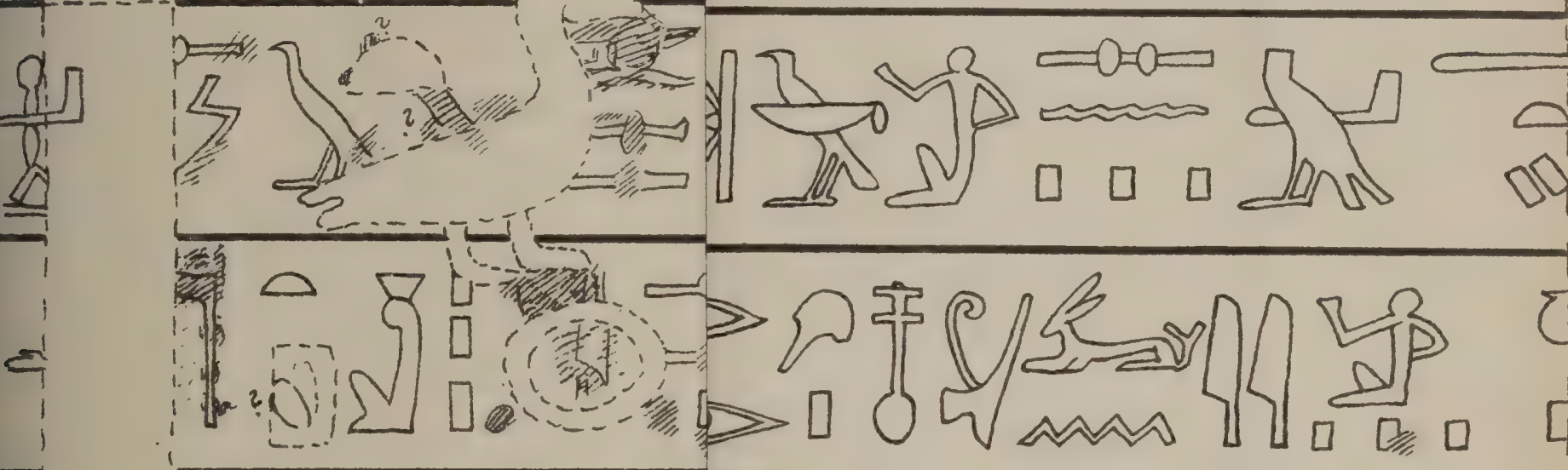

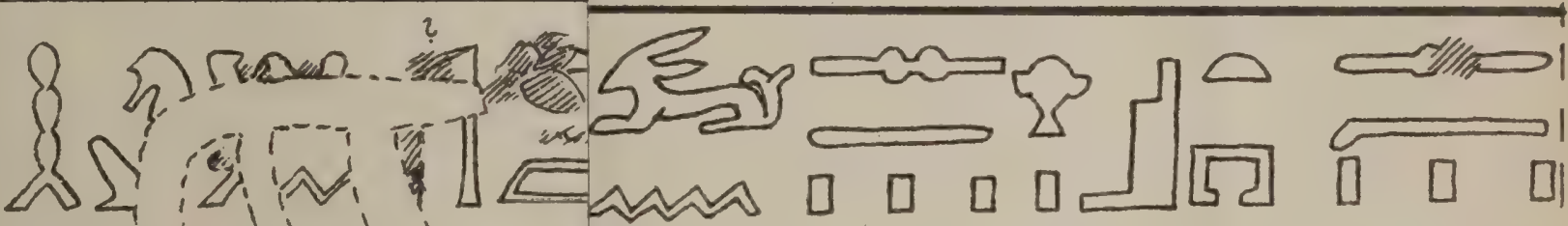
$1 !$ 12 ag? 还 i $\begin{array}{lll}0 \\ 0\end{array}$ a

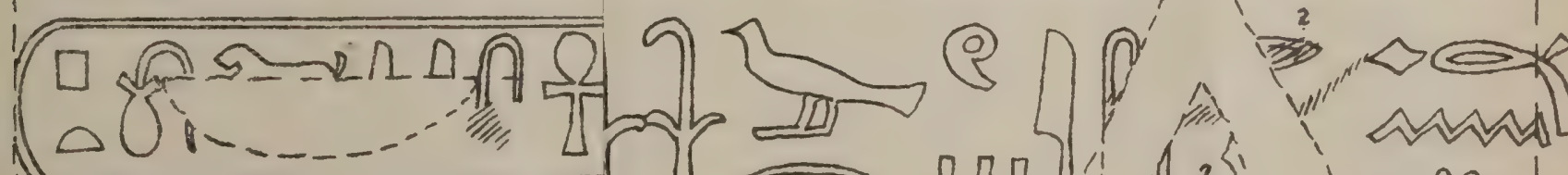




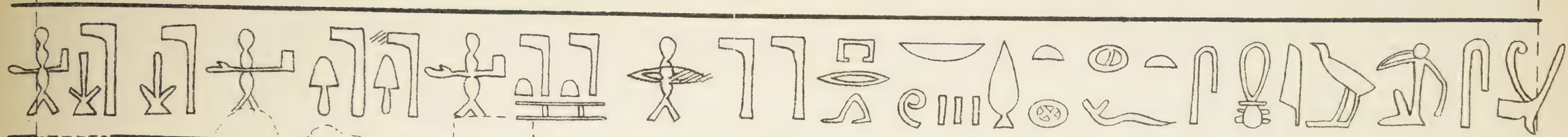

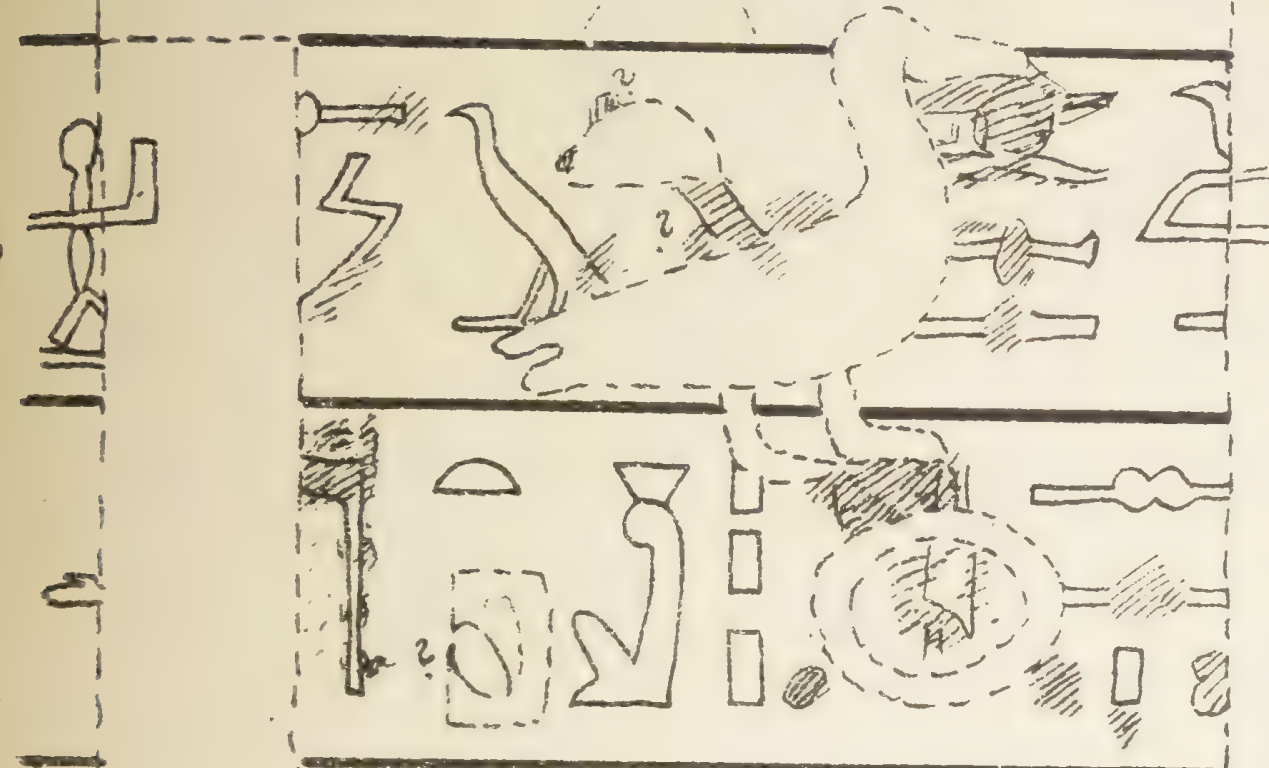

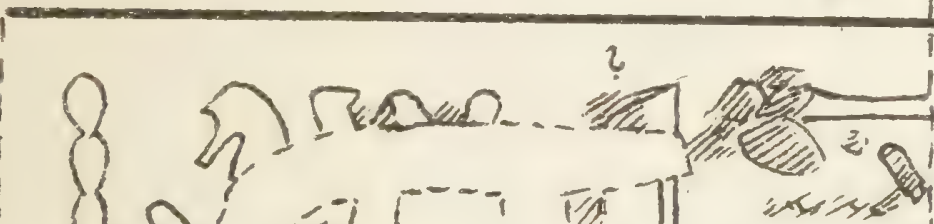

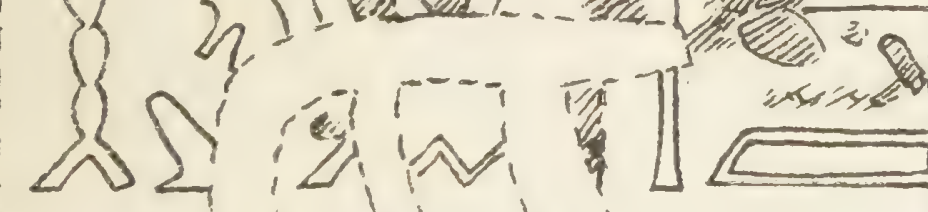
12

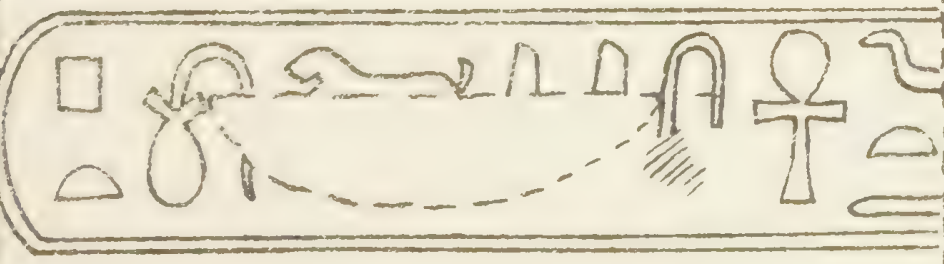

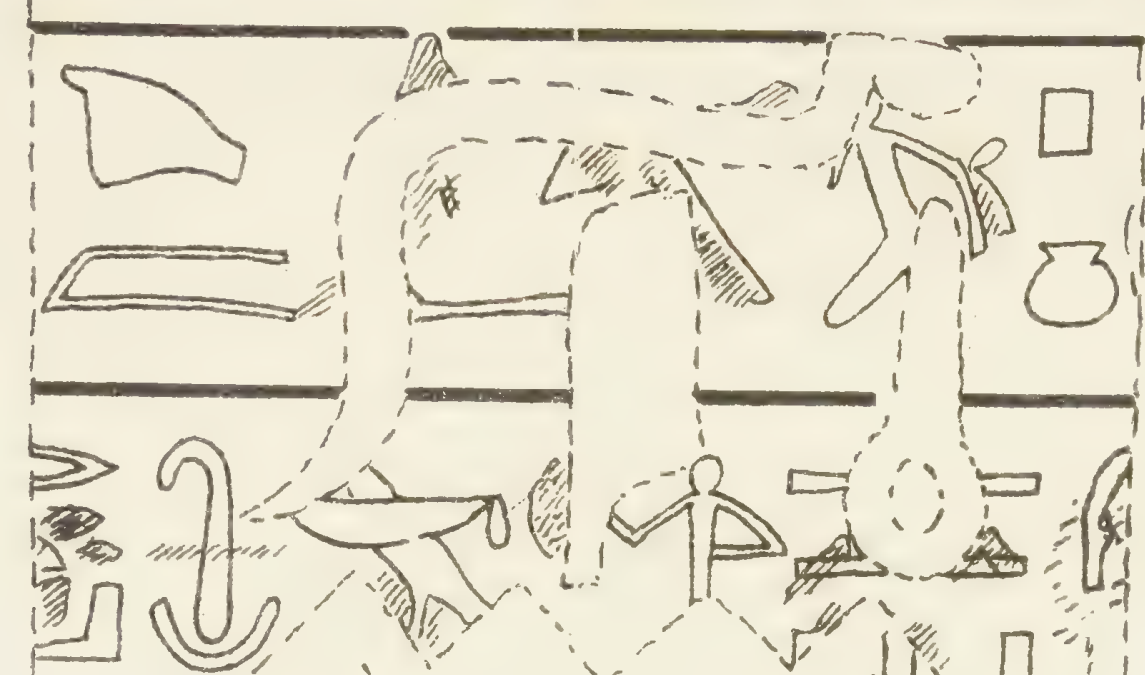

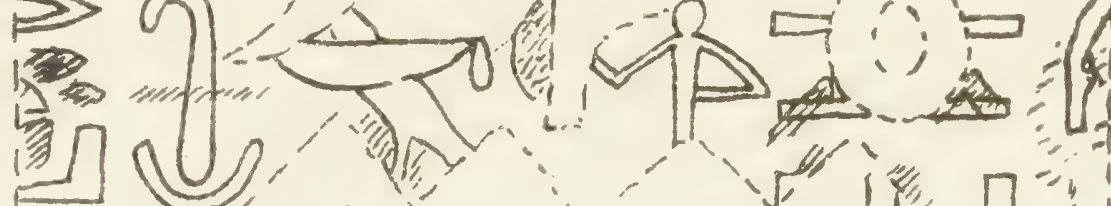
1212 $5.20<100 \%$ ?

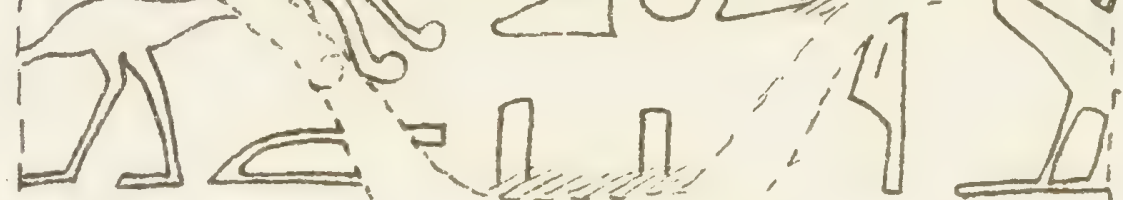

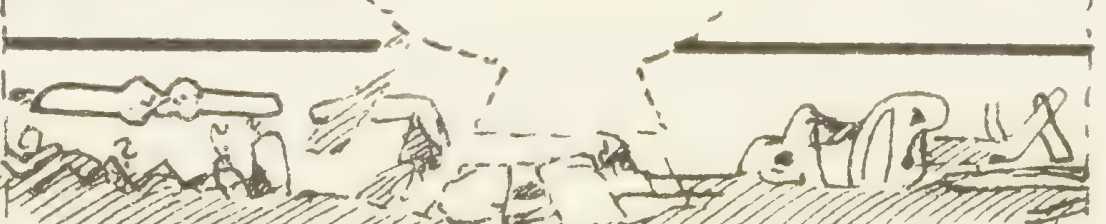

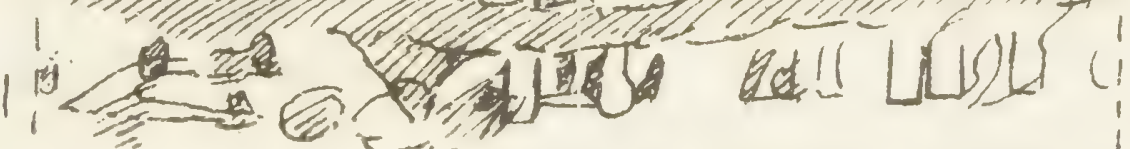

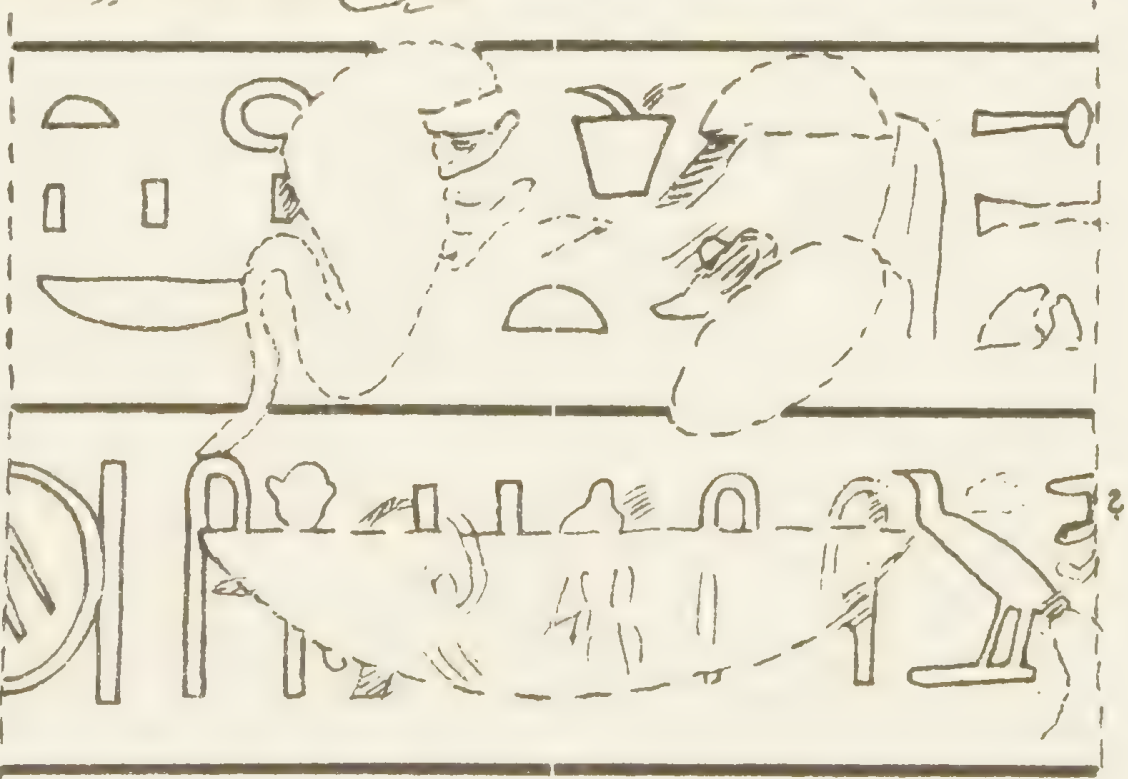

$n R \Omega 0=\square$

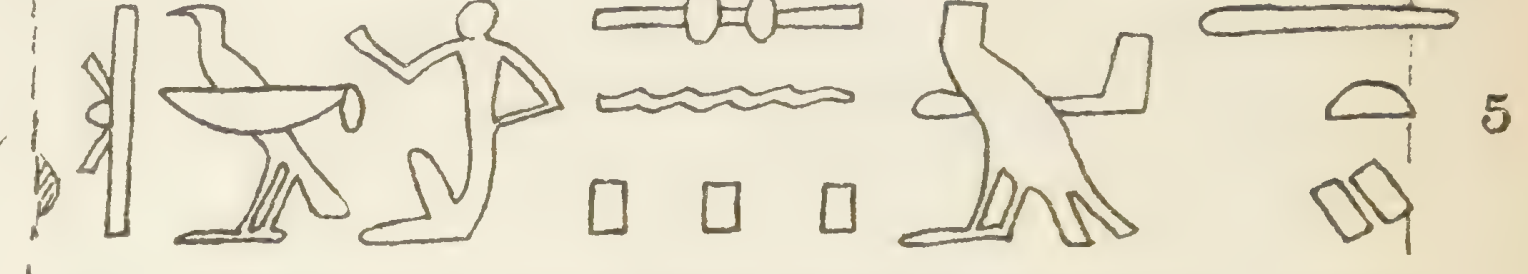
\af

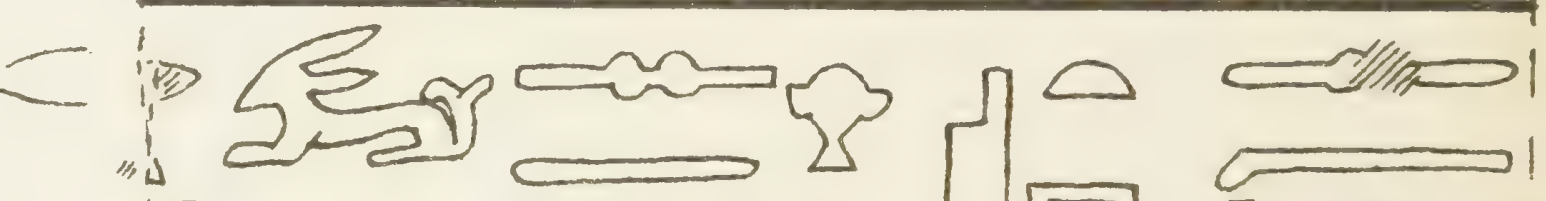

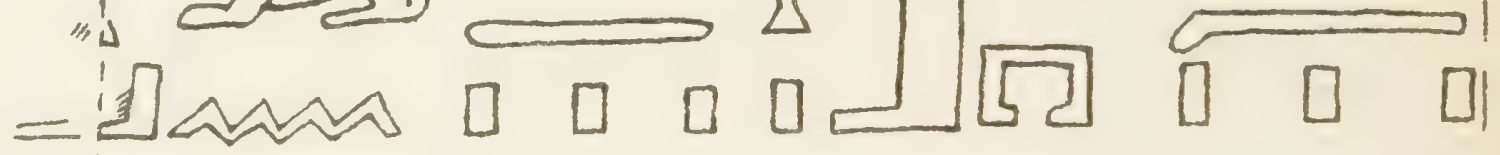

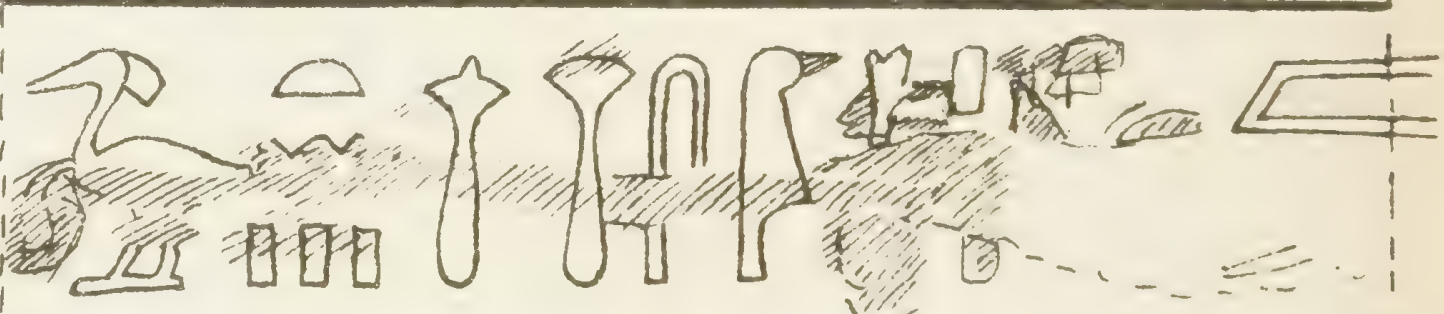

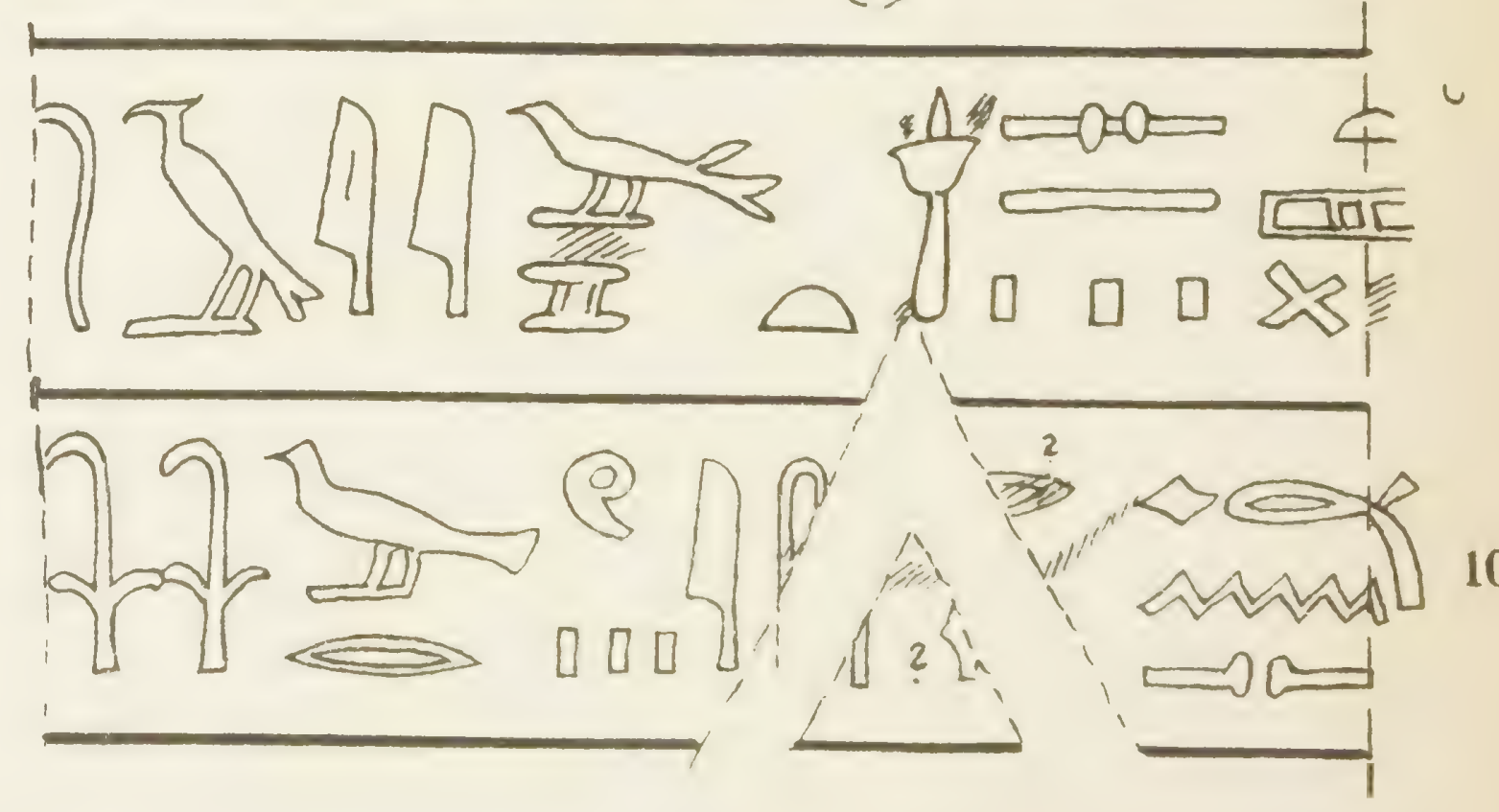


e of Philae, $d$ (upper half).

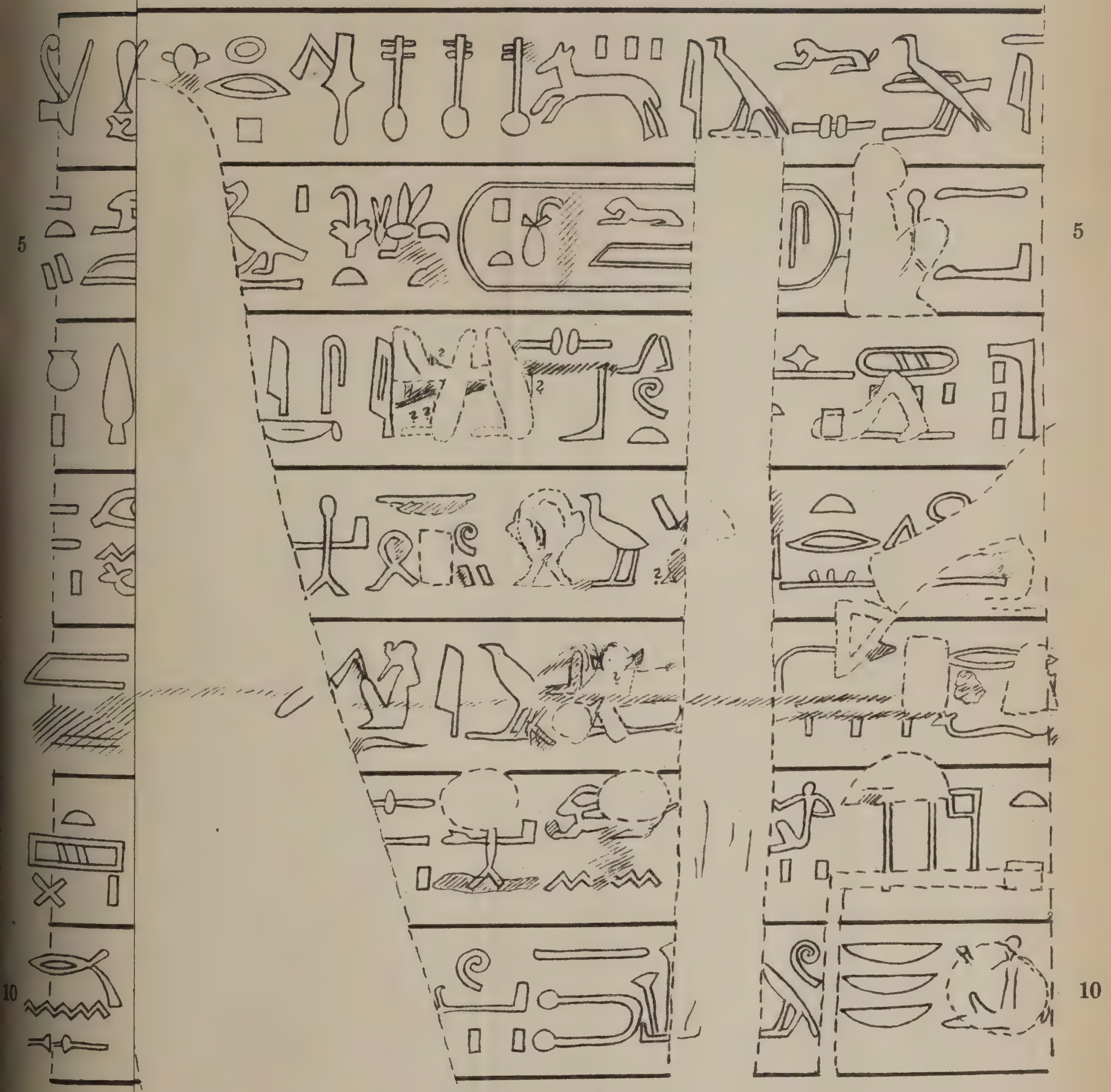




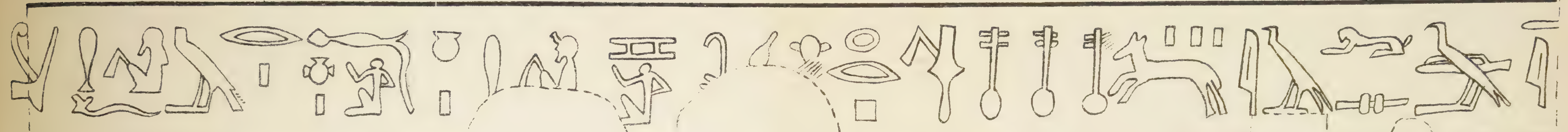

5 ल 5

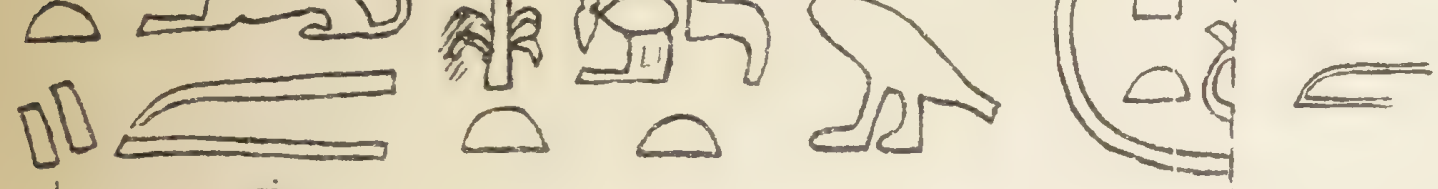
$\square_{1} \Omega($ E

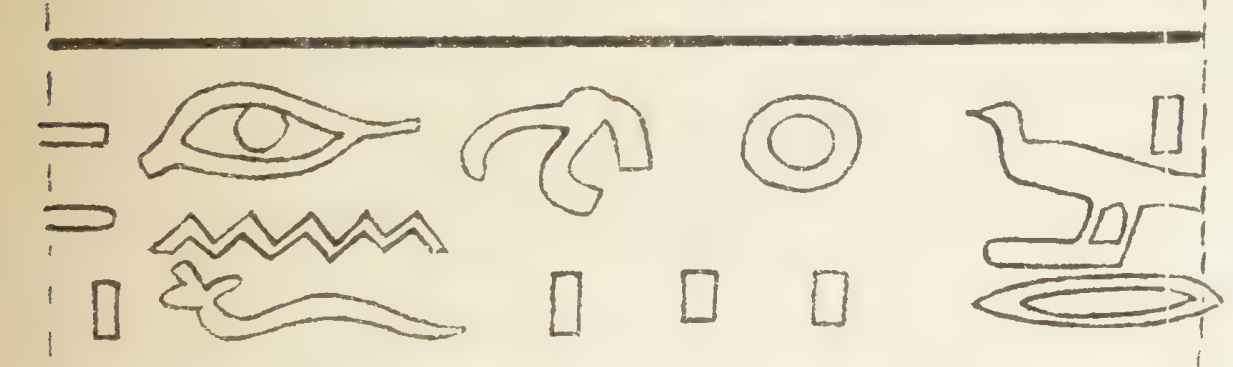
$\rightleftarrows$ \&

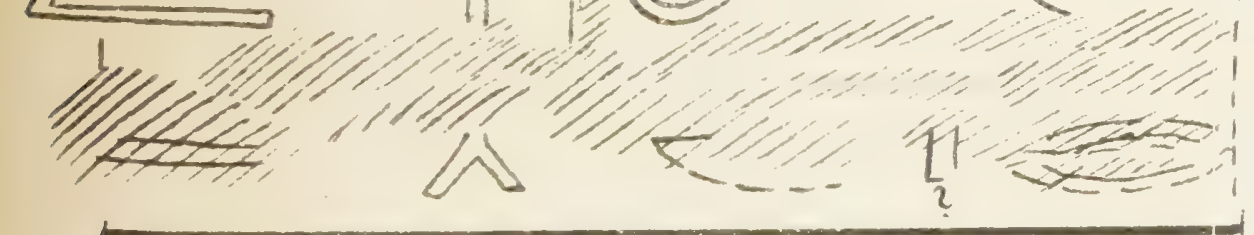

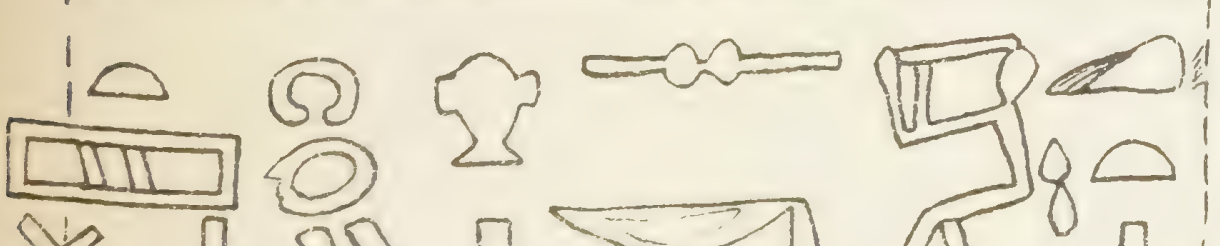
is $0000 \Longrightarrow 1 \pi^{\circ}$

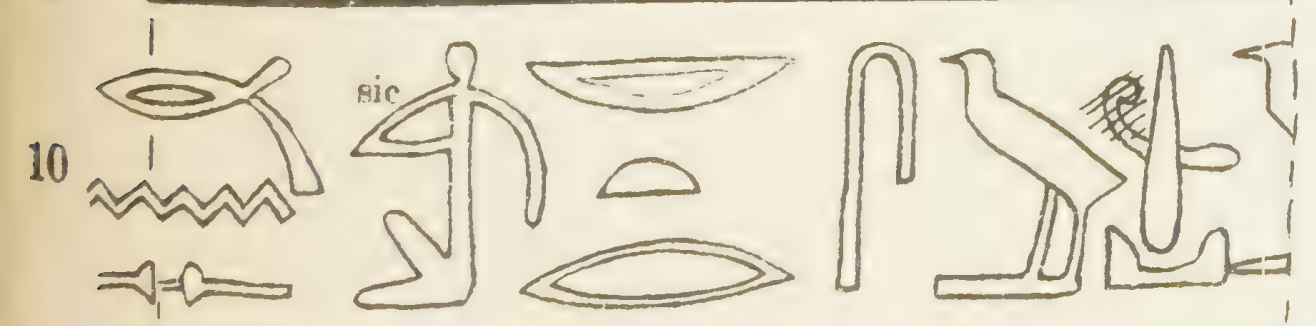
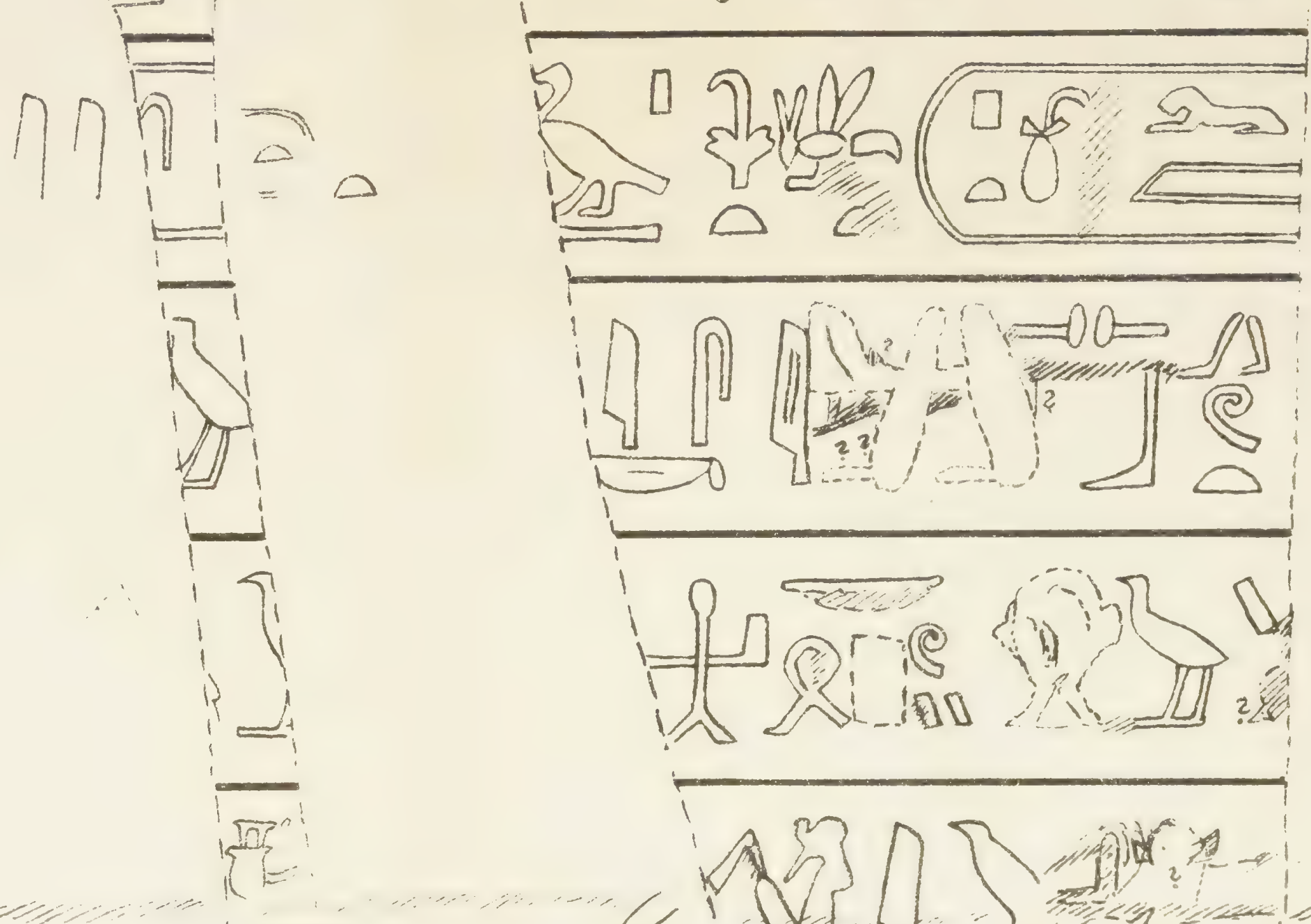

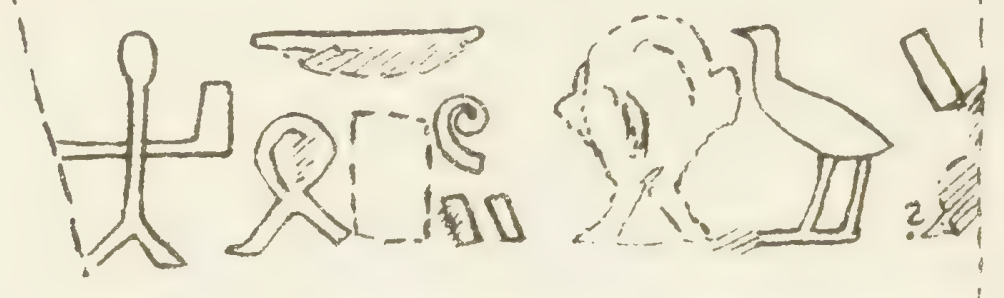
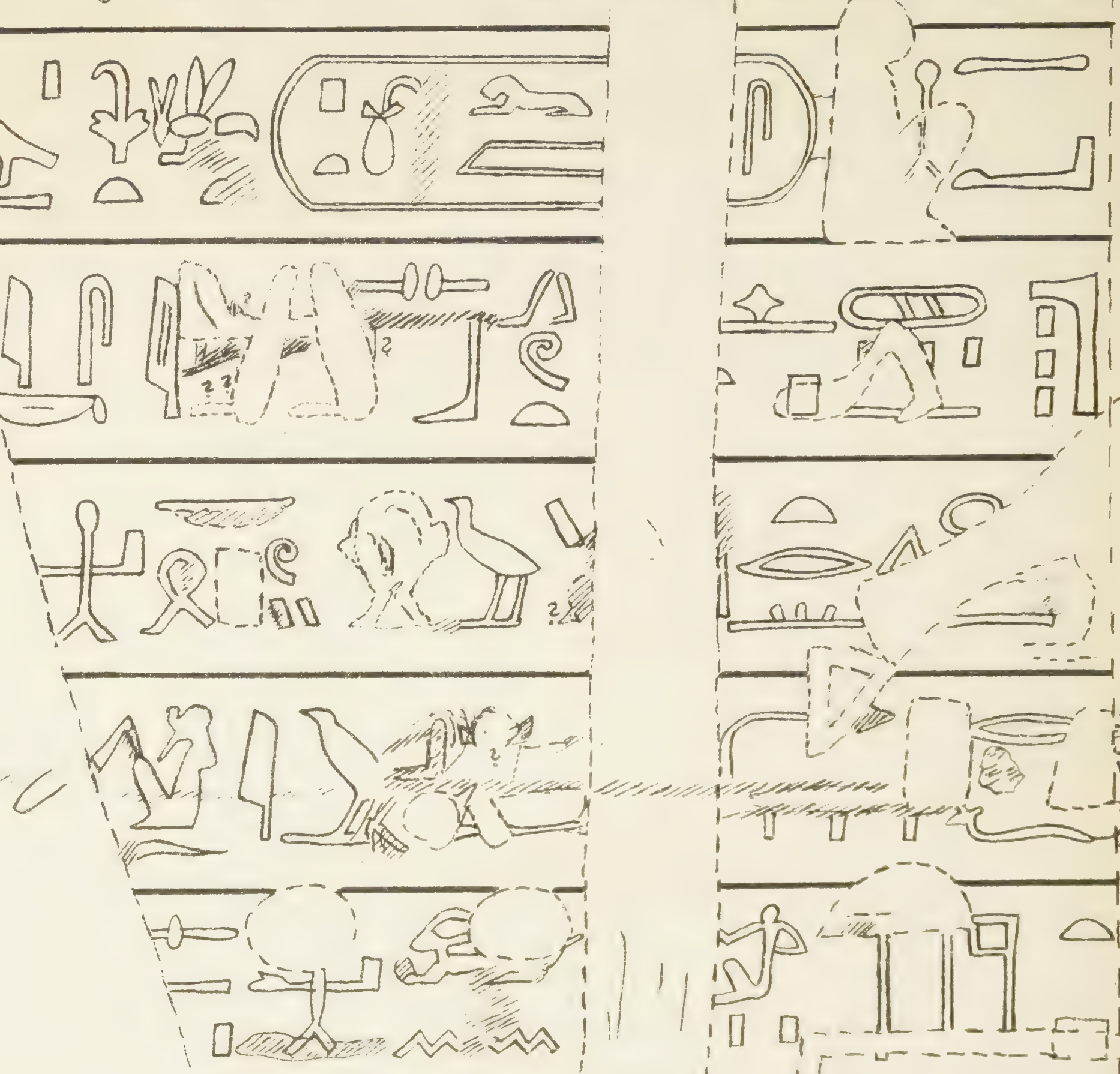

5 CIII)

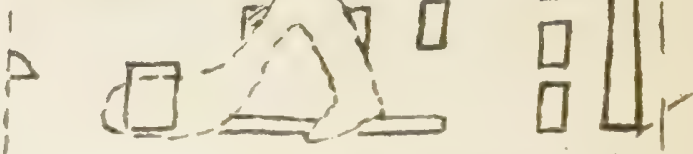

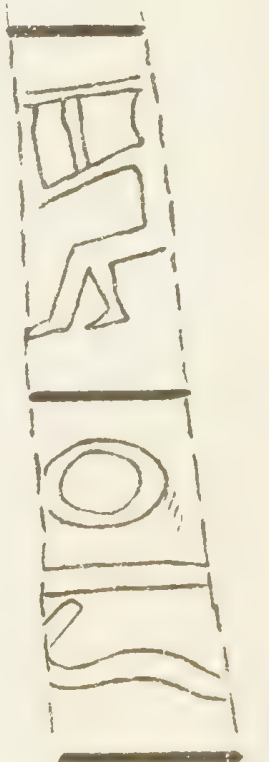

$\Longleftrightarrow \Delta$

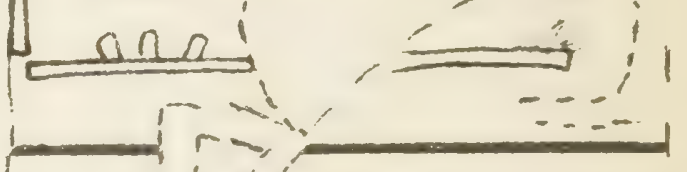

C

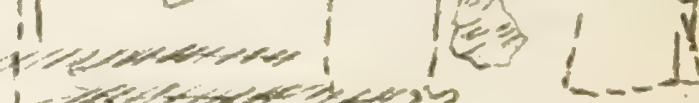
Tा 色 I 1] $B_{1} \ldots$ (c) NGL: 11 $10 \sqrt{2}=-4$ 


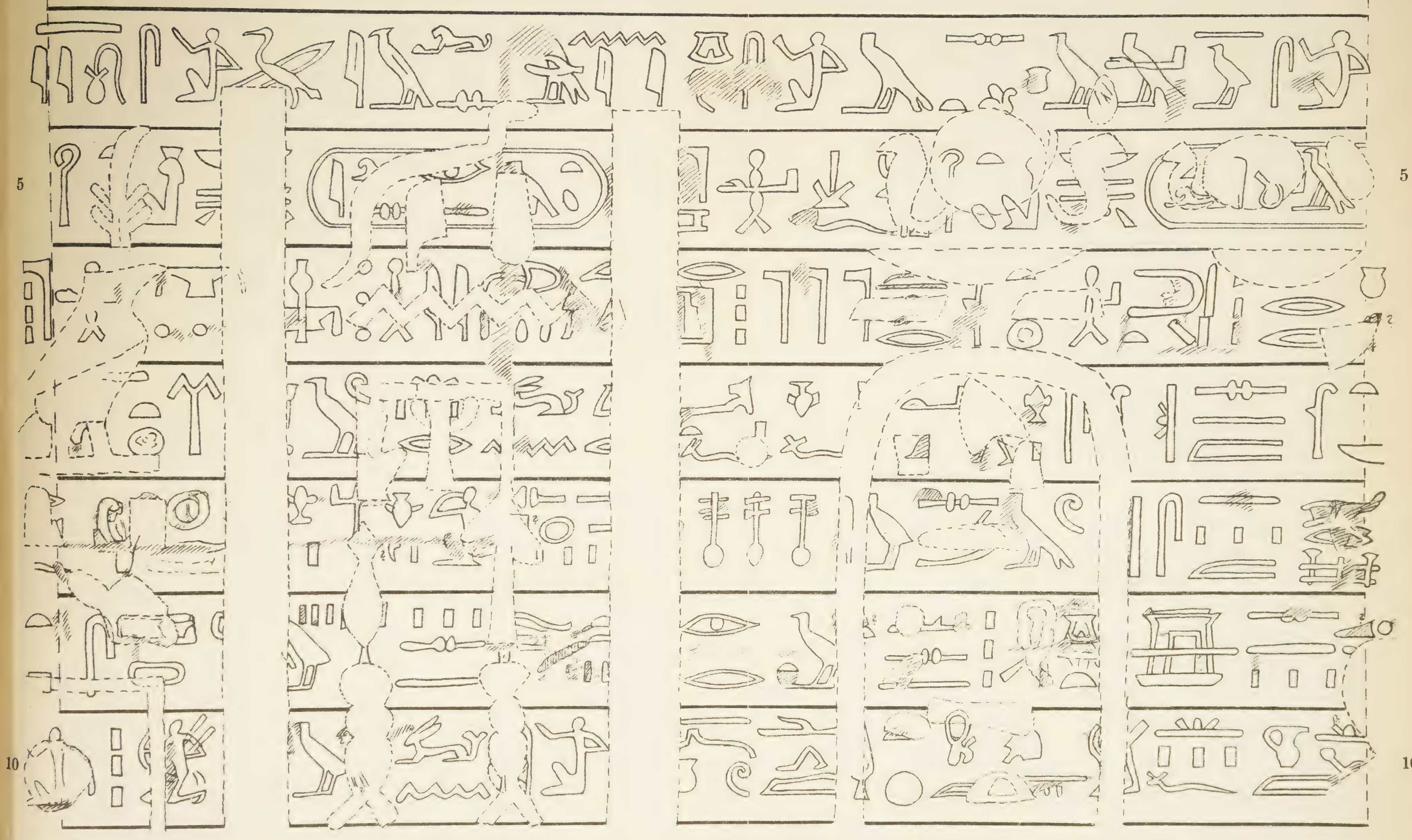


er half).

$\frac{1}{1}$

$\sqrt{1}: \infty 00$

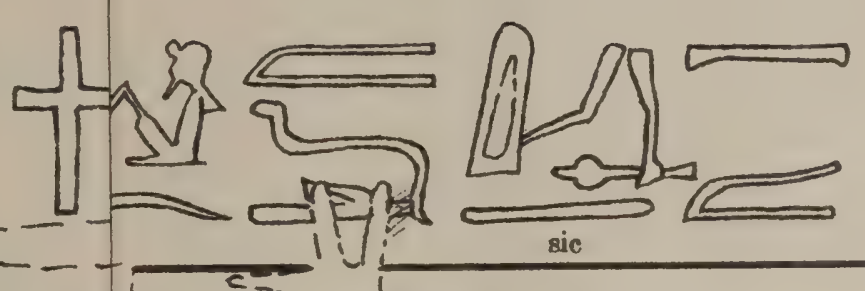

O

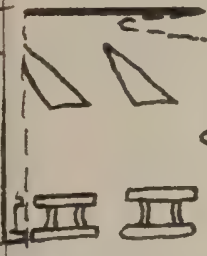

得

D. 3 .

$\infty_{m} \ll$

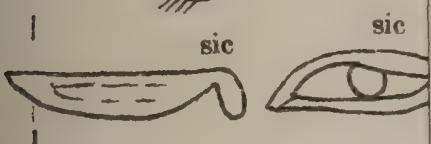

i

o

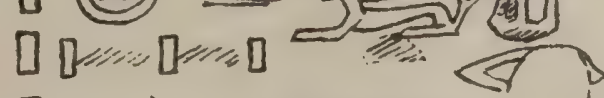

口

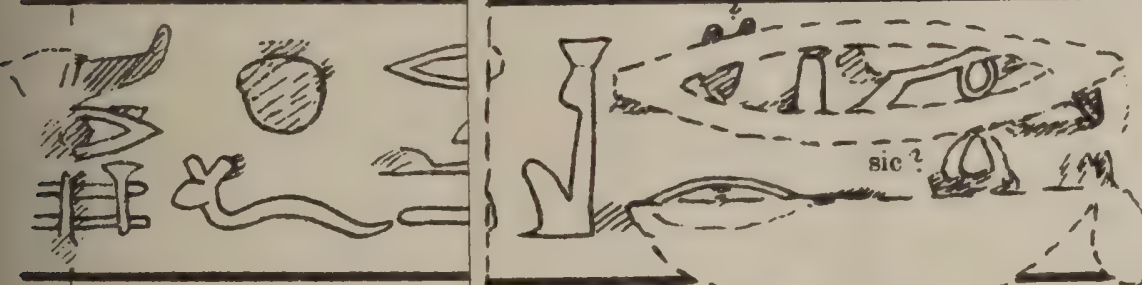

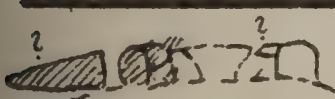

!

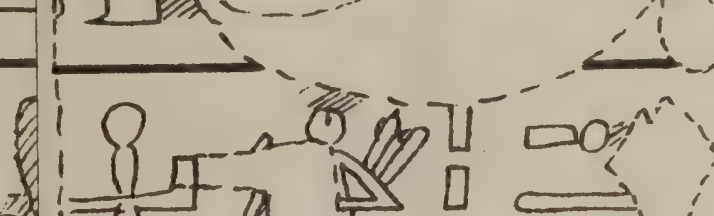

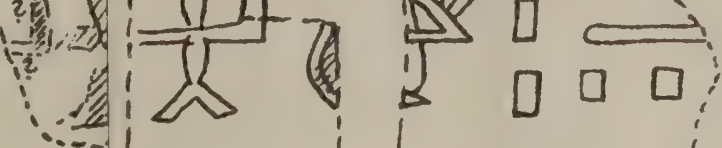

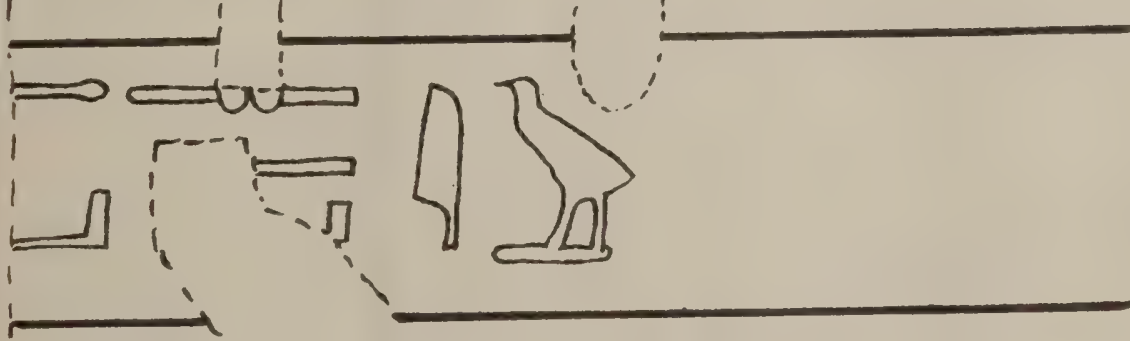




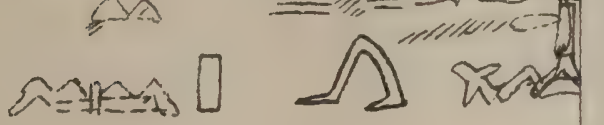

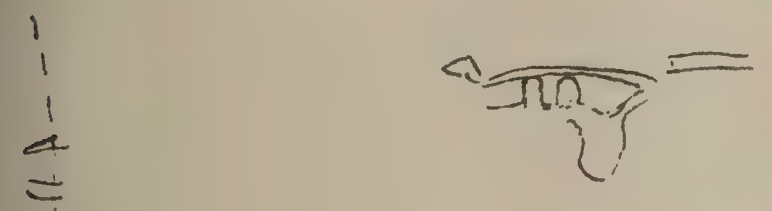

s

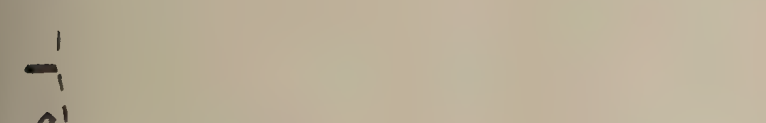

AN
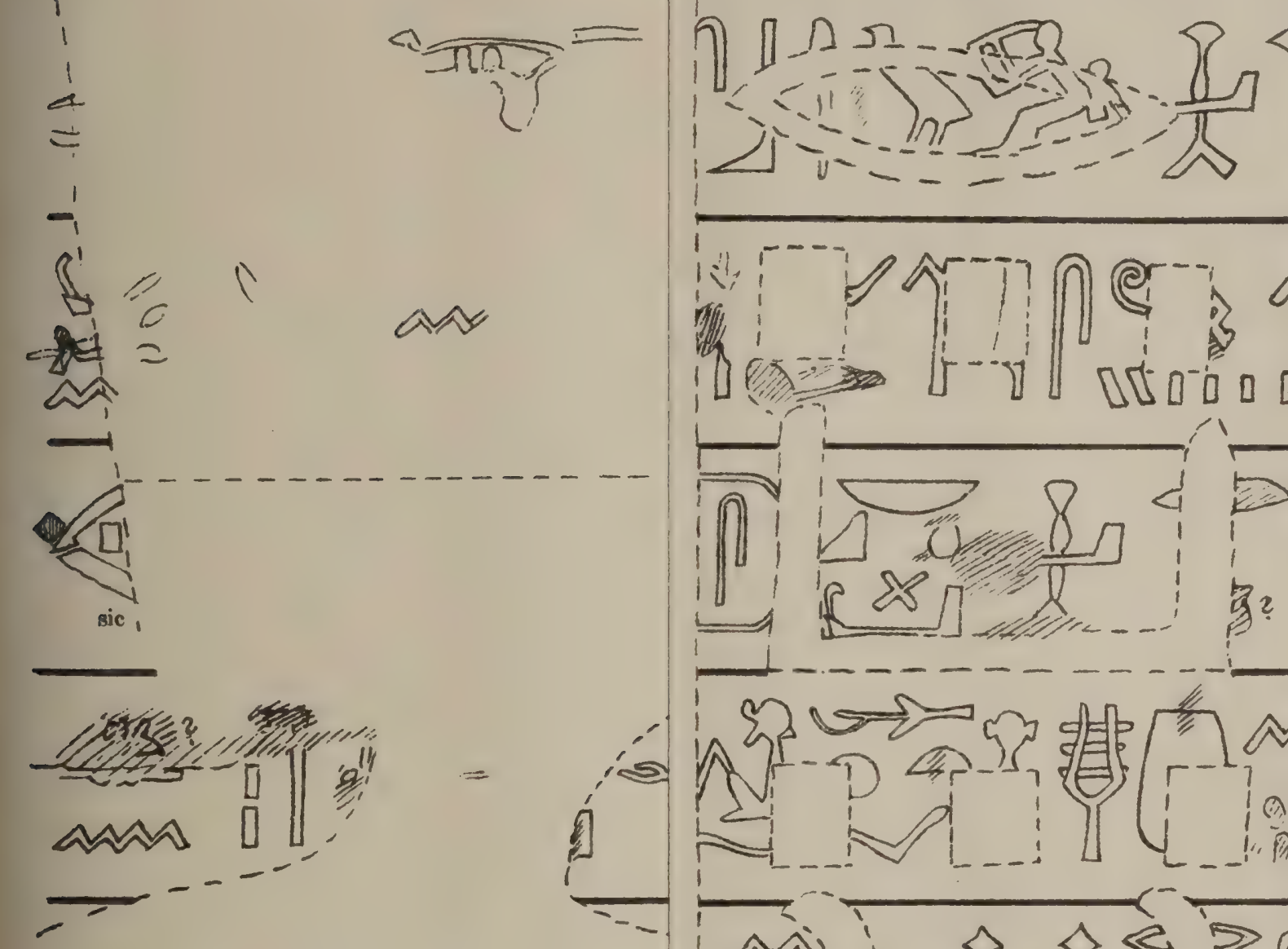

GAT]巴

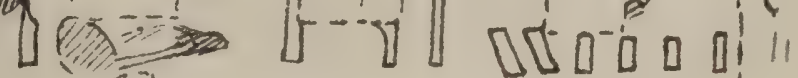
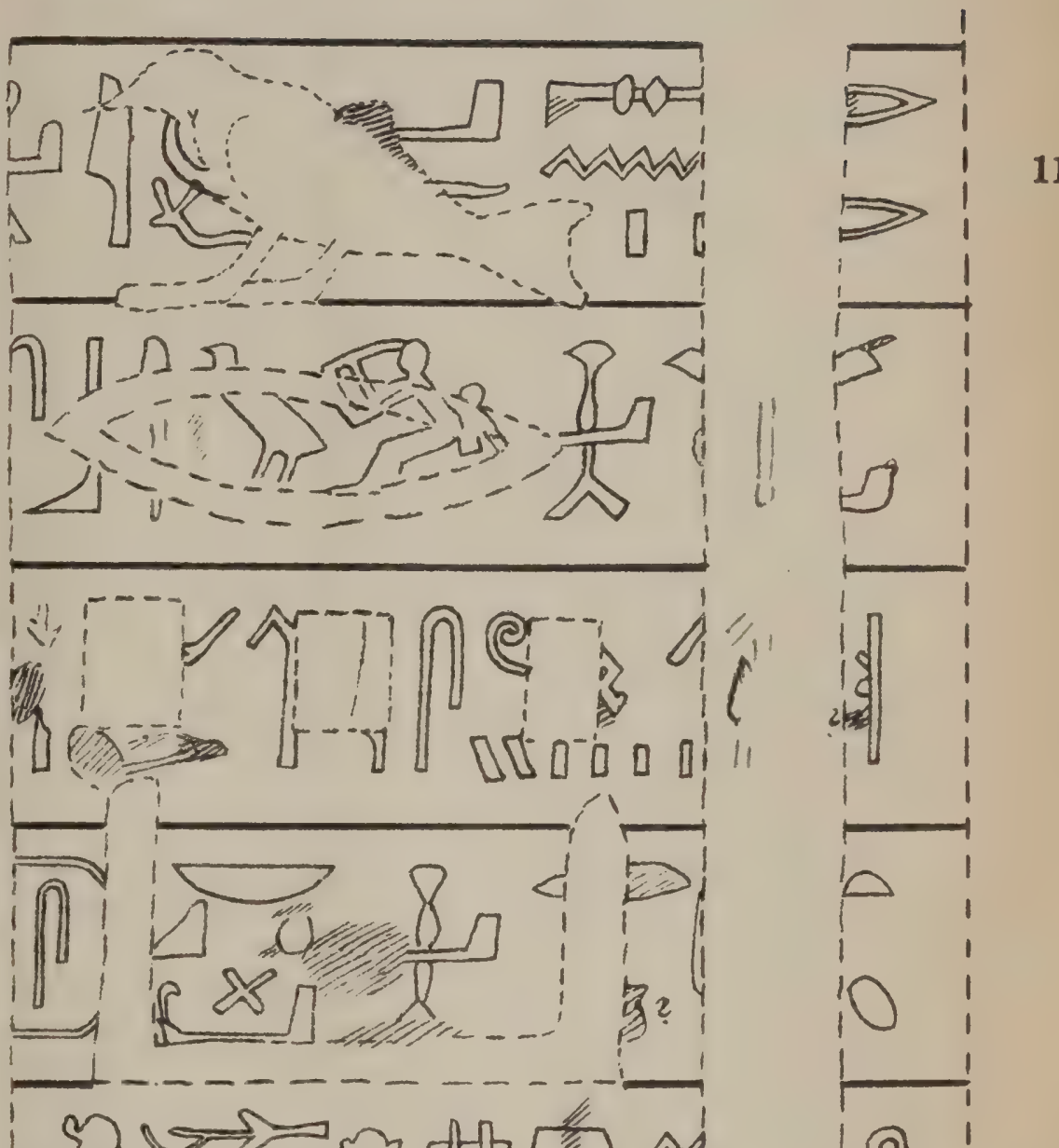

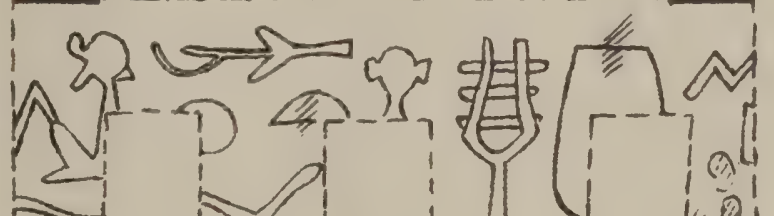

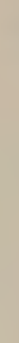

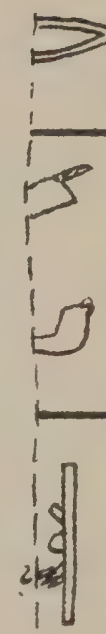

$10 \begin{aligned} & 1 \\ & 1 \\ & 1 \\ & 1 \\ & 1 \\ & 1 \\ & 1\end{aligned}$

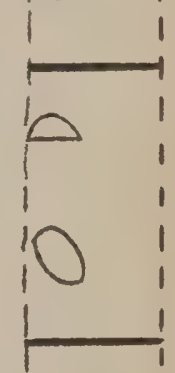

$1 \cap \begin{array}{ll}1 & \\ 1 & 15\end{array}$

8

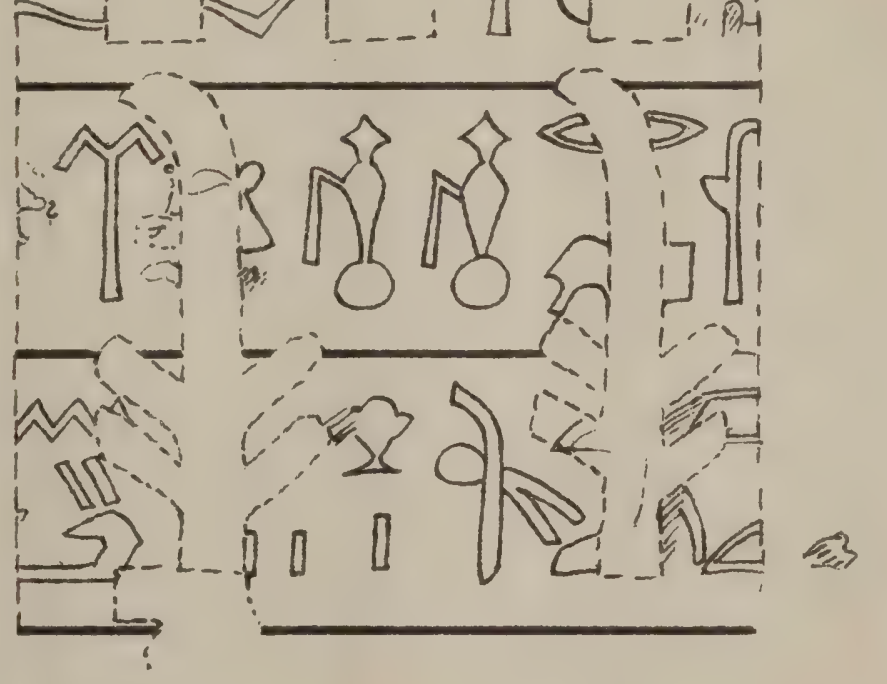



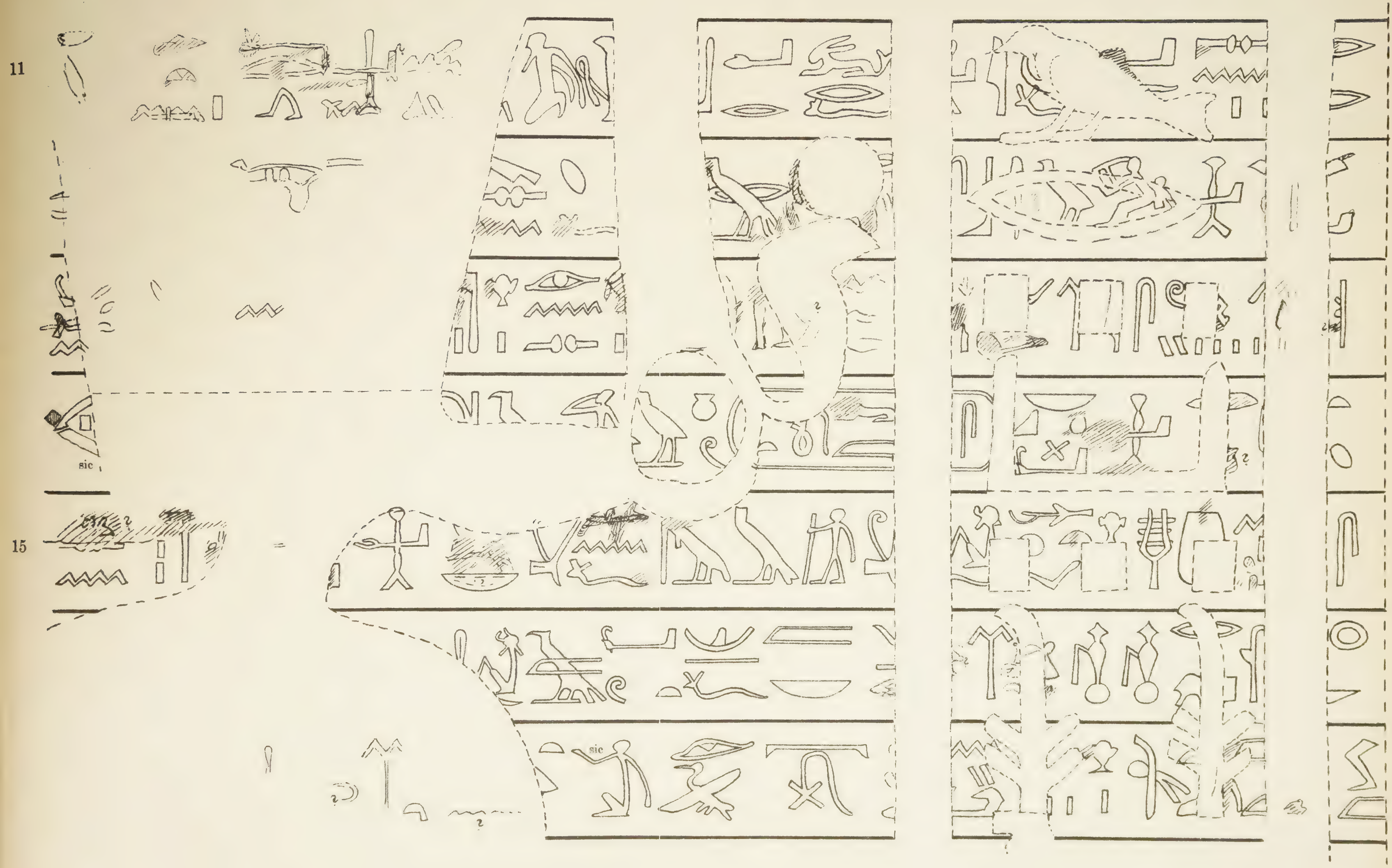

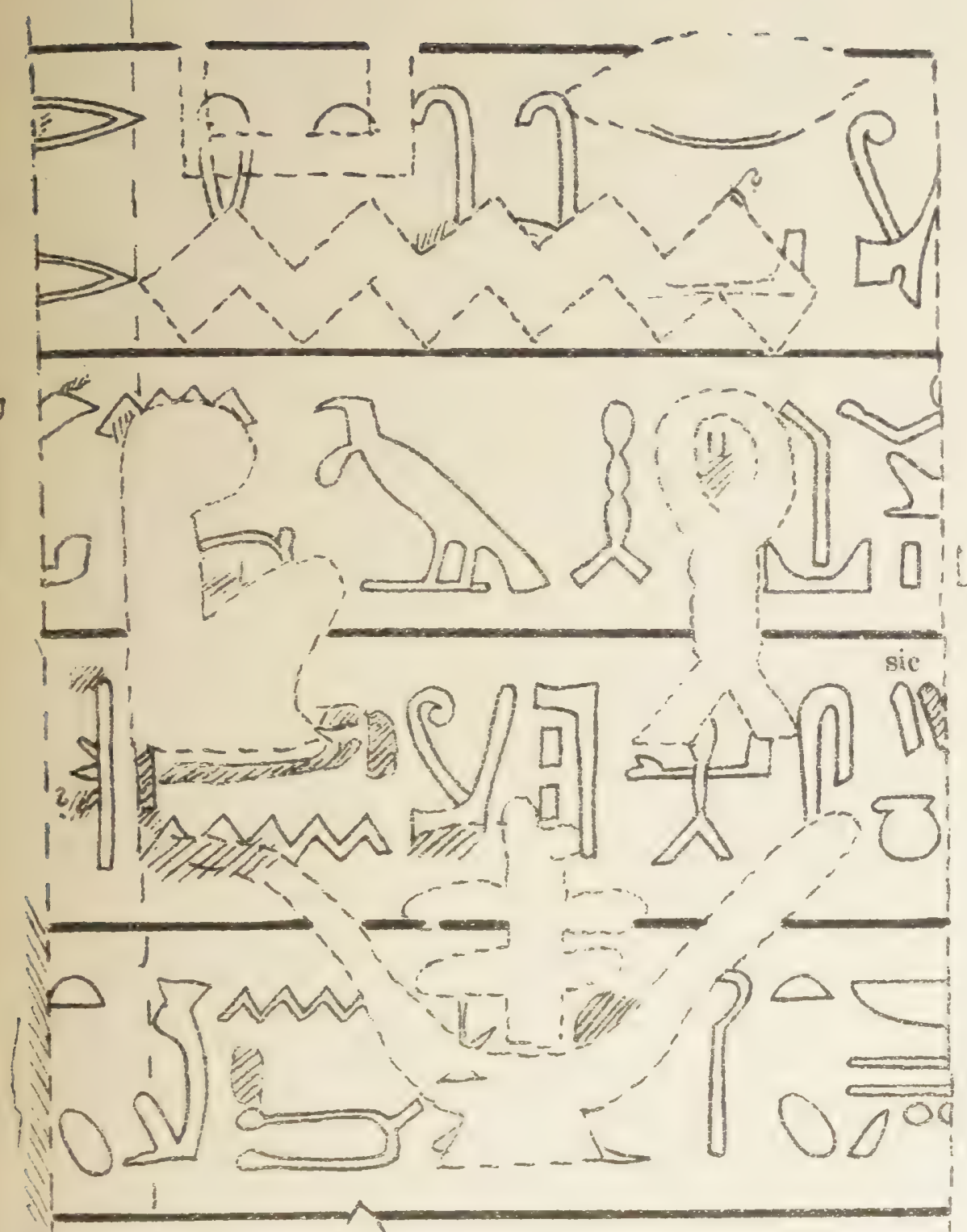

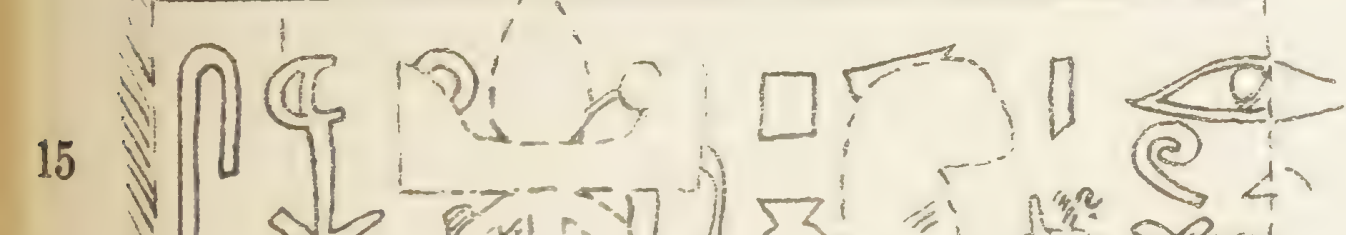

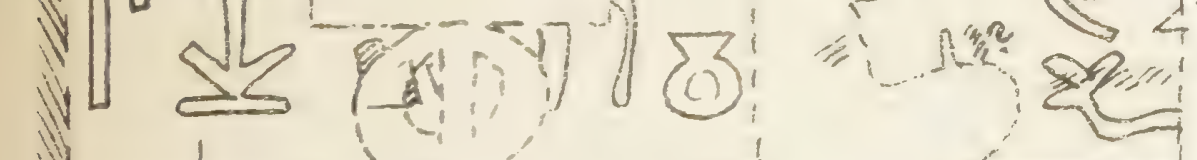
$\sqrt{01000}$ (1) $\int_{n} \sqrt{2} \infty$ $71, \ldots d n$

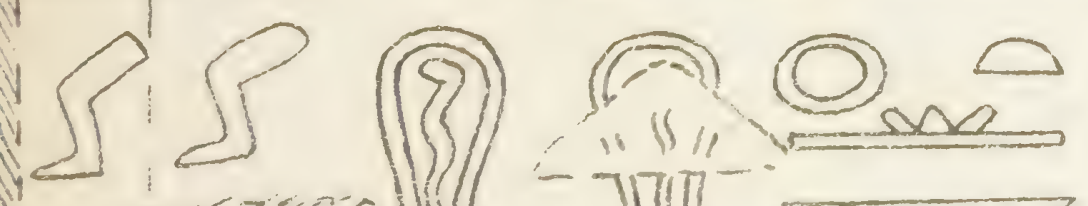
$\sqrt{\rightleftarrows}$
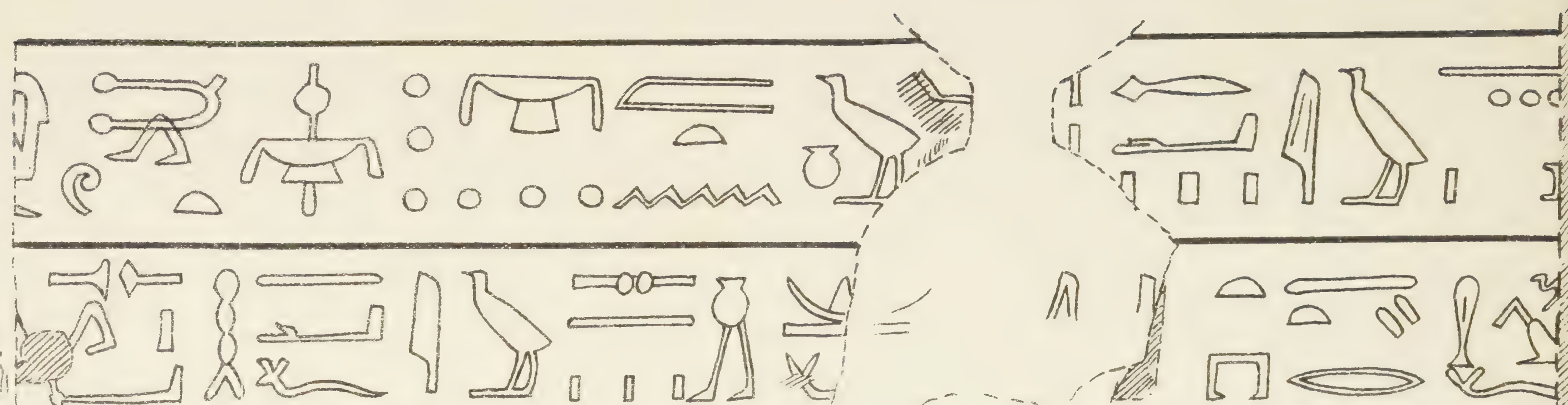

(I)

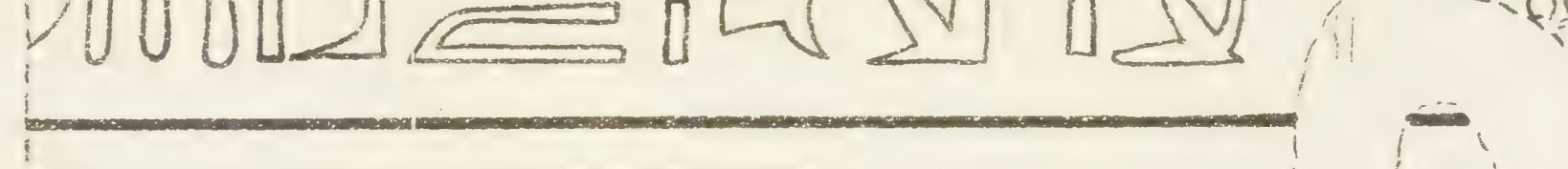

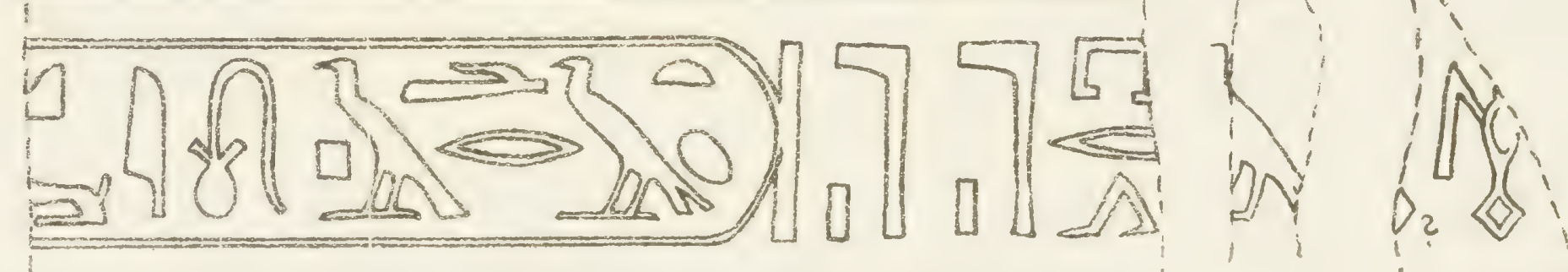

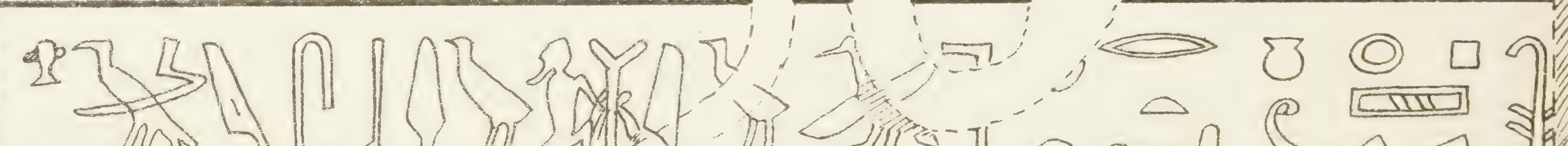

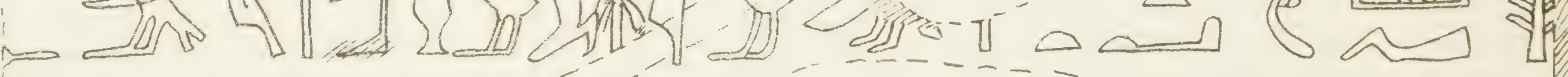

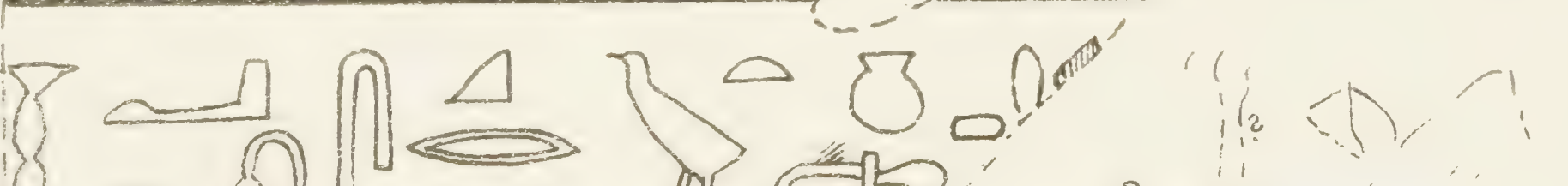

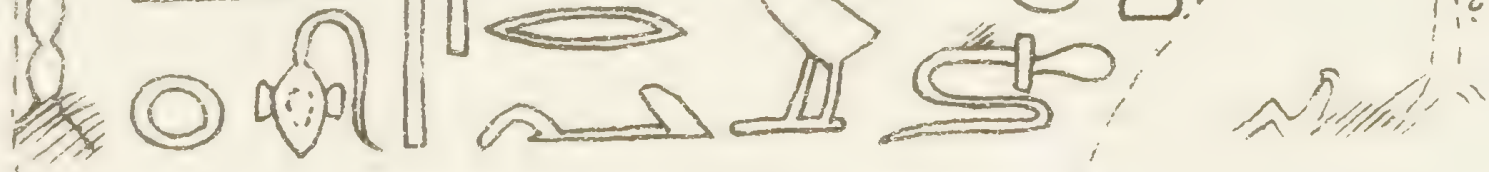

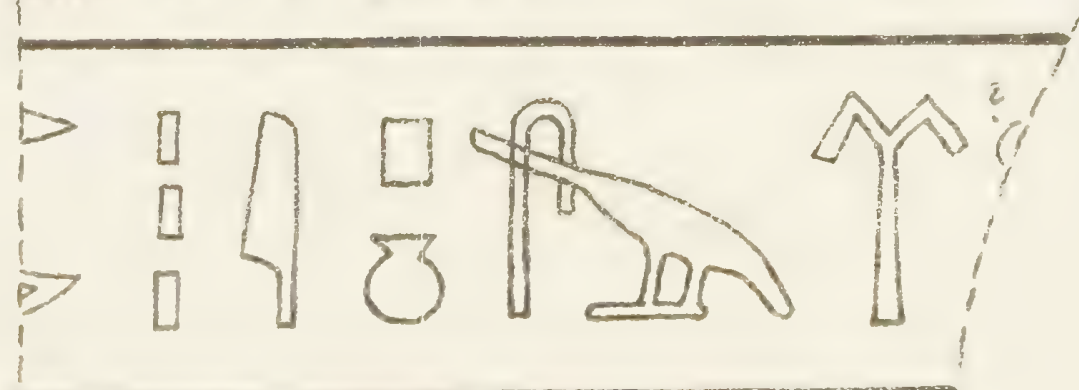
$\bigcirc$

\begin{tabular}{lllll}
\hline & 0 & 0 & 0
\end{tabular}

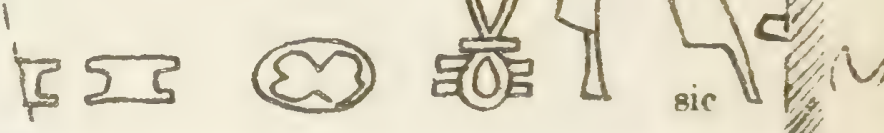

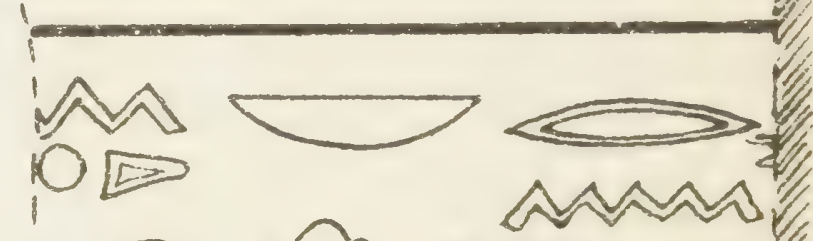
(0)

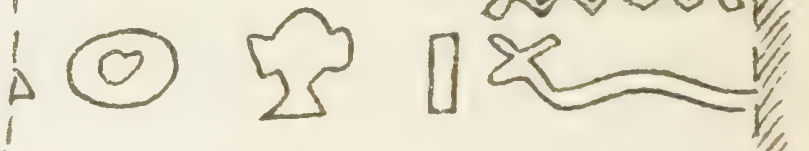
$\Longrightarrow 8000 \%$ 

期(

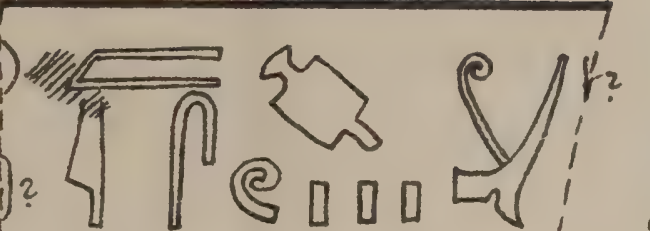

औ 4 i 12
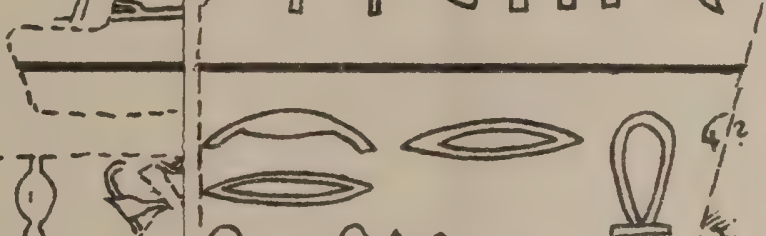

$\pi 1$
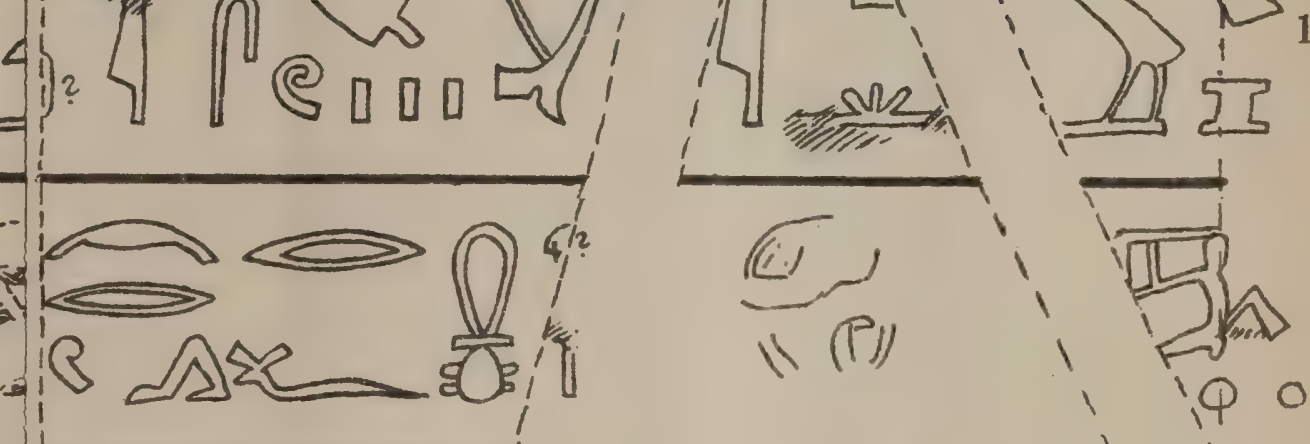

11

in 0 ,

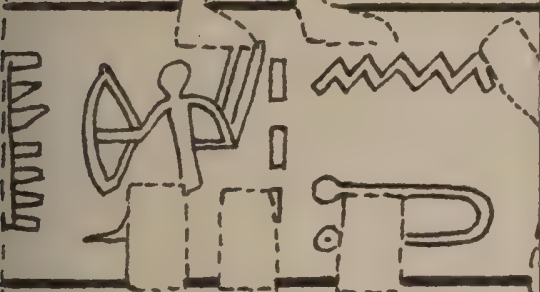

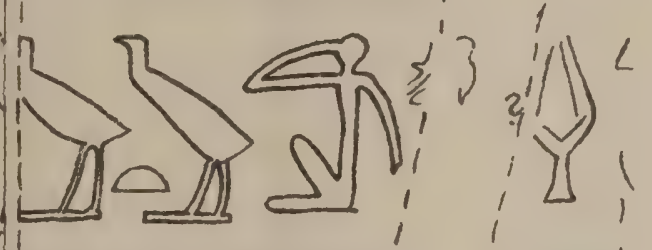

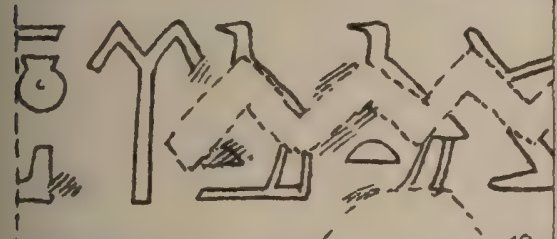

=) $122: \sqrt{2}$

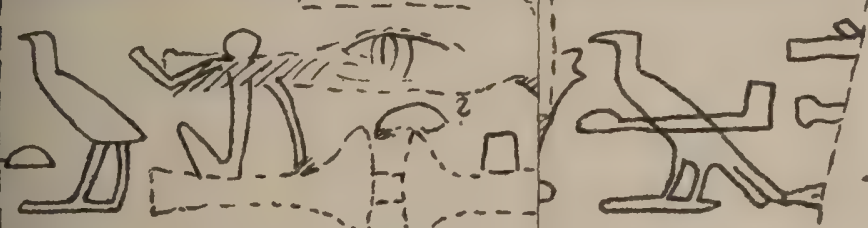

L ……… Dave =

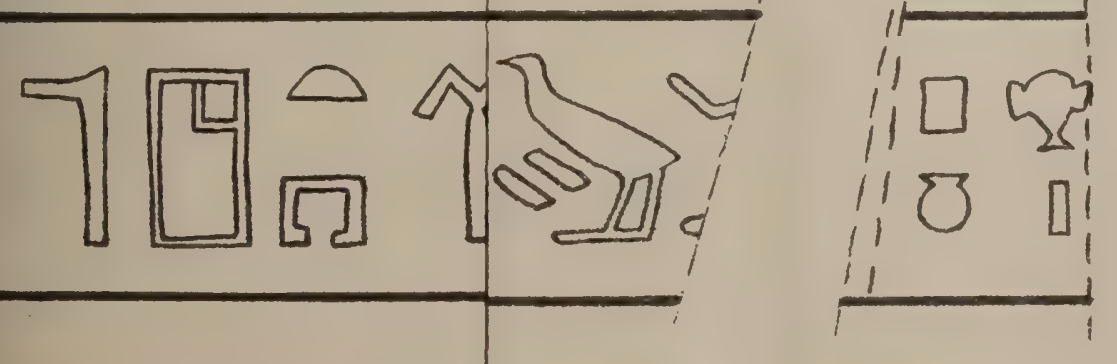


11

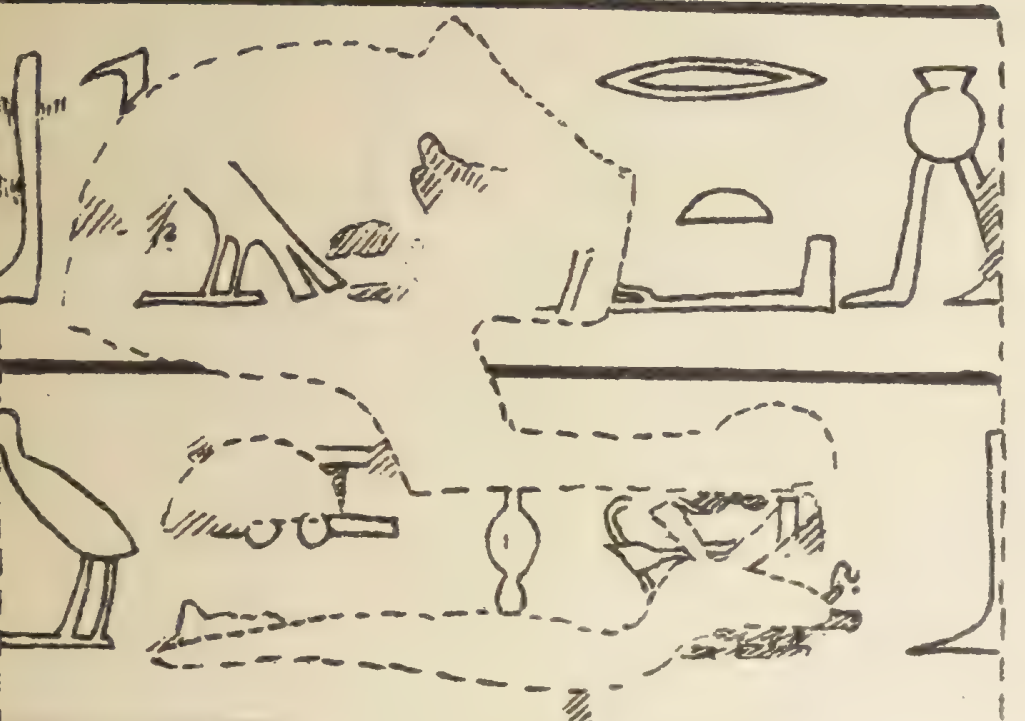

$\approx$ 只- - in

a 0 (a)

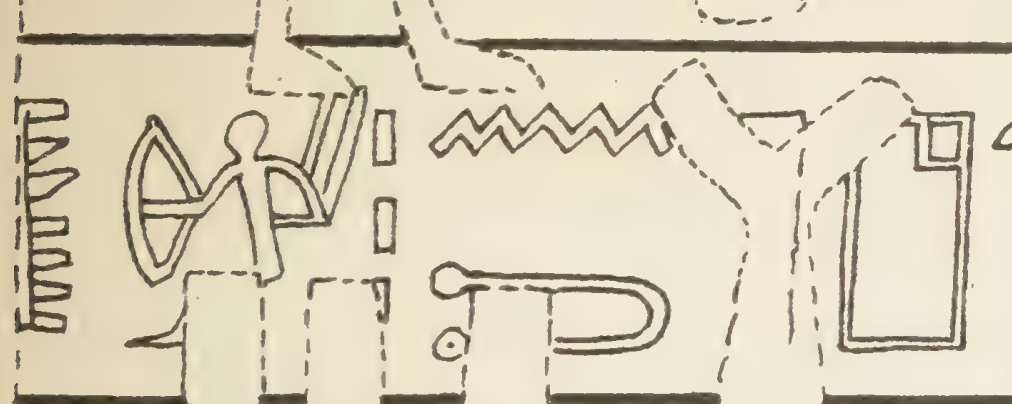

$\longrightarrow \ldots$

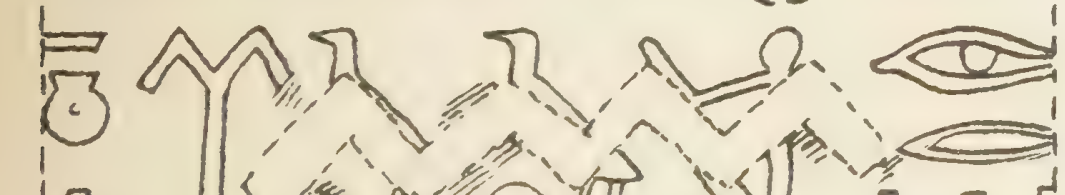

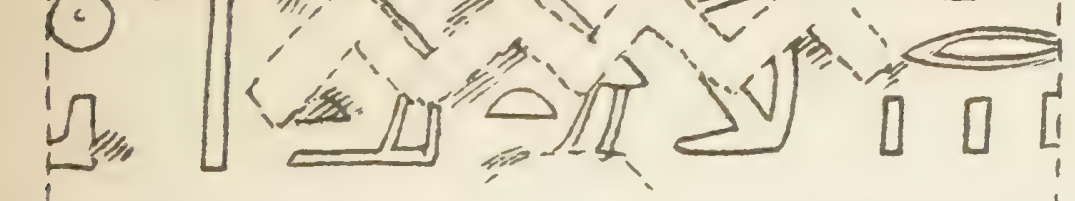

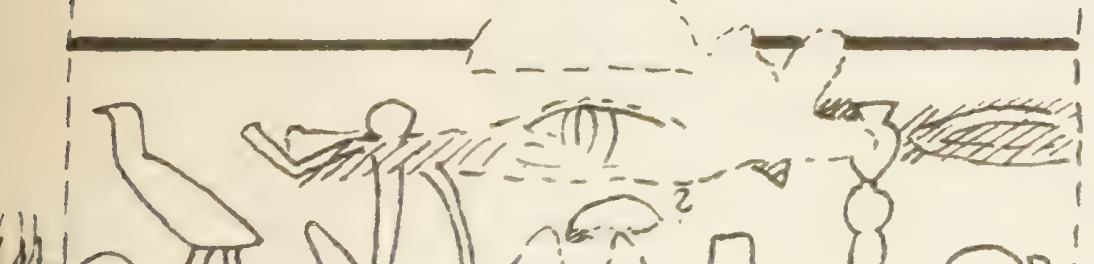

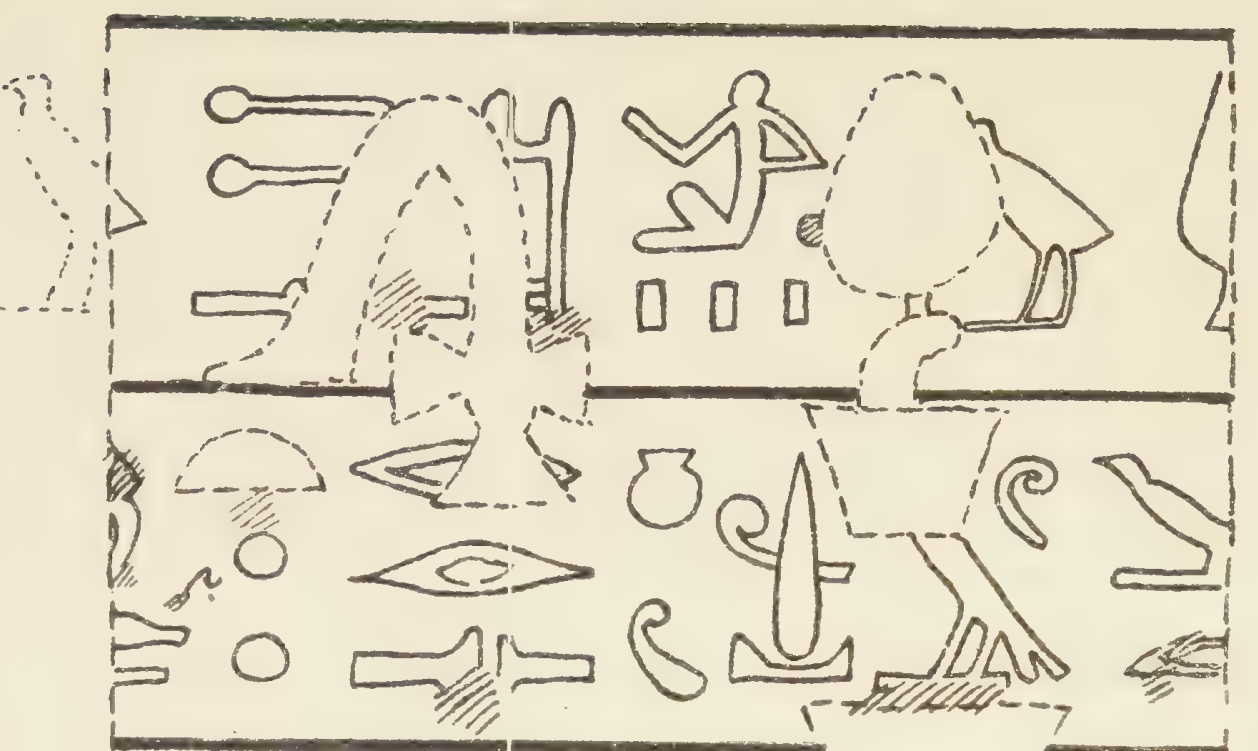

(5)

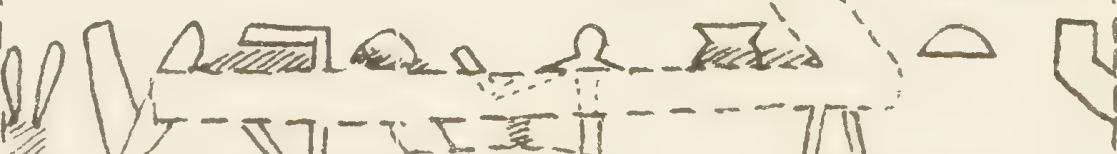
皮
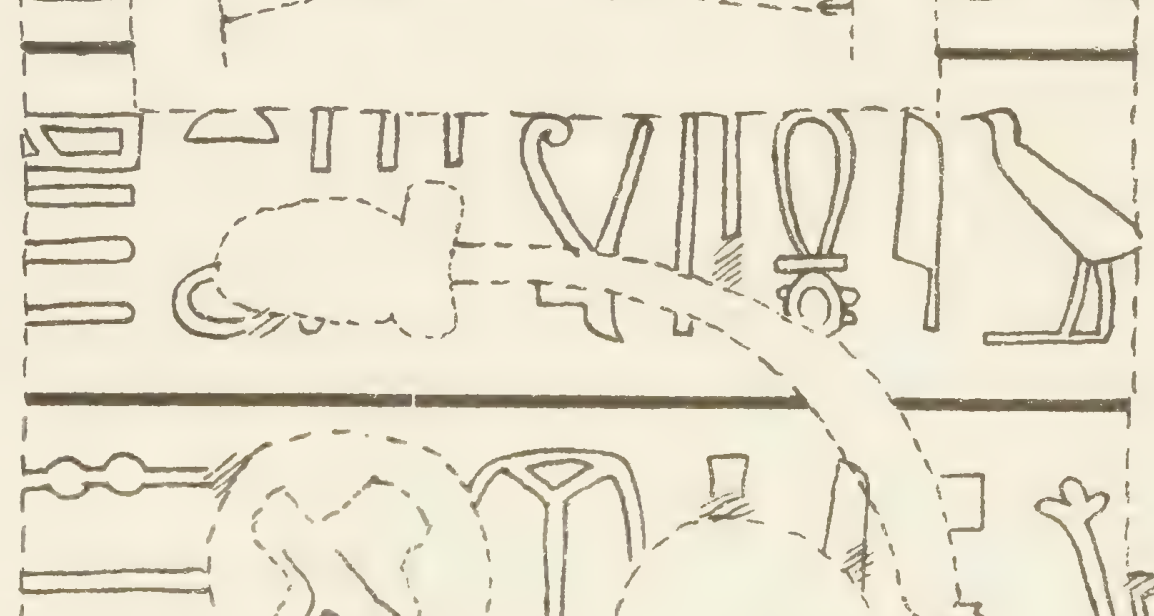

1)

$\longleftrightarrow \ll \frac{4 / 2}{1}$

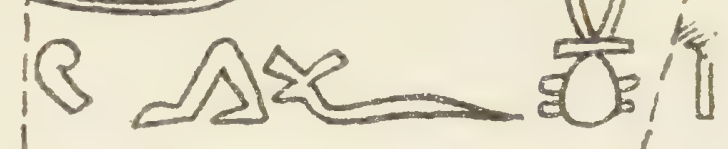

\section{$\sum \int \sqrt{0} \frac{0}{2}$}

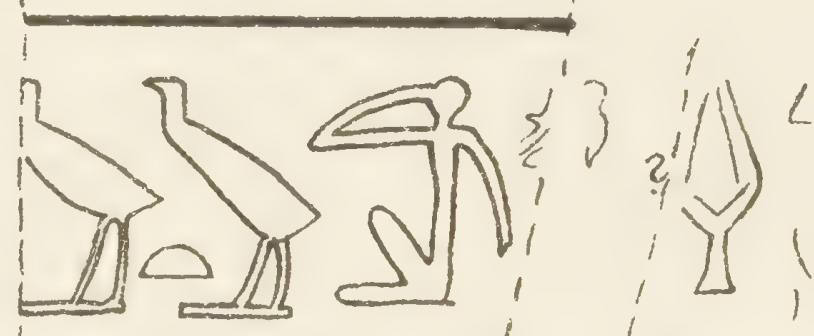

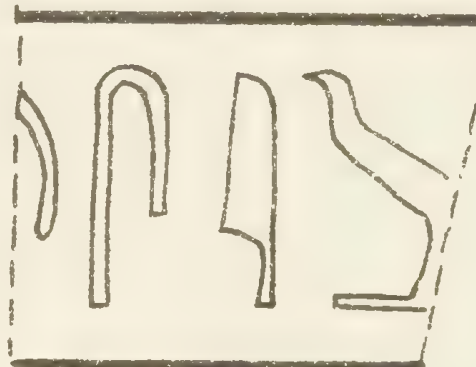
320 象 $\sqrt{4}: 3 b_{11}$ 1 粠空 E, i i II (P)

\section{cas}

$0<$
1, $1100 !$ 


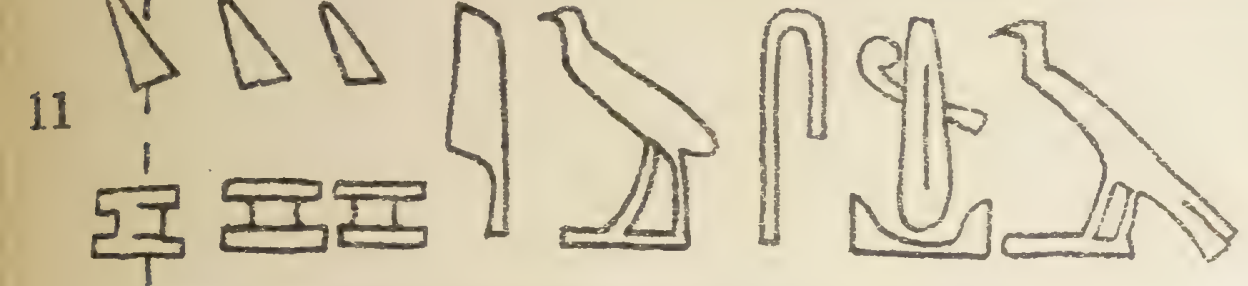

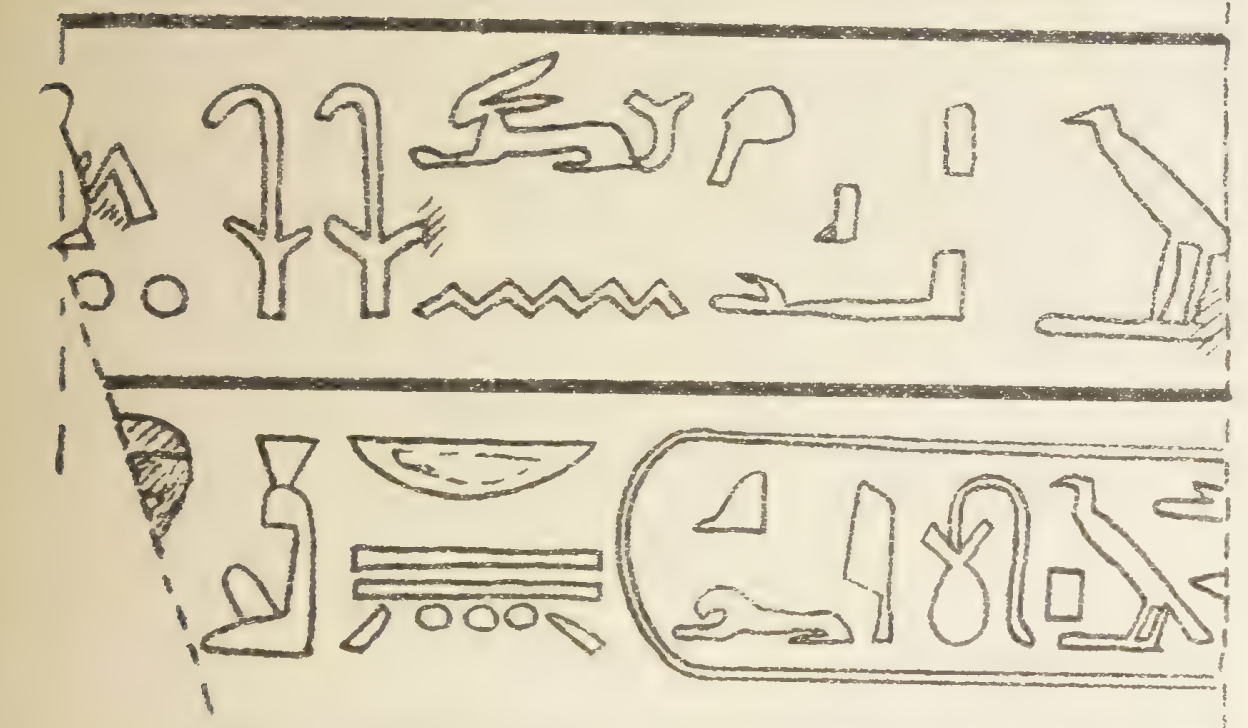

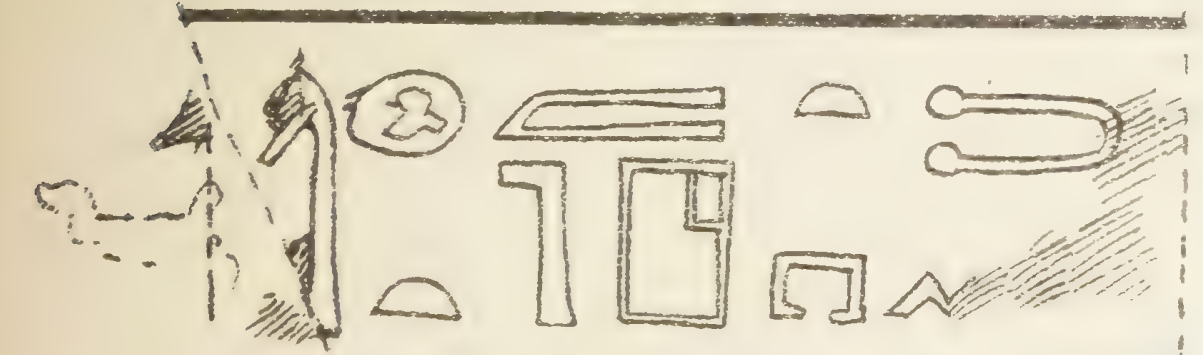

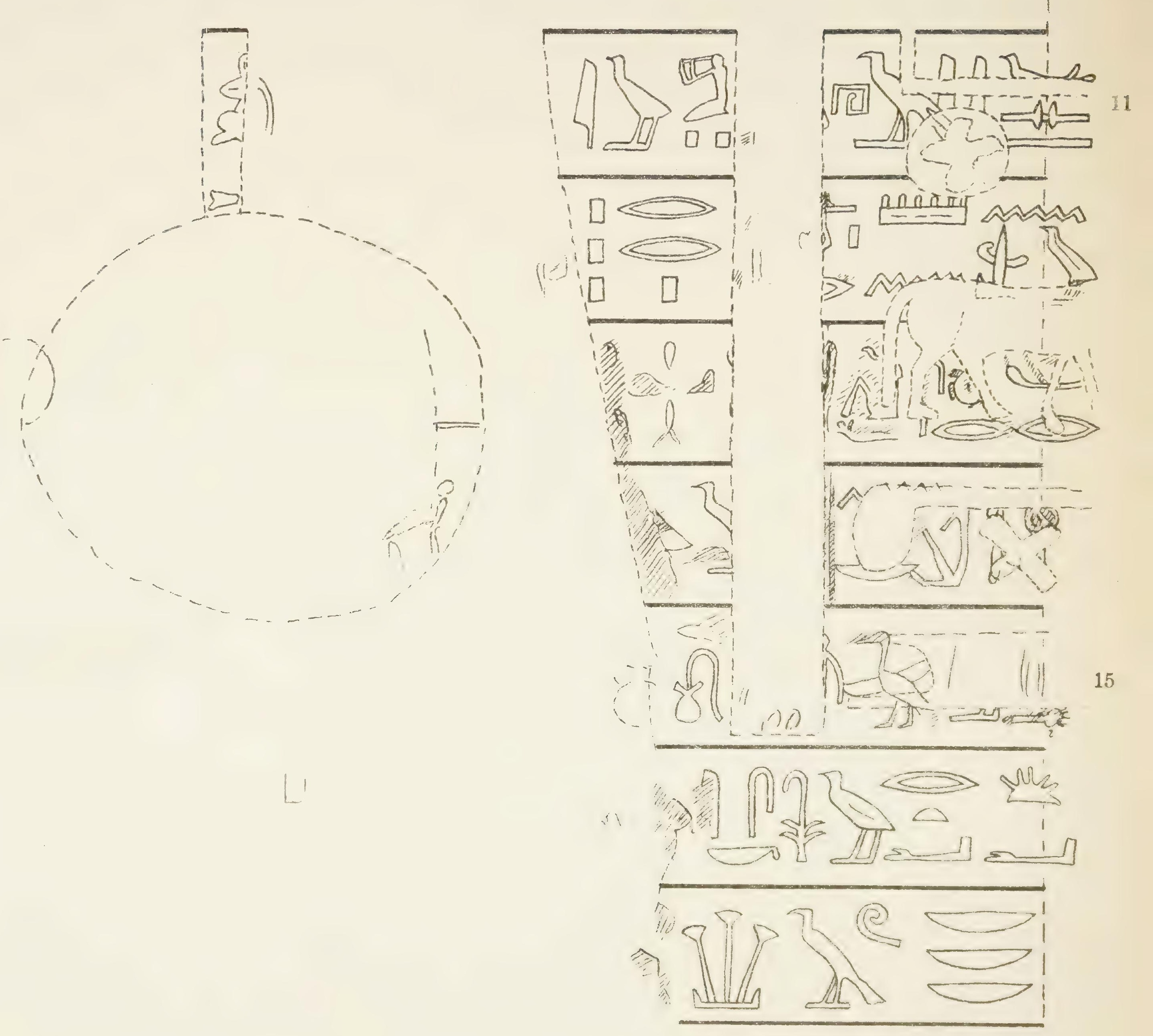




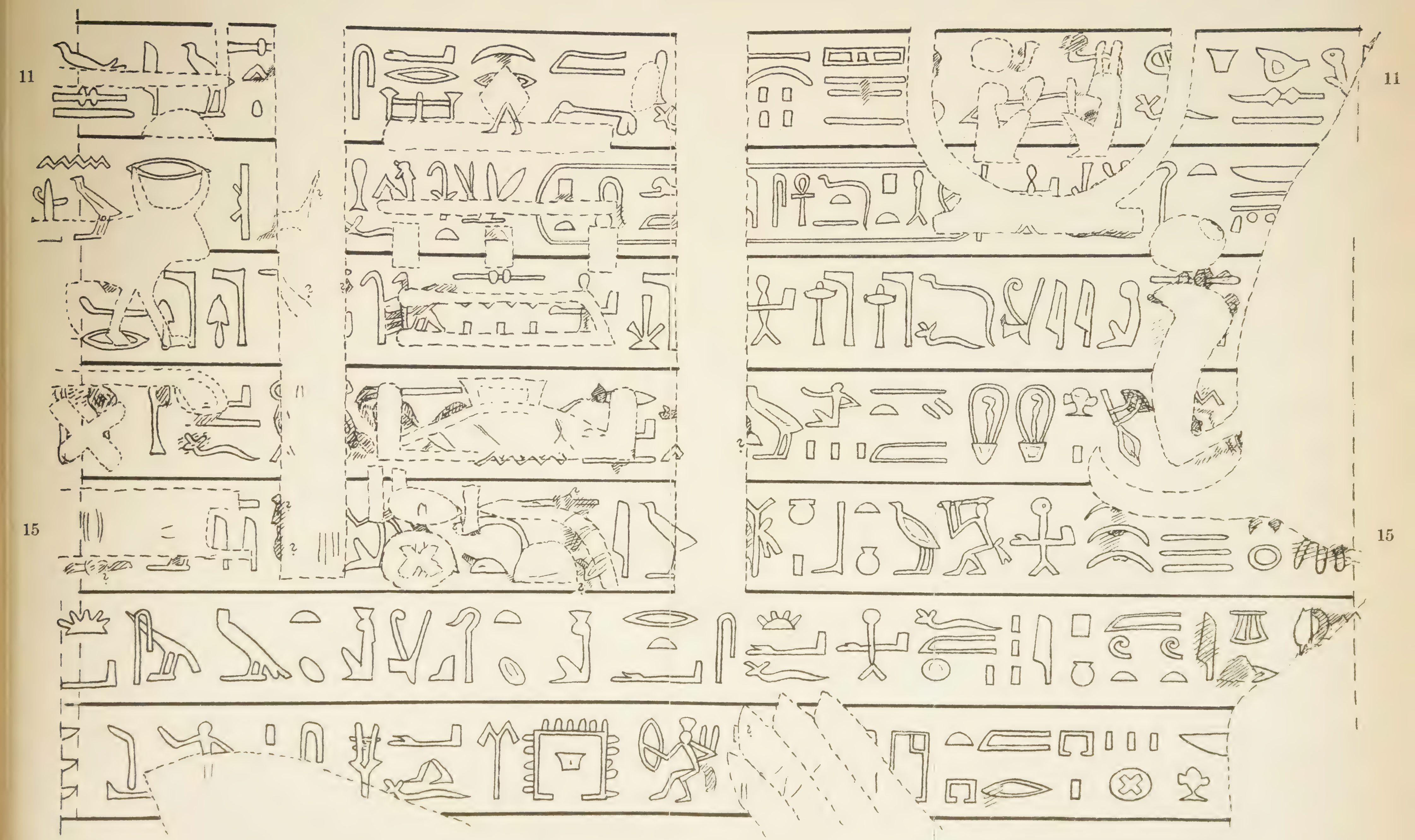




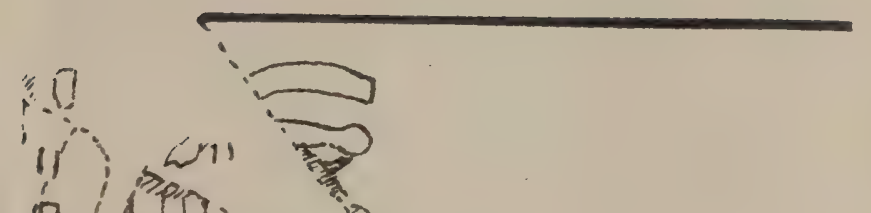

1

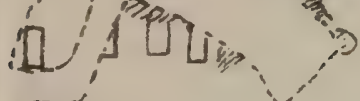
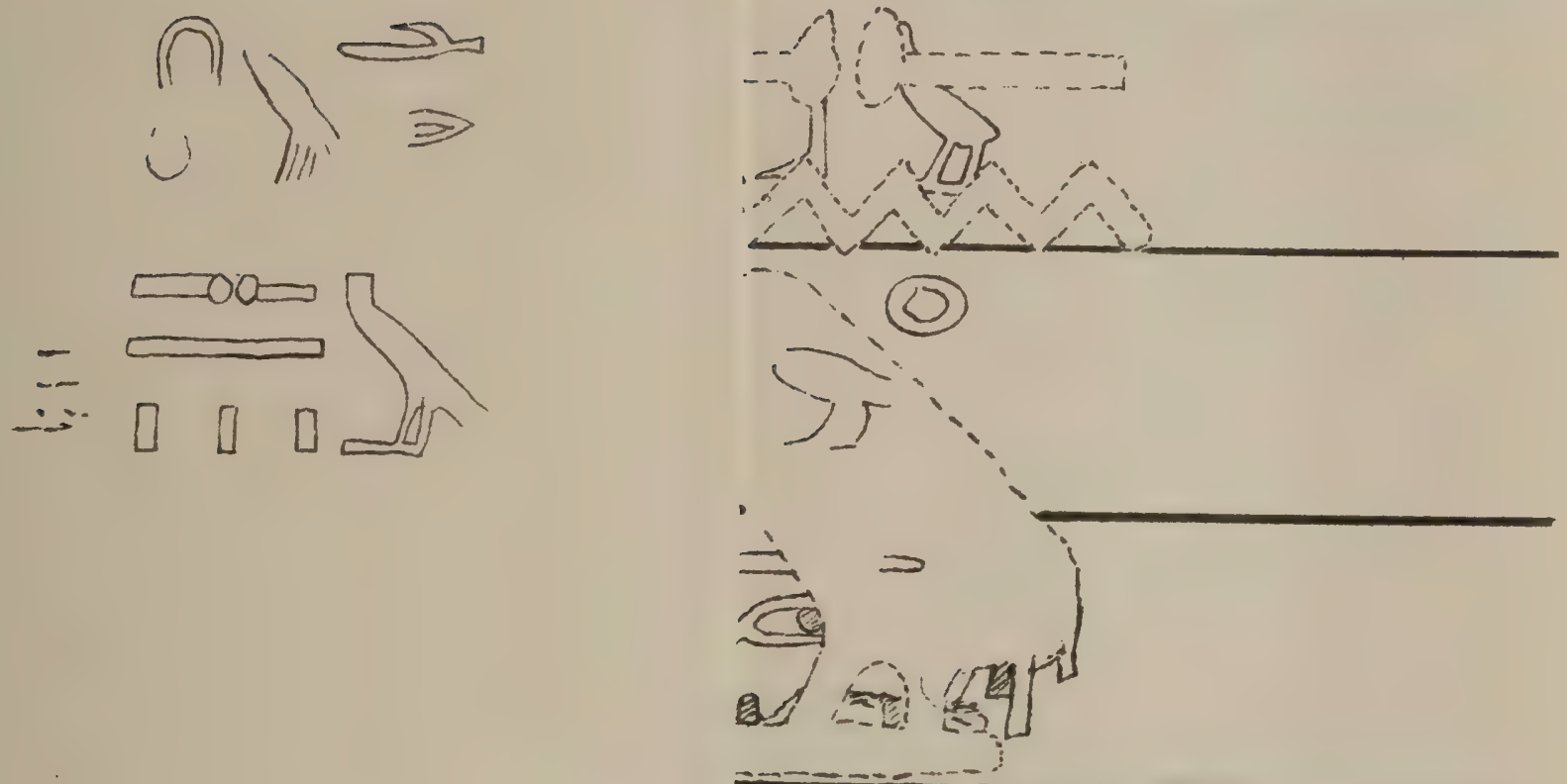
Second Bilingual Decree of Philae, Der

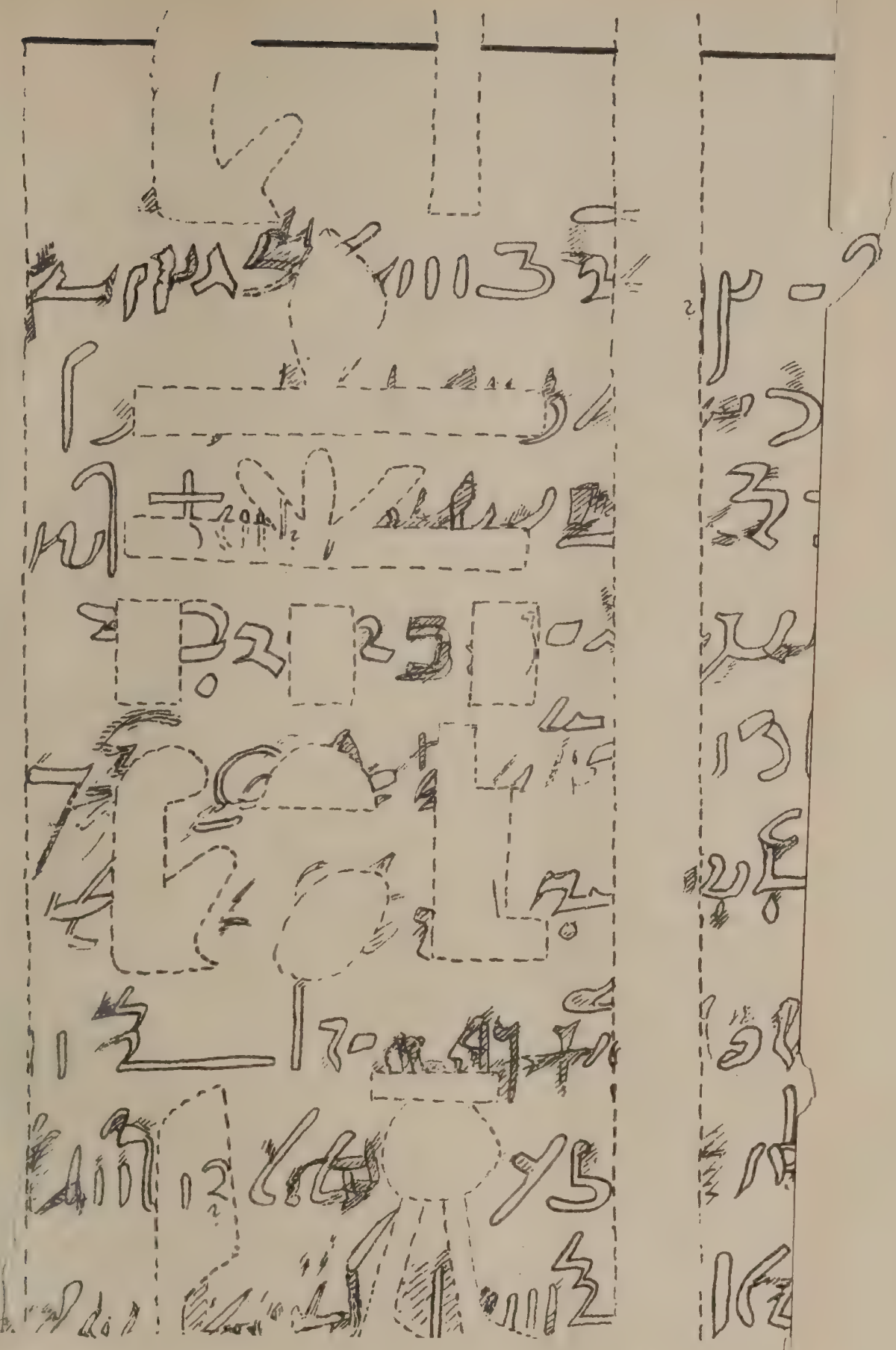




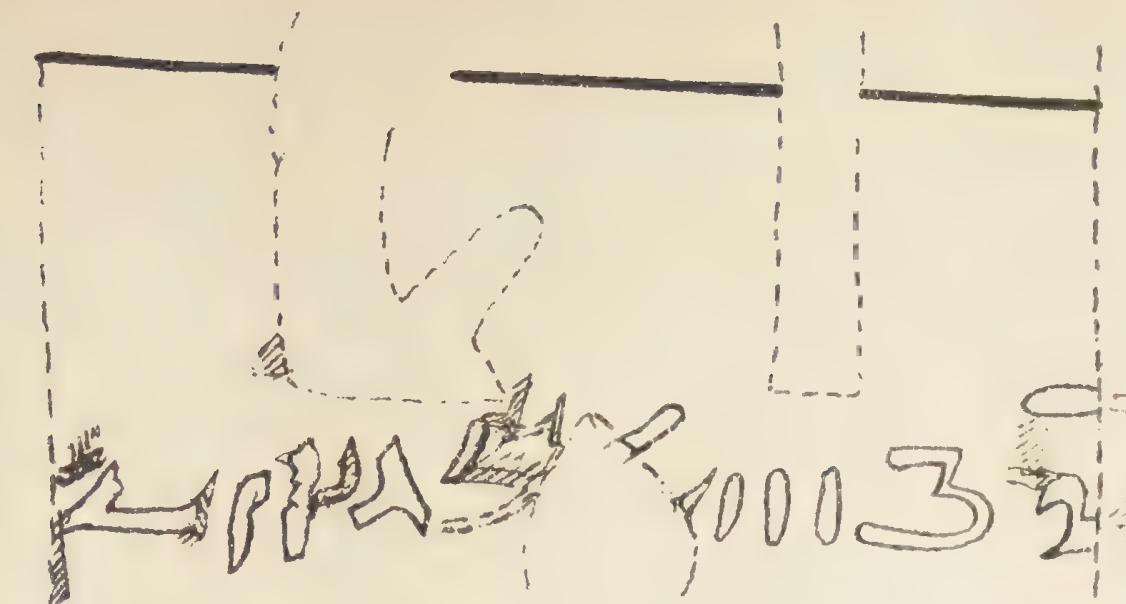

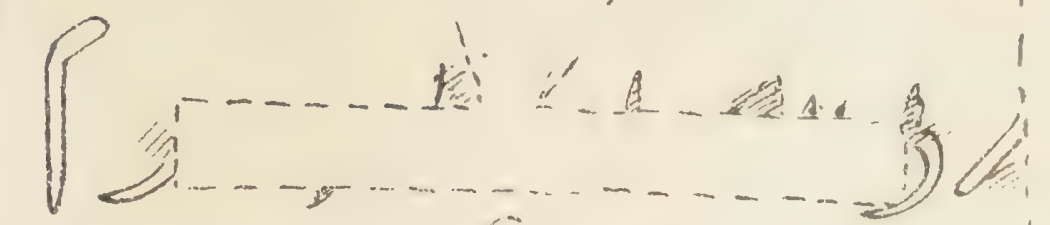

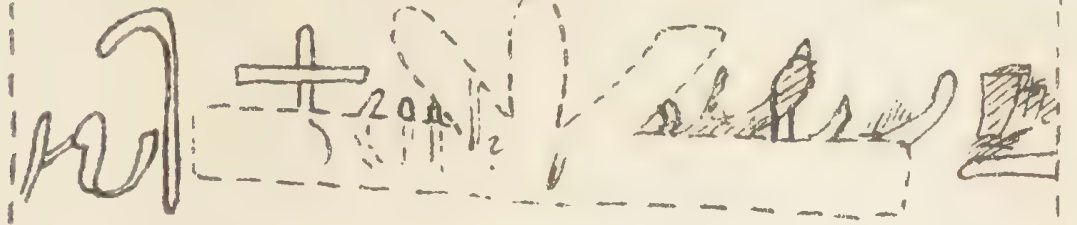

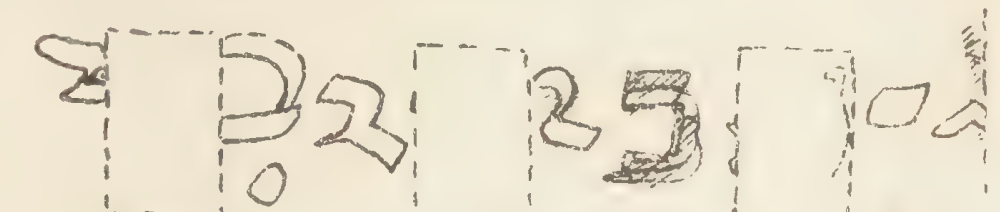

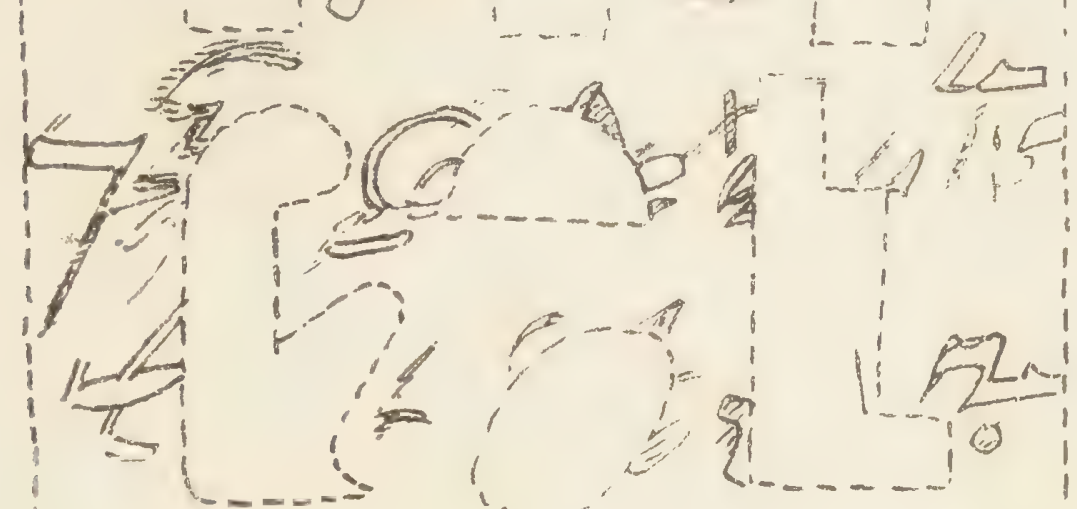

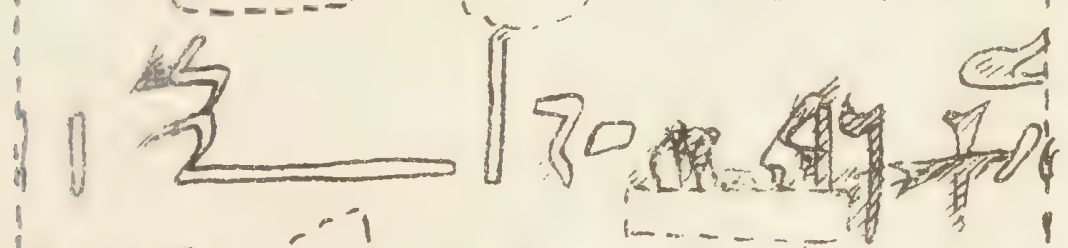
Aiding

9g.

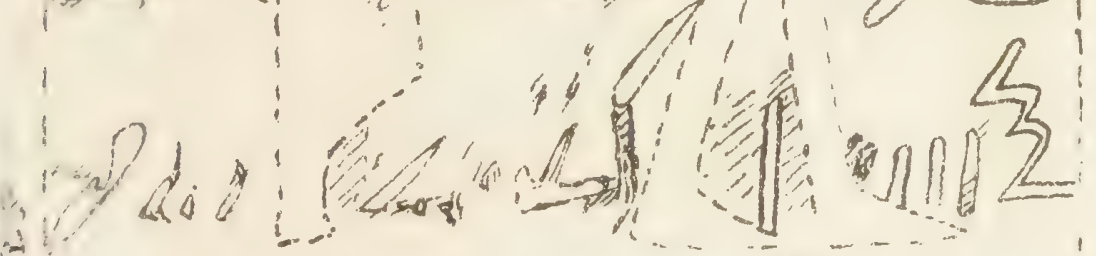
Yoce

W

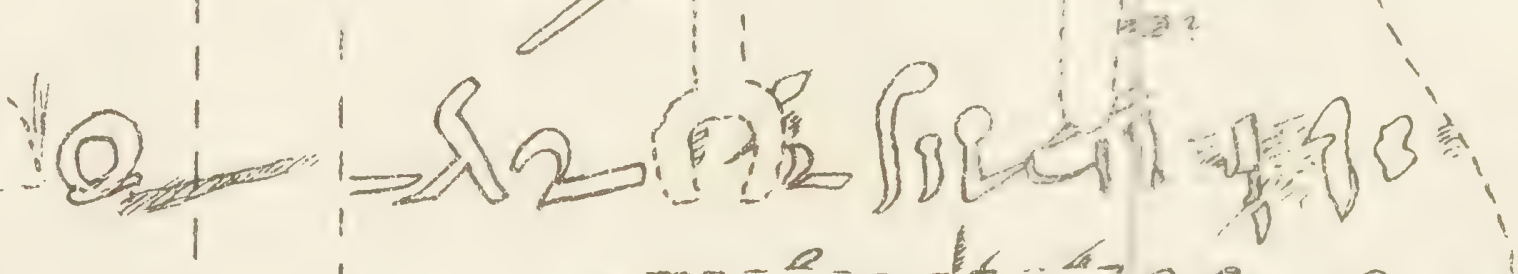

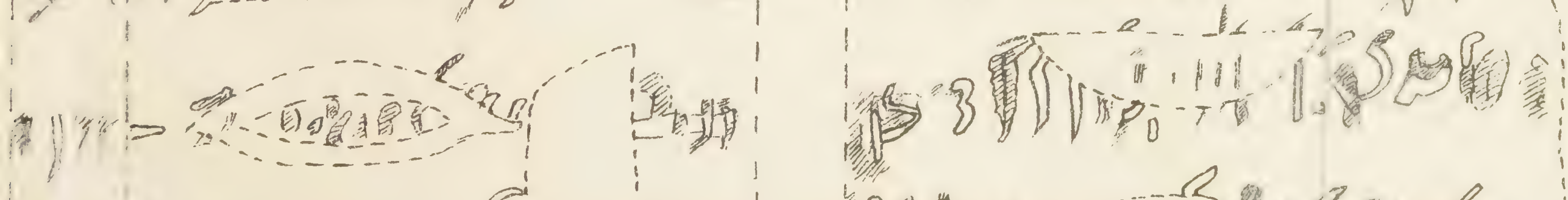

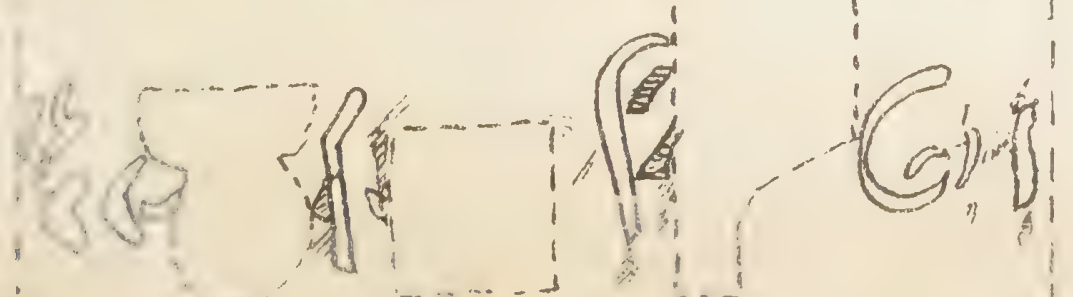
$=$ 非进 
Second Bilingual Decree of Philae, Demotic text $b$.

PLATE 34

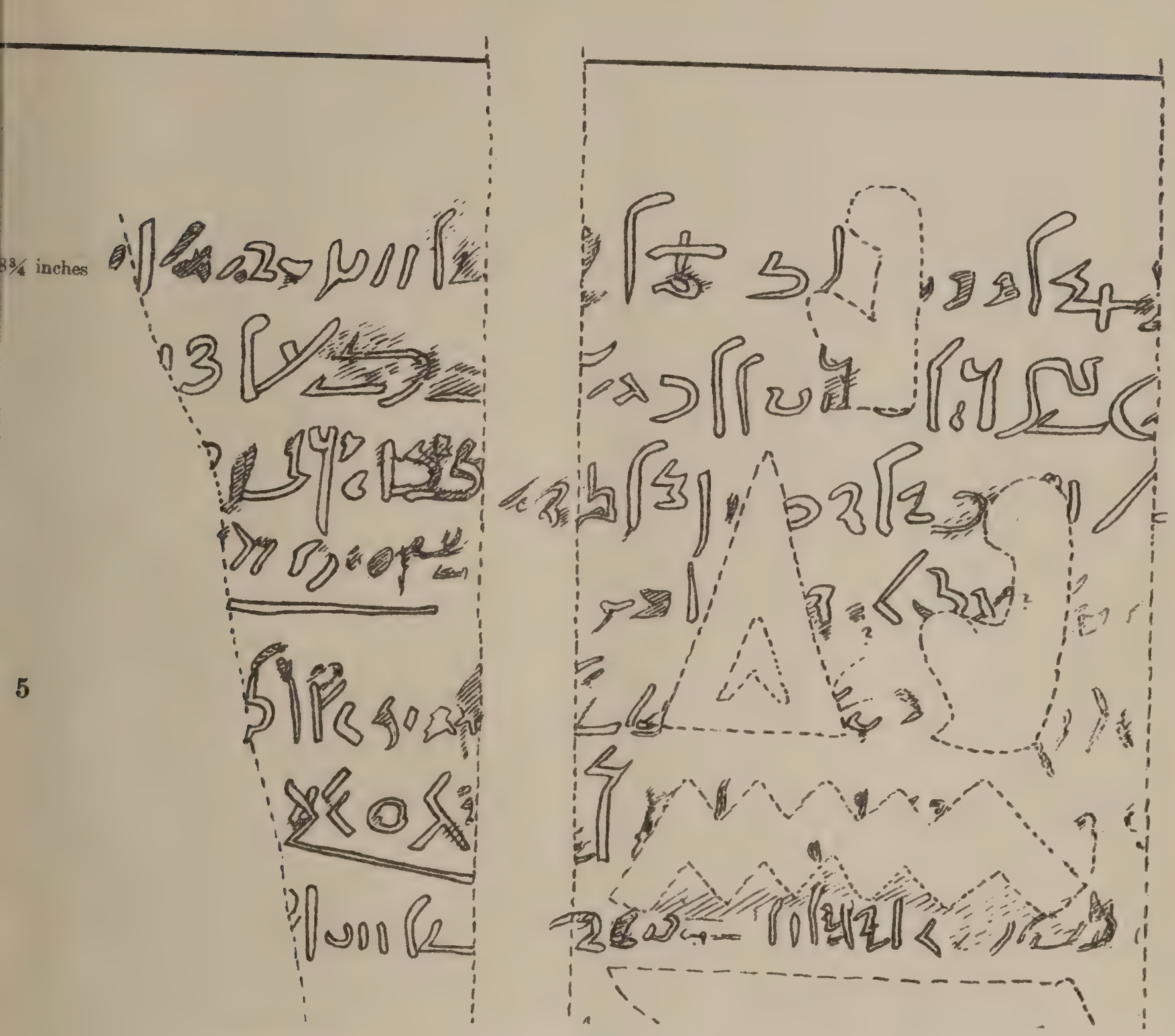


Second Bilingual Decree of Philae, Demotic text $c$.

PLATE 35

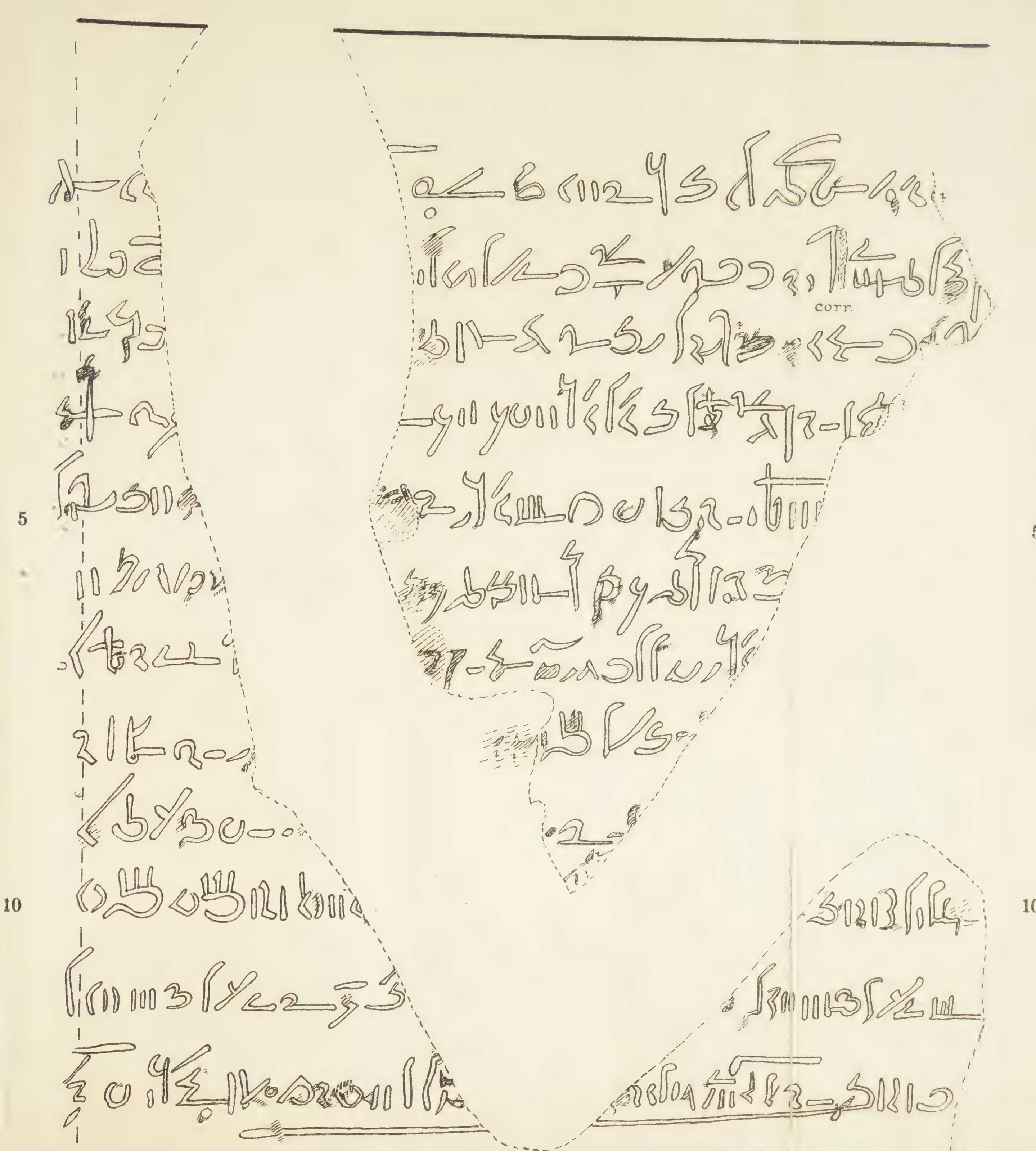

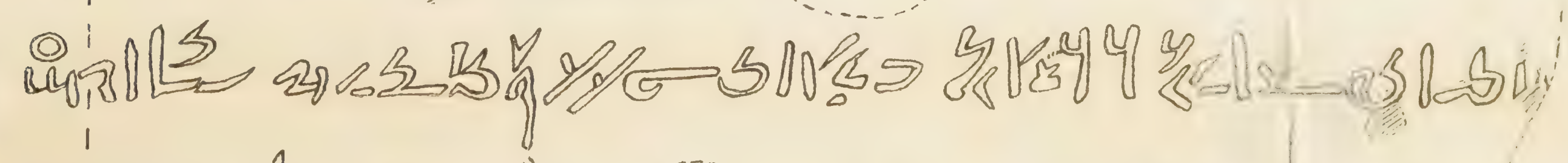

a 
Second Bilingual Decree of Philae, Demotic

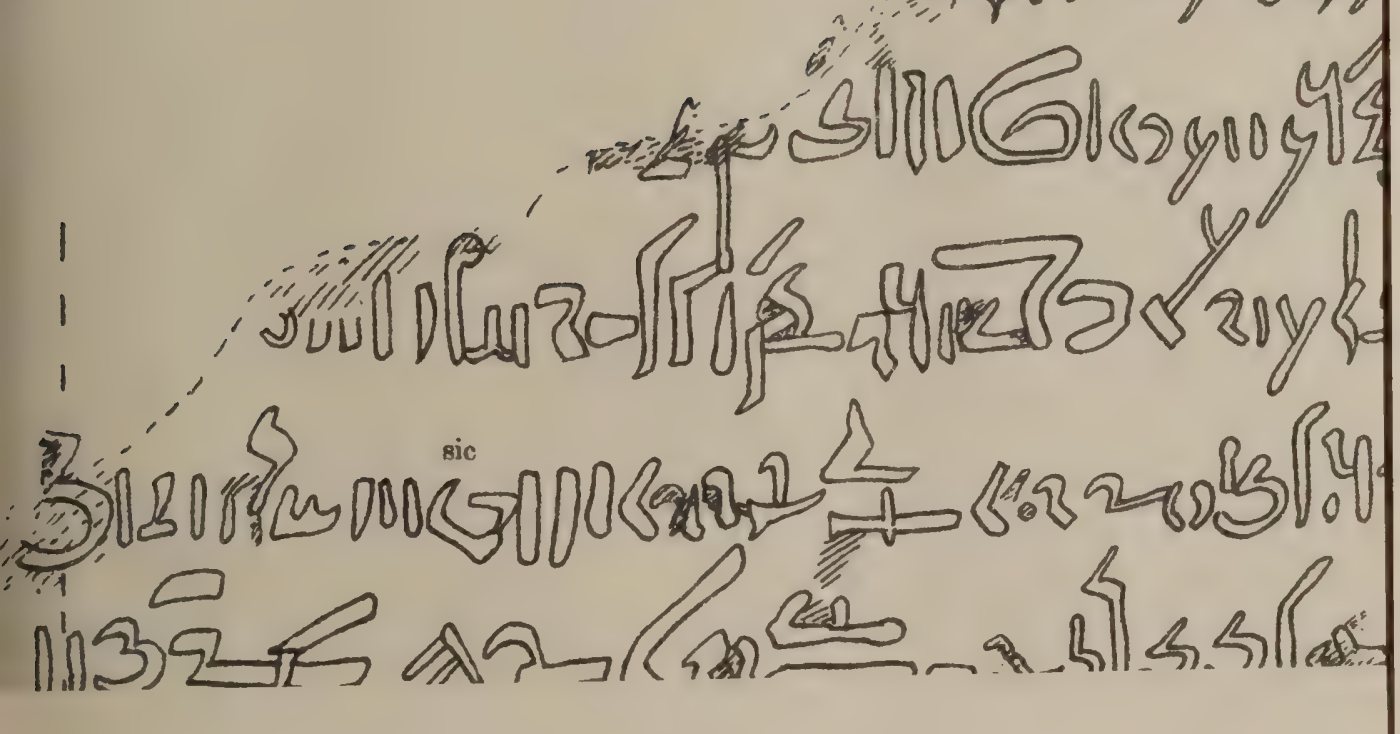




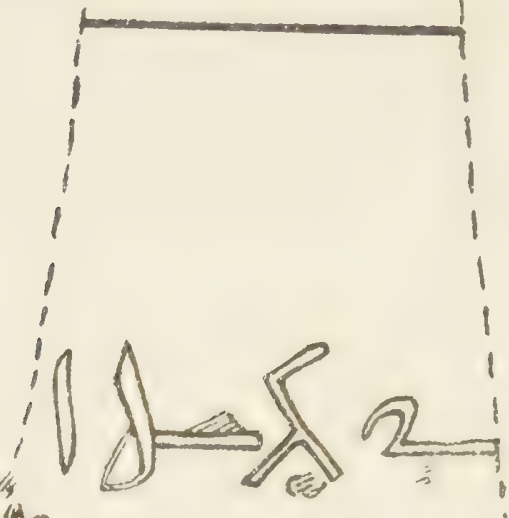

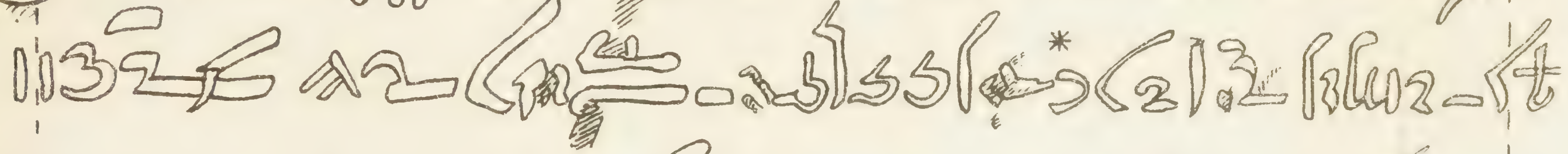

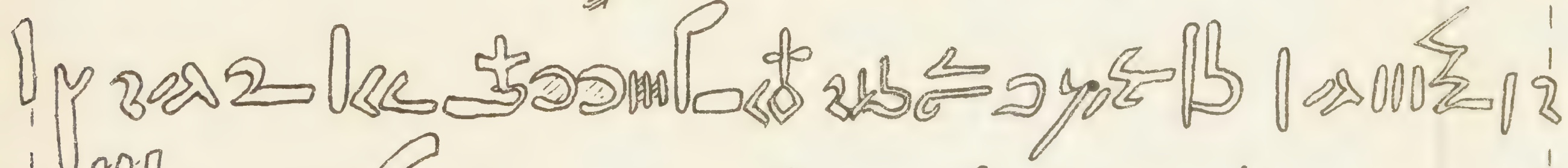

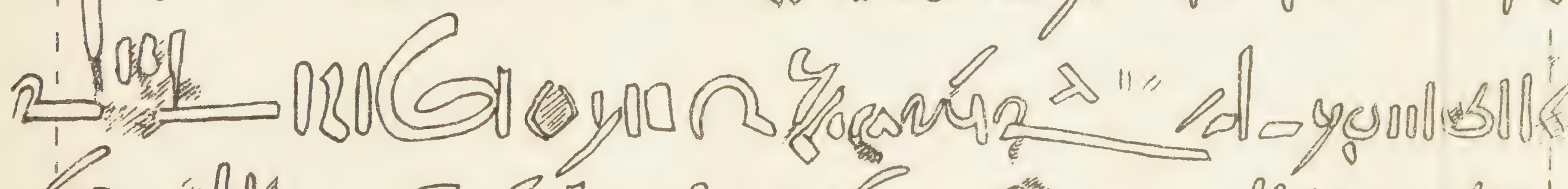

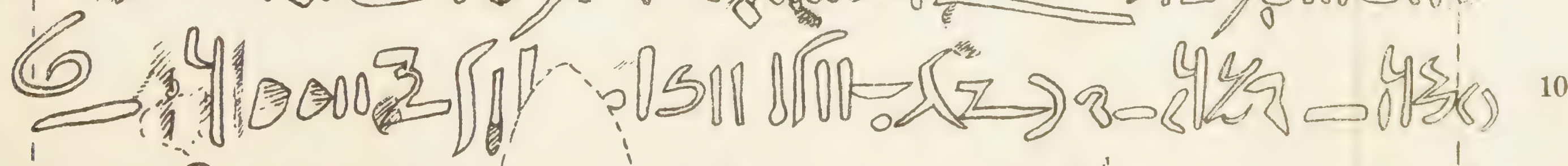

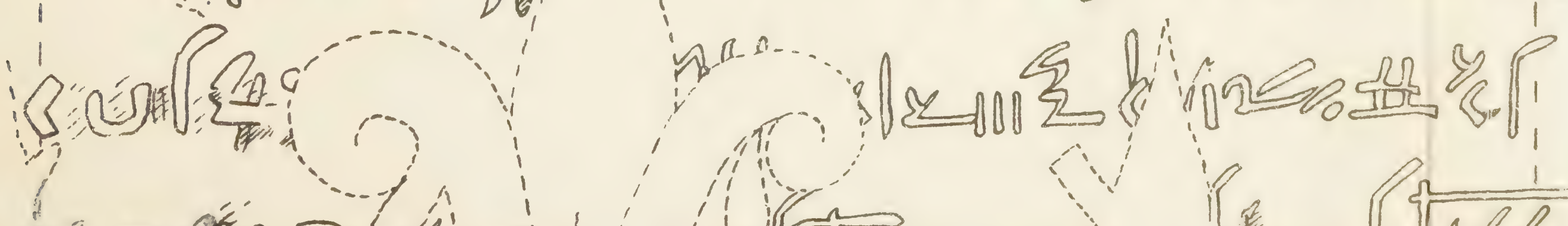

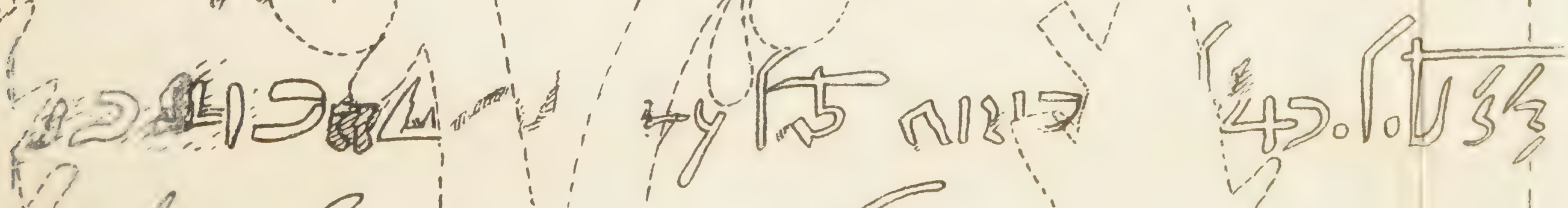

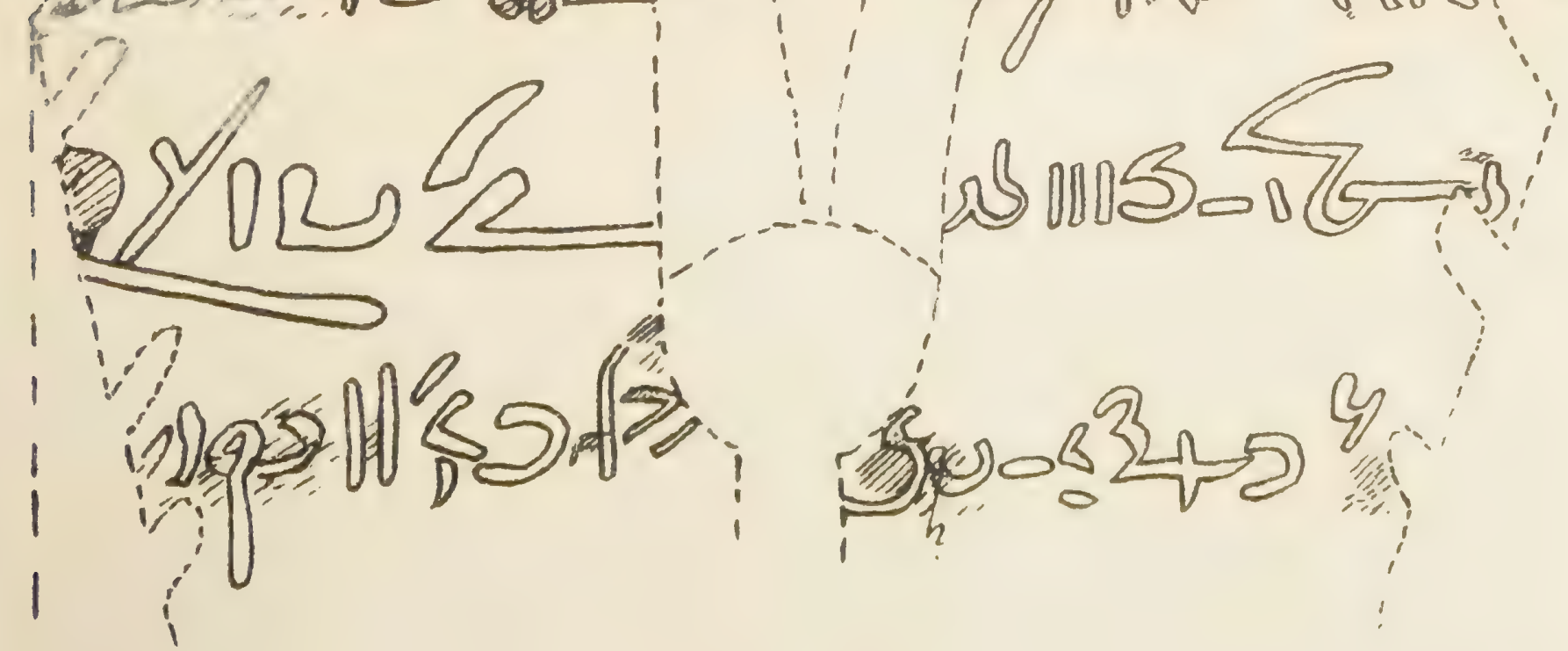


Second Bilingual Decree of Philae, Demotic tex

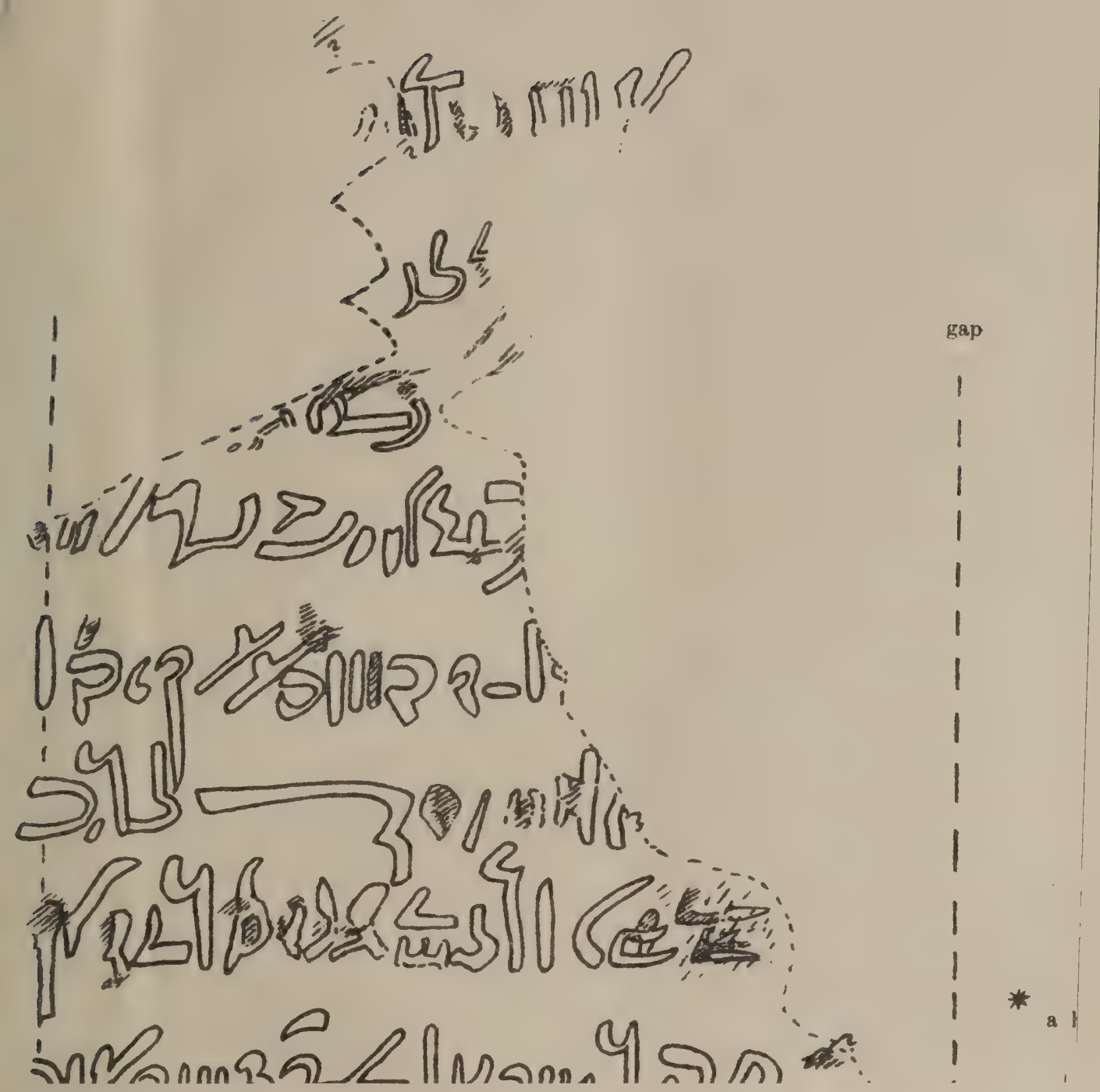




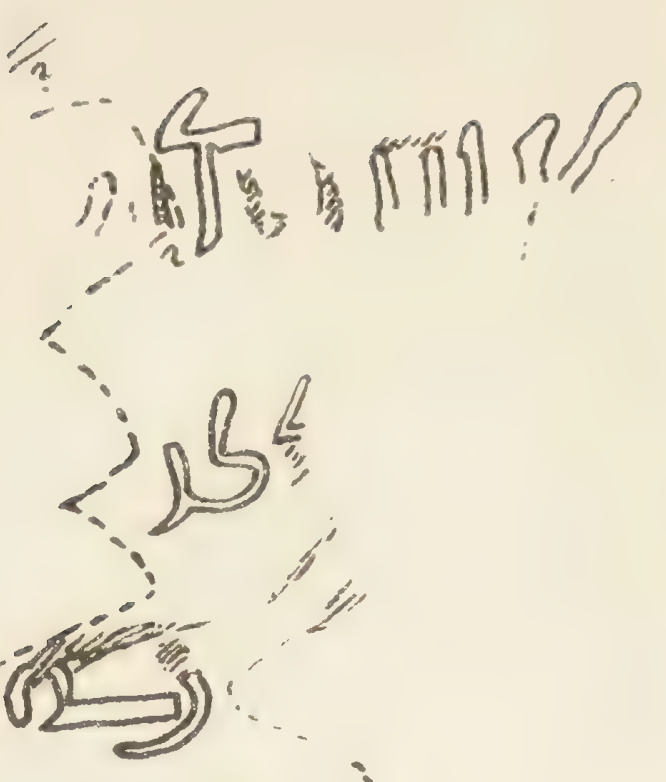

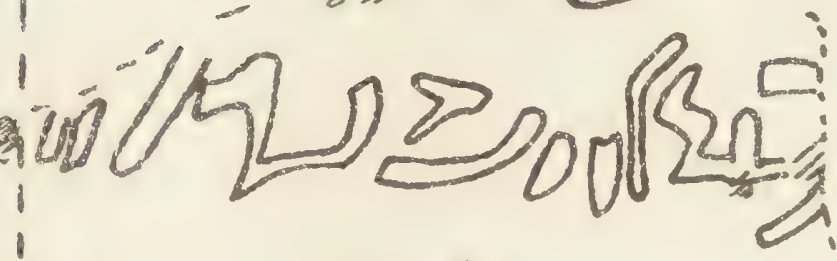

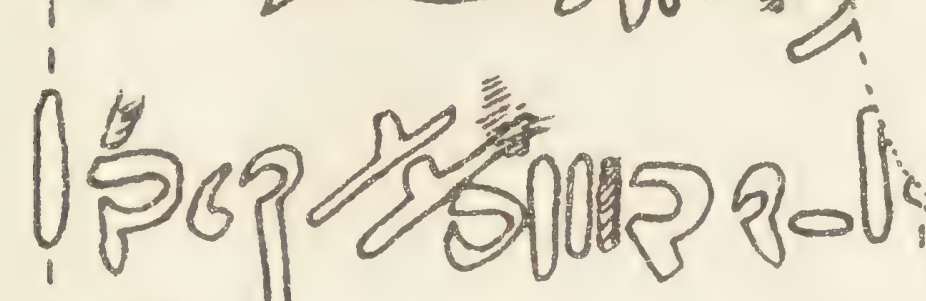

2013

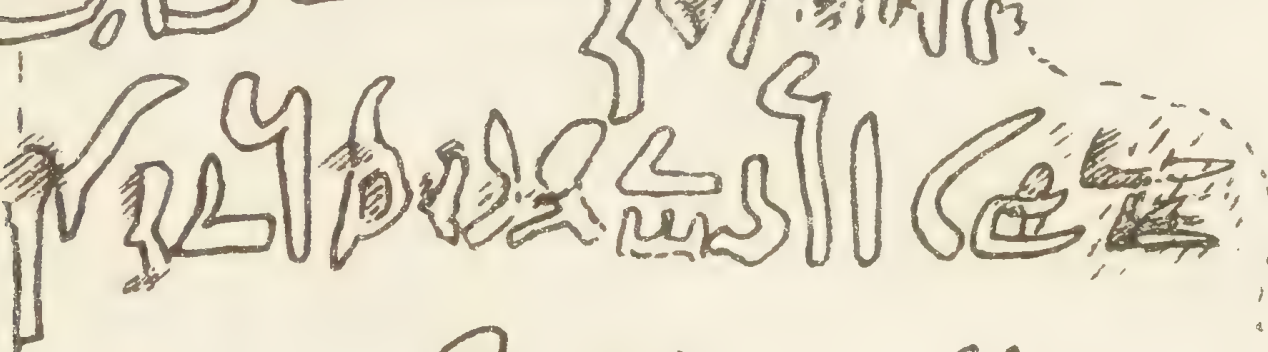

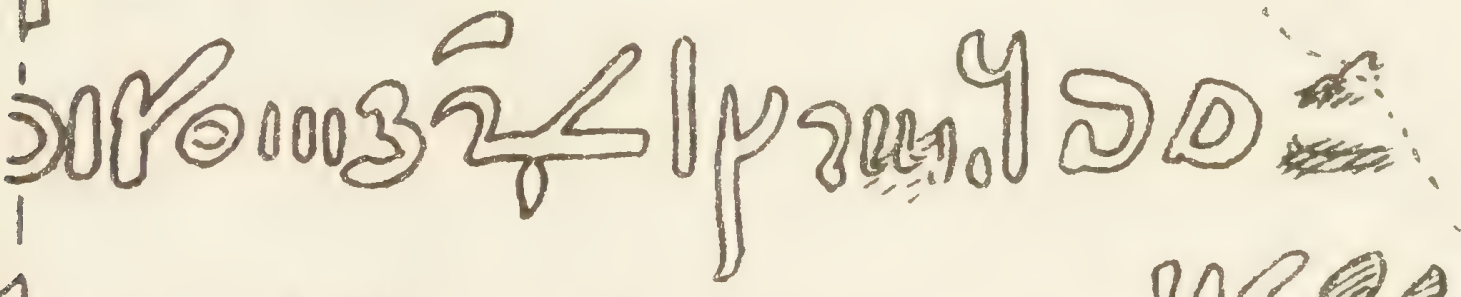

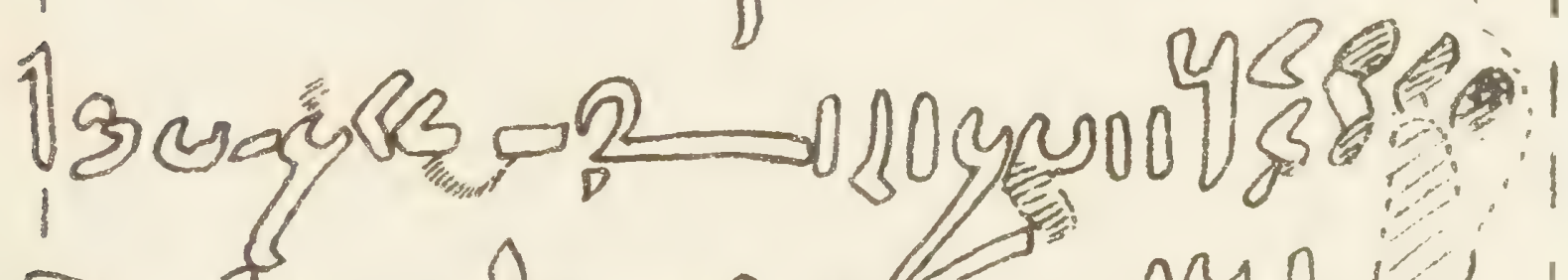

700 月0.

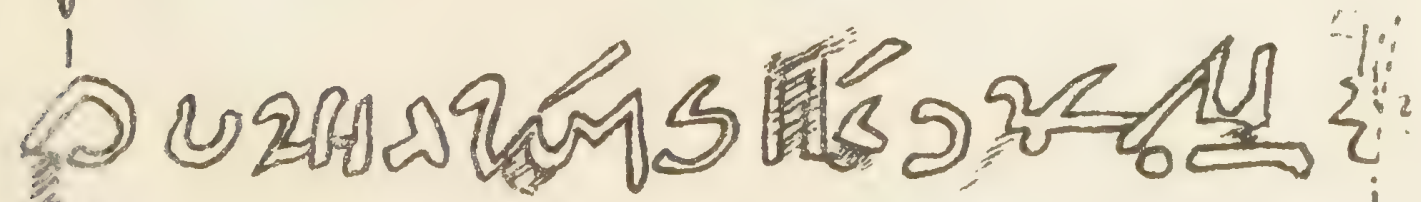

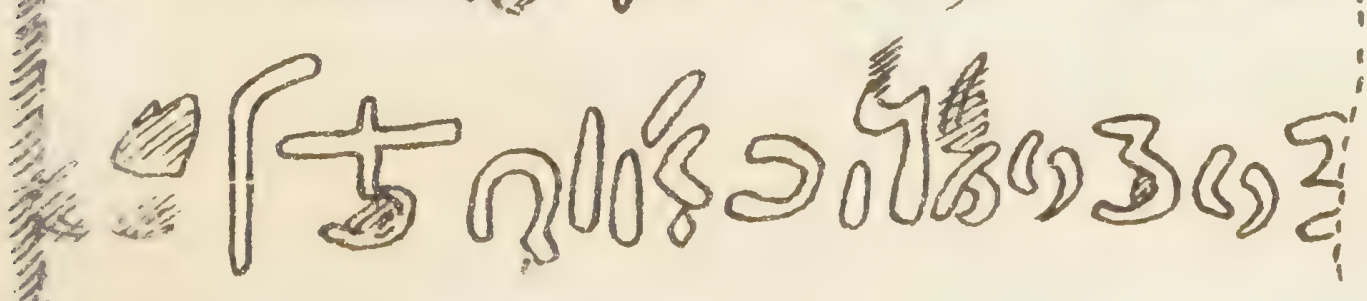

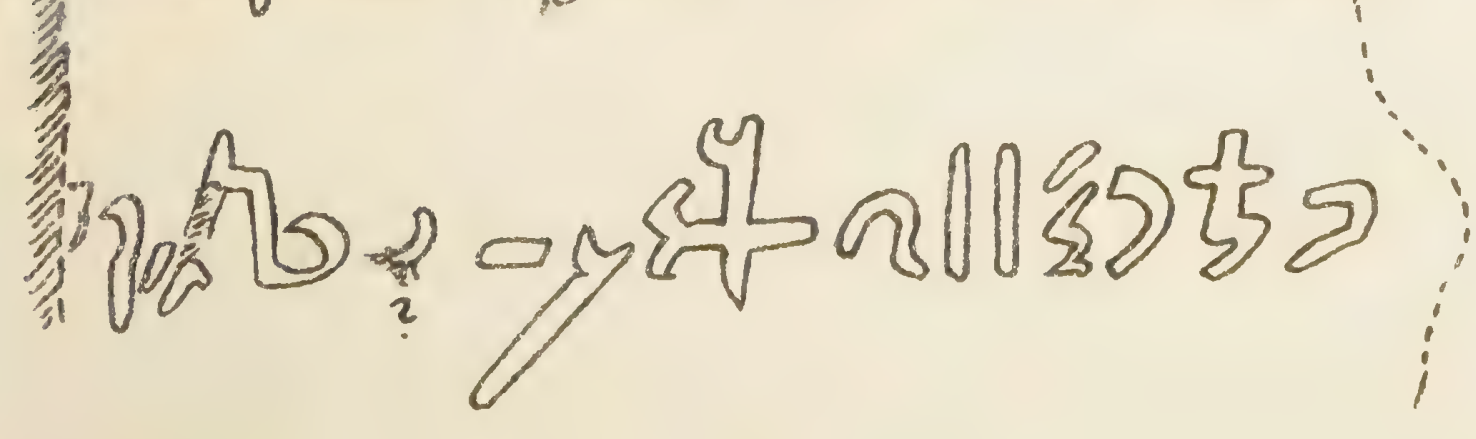
sinche

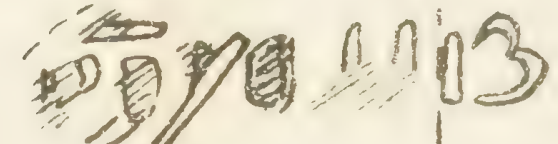

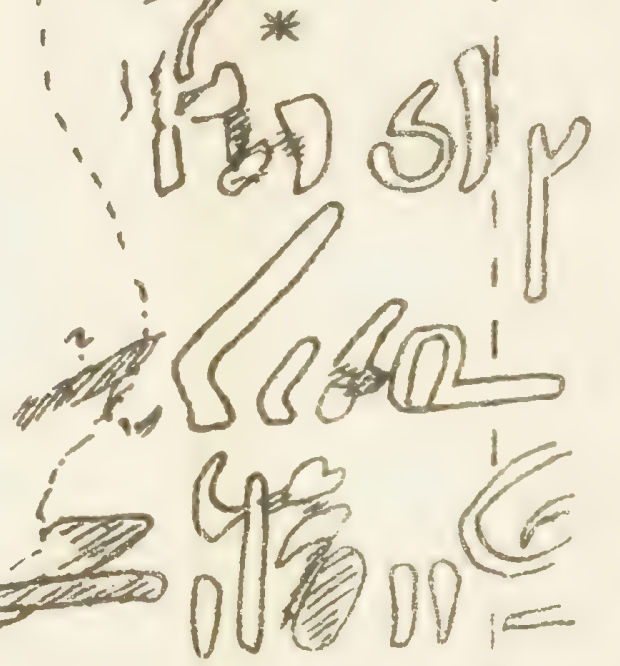




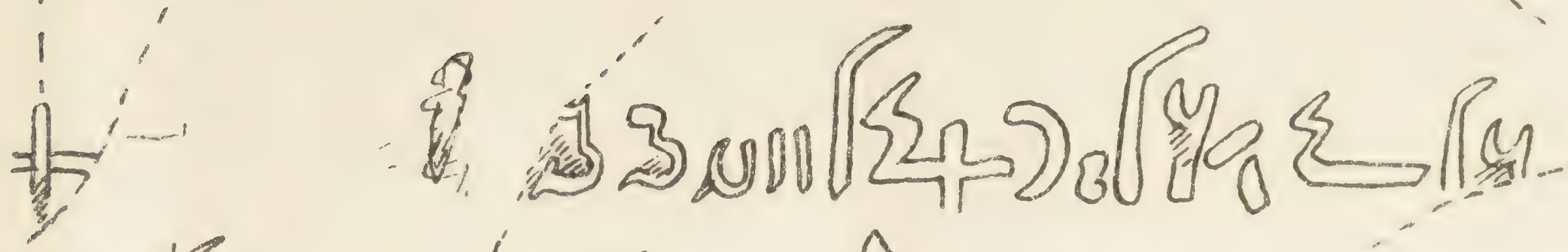

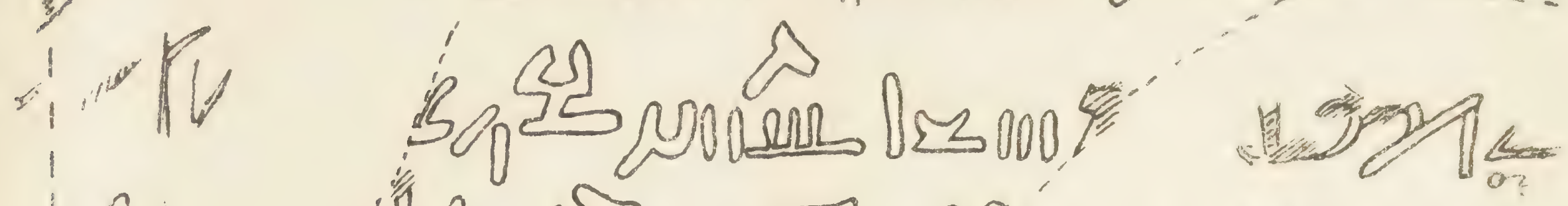
1)

M Solot B0.

5 "us

10

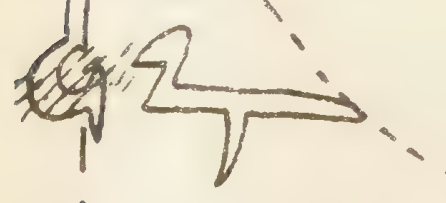

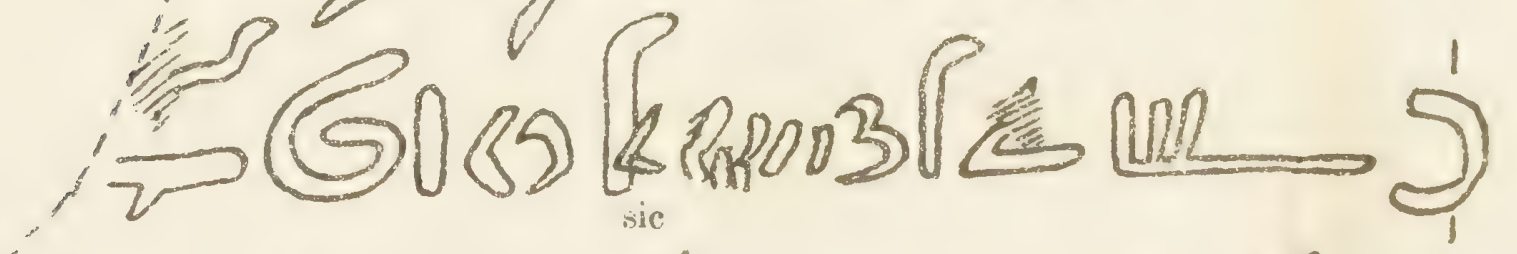

-1 U.

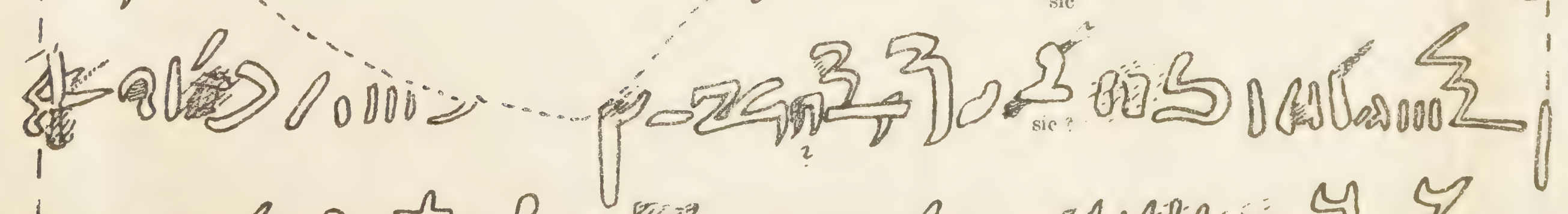

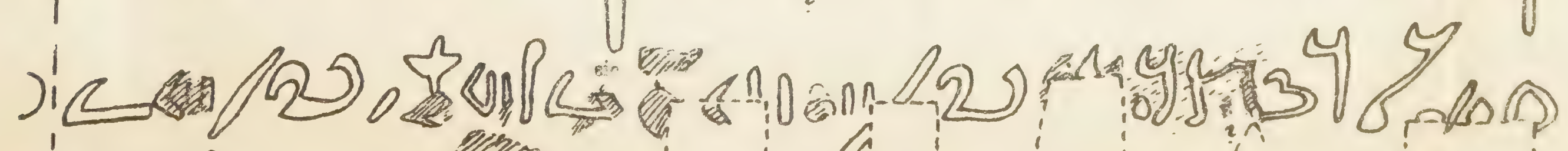

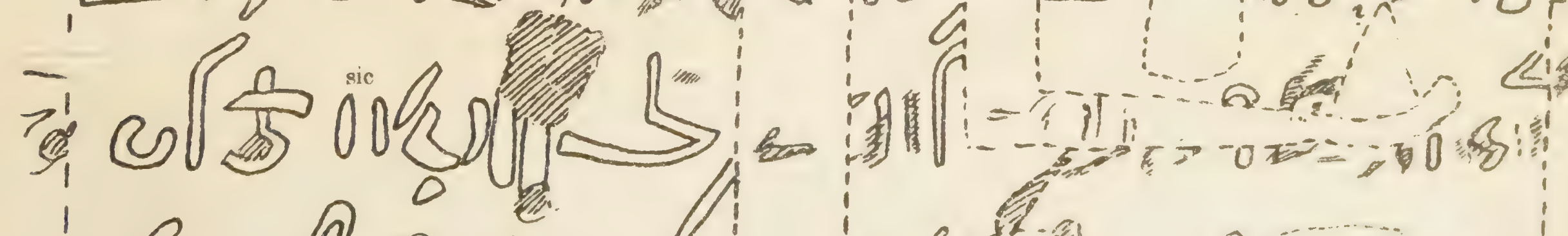
“ 
Second Bilingual Decree of Philae, Demotic text g.

PLATE 39

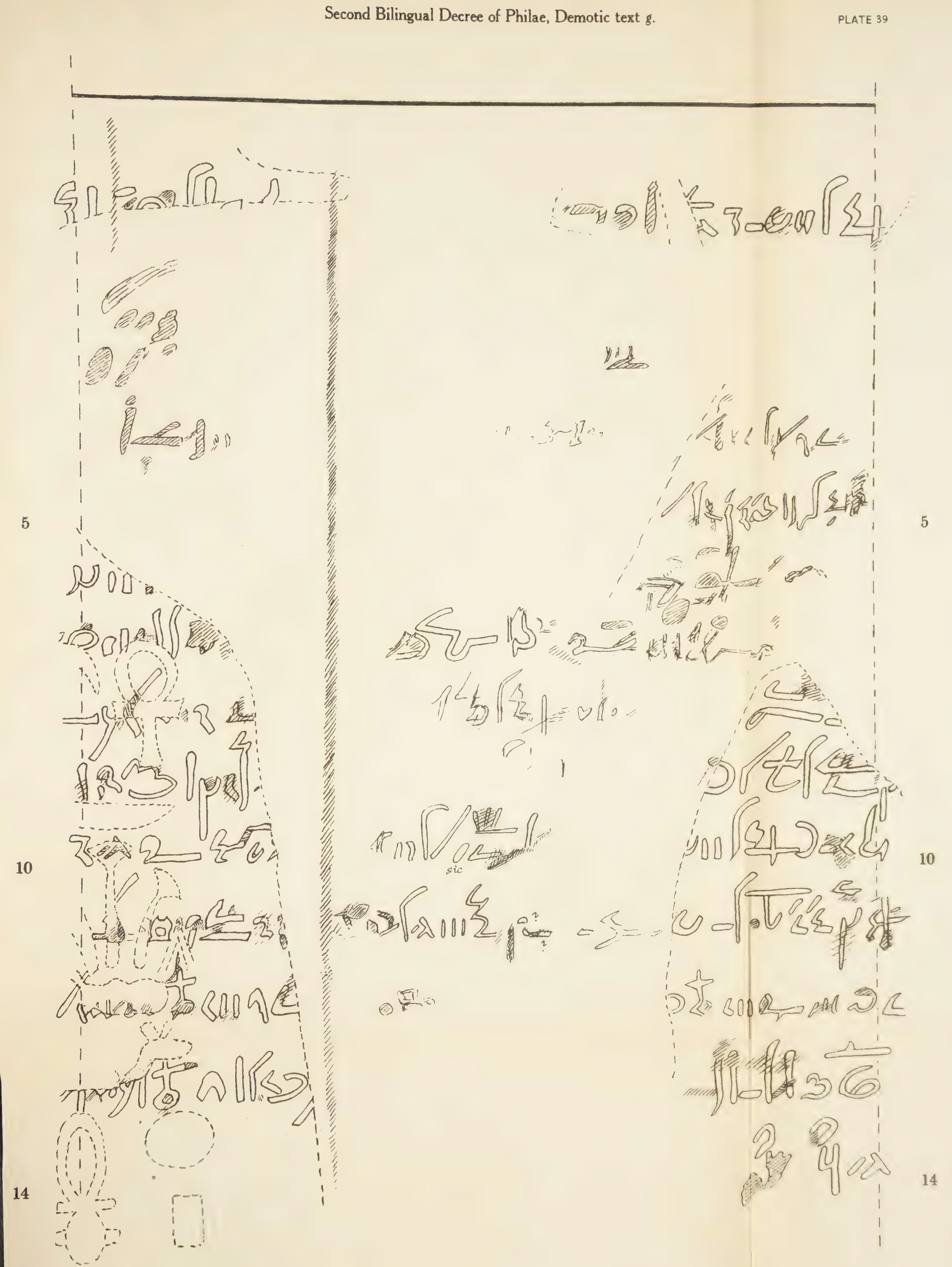


Second Bilingual Decree of Philae, Demotic text $h$.
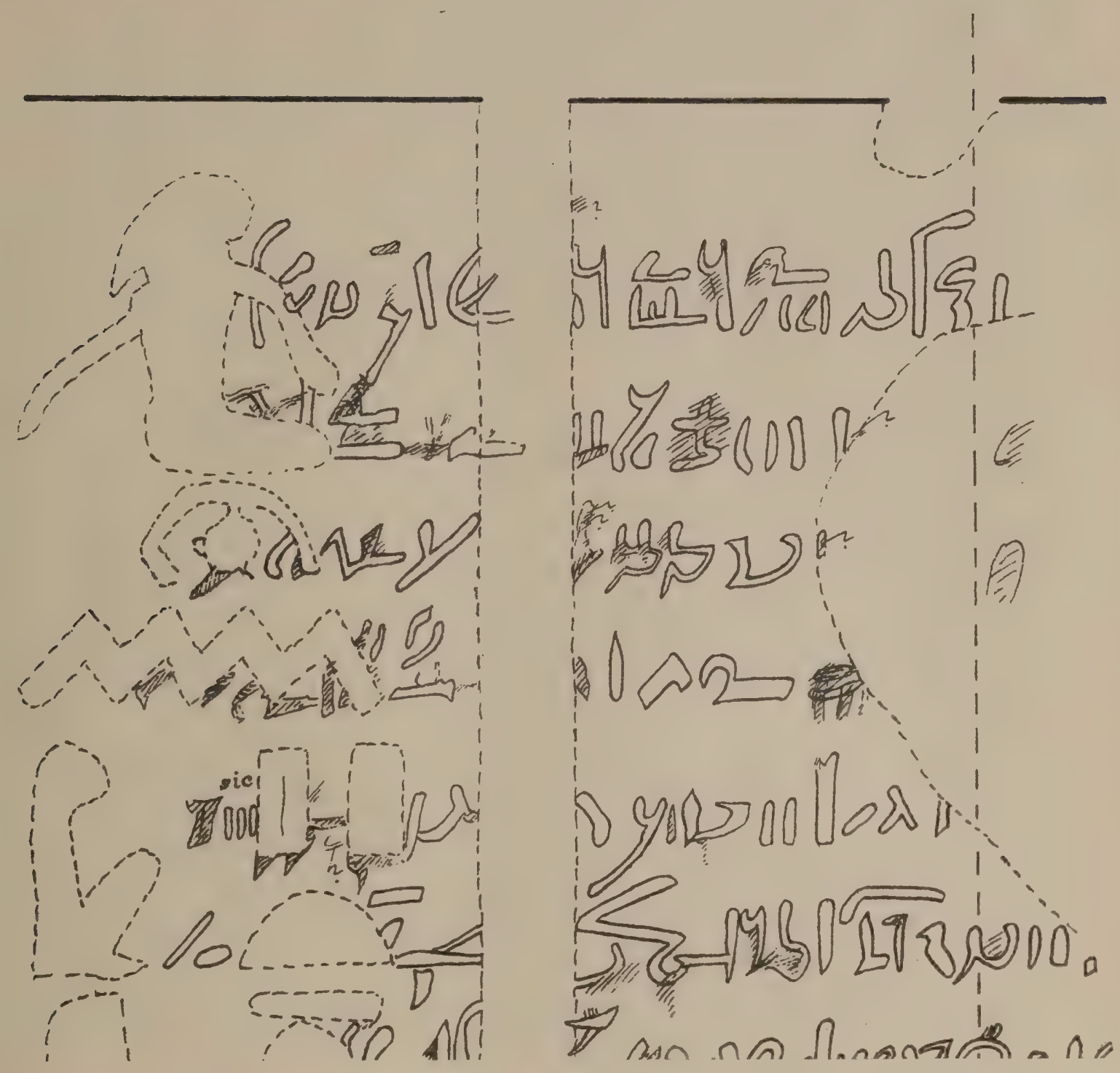

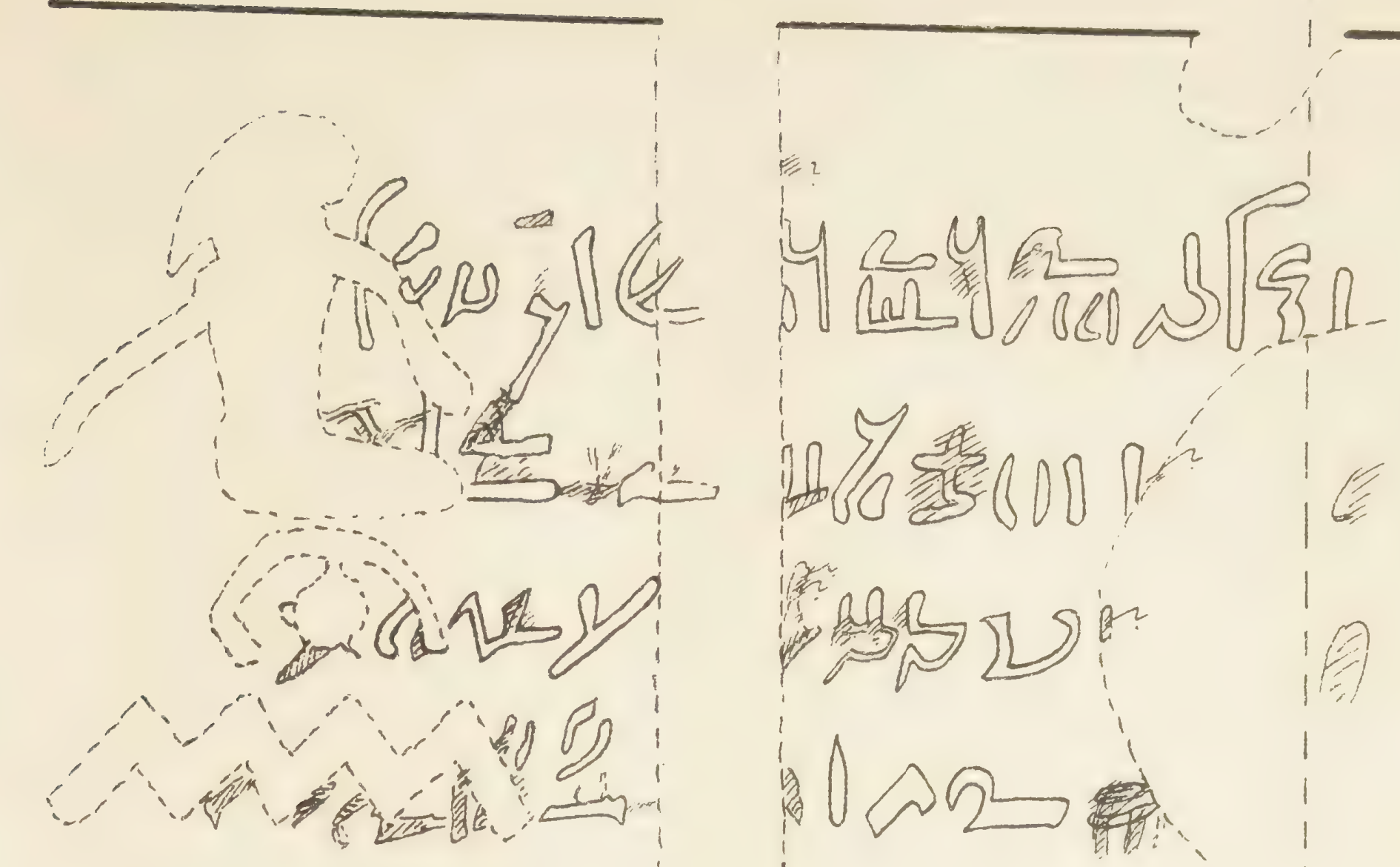

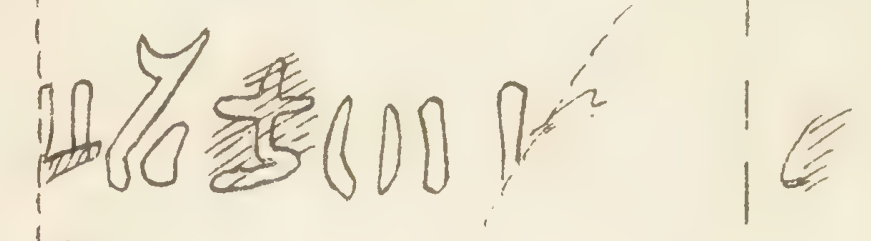

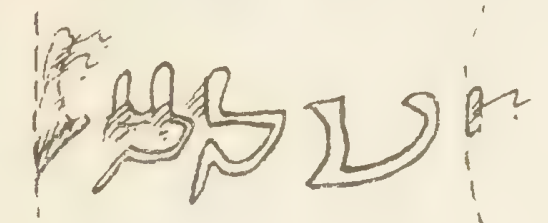
10乞

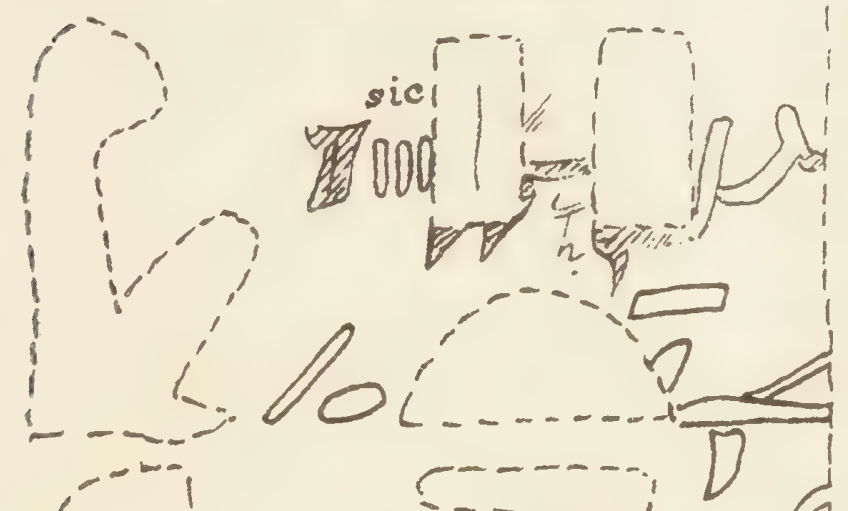

$$
\text { (n) }
$$

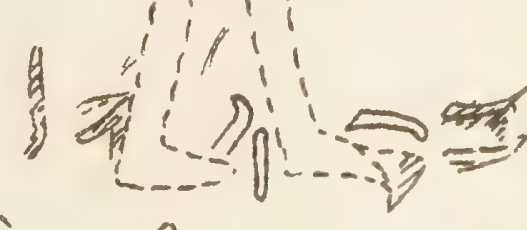

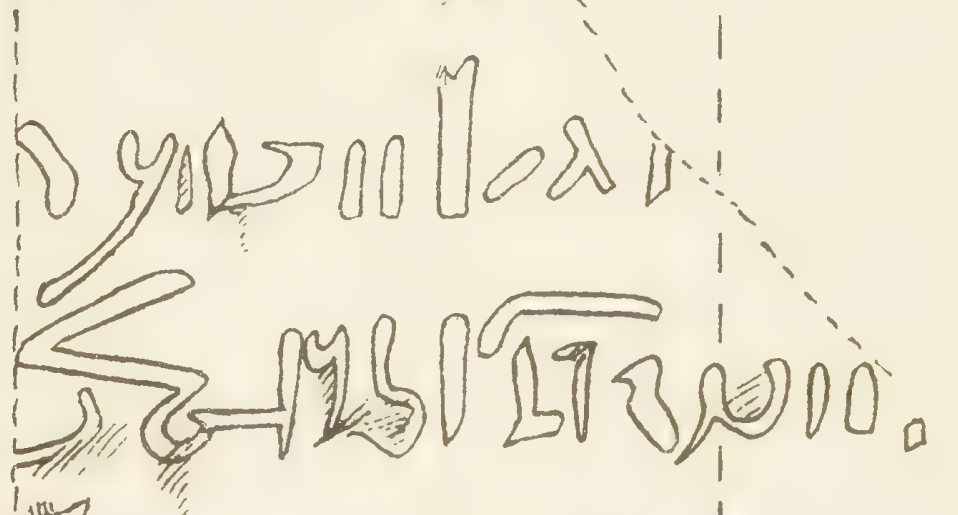

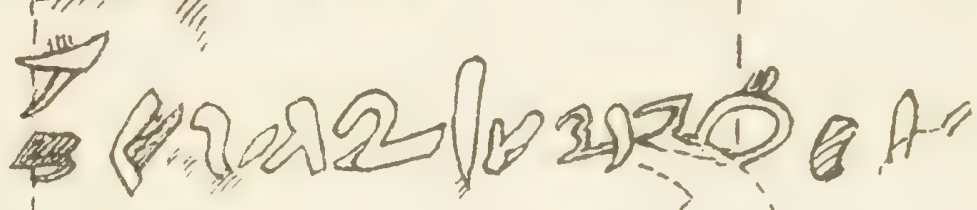

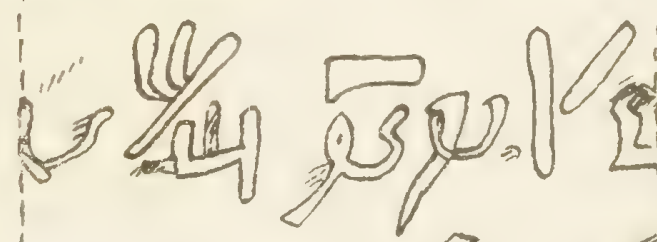

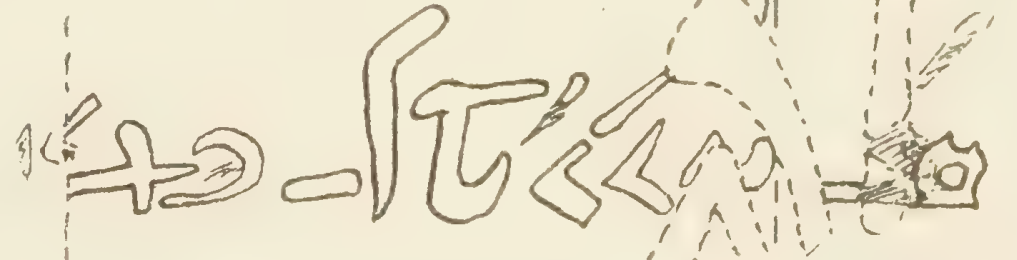

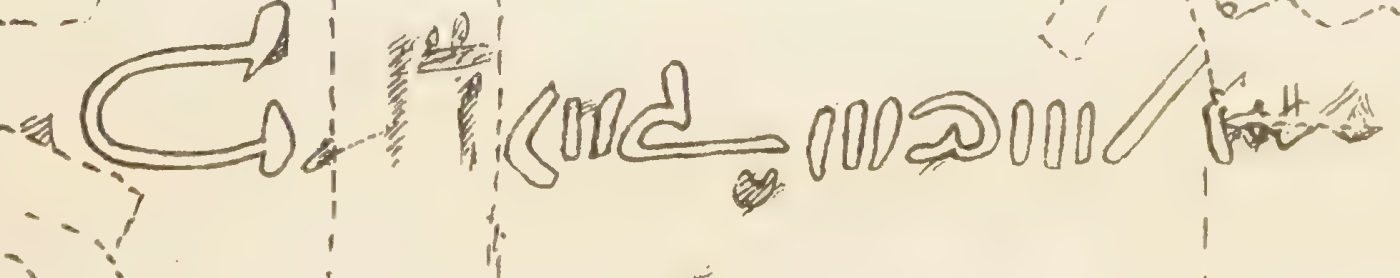

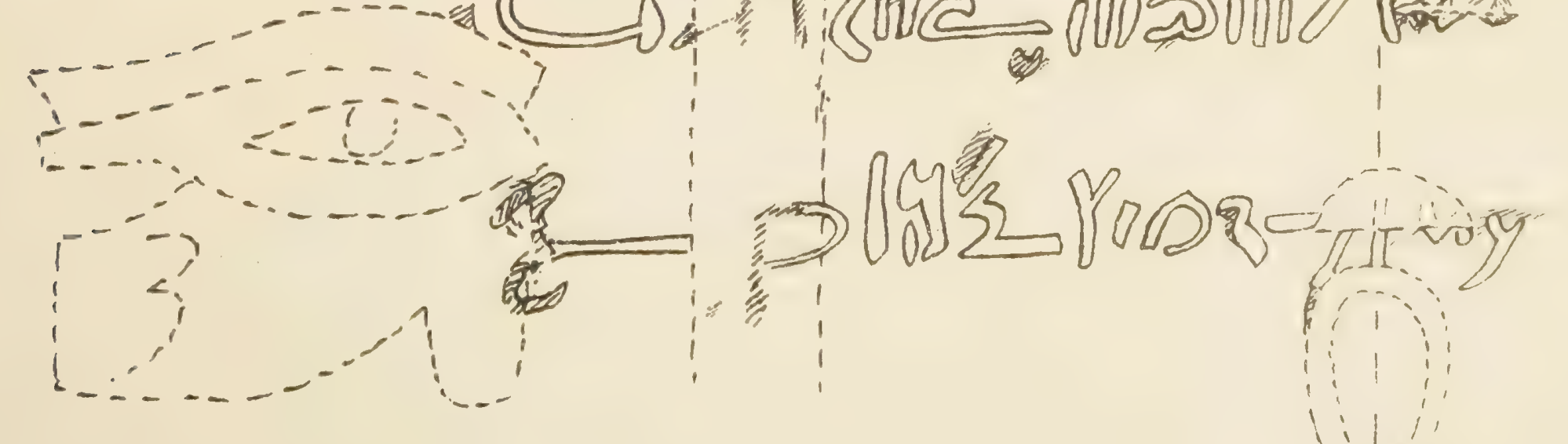




\title{
EGYPTOLOGICAL RESEARCHES
}

\author{
VOL. III \\ THE \\ BILINGUAL DECREES OF PHILAE
}

BY

W. Max Müller.

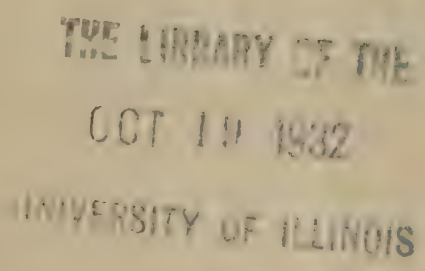

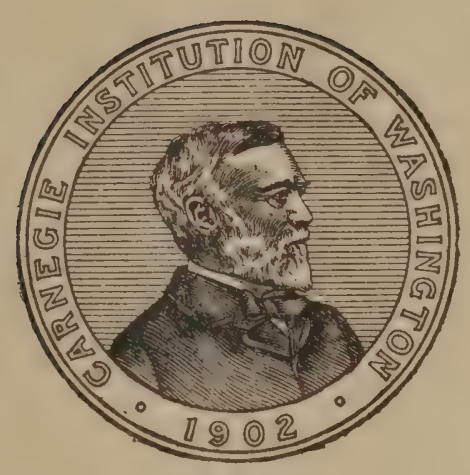

Published by the Carnegie Institution of Washington WASHINGTON, I920 







\section{ond \\ $60^{2}$}

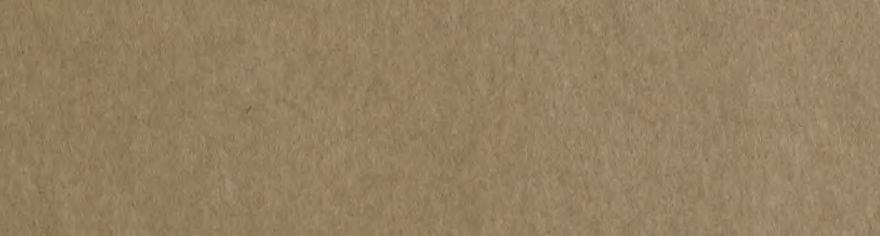

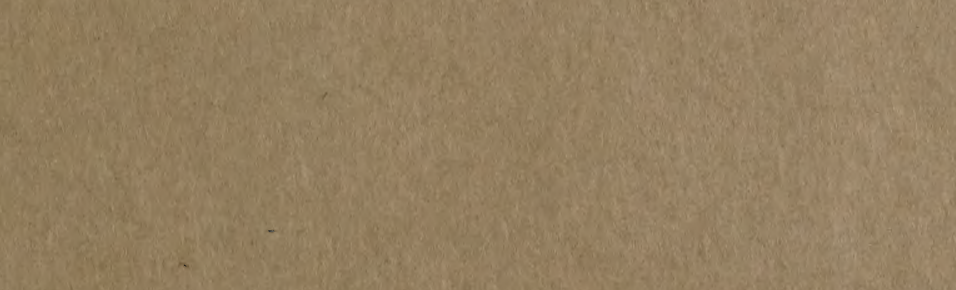

int

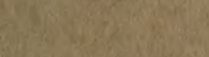

5.

(c)

\section{yertes}

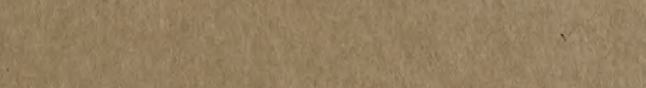

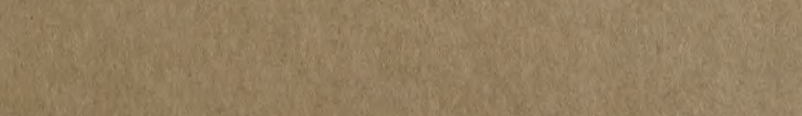

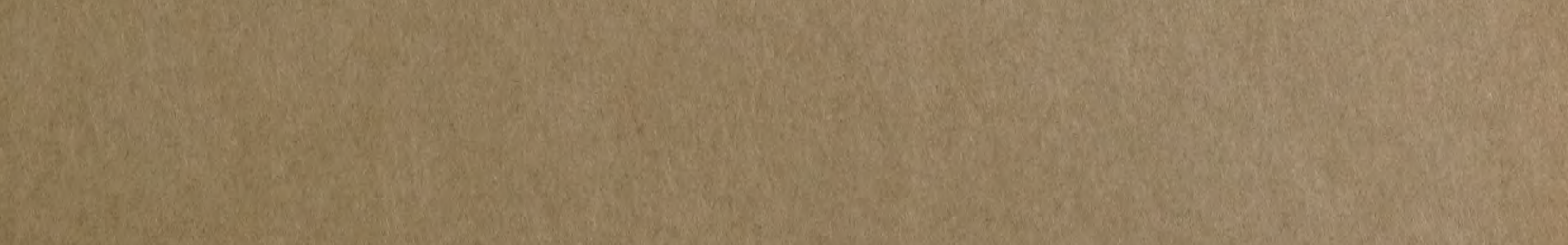
Q6. 1850 
